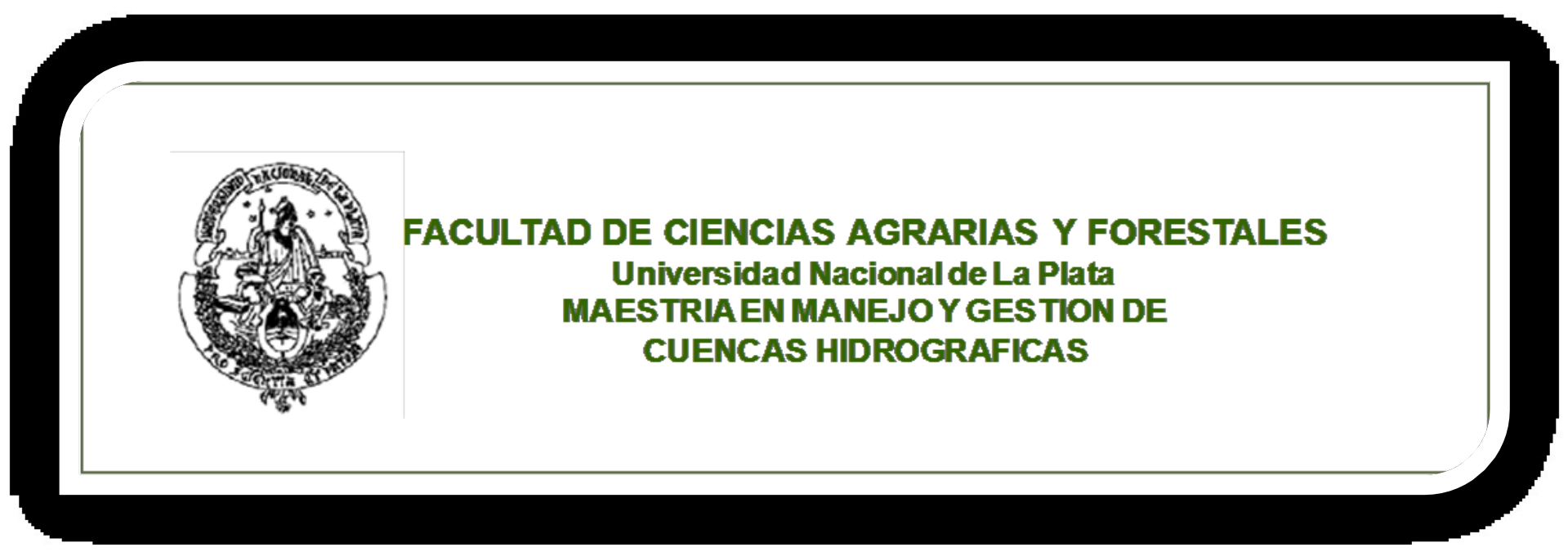

Propuesta de Lineamientos Conceptuales y Metodológicos para la Planificación de la Gestión Sostenible de la Cuenca Hidrográfica del Río Bogotá, desde una perspectiva regional.

“La Planificación, la Gestión y el Ordenamiento Ambiental desde la articulación de las Cuencas Hidrográficas"

\author{
PROYECTO DE GRADO \\ Ernesto Villegas Rodríguez
}

Director:

DOCTOR JEAN- FRANÇOIS JOLLY

DOCENTE PONTIFICIA UNIVERSIDAD JAVERIANA-BOGOTÁ COLOMBIA

Co-Director(a)

DOCTORA MARGARITA ALCONADA

DOCENTE UNIVERSIDAD NACIONAL DE LA PLATA ARGENTINA 
NOTA DE ACEPTACIÓN

NOTA DE CALIFICACIÓN TESIS.

PRESIDENTE.

JURADO 1.

JURADO 2.

La Plata, Argentina - 2014. 


\section{AGRADECIMIENTOS}

El autor expresa sus agradecimientos a:

A mi esposa Aura Yolanda, quien con su apoyo y amor hicieron posible tanto este trabajo como mi desarrollo profesional.

A mis Hijos Carlos Santiago y María Camila, quienes con su paciencia y disponibilidad de sus tiempos hicieron posible la terminación de mi trabajo.

Jean-François Jolly, Docente y amigo de la Pontificia Universidad Javeriana, sede Bogotá, por su apoyo y a Margarita Alconada, por su orientación y paciencia en el desarrollo del presente proyecto. 


\title{
Propuesta de Lineamientos Conceptuales y Metodológicos para la Planificación de la Gestión Sostenible de la Cuenca Hidrográfica del Río Bogotá, desde una perspectiva regional. \\ "La Planificación, la Gestión y el Ordenamiento Ambiental desde la articulación de las Cuencas Hidrográficas"
}

\section{Proposed Conceptual and Methodological Guidelines for Planning the Sustainable Management of the Bogotá River Watershed, from a regional perspective. "The Planning, Management and Environmental Planning from the joint Watershed"}

\begin{abstract}
RESUMEN
El conocimiento previo de normas y su aplicación en el contexto nacional regional y local colombiano, como su verdadero valor en el Ordenamiento Territorial (OT), su aplicabilidad al nuevo orden regional a través de la cuenca hidrográfica, ha llevado al planteamiento de lineamientos conceptuales y metodológicos para la planificación de la gestión sostenible de la cuenca hidrográfica, en este caso la cuenca alta y media del Río Bogotá a través de las subcuencas del Río Negro, Carare, Gachetá Batá y del Sumapáz su articulación desde una perspectiva regional con la denominada Estructura Ecológica Regional (EER). Por tal motivo, en este trabajo se propone LA CUENCA HIDROGRÁFICA COMO ENLACE DEFINITIVO PARA UNA NUEVA ESTRUCTURA EN EL ORDENAMIENTO TERRITORIAL (OT) y la gestión territorial, que incida en el cambio de la organización administrativa y política en el territorio, que hoy se propone en el marco jurídico colombiano. Para ello, se debe consolidar la cuenca hidrográfica como la Unidad de Gestión Territorial, donde actores y gestores del desarrollo territorial, participen de forma conjunta entre lo público y lo privado con los catorce (14), NOAT y las cinco (5) Unidades de Planificación que constituyen el lineamiento en la armonización territorial para impulsar y promover la participación de los actores, en asocio entre gobernantes y gobernados en temas de gestión conocida como la cogestión administrativa hacia una gobernanza territorial; basados en los valores sostenibles del territorio, que contribuyan a la construcción y transformación de una nueva forma de gestión y de planificación territorial.
\end{abstract}

Palabras Claves: Cuenca hidrográfica, Ordenamiento Territorial, Estructura Ecológica Regional, Núcleo de Ordenamiento Ambiental territorial, Unidades de Gestión Territorial.

\begin{abstract}
Prior knowledge of standards and their implementation in the Colombian local, regional and national context, as its true value in Land Management (OT), its applicability to the new regional order through the watershed has led to guidelines and conceptual approach methodology for planning sustainable management of the watershed, in this case the upper and middle basin of the Bogotá River through the Black River watersheds, Carare, Gachetá Sumapaz Batá and articulation from a regional perspective with known structure ecological Regional (EER). Therefore, in this paper WATERSHED AS A DEFINITIVE LINK TO A NEW STRUCTURE IN THE TERRITORIAL (OT) and land management that affects the change of administrative and political organization in the territory proposed today proposed in the Colombian legal framework. To do this, we must consolidate the watershed as the Land Management Unit, where actors and managers of territorial development, participate jointly by public and private with fourteen (14) NOAT and five (5) units planning guideline in forming the territorial harmonization to encourage and promote the participation of stakeholders, in partnership between rulers and ruled in management known as administrative co towards territorial governance; based on sustainable values of the area, which contribute to the construction and transformation of a new form of territorial management and planning.
\end{abstract}

Keywords: Watershed, Land, Regional Ecological Network, Core territorial Environmental Planning, Territorial Management Units. 


\section{CAPITULO 1}

\section{MARCO REFERENCIAL Y METODOLÓGICO}

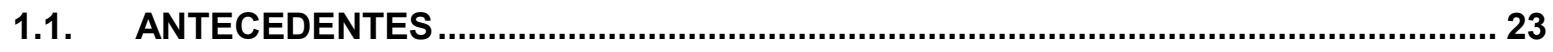

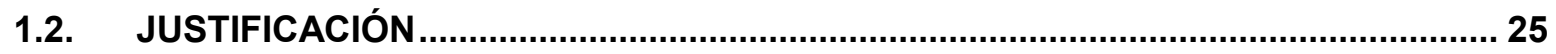

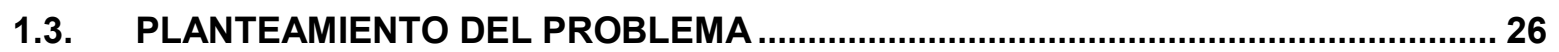

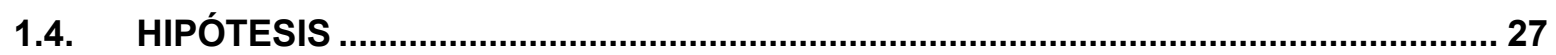

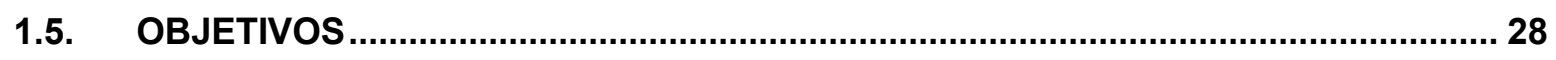

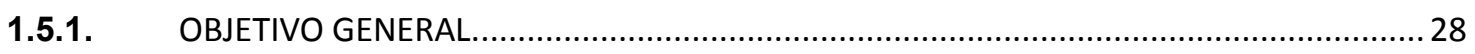

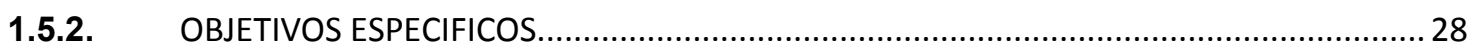

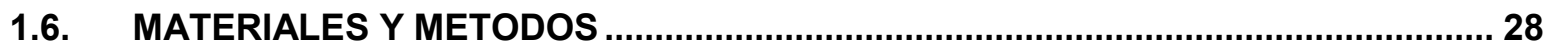

1.6.1. TIPO Y NIVEL DE INVESTIGACIÓN CUALITATIVA. .......................................................2

1.6.2. LA ESTRATEGÍA METOdologíCA DE INVESTIGACIÓN..................................................29

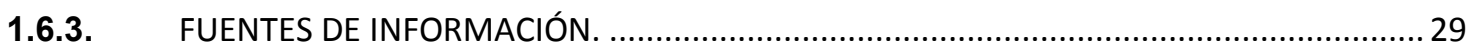

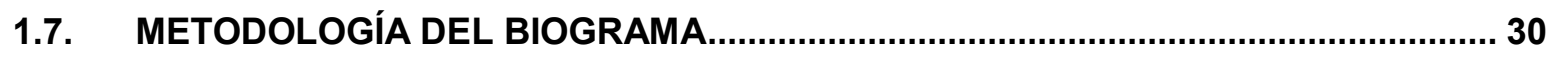

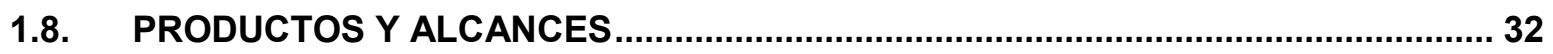

CAPITULO 2

MARCO CONCEPTUAL Y TEÓRICO

2.1. ELEMENTOS CONCEPTUALES Y CRITERIOS ESTRUCTURANTES PARA EL ANÁLISIS TERRITORIAL E INCORPORACIÓN AL TEMA REGIONAL ..................... 34

2.2. MARCO CONCEPTUAL Y TEÓRICO DEL ORDENAMIENTO TERRITORIAL........... 36

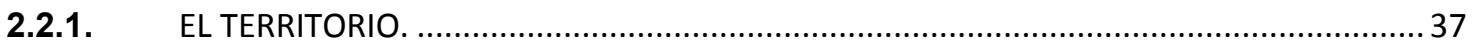

2.2.2. LAS INCIDENCIAS DE LAS PROPUESTAS DE ESTRUCTURA ECOLÓGICA PRINCIPAL (EPP), REGIONAL PARA LA CONFORMACIÓN DEL ÁREA DE ESTUDIO. 
2.2.3. LA CONSTITUCIÓN DE LA REGIÓN ADMINISTRATIVA Y DE PLANEAMIENTO ESPECIAL (RAPE), ENTRE EL DISTRITO CAPITAL DE BOGOTÁ Y EL DEPARTAMENTO DE CUNDINAMARCA...

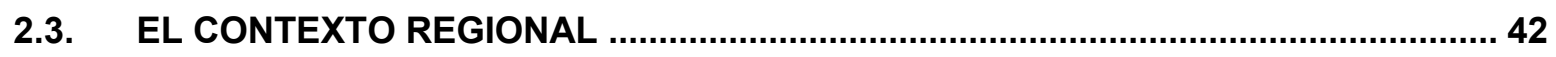

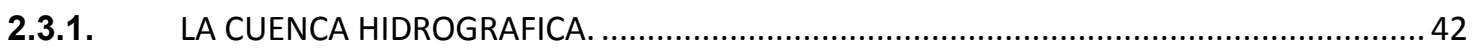

2.4. LA ZONIFICACIÓN AMBIENTAL Y SU RELACIÓN CON LA ESTRUCTURA

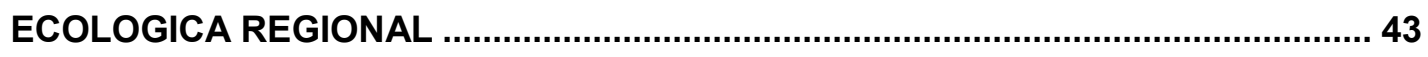

2.5. PRICIPALES PROBLEMAS ASOCIADOS A LA DIMENSIÓN AMBIENTAL EN LA CONSERVACIÓN, USO Y RECUPERACIÓN DEL RECURSO HÍDRICO EN LA

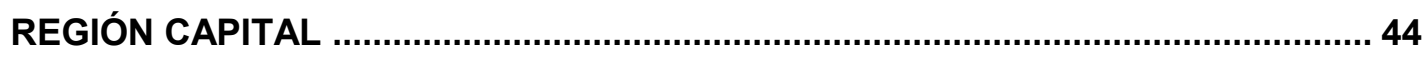

2.6. LA ASOCIACIÓN E INTEGRACIÓN TERRITORIAL .............................................. 46

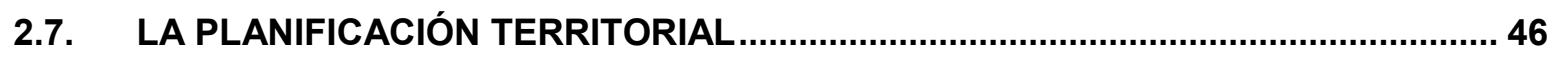

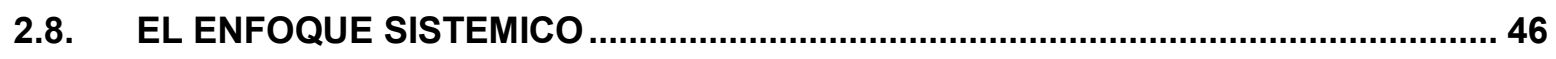

2.9. LA CUENCA HIDROGRAFICA COMO ELEMENTO ESTRUCTURANTE DEL

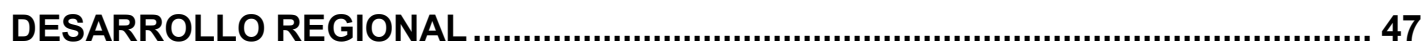

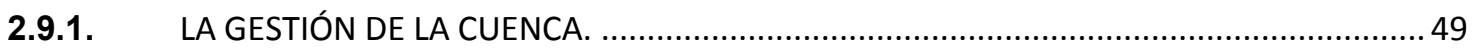

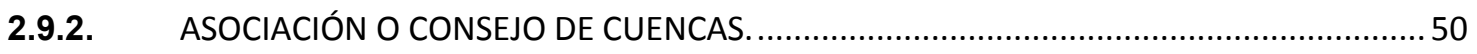

2.9.3. ASOCIACIÓN DE GESTIÓN Y COMITÉS DE CUENCAS............................................... 50

2.9.4. LAS UNIDADES TERRITORIALES Y DE GESTIÓN (UTG). ............................................ 50

2.10. UNA APROXIMACIÓN A LO REGIONAL: EJEMPLOS DE ORDENAMIENTO TERRITORIAL ................................................................................................... 51

2.11. LA INCIDENCIA DE CADA UNA DE LAS DIMENSIONES DEL DESARROLLO EN EL CONCEPTO DE REGIÓN ............................................................................... 60

2.11.1. LA DIMENSIÓN AMBIENTAL Y EL COMPONENTE FISICO -BIÓTICO............................... 61

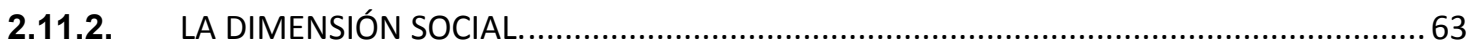

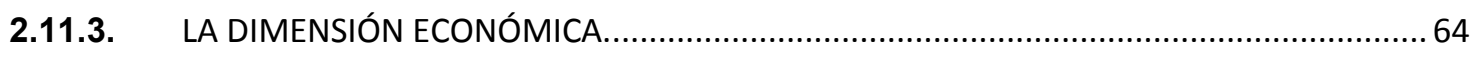

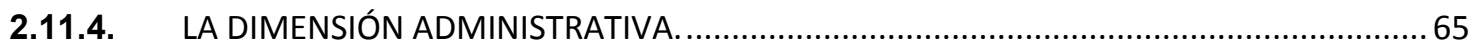

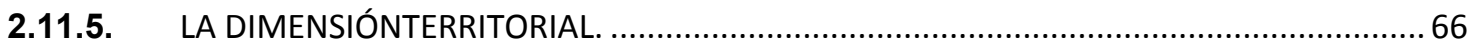




\section{CAPITULO 3}

\section{MARCO POLITICO LEGAL Y NORMATIVO}

3.1. ANALISIS DE POLÍTICAS, NORMAS Y LEYES EXPEDIDAS EN COLOMBIA, PARA EL DESARROLLO TERRITORIAL, SU APLICACIÓN A LA REALIDAD COLOMBIANA DESDE LA PERSPECTIVA INSTITUCIONAL .................................69

3.1.1. EL CONCEPTO NACIONAL. 69

3.1.2. LOS PLANES NACIONALES DE DESARROLLO Y SU RELACIÓNCON EL ÁNALISIS TERRITORIAL, REGIONAL Y DE DESARROLLO TERRITORIAL

3.2. ESTABLECIMIENTO DE LOS MECANISMOS QUE PERMITEN AL MUNICIPIO EN EJERCICIO DE SU AUTONOMÍA, PROMOVER EL ORDENAMIENTO TERRITORIAL

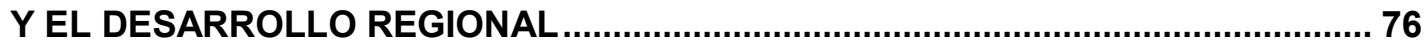

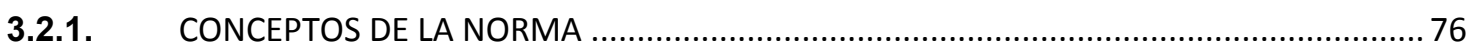

3.2.2. LA POLÍTICA PÚBLICA AMBIENTAL PARA LA INTEGRACIÓN REGIONAL ......................... 77

3.3. ANTECENDETES TÉCNICOS AMBIENTAL EN LA CONSTRUCCIÓN DE LA VISIÓN REGIONAL 79

3.4. LOS INSTRUMENTOS DE PLANIFICACIÓN, GESTIÓN Y LOS PLANES ESTRATEGICOS INSTITUCIONALES DE DESARROLLO TERRITORIAL ............ 79

3.5. LOS ASPECTOS NORMATIVO Y LEGAL (CONTEXTO NACIONAL) ...................... 81

3.5.1. EL MARCO NORMATIVO NACIONAL PARA LA ORDENACIÓN DEL TERRITORIO .............82

3.5.2. ENTRE LA NORMATIVIDAD QUE ACTUALMENTE ORIENTA DE MANERA GENERICA LOS PROCESOS DE PLANIFICIACIÓN AMBIENTAL DEL TERRITORIO

3.6. LA POLÍTICA NACIONAL AMBIENTAL DE COLOMBIA ......................................... 84

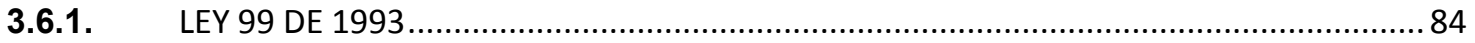

3.6.2. LEY 152 DE 1994 O LEY ORGANICA DEL PLAN DE DESARROLLO

3.6.3. LEY 136 DE 1994: POR LA CUAL SE DICTAN NORMAS TENDIENTES A MODERNIZAR LA ORGANIZACIÓN Y EL FUNCIONAMIENTO DE LOS MUNICIPIOS.

3.6.4. LEY 388 DE 1997: DEL ORDENAMIENTO TERRITORIAL MUNICIPAL. .85

3.6.5. LEY 617 DE 2000: POR LA CUAL SE REFORMA PARCIALMENTE LA LEY 136 DE $1994 \ldots . . .86$ 
3.6.6. DECRETO 1729 DE 2002. GUÍA TÉCNICO CIENTIFICA PARA EL ORDENAMIENTO Y MANEJO DE CUENCAS HIDROGRRAFICAS

3.6.7. DECRETO 3600 DEL 20 DE SEPTIEMBRE DE 2007, DEL MINISTERIO DE AMBIENTE, VIVIENDA Y DESARROLLO TERRITORIAL

3.6.8. LEY ORGÁNICA DE ORDENAMIENTO TERRITORIAL (LOOT) O LEY 1454 DE 2011

3.7. LA CONSTITUCIÓN DE LA REGIÓN ADMINISTRATIVA Y DE PLANEAMIENTO ESPECIAL (RAPE), ENTRE EL DISTRITO CAPITAL DE BOGOTÁ Y EL DEPARTAMENTO DE CUNDINAMARCA 88

3.8. LA NORMATIVIDAD QUE RIGE LA ACTIVIDAD MINERA Y LA ORDENACIÓN DEL TERRITORIO 89

3.9. AMENAZAS Y ATENCIÓN DE DESASTRES EN EL ORDENAMIENTO DEL TERRITORIO 90

3.9.1. OBLIGACIONES Y FUNCIONES DE LOS ACTORES CON RELACIÓN A LA GESTIÓN DEL RIESGO.

3.10. EL CONTEXTO LOCAL 90

3.10.1. ASPECTOS NORMATIVOS Y LEGALES: PLANES DE DESARROLLO DEL DISTRITO CAPITAL

3.10.2. LA COSTITUCIÓN POLÍTICA NACIONAL DE 1991, EJE CENTRAL DEL ORDENAMIENTO DEL TERRITORIO PARA LA ORDENACIÓN DE LA CUENCA DEL RÍO BOGOTÁ...

3.10.3. ANTECEDENTES POLITICOS EN LA COSNTRUCCIÓN DEL CONCEPTO REGIONAL EN EL ÁREA DE LA CUENCA DEL RÍO BOGOTÁ....

3.10.4. RESOLUCIÓN No. 3194 DEL 23 DE NOVIEMBRE DE 2006, POR LA CUAL SE APRUEBA EL PLAN DE ORDENACIÓN Y MANEJO DE LA CUENCA DEL RÍO BOGOTÁ.

3.11. LOS PLANES DE ORDENAMIENTO TERRITORIAL EN LA REGIÓN DE BOGOTÁ CUNDINAMARCA

3.12. LOS DOCUMENTOS CONPES (PROMULGADOS EN EL ÁREA DE ESTUDIO) ... 96 


\section{CAPITULO 4 \\ DIAGNOSTICO Y CARACTERIZACIÓN}

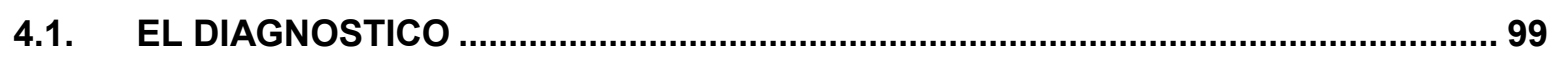

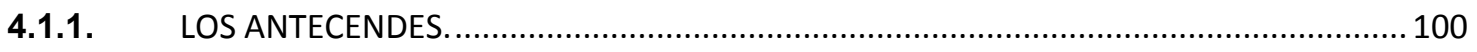

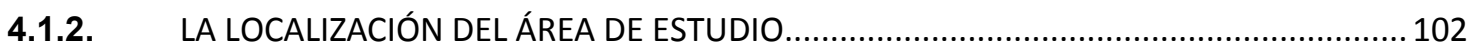

4.1.3. GENERALIDADES ESTRUCTURALES Y DESCRIPCIÓN DE LA LOCALIZACIÓN DEL ÁREA DE

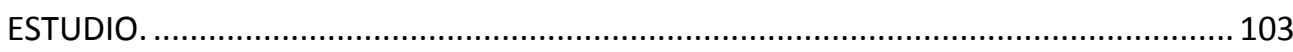

4.1.4. IDENTIFICACIÓN DE LOS PROBLEMAS MAS ASOCIADOS AL DIAGNOSTICO DE LAS SUBCUENCAS ALTA Y MEDIA DEL RÍO BOGOTÁ........................................................ 108

4.1.5. EL RECURSO HIDRICO COMO DETERMINANTE DEL ORDENAMIENTO AMBIENTAL DEL

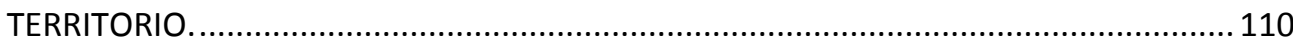

4.2. LA CARACTERIZACIÓN AMBIENTAL ......................................................... 111

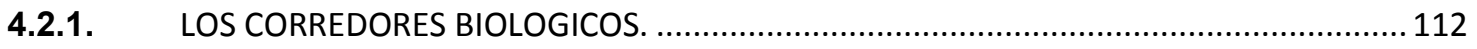

4.3. LA SITUACIÓN AMBIENTAL DE LA CUENCA .................................................... 112

4.4. LAS CUENCAS HIDROGRAFICAS ............................................................... 113

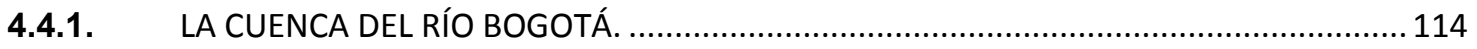

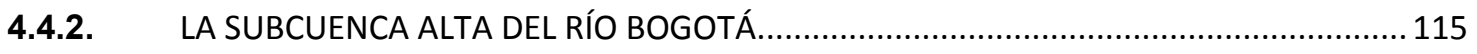

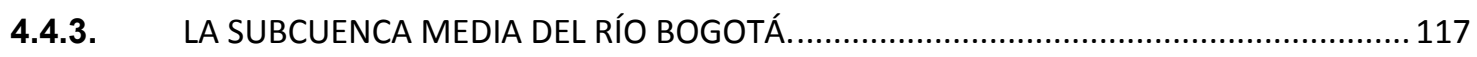

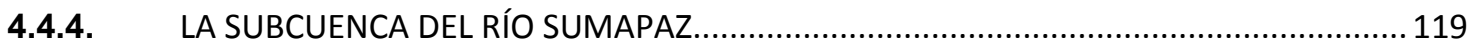

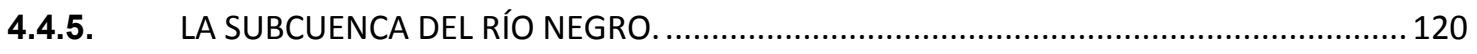

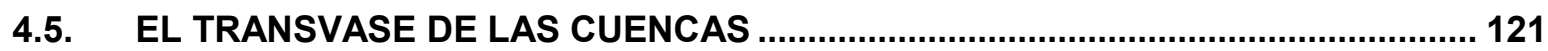

4.6. EL NIVEL DE VUNERABILIDAD Y AMENAZA DEL RECURSO HIDRICO; CON BASE EN EL REFERENTE DE LA OLA INVERNAL ......................................... 122

4.7. LA CARACTERIZACIÓN DE LAS DIMENSIONES DEL DESARROLLO................. 128

4.8. LA CARACTERIZACIÓN Y VALORACIÓN DE LA DIMENSIÓN AMBIENTAL (BIOGRAMA) 129

4.9. CARACTERIZACIÓN DE LA DIMENSIÓN SOCIAL 131 
4.9.1. LA SITUACIÓN SOCIAL DE LA CUENCA Y SU ÁREA DE REFERENCIA CON LA ESTRUCTURA

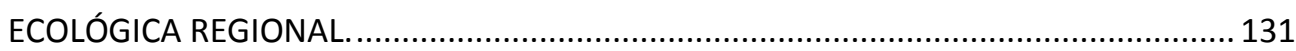

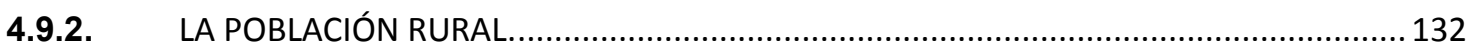

4.9.3. LA INFORMACIÓN ECONOMICA Y SOCIAL DEL ÁREA DE ESTUDIO.......................133

4.9.4. LA CARACTERIZACIÓN SOCIAL DEL ÁREA DE LA CUENCA HIDROGRAFICA DEL RÍO BOGOTÁ, Y SU ENTORNO CON LA ESTRUCTURA ECOLÓGICA REGIONAL POR MUNICIPIO.

4.10. LA CARACTERIZACIÓN Y LA VALORACIÓN DE LA DIMENSIÓN SOCIAL ......... 142

4.11. LA JERARQUIA URBANA, LA ESPACIALIZACIÓN TERRITORIAL DEL ÁREA DE LA CUENCA HIDROGRAFICA DEL RÍO BOGOTÁ Y SU ENTORNO CON LA ESTRUCTURA ECOLÓGICA REGIONAL ............................................................ 143

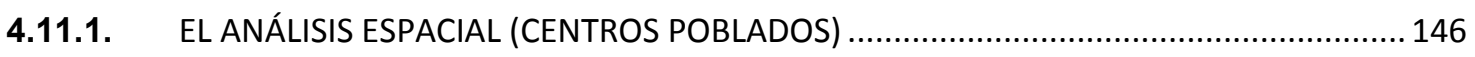

4.11.2. LA SITUACIÓN POLITICO - ADMINISTRATIVA DE LA CUENCA DEL RÍO BOGOTÁ Y SU ÁREA DE LA ESTRUCTURA ECOLÓGIVA REGIONAL ................................................ 147

4.11.3. LOS ACTORES EN LA PARTICIPACIÓN Y EN LA GESTIÓN DEL TERRITORIO ..................... 149

4.11.4. LAS INSTANCIAS DE PARTICIPACIÓN DE LOS ACTORES ............................................ 150

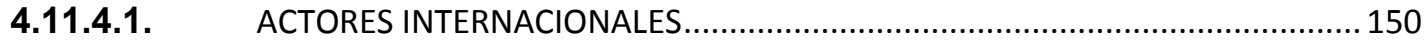

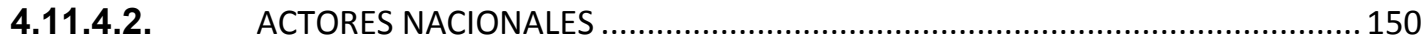

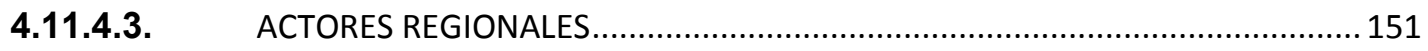

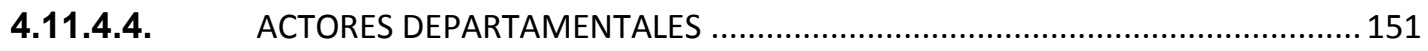

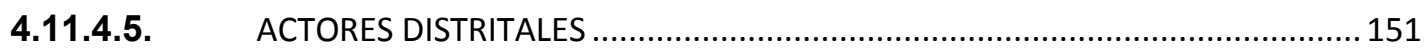

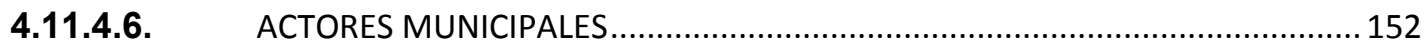

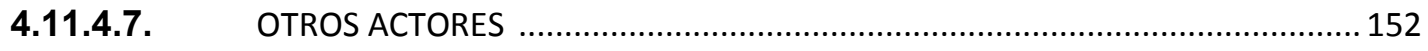

4.12. CARACTERIZACIÓN DE LA DIMENSIÓN ECONÓMICA Y SU ÁREA DE

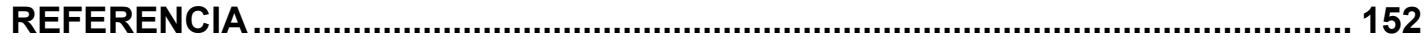

4.12.1. EL INGRESO MUNICIPAL COMO PARTE DEL DESARROLLO TERRITORIAL......................158

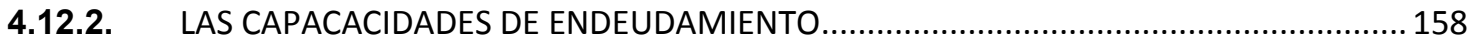

4.13. LA CARACTERIZACIÓN Y LA VALORIZACIÓN DE LA DIMENSIÓN ECONÓMICA 


\section{CAPITULO 5}

FORMULACIÓN DE LOS LINEAMIENTOS CONCEPTUALES Y METODOLOGICOS PARA

LA PLANIFICACIÓN Y LA GESTIÓN SOSTENIBLE DE LAS SUBCUENCA DEL RÍO BOGOTA Y SU ÁREA DE INFLUENCIA DESDE UNA PERSPECTIVA REGIONAL

\subsection{DIRECTRICES Y ESTRUCTURA PARA LA ARMONIZACIÓN DE LOS}

LINEAMIENTOS

5.1.1. ARMONIZACIÓN DEL ORDENAMIENTO TERRITORIAL $Y$ LAS SUBCUENCAS HIDROGRAFICAS DE BOGOTÁ.

5.2. LINEAMIENTOS PARA LA ZONIFICACIÓN DEL TERRITORIO Y LA ARMONIZACIÓN CON LOS INSTRUMENTOS DE PLANIFICACIÓN DEL TERRITORIO 168

5.2.1. MOMENTO UNO: APROXIMACIÓN A LOS INSTRUMENTOS DE PLANEAMIENTO PARA LA FORMULACIÓN DE LA ESTRATEGIA DE ARMONIZACIÓN Y DESARROLLO DE LA SUBCUENCA HIDROGRAFICA

5.2.2. EL ACERCAMIENTO DE LAS REGIONES ADMINISTRATIVAS Y DE PLANIFICACIÓN (RAP), HACIA EL DESARROLLO REGIONAL

5.2.3. LA COSNTITUCIÓN DE LOS NUCLEOS DE ORDENAMIENTO AMBIENTAL TERRITORIAL (NOAT), COMO UNIDADES DE GESTIÓN

5.2.4. LA ARMONIZACIÓN DE LOS INSTRUMENTOS DE GESTIÓN REGIONAL (NOAT) 173

5.2.5. MOMENTO DOS: LA APROXIMACIÓN DE LA ESTRATEGIA PARA LA ARMONIZACIÓN.178

5.2.6. MOMENTO TRES: LA APROXIMACIÓN A LAS DETERMINANTES DE LA GESTIÓN DE LA PARTICIPACIÓN COMUNITARIA

5.2.6.1. IDENTIFICACIÓN Y CLASIFICACIÓN DE LOS ACTORES PARA EL FORTALECIMIENTO DE LAS UNIDADES DE PLANIFICACIÓN Y DE GESTIÓN (NOAT)

5.3. LA CONFORMACIÓN DE LOS MIEMBROS DEL CONSEJO DE CUENCA.......... 183

5.3.1. COMITÉ DE CUENCA Y CONSEJOS DE CUENCA 183

5.3.2. LAS COMPETENCIAS DEL COMITÉ DE LA CUENCA 188 
5.3.3. LAS RESPONSABILIDADES DEL COMITÉ DE LA CUENCA

5.3.4. LA CONFORMACIÓN DE LOS MIEMBROS DEL COMITÉ DE

CUENCA

5.4. DIVISIÓN TERRITORIAL Y REGIONALIZACIÓN EN EL ÁREA .............................. 193

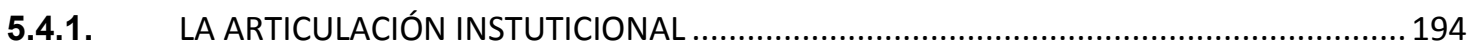

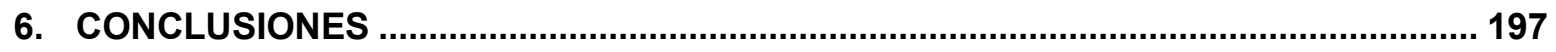

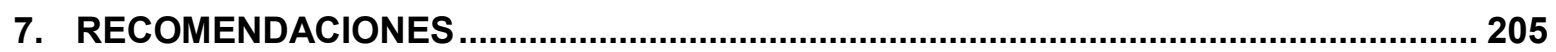

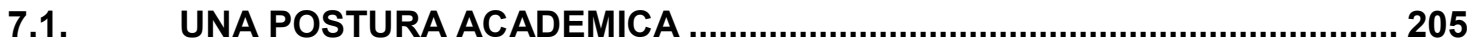

7.2. UNA POSTURA HACIA LAS INSTITUCIONES ....................................... 205

7.3. UNA POSTURA EN CUANTO A LA INCIDENCIA DE LA PARTCIPACIÓN CIUDADANA Y DEL SECTOR PRIVADO EN LAS DECISIONES EN LOS PROCEOS DE PARTICIPACIÓN EN LA APLICABILIDAD DE LOS INSTRUMENTOS DE PLANIFICACIÓNY DE GESTIÓN DEFINIDOS ........... 207

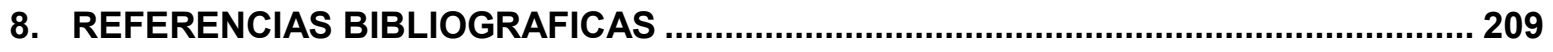

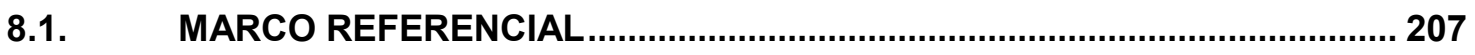

8.2. NORMAS Y ACUERDOS .................................................................... 213

8.3. NORMAS Y ACUERDOS INTERNACIONALES ........................................ 214

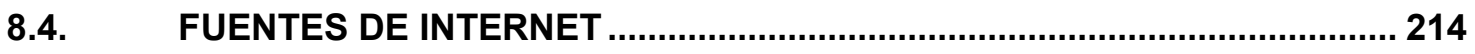

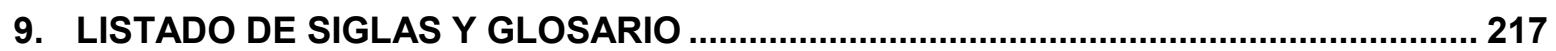

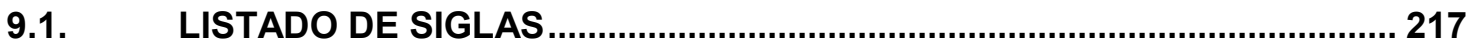

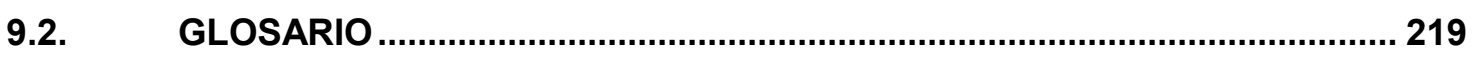

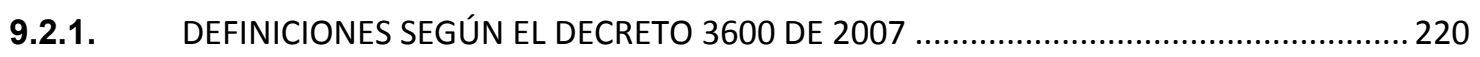


INDICE DE TABLAS

TABLA No. 3.1. LOS PLANES NACIONALES DE DESARROLLO Y SU RELACIÓN CON LOS ANÁLISIS TERRITORIAL Y REGIONAL Y EL DESARROLLO TERRITORIAL

TABLA No. 3.2. LOS PLANES DE DESARROLLO INSTITUCIONALES VISTOS DESDE LO AMBIENTAL

TABLA No. 3.3. LEY 99 DE 1993

TABLA No. 3.4. PLANES DE DESARROLLO DISTRITALES

TABLA No. 3.5. ASPECTOS NORMATIVOS CONSEJO NACIONAL DE POLITICAS ECONOMICA Y SOCIAL

TABLA No. 4.6. LOS MUNICIPIOS ÁRES DE ESTUDIO

TABLA No. 4.7. SINTESIS DE LAS PRINCIPALES PROBLEMATICAS IDENTIFICADAS EN EL DIAGNOSTICO POMCA DEL RÍO BOGOTÁ

TABLA No. 4.8. OFERTA Y DEMANDA DE LAS AGUAS SUPERFICIALES EN LAS SUBCUENCAS ALTA Y MEDIA DEL RIO BOGOTÁ

TABLA No. 4.9. COBERTURA DE USOS DEL SUELO

TABLA No. 4.10. CLASIFICACIÓN DE INDICADORES AMBIENTALES

TABLA No. 4.11. CLASIFICACIÓN DE INDICADORES SOCIALES

TABLA No. 4.12. CLASIFICACIÓN DE INDICADORES ECONÓMICOS

TABLA No. 4.13. DENSIDAD DE LA POBLACIÓN

TABLA No. 4.14. TASA ANUAL DE CRECIMIENTO DEL TOTAL DE LA POBLACIÓN

TABLA No. 4.15. COBERTURA DE ECOSISTEMAS Y VALORES MEDIOS DE LA TASA DE CRECIMIENTO POBLACIONAL (\%), EN PROVINCIAS DE CUNDINAMARCA DEFINIDAS EN EL POMCA

TABLA No. 4.16. POBLACIÓN DE LA CUENCA HIDROGRAFICA DEL RÍO BOGOTÁ Y DEL ÁREA DE REFRERENCIA 2011

TABLA No. 4.17. NECESIDADES DE VIVIENDA POR MUNICIPIO (ZONA RURAL Y ZONA URBANA)

TABLA No. 4.18. TASA BRUTA DE ANALFABETISMO POR MUNICIPIO (ZONA URBANA Y ZONA RURAL) PARA LA POBLACIÓN MAYOR DE QUINCE AÑOS

TABLA No. 4.19. POBLACIÓN POBRE SEGÚN (NBI) Y MISERIA POR MUNICIPIO (ZONA URBANA Y RURAL)

TABLA No. 4.20. CATEGORIZACIÓN DE LOS MUNICIPIOS EN 2010

TABLA No. 4.21. INGRESOS POR MUNICIPIO AÑOS 2007 - 2008 - 2009 
TABLA No. 4.22. RESUMEN DE ESFUERZO FISCAL AÑOS 2009 - $2010-2011$ 


\section{INDICE DE FIGURAS}

FIGURA No. 1.1. DIAGRAMA METODOLOGÍCO

FIGURA No. 1.2. ESTADO DE LA VARIABLE EN LA UNIDAD DE PLANIFICACIÓN TERRITORIAL, SEGÚN LOS COLORES DE LA METODOLOGÍA DEL BIOGRAMA

FIGURA No. 2.3. MARCO CONCEPTUAL Y TEORICO DEL ORDENAMIENTO TERRITORIAL

FIGURA No. 2.4. ESTRUCTURA SISTEMATICA DE LAS DIMENSIONES DEL DESARROLLO COMO SISTEMA

FIGURA No. 2.5. LA DIMENSIÓN AMBIENTAL

FIGURA No. 2.6 LA DIMENSIÓN SOCIAL

FIGURA No. 2.7. LA DIMENSIÓN ECONÓMICA

FIGURA No. 2.8. LA DIMENSIÓN ADMINISTRATIVA

FIGURA No. 2.9. LA DIMENSIÓN TERRITORIAL

FIGURA No. 4.10. LA CUENCA DEL RÍO BOGOTÁ

FIGURA No. 4.11. CUENCA DEL RÍO BOGOTÁ ALTA

FIGURA No. 4.12. SUBCUENCA MEDIA DEL RÍO BOGOTÁ

FIGURA No. 4.13. DESLIZAMIENTOS Y DAÑOS EN LA INFRAESTRUCTURA

FIGURA No. 4.14. SINTESIS Y CARACTERIZACIÓN DE LA ESPACIALIZACIÓN DE BIOGRAMA EN LA DIMENSIÓN AMBIENTAL

FIGURA No. 4.15. SINTESIS Y CARACTERIZACIÓN DE LA ESPACIALIZACIÓN DE BIOGRAMA EN LA DIMENSIÓN AMBIENTAL

FIGURA No. 4.16. SINTESIS Y CARACTERIZACIÓN DE LA ESPACIALIZACIÓN DE BIOGRAMA EN LA DIMENSIÓN AMBIENTAL

FIGURA No. 4.17. SINTESIS DE BIOGRAMA - DESEQUILIBRIO TERRITORIAL EN LO AMBIENTAL, SOCIAL Y ECONOMICO

FIGURA No. 5.18. LA ARMONIZACIÓN DE LOS INSTRUMENTOS

DE PLANEACIÓN Y DE GESTIÓN TERRITORIAL

FIGURA No. 5.19. ESQUEMA ORGANIZACIONAL PARA LA PLANIFICACIÓN REGIONAL DESDE EL TERRITORIO DE LAS SUBCUENCA HIDROGRÁFICA

FIGURA No. 5.21. DIRECTRICES PARA EL FUNCIONAMIENTO Y LA COORDINACIÓN PARA LA GESTIÓN DEL PLAN DE ORDENACIÓN Y MANEJO DE LA CUENCA DEL RÍO BOGOTÁ.

FIGURA No. 5.22. COMITÉ DE CUENCA 


\section{INDICE DE MAPAS}

MAPA No. 2.1. EL CONTEXTO HISTORICO 1

MAPA No. 2.2. EL CONTEXTO HISTORICO 2

MAPA No. 2.3. EL CONTEXTO NACIONAL 1

MAPA No. 2.4. EL CONTEXTO NACIONAL 2.

MAPA No. 2.5. EL CONTEXTO NACIONAL 3.

MAPA No. 2.6. EL CONTEXTO NACIONAL Y LAS PROPUESTAS ESTRATEGICAS 5

MAPA No. 2.7. EL CONTEXTO LOCAL BOGOTÁ Y CUNDINAMARCA 59

MAPA No. 4.8. LOCALIZACIÓN GENERAL DEL ÁREA DE LA CUENCA DEL RÍO BOGOTÁ CUENCA DEL RÍO BOGOTÁ

MAPA No. 4.9. CARACTERIZACIÓN DE LOS MUNICIPIOS DEL ÁREA DE ESTUDIO 105

MAPA No. 4.10. ESPACIALIZACIÓN DEL ÁREA DE ESTUDIO 106

MAPA No. 4.11. LOCALIZACIÓN DE ECOSISTEMAS EN LA CUENCA HIDROGRAFICA DE RÍO BOGOTÁ

MAPA No. 4.12. NECESIDADES DE LA VIVIENDA URBANA Y DE LA VIVIENDA RURAL EN LOS CONTEXTOS DE LA CUENCA Y DE LA ESRUCTURA ECOLOGICA REGIONAL

MAPA No. 4.13. NECESIDADES DE VIVIENDA POR HOGARES 137

MAPA No. 4.14. TASA DE ANALFABETISMO URBANO Y RURAL 139

MAPA No. 4.15. VIVIENDAS Y SANEAMIENTO 141

MAPA No. 4.16. LA JERARQUÍA URBANA DE LA CUENCA DEL RÍO BOGOTÁ Y SU RELACIÓN DENTRO DE LA ESTRUCTURA ECOLOGICA REGIONAL

MAPA No. 4.17. LA INTEGRACIÓN ESPACIAL

MAPA No. 4.18. LA ESPACIALIZACIÓN Y LA CATEGORIZACIÓN MUNICIPAL

MAPA No. 5.19. LA ARMONIZACIÓN ESPACIAL DE LOS INSTRUMENTOS DE PLANIFICACIÓN (NOAT)

MAPA No. 5.20. LA ESPACIALIZACIÓN DE LAS UNIDADES DE PLANIFICACIÓN (NOAT)

MAPA No. 5.21. LA ESPACIALIZACIÓN DE LOS IMPACTOS AMBIENTALES SOCIALES Y ECONOMICOS EN EL TERRITORIO A PARTIR DEL BIOGRAMA

MAPA No. 5.22. LOS DETERMINANTES CARTOGRAFICOS DE LA LINEA BASE DE LA ESTRUCTURA ECOLÓGICA REGIONAL

MAPA No. 5.23. LA ARMONIZACIÓN INTEGRACIÓN Y GESTIÓN TERRITORIAL 
MAPA No. 5.24. ZONIFICACIÓN ESPACIAL DEL COMITÉ DE CUENCA Y DE LOS CONSEJOS DE CUENCAS A TRAVÉS DE LA INTEGRACIÓN TERRITORIAL DE LOS (NOAT)

MAPA No. 5.25. INSTANCIAS TERRITORIALES DE GESTIÓN Y DE PLANIFICACIÓN TERRITORIAL

MAPA No. 5.26. LAS VARIABLES PARA LA REGIONALIZACIÓN FUNCIONAL: FACTORES TERRITORIALES (FISIOGRAFIA E HIDROGRAFIA)

MAPA No. 6.27. ESPACIALIZACIÓN DEL IMPACTO DE CADA UNA DE LAS DIMENSIONES EN EL TERRITORIO 


\section{INDICE DE ANEXOS}

ANEXO No. 1 TABLA DE SUBREGIONES DE PLANIFICACIÓN SEGÚN LA GOBERNACIÓN DE CUNDINAMARCA

ANEXO No. 2 TABLA RANKING DE DESEMPEÑO FISCAL MUNICIPAL 2009

ANEXO No. 3 TABLA RANKING DE DESEMPEÑO FISCAL MUNICIPAL 2010

ANEXO No. 4 TABLA RANKING DE DESEMPEÑO FISCAL MUNICIPAL 2011

ANEXO No. 5 DIMENSIÓN AMBIENTAL. RESULTADO DEL BIOGRAMA TENIENDO EN CUENTA CADA UNA DE LAS VARIABLES POR MUNICIPIO DENTRO DEL ÁREA DE ESTUDIO

ANEXO No. 6 DIMESIÓN SOCIAL. RESULTADO DEL BIOGRAMA TENIENDO EN CUENTA CADA UNA DE LAS VARIABLES POR MUNICIPIO DENTRO DEL ÁREA DE ESTUDIO

ANEXO No. 7 DIMENSIÓN ECONÓMICA. RESULTADO DEL BIOGRAMA TENIENDO EN CUENTA CADA UNA DE LAS VARIABLES POR MUNICIPIO DENTRO DEL ÁREA DE ESTUDIO

ANEXO No. 8 RESULTADOS GENERALES DEL DIAGNOSTICO PARA EL ANALISIS DEL INDICE DE DESARROLLO SOSTENIBLE

ANEXO No. 9 RESULTADOS DIMENSIÓN SOCIAL - INDICE DE DESARROLLO SOSTENIBLE.

ANEXO No. 10 RESULTADOS DIMENSIÓN ECONOMICA - INDICE DE DESARROLLO SOSTENIBLE.

ANEXO No. 11 RESULTADOS DIMENSIÓN AMBIENTAL - INDICE DE DESARROLLO SOSTENIBLE. 


\section{INTRODUCCIÓN}

El ordenamiento regional, pensado a partir del estudio de la unidad física de la cuenca hidrográfica en el cual son considerados tanto los aspectos ambientales, sociales, económicos, político-administrativos como los territoriales llevados hacia la visión del concepto de región, es el escenario propicio que surge para plantear procesos administrativos desde la perspectiva del ordenamiento territorial de la gestión y planificación territorial. Por consiguiente, para este trabajo de tesis se tomará la unidad física de la cuenca hidrográfica alta y media del Río Bogotá y su interrelación espacial con la denominada Estructura Ecológica Regional (EER), como parte del conocimiento en la caracterización del territorio, base importante para identificar, diseñar los lineamientos, conceptos metodológicos para la planificación y la gestión sostenible objetivo central del desarrollo del respectivo trabajo.

El punto de partida es considerar las bases políticas públicas, normas determinadas desde las distintas disposiciones en Leyes, Decretos, Acuerdos como Convenios para visualizar la conveniencia e importancia en el desarrollo del presente trabajo, ya que están directamente sustentadas desde la Constitución Nacional de 1991, que ha sido clara en el manejo del tema ambiental como del territorial, así como, las leyes que son expuestas y analizadas en el capítulo tres ${ }^{1}$. Igualmente se utilizará la información preexistente elaborada por el Instituto Geográfico Agustín Codazzi (IGAC), la academia y grandes exponentes nacionales como Alberto Mendoza Morales, Jaime Castro y Orlando Fals Borda, entre otros, y un amplio espectro bibliográfico relacionado con el tema de la inclusión de la cuenca hidrográfica como parte esencial en la toma de decisiones en la ordenación y administración del territorio.

En el marco de la nueva Constitución de $1991^{2}$ se evidencia un nuevo enfoque en la concepción de la planificación del desarrollo territorial, que introduce a la dimensión ambiental como ordenador en las políticas públicas, de tal suerte que el desarrollo económico y social debe ser compatible con la conservación, preservación, protección, recuperación de los recursos naturales que requieren las próximas generaciones para su desarrollo, constituyéndose así en un marco general de orientación para las políticas ambientales, que se dicten desde el gobierno nacional. De este modo, sus lineamientos de política nacional, regional, local y los proyectos estratégicos vistos desde el Plan Nacional de Desarrollo (PND), deberán articularse a todas las acciones orientadas al aprovechamiento de los recursos naturales en particular del recurso hídrico, en perspectiva de sus usos sostenibles en el territorio, teniendo en cuenta los factores sociales y económicos como los administrativos.

\footnotetext{
1 Por ejemplo, la Ley Orgánica de Ordenamiento Territorial (LOOT) y la Ley 388 de 1997, cuyas características conceptuales y metodológicas son insumos para el desarrollo de los objetivos trazados en el presente trabajo de tesis; además de normas que tienen directa relación con el desarrollo regional como el Decreto 3600 de 2007.

${ }^{2}$ La misma Constitución Política de 1991 definió 3 principios básicos para entender y aplicar la planificación de los usos del suelo en el país:
}

- Se estableció que a la propiedad privada le es inherente una función social y ecológica y que por motivos de utilidad pública, el interés privado deberá ceder al interés público o social, asignándole entonces al Estado el deber de promover el acceso progresivo a la propiedad de la tierra (Art. $58 \mathrm{CN}$ de 1991)

- Se permitió la intervención directa, o por delegación, del Estado en los usos del suelo (Art. 334 CN de 1991)

- Se instauró la participación de los municipios en las plusvalías generadas en el desarrollo urbano con miras a una distribución equitativa de cargas y beneficios (Artículos 13 y 82 CN de 1991). 
Con el fin de alcanzar el Desarrollo Regional como objetivo de planificación de manera sostenible, se propone que la cuenca hidrográfica sea la unidad física de estudio. El argumento esencial, que lleva al planteamiento de la cuenca hidrográfica y de la Estructura Ecológica Regional (EER), como unidades hacia la proyección regional, es la necesidad de mantener y de recuperar hasta donde sea posible la integralidad ecológica de los ecosistemas de alta montaña (paramos), para garantizar los procesos que permitan el adecuado funcionamiento del ciclo hidrológico y de los elementos del paisaje asociados a éste, tales como la cobertura, la vegetación, y el suelo. Los ecosistemas presentan condiciones climáticas especiales, un equilibrio natural y una esencial participación en la regulación del agua superficial y subterránea. Los humedales, en general, el suelo de páramo, y las lagunas, en particular, se comportan como los principales elementos de la (EER), medios retenedores y productores de agua; los páramos es la fábrica y el depósito natural del recurso hídrico, debido a la alta precipitación, a la baja tasa de evaporación y a la alta capacidad de retención de agua por parte de los componentes del ecosistema ${ }^{3}$ teniendo en cuenta que el río Bogotá nace en el páramo conocido con el nombre de Guacheneque localizado en el municipio de Villa Pinzón cuenca alta.

Por supuesto, se determina la importancia de reconocer escenarios de planificación y de gestión administrativa, que en el territorio deben articular desde las características escénicas el futuro de la población tanto la asentada en el área de estudio como la que está en el área de referencia periferia.

Como antecedente, y reconocimiento de lo anterior, estas zonas de alta montaña en Colombia han tenido procesos poblacionales y desarrollos productivos en forma constante, procesos que se aprecian en la distribución de la población: 476 municipios, es decir, el $46.8 \%$ de los municipios del país, poseen territorios en alta montaña y tienen territorio por encima de los 2.700 metros sobre el nivel del mar (msnm), al tiempo que 272 municipios (el 26.6\%) tienen superficie arriba de los 3.300 msnm y que 40 municipios tienen cabeceras urbanas arriba de los $2.700 \mathrm{msnm}$. Uno de los datos más significativos al respecto es que de acuerdo con la Empresa de Acueducto y Alcantarillado de Bogotá $(\mathrm{EAAB})^{4}$, el $90 \%$ del agua de consumo en Bogotá proviene de diferentes áreas de captación que involucran ecosistemas de alta montaña. Lo anterior indica una estrecha relación de dependencia de la población en general con este tipo de ecosistemas.

Respecto a la metodología, a fin de abordar la temática planteada se destaca el uso del BIOGRAMA (Índice de desarrollo Sostenible IDS - Desequilibrios territoriales) que permite estimar el nivel de desarrollo sostenible de los territorios y cuya finalidad es determinar los desequilibrios territoriales dentro del área de estudio teniendo en cuenta el análisis social, económico, ambiental y administrativo, este último desde la visión del manejo presupuestal. La Cuenca hidrográfica del Rio Bogotá, y su armonía con el área de la EER. Para ello, se hace la formulación de Unidades Territoriales de Gestión que denominamos Núcleos de Ordenamiento Ambiental Territorial NOAT, para así plantear la articulación de los distintos instrumentos de planeación y de gestión territoriales existentes reconocidos en las distintas políticas públicas estudiadas hacia una perspectiva regional.

\footnotetext{
${ }^{3}$ El páramo colombiano identificado por su organización ambiental y sus interacciones ecológicas, corresponde a biomas dispersos sobre dorsales de cordilleras que sobrepasan los 3.000 y 4.000 m.s.n.m. Estos son como el techo del sistema hídrico colombiano. La hidrología de mayor desarrollo surge desde las máximas altitudes.

${ }^{4}$. La sigla determina la Empresa de Acueducto y Alcantarillado de Bogotá, empresa encargada del suministro del agua potable, proyectos de restauración forestal en áreas de su jurisdicción como la compra de predios para conservar al futuro el recurso hídrico.
} 
Esta metodología ha sido utilizada en varios proyectos de planificación en Sudamérica, como por ejemplo en Brasil, donde la Secretaria de Desarrollo Territorial del Ministerio de Desarrollo Agrario analizó 150 territorios en los que se ejecutó la política de desarrollo rural. Para ejecutar su plan de trabajo se hizo uso de un instrumento simple que permitiese realizar el análisis comparativo de la evolución de los índices de desarrollo sostenible y se utilizó para tal efecto la metodología del Biograma que se constituyó en una herramienta de trabajo de gestión en los territorios rurales brasileños. En Colombia, el Instituto Interamericano de Cooperación para la Agricultura- IICA, la utilizó con el fin de establecer los sistemas de evaluación y de medición de desarrollo de los territorios en 100 municipios del país, buscando así la transformación de dichos territorios mediante una distribución ordenada de las actividades productivas, de conformidad con el potencial de recurso naturales y humanos allí presentes. Esto llevó a la puesta en marcha en el territorio de políticas económicas, sociales, ambientales y culturales sustentadas en procesos descentralizados y participativos. Igualmente en Perú, esta propuesta metodológica fue aplicada en todo el país como herramienta para la gestión y el análisis del desarrollo de los territorios rurales por el conocido como "Observatorio Peruano de Cadenas Agro productivas y Territorios Rurales". Estos antecedentes proporcionan invaluables experiencias para aplicar la metodología del Biograma ${ }^{5}$ para el área que está determinada entre los 38 municipios de las subcuenca alta y media del Río Bogotá y su área de influencia de la ciudad de Bogotá.

La metodología en el marco de la construcción del trabajo se identificó cinco capítulos en los cuales el primero se estableció el marco del protocolo de investigación donde se identificaba el objetivo central y su relación con los resultados en los objetivos específicos, la hipótesis, la metodología, su hipótesis y su alcance y productos; el segundo capítulo, se abordaron los elementos conceptuales y criterios estructurantes para el análisis territorial e incorporación al tema regional; un tercer capítulo, cuyo énfasis se centró en el análisis de políticas, normas y leyes expedidas en Colombia para el desarrollo territorial su aplicación a la realidad colombiana desde la perspectiva institucional, un cuarto capítulo determinante para la investigación donde se hace realizó el diagnóstico y la caracterización del área de estudio, finalmente un quinto capítulo resultado del compendio de los anteriores donde se establece la formulación de los lineamientos conceptuales y metodológicos para la planificación y la gestión sostenible de la cuenca alta y media del Río Bogotá y su área de influencia desde una perspectiva regional.

Por lo expuesto anteriormente, el ordenamiento y el manejo integral de cuenca hidrográfica se convierten en el objetivo fundamental de este trabajo que busca también contribuir al debate teórico y práctico de la inclusión de la "dimensión ambiental" como base de un nuevo ordenamiento hacia la visión regional: Así podrán plantearse desde esta visión, la propuesta a partir de las subcuencas alta y media del Río Bogotá y su articulación con la Estructura Ecológica Regional desde las subcuencas del Río Negro, Carare, Gachetá, Batá y del Sumapáz , un escenario en el modelo de desarrollo regional con el fin de determinar los alcances de lineamientos conceptuales para la planificación y gestión sostenible del territorio, visión del objetivo central planteado.

\footnotetext{
${ }^{5}$ Expuestas por el autor Sergio Sepúlveda, en sus proyectos de investigación publicados en la Metodología para estimar el nivel de Desarrollo Sostenible de Territorios 2008, que resultan necesarios para efectuar la regionalización en nuestro estudio a partir de un proyecto de caso.
} 


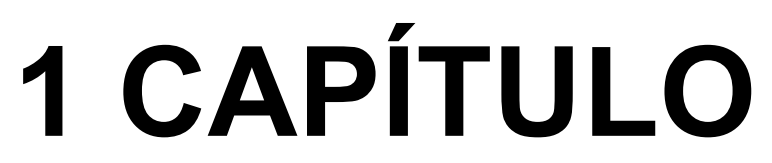

MARCO REFERENCIAL Y METODOLOGICO 


\subsection{ANTECEDENTES}

Es fundamental indagar en conceptos y en planteamientos referentes al ordenamiento territorial, lo que podamos conocer a través de la historia en los dos últimos siglos, entre (s. XIX y s. XX), para ello, nos apoyaremos en mapas en lo más representativo de las divisiones administrativas y planteamientos del siglo $X X$ en lo económico, social y ambiental, y lo recorrido en la primera década del siglo XXI. Por lo tanto, la aplicabilidad de instrumentos de planificación en Colombia, han determinado grandes cambios en lo relacionado con la división político administrativa, como son el paso del centralismo al federalismo fortalecidos por las constituciones de 1883 y 1886, hasta llegar a la actual Constitución de 1991, la cual se ahonda en la descentralización territorial en términos políticos, fiscales y administrativos.

Sin embargo, las normativas en lo relacionado al ordenamiento territorial no tuvieron una definición de políticas - marco claras, que den directrices y lineamientos al país como Estado soberano al desarrollo y consolidación regional, aspectos cada vez más necesarios en un mundo globalizado y en donde los tratados de libre comercio ejercen presiones externas que de alguna manera condicionan el desarrollo hacia el fortalecimiento y concreción de lo regional.

Según Ángela Andrade, (2005) "esto ha permitido que se dé un desarrollo legislativo fragmentado y por supuesto una forma aislada de gobernar la totalidad del territorio". De aquí, la importancia del territorio como elemento integrador donde lo social, lo económico, lo cultural, lo administrativo y lo ambiental, hallen la interrelación entre sí, se consoliden en la región y sean gestionadas y ordenadas a partir de la Unidad de Gestión (UG), como la cuenca hidrográfica.

En los últimos 20 años, se ha venido operando la organización territorial del país desde una concepción descentralizada, pero con muchas debilidades pues aún es fuerte el centralismo del gobierno nacional en todo el territorio en cuanto a la toma de decisiones económica, sociales y de inversión públicas. A pesar de lo anterior, el artículo 286 de la Constitución de 1991, reconoce como entidades territoriales a los departamentos, municipios, distritos, territorios indígenas y establece la posibilidad de crear regiones, provincias ya sea como figuras administrativas de planificación o como entidades territoriales. Actualmente el país se encuentra dividido en entes territoriales políticoadministrativos, integrados por 32 departamentos (solo 3 tienen divisiones provinciales), 1123 municipios registrados en el DANE (los cuales se dividen en veredas ${ }^{1}$ ).

En el contexto del desarrollo de la Constitución del 1991, se han expedido varias normas para el ordenamiento del uso del suelo y no del ordenamiento territorial, como por ejemplo la ley 388/97, que instauró los Planes de Ordenamiento territorial (POT), y plantea desde una visión urbana el uso del suelo a nivel municipal, dejando por fuera la visión regional y el ordenamiento ambiental. Su visión fue elaborada desde el carácter urbano esencialmente. Después de diez años (1997-2007), se promulga el decreto 3600 del Ministerio de Ambiente, Vivienda y Desarrollo Territorial, cuya finalidad es la reglamentación de las disposiciones de las Leyes 99 de $1993^{2}$ y 388 de 1997, relativas a las determinantes de ordenamiento del suelo rural. A pesar de estos instrumentos de

\footnotetext{
1 Reciben el nombre de veredas en Colombia la división territorial al interior de un municipio, se identifican viviendas dispersas donde prima la unión comunitaria. Conectadas cada una de ellas por los llamados caminos veredales.

${ }^{2}$ Relativa a la política ambiental de Colombia, y que crea el Sistema Nacional Ambienta- SINA.
} 
planificación, no se ha alcanzado armonizar el tema urbano con el tema rural y el concepto de región aparece difuso.

Durante este mismo periodo la cuenca hidrográfica, se convierte en el enlace entre la ciudad y el campo, entre lo construido y lo natural, lo productivo y la sostenibilidad rural, entre lo institucional y lo territorial, al haberse expedido con el instrumento de planificación Decreto 1729 de 20023" "Guía Tecno-Científica para la Ordenación de Cuencas Hidrográficas", como política prioritaria en la ordenación del territorio en la cual se debe armonizar las distintas organizaciones administrativas, el departamento y el municipio. Por lo tanto, es en la cuenca hidrográfica donde se pueden armonizar los planes de desarrollo nacional, departamental y municipal, las inversiones públicas y privadas, y, por ende, la participación compartida de la sociedad civil.

En síntesis, no obstante existen instrumentos jurídicos, estos no están planteados para su articulación regional. Como surge de los instrumentos anteriormente mencionados ${ }^{4}$, la Cuenca Hidrográfica es el eje estructural para el ordenamiento del territorial, pero no se establece el método de gestión para su aplicación. Por lo tanto, se hace necesario la construcción de lineamientos conceptuales y metodológicos para la planificación y gestión sostenible del territorio, los cuales se propondrán a partir del estudio de caso de las subcuencas hidrográfica del Río Bogotá y su armonización con la Estructura Ecológica Regional (EER), desde una perspectiva regional. Así podrán armonizarse y articularse entre sí las instancias político-administrativas existentes y estas, a su vez, armonizarse con las dimensiones del desarrollo ambiental (coberturas y recurso hídrico), social, económica, administrativa y territorial y llegar a los lineamientos del desarrollo regional (departamental y municipal) que permitan articular la acción local y aprovechar las ventajas competitivas regionales. En efecto, es fundamental valorar la cohesión social, económica y geográfica de los territorios del área de la cuenca del Río Bogotá y la EER, y hacer de ella la base para el desarrollo del país.

En la Constitución de 1991, el concepto de región está contenido en el artículo 306 que se transcribe a continuación: "Dos o más departamentos podrán constituirse en regiones administrativas y de planificación, con personería jurídica, autónoma y patrimonio propio. Su objeto principal será el desarrollo económico y social del respetivo territorio". Sin embargo, se plantea la creación de las regiones a partir de los límites departamentales existentes, los cuales en muchas ocasiones no representan las realidades ambientales, culturales, históricas y económicas que poseen las poblaciones en los territorios creados. Se destaca que si bien la Constitución establece parámetros para flexibilizar estas decisiones $^{5}$, aquellas consideraciones no han sido tenidas en cuenta hasta la fecha.

Una de las propuestas que han sido elaboradas para la regionalización del país se gestó desde La Comisión de Ordenamiento Territorial (COT) en el año de 1994, ésta se centró en el estudio de La Región Administrativa y de Planificación (RAP), para lo cual propuso cartográficamente la regionalización de Colombia en 8 regiones, como agrupaciones

\footnotetext{
${ }^{3}$ Dicho Decreto lo expidió el_Instituto de Hidrología, Meteorología y Estudios Ambientales de Colombia. IDEAM en el año 2007

${ }^{4}$ Constitución de 1991, Ley 99, Ley 388, Decreto 3600, Decreto 1729, Proyecto de Ley Orgánica de Ordenamiento Territorial.

${ }^{5}$ Artículos 306 Dos o más departamentos podrán constituirse en regiones administrativas y de planificación, con personería jurídica y patrimonio propio. Su objetivo principal será el desarrollo económico y social del respectivo territorio. Artículo 307 La respectiva Ley orgánica de ordenamiento territorial, establecerá las condiciones para consolidar la conversión de la región en entidad territorial. La decisión tomada por el Congreso se someterá en cada caso a referendo de los ciudadanos de los departamentos interesados.
} 
departamentales $^{6}$, teniendo en cuenta principios como el equilibrio regional, la integración territorial y los fundamentos socio-históricos ${ }^{7}$. Así mismo, se desarrolló un amplio proceso normativo sobre la ocupación del territorio mediante la Ley 99 de 1993, sobre la política ambiental nacional, los planes de ordenamiento territorial con énfasis en lo municipal (POT, creados por la Ley 388 de 1997), y la ordenación de las cuencas hidrográficas en Colombia, a partir de los decretos (1729/02 - 1640/12), donde se establecen la metodología y los instrumentos de planificación, además se establece el nivel de jerarquía mayor en los Planes de Ordenamiento Territorial Municipal (POTM).

Finalmente, después de un largo proceso de más de veinte años fue promulgada la Ley Orgánica de Ordenamiento Territorial - $(\text { LOOT) })^{8}$ que se identifica con la Ley 1454 de 2011. Al reafirmar los principios rectores del ordenamiento territorial: la soberanía y unidad nacional; autonomía; descentralización; integración; regionalización; sostenibilidad; participación; solidaridad y equidad territorial; diversidad; gradualidad y flexibilidad; prospectiva; asociatividad; equidad social y equilibrio territorial.

Por lo tanto, con la promulgación de las leyes y decretos mencionados, se establece el marco legal territorial, que se convierte en la base de la ordenación del país, teniendo en cuenta las características ambientales en el territorio. Así, el proceso de ordenación de la cuenca hidrográfica recobra vigencia como máxima actuación en el territorio, donde programas y proyectos, tanto nacional como local, se involucran en uno solo, con el propósito de darle el impulso a la nación para el desarrollo equilibrado en asocio con las instancias departamentales y municipales, las cuales estarían directamente conformadas desde las cuencas hidrográficas.

\subsection{JUSTIFICACIÓN}

La falta de una fase de armonización que garantice la ejecución de los lineamientos conceptuales y metodológicos para la planificación, la gestión sostenible, desde una perspectiva regional a partir de la cuenca hidrográfica del Río Bogotá, ha hecho que en el pasado la implementación de los planes de ordenamiento no tenga ninguna trascendencia y se queden en simples propuestas. Es entonces necesario contar con una fase de armonización y plantear el proceso de regionalización en donde se establezcan claramente los recursos humanos, técnicos para la armonización de la variabilidad de instrumentos de planificación que permitan hacer de la Cuenca Hidrográfica el instrumento viable en la gestión y planificación regional.

Es importante para las Autoridades Ambientales conocidas como Corporación Autónoma Regional (CAR), que las herramientas conceptuales y metodológicas para la realización y de armonización de las gestiones públicas dispongan de los recursos humanos, técnicos, económicos, financieros para su ejecución, de tal manera que la Estructura Ecológica Regional, pueda integrarse como eje estructural de la unidad de cuenca hidrográfica y se vuelva una realidad para el ordenamiento territorial.

Para que el modelo propuesto de armonización como espacio de ordenamiento territorial, pueda llegar al planteamiento de la figura de la región a través de la cuenca hidrográfica,

\footnotetext{
${ }^{6}$ Con base en la experiencia de los CORPES, los cuales deberían por la Constitución del 91 convertirse en Regiones Administrabas de Planeación identificadas bajo la sigla RAP.

${ }^{7}$ Para mayor información sobre esta propuesta se puede ver: Op. Cit., FALS BORDA (1996)

${ }^{8}$ Ley 1454 de junio 28 de 2011 LOOT "por la cual se dictan normas orgánicas sobre ordenamiento territorial y se modifican otras disposiciones".
} 
los lineamientos y conceptos que se propongan en el presente trabajo deben ser la base para orientar a los diversos actores del sector público e institucionales comprometidas con el proceso de elaboración, aprobación y aplicación de los distintos instrumentos de planificación y de gestión en el territorio. Que se vuelvan una realidad la base de lo regional como parte del ordenamiento jurídico, posterior desarrollo y crecimiento del territorio, es lo que nos impulsa proponer el modelo regional con la visión de la cuenca hidrográfica, llevar desde un ejercicio propositivo la realidad de región.

\subsection{PLANTEAMIENTO DEL PROBLEMA}

Es largo el proceso que Colombia ha tenido que afrontar en temas relacionados con el ordenamiento del territorio y con la ordenación de cuencas hidrográficas. Durante las últimas décadas, si bien se han hecho propuestas de nuevas regiones desde enfoques económicos, sociales, político-administrativos, la cuenca hidrográfica se encuentra dentro del orden geográfico en los estudios ambientales (sistema hidrográfico), pero no aparece aquella como propuesta territorial del Estado.

Por lo tanto, se han expedido normas jurídicas, todas desde contextos territoriales diferentes con visiones encontradas entre distintos gobiernos o administraciones, lo que ha permitido que el desarrollo y el crecimiento del país queden en manos de los planes de desarrollo en el contexto nacional, departamental como municipal ${ }^{9}$ pero no se ha alcanzado a tener una legislación unificadora a nivel de país. Así mismo, no se ha avanzado en la regionalización territorial a partir de la definición de cuencas hidrográficas, considerando en estos aspectos los ambientales, sociales, económicos, jurídico y administrativos.

Por consiguiente, la Constitución de 1991, en sus artículos 306 y 307, abre la puerta a la regionalización en cuanto el artículo 306 cita: "dos o más departamentos podrán constituirse en regiones administrativas y de planificación, con personería jurídica, autonomía y patrimonio propio. Su objeto principal será el desarrollo económico y social del respectivo territorio". Mientras tanto el artículo $307^{10}$ precisa: "la respectiva ley orgánica previo concepto de la Comisión de Ordenamiento Territorial, establecerá las condiciones para solicitar la conversión de la región en entidad territorial".

Hay que resaltar la importancia de la región desde los principios rectores de la Ley Orgánica de Ordenamiento Territorial ${ }^{11}$. En el marco de esta Ley, la cuenca hidrográfica, es la que reúne las bases para la conformación regional al incorporar las relaciones geográficas, económicas, culturales y funcionales, a partir, de ecosistemas bióticos y biofísicos, de entidades locales, departamentales, de equipamientos e infraestructura económica y productiva y de relaciones entre las formas de vida urbana y rural.

Sin lugar a duda, ha habido progresos en la organización político - administrativa, de Colombia, pero es necesario avanzar en los ajustes institucionales y de competencias,

\footnotetext{
${ }^{9}$ Esto quiere decir que cada cuatro años asumen un nuevo gobierno con un nuevo plan de desarrollo; entendiéndose el plan desde la estructura de la Ley 152 de 1994 (Ley Orgánica del Plan).

Cabe anotar que este reconocimiento de la regionalización si bien tiene dos propósitos, el económico y el político, siempre dejando de lado la dimensión ambiental, además de no definir qué se debe entender por región.

${ }^{11} \mathrm{He}$ aquí algunos extractos que apoyan este argumento: "Regionalización. El ordenamiento territorial promoverá el establecimiento de Regiones Administrativas y de Planificación como marcos de relaciones geográficas, económicas, culturales, y funcionales, a partir de ecosistemas bióticos y biofísicos, de identidades culturales locales, de equipamientos e infraestructuras económicas y productivas y de relaciones entre las formas de vida rural y urbana, en el que se desarrolla la sociedad colombiana y hacia donde debe tender el modelo de Estado republicano unitario".
} 
encaminadas a solucionar los problemas correspondientes al ordenamiento territorial. Existe actualmente un modelo lineal de organización político-administrativo del Estado que no concuerda con la diversidad territorial del país, pues les da competencias por igual a todas las entidades, sin reflexionar sobre sus niveles de desarrollo diferenciales, ni sobre sus respectivas capacidades para asumirlas adecuadamente.

Igualmente, existen falencias en los mecanismos de articulación regional que originan una graduación más amplia de niveles de organización territorial y de planificación que hacen necesario establecer alternativas de organización territorial, que permitan la gestión y la gobernabilidad de acuerdo con la diversidad de territorialidades que caracterizan al país y que evolucionan permanentemente. Se requieren instancias y formas que faciliten la asociatividad flexible y ágil entre entidades territoriales de diferente orden.

Además la división político - administrativa de las entidades territoriales no están articuladas lo que, limita las posibilidades de una gestión pública integrada entre entes territoriales, con características socioculturales y/o económicas equivalentes, ya que, no existe una experiencia administrativa apropiada de integración territorial supramunicipal y supradepartamental. Consecuentemente, no hay políticas territoriales que reconozcan la gran diversidad regional del país para que se procure un desarrollo más equilibrado y por lo tanto, con mayor cohesión territorial.

Por lo tanto, es posible plantear la región como la alternativa política y administrativa, donde la cuenca hidrográfica es la unidad física, que, en armonía con la Estructura Ecológica Regional (EER), posibilita un desarrollo futuro y logra la socialización entre planes de desarrollo y planes de ordenamiento, entre políticas públicas y participación conjunta entre sociedad civil, gremios e instituciones ${ }^{12}$.

\subsection{HIPÓTESIS}

La organización territorial por departamentos en Colombia ha llevado a la centralización en las decisiones de las políticas públicas en la aplicación de los mecanismos e instrumentos territoriales de articulación regional, los cuales han dificultado la interrelación con los diferentes niveles de organización territorial y de planeación en la organización del territorio en cuencas hidrográficas posibilitando la aplicación de herramientas de planificación y de gestión territorial, promoviendo el uso sostenible desde la perspectiva regional y contribuyendo al desarrollo económico, social y administrativo.

Sin embargo, la unidad operativa adecuada para el avance del Modelo de Desarrollo Regional (MDR), postula la formulación de lineamientos conceptuales y metodológicos para la planificación de la gestión sostenible a través de la cuenca del Rio Bogotá desde una perspectiva regional, es decir, desde una perspectiva mayor a la propia cuenca al articular las subcuencas de Río Negro, Carare, Gachetá, Batá y Sumapáz. Con esta hipótesis se pretende verificar la existencia de las múltiples formas de regionalización de

\footnotetext{
${ }^{12}$ Para los fines de argumento, el ordenamiento ambiental territorial es un instrumento fundamental y complementario para el desarrollo; tiene que ver por una parte, con la organización político administrativa que adopte el Estado, para gobernar las diversas instancias territorialidades surgidas de la evolución económica, social, política y cultural del país en el siglo pasado y por otra parte, con los cambios en la ocupación física del territorio por las distintas externalidades, como resultado de la acción humana y de la misma naturaleza que ha venido afrontado los problemas políticos.
} 
la política pública, conocer los vacíos de articulación y coordinación, e igualmente identificar soluciones y alternativas, desde un nuevo MDR articulando la cuenca con la Estructura Ecológica Regional (EER).

Por lo tanto, la definición de cuencas hidrográficas $(\mathrm{CH})$ que consideren la realidad político-administrativa y tengan una visión ambiental, social y económica, posibilita reordenar al país con un criterio científico y conducente a establecer las políticas de desarrollo requeridas. Este criterio de organización y armonización entre la $\mathrm{CH}$ y EER hacia lo regional, donde se considera la diversidad de paisajes y posibilita que se establezcan las bases que demuestren la necesidad de definir formas de asociación político-administrativas flexibles y dinámicas entre entidades territoriales de diferente orden desde lo municipal y departamental.

\subsection{OBJETIVOS}

\subsubsection{Objetivo General}

A partir de las subcuenca Alta y Media del Rio Bogotá y de su articulación con la Estructura Ecológica Regional (EER), plantear un modelo de desarrollo regional, con el fin de determinar los lineamientos conceptuales y metodológicos para la planificación y la gestión sostenible del territorio.

\subsubsection{Objetivos Específicos}

Analizar los elementos conceptuales del desarrollo territorial con el fin de identificar los factores que inciden en la interpretación del concepto de región en el área de influencia de las subcuencas del Río Bogotá, a partir de los elementos conceptuales del desarrollo territorial.

$>$ Determinar los elementos de articulación de la Cuenca Hidrográfica del Río Bogotá con la Estructura Ecológica Regional, con el fin de considerar el nivel de desarrollo sostenible considerando tanto el ordenamiento territorial y como la gestión del recurso hídrico.

$>$ Identificar los lineamientos, conceptuales y metodológicos para la planificación y la gestión sostenible del territorio desde la visión de la cuenca hidrográfica y de su articulación a la EER aplicando para tal efecto el concepto de unidades de planificación y de gestión y de desequilibrios territoriales.

\subsection{MATERIALES Y METODOS}

\subsubsection{Tipo y Nivel de Investigación Cualitativa - descriptiva - analítica}

Para la presente investigación se plantea un diseño metodológico cualitativo, descriptivo y analítico que permita plantear un modelo de desarrollo regional desde la cuenca hidrográfica, definiendo fortalezas y debilidades. Se identificarán los procesos de configuración territorial como productos sociales, dinámicos y complejos, que están en permanente movilidad, construcción y desarrollo, y que en tal medida, admiten una lectura interdisciplinaria para analizar y comprender un contexto normativo o jurídico 
determinado, en el que le son transversales los valores, percepciones y significados de los sujetos que lo construyen ${ }^{13}$.

Se efectuará la recolección y el análisis de datos, denominados categorías, formulando preguntas, efectuando comparaciones y extrayendo esquemas e integrando dichos datos. Se busca construir y aportar conceptos y lineamientos para el ordenamiento territorial más que comprobarlos, considerando significados alternativos de los fenómenos a través de la identificación, desarrollo y relación de los conceptos constitutivos de la teoría territorial.

\subsubsection{La estrategia metodológica de investigación}

A través de las Subcuencas alta y media de la cuenca del Río Bogotá, se establecerá el área de referencia que permitirá la relación con la ciudad de Bogotá, por ser esta el área de mayor incidencia que ejerce sobre las subcuencas, especialmente en la Subcuenca media, la cual pertenece la ciudad de Bogotá, determinación que nos lleva a fijar espacios territoriales, como Río Negro, Río Carare, Río Gachetá, Río Batá y la cuenca del Río Sumapáz. Lo cual, nos permite identificar las bases territoriales desde la estructura municipal, el uso del suelo y determinar con ello, la Estructura Ecológica Regional. Además la aplicabilidad de cada una de las dimensiones del desarrollo, planteando el concepto de Unidades de Planificación y de Gestión Territorial, herramienta con la cual se determinan las relaciones y desequilibrios territoriales entre cada una de las dimensiones. Así mismo, se realizará un análisis de las políticas, normas y leyes expedidas en Colombia, para el desarrollo territorial y su aplicación a la realidad colombiana desde la perspectiva institucional.

Se recogerá la información de las características biofísicas de la región de referencia como la región objeto ${ }^{14}$ analizando tanto sus potencialidades como sus debilidades para incorporarlas al marco de referencia territorial.

Se identificarán algunas características de requerimiento a través de la dimensión ambiental (componente físico-biótico), social, económica y administrativa. Por lo tanto, la cartografía a utilizar será la planteada en los estudios del Plan de Ordenamiento y Manejo de la Cuenca Hidrográfica (POMCA 2002) del Río Bogotá, donde se encuentra definida la territorialidad y su división en subcuencas en alta y media. Se utilizará para su análisis la metodología del Biograma, mediante programa de ArcView, en donde cada una de las dimensiones del desarrollo será representada y analizada.

\subsubsection{Fuentes de información}

Las fuentes de información son la consulta a expertos en ordenamiento y gestión territorial con énfasis ambiental, servidores públicos a cargo de las políticas estudiadas (Departamento de Planeación Nacional (DNP), Gobernación de Cundinamarca, Corporación Autónoma Regional de Cundinamarca (CAR), Secretaria Distrital de Ambiente del Distrito Capital, entre otros), los estudios de centros de investigaciones, los planes de desarrollo, la legislación, los documentos de discusión de diferentes entidades y de la prensa, documentos del gobierno, los documentos de la Consejo Nacional de

\footnotetext{
${ }^{13}$ En este sentido, véase las características de la investigación de tipo cualitativo, señaladas por: Galeano, Eumelia. Diseño de proyectos en la investigación cualitativa, Fondo Editorial Universidad Eafit, Medellín, 2004, 82 p.

14 Para fines de intervención se entenderá por Región de referencia el territorio o áreas adyacentes que interactúan con el área de intervención directa, para el área llamada región o área objetivo nos referimos al área en la cual planteamos la intervención análisis y formulación.
} 
Políticas Económicas y Sociales (CONPES), los archivos, actas, proyectos de investigación, artículos de revista, producciones investigativas y monografías. Mediante la revisión y evaluación de la información obtenida se identificarán los factores que inciden en la interpretación del concepto de región. Se efectuará un análisis de los conceptos de territorio, de cuenca hidrográfica, de organización político administrativa y un análisis de los planes de desarrollo y territoriales del área de estudio.

\subsection{METODOLOGÍA DEL BIOGRAMA ${ }^{15}$}

La metodología del Biograma es un instrumento didáctico de trabajo, de fácil manejo, que permite estimar $y$, a la vez, representar de manera rápida, en una imagen, el grado relativo de desarrollo regional del proceso que se esté analizando; sus resultados serán la base para la valoración del territorio. Comprende un análisis y una interpretación de la naturaleza actual y la composición de los fenómenos de integración regional. (Sergio Sepúlveda 2008), el enfoque se hace sobre conclusiones dominantes o sobre unidades establecidas con anterioridad en la zonificación del territorio que llamaremos NOAT, lo cual conduce a datos específicos de las realidades de cada una de las unidades; con el fin de establecer equilibrios o desigualdades, que nos lleve a determinar acciones para el mejoramiento de la gestión territorial.

Según la metodología denominada de desequilibrios territoriales de Sergio Sepúlveda el BIOGRAMA", "Es el nombre dado al diagrama multidimensional y a los índices respectivos que representan gráficamente el Estado de una unidad". Dicha imagen revela el grado de desarrollo de la unidad de análisis en cuestión, los aparentes desequilibrios entre las diversas dimensiones del desarrollo, por ende, los posibles niveles de conflicto existentes. Estas dimensiones del desarrollo evidencian la lógica que las vincula y, al mismo tiempo, representa el nivel de desarrollo de acuerdo con las características presentadas en la aproximación dimensional del diagnóstico. Para realizar el Biograma, se utilizarán indicadores reales de cada una de las dimensiones en lo económico, social, ambiental y político-institucional. La imagen del Biograma, se representa mediante un gráfico de telaraña, en la cual cada radio (eje) representa un indicador de cálculo de cada dimensión. (Véase Figura 1. $1^{17}$ ).

Mediante esta representación gráfica se visualiza, de manera didáctica e instantánea, el estado de desarrollo general de la unidad de análisis en un momento determinado. También permite analizar varias unidades de ambientales (UA), en el mismo momento y representar la situación relativa de cada una de ellas y, por ende, realizar un análisis comparativo. Adicionalmente, la posibilidad de contar con representaciones gráficas para cada una de las dimensiones, permite establecer el grado de desempeño de cada una de ellas. Eso proporciona una primera aproximación del grado de estabilidad de cada unidad

\footnotetext{
${ }^{15}$ Conceptualmente, el Biograma es un diagrama multidimensional y los Índices respectivos que representa gráficamente el "estado de un sistema". Dicha imagen revela el grado de desarrollo sostenible de la unidad de análisis en cuestión, los aparentes desequilibrios entre las diversas dimensiones y, por ende, los posibles niveles de conflicto existentes. Además de generar un "estado de la situación actual" de la unidad de planificación territorial estudiada, el Biograma, por su propia naturaleza, permite realizar un análisis comparativo del sistema analizado en diversas dimensiones del desarrollo (Sergio Sepúlveda 2008).

${ }^{16}$ Dicha metodología permite estimar el nivel de desarrollo sostenible de territorios. Ver Sergio Sepúlveda S. - san José de Costa Rica. :IICA, 2008132 páginas. (Desarrollo Rural; desarrollo Regional; Desarrollo Sostenible; Ordenación de Recursos).

${ }^{17}$ Ver la Metodología para estimar el Nivel de Desarrollo Sostenible de Territorios, Pagina 11, Dimensiones del desarrollo.
} 
territorial en forma individual, y permite formarse una idea de la contribución de cada dimensión del desarrollo al sistema regional de la cuenca hidrográfica ${ }^{18}$.

Figura 1. 1. DIAGRAMA METODOLÓGICO.

\begin{tabular}{|c|c|}
\hline \multicolumn{2}{|c|}{ DESEQUILIBRIOS TERRITORIALES } \\
\hline $\begin{array}{c}\text { BIOGRAMA } \\
\text { GRAFICO TELARAÑA }\end{array}$ & $\begin{array}{c}\text { IMAGEN DEL DESARROLLO } \\
\text { DE UN TERRITORIO }\end{array}$ \\
\hline S10 S11 $\begin{array}{l}1.00 \\
0.80 \\
0.60 \\
0.40 \\
0.20 \\
0.00\end{array}$ & $\begin{array}{l}\text { En este caso en particular, para la estimación del Biograma se } \\
\text { utilizaron } 11 \text { indicadores por lo que el gráfico de telaraña } \\
\text { contará con } 11 \text { radios. Por definición, cada uno de los radios del } \\
\text { círculo tiene un valor de } 1 \text {, por lo que el valor de cada indicador } \\
\text { individual variará entre } 0 \text { y } 1 \text {, siendo } 0 \text { el nivel mínimo de } \\
\text { desempeño y } 1 \text { el máximo. De esta manera, cuanto más amplia } \\
\text { y homogénea sea el área delimitada, superior será el } \\
\text { desempeño de la unidad estudiada. Por lo tanto, se presenta el } \\
\text { esquema de desequilibrios territoriales de algunos centros } \\
\text { urbanos representativos dentro del área de estudio. } \\
\text { El grafico: Municipio de Soacha aspectos sociales. }\end{array}$ \\
\hline
\end{tabular}

Fuente: Metodología Biograma Desequilibrios territoriales. Sergio Sepúlveda, 2008.

Para el nivel de argumentación y de análisis, el Biograma establece cinco colores para la caracterización de cada una de las unidades de planificación territorial establecidas. Cuando el área sombreada equivale a un índice por debajo de 0.2 , éste se representa en rojo, simbolizando un estado de la variable utilizada dentro de la unidad analizada con una alta probabilidad de colapso; para niveles entre 0.2 y 0.4 , se utiliza el color anaranjado, indicando una situación crítica; de 0.4 a 0.6 el color es amarillo, correspondiendo a una variable dentro de la unidad de análisis inestable; de 0.6 a 0.8 la representación es en azul, simbolizando una variable estable; finalmente, de 0.8 a 1 el color es verde y se considera como la situación óptima de la variable utilizada dentro de la unidad de planificación territorial. A continuación se relaciona la barra de colores con su respectivo significado. (Véase Figura 1.2.), al igual el uso del Biograma permitirá alcanzar los objetivos específicos dos (2) y tres (3).

Dicha metodología, ha tenido resultados especialmente en el caso de Colombia la versión 2005 de desequilibrios territoriales fue complementada y adaptada a la información estadística de Encuesta de Hogares para generar un proceso de evaluación y monitoreo del Proyecto Áreas de Desarrollo Alternativo Municipal (ADAM). La presentación de la nueva versión 2008 de este instrumento se ha estructurado de la forma donde se presenta una síntesis de los elementos conceptuales del desarrollo sostenible de los territorios rurales y el enfoque territorial rurales, la metodología del Biograma, se ha utilizado como instrumento en tres países, a saber Brasil, (Brasil: Los territorios de Medio Alto Uruguay, en Río Grande del Sur y El Suroeste del Paraná). Colombia, (Corredor Ipiales-Santander de Quilichao y Subregión de Atrato. y Perú, (Las regiones de Tumbes y Ayacucho).

\footnotetext{
${ }^{18}$ Instituto Interamericano de Cooperación para la Agricultura; metodología para estimar el nivel de desarrollo sostenible territorios, pagina 26 Sergio Sepúlveda 2008.
} 


\section{Figura 1. 2. EL ESTADO DE LA VARIABLE EN LA UNIDAD DE PLANIFICACIÓN TERRITORIAL SEGÚN LOS COLORES DE LA METODOLOGÍA DEL BIOGRAMA}

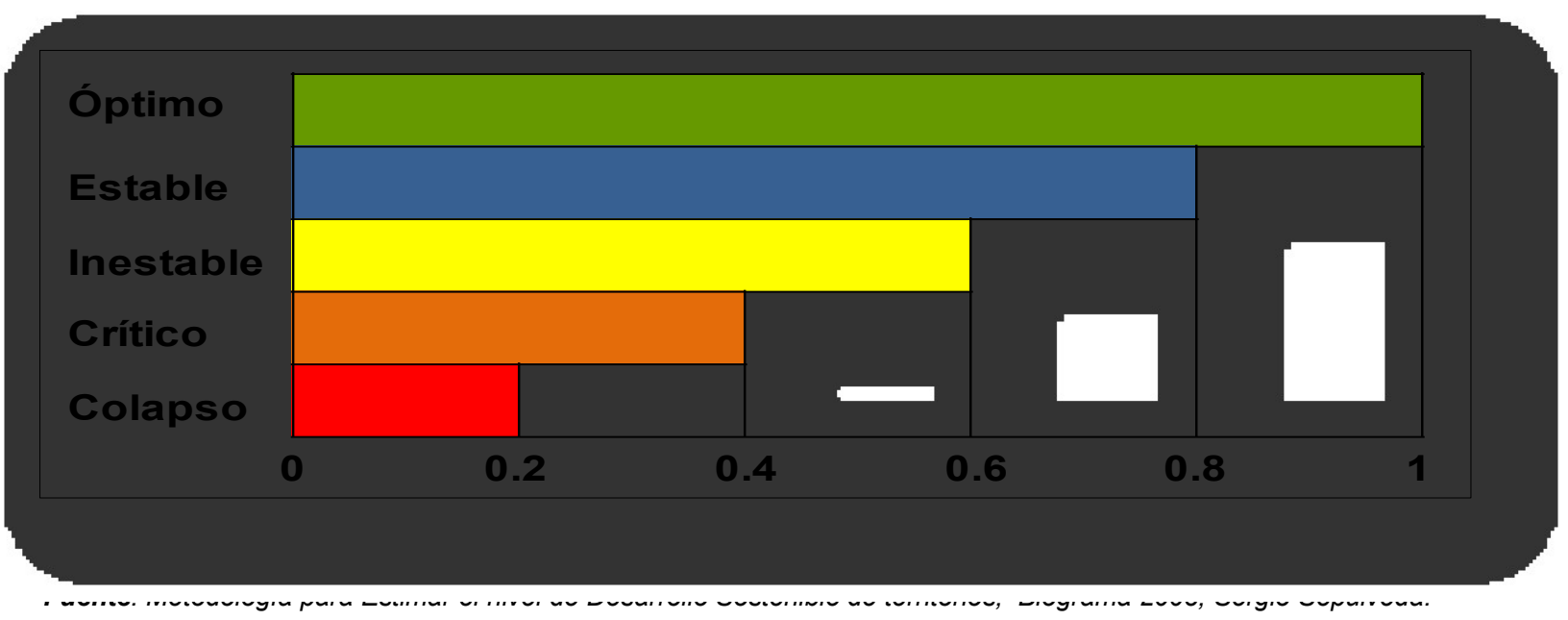

\subsection{PRODUCTOS Y ALCANCES}

El principal producto de esta investigación es la elaboración de una propuesta metodológica de desarrollo regional a partir del concepto de la cuenca hidrográfica que contenga los lineamientos conceptuales y metodológicos para la planificación y gestión sostenible del territorio. Así mismo, se definirán las etapas en que debe abordarse la planificación y gestión desde la perspectiva regional. La cuenca Alta y Media del Río Bogotá y su área de influencia determinada por las Subcuencas, localizadas en el departamento de Cundinamarca, es el caso de estudio sobre el cual se hace el análisis.

El trabajo investigativo, como resultado de la tesis para optar por el título de Magister en Manejo y Gestión de Cuencas Hidrográficas, podrá ser consultado por otros investigadores, la academia, los funcionarios del sector público y del sector privado. En él encontrarán lineamientos y conceptos metodológicos con la ayuda de mapas y de gráficas que les permita un mejor entendimiento en la percepción del tema en Colombia, lo que permite localizar los centros de división territorial o centros poblados de un municipio, un enlace de lo regional para el desarrollo de la Gestión y de la Planificación Territorial a partir de la ordenación y Manejo y Gestión de cuencas hidrográficas. 


\section{CAPÍTULO}

MARCO CONCEPTUAL Y TEÓRICO 


\subsection{ELEMENTOS CONCEPTUALES Y CRITERIOS ESTRUCTURANTES PARA EL ANÁLISIS TERRITORIAL E INCORPORACIÓN AL TEMA REGIONAL.}

En el marco del cumplimiento del objetivo general, planteado para la realización de los lineamientos conceptual y metodológico, para la planificación y la gestión sostenible desde una perspectiva regional, e incorporando la cuenca hidrográfica, como una de las unidades físicas para el debate del nuevo ordenamiento político y administrativo; el trabajo de grado planteará la cuenca hidrográfica en armonía con la Estructura Ecología Regional como alternativa institucional, en el debate de asociarlo a lo regional como instancia en un orden administrativo que cambie las bases de ordenar jurídicamente el territorio colombiano.

El elemento que se establece como conector para el desarrollo de los objetivos específicos, lo constituye la cuenca hidrográfica y su armonización territorial, a través del concepto territorial y de la Estructura Ecológica Regional. Además, se presenta la estructura general con base a las necesidades detectadas en los antecedentes y el planteamiento del problema, igualmente a partir de indagar desde los resultados resientes en la información secundaria estudiada establecida a lo largo de los últimos años, identificándose las estrategias conceptuales y metodológicas que aporten al proyecto, con ello acercarnos al desarrollo del marco conceptual y teórico.

Seguidamente y teniendo en cuenta que para tal fin, se debe incorporar de manera holística y sistémica, el desarrollo oportuno del concepto de dimensiones del desarrollo, las cuales lograrán identificar a su interior las potencialidades y problemas que se propongan para su ordenación. El fin, es profundizar en cada una de las dimensiones en lo ambiental, social, económico, administrativo y territorial el procesamiento metodológico para el fortalecimiento regional, que permita ordenar, planificar y estructurar el nuevo enfoque de la organización político administrativa en Colombia; hoy en día conformadas por las instancias Departamental y Municipal.

Este tipo de trabajos como investigación académica puede aportar tanto a los institutos de investigación como al mismo gobierno, sector privado y a los estudiantes especializados en dichos temas, teniendo en cuenta que en Colombia, se han venido desarrollando durante los últimos diez años, posturas de organización espacial, con la puesta en marcha de un amplio marco legal y normativo que identifica las bases estructurales de la nueva visión regional, las cuales desde un enfoque participativo se ha logrado plantear un nuevo esquema de gestión y planificación en el desarrollo territorial a través de los Planes de Ordenamiento Territorial denominados POT; cuyo resultado desde una visión muy urbanística llevó al planteamiento de los usos del suelo, descuidando básicamente la articulación con la territorialidad en la ruralidad por supuesto, muy distante del tema regional; a los cinco años exactamente se complementa en el marco conceptual regional, a través de las Corporaciones Autónomas Regionales (CAR), y con la aplicación de la política ambiental, le da un nuevo orden a la visión y organización territorial, constituyéndose el Ordenamiento de Cuencas Hidrográficas, de mayor jerarquía que los Planes de Ordenamiento Territorial (POT). Los Planes de Ordenación y Manejo Ambiental de Cuenca Hidrográfica (POMCA); enmarcándose en la conformación regional al poderse articular en ello, departamentos y municipios, compartiendo entre cada uno de los territorios los servicios ambientales ${ }^{19}$.

\footnotetext{
${ }^{19}$ Entender la cuenca hidrográfica definida como la Unidad de territorio donde las aguas fluyen naturalmente conformando un sistema interconectado, en la cual interactúan aspectos biofísicos, socioeconómicos y culturales; como elemento de ordenación y manejo del desarrollo territorial, teniendo lo ambiental como un insumo muy importante para poder indagar a su interior las bases conceptuales y metodológicas del desarrollo regional.
} 
Entrada la primera década del siglo XXI, como complemento a los conceptos de crecimiento en el desarrollo urbano, se fortalece la expansión de los territorios urbanos en áreas agrologicamente aptas para el desarrollo agrícola y ganadera, cambios al paisaje natural por uno de mayor impacto como es la vivienda para estratos altos, vivienda dispersa para lo cual se ha venido reglamentando el uso del suelo rural y el desarrollo de actuaciones urbanísticas de parcelación y edificación en este tipo de suelo, (Decreto 3600 de 2007). Lo anterior ha ocasionado un gran debate sobre el desarrollo del territorio, asociado al ordenamiento del suelo en la lotificación de grandes áreas urbanizables para la vivienda y servicios complementarios en suelo rural, que acarrea presión al medio ambiente. Lo anterior genera un crecimiento de las cabeceras municipales que no han podido afrontar las demandas del pasado en temas de infraestructura productiva especialmente y básica; además de poner en riesgo estratégicamente la Estructura Ecológica Principal de su territorio (EEP) ${ }^{20}$.

Por lo tanto, a partir de las relaciones Nación - Municipio, se puede decir que los planes de ordenamiento territorial al igual que el Ordenamiento y Manejo Integral de Cuencas Hidrográficas se complementan en aspectos de ordenamiento y de manejo territorial, porque son de carácter supramunicipal e intermunicipal y se regulan a través de determinantes de superior jerarquía y les corresponden a las "Corporaciones Autónomas Regionales CAR o de Desarrollo Sostenible" definir la aplicación de los lineamientos ambientales en lo referente, por ejemplo, a la extensión máxima de los corredores viales suburbanos respecto del perímetro urbano de los centros poblados y velar por la zonificación ambiental del territorio.

Para la construcción del marco teórico y conceptual, y, la realización de los lineamientos para la planificación y la gestión sostenible desde una perspectiva regional, e incorporar la cuenca hidrográfica como una de las unidades físicas para el debate del nuevo ordenamiento político y administrativo. Es básico entender la coexistencia de varios instrumentos de planificación que inciden directamente en el ordenamiento y la asociatividad en la conformación de nuevos territorios trayéndose al debate diario la conveniencia de nuevos horizontes territoriales y asociaciones administrativas en el manejo integral y sostenible del territorio.

Cabe anotar que los mismos instrumentos de planificación reconocen el manejo del concepto de Unidades de Planificación y de Gestión (UPG) como planteamiento para la gestión del territorio; teniendo en cuenta las características ambientales (biofísicas), sociales y económicas, e incorporando los conceptos de gestión en una verdadera planificación territorial y desarrollo regional, aporte metodológico que será abordado en el capítulo de formulación del presente trabajo.

A continuación, se presenta el marco conceptual y teórico que ayuda a entender y profundizar en los principios de ordenación territorial desde una visión regional (véase figura 2.3.). La importancia de cada uno de los conceptos, es valorada en los aportes teóricos que pueden incidir en el insumo, para llegar a los planteamientos de nuevos escenarios deseados teniendo en cuenta el marco conceptual y teórico el ordenamiento territorial entre ellos; el contexto regional; La zonificación ambiental y su relación hacia la Estructura Ecológica Regional; principales problemas asociados a la dimensión ambiental en la conservación, uso y recuperación del recurso hídrico en la región capital; la asociación e integración territorial; la planificación territorial; el enfoque sistémico; la cuenca hidrográfica como elemento estructurante del desarrollo

\footnotetext{
${ }^{20}$ Definida por el Decreto 3600 de 2007 como el cconjunto de elementos bióticos y abióticos que dan sustento a los procesos ecológicos esenciales del territorio, cuya finalidad principal es la preservación, conservación, restauración, uso y manejo sostenible de los recursos naturales renovables, los cuales brindan la capacidad de soporte para el desarrollo socioeconómico de las poblaciones.
} 
regional; una aproximación a lo regional: algunos Ejemplos de ordenamiento territorial; la incidencia de cada una de las dimensiones del desarrollo en el concepto de región.

\section{Figura 2.3. MARCO CONCEPTUAL Y TEÓRICO DEL ORDENAMIENTO TERRITORIAL}

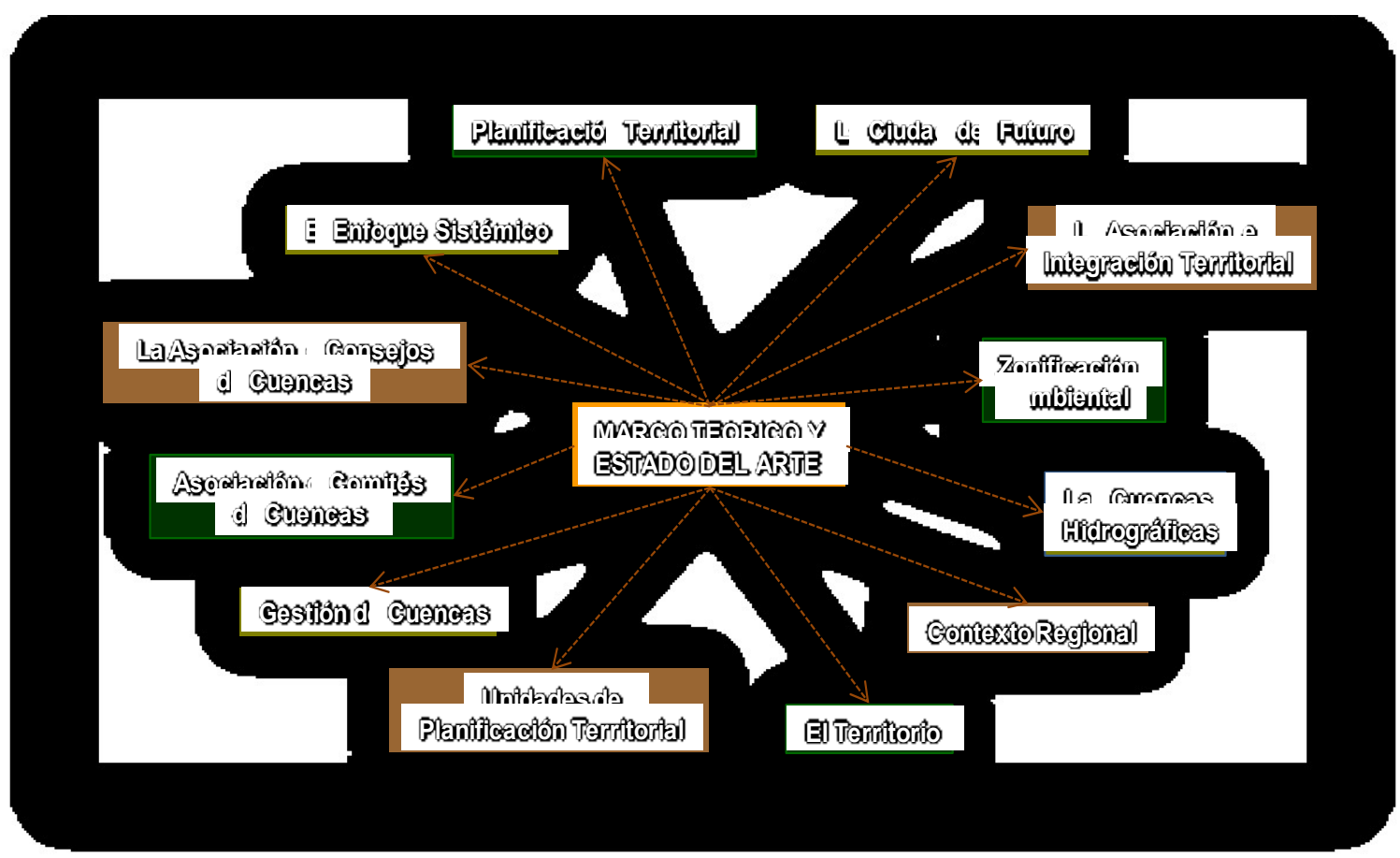

Fuente: Elaboración propia

\subsection{MARCO CONCEPTUAL Y TEÓRICO DEL ORDENAMIENTO TERRITORIAL}

La complejidad del marco conceptual y teórico de la problemática territorial y regional constituye tal vez la causa categórica de la ausencia de un consenso amplio en el tratamiento de los problemas territoriales. No resulta fácil renunciar a los enfoques teóricos de un tipo de desarrollo regional inspirado en el desarrollo y en el crecimiento de los postulados económicos.

Por lo tanto, la Cuenca Hidrográfica, como instancia para la integración regional es incorporar la dimensión ambiental al nuevo concepto, teniendo la Estructura Ecológica Principal como su principal elemento estructural donde el diseño, construcción y mantenimiento en la prestación de servicios ambientales por comparación con la estructura existente en el territorio, es posible proponer un esquema de ordenamiento que tienda a la gestión conjunta y adecuada del territorio, teniendo en cuenta cuatro modalidades básicas de uso: la conservación, el uso sostenible, la restauración y la recuperación ambiental.

Sin embargo, el marco teórico aproxima la descripción del análisis territorial y regional que se comentó en la introducción y antecedentes e integra la teoría y la práctica a la investigación. Por lo tanto, la importancia que tiene el marco teórico en la conceptualización del desarrollo regional sería la inclusión de la Cuenca Hidrográfica como la unidad física en el conocimiento del territorio. La Estructura Ecológica Principal analiza la aplicación de los conceptos de los ecosistemas estratégicos (Marques y Acosta, 1994; Márquez, 1996), propone "ciertos ecosistemas y áreas naturales que prestan servicios ecológicos de los cuales dependen en alto grado la viabilidad de procesos sociales", tal es el caso, por ejemplo, de áreas y ecosistemas, 
como los páramos como de Chingaza, que proveen agua o energía a la ciudad de Bogotá. El concepto Estructura Ecológica Principal va más allá, al considerar que la provisión adecuada de servicios ecológicos depende de un conjunto articulado de elementos naturales (bosques, páramos, ríos entre otros y que incluye en especial los ecosistemas estratégicos), los cuales conforman una estructura equiparable a los embalses y a los acueductos para proveer agua, a la infraestructura vial para movilidad, a los tendidos eléctricos para el caso de la distribución de energías, es una herramienta que facilita el proceso de conceptualización, entendiendo las dinámicas posibles para las asociaciones e integración de los territorios hoy existente, pero desarticulado a las decisiones e inversiones administrativas y políticas como es el caso de la figura administrativa de los departamentos actuales.

\subsubsection{El Territorio}

Son innumerables las interpretaciones del territorio que se han realizado tanto desde la academia como desde el Estado y, finalmente, desde la planificación y la ordenación. Para autores como Alberto Mendoza Morales y Jaime Castro, el territorio puede ser entendido como "el resultado de un proceso de construcción social, que depende de la calidad de sus instituciones, de la organización de sus actores más representativos, de los planes y estrategias de desarrollo que se consigan para afrontar los desafíos y oportunidades, así como de la capacidad de decisión para dirigir su propio desarrollo"21

Otras definiciones utilizadas en el ámbito de la geografía como contenido conceptual. Han llevado a plantear que el territorio es el objeto por excelencia de la investigación geográfica frente a otros términos también muy usados tales como es el paisaje, la región geográfica o el lugar. Desde la tradición física, el término territorio puede entenderse como un sinónimo de superficie terrestre, es decir, de relieve o, en su sentido más amplio como el que le otorgaba F. Von Richthofen, de la interface entre litosfera, atmosfera e hidrosfera.

Desde la tradición ecológica, el término territorio puede entenderse como sinónimo de medio natural, con lo que suele hablarse de relaciones entre sociedad y territorio, mientras desde la tradición espacial, el territorio se entiende como un sistema espacial, es decir, como un conjunto de lugares interconectados por redes y flujos horizontales. También puede usarse como sinónimo de espacio absoluto sobre el que los distintos objetos y fenómenos se depositan. Desde la tradición paisajística, el territorio o bien entendido como el sinónimo de paisaje natural, de paisaje cultural, de conjunto de construcciones, aprovechamiento y usos que una sociedad hace sobre el suelo. (Alberto Mendoza Morales SGC 2011).

El territorio de lo social, se entiende como el sistema socio ecológico, que reúne la sociedad y el medio que ésta habita. El territorio se estudia tanto en sus vínculos verticales (sociedad y medio físico), como en sus características (organización económica, política, demográfica, espacio construido, medio físico en cuanto condiciona a la sociedad, entre otras), como en sus vínculos horizontales (entre los diversos sub-territorios que lo conforman).

\footnotetext{
${ }^{21}$.Definiciones más representativas utilizadas en los libros de Alberto Mendoza Morales Colombia Estado Región; además de Jaime Castro en su libro la Cuestión Territorial.
} 


\subsubsection{La incidencias de las propuestas de Estructura Ecológica Principal (EPP), para la conformación del área de estudio}

El diseño de propuestas de EEP, se ha centrado para la región central del país con un área diferente para cada propuesta; llevando a procesos diferentes para cada administración de turno, pero dejando para el lector un margen de experiencia que puede ser motivada para planeamientos acordes.

La Estructura Ecológica Principal (EEP) es, ante todo, un eje estructural de ordenamiento ambiental territorial en tanto contiene un sistema espacial, estructural y funcionalmente interrelacionado, vital para el mantenimiento del equilibrio ecosistémico del territorio, de manera que se garantice la planificación para ordenar espacialmente los usos del suelo y el manejo del agua, para garantizar la conservación de la biodiversidad y los servicios ecosistémicos (MADV- DDT, 2010).

Por lo tanto, la EEP debe estar constituida por todos aquellos elementos del paisaje (áreas y coberturas) presentes y futuros, necesarios para el mantenimiento del correcto funcionamiento del sistema socio-ecológico, para garantizar el adecuado suministro de servicios ecosistémicos (ambientales), básicos para el bienestar humano. En 1988 Van Der Hammen, escribió el plan ambiental de la subcuenca alta del Río Bogotá, en el cual expresó "la necesidad de crear una propuesta de Estructura Ecológica para la Sabana de Bogotá para la optimización de una planificación ambiental futura".

En el 2003, dos notables investigadores colombianos, Van der Hammen y Andrade, hacen una aproximación a la propuesta de Estructura Ecológica Principal, evaluando el estado de conservación de los distritos biogeográficos del país, como instrumento de uso del suelo que depende de la capacidad de carga de los ecosistemas la función y de la estructura de los mismos. Según van der Hammen (2003), la EEP, es: "La propuesta de ordenamiento de la cobertura vegetal, del uso y del manejo de la tierra y del agua, que garantiza la conservación (preservación y restauración) de la biodiversidad, los recursos biológicos y los servicios ambientales." La implementación de la EEP, implica en el futuro el estudio detallado de las áreas a incorporar y la definición de categorías según los Sistemas de Áreas Protegidas.

Con base a las propuestas de EEP, la Mesa de Planificación Regional, hace unos lineamientos para la consolidación de la EEP y establece valores de conservación así como unos objetivos de manejo y unas estrategias para su conservación, restauración y aprovechamiento sostenible. Posteriormente en el 2008, el Instituto de Recursos Biológicos "Alexander Von Humboldt (IAVH)", elaboró la propuesta de estructura ecológica para la región central en la cual estaban incluidos los departamentos de Cundinamarca, Boyacá, Tolima y Meta.

Como lo estableció Von Humboldt, dicha estructura está conformada por dos grandes componentes: la Estructura Ecológica Principal (o de soporte), que corresponde al conjunto de ecosistemas naturales interconectados estructural y funcionalmente, necesarios para sostener los procesos y funciones ecológicas esenciales y la oferta de servicios ecosistémicos que soportan el desarrollo socioeconómico y cultural de las poblaciones en el territorio; y la infraestructura ecológica que corresponde al conjunto de elementos construidos o transformados por el hombre que prestan los servicios ecosistémicos que soportan el desarrollo socioeconómico y cultural de las poblaciones en el territorio.

Por último, en el 2010, Remolina hace la propuesta de Estructura Ecológica Regional (EER) para lá Region. Capital, la Guía técnica para su declaración y consolidación. 
Según Remolina, "La finalidad de la Estructura Ecológica Regional es la de preservación, rehabilitación y recuperación de la estructura y de la función de las áreas productoras de servicios ecosistémicos que sostienen la vida y el desarrollo del territorio".

Las diferentes propuestas de estructura ecológica (EEP y EER), tienen el valor de ser las primeras en el país en poner en el papel el concepto de estructura ecológica con visión regional. La propuesta de Van Der Hammen, tiene un valor ecológico grande y buscaba armonizarse con el área distrital para hacer una propuesta más ajustada a la realidad, mientras la propuesta de $\mathrm{I} \mathrm{AVH}$, es la más ambiciosa de todas en cuanto a los municipios incluidos.

Según el MADV DDT (2010), la EE, es ante todo un eje estructural de ordenamiento ambiental territorial, en tanto contiene un sistema espacial, estructural y funcionalmente interrelacionado, vital para el mantenimiento del equilibrio ecosistémico del territorio, de manera que se garantice la planificación para ordenar espacialmente los usos del suelo y el manejo del agua, para garantizar la conservación de la biodiversidad y los servicios ecosistémicos.

Para esto, se debe definir la EEP, de la nación hacer la delimitación de los páramos y de los humedales, realizar el deslinde de los humedales y la zonificación y la ordenación de reservas forestales nacionales. Una de las metas del actual Plan Nacional de Desarrollo 2010 - 2014 (PND), es precisamente definir la EEP de la Nación a escala (1:100.000 a 1:500.000), lo que implica que el $100 \%$ de reservas forestales de la Ley $2^{a}$ de 1959 , sean redelimitadas, ordenadas y zonificadas ambiental y territorialmente (PND 2010-2014).

De esta manera, según Van Der Hammen y Andrade, (2003), Instituto de Investigación de Recursos Biológicos Alexander Von Humboldt (IAVH), (2008), la EE, puede entenderse como la sumatoria de las áreas consideradas bajo la expresión de una norma como Determinantes Ambientales del ordenamiento territorial (es decir, de aquellas definidas y delimitadas mediante actos administrativos según el numeral. 1 del artículo decimo de la Ley 388 de 1997),cita: "las áreas de soporte ecológico (infraestructura ecológica) que brinden representatividad ecosistémica y claves para la prestación de los servicios ecosistémicos y las áreas útiles para mitigación y adaptación a riesgos relacionados con el cambio ambiental'22, lo cual no está determinado específicamente en ninguna de las propuestas de EEP, ya que es un sistema dinámico que se tiene que adaptar al tiempo en el cual se está ejecutando y

22 El Cambio ambiental es el resultado de un conjunto de cambios atmosféricos, climáticos, ecológicos y biogeoquímicos acelerados y acentuados por las actividades humanas de asentamiento, producción, extracción y consumo, que solos o combinados, conllevan cambios multiescalares en el funcionamiento del sistema terrestre (Duarte et al. 2006; Steffen et al. 2004; Vitousek 1994), de manera que afectan directamente el bienestar y la supervivencia humanas en el planeta entero. Al interior del cambio global ambiental se identifican los siguientes procesos (Vitousek 1994; Steffen et al. 2004): (i) Los procesos climáticos - atmosféricos (ej. cambio climático, variabilidad climática, lluvia ácida, deterioro de la capa de ozono); (ii) la pérdida de biodiversidad (ej. transformación de las coberturas -ecosistemas- y usos del suelo, el rompimiento de barreras biogeográficas, invasión de especies, sobrexplotación) y (iii) la modificación de ciclos biogeoquímicos (ej. cambio en ciclos de Nitrógeno, Fósforo, Potasio, Carbono y la contaminación). De acuerdo con la tipificación de impulsores de transformación y pérdida de biodiversidad definidos y descritos en el documento de Política Nacional de Gestión Integral para la Conservación de la Biodiversidad y sus Servicios Ecosistémicos (PNGIBSE), el cambio ambiental en Colombia es el resultado de la combinación de al menos cinco procesos principales:

a. Cambio de uso de la tierra, ocupación del territorio y fragmentación de los ecosistemas que producen transformación o pérdida biodiversidad.

b. Disminución, pérdida o degradación de elementos de los ecosistemas nativos y Agroecosistemas.

c. Invasiones biológicas.

d. Contaminación y toxificación.

e. Cambio climático. 
no terminar siendo una fotografía de un momento determinado. Teniendo en cuenta que en el ordenamiento regional denominará la EER, constituida la base fundamental de la gestión, planeación y ordenamiento del territorio; siendo útil para la toma de decisiones de uso del suelo, procurando hacerlo más sostenible y productivo en el tiempo, lo que redundará en el mejoramiento de las condiciones de la población que lo habita.

\subsubsection{La Constitución de la Región Administrativa y de Planeamiento Especial (RAPE), entre el Distrito Capital de Bogotá y el Departamento de Cundinamarca.}

En el año 2012, comienza en Colombia, con cambios en las administraciones municipales, cambios que se deben tener en cuenta por los nuevos Planes de Desarrollo que deben tener como visión la integración regional. A esto se suma la recién estrenada Ley Orgánica de Ordenamiento Territorial (LOOT), donde se vislumbra el proyecto de regionalización con la Región Administrativa de Planeación para la Región Central, y la revisión y ajuste de los Planes de Ordenamiento Territorial, en varios municipios dentro del área tanto en el área general de la cuenca del Río Bogotá como de la EER. Todo aquello, implica necesariamente repensar los territorios en varios de los contextos territoriales con los retos de hoy y las necesidades del futuro.

No se puede dejar de un lado las ciudades que cada vez se corresponden menos con los límites municipales en muchas zonas del área de estudio, por el expansionismo de sus áreas hacia su entorno rural $\mathrm{y}$, por supuesto, la metropolización, si bien, es un fenómeno que lleva ya un tiempo manifestándose en el territorio de la Región Capital entre la ciudad de Bogotá D.C., y el departamento de Cundinamarca, no se ha reconocido lo suficiente a nivel institucional y de políticas como la unidad de gestión válida para el desarrollo y la planificación de los territorios. La escala y la visión regional es entonces uno de los temas claves para la gestión urbana y rural de hoy en el territorio que comprende tanto la cuenca del Río Bogotá como su interrelación espacial con la EER.

Por lo tanto, a partir de la promulgación de la Constitución Política de 1991, y conforme a su artículo 325, el Distrito Capital, podrá conformar una región con otras entidades territoriales de carácter departamental, con el fin de garantizar la ejecución de planes y programas de desarrollo integral como también la prestación oportuna de los servicios a su cargo. Posteriormente se dieron algunos actos administrativos como respaldo a la iniciativa como el Decreto ley 1421 de 1993, quedan iniciativas al Alcalde Mayor de la ciudad de Bogotá para presentar iniciativas de carácter asociativo, de conformidad con las normas; igualmente, el Plan de Desarrollo Económico, Social, Ambiental y de Obras públicas para Bogotá D.C., 2008 - 2012 "BOGOTÁ POSITIVA PARA VIVIR MEJOR" incluyó el objetivo estructurante "Ciudad Global", como la meta para la creación de la Región Administrativa y de Planeamiento Especial.

Según la exposición de motivos del proyecto de Acuerdo distrital por la cual se autoriza la constitución de la Región Administrativa y de Planeación Especial, "esta perspectiva que asume el concepto de región como categoría de análisis, a más de consultar realidades que rebasan los límites político-administrativos, exime de recurrir a la descripción territorial como elemento definitorio de la RAPE. Así, la RAPE está llamada a ser una entidad abierta cuya configuración puede variar en tanto está determinada por la densidad de las relaciones resultantes de la interacción de los diversos factores. Su diseño, en consecuencia y consonancia con el concepto de región debería reconocer, potenciar y fortalecer esas relaciones entre los territorios". 
De acuerdo a lo anterior, la propuesta buscará como estrategia territorial unificar las tendencias de crecimiento y desarrollo, asegurando con ello, la expansión de las mejores oportunidades educativas, laborales y económicas de la Sabana, hacia la periferia del departamento de Cundinamarca. A través de esta figura de armonización territorial se aprovecharán las ventajas de la proximidad y de cercanía de los factores productivos en el territorio, teniendo en cuenta las economías de escala y asegurando por supuesto las condiciones para garantizar mayor competitividad, mejores condiciones de calidad de vida a la ciudadanía, como enfrentar los retos determinados por la globalización.

Igualmente, la ciudad de Bogotá D.C., como unidad administrativa y territorial ha sido desbordada por complejas dinámicas que hacen necesario abandonar la noción de ciudad para abrir paso al concepto de región, trátese de Región Metropolitana, de Ciudad Región o de Región Capital, entre otras.

De su lado, la Ley Orgánica de Ordenamiento Territorial LOOT (Ley 1454 de 2011), "por la cual se dictaron normas orgánicas sobre Ordenamiento Territorial" que permiten fortalecer las bases y condiciones para construir instancias regionales que faciliten la planificación y el ordenamiento regional del territorio, por tres razones:

$>$ El impacto que generan las decisiones de la ciudad en materia de planificación y de utilización de los recursos naturales que en parte se ubican dentro del área de la región.

$>$ La falta de control que tienen los habitantes de la región sobre organismos de gobierno y sus decisiones, lo que genera efectos adversos en el territorio y en los recursos regionales.

$>$ La posibilidad de generar economías de escala a nivel regional y una mejora en la prestación de los servicios públicos, lo que tendría consecuencias positivas sobre la calidad de vida de los habitantes de la región.

En esta perspectiva, el valor agregado de este trabajo de investigación propenderá por la puesta en marcha de los instrumentos de planeamiento para la gestión administrativa del territorio hacia la armonización de los distintos contextos territoriales que se han venido identificando. Finalmente, se buscará la armonización territorial, cuyo objetivo consiste en aunar esfuerzos para articular la inversión entre los entes territoriales, correspondientes a los planes de desarrollo de las entidades que conforman la RAPE, con el propósito de promover el desarrollo económico de sus territorios y el mejoramiento social de los habitantes de Bogotá y Cundinamarca en asocio de las figuras de manejo del territorio como es la Cuenca Hidrográfica y la Estructura Ecológica Regional.

Para lograr identificar para el área de estudio y definir desde el objetivo central del trabajo, con la cual se determinaran los lineamientos conceptuales y metodológicos para la planificación y gestión sostenible, para la cuenca hidrográfica del Río Bogotá como ejercicio de caso, desde una perspectiva regional; se soporta directamente desde la "Planificación y Gestión y el Ordenamiento Ambiental desde la articulación de las Cuencas Hidrográficas". Establece por lo tanto, el estudio de los elementos estructurante del componente ambiental, a través de la Estructura Ecológica Regional, donde se establecerán los conectores de gestión y de planificación territorial, que conlleven al fortalecimiento de los procesos participativos de la ciudadanía, gremios y sectores protagonistas en el desarrollo territorial desde una visión regional. Lo cual permite plantear el concepto de Unidades de Planificación soportadas normativamente por el Decreto 3600 de 2007, simbolizadas para el caso de la propuesta metodológica 
hacía con los llamados Núcleos de Ordenamiento Ambiental Territorial (NOAT), tendrán como función, la de armonizar los instrumentos de planificación y de ordenación, con miras al desarrollo sostenible del territorio, pudiéndose desarrollar en cada una de ellas planes programas y proyectos en la integralidad de la incidencia de cada una de las dimensiones del desarrollo en el concepto de región.

\subsection{EL CONTEXTO REGIONAL}

La creciente relevancia de las regiones es pues consecuencia del cambio en las territorialidades ligadas al anterior modelo de desarrollo y de gestión pública y en las prácticas sociales y políticas tradicionales. En el contexto de globalización, descentralización y fortalecimiento de la democracia y de redefinición de las relaciones entre el Estado, la sociedad civil y los mercados, emergen nuevos problemas regionales que demandan novedosos desarrollos teóricos y el diseño de paradigmas, formas de intervención e instituciones públicas alternativas.

La creación de capacidades locales y regionales de gestión tiene que ver, también, con el desarrollo de las actividades productivas en el territorio. Es ésta, curiosamente, la dimensión más ausente en la discusión sobre la organización territorial; Los departamentos y las provincias tienen en común que son entidades intermedias entre los municipios y la nación y ambos tienen carácter supramunicipal, aunque las provincias son de carácter Intra-departamental. También se puede plantear que una provincia de carácter administrativa pueda convertirse en una entidad territorial y se vuelva entidad complementaria o sustitutiva de los departamentos.

Se observan dos postulados, el primero como región central integrados por los departamentos de Boyacá, Cundinamarca, Tolima y el Huila; como también la localización del departamento de Cundinamarca donde se delimita el área objeto de esta propuesta; donde la cuenca del Río Bogotá, la establecemos desde su cuenca alta y media y estas relacionadas con la subcuenca del Sumapáz área que nos lleva a relacionarla por la importancia que tiene para la ciudad de Bogotá; territorio determinado y organizado a través de la Estructura Ecológica Regional.

\subsubsection{La Cuenca Hidrográfica}

La gestión del planeamiento territorial suele adoptar el concepto de cuenca hidrográfica como referente territorial en la ordenación del uso y en el manejo de tierras. El agua conforma un recurso de flujo cuya oferta está más o menos condicionada por los elementos constitutivos naturales del territorio. ${ }^{23}$ Otros conceptos se pueden definir desde una visión universal como una concavidad de la Tierra, una depresión del terreno, un recinto natural ocupado por un océano, un mar, un lago o avenado por un río principal y sus afluentes. En todos los casos la cuenca tiene origen estructural y el agua siempre está presente. Según sus características, las cuencas son exorreicas si drenan a mares y océanos; endorreicas si drenan a lagos y lagunas; arrecias si sus aguas se evaporan o se filtran en el terreno. ${ }^{24}$

La cuenca, en todas sus formas y tamaños, son recintos de vida. En esas hondonadas se da la interdependencia de seres y cosas en su forma más directa y elemental. Allí interactúan, en forma permanente, agua, flora y fauna incluida la especie zoológica

\footnotetext{
${ }^{23}$ Decreto 1504 de espacio público, reglamentario de la Ley 388 de 1997 por el cual se reglamenta el manejo del espacio público en los planes de ordenamiento territorial. Es un deber del Estado velar por la protección de la integridad del espacio público y por su destinación al uso común, el cual prevalece sobre el interés particular en el cumplimiento del urbanismo, los municipios y distritos deberán dar prelación a la planeación, construcción, mantenimiento y protección del espacio público sobre los demás usos del suelo.

${ }^{24}$ Maestría en Gestión y Manejo de Cuencas Hidrografías Universidad Nacional de la Plata Argentina (2009).
} 
más activa, la humana. La cuenca es, por eso, escenarios idóneos para la gestión integral sobre el territorio y su población. Ella ofrece la base indispensable y concreta para el ordenamiento territorial del país y el piso firme, donde se instala, de manera natural, la administración político-administrativa de la nación ${ }^{25}$.

El proceso de llevarse a cabo el ordenamiento territorial a partir de la plantear la cuenca hidrográfica como unidad de planeamiento, que abarquen uno o más departamentos y por supuestos municipios, se crea la planificación de dos o tres unidades. El punto está, en reconocer la cuenca hidrográfica como la unidad determinante para planificar el ordenamiento jurídico y administrativo del territorio, se está prácticamente induciendo al ordenamiento territorial desde lo ambiental, es decir, que se planifique un recurso desde la gestión hídrica como base de la ordenación, en un entorno donde se localizan actividades para la conservación ambiental protección y restauración, sector productivas y de asentamiento poblacional, en fin, toda una serie de actividades que inciden en el desarrollo y crecimiento de un país.

\subsection{LA ZONIFICACIÓN AMBIENTAL ${ }^{26} \mathrm{Y}$ SU RELACIÓN CON LA ESTRUCTURA ECOLÓGICA REGIONAL}

Con base en lo anterior, el establecimiento de la zonificación ambiental se considera como la herramienta asociada a la prospectiva territorial, en la cual se establecen las áreas de conservación y de preservación del sistema orográfico o de montaña tales como: cerros, montañas, colinas, volcanes y nevados. Las áreas para la conservación y la preservación del sistema hídrico están conformadas por elementos naturales y elementos artificiales.

$>$ Los elementos naturales son aquellos los relacionados con corrientes de agua, tales como: cuencas y microcuencas, manantiales, ríos, quebradas, arroyos, playas fluviales, rondas hídricas, zonas de manejo, zonas de bajamar y protección ambiental, y relacionados con cuerpos de agua tales como mares playas, pantanos, humedales, rondas hídricas, zonas de manejo y protección ambiental.

> Los elementos artificiales o construidos son aquellos, relacionados con corrientes de agua, tales como: canales de drenaje, alcantarillas, aliviaderos, diques, presas, represas, rondas hídricas, zonas de manejo y protección ambiental y relacionados con cuerpos de agua tales como: embalses, lagos, melles, puertos, tajamares, rompeolas, escolleras, rondas hídricas, zonas de manejo y protección ambiental.

Además de las áreas de especial interés ambiental, científico y paisajístico, tales como los Parques naturales del nivel nacional, regional, departamental y municipal y las Áreas de reserva natural, santuarios de fauna y flora se constituyen como los elementos estructurales para la zonificación ambiental del territorio. Según Germán Márquez (2008), "dicha zonificación se concibe como el conjunto interactivo de áreas y ecosistemas estratégicos, interconectados estructural y funcionalmente por corredores ecológicos, así como otras áreas y ecosistemas de importancia ecológica, en medio de una infraestructura bajo uso humano, idealmente sostenible."

\footnotetext{
${ }^{25}$ Tomado de los escritos del Doctor Alberto Mendoza Morales; presidente activo de la Sociedad Geográfica de Colombia; además planificador reconocido por sus debates ante el Congreso de la República como ponente en el proyecto de la Ley Orgánica de Ordenamiento Territorial en el referente tema ambiental en la organización regional para Colombia.

${ }^{26}$ Se establece claramente la zonificación del territorio rural, con la promulgación del Decreto 3600 de 2007 por el cual se reglamentan las disposiciones de las leyes 99 de 1993 y 388 de 1997 relativas a las determinantes de ordenamiento del suelo rural y al desarrollo de actuaciones urbanísticas de parcelación y edificación en este tipo de suelo y se adoptan otras disposiciones.
} 
Así los conceptos de estructura ecológico y de zonificación ambiental se conjugan, pero con una proyección más amplia al implicar una visión más integral y de conjunto del concepto de regiones y la necesidad de que se mantenga una estructura adecuada a las necesidades de las mismas, la zonificación ambiental debe estar en condiciones de garantizar la provisión de los bienes y servicios no sólo para alcanzar y hacer sostenible el desarrollo sino hacer competitiva la región. La estructura ecológica de una región puede o no ser la adecuada a las necesidades sociales y del desarrollo, su gestión debe tender a adecuarla, lo cual puede implicar su conservación o mantenimiento, o restauración, como de otras infraestructuras que, como la vial o la de servicios, son complementarias y fundamentales para el buen funcionamiento de la sociedad.

\subsection{PRINCIPALES PROBLEMAS ASOCIADOS A LA DIMENSIÓN AMBIENTAL EN LA CONSERVACIÓN, USO Y RECUPERACIÓN DEL RECURSO HÍDRICO EN LA REGIÓN CAPITAL.}

Se relacionan las principales problemáticas asociadas al recurso hídrico en la cuenca del Río Bogotá, las cuales constituyen una síntesis de los elementos que inciden hacia el futuro en la viabilidad ambiental para su conservación. Su finalidad es determinar el grado de impacto con base en la presencia de elementos que han venido siendo representativos para su planteamiento en la focalización de programas y proyectos sectoriales avalados por la nación el departamento y el municipio elementos constitutivos para ser valorados desde su intervención a partir de unidades de gestión. Cabe anotar, que muchas de las iniciativitas para la recuperación del río Bogotá, han estado inscritos en los programas de los distintos planes de desarrollo como del Distrito Capital, Departamento de Cundinamarca y municipios y planes de acción en las distintas administraciones de la Corporación Autónoma Regional CAR de Cundinamarca por más de tres décadas continuas.

\section{$>$ La contaminación del agua en la subcuenca alta y media del Rio Bogotá}

El deterioro de las subcuencas del Rio Bogotá, es un problema reconocido desde hace más de 20 años por el vertimiento en la subcuenca alta de aguas industriales asociadas a la actividad de las curtiembres, y el gran deterioro que el rio sufre por el vertimiento de aguas servidas en la ciudad de Bogotá. Son múltiples las acciones que se han implementado para su descontaminación sin embargo no se ha dado una respuesta efectiva a la solución de contaminación del Rio Bogotá y por el contrario los problemas se mantienen y se siguen profundizando.

La alta intervención de la cobertura natural en la Subcuenca alta y media del Rio Bogotá.

La subcuenca alta del Rio Bogotá evidencia un fuerte deterioro con el predominio de cobertura de origen antrópico constituyendo el $58 \%$ de las coberturas existentes y con una baja representación de coberturas que favorecen la permanencia del recurso hídrico como son los páramos y bosques.

De los páramos solo permanecen relictos que representan el $3,2 \%$ de la cobertura total y son sujetos a una fuerte presión por el cultivo de la papa y el establecimiento de pastos. Tal es el caso del Complejo de Paramos de Rabanal y Rio Bogotá, donde el 39\% del páramo esta intervenido por coberturas antrópicas. La situación es crítica si se considera que en un periodo de 18 años (1995 a 2003 se perdieron 3.000 ha de paramo. 
La cuenca media presenta una situación similar de deterioro. Tiene el predominio de coberturas antrópicas (55\%) y las coberturas naturales importantes para la conservación y permanencia del recurso hídrico como son los páramos y bosques tienen una baja representación con el 3,9\% y 4,6\% respectivamente. Es esta cuenca la tendencia es hacia la perdida de las áreas de paramos y la cual para el periodo de 1985- 2003 fue del $17 \%$.

\section{$>$ La desecación de humedales en el Distrito Capital y la Región.}

De las 50.000 hectáreas de humedales que existían en Bogotá en 1950, solo se conservan 500 hectáreas (Conservación Internacional, 2000 op. cit.; Calvachi, 2003). Las principales fuentes de desecación de humedales están asociadas a la "adecuación" de tierras agropecuarias, expansión de obras de infraestructura y consolidación de asentamientos humanos legales e ilegales.

En la actualidad se carece de un inventario y caracterización de humedales para la región como fuente de información confiable para formular medidas asociadas a su manejo y conservación.

\section{$>$ Las inundaciones periódicas en la Subcuenca media del Rio Bogotá}

La Subcuenca media del Rio Bogotá, presenta una de las zonas de mayor amenaza por inundación asociada a su plano de desborde conforme a los resultados del POMCA, 2006. Esta evaluación ha sido confirmada por los hechos registrados en el fuerte periodo de invierno de 2010-2011 en donde se presentaron desbordamientos de Cajicá y Chía principalmente.

Esto indica claramente que las geoformas asociadas al Rio Bogotá, como son el plano de inundación mismo y las terrazas bajas están sujetas a la amenaza de inundaciones periódicas, aún más con el incremento de las temporadas invernales.

\section{$>$ La reducción del área total de humedales.}

De las 50.000 hectáreas de humedales que existían en Bogotá en 1950, solo se conservan 500 hectáreas (Conservación Internacional 2000 op. cit.; Calvachi 2003). Las principales fuentes de desecación de humedales están asociadas a la "adecuación" de tierras agropecuarias, expansión de obras de infraestructura y consolidación de asentamientos humanos legales e ilegales.

En términos generales la información secundaria existente muestra la tendencia a su desecación pero no existen cifras precisas producto de un monitoreo o análisis multitemporal del cambio de los humedales tanto de la Sabana como del Distrito Capital, lo que dificulta consolidar cifras.

En la actualidad se carece de un inventario y caracterización de humedales para el área de estudio como fuente de información confiable para formular medidas asociadas a su manejo y conservación.

\section{$>$ La fuerte presión para las aguas subterráneas en la Subcuenca media del Rio Bogotá.}

En términos generales los estudios sobre aguas subterráneas han permitido establecer una sobreexplotación del recurso e identificación de áreas críticas para su aprovechamiento, como es el caso del occidente de la Sabana de 
Bogotá en los municipios de Tenjo, El Rosal, Madrid, Funza, Facatativá y parte de los municipios de Cota, Tabio, Tenjo y Subachoque. Esta área ha sido identificada como critica. Así mismo se destaca la vulnerabilidad del agua subterránea a la contaminación por la facilidad con la que ingresan sustancias al acuífero a través de la infiltración.

\subsection{LA ASOCIACIÓN E INTEGRACIÓN TERRITORIAL}

Respecto a la integración territorial y como considerarla en el tema de la ordenación; se requiere considerar la Ley Orgánica de Ordenamiento Territorial (LOOT) que se ha venido discutiendo a lo largo de los últimos años. El objetivo central de la Ley es la de crear condiciones para promover la paz, el desarrollo sostenible con visión estratégica, la equidad y el equilibrio de las entidades territoriales.

La LOOT reconoce la importancia de la integración territorial para el desarrollo político y administrativo dentro del territorio nacional, son tres las instancias a saber: I) entidades territoriales; II) instancias de integración territorial y III) áreas de desarrollo territorial; cada una de ellas desde la perspectiva de las cuencas hidrográficas son unidades de planificación para el análisis biofísico, social, económico, administrativo, y su posterior incorporación al debate la gestión y participación de actores.

\subsection{LA PLANIFICACIÓN TERRITORIAL}

En el sentido amplio de la palabra, la planificación territorial pude ubicarse entre los dos sectores, el económico y el social, en la medida en que se amplían y se profundizan las escalas de la producción, la especialización y las relaciones económicas, aumentaría la importancia del aspecto territorial. Por lo tanto, la planificación territorial es un subsistema del sistema de planificación de la economía, lo que ha posibilitado activar el desarrollo económico y social a todo lo largo y ancho del país.

El territorio como tal debe ser más que un nivel organizativo o delimitado administrativamente, y concebirse como un ente activo y decisivo del desarrollo económico local y no solo un espacio o soporte geográfico del desempeño de las entidades. Sin embargo, un tema de vital importancia en la aplicación territorial del enfoque de planificación a partir de las potencialidades endógenas, es el referido a la transferencia de competencias de cada uno de los entes locales que integral el área de estudio, relaciones institucionales que permitan estimular los procesos de planificación del desarrollo económico territorial, siempre y cuando se incentive incrementar la capacidad de autogobierno de las autoridades locales a fin de propiciar el desarrollo de iniciativas integrales en la valoración de proyectos.

\subsection{EL ENFOQUE SISTÉMICO}

No es propósito del presente capitulo constituirse en un tratado de la teoría general de los sistemas. Se pretende solamente revisar los conceptos y principios básicos en que se fundamenta, su desarrollo y sus posibilidades como soporte conceptual y herramienta de apoyo en el desarrollo del enfoque sistémico para la ordenación territorial en el enlace o conexión de la cuenca hidrográfica al enfoque regional, como parte de la gestión y ordenamiento político/administrativo de nuevos territorios teniendo en cuenta la estructura de la dimensión ambiental como la base de su ordenación.

El enfoque sistémico se caracteriza por la realización de una serie de actividades o subprocesos que, en un orden predeterminado están orientadnos al logro de los 
objetivos específicos. La base del enfoque sistémico lo constituye un proceso dinámico que sigue el ciclo de la planificación, ejecución y control. Sin embargo, constituye en el meollo de una tecnología y tecnocracia, y quienes la ejercen son los nuevos utopistas de nuestro tiempo.

Para empezar, se introduce una acepción del concepto de dimensiones del desarrollo; con el cual se propone caracterizar cada unidad, de ellas en términos de sus funciones y argumentación requerida para contribuir a la finalidad del ordenamiento territorial, su aplicación en unidades de planificación y por ende, en la concepción de cada una de ellas se relacionan al proceso visto desde la prospectiva en la puesta de escenarios para la incorporación de la unidad física de la cuenca hidrográfica como la ordenación de las bases de lo regional.

\subsection{LA CUENCA HIDROGRÁFICA COMO ELEMENTO ESTRUCTURANTE DEL DESARROLLO REGIONAL}

"Por qué", "lo que se va a hacer", son dos preguntas que pueden aclarar las bases de intervención para el planteamiento del eje central de dicho trabajo. Planteamiento para la realización de los lineamientos conceptual y metodológicos, para la planificación y la gestión sostenible desde una perspectiva regional, al reconocer e incorporar la cuenca hidrográfica como una de las unidades físicas reconocidas para el ordenamiento territorial, donde a su interior se identifican los factores determinantes para la planeación territorial como son los sociales, económicos, culturales, administrativos y por supuesto los ambientales, donde en cada uno de ellos se pueden identificar sus problemas como sus potencialidades actuales y a futuro para la proyección de los distintos planes de desarrollo. Hoy en día, se busca para el ordenamiento territorial la inclusión del componente ambiental y aún más la problemática del recurso hídrico como instancia de desarrollo para las comunidades y sectores económicos en general.

Distintos autores entre ellos, Alberto Mendosa Morales en su libro "Colombia Estado Regional" incorpora el debate de las cuencas hidrográficas como determinantes de la fisonomía regional del país, dentro de sus límites, representan territorios que sirven de referencia para trazar límites apropiados a las entidades político-administrativas y a los usos de la tierra. Por lo tanto, para el debate del nuevo ordenamiento políticoadministrativo, que exige la nueva figura en la organización, jurídica, política y administrativa, ya que la actual organización ha perdido su vigencia en el país; conceptos soportados por expertos entre ellos los Doctores Alberto Mendoza Morales, Jaime Castro, Julio Carrizosa Umaña, entre otros.

Por lo tanto, en un país con diversidad geográfica, económica y social responder a las necesidades y oportunidades de cada una de las regiones es uno de los retos que enfrenta la implementación de políticas y estrategias de desarrollo. El presente documento considera la aplicabilidad del concepto de cuenca hidrográfica como elemento estructurante del desarrollo regional. Por lo tanto, se busca entender de manera sencilla el arte de armonizar los instrumentos de planeación y de gestión, dentro de sus distintos escenarios territoriales, nacionales, departamentales, distritales y municipales, para relacionar cada uno de los instrumentos con su contexto, se utilizará el término de los niveles de prevalencia como determinantes en los instrumentos para la planificación; quiere decir su incidencia en los distintos contextos de la geografía política social y económica.

En estricto sentido semántico y según el Diccionario de la Real Academia Española, "armonizar: consiste en hacer que unas cosas se correspondan con otras". Para este caso, se trata de definir la manera como los diferentes instrumentos de planeación se correspondan entre sí en la ordenación del territorio en la Región Capital, de tal 
manera que la definición de la cuenca hidrográfica obedezca a la unidad física y geográfica de los diferentes factores de financiación de programas y proyectos con criterios de ordenación existentes, para concurrir en una sola figura regional.

Se entiende entonces que sin una armonización de los diferentes instrumentos de planeación entre los municipios que integran el territorio determinado por las subcuenca hidrográfica en este caso por el Río Bogotá, serian muchísimos los posibles recursos económicos que se podrían perder, al no tener de forma integral las decisiones en la focalización y/o localización de proyectos como soluciones conjuntas en la solución de un problema que se ha venido dando de forma individual. Lo anterior, en vez de ser una debilidad se convierte en una fortaleza al determinar desde la planificación instancias de gestión y planificación del territorio a partir de unidades de gestión integradas por un número determinado de municipios que comparten problemas comunes. Sin embargo, esa armonización pasa por tres escenarios: un escenario legal o jurídico, otro técnico y otro más financiero.

Corresponde a la armonización de cuenca hidrográfica, con los instrumentos de planificación y de gestión territorial identificar las bases territoriales o los distintos niveles de subordinación y prevalencia de los distintos planes que tienen presencia dentro del área de estudio de la cuenca hidrográfica entre ellos, el plan departamental de Cundinamarca, los planes municipales de las entidades que comprenden el área de estudio y las entidades corporativas denominadas Corporaciones Autónomas Regionales (CAR).

Los niveles de prevalencia son considerados por la ley 388 de 1997, como los valores de jerarquía que determinan la subordinación que debe existir entre las determinaciones de los diferentes instrumentos de planificación y de gestión del ordenamiento físico, tales como: los sistemas estructurantes, la clasificación del suelo, usos, ecosistemas estratégicos (conservación, protección, restauración, preservación, uso sostenible del recurso hídrico y tendencias poblacionales entre otros). Se identifican de acuerdo a la aceptación del área que enmarca la subcuenca en el caso del Río Bogotá.

Para determinar los alcances de los instrumentos de planificación y de gestión que puedan aportan recursos económicos, mayor fortalecimiento institucional para la conformación de la región como tal, es importante tener en cuenta el concepto con el cual se estableció el área de estudio de las Subcuencas del Río Bogotá, en lo relacionado a la Conservación, Protección y Preservación del Recurso Hídrico de la denominada Región Capital.

Por lo tanto, para la armonización de los instrumentos de planeación de las subcuencas del Río Bogotá, es importante tener la claridad en los siguientes niveles y conceptos como son: los niveles de prevalencia para armonizar cada uno de los instrumentos de planeación y de gestión a saber ${ }^{27}$, teniendo en cuenta los determinantes que se relacionan a continuación:

$>$ Las determinaciones del nivel nacional.

$>$ Las determinaciones del nivel departamental.

$>$ Las determinaciones del nivel metropolitano.

$>$ Las determinaciones del nivel distrital.

$>$ Las determinaciones del componente general del Plan de Ordenamiento Territorial.

\footnotetext{
${ }^{27}$ Determinados a partir de lineamientos de la Ley 388 de 1997, donde se establecen las características para el desarrollo de la planificación territorial.
} 
$>$ Las determinaciones del componente urbano y rural de los Planes de Ordenamiento Territorial.

$>$ Las determinaciones de los planes de ordenación y manejo de cuencas hidrográficas las determinantes que rigen las unidades mínimas de actuación.

$>$ Las determinantes que rigen para las Unidades de Planeamiento Intermedio del suelo rural (UPR).

\subsubsection{La Gestión de Cuenca}

Los gobiernos nacionales establecen las políticas para el uso y la protección de los recursos hídricos en un país que deberán ser eficaces en muchas escalas territoriales, allí donde se implementan políticas a escala de cuenca, existe la oportunidad de generar soluciones para toda la cuenca y resolver controversias aguas arriba, aguas abajo (para un río) y de región a región; el enfoque de todo el territorio de la cuenca permite la evaluación de un impacto a nivel de unidades territoriales. Las políticas nacionales, así como también los acuerdos internacionales y los convenios regionales para aguas transfronterizas, se aplican a cuencas naturales. La relación que existe entre la gestión de los recursos hídricos dentro de un país y la gestión del agua en cuencas se vuelve de esta manera más dinámicas y más sensibles a las circunstancias cambiantes sean estas ambientales, sociales y económicas ${ }^{28}$.

Una de las problemáticas que enfrentan los administradores del agua es el hecho que se puede provocar o intensificar conflictos entre comunidades en una cuenca local o en cuencas transfronterizas compartidas por más de un país. Muchas son las fortalezas de la ordenación y del manejo de cuencas; en lo regional, la gestión enfrenta hoy en día un gran problema debido a la variabilidad e incertidumbre naturales de los patrones meteorológicos. Con el cambio climático, es probable que este problema empeore ${ }^{29}$. En Colombia en algunas cuencas especialmente la cuenca del río Bogotá al igual que la cuenca baja del Río Magdalena, se vieron más precipitaciones mayores caudales en los ríos generando mayores inundaciones. Estos cambios se vieron agravados debido a las variaciones tales como el crecimiento demográfico y económico, la urbanización. Lo sucedido en el año 2010 en Colombia especialmente en el sur de los departamentos del Caribe y el área periférica de la ciudad de Bogotá D.C. Ilamada la Sabana de Bogotá, que pertenece a la gran área de la cuenca media del río Bogotá. ${ }^{30}$

\subsubsection{Asociación o Consejo de Cuencas ${ }^{31}$}

Para esta propuesta territorial el tema de la asociación o del consejo de cuenca puede ser un grupo formal o informal y puede estar integrado por funcionarios del gobierno,

\footnotetext{
${ }^{28}$ Organismos de cuencas, Problemas y desafíos que enfrentan los administradores de agua.

${ }^{29}$ EI IDEAM de fecha 6 de diciembre de 2010, mediante el cual se indicó que el Fenómeno de La Niña 2010-2011 alteró el clima nacional desde el comienzo de su formación en el mes de junio de 2010, ocasionando en los meses de julio y noviembre las lluvias más intensas y abundantes sin registro de tales magnitudes en el país, en las regiones Caribe, Andina y Pacífica; además hizo que no se presentara la temporada seca de mitad de año en el norte y centro de la Región Andina. Los meses de agosto y septiembre se comportaron también con lluvias muy por encima de lo normal en la región Caribe y en el norte de la región Andina. Como consecuencia de ello, las partes baja y media de los ríos Cauca y Magdalena, así como algunos de sus afluentes, han presentado niveles nunca antes registrados en la historia de la hidrología colombiana

${ }^{30}$ EI IDEAM (Instituto de Hidrología, Meteorología y Estudios Ambientales pronosticó para el año 2010 el llamado fenómeno de la niña en el área central especialmente, donde municipios deberían tener activados los comités de desastres especialmente en el tema de sequía. Los resultados del año fue el contrario dándose el fenómeno del niño ocasionando grandes inundaciones. Por lo tanto, la pérdida total de más de 30 centros poblados en la región Caribe y perdidas del área productiva de alimentos y abastecedora de la ciudad de Bogotá, fue el resultado probable del cambio climático.

${ }^{31}$ Manual para la gestión integrada de recursos hídricos en cuenca; roles y tipos de organismos de cuencas ejemplo utilizado en los comités para la integración de la cuenca hidrográfica del río Paraíba do Sul Brasil: un organismo de cuenca en un país federal.
} 
miembros del poder legislativo (Concejales municipales, Asambleas departamentales, diputados departamentales), representantes de ONG y ciudadanos comunes que se reúnen con el objetivo de tratar cuestiones relativas a la gestión del agua y a los procesos de desarrollo productivo y todo lo relacionado con la base formal del crecimiento del territorio. Por lo general, los consejos se crean para asesorar al gobierno; en nuestro caso, la investigación propone el desarrollo de los consejos de cuencas, como la instancia en la interlocución entre cada una de las Unidades de Planificación Territorial (UPT), donde al interior de ellas serán representativos cada uno de los sectores y actores de la unidad siempre referente con el planteamiento o referente regional.

\subsubsection{Asociación de Gestión y Comités de Cuencas ${ }^{32}$}

Una asociación u organismo de cuenca toma decisiones en materia de planificación; puede elaborar y poner en vigor normas u otorgar consentimientos para actividades que estén directamente relacionados con los usos del suelo además respaldados por la zonificación ambiental establecida. Esta por lo general fundada sobre principios de función pública según los cuales se prestan un servicio a la comunidad con algo de autonomía dentro de un marco jurídico nacional. En algunos casos, puede también ser responsable de la política hídrica, la recolección o producción de datos; el intercambio de información entre las distintas regiones y la generación de conciencia pública.

\subsubsection{Las Unidades Territoriales y de Gestión (UTG)}

Son consideradas como una herramienta mediante la cual se pretende orientar la actuación de los comités y consejos de cuencas en el área que se establece entre las subcuenca para el Río Bogotá en (Alta y Media) y su armonización con la Estructura Ecológica Regional que comprende las subcuencas del Río Negro, Carare, Gachetá, Batá y Sumapáz, localizadas al oriente y sur, con el objetivo de vincular todos los actores con el territorio, así como los proyectos, estudios e investigaciones que se han realizado para esta cuenca y su área establecida.

Se organiza conforme a la información que se ha generado, caracterizando de manera muy sucinta los principales componentes del territorio. Se incluyen los principios de ordenamiento ecológico y con base a la división del territorio que considera esta herramienta de planificación, agregándole la división de las subcuencas de tercer orden, se identificaran las respectivas Unidades Territoriales de Gestión, las cuales son la base para la identificación en el territorio de los objetivos de manejo del proyecto de investigación. Esta herramienta de gestión, debe leerse a partir de la interpretación del Biograma.

La Unidad Territorial y de Gestión, servirá para la valoración Económica de Servicios Ambientales, para la Gestión de Áreas Naturales y Espacios Culturales, Evaluación Ambiental de Proyectos e Inversiones, disminuir conflictos Ambientales y de la participación ciudadana. La Unidad Territorial estará orientada para asesorar y orientar al sector público y privado, con la participación de la sociedad civil, está orientado por un enfoque que integra las múltiples y complejas relaciones entre los diferentes componentes del territorio entre ellos los usos del suelo, la distribución y características de los recursos naturales, el comportamiento demográfico de la población y las redes de infraestructura presentes y futuras.

\footnotetext{
${ }^{32}$ Manual para la gestión integrada de recursos hídricos en cuenca; Aportes de Apele Romane, Una experiencia de la administración Nacional del agua de Rumania y sus direcciones generales y comités de cuencas.
} 
Cabe resaltar que en el proceso de integración se debe tener en cuenta los siguientes insumos: subcuencas, alta y media del Río Bogotá, división administrativa de los municipios que hacen parte integral del área tanto de la cuenca del Río Bogotá, como de la Estructura Ecológica Regional, ecosistemas estratégicos. La Unidad Territorial y de Gestión, coordina el funcionamiento de la Informática Aplicada, contribuye al desarrollo de investigaciones, prácticamente estamos induciendo al ordenamiento territorial a que se planifique hacia el recurso que es el recurso hídrico en este caso, y proporcionando para la planificación integral y sistémica, donde la unidad de planificación territorial es la base a todo, los recursos que se pueden gestionar puede fortalecer la autonomía municipal y el fortalecimiento regional.

\subsection{UNA APROXIMACION A LO REGIONAL: EJEMPLOS DE ORDENAMIENTO TERRITORIAL}

Lo abordado de manera gráfica y espacialmente, se constituye en un insumo necesario en la toma de decisiones cuando desde lo político y administrativo queremos intervenir y ordenar el territorio, es partir de los antecedentes de las distintas etapas históricas que Colombia ha tenido en los últimos cien años; se puede mostrar en las distintas etapas de nuestra historia como el ordenamiento jurídico ha enmarcado procesos políticos que han trascendido lo social y ambiental en un país de regiones social y culturalmente reconocidas. Pues en este sentido, son varios los elementos que podemos simplificar en los siguientes mapas (Contexto histórico); conforman el concepto de regiones enmarcadas desde lo geográfico, lo económico, lo político $^{33}$

En la Constitución Nacional de 1991, se reconoció la existencia de las regiones las cuales se pueden determinar desde las Regiones Administrativas de Planificación. Según Alberto Mendoza Morales uno de los espetos ha sido muy insistente en ponderar la importancia que tiene el aspecto geográfico y las cuencas hidrográficas en este tema de ordenamiento político y administrativo, que no pocas veces se tiene en cuenta cuando se trabaja en él. Por lo tanto, la Constitución le dio un avance importante y significativo, más no suficiente al reconocer las regiones así como el carácter Multiétnico de nuestra sociedad. Precedente al desarrollo metodológico que nos permite identificar las bases conceptuales y metodológicas para el desarrollo regional, es necesario aclarar o mejor insistir en lo siguiente:

El país se caracteriza por la presencia de conjuntos de departamentos y municipios que comparten factores diferenciales que deben ser atendidos con acciones de política consecuentes con esa diversidad. Los factores diferenciales que se establecen para identificar regiones, corresponden a lógicas espaciales anteriormente mencionadas en el párrafo anterior, incluyendo la urbanas, ambientales, de enclave fronterizo, de integración a la economía mundial, e iniciativas institucionales en marcha, entre otras.

Con el fin de establecer criterios primarios de equilibrio, los factores diferenciales son utilizados de forma asociada entre cada una de las propuesta que se describirán en este acápite. Con ello, se identifican relaciones e interdependencias con diversos niveles de complejidad. Metodológicamente, el proceso seguido, supone no sólo la agregación de información especializada, sino las distintas etapas en la historia colombiana, en donde se establecieron las regiones en las provincias y departamentos como la división de ellos en esos momentos de la historia; la secuencia virtual y analítica de la cartografía que se presenta a continuación no se hace desde un análisis teórico textual, si no la de demostrar las etapas que en Colombia se han establecido a lo largo de los últimos años de una forma espacial gráfica.

\footnotetext{
${ }^{33}$ Según las definiciones del antropólogo Roberto Pineda Giraldo.
} 
Finalmente, este acápite sólo representa una aproximación espacial que metodológicamente aporta el conocimiento de la continua transformación de la división política administrativa de los territorios colombianos. Su propósito fundamental es obtener un conjunto de visiones de regiones, cuyas dinámicas ambientales, sociales, económicas y políticas constituyen, en su conjunto, un reto para la planificación sostenible del territorio nacional; lo que en efecto equivale a las distintas instancias histórica con mayores incidencias en la geografía colombiana; muchas de ellas son espacializaciones que no llegaron hacer consolidadas, y otras que obedecen a las instancias legales normativas como, las regiones llamadas, Corporación Regional de Planificación Económica y Social (CORPES), liquidadas a finales de la década de los noventa, por la ley 152 de 1994.

Algunas de las espacializaciones que se muestran a continuación, (Véase Mapas del 2.1. al 2.7.), son con el ánimo de conocer las distintas figuras administrativas que Colombia ha experimentado a lo largo de su historia, pero que no es el propósito para este proyecto el de indagar en su historia. Al contrario es mostrar la fortaleza que se tiene a nivel de la planificación territorial, en determinar la mejor posición en el caso que se determine en un nuevo ordenamiento político y administrativo que podamos mostrar desde una nueva visión tomando la cuenca hidrográfica como nueva alternativa administrativa. 
Mapa 2. 1. CONTEXTO HISTORICO - 1.

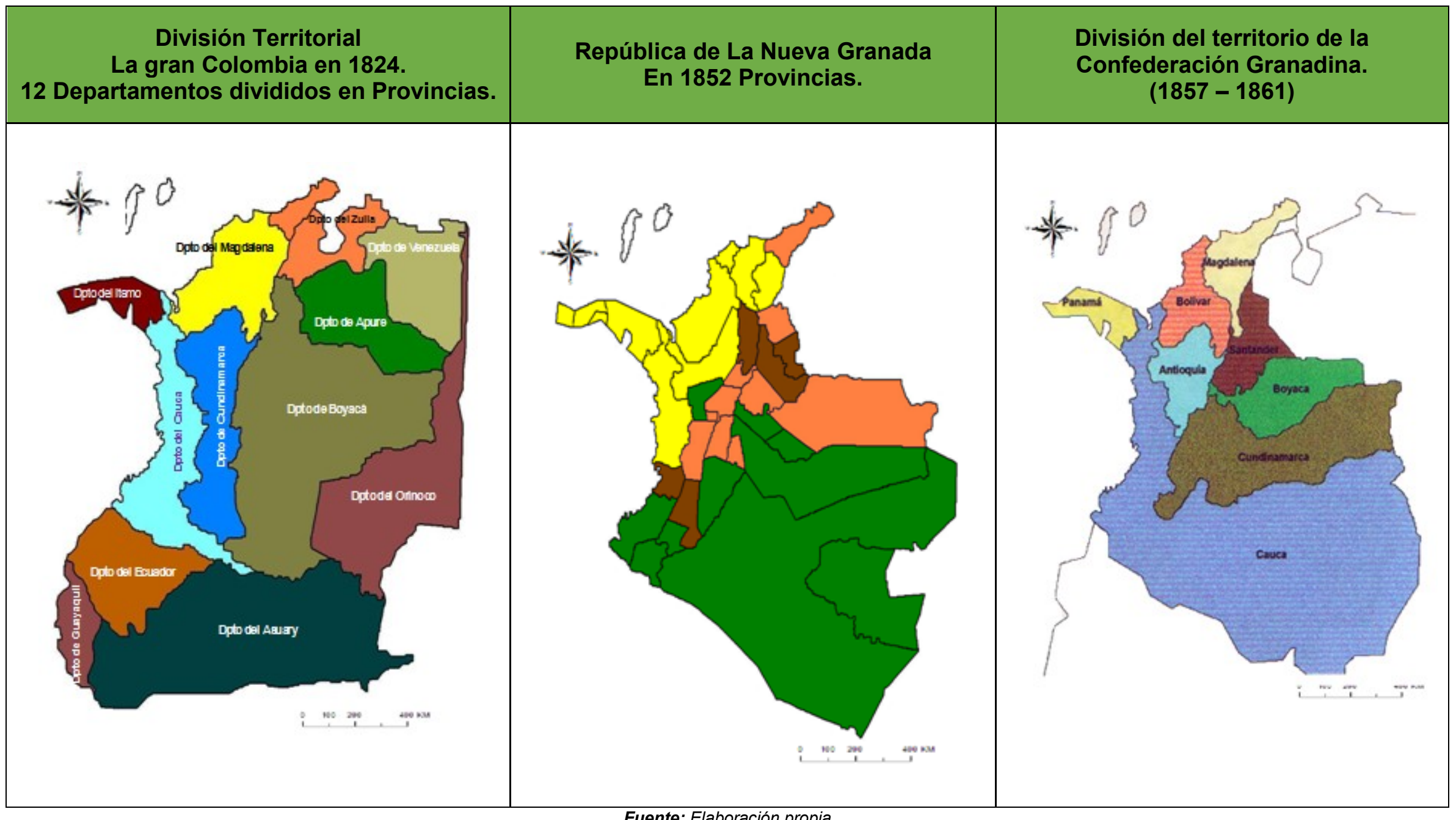

Fuente: Elaboración propia 
Mapa 2. 2. CONTEXTO HISTORICO - 2.

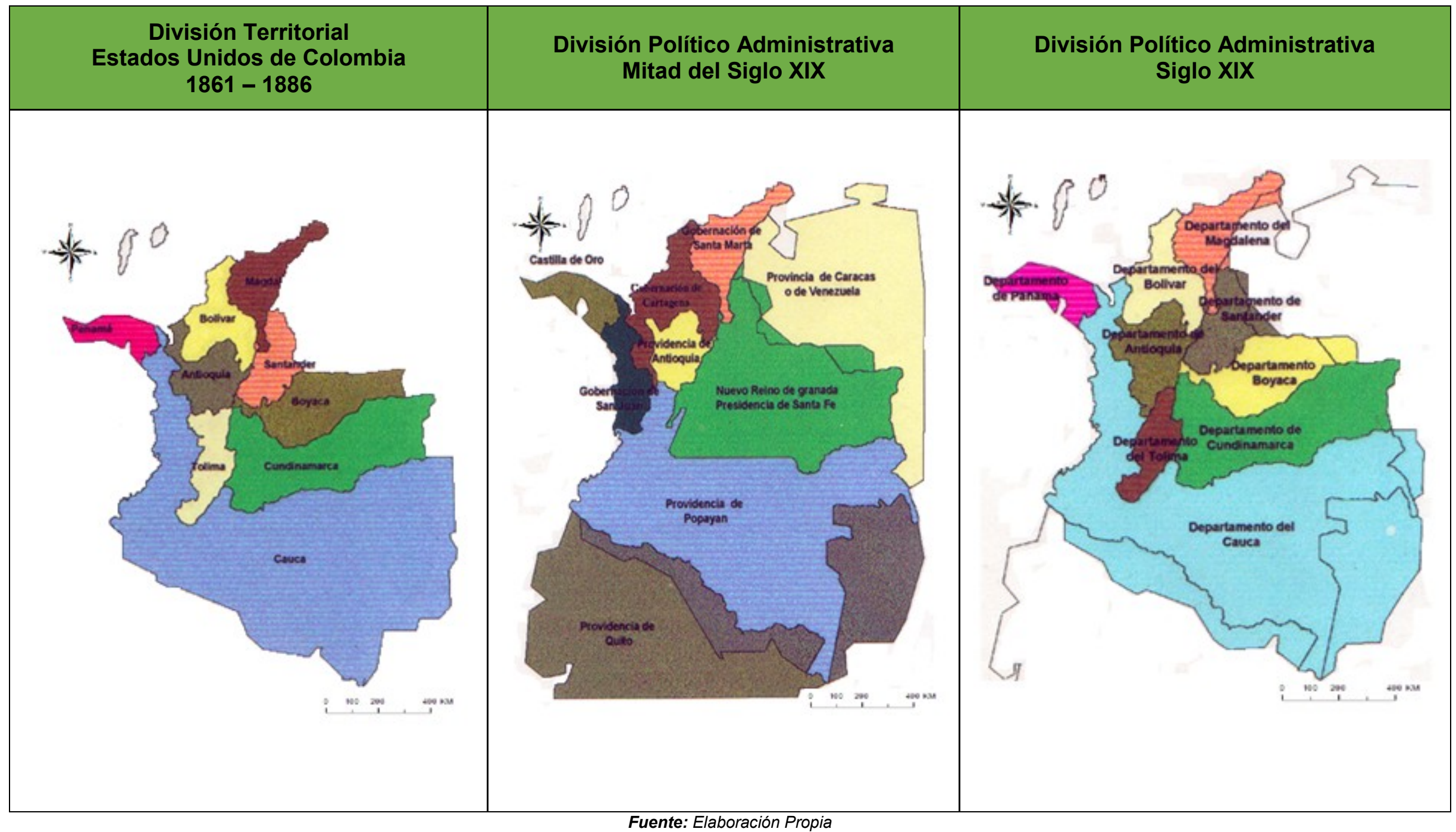


Mapa 2. 3. CONTEXTO NACIONAL - 1 .

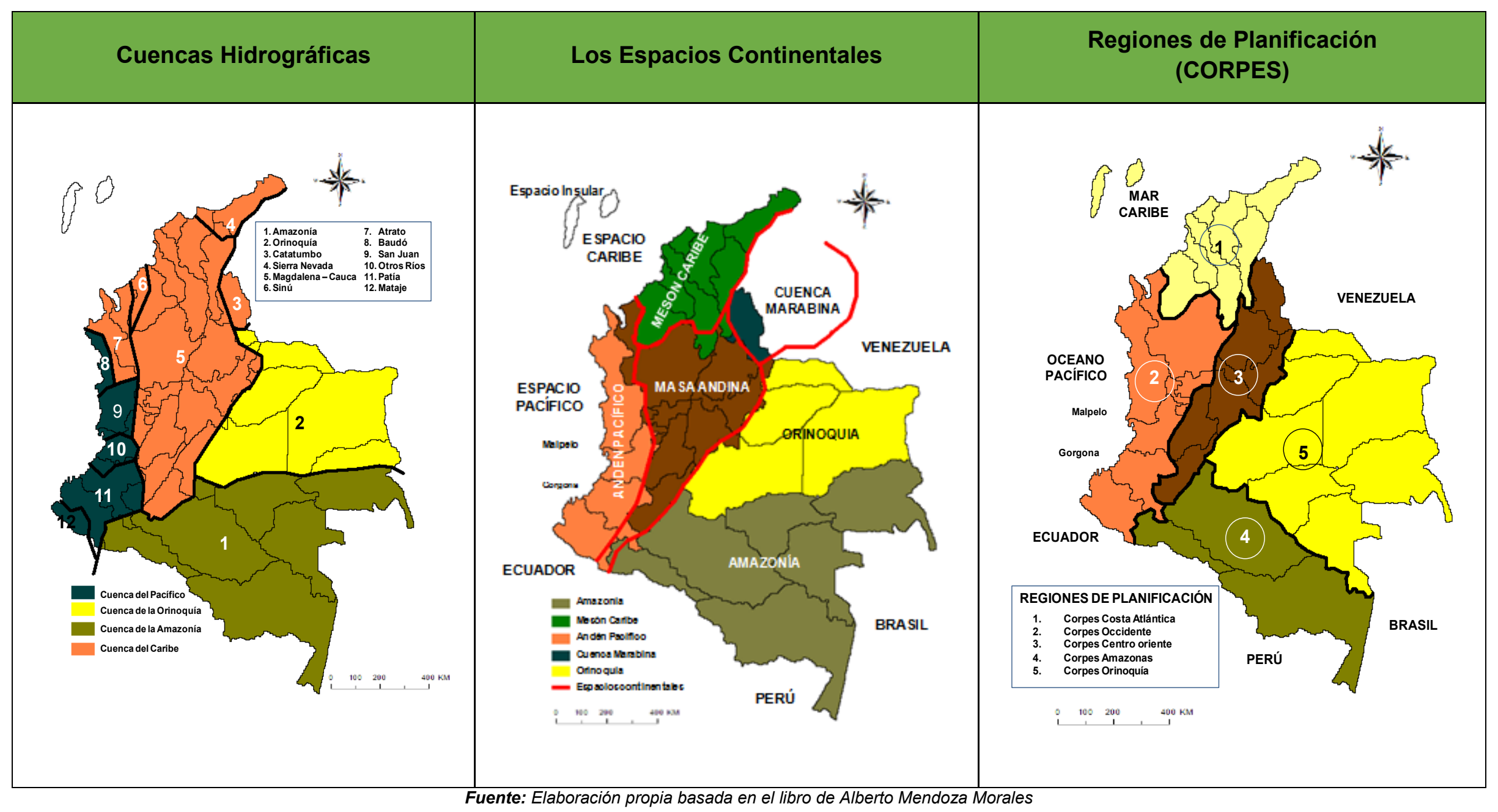


Mapa 2. 4. CONTEXTO NACIONAL - 2.

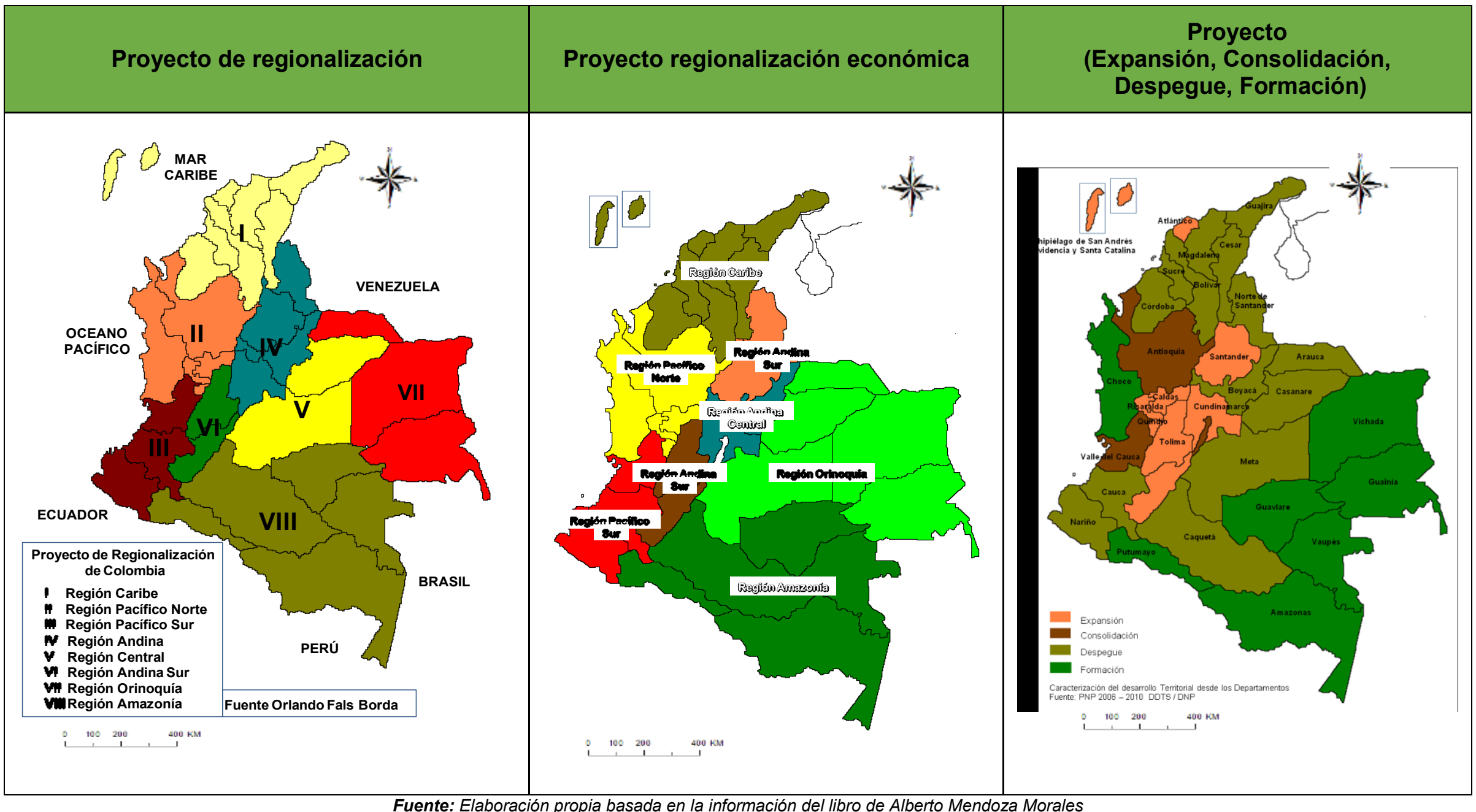

Fuente: Elaboración propia basada en la información del libro de Alberto Mendoza Morales 
Mapa 2.5. CONTEXTO NACIONAL - 3.

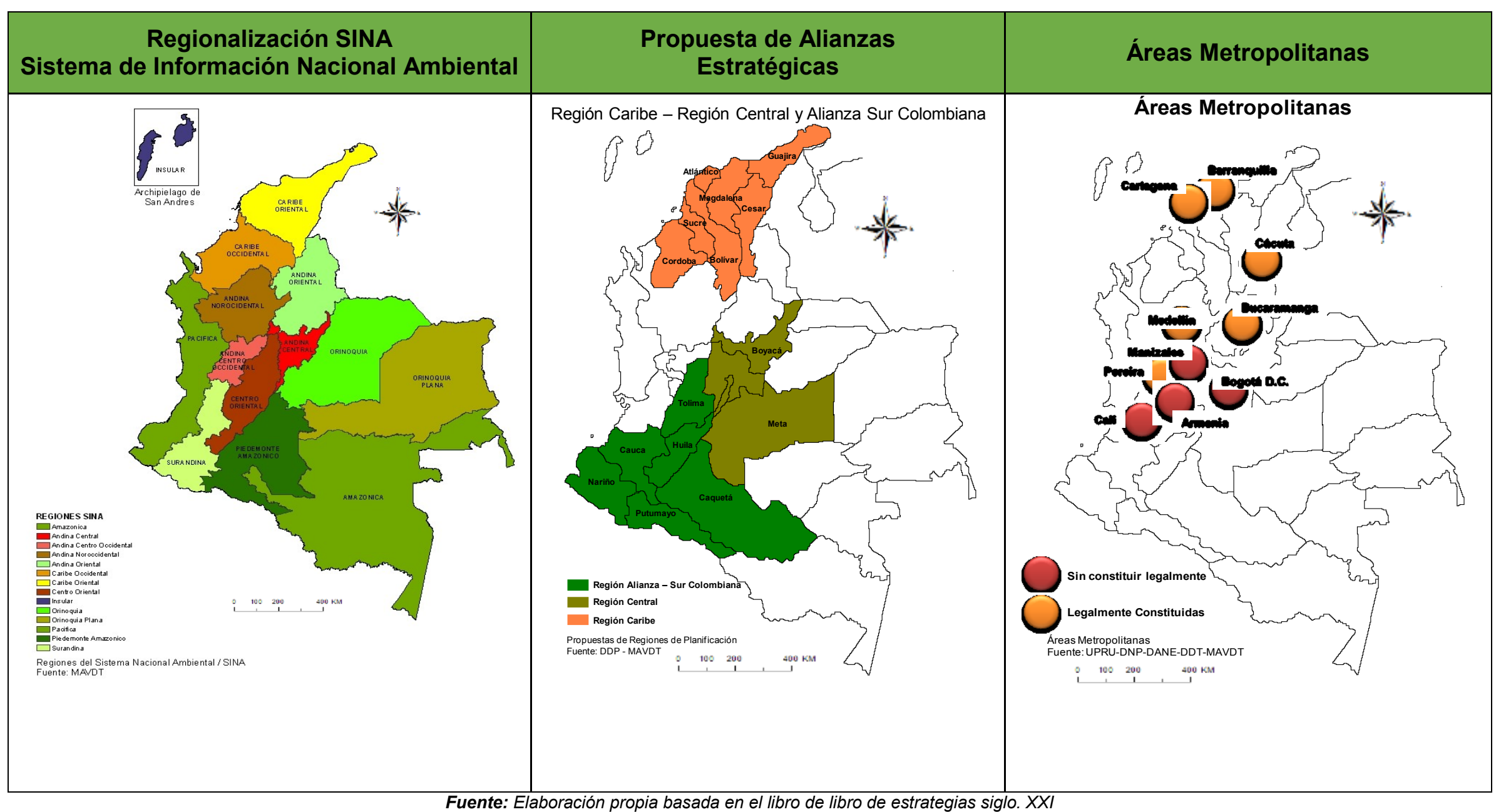

Fuente: Elaboración propia basada en el libro de libro de estrategias siglo. XXI 
Mapa 2. 6. CONTEXTO NACIONAL Y LAS PROPUESTAS ESTRATEGICAS

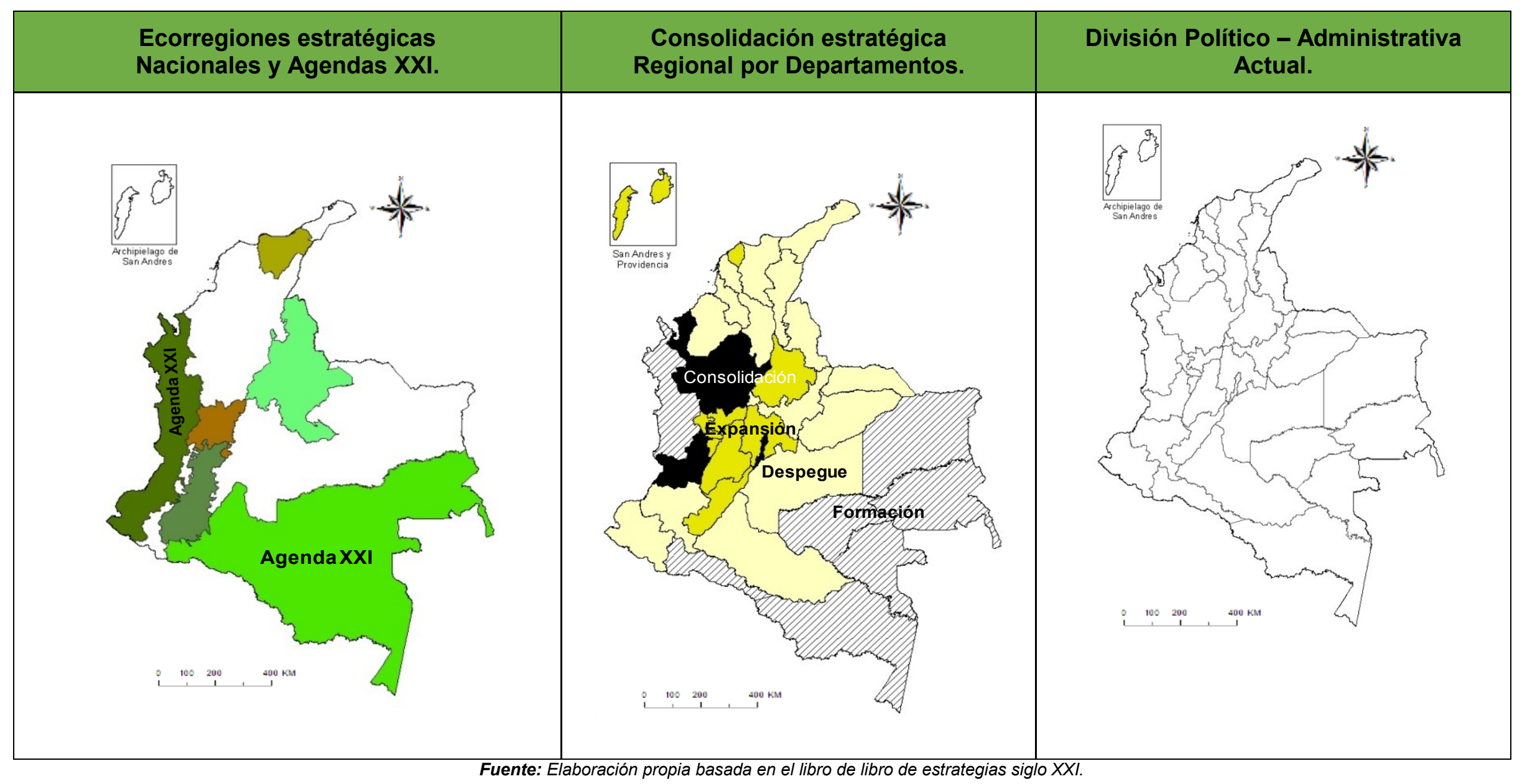


Mapa 2. 7. CONTEXTO LOCAL: BOGOTA D.C. Y CUNDINAMARCA (Una aproximación a lo regional y Geográfico).

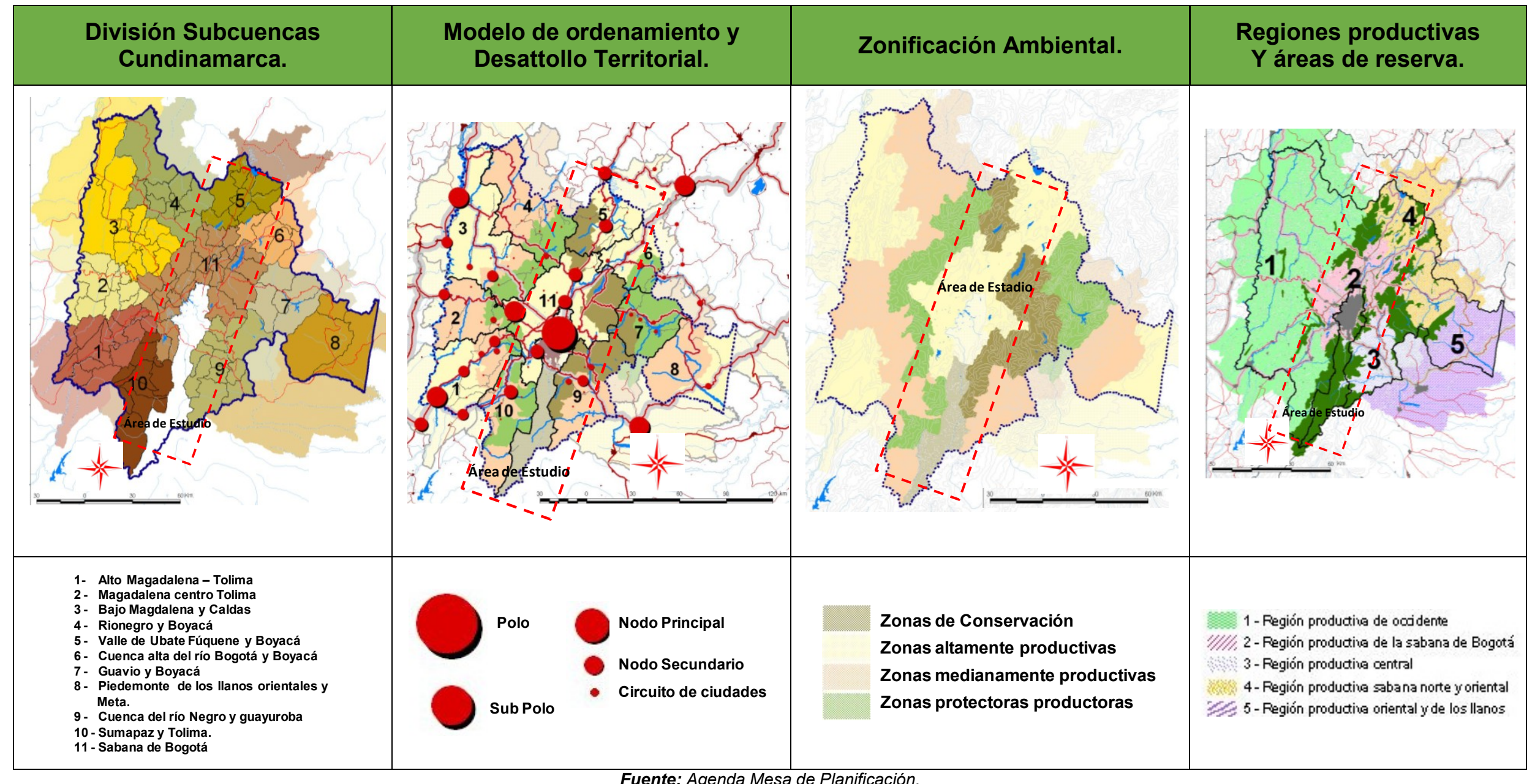




\subsection{LA INCIDENCIA DE CADA UNA DE LAS DIMENSIONES DEL DESARROLLO EN EL CONCEPTO DE REGIÓN.}

Se seleccionaron cinco Dimensiones del Desarrollo (DD), para el proyecto, aplicables para el área de la jurisdicción de las subcuenca alta y media del Río Bogotá y su área que se conformó a través de la Estructura Ecológica Regional. La Dimensión ambiental, la Dimensión económica, la Dimensión social, la Dimensión administrativa y la Dimensión territorial. Las cuales se enmarcan en las características en una eventual toma de decisiones en el ordenamiento territorial.

En cada una de las dimensiones se tiene una visión de análisis donde primero se establece lo técnico y segundo la gestión y planificación territorial que servirán como insumo en el fortalecimiento para identificar los lineamientos conceptuales y metodológicos, para la planificación y la gestión sostenible desde una perspectiva regional. Cada una de las dimensiones se caracteriza en estudios realizados por el Instituto Geográfico Agustín (IGAC) aportados para el ordenamiento territorial municipal (1998).

La Dimensión ambiental en los nuevos postulados del ordenamiento territorial, directamente desde la promulgación de la Ley 388 de 1997, se le dio el carácter de transversalidad a las demás dimensiones del desarrollo, lo que nos permite disponerlas y relacionarlas estratégicamente alrededor de ella, tal como se esquematiza Estructura sistemática de las Dimensiones del Desarrollo como sistema. (Véase figura 2.4.).

En definitiva, se espera que la siguiente estructura sistémica del desarrollo territorial desde la planificación y de la gestión territorial, fortalezca la percepción para ordenar desde un enfoque regional, oriente la definición y diseño de la estructura organizacional (con quien hacer) e instrumental (con que hacer) en cada Dimensión del Desarrollo, el análisis e interpretación con argumentos sólidos el diagnostico territorial y llevar a la mejor escenario la formulación donde se represente el mejoramiento de la calidad de vida de la población y el fortalecimiento de las instituciones, para que se pueda cumplir con las exigencias de este mundo globalizado. 


\section{Figura 2.4. ESTRUCTURA SISTEMÁTICA DE LAS DIMENSIONES DEL DESARROLLO COMO SISTEMA}

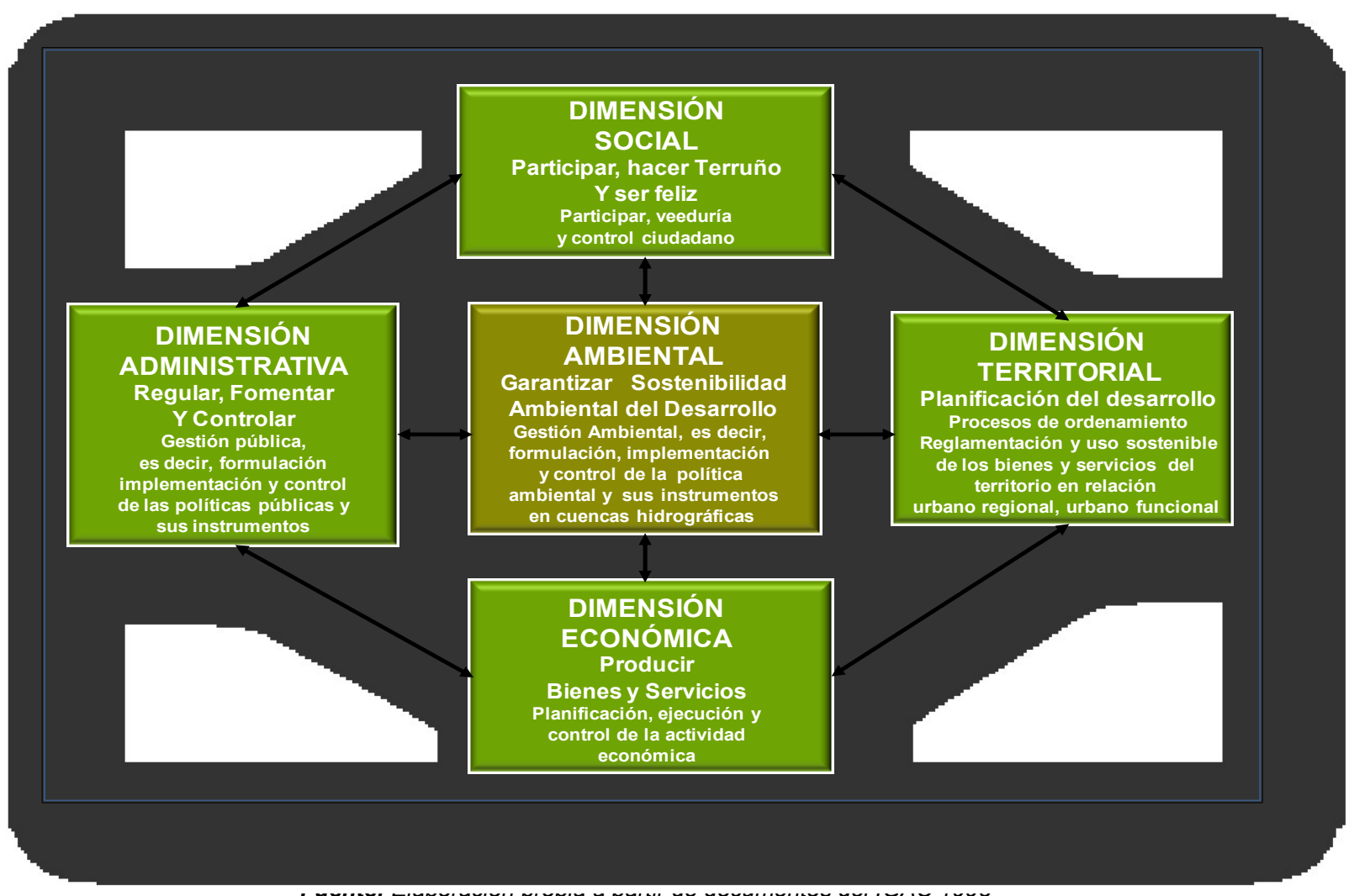

\subsubsection{La Dimensión Ambiental y el componente físico biótico}

Esta dimensión reconoce al ambiente como base de la vida $\mathrm{y}$, por lo tanto, como fundamento del desarrollo. También reconoce al ser humano como parte integral del ambiente y valora, con especial atención, los efectos positivos y negativos, de su accionar en la naturaleza, pero también, la forma en que la naturaleza afecta a los seres humanos.

La misión del componente físico biótico en el ordenamiento territorial es garantizar la sostenibilidad ambiental del desarrollo y será realizada a través de los procesos sistémicos del análisis del componente, la climatología, hidrología, geología, la geomorfología, cobertura y uso del suelo, las amenazas naturales, la implementación, control de la política ambiental y de sus instrumentos. La dimensión ambiental representa la base natural sobre la que se sustenta el desarrollo de la región o del territorio, es decir, constituye por un lado, las posibilidades ecosistémicas para generar bienes y servicios ambientales, y por otro lado, las posibilidades culturales para entender, aprovechar y proteger responsable y sosteniblemente al medio ambiente, análisis que conlleva la interpretación del físico biótico con énfasis en la gestión territorial, se interpretará en lo referente a: el clima, las aguas, los suelo, el relieve, las actividades socioecómicas, riesgos, desastres y síntesis ambiental apoyada de la zonificación ambiental del territorio. (IGAC 1998-Véase figura 2.5.).

Por otra parte, la unidad geográfica y física como sistema ambiental (cuencas hidrográficas, p.ej.), muchas veces traspasa los límites políticos y administrativos de 
municipios y departamentos. Por eso, el manejo de los recursos naturales exige una visión comprensiva y participativa del tema, que incluye tanto a los actores locales como a los nacionales. En efecto, la participación ciudadana resulta fundamental, ya que una ciudadanía alerta y activa es la mejor garantía para generar un cambio e impulsar patrones de uso que aseguren un equilibrio entre la producción y la conservación.

Por supuesto, es necesario analizar cuáles actores sociales son los más susceptibles de convertirse en agentes multiplicadores de cambio. Es necesario recordar que una estrategia de desarrollo de este tipo debe promover el manejo racional e integral de los recursos naturales, generando acciones que contribuyan a mejorar las condiciones sociales de la población.

Figura 2.5. LA DIMENSIÓN AMBIENTAL

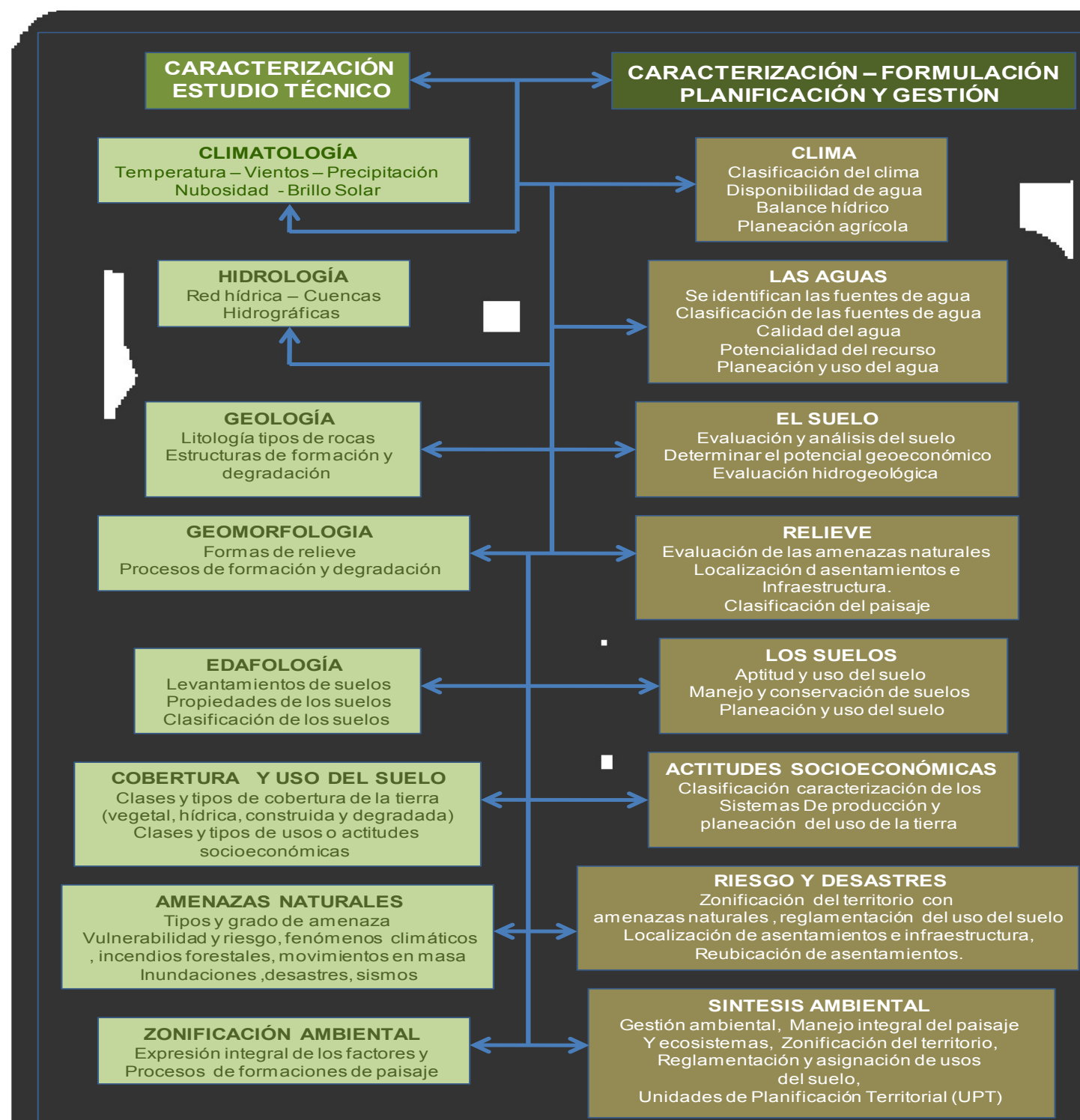

Fuente: Elaboración a partir de documentos del IGAC (1998). 


\subsubsection{La Dimensión Social}

Esta Dimensión del desarrollo está conformada por la dotación de los recursos humanos y simbólicos del territorio. Involucra, por un lado, la población, los aspectos demográficos, las condiciones de salud, alimentación, vivienda, educación, empleo, ingresos, carácter de asociación y participación de las comunidades en el caso de tomas de decisión desde la visión de la aplicabilidad de los instrumentos de participación ciudadana previstos en la Ley 134 de 1994, y por otro, el mundo simbólico, representado en paradigmas de principios, valores, lengua, arte, mitos, religiones etc. (IGAC 1998 - Véase Figura 2. 6.).

Figura 2. 6. DIMENSIÓN SOCIAL

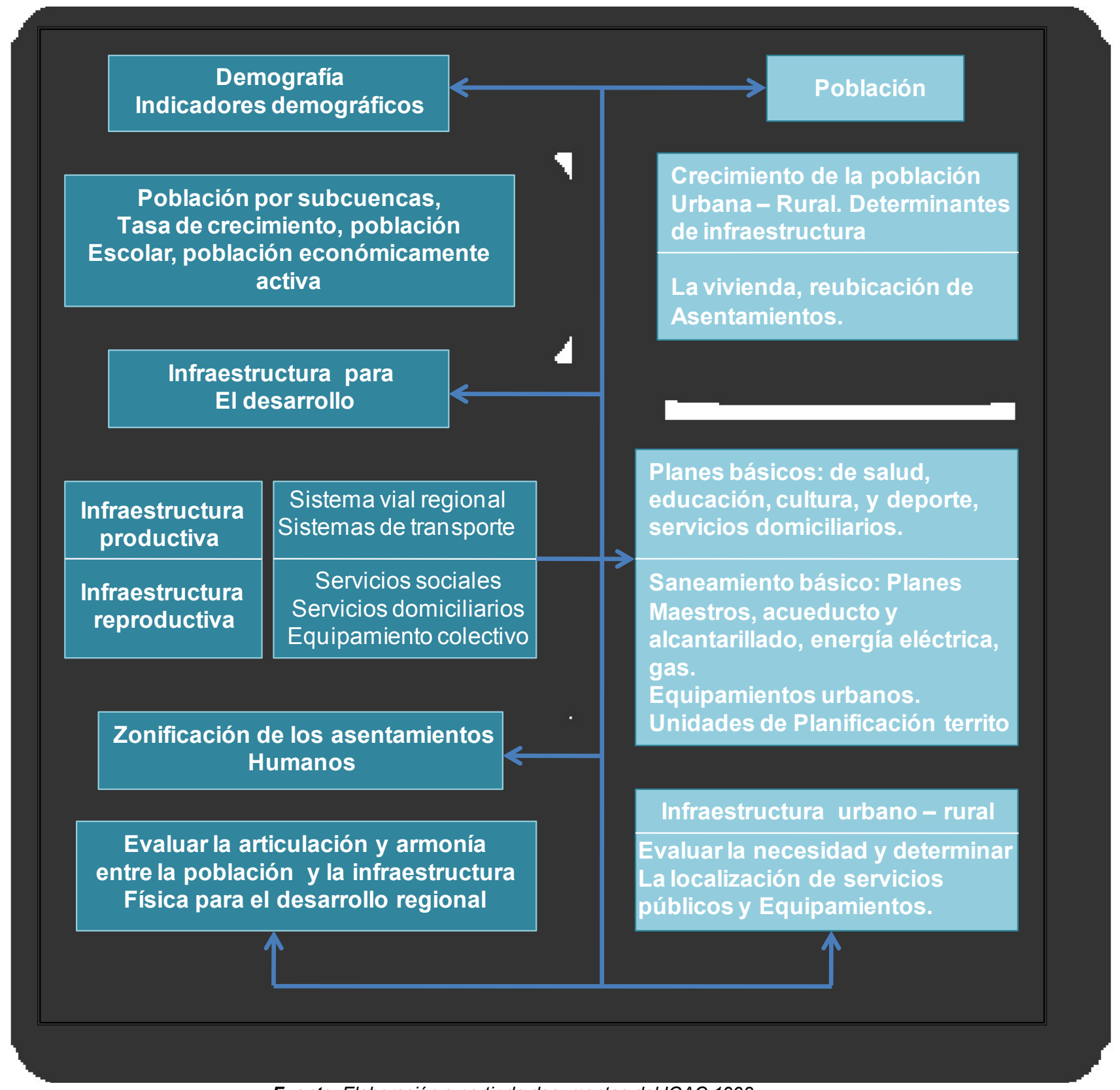

Fuente: Elaboración a partir de documentos del IGAC 1998 


\subsubsection{La Dimensión Económica}

La dimensión económica, está conformada por la infraestructura económica de las actividades socioeconómicas y de desarrollo económico en el territorio, se representará, por la dotación de bienes y servicios creados y construidos con fines productivos. Involucra las infraestructuras productivas, energéticas, científico - tecnológicas y financiera. La evaluación fiscal de los municipios y su gestión será causa de análisis para determinar el posicionamiento de cada una de las entidades territoriales como determinante en el mejoramiento institucional y administrativo. (IGAC 1998Véase Figura 2. 7.).

Figura 2.7. LA DIMENSIÓN ECONÓMICA

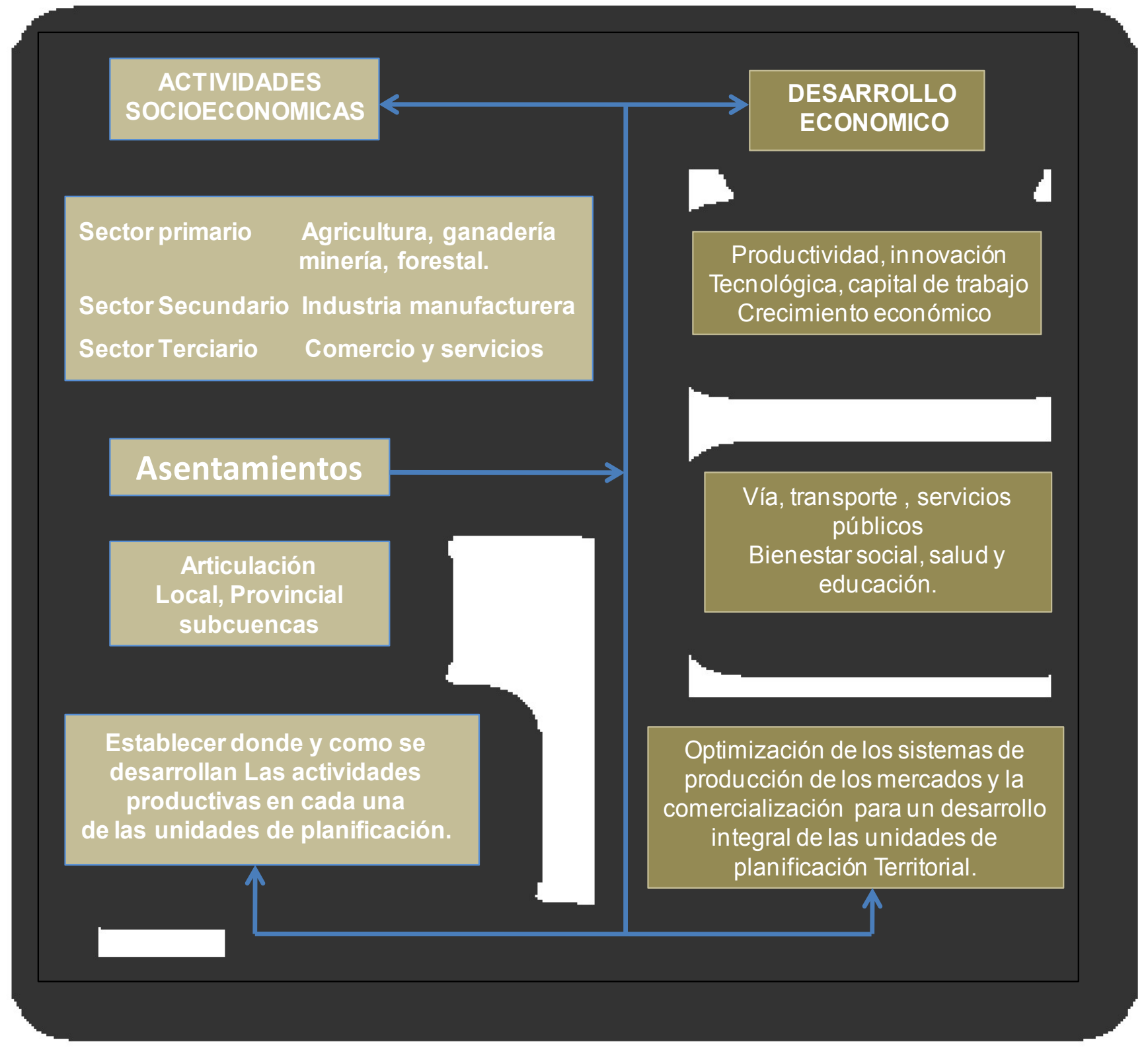




\subsubsection{La Dimensión Administrativa}

La dimensión administrativa busca regular, fomentar y controlar, a través de la planificación y gestión del ordenamiento territorial, procesos sistémicos de planificación e implementación en el control de las políticas públicas y sus instrumentos en su respectiva armonización (Planes de Desarrollo y Ordenamientos territoriales). Por lo tanto, el ordenamiento territorial, constituye un principio básico de la gestión pública y consistirá en garantizar que la planificación del desarrollo involucre procesos de ordenamiento que permitan la reglamentación y uso sostenible de los bienes y servicios del territorio (IGAC 1998 - Véase Figura 2. 8.)

Figura 2.8. LA DIMENSIÓN ADMINISTRATIVA

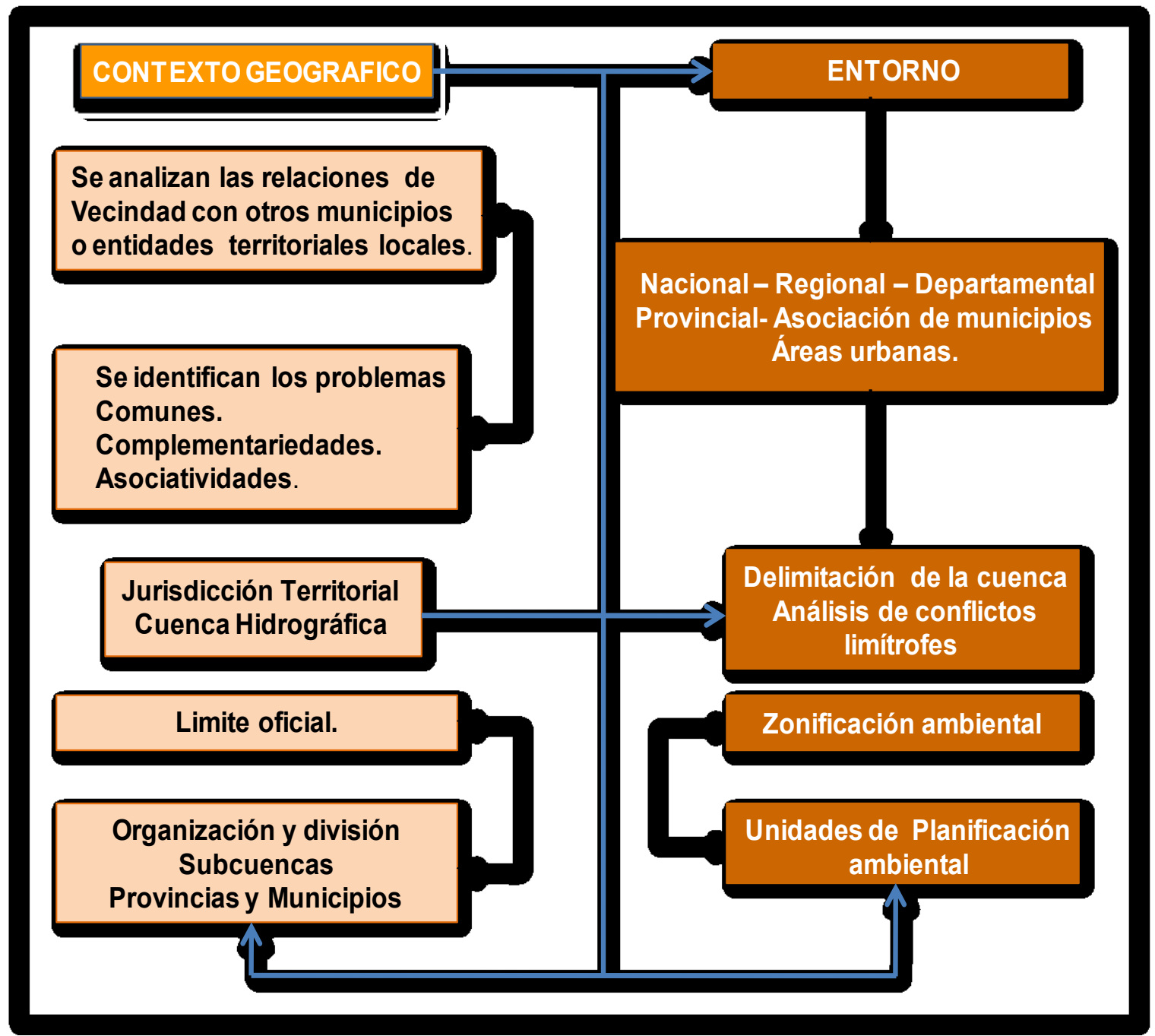

Fuente: Elaboración a partir de documentos del IGAC 1998 


\subsubsection{LA DIMENSIÓN TERRITORIAL}

Con la dimensión territorial, se busca regular, fomentar e integrar, a través de la espacialización de los conceptos de lo urbano funcional y urbano regional, la aplicación de las respectivas políticas públicas, además de la espacialización de lo ambiental, social, económico y administrativo, teniendo en cuenta para tal fin, la aplicación de la Unidades de Gestión Territorial, a través de la unidad física y geográfica de la cuenca hidrográfica en asociación con la Estructura Ecológica Regional, teniendo en cuenta el desarrollo productivo y el desarrollo social (IGAC 1998 - Véase Figura 2. 9.).

\section{Figura 2.9. LA DIMENSIÓN TERRITORIAL}

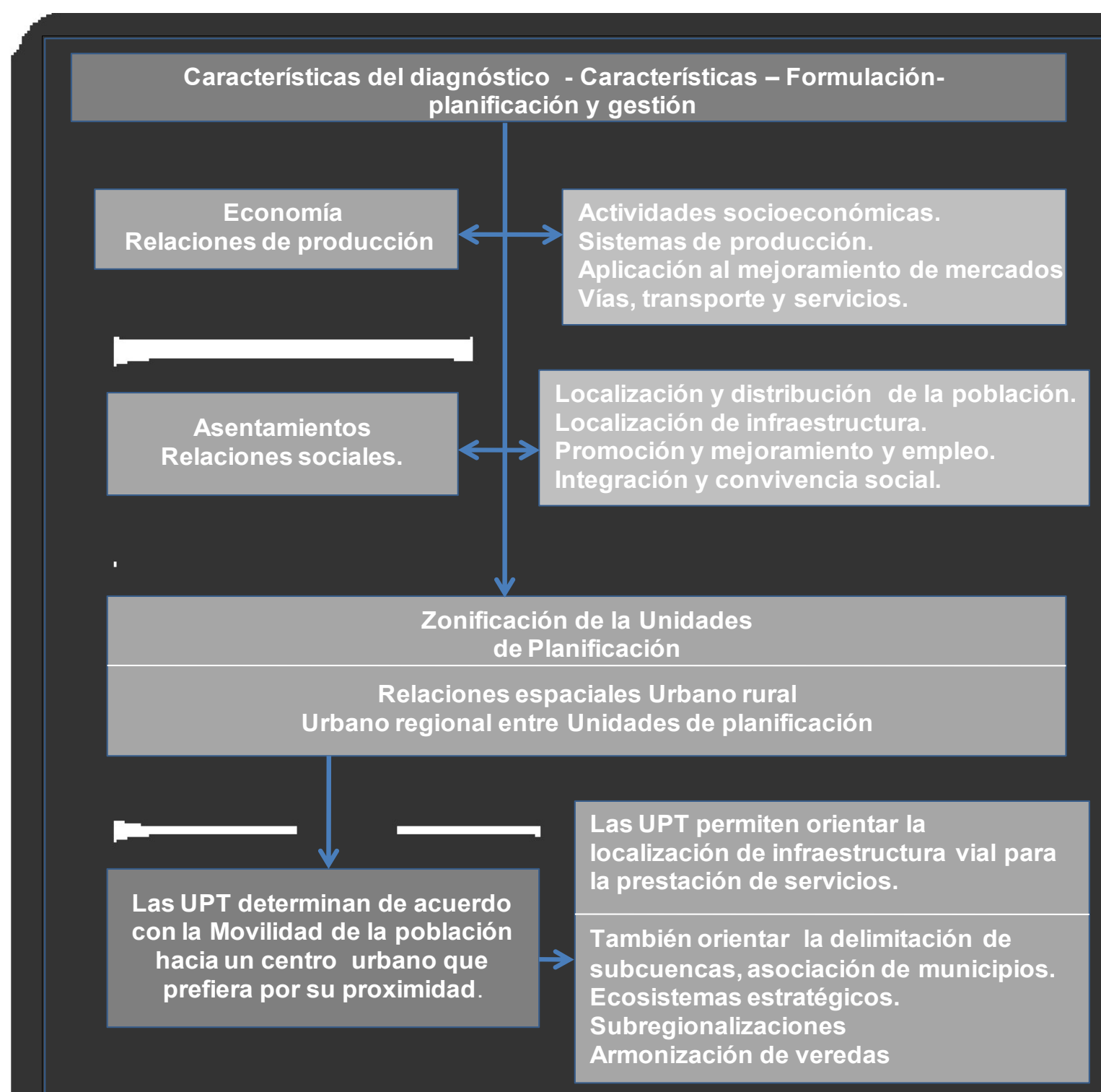

Fuente: Elaboración a partir de documentos del IGAC 1998. 
Cada una de las dimensiones anteriores, proporcionan tres características importantes:

1. Bases conceptuales, las cuales son utilizadas para los procesos de caracterización de los estudios Planes de Ordenamiento Territorial Municipal, como también para el Manejo integral de Cuencas Hidrográficas e incorporarlas a los programas y proyectos de la inversión plurianual de los Planes de Desarrollo.

2. Caracterización de lo técnico, que permite dar las bases para la interrelación de los factores en la relación de la Gestión y la planificación territorial.

3. Directrices para la toma de decisiones, relacionadas con la caracterización técnica de la dimensión por ejemplo la Ambiental; si tomamos la primera columna de la Dimensión Ambiental identificada con el nombre "Caracterización Estudio Técnico" podemos determinar lo siguiente con base en la información suministrada, Temperatura - Vientos - Precipitación - Nubosidad - Brillo Solar; "Caracterización Formulación Planificación y Gestión" se puede determinar análisis del clima - Disponibilidad de agua - Balance hídrico, finamente tomar decisiones en temas como la planificación agrícola en el territorio.

Las tres interrelacionadas proporcionan las bases para proponer escenarios plausibles al futuro, teniendo en cuenta las directrices de los instrumentos de planificación y de gestión, por ejemplo, la armonización de los instrumentos de planificación como son los planes de desarrollo desde el contexto nacional, departamental y municipal y los distintos planes de ordenamiento territorial entre la articulación de sus programas y proyectos. 


\section{CAPÍTULO}

\section{MARCO POLÍTICO LEGAL Y NORMATIVO}




\subsection{ANÁLISIS DE POLÍTICAS, NORMAS Y LEYES EXPEDIDAS EN COLOMBIA PARA EL DESARROLLO TERRITORIAL SU APLICACIÓN A LA REALIDAD COLOMBIANA DESDE LA PERSPECTIVA INSTITUCIONAL}

Se realizará un reconocimiento de las políticas públicas expedidas en Colombia, relacionadas con el tema del desarrollo territorial y regional, su aplicación a la realidad colombiana teniendo como determinante en su análisis la perspectiva institucional. Sin embargo, desde algunas disciplinas de la planificación regional, se emprenderá la interpretación de algunas nociones que posteriormente se referirán al contexto regional proporcionando los insumos necesarios para plantear los lineamientos y conceptos que puedan soportar la posición de introducir la unidad física de la cuenca hidrográfica, los postulados institucionales para ordenar, planificar y gestionar el desarrollo del territorio teniendo como objetivo la consolidación de la figura regional en las decisiones para el nuevo orden de las entidades que se propongan con la finalidad de constituir el nuevo marco político y administrativo.

Para ello, se debe partir entendiendo las distintas posiciones de los marcos legales que a lo largo de varias décadas se ha promulgado y por lo tanto, incidido en el orden territorial colombiano. Se podrá observar el análisis de normas y leyes expedidas en Colombia y su aplicación a la realidad nacional teniendo la perspectiva institucional como análisis; además los planes nacionales de desarrollo y su relación con los análisis territoriales, regional y el desarrollo territorial; los instrumentos de planificación y de gestión ${ }^{34}$ y los planes estratégicos institucionales de desarrollo territorial entre otros.

\subsubsection{El Contexto Nacional}

Se puede decir que en el año 1954, se da un evento importante a introducirse en el país el concepto de "Ordenamiento y Desarrollo Integral de Cuencas", con base en el modelo de la "Teneesse Valle Authority - T.V.A", de Estados Unidos de América. Y posteriormente, creándose la Corporación Autónoma Regional del Valle del Cauca - CVC, principalmente en la décadas del 60 y 70, los temas de desarrollo y ordenamiento territorial se ajustaron institucionalmente a las Corporaciones Autónomas Regional; creándose en distintas partes del país, muchas de las cuales ya no se enmarcarían dentro del concepto original de ordenamiento y desarrollo integral de cuencas hidrográficas y con la promulgación de la Ley 99 de 1993, se cambiarían definitivamente sus funciones y naturaleza de desarrollo regional hacia labores propias de la gestión y protección ambiental.

Así, se debe destacar el hecho de que durante los años 70 y 80 , se empiezan a dar en el país las primeras normas sobre conservación y aprovechamiento sostenible de los recursos naturales, las cuales se enfocaron al tratamiento de temas como el manejo integral de las cuencas hidrográficas y la definición de normas sobre uso y manejo de recursos naturales, todas ellas con claros enfoques de análisis territorial y ambiental. Por ello, es importante destacar que antes de la década de los 70, en Colombia, existían normas ambientales dispersas sobre cada materia. Con la expedición de Decreto - Ley 2811 de 1974, el país empieza a mostrar interés por asuntos ambientales, como los humedales y el ordenamiento de cuencas hidrográficas, recursos muy importantes para el

\footnotetext{
${ }^{34}$ Los instrumentos de planificación se entienden como las instancias gubernamentales en la promulgación de nomas de jerarquía nacional, departamental y municipal que inciden directamente en los procesos de planificación y de gestión territorial.
} 
desarrollo económico y social de la población, convirtiéndose además en la primera legislación integrada para el manejo de recursos naturales en América Latina.

En cuanto a las propuestas de autonomía y conformación regional en Colombia, han sido varios los intentos que se pueden identificar, algunos de ellas liderados por los departamentos del Caribe; discusiones sobre autonomía regional en departamentos del sur del país como Nariño y Putumayo, propuestas federalistas en Antioquía y de separación en el norte de Santander (Cúcuta) ${ }^{35}$ durante los años 80 y 90 , hasta propuestas de asambleas constituyentes en los departamentos del Tolima, Caquetá, Huila y Putumayo; durante los 90, se llevaron iniciativas como la Alianza Sur, con planteamientos alternativas a la fumigación de cultivos ilícitos.

En cuanto al papel de la academia, el tema territorial ha sido muy productivo en las dos últimas décadas, sobresaliendo variadas investigaciones llevadas a cabo por centros de investigación en temas relacionados con el espacio y territorio, universidades y organismos independientes como la Fundación Social, la Friedrich Ebert Stiftung en Colombia (FESCOL), la Asociación Colombiana de Investigadores Urbano Regionales (ACIUR), el Instituto de Estudios Políticos (IEPRI), el Centro Interdisciplinario de Estudios Regionales (CIDER) de la universidad de los Andes, el Instituto de Estudios Ambientales (IDEA) y la Red de Espacio y Territorio (RET) de la Universidad Nacional de Colombia, más una serie de asociaciones de geógrafos, sociólogos y economistas, que han buscado el rescate de la dimensión territorial desde perspectivas políticas, culturales y ambientales.

En la década del 90, se promulgó la Ley 99 de 1993, con la cual se ajustó la normatividad y la institucionalidad del sector ambiental en Colombia, a las nuevas condiciones económicas, políticas y sociales. Recientemente se han promovido otro tipo de iniciativas de ordenamiento territorial, desde lógicas productivas, culturales y de eficiencia dentro de las que vale destacar acuerdos de voluntades como la Mesa de Planificación Regional Bogotá Cundinamarca; la Comisión Tripartita en Medellín y Antioquia; lo mismo que procesos asociados a Programas de Desarrollo y Paz ${ }^{36}$, Planes Regionales de Desarrollo Sostenible ${ }^{37}$ y Programas para la Reconstrucción de sitios afectados por desastres naturales ${ }^{38}$, que en ocasiones han contado con apoyo institucional regional y nacional e internacionales. A continuación, presentamos los distintos planes de desarrollo y su relación con los análisis regionales y el desarrollo territorial.

\footnotetext{
${ }^{35}$ BUSTAMANTE, Ana Marleny. Subnacionalismo en la frontera. Caso de Táchira (Venezuela) - Norte de Santander (Colombia). En: Revista territorios No. 10- 11. Universidad de los Andes. CIDER-ACIUR. Febrero de 2004

${ }_{36}$ Programa de Desarrollo y Paz del Magdalena Medio y otros procesos regionales y comunitarios que se vienen desarrollando desde los años 90 en Apartado y el Urabá Antioqueño en torno a laboratorios de Paz.

${ }^{37}$ Los más destacados se han dado en la Sierra Nevada de Santa Marta, distintas propuestas de apoyo al Macizo colombiano y regímenes especiales para la protección de la biodiversidad en San Andrés y Providencia. También se pueden mencionar las Agendas XXI regionales en el pacífico y la Amazonía colombiana, e intentos por definir políticas de estado para estas dos macrorregiones.

${ }^{38}$ Entre otros: el Programa de Reconstrucción del Eje Cafetero adelantado por el FOREC a comienzos del Siglo XXI y el Plan de Desarrollo Sostenible de la Ecorregión de la Mojana y el desarrollo de políticas explícitas de desarrollo económico y social para dicha Región, desarrolladas en los Documentos CONPES 3146 de 2001 (que estableció la estrategia para consolidar la ejecución del Plan Nacional de Prevención y Atención de Desastres en Colombia para el corto y mediano plazo), y 3421 de 2006, por medio del cual se establecieron algunas estrategias para la reactivación económica y social de la región de la Mojana.
} 


\subsubsection{Los planes nacionales de desarrollo y su relación con los análisis: Territorial, Regional y el Desarrollo Territorial.}

A lo largo de cinco décadas encontramos un marco legal normativo y político, el cual el país ha querido plantear su transformación social, económica y ambiental. Cada uno de los distintos planes incidieron en el ordenamiento territorial, como en el fortalecimiento institucional, en fin, en un país donde las reformas y ajustes de instituciones públicas se proponen entre legislaciones administrativas de cada cuatro años, en fusiones o liquidaciones o en nuevas, son las constantes de los ajustes que dichas las reformas que durante cada uno de los gobiernos establecen, no han podido repercutir en un país de forma positiva a las puertas de la globalización económica e institucional en términos de gestión del siglo XXI.

La administración pública requiere que el territorio nacional esté repartido en porciones de diferentes tamaños, ordenadas en diferentes niveles asignados según funciones (Alberto Mendoza Morales posición en la determinación de metodología del ordenamiento territorial), son algunas de las características que los planes de desarrollo postulan desde la visión de los procesos de la descentralización administrativa y territorial que se ha venido proponiendo desde la décadas de los ochenta; pero cada vez hemos llegado al centralismo en las decisiones territoriales, dejando a municipios y departamentos atados a las decisiones del gobierno central.

El conocimiento administrativo y político del país lo podemos entender a lo largo de cada uno de los planes de desarrollo, teniendo como referente el gobierno de Carlos Lleras Restrepo, (1966 - 1970), hasta el gobierno de Juan Manuel Santos, (2010 - 2014). En cada uno de ellos, se determinaron políticas públicas dedicadas al desarrollo industrial, social y económico; no obstante en el periodo de Ernesto Samper, (1994 - 1998), se observa la promulgación de un marco legal considerable de políticas públicas que muchas de ellas son la estructura legal en lo social, territorial y ambiental.

La tabla documental que se presenta, (Véase Tabla 3.1.), comprende, los aspectos más importantes de cada uno de los Planes Nacionales de Desarrollo (PND), su relación con el análisis y desarrollo territorial y regional, teniendo en cuenta la creación de instancias institucionales en el fortalecimiento de las políticas públicas social y económica; las cuales inciden en el desarrollo urbano y rural.

\section{Tabla 3. 1. PLANES NACIONALES DE DESARROLLO Y SU RELACIÓN CON LOS ANÁLISIS TERRITORIAL Y REGIONAL Y EL DESARROLLO TERRITORIAL.}

\begin{tabular}{|c|c|c|c|}
\hline AÑO & PRESIDENTE & $\begin{array}{l}\text { NOMBRE } \\
\text { DEL PLAN }\end{array}$ & CONTENIDO/PROGRAMA \\
\hline $1966-1970$ & $\begin{array}{l}\text { El gobierno de } \\
\text { Carlos Lleras } \\
\text { Restrepo }\end{array}$ & & $\begin{array}{l}\text { Se planteó, en su Plan de Desarrollo, que los } \\
\text { desequilibrios regionales eran el resultado de los } \\
\text { procesos migratorios históricos y de la } \\
\text { configuración regional y urbana del País. Para } \\
\text { solucionar esta problemática, se dispusieron } \\
\text { acciones encaminadas a reorientar las } \\
\text { migraciones, impulsando por ello algunos polos de } \\
\text { crecimiento en las ciudades de Medellín, Cali y } \\
\text { Barranquilla, al igual que la realización de } \\
\text { reformas agrarias para reducir la migración }\end{array}$ \\
\hline
\end{tabular}




\begin{tabular}{|c|c|c|c|}
\hline AÑO & PRESIDENTE & $\begin{array}{l}\text { NOMBRE } \\
\text { DEL PLAN }\end{array}$ & CONTENIDO/PROGRAMA \\
\hline & & & $\begin{array}{l}\text { campo-ciudad; la adecuación del equipamiento de } \\
\text { las ciudades; y el fortalecimiento del desarrollo de } \\
\text { ciudades intermedias. Durante este periodo se } \\
\text { crea el Instituto Nacional de Recursos naturales y } \\
\text { Ambiente (INDERENA), el cual tendría bajo su } \\
\text { responsabilidad la ejecución de acciones para la } \\
\text { ordenación de cuencas hidrográficas. }\end{array}$ \\
\hline $1970-1974$ & $\begin{array}{l}\text { Gobierno de } \\
\text { Misael Pastrana: }\end{array}$ & $\begin{array}{l}\text { Las Cuatro } \\
\text { Estrategias }\end{array}$ & $\begin{array}{l}\text { Con la asesoría del economista Lauchlin Currie, } \\
\text { se orientó hacia objetivos de fomento a la } \\
\text { industria y el desarrollo urbano, lo mismo que a } \\
\text { las exportaciones; el aumento de la productividad } \\
\text { agrícola y la redistribución del ingreso. } \\
\text { Igualmente, se fortalecieron políticas y programas } \\
\text { de intervención en cuencas hidrográficas, y se } \\
\text { promulgó el Código Nacional de Recursos } \\
\text { Naturales Renovables y de Protección al Medio } \\
\text { Ambiente. }\end{array}$ \\
\hline $1986-1990$ & $\begin{array}{ll}\text { Gobierno } & \text { de } \\
\text { Virgilio Barco } & \end{array}$ & $\begin{array}{l}\text { Plan de } \\
\text { Economía } \\
\text { Social }\end{array}$ & $\begin{array}{l}\text { Se desarrollan las primeras medidas para apoyar } \\
\text { la descentralización, dándose también, por } \\
\text { primera vez, la posibilidad de integrar políticas de } \\
\text { desarrollo económico y políticas sociales con } \\
\text { perspectiva regional, a través de una política de } \\
\text { desarrollo territorial que, en efecto, se plantea } \\
\text { como una estrategia fundamental en su plan de } \\
\text { desarrollo. Dentro de las realizaciones centrales } \\
\text { de este plan se tiene la formulación de la ley } 9 \text { de } \\
1989 \text { (Ley de Reforma Urbana) y la integración } \\
\text { regional a través de los CORPES }\end{array}$ \\
\hline $1992-1994$ & $\begin{array}{l}\text { Gobierno de Cesar } \\
\text { Gaviria Trujillo }\end{array}$ & $\begin{array}{l}\text { La Revolución } \\
\text { Pacífica }\end{array}$ & $\begin{array}{l}\text { Se avanzó en la aplicación de reformas } \\
\text { estructurales e institucionales para la promoción } \\
\text { de la apertura económica, y en la sanción de una } \\
\text { nueva Constitución Política para Colombia. }\end{array}$ \\
\hline
\end{tabular}




\begin{tabular}{|c|c|c|c|}
\hline AÑO & PRESIDENTE & $\begin{array}{l}\text { NOMBRE } \\
\text { DEL PLAN }\end{array}$ & CONTENIDO/PROGRAMA \\
\hline $1994-1998$ & $\begin{array}{lr}\text { Gobierno } & \text { de } \\
\text { Ernesto } & \text { Samper } \\
\text { Pizano } & \end{array}$ & El Salto Social & $\begin{array}{l}\text { En la Política Urbana del Salto Social el tema del } \\
\text { desarrollo territorial se circunscribió, } \\
\text { fundamentalmente, al desarrollo urbano bajo una } \\
\text { visión integral de la ciudad como unidad socio- } \\
\text { espacial básica, articulando acciones sobre los } \\
\text { atributos urbanos (suelo urbano, servicios } \\
\text { públicos, vivienda, equipamiento, transporte } \\
\text { urbano y espacio público), en la búsqueda de } \\
\text { ciudades más competitivas, gobernables, } \\
\text { solidarias, ambientalmente sostenibles, y con } \\
\text { mayores niveles de identidad colectiva. } \\
\text { Adicionalmente, el Salto Social formuló una } \\
\text { política ambiental específica, cuyo objetivo fue } \\
\text { avanzar, gradualmente, hacia un desarrollo } \\
\text { humano sostenible, considerando al medio } \\
\text { ambiente como un factor básico para conseguir tal } \\
\text { propósito. }\end{array}$ \\
\hline 1998- 2002 & $\begin{array}{l}\text { Gobierno de } \\
\text { Andrés Pastrana } \\
\text { Arango }\end{array}$ & $\begin{array}{lr}\text { Cambio } & \text { para } \\
\text { Construir } & \text { la } \\
\text { Paz } & \end{array}$ & $\begin{array}{l}\text { Planteó como supuesto fundamental: "Sin paz no } \\
\text { hay desarrollo y sin desarrollo no hay paz". Por } \\
\text { ello, se formularon acciones de corto y mediano } \\
\text { plazo en esta perspectiva tales como, el Fondo } \\
\text { para la Paz, e intervenciones integrales en zonas } \\
\text { de conflicto armado relacionadas, principalmente, } \\
\text { con el fortalecimiento de la seguridad y la } \\
\text { convivencia. } \\
\text { Las principales acciones territoriales definidas } \\
\text { durante el gobierno de Andrés Pastrana Arango, } \\
\text { se centraron en la atención prioritaria a regiones } \\
\text { de interés particular, tales como la región Caribe y } \\
\text { el Eje cafetero. Asimismo, el Plan incorporó la } \\
\text { visión de ecosistemas estratégicos desde la } \\
\text { perspectiva de las ecorregiones estratégicas, en } \\
\text { un ejercicio de construcción colectiva, mediante la } \\
\text { percepción del agua como eje estructurante. En } \\
\text { efecto, tal ejercicio permitió visualizar } \\
\text { potencialidades ambientales significativas de } \\
\text { diferentes regiones del País }{ }^{39} \text {. }\end{array}$ \\
\hline $\begin{array}{l}2002-2006 \\
2006-2010\end{array}$ & $\begin{array}{l}\text { Gobierno } \\
\text { Álvaro } \\
\text { Vélez }^{40}\end{array}$ & $\begin{array}{l}\text { Hacia un } \\
\text { Estado } \\
\text { Comunitario. }\end{array}$ & $\begin{array}{l}\text { De los dos; al se destacan los énfasis dados a los } \\
\text { temas de seguridad interna y la focalización de la } \\
\text { inversión en regiones deprimidas y en conflicto. } \\
\text { Así, el último cuatrienio apuesta por un horizonte } \\
\text { definido de políticas públicas para concertar y } \\
\text { focalizar acciones que permitan afianzar la } \\
\text { seguridad y fomentar la competitividad, mediante }\end{array}$ \\
\hline
\end{tabular}

${ }^{39}$ Plan de Gobierno Ambiental, Andrés Pastrana Arango, 1998-2002.

40 Plan Nacional de Desarrollo "Hacia un Estado Comunitario 2002 -2006", adoptado a través de la Ley 812 de 2003 ; y "Estado Comunitario: Desarrollo para todos 2006 - 2010", adoptado con la ley 1151 de 2007. 


\begin{tabular}{|c|c|c|c|}
\hline AÑO & PRESIDENTE & $\begin{array}{l}\text { NOMBRE } \\
\text { DEL PLAN }\end{array}$ & CONTENIDO/PROGRAMA \\
\hline $\begin{array}{l}2002-2006 \\
2006-2010\end{array}$ & $\begin{array}{l}\text { Gobierno } \\
\text { Álvaro } \\
\text { Vélez }^{41}\end{array}$ & $\begin{array}{l}\text { Estado } \\
\text { Comunitario } \\
\text { desarrollo } \\
\text { para todos. }\end{array}$ & $\begin{array}{l}\text { distintas estrategias de enfoque regional y } \\
\text { subregional. } \\
\text { En este sentido, se han propuesto algunos } \\
\text { siguientes ejes estratégicos de desarrollo } \\
\text { relacionados con: } \\
\text { a) la planificación ambiental con la ordenación } \\
\text { territorial y la planificación del desarrollo en los } \\
\text { distintos niveles territoriales; b) la implementación } \\
\text { de Evaluaciones Ambientales Estratégicas; c) el } \\
\text { diseño e implementación de una Política } \\
\text { Ambiental Urbana; d) la ejecución de } \\
\text { Macroproyectos de interés nacional con énfasis } \\
\text { en vivienda de interés social; la implementación } \\
\text { de } 32 \text { Planes Departamentales de Agua y } \\
\text { Saneamiento Básico y esquemas de operación de } \\
\text { servicios públicos básicos de carácter regional; e) } \\
\text { la articulación de planes de movilidad y sistemas } \\
\text { de transporte masivo con procesos de } \\
\text { ordenamiento territorial existente; f) el diseño de } \\
\text { mecanismos para la gestión integral del riesgo en } \\
\text { articulación con los planes de desarrollo, los } \\
\text { planes de ordenamiento y los planes ambientales; } \\
\text { g) la incorporación de la dimensión regional como } \\
\text { dimensión transversal del desarrollo; h) la puesta } \\
\text { en marcha de estrategias regionales de } \\
\text { productividad y competitividad, con la } \\
\text { implementación de Agendas Internas } \\
\text { departamentales y sectoriales }{ }^{2} \text {; i) la intervención } \\
\text { diferenciada de grupos de departamentos que } \\
\text { tienen mayores o menores grados de desarrollo } \\
\text { territorial; j) la intervención de políticas de Estado } \\
\text { en zonas estratégicas y evidentemente rezagadas } \\
\text { con respecto a las demás regiones, entre otras. }\end{array}$ \\
\hline $2010-2014$ & $\begin{array}{l}\text { Gobierno Juan } \\
\text { Manuel Santos. }\end{array}$ & $\begin{array}{l}\text { Prosperidad } \\
\text { para todos. }\end{array}$ & $\begin{array}{l}\text { Al posesionarse en el mes de agosto de } 2010 \text {, el } \\
\text { gobernó de Juan Manuel Santos, asume los retos } \\
\text { de impulsar el mejoramiento de las relaciones } \\
\text { internacionales entre Venezuela y Ecuador, rotas } \\
\text { en el gobierno anterior de Uribe Vélez, además de } \\
\text { la reforma en lo relacionado a la salud; dos } \\
\text { condiciones que fueron prioritarias en su campaña } \\
\text { política. El } 2010 \text { el cambio climático lo recibió con } \\
\text { las lluvias más fuertes de las últimas décadas, } \\
\text { ocasionado inundaciones sin precedentes al ser } \\
\text { inundadas más de } 30 \text { centros poblados de las }\end{array}$ \\
\hline
\end{tabular}

${ }^{41}$ Plan Nacional de Desarrollo "Hacia un Estado Comunitario 2002 -2006", adoptado a través de la Ley 812 de 2003 ; y "Estado Comunitario: Desarrollo para todos 2006 - 2010", adoptado con la ley 1151 de 2007.

${ }^{42}$ Las Agendas Internas son, esencialmente, instrumentos de planificación económica coordinados por el DNP, con el propósito de estimular y orientar los sistemas productivos más promisorios y estratégicos para la economía nacional y el mercado internacional y, en consecuencia, para la generación de empleo formal. A pesar de que estos instrumentos se enmarcan en las metas de Visión Colombia II Centenario: 2019, y procuran establecer compromisos a nivel sectorial y departamental, requieren de mayores implicaciones de los gobiernos y empresas regionales, al mismo tiempo que sendos esfuerzos de parte del Gobierno Nacional en infraestructura básica para la competitividad. 


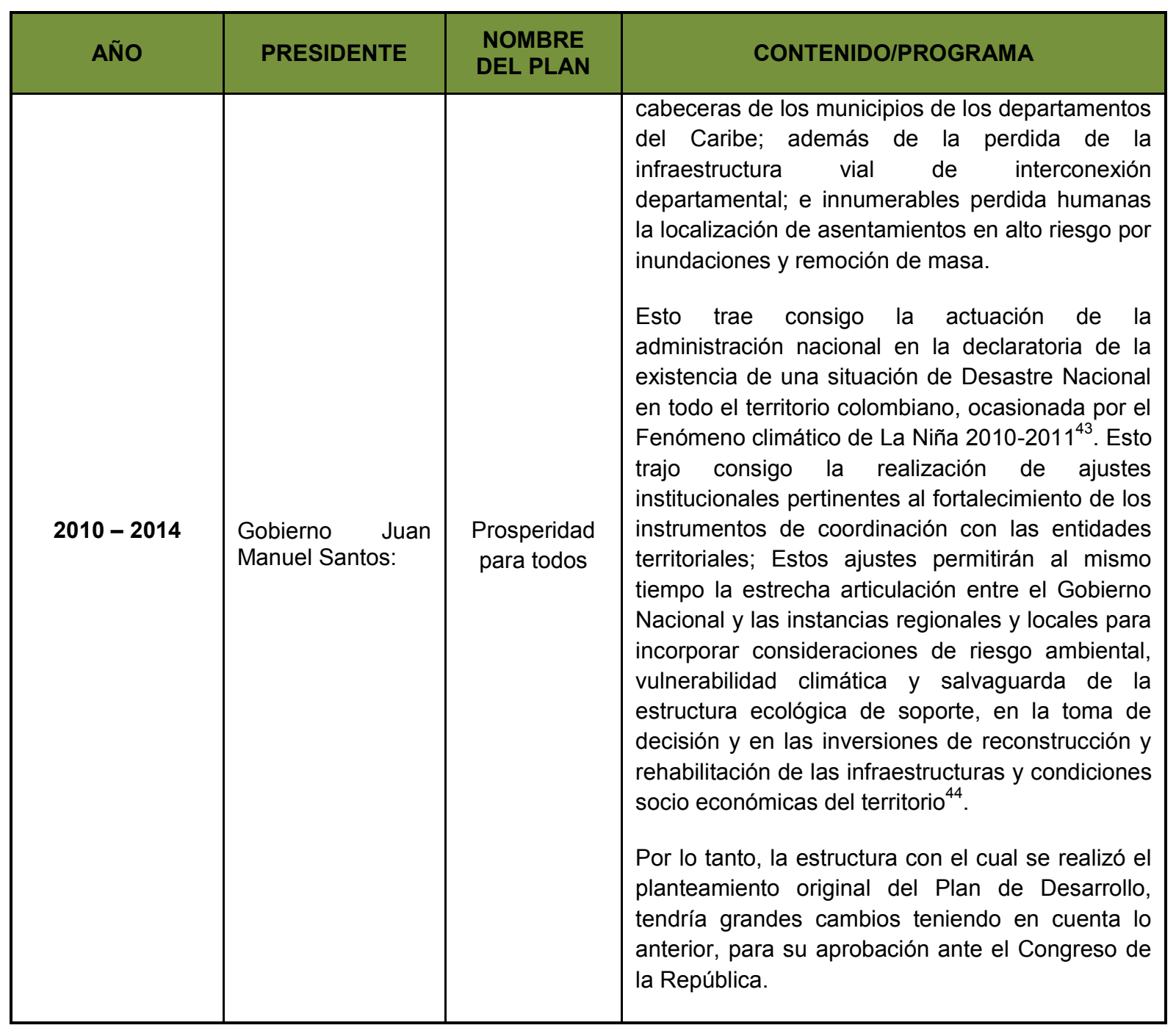

Fuente: Elaboración propia a partir del análisis de los planes de desarrollo.

\footnotetext{
${ }^{43}$ El cambio climático para Colombia se ha venido acentuando a lo largo de las temporadas secas y de lluvia, el Instituto de Hidrología ,Meteorología y Estudios Ambientales de Colombia IDEAM de fecha 6 de diciembre de 2010, mediante el cual se indicó que el Fenómeno de La Niña 2010-2011 alteró el clima nacional desde el comienzo de su formación en el mes de junio de 2010, ocasionando en los meses de julio y noviembre las lluvias más intensas y abundantes sin registro de tales magnitudes en el país, en las regiones Caribe, Andina y Pacífica; además hizo que no se presentara la temporada seca de mitad de año en el norte y centro de la Región Andina. Los meses de agosto y septiembre se comportaron también con lluvias muy por encima de lo normal en la región Caribe y en el norte de la región Andina.

${ }^{44}$ Decreto 4579 del 7 de diciembre de 2010, el Gobierno Nacional declaró la existencia de una situación de Desastre Nacional en todo el territorio colombiano, ocasionada por el Fenómeno climático de La Niña 2010-2011, que alteró el clima nacional desde el comienzo de su formación en el mes de junio de 2010, ocasionando en los meses de julio y noviembre las lluvias más intensas y abundantes nunca antes registradas en el país.
} 


\subsection{ESTABLECIMIENTO DE LOS MECANISMOS QUE PERMITEN AL MUNICIPIO, EN EJERCICIO DE SU AUTONOMÍA, PROMOVER EL ORDENAMIENTO TERRITORIAL Y EL DESARROLLO REGIONAL.}

\subsubsection{Conceptos de la Norma}

Si bien la Ley 388 de 1997, establece espacios de participación durante el proceso de ordenamiento, (diagnostico, prospectiva y formulación), y posteriormente en los procesos o etapas de revisión, reajuste de los Planes de Ordenamiento territorial (POT), las bases y condiciones que las administraciones puedan modificar y/o actualizar el Plan de Ordenamiento Territorial (POT), a través de consultas interinstitucionales en los énfasis de su segundo objetivo que establece "los mecanismos que permiten al municipio, en ejercicio de su autonomía, promover el ordenamiento de su territorio, el uso equitativo y racional del suelo, la preservación y defensa del patrimonio ecológico y cultural localizado en su ámbito territorial y la prevención de desastres en asentamientos de alto riesgo, así como la ejecución de acciones urbanísticas eficientes". Resulta válido entonces establecer claramente a quién le corresponde por competencia legal, hacer la tarea de la armonización del ordenamiento territorial en la Región; como también la visión con la cual cada uno de los POTS, se revisan y actualizan teniendo en cuenta su articulación como es el caso a la Ley Orgánica de Ordenamiento Territorial (LOOT).

Por lo tanto, son las entidades municipales las encargadas para el ejercicio en la armonización de los instrumentos de planeación existentes, en coordinación con las entidades ambientales de su jurisdicción con el fin de concurrir en el territorio las políticas nacionales y regionales. Al respecto la Ley 388 de 1997, subordina la formulación de los Planes de Ordenamiento Territorial, a las determinantes que impartan las Corporaciones Autónomas Regionales, otorgándole a estas competencias para revisarlo y aprobar sus componentes en materia ambiental. Por lo tanto, la Ley 388 , señala en el artículo $10^{\circ}$ : "la elaboración y adopción de los planes de ordenamiento territorial, los municipios y distritos deberán tener en cuenta las siguientes determinantes, que constituyen normas de superior jerarquía, en sus propios ámbitos de competencia, de acuerdo con la Constitución y las Leyes: Las relacionadas con la conservación y protección del medio ambiente, los recursos naturales y la prevención de amenazas y riesgos naturales."45

\footnotetext{
${ }^{45}$ Ley 388 de 1997 artículo 10 literal, (a) Las directrices, normas y reglamentos expedidos en ejercicio de sus respectivas facultades legales, por las entidades del Sistema Nacional Ambiental, en los aspectos relacionados con el ordenamiento espacial del territorio, de acuerdo con la Ley 99 de 1993 y el Código de Recursos Naturales, tales como las limitaciones derivadas del estatuto de zonificación de uso adecuado del territorio y las regulaciones nacionales sobre uso del suelo en lo concerniente exclusivamente a sus aspectos ambientales.

(b) Las regulaciones sobre conservación, preservación, uso y manejo del medio ambiente y de los recursos naturales renovables, en las zonas marinas y costeras; las disposiciones producidas por la Corporación Autónoma Regional o la autoridad ambiental de la respectiva jurisdicción, en cuanto a la reserva, alindamiento, administración o sustracción de los distritos de manejo integrado, los distritos de conservación de suelos, las reservas forestales y parques naturales de carácter regional; las normas y directrices para el manejo de las cuencas hidrográficas expedidas por la Corporación Autónoma Regional o la autoridad ambiental de la respectiva jurisdicción; y las directrices y normas expedidas por las autoridades ambientales para la conservación de las áreas de especial importancia ecosistémica. (c) Las políticas, directrices y regulaciones sobre conservación, preservación y uso de las áreas e inmuebles consideradas como patrimonio cultural de la Nación y de los departamentos, incluyendo el histórico, artístico y arquitectónico, de conformidad con la legislación correspondiente. (d) El señalamiento y localización en donde cabe reiterar que ante un eventual conflicto entre autoridades ambientales, este se dirime observando el orden jerárquico del Sistema Nacional Ambiental SINA que establece el parágrafo del artículo $4^{\circ}$ de la Ley 99 de 1993.
} 
Con base en lo anterior, la conservación ambiental, protección ambiental de los recursos naturales y la prevención de amenazas y riesgos naturales a la gestión del riesgo, son la base en la orientación de los planes de ordenamiento territorial a través de la Estructura Ecológica Principal (EEP), que para el caso de la ciudad de Bogotá; su POT, determina la cuenca del Río Bogotá como estructura ambiental a través de la armonización de la Estructura Ecológica Distrital (EED) y la Estructura Ecológica Regional. (Convenio 1441 de 2010), entre la Secretaria Distrital de Ambiente (SDA) y Universidad Santo Tomas de Aquino (USTA); algunos principios ambientales para dicha armonización se sustentan a través de:

$>$ Función social y ecológica de la propiedad.

$>$ Prevalencia del interés general sobre el particular.

$>$ Distribución equitativa de las cargas y beneficios.

Otra de las características de la Ley 388, en cuanto al impacto en la planificación territorial es la debilidad en la definición e instrumentación referente al tema regional, lo cual debilita la articulación hacia el ordenamiento y la gestión municipal y los procesos que sobre él municipio se puedan dar; por lo tanto, se considera uno de los principales inconvenientes que enfrenta cualquier proceso de ordenamiento cuyo objetivo sea la construcción de visiones territoriales y de acuerdos sociales que trasciendan las fronteras políticoadministrativas de los municipios. El principal reto lo constituye, por consiguiente, lograr que estas fronteras dejen de verse como límites que los separan y empiecen a entenderse como puntos de encuentro y armonización territorial. Lo cual, se puede determinar teniendo en cuenta la gestión del recurso hídrico traspasando la cuenca hidrográfica como instancia de armonización territorial.

\subsubsection{La Política Pública Ambiental para la integración regional}

En Colombia las políticas públicas referentes al medio ambiente evidencian una situación compleja, y discontinua, pues éstas, se encuentran enmarcadas en cada uno de los de los Planes Nacionales de Desarrollo, evidenciándose su relación con los distintos programas y proyectos, cuyos impactos interfieren con las dinámicas de las directrices ambientales, por lo tanto, su revisión contante en pro y defensa de los proyectos de algunos sectores como hidrocarburos, minería y de infraestructura desde la visión nacional, imposibilitan una visión regional, ya que su armonización con las instancias departamentales y municipales a través de sus planes de desarrollo, evidencian la importancia de tener en cuenta el armonizarse territorialmente de forma integral, teniendo en cuenta la relación de programas y proyectos.

En la década de los 70 , se formuló un primer instrumento moderno para abordar los problemas ambientales. el Decreto 2811 de 1974, con el cual se crea el Código Nacional de Recursos Naturales, que constituyó un conjunto normativo moderno para su época y que delimitó y trazó el horizonte jurídico para el manejo y conservación de los recursos naturales en Colombia.

Desde mediados de la década de los 80 , se inicia el proceso de descentralización, lo cual conllevaría a facilitar un proceso de regionalización en un horizonte de tiempo. Sin embargo, lo que se ha visto es que este proceso no se ha dado en Colombia y especialmente en la última década el enfoque centralista de los gobiernos de turno no han permitido que el desarrollo regional se consolide. 
Un problema persistente en la formulación de política pública ambiental se percibía a comienzos de la década de los 90, cuando se apreciaba que los componentes del proceso productivo eran sometidos a un análisis económico, pero en conjunto el proceso extractivo y de producción como un todo en la dimensión ambiental no se veía claro.

Sin embargo, con la promulgación de la Constitución Política, en 1991, se hizo evidente la necesidad de abordar la dimensión ambiental, es decir, que los recursos naturales son apenas un componente más de la dimensión ambiental. Esto tuvo su razón de ser como resultado de la Conferencia de Río de Janeiro en 1992, que presionó a los gobiernos del mundo para formular e incorporar mecanismos integrales que le dieran a la problemática ambiental un papel central, decisivo y estratégico para el desarrollo de las naciones.

Adicionalmente un tema esencial en la formulación de políticas públicas ambientales ha sido la baja participación de la sociedad nacional aun cuando en 1994, se introducen mecanismos de participación ciudadana. Este ha sido un proceso lento y muchas veces esquivo a la participación de la sociedad en este campo. En la actualidad podemos identificar la adopción de algunas políticas ambientales y lineamientos de política encaminados a la protección y conservación del medio ambiente, entre ellas, podemos conocer las siguientes:

$>$ Política de Ordenamiento Integrado y Desarrollo Sostenible de las Zonas costeras.

$>$ Política Nacional de Biodiversidad.

$>$ Política para la Gestión de la Fauna Silvestre.

$>$ Política de Bosques.

$>$ Política para la consolidación del Sistema Nacional de áreas protegidas.

$>$ Política de Educación Ambiental.

$>$ Política para la formación ciudadana en la Gestión Ambiental.

$>$ Política de producción más limpia.

> Política para la Gestión Integral de Residuos Sólidos.

> Política Nacional de Manejo Integral de Residuos sólidos.

$>$ Lineamientos de Política para el Uso y Manejo de Plaguicidas.

$>$ Lineamientos para la Política de Ordenamiento Ambiental del Territorio.

$>$ Lineamientos Ambientales para la Gestión Urbano - Regional en Colombia.

$>$ Lineamientos de Política para el Manejo Integral del Agua.

$>$ Lineamientos de Política para humedales interiores en Colombia.

$>$ Lineamientos de Política ambiental para el Desarrollo Urbano.

$>$ Lineamientos de una Política de participación ciudadana en la Gestión Ambiental.

$>$ Lineamientos de política ambiental para la región central. Propuesta técnica con énfasis en la Estructura Ecológica Regional - EER.

$>$ Bases para una Política de Población y Medio Ambiente.

$>$ Estrategias para un Sistema Nacional de Áreas Protegidas

\subsection{ANTECEDENTES TÉCNICOS AMBIENTALES EN LA CONSTRUCCIÓN DE LA VISIÓN REGIONAL.}

La construcción de una visión regional que permite identificar el sentido de la intervención del Estado y su prospección en el largo plazo es el producto histórico de las decisiones que desde lo político han dado paso a la formulación de diferentes instrumentos de planificación y su ejecución parcial o total. En el caso de la región Bogotá Cundinamarca, en la última década se adelantaron diferentes iniciativas interinstitucionales que se fueron construyendo sobre el tema de lo ambiental, 
La revisión de antecedentes que se expresa en este documento, establece una serie de categorías de información que permitan entorno a la visión de ciudad región, identificar las condiciones institucionales en las cuales diferentes agentes han previsto la intervención de los recursos naturales y las responsabilidades ambientales generadas por el desarrollo de las actividades humanas, considerando la importancia y hegemonía de Bogotá, por la concentración socio económica de la población del país.

\subsection{LOS INSTRUMENTOS DE PLANIFICACIÓN, GESTIÓN ${ }^{46}$ Y LOS PLANES ESTRATÉGICOS INSTITUCIONALES DE DESARROLLO TERRITORIAL}

Al revisar la estructura programática de las diferentes instituciones que participan de la gestión ambiental en la región de Bogotá, se identificaron los principales planes que expresan el interés y tipo de intervención, teniendo en cuenta características ambientales, sociales, económicas y el énfasis ambiental para la articulación y armonización entre ellos. (Véase Tabla 3. 2.).

\section{Tabla 3. 2. LOS PLANES DE DESARROLLO INSTITUCIONALES VISTOS DESDE LO AMBIENTAL}

\begin{tabular}{|c|c|}
\hline PLAN & PRINCIPALES ASPECTOS AMBIENTALES \\
\hline $\begin{array}{l}\text { Plan de Desarrollo Nacional } \\
2006-2010 .\end{array}$ & $\begin{array}{l}\text { La atención aspectos centrales de desarrollo territorial sostenible, } \\
\text { incorporando decisiones programáticas, en temas como agua potable, } \\
\text { vivienda de interés social, ordenamiento territorial, la gestión del riesgo, } \\
\text { manejo de cuencas hidrográficas y priorización en el mega proyecto del río } \\
\text { Bogotá. }\end{array}$ \\
\hline $\begin{array}{l}\text { Plan de Desarrollo “Bogotá } \\
\text { Positiva: para vivir mejor. } \\
2008-2012 \text {. }\end{array}$ & $\begin{array}{l}\text { Establece como estrategias para considerar el modelo ambiental a través } \\
\text { del ajuste del Plan de Ordenamiento Territorial, dentro del cual considera el } \\
\text { proceso de integración regional. Consolidar una acción colectiva para el } \\
\text { mejoramiento del hábitat a través de instrumentos de coordinación } \\
\text { institucional. Se destaca la acción en armonizar los procesos de desarrollo, } \\
\text { con la recuperación, conservación y consolidación de la estructura } \\
\text { ecológica principal. Amplia la participación de la intervención en el territorio } \\
\text { rural a través de su incorporación en el modelo de ocupación. }\end{array}$ \\
\hline $\begin{array}{l}\text { Plan de Desarrollo } \\
\text { Departamental } \\
\text { "Cundinamarca, corazón de } \\
\text { Colombia, 2008-2012". }\end{array}$ & $\begin{array}{l}\text { Su orientación es a definir una estrategia de integración regional dentro de } \\
\text { las acciones de la Región Capital considerando elementos de equidad, } \\
\text { competitividad, sostenibilidad, identidad cultural y autonomía administrativa } \\
\text { de los municipios. Acciones coordinadas desde la Mesa Bogotá - } \\
\text { Cundinamarca, a través de la Agenda Ambiental y el Plan Regional de } \\
\text { Competitividad. }\end{array}$ \\
\hline $\begin{array}{l}\text { Plan de Ordenamiento y } \\
\text { Manejo de Cuencas POMCA } \\
\text { (Río Bogotá, Suarez. Sisga - } \\
\text { Aves, Sumapáz, } \\
\text { Tunjuelo y Fucha). }\end{array}$ & $\begin{array}{l}\text { Como ejes programáticos se consideraron, la gestión integral del agua y el } \\
\text { saneamiento básico, así como el desarrollo ambiental sostenible que } \\
\text { incorpora la gestión integral de ecosistemas y biodiversidad; manejo de } \\
\text { cuencas en POMCAS y la gestión integral del riesgo. }\end{array}$ \\
\hline $\begin{array}{l}\text { Planes de Gestión Integral de } \\
\text { Residuos Sólidos (PGIRS) }\end{array}$ & $\begin{array}{l}\text { Establece las características propias para el adecuado manejo y disposición } \\
\text { de los residuos sólidos en el orden regional. }\end{array}$ \\
\hline \multirow[t]{2}{*}{$\begin{array}{l}\text { Plan de Saneamiento y } \\
\text { Manejo de Vertimientos } \\
\text { (PSMV) }\end{array}$} & $\begin{array}{l}\text { Estos planes abordan la temática referente al recurso hídrico utilizado y su } \\
\text { correcto vertimiento a las fuentes hídricas. }\end{array}$ \\
\hline & Establece ejes programáticos para el desarrollo sostenible: manejo y \\
\hline
\end{tabular}

\footnotetext{
${ }^{46}$ Los instrumentos de planificación se entienden como las instancias gubernamentales en la promulgación de nomas de jerarquía nacional, departamental y municipal que inciden directamente en los procesos de planificación y de gestión territorial.
} 


\begin{tabular}{|c|c|}
\hline PLAN & PRINCIPALES ASPECTOS AMBIENTALES \\
\hline $\begin{array}{c}\text { Plan de Acción Trienal (PAT) } \\
\text { CAR } 2007 \text { - } 2011 .\end{array}$ & $\begin{array}{l}\text { conservación del recurso hídrico; manejo y conservación de ecosistemas } \\
\text { estratégicos y biodiversidad; manejo y administración de parques } \\
\text { recreacionales y ecoturismo y consolidación del sistema regional de áreas } \\
\text { protegidas - SIRAP. }\end{array}$ \\
\hline $\begin{array}{l}\text { Plan de Gestión Ambiental } \\
\text { Regional (PGAR) CAR. } \\
\text { 2001-2010. }\end{array}$ & $\begin{array}{l}\text { Identifica como base para la gestión ambiental el fortalecimiento de los } \\
\text { instrumentos de ordenamiento territorial, establece como programas de } \\
\text { impacto regional: uso eficiente del agua; protección de cuencas } \\
\text { hidrográficas; preservar y restaurar los ecosistemas estratégicos } \\
\text { promoviendo el uso sostenible; establecer las medidas para el cumplimiento } \\
\text { y consolidación del SIRAP; establecer herramientas para el ordenamiento y } \\
\text { gestión sostenible del uso del suelo. En el modelo de territorio Bogotá - } \\
\text { Región, promover y participar en la formulación del modelo concertado del } \\
\text { desarrollo para Bogotá y Cundinamarca. }\end{array}$ \\
\hline $\begin{array}{l}\text { Plan de Acción Trienal (PAT) } \\
2007 \text { - 2001. CORPOGUAVIO. }\end{array}$ & $\begin{array}{l}\text { La estrategia incorpora elementos de la gestión hídrica nacional, } \\
\text { fortaleciendo la participación social e institucional en la gestión ambiental } \\
\text { subregional. Adelantar procesos de ordenación ambiental de los territorios. } \\
\text { Contribuir a los procesos productivos sostenibles en la región. Considera } 5 \\
\text { elementos para la gestión integral del recurso hídrico: uso eficiente del } \\
\text { agua, conocimiento, conservación y uso sostenible de la biodiversidad, } \\
\text { promoción de procesos productivos competitivos y sostenibles, bienes y } \\
\text { servicios amigables con el ambiente. }\end{array}$ \\
\hline $\begin{array}{l}\text { Plan de Gestión Ambiental } \\
\text { (PGAR). CORPOGUAVIO } \\
\text { 2002 - } 2012 .\end{array}$ & $\begin{array}{l}\text { Establece como objetivo garantizar la oferta de servicios ambientales, a } \\
\text { través de la solución de conflictos de uso del suelo. Establece la valoración } \\
\text { de la oferta ambiental en su capacidad actual y potencial para ofrecer } \\
\text { bienes y servicios ambientales. Valora la importancia de los ecosistemas } \\
\text { estratégicos a fin de determinar la gestión ambiental en el territorio. Como } \\
\text { unidad de gestión se plantea la cuenca hidrográfica. }\end{array}$ \\
\hline $\begin{array}{l}\text { Plan de Gestión Ambiental } \\
\text { PGA. }\end{array}$ & $\begin{array}{l}\text { Está enmarcado en un entorno regional, planteado para que se articule con } \\
\text { políticas de orden nacional y regional a largo plazo. }\end{array}$ \\
\hline $\begin{array}{l}\text { Plan Estratégico secretaria } \\
\text { Distrital de Planeación } \\
\quad 2008-2012 \text {. }\end{array}$ & $\begin{array}{l}\text { Propone la articulación de los sectores de gobierno y liderar la construcción } \\
\text { del modelo de ciudad. Su direccionamiento estratégico se orienta a la } \\
\text { coordinación de las políticas públicas territoriales, dentro de lo cual } \\
\text { considera dos programas relacionados con ciudad-región: prospectiva de } \\
\text { ciudad con los estudios para la ciudad y la región dentro de una acción de } \\
\text { planeación de la política pública; y programa de liderazgo para la } \\
\text { integración regional con los departamentos de Cundinamarca, Meta, } \\
\text { Boyacá y Tolima. }\end{array}$ \\
\hline
\end{tabular}

Fuente: Planes institucionales vigentes.

\subsection{LOS ASPECTOS NORMATIVO Y LEGAL (CONTEXTO NACIONAL)}

La planificación territorial, el Manejo y ordenación de cuencas hidrográficas, toma un gran viraje desde los aspectos legales territoriales, teniendo como referencia tres aspectos que se pueden resaltar:

La promulgación de la Constitución de 1991.

$>$ La creación del Ministerio de Medio Ambiente.

$>$ La conformación del Sistema Nacional Ambiental - SINA.

Por lo tanto; la planificación ambiental del desarrollo territorial sostenible a través de las cuencas hidrográficas, se constituye en un proceso continuo y permanente de construcción social, económica y ambiental, y, por ello, es más una práctica ambiental que un ejercicio racional. Sin embargo, un proceso de ordenación concebido para aplicar en las cuencas debe estar orientado por unos principios que sean comunes a cualquier ejercicio de planificación. En este sentido, se han definido con las autoridades 
ambientales algunos de los principios orientadores que se relacionan a continuación. (Guía Técnico Científica para la Ordenación y Manejo de Cuencas Hidrográficas en Colombia Versión 2011).

$>$ Principio 1: Construcción local de lo regional con visión nacional y solidaridad global. La Ordenación de Cuencas es un proceso que debe ser construido de "abajo hacia arriba" sin descuidar los escenarios regionales y nacionales que prefiguran la construcción de territorio y sin descuidar las visiones globales que privilegian la articulación entre los diferentes niveles y generan capacidad institucional para el cumplimiento de las metas de desarrollo sostenible.

$>$ Principio 2: Proceso permanente de participación, concertación, planeación, ejecución, seguimiento y ajuste con todos los actores. Este principio propicia la participación de los diferentes actores en todas las fases de la ordenación y parte de un análisis de los mismos en el cual se identifiquen los diversos intereses para que estos se releven en el proceso de planificación.

$>$ Principio 3: Enfoque sistémico y gestión integral. Se reconoce una visión de contexto en la comprensión de la relación sociedad-naturaleza para orientar acciones conducentes a la ordenación de cuencas. La gestión integral constituye de esta manera un proceso dinámico relacionado con los complejos sistemas representados por las cuencas hidrográficas orientada a la toma de decisiones sobre el uso y manejo integral del agua. La gestión va precedida de la planificación y esta a su vez tiene como pre-requisito la evaluación que abarca tanto las dinámicas de oferta y demanda de recurso hídrico como la situación del uso del suelo y aspectos medio ambientales. Subyace a este principio el reconocimiento del ciclo hidrológico como referente conceptual del proceso de gestión integrada y en este sentido la noción de cuenca desde su concepción física abarca la dinámica de las aguas en sus diferentes estados: atmosférico, superficial y subterráneo.

> Principio 4: Construcción articulada, compartida y transparente de la información y del conocimiento. La optimización de los datos recolectados, el flujo de información procesada y el conocimiento generado en gracia a este principio se convierte en un instrumento de democracia que fundamenta la toma de decisiones.

> Principio 5: Equidad social en el acceso a los recursos naturales y respeto al patrimonio cultural y natural. Garantiza el abastecimiento confiable y adecuado de cantidades de agua de calidad suficiente a todos los usuarios (para diversos usos) aunque subsistan diferencias considerables entre los diferentes grupos de usuarios respecto de su capacidad de pago. Si bien el cobro volumétrico del costo completo puede ser apropiado para muchos, y deseable por razones de una distribución eficiente, quizás sea necesario efectuar una provisión especial para la población de escasos ingresos. Este principio además tiene que ver con la consideración de ecosistemas de manejo especial y patrimonio cultural en los planes de ordenación.

> Principio 6: convivencia y competitividad sostenible. Este principio se refiere a la necesidad de mantener un equilibrio de estructura y función entre todos los elementos del sistema natural para garantizar su sostenibilidad. Supone armonizar intereses socioeconómicos y culturales con la base natural que ofrecen los 
ecosistemas y particularmente la cuenca hidrográfica.

Principio 7: Articulación con los planes de ordenamiento territorial, planes de vida, planes de desarrollo etnocultural, planes de desarrollo y expansión sectorial. En el enfoque sistémico y específicamente en ordenación de cuencas es necesario articular normas, planes, estrategias e instrumentos para superar conflictos generados en visiones parciales y desconocimiento del orden jurídico administrativo, político e institucional.

\subsubsection{El marco normativo nacional para la ordenación del territorio.}

Existen en Colombia diferentes instrumentos de planeación y determinantes normativos, leyes ordinarias, orgánicas y definiciones sobre uso del territorio, entre los cuales se pueden mencionar la Ley 152 de 1994, por la cual se establece la Ley Orgánica del Plan de Desarrollo, atendiendo los niveles nacional, departamental y municipal, y la Ley 388 de 1997, por mandato del artículo 41 de la Ley 152 de 1994, que establece para el caso de los municipios, además de los Planes de Desarrollo regulados por esta Ley, contarán con Plan de Ordenamiento y de Desarrollo Territorial.

La Ley 388 de 1997 o Ley de Desarrollo Territorial, se fija como primer objetivo "Armonizar y actualizar las disposiciones contenidas en la Ley $9^{a}$ de 1989, con las nuevas normas establecidas en la Constitución Política Colombia de 1991, la Ley Orgánica del Plan de Desarrollo, la Ley Orgánica de Áreas Metropolitanas y la Ley 99 de 1993 por la que se crea el Sistema Nacional Ambiental». Además hace referencia a la autonomía municipal, al uso equitativo del territorio y a la utilización del suelo, la función social y ecológica de la propiedad, la prevalencia del interés general sobre el particular y la distribución equitativa de las cargas y los beneficios, como principios rectores de esta ley.

\subsubsection{Entre la normatividad que actualmente orienta de manera genérica los procesos de planificación ambiental del territorio}

El tener una visión clara de las normas que orientan los procesos de planificación ambiental territorial, ayudan de tal manera, el obtener la capacidad hacia la toma de decisiones tanto para las entidades territoriales del orden público como en la participación de los sectores privados y por supuesto la participación de la sociedad civil. Todo esto significa la puesta en marcha de programas y proyectos articulados a los regímenes establecidos por los mismos instrumentos de planificación y de gestión en una propuesta coherente en armonía con los territorios, en el ámbito de sostenibilidad, social, económico y ambiental.

Esto podría entenderse también como las características en la identificación de las condiciones con las cuales las entidades territoriales pueden plantear una visión clara y precisa de desarrollo y crecimiento con base en las necesidades globales e igualmente articuladas a las necesidades locales y regionales.

Por lo tanto, las explicaciones precedentes nos ayudan a plantear con el conocimiento previo de los instrumentos, el planteamiento de las bases conceptuales y metodológicas hacia la propuesta de la región teniendo como base la cuenca. Se relacionan a continuación:

El Código de Recursos Naturales Renovables y de Protección al Medio Ambiente 
Decreto $2811 / 74$.

La Ley 99/93 que crea el Ministerio del Medio Ambiente, se reordena el sector público encargado de la gestión y conservación del medio ambiente y los recursos naturales renovables, se organiza el Sistema Nacional Ambiental.

El Decreto 1729/02 por el cual se reglamenta la Parte XIII, Título 2, Capítulo III del Decreto-ley 2811 de 1974 sobre cuencas hidrográficas, parcialmente el numeral 12 del artículo $5^{\circ}$ de la Ley 99 de 1993 y se dictan otras disposiciones.

El decreto 1604/03 que define la necesidad de priorizar las cuencas hidrográficas críticas por su avanzado estado de degradación, con base en la calificación del grado de alteración antrópica que sufre cada uno de los recursos naturales contenidos en ellas.

La planificación sostenible de los ecosistemas asociados al recurso hídrico, cuenta con normas complementarias como el Decreto 1449 de 1977 que se refiere a la protección y conservación de los bosques sobre protección de las rondas de los ríos.

$>$ El Decreto 1541 de 1978 que reglamentar las normas relacionadas con el recurso agua en todos sus estados, sobre el dominio de las aguas, cauces y riberas, su aprovechamiento, restricciones y limitaciones.

- El Decreto1594 de 1984, dictar las normas en cuanto al uso del agua y residuos líquidos y fija los criterios de calidad establecidos por este Decreto, son guías para ser utilizados como base de decisión en el ordenamiento, asignación de usos al recurso y determinación de las características del agua para cada uno que orientan los procesos de planificación, administración y ordenamiento para el aprovechamiento sostenible del recurso hídrico, los usos y horizonte de calidad.

\subsection{LA POLÍTICA NACIONAL AMBIENTAL DE COLOMBIA}

\subsubsection{Ley 99 de 1993.}

Como un paso importante en el desarrollo de los principios ambientales de la Constitución Política Colombiana de 1991, se expide la Ley 99 de 1993, que consigna diversas consideraciones para el manejo general de la problemática ambiental, a través de diversos instrumentos como la creación del Ministerio de Ambiente, Vivienda y Desarrollo Territorial, crea una estructura orgánica compuesta por planificadores, coordinadores y ejecutores en los ámbitos nacionales, regionales y locales. Estos organismos van a conformar el Sistema Nacional Ambiental (SINA), cuyos componentes y su interrelación define los mecanismos de actuación del estado y la sociedad civil. El artículo 4 de esta Ley señala además, que el sistema será integrado por los componentes que se relacionan a continuación (Véase Tabla 3.3.). 
Tabla 3. 3. LEY 99 DE 1993

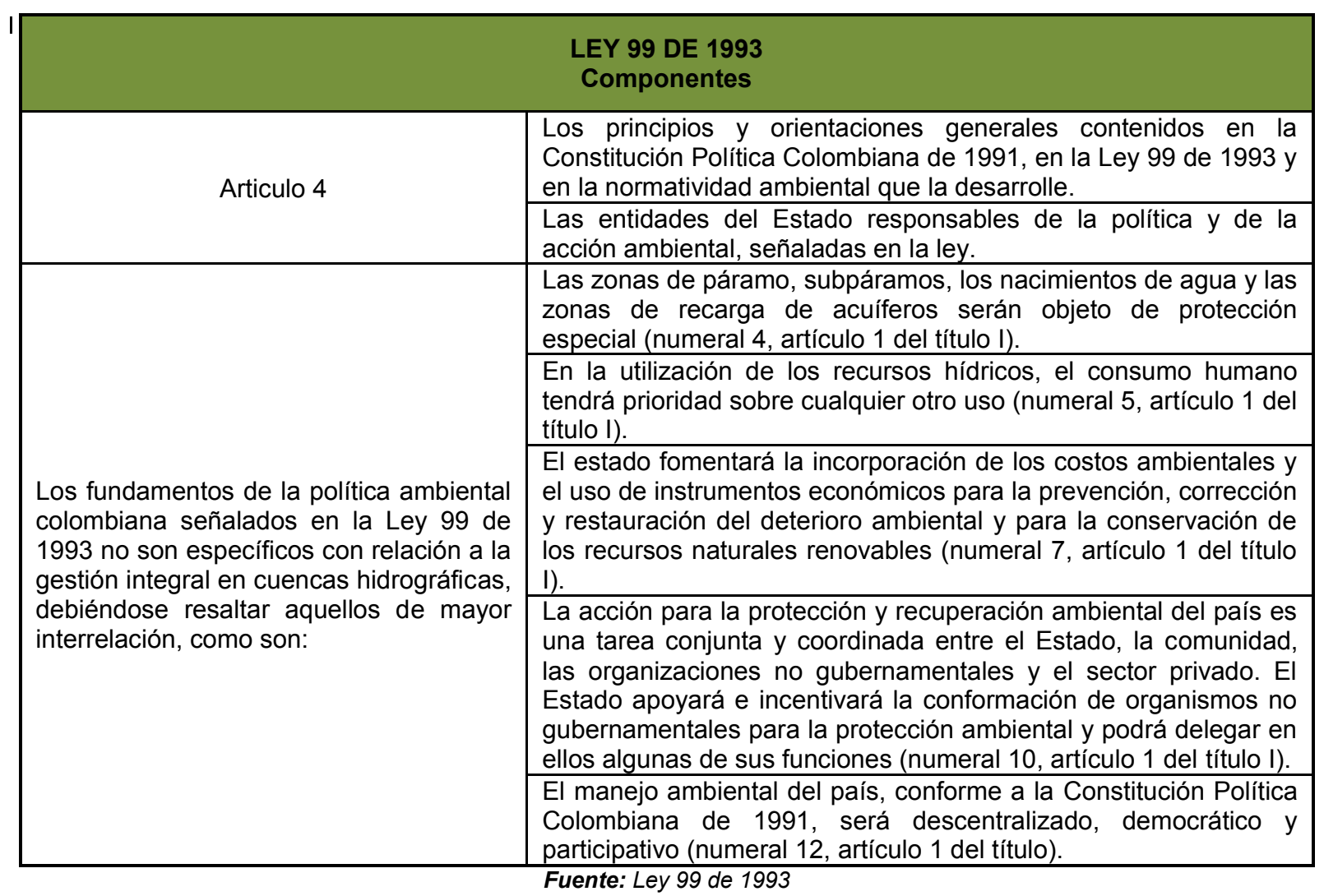

\subsubsection{LEY 152 DE 1994 O LEY ORGÁNICA DEL PLAN DE DESARROLLO}

Es relevante para este estudio esta ley, ya que se deben de articular lo Planes de desarrollo con los planes de ordenamiento de las cuencas hidrográficas, pues este plan de ordenación de la cuenca prima sobre cualquier otro plan. En cumplimiento de lo previsto en la Constitución Política Colombiana de 1991, se expide la Ley 152, Ley Orgánica del Plan de Desarrollo conforme con el artículo $2^{\circ}$ a la Nación, a las entidades territoriales y a los organismos públicos de todo orden, establece los procedimientos y mecanismos para la elaboración, aprobación, ejecución, seguimiento, evaluación y control de los planes de desarrollo. Las áreas metropolitanas en cumplimiento de lo previsto por el artículo 14 de la Ley 128 de 1994, y en concordancia justamente con la Ley 152, consagra como atribución esencial de la Junta Metropolitana, la de "Adoptar el Plan Integral de Desarrollo Metropolitano".

\subsubsection{Ley 136 de 1994: por la cual se dictan normas tendientes a modernizar la organización y el funcionamiento de los municipios.}

Esta ley contiene todos los apartes relacionados con el Municipio colombiano, desde su creación, administración y desarrollo. Son funciones del Municipio, la administración de los asuntos propios y la prestación de servicios públicos que determine la ley; ordenar el desarrollo de las entidades territoriales denominadas Municipios y construir obras de infraestructura que demande el progreso de la entidad territorial municipal. 
El numeral 4 del artículo $3^{\circ}$ de la Ley en comento, establece también como función de los Municipios la planificación del desarrollo económico, social y ambiental de su territorio, en coordinación con otras entidades territoriales. El numeral 5 del mismo artículo señala como función municipal la solución de necesidades insatisfechas de salud, educación, saneamiento ambiental, agua potable, servicios públicos domiciliarios, vivienda, recreación y deporte, prestando especial atención a la niñez, la mujer, la tercera edad y los sectores discapacitados, directamente y en concurrencia, complementariedad y coordinación con las demás entidades territoriales y la Nación, en los términos que defina la ley. La Ley 136, regula lo relacionado con el funcionamiento e integración de los Concejos, ocupándose de sus integrantes a partir del artículo 42, hasta el 70.

\subsubsection{Ley 388 de 1997: del Ordenamiento Territorial Municipal.}

La Ley de Desarrollo Territorial es un conjunto de principios, instrumentos y disposiciones sobre planificación y gestión territorial, que deben ser utilizados por las administraciones locales, en coordinación y concurrencia con los Departamentos, Áreas Metropolitanas y Nación, con el fin de lograr un ordenamiento físico - territorial, que promueva el desarrollo socioeconómico en armonía con la naturaleza, garantizando el acceso a los diversos sectores poblacionales, a los servicios, vivienda, infraestructuras y equipamientos de tal forma que se eleve la calidad de vida y se alcance un desarrollo sustentable.

La Ley del ordenamiento territorial municipal Ley 388 de 1997, surgió ante la necesidad de actualizar la base legislativa para el manejo de los asuntos urbanos en Colombia, no sólo atendiendo los nuevos principios constitucionales y la Ley Orgánica del Plan de Desarrollo, sino ajustándose a las nuevas dinámicas urbanas y teniendo como marco la política urbana del actual gobierno. La ley ha sido concebida a partir de un enfoque integral del desarrollo urbano, reconociendo los procesos socioculturales y políticos, que explican la producción del espacio urbano, sin ignorar su interdependencia con los aspectos rurales y regionales.

\subsubsection{Ley 617 de 2000: por la cual se reforma parcialmente la ley 136 de 1994.}

La Ley 617 de 2000, llamada de racionalización del gasto público o Ley de Ajuste Fiscal, hace parte del paquete de reformas estructurales de segundo nivel, al parecer pactadas por el gobierno nacional en el acuerdo extendido con el Fondo Monetario Internacional. Esta norma está dirigida al fortalecimiento de la descentralización y para ello impone la necesidad de racionalización del gasto público a los entes territoriales, lo que llevó al recorte de nóminas y reasignación de funciones en los distintos despachos administrativos de los Municipios y Departamentos.

En cuanto a la categorías de Municipios, el texto de la norma no solo fija las mismas sino que, además, establece que los Alcaldes a más tardar el 31 de octubre de cada año deben informar que categoría corresponderá a sus respectivos Municipios, con fundamento en conceptos claros de la Contraloría General de la Nación y a partir del monto de ingresos proyectados para el ejercicio correspondiente.

\subsubsection{Decreto 1729 de 2002. Guía técnico científica para el ordenamiento y manejo de cuencas hidrográficas.}

Proviene del Ministerio del Medio Ambiente, Vivienda y Desarrollo Territorial, sobre ordenación de cuencas, modificando así el Decreto 2857/81 la parte XIII, Título II, 
Capítulo III del Decreto-Ley 2811 de 1974, sobre cuencas hidrográficas. Diario Oficial, noviembre 10 de 1981; este decreto 1729 de 2002, igualmente fijo las pautas generales comprometidas en el numeral 12 del artículo 5 de la Ley 99 de 1993. Define que la ordenación de una cuenca tiene por objeto principal el planeamiento de uso y manejo sostenible de sus recursos naturales renovables, de manera que se consiga mantener o restablecer un adecuado equilibrio entre el aprovechamiento económico de tales recursos y la conservación de la estructura físico- biótico de la cuenca y particularmente de sus recursos hídricos. Un alcance claro del Decreto 1729 de 2002, es señalar las etapas del proceso de planificación y dar una indicación explícita de lo que las autoridades a cargo de la ordenación necesitan hacer.

El Decreto 1729 de 2002, el cual en su totalidad retoma el Decreto 2857de 1981, lo articula a la Ley 388de 1997, relacionada con los Planes de Ordenamiento Territorial, lo actualiza en relación a los nuevos escenarios que crea la Ley 99 de 1993, en relación a la competencia para la declaración del Plan de Ordenamiento. Con base en el artículo 33, la competencia corresponderá a la autoridad ambiental regional con jurisdicción en la cuenca, o en caso en que dos o más corporaciones tengan jurisdicción sobre una cuenca hidrográfica común, la responsabilidad estará a cargo de una Comisión Conjunta.

\subsubsection{El decreto 3600 del 20 de septiembre de 2007, del Ministerio de Ambiente, Vivienda y Desarrollo Territorial.}

Por el cual se reglamentan las disposiciones de las Leyes 99 de 1993 y 388 de 1997, relativas a las determinantes de ordenamiento del suelo rural y al desarrollo de actuaciones urbanísticas de parcelación y edificación en este tipo de suelo y se adoptan otras disposiciones en desarrollo de las Leyes 99 de 1993,142 de 1994 y 388 de 1997. Referente al suelo rural determinó con el fin de garantizar el desarrollo sostenible de éste, en los procesos de formulación, revisión y/o modificación de los planes de ordenamiento territorial, los municipios y distritos deberán dar cumplimiento a las determinantes que se desarrollan en el presente Decreto, las cuales constituyen normas de superior jerarquía en los términos del artículo 10 de la Ley 388 de 1997.

Cuando el decreto se refiera a planes de ordenamiento territorial, se entenderá que comprende todos los tipos de planes previstos en el artículo 9 de la Ley 388 de 1997. Define las categorías del suelo rural y modifica lo dispuesto en los artículos 14, y 17 de la Ley 388 de 1997, en el componente rural del plan de ordenamiento y en su cartografía se deberán determinar y delimitar cada una de las categorías de protección y de desarrollo restringido a que se refieren los artículos siguientes, con la definición de los lineamientos de ordenamiento y la asignación de usos principales, compatibles, condicionados y prohibidos correspondientes.

\subsubsection{La Ley Orgánica de Ordenamiento Territorial (LOOT) o Ley 1454 de 2011.}

La Regionalización; en el ordenamiento territorial promoverá el establecimiento de Regiones Administrativas y de Planificación como marcos de relaciones geográficas, económicas, culturales, y funcionales, a partir de ecosistemas bióticos y biofísicos, de identidades culturales locales, de equipamientos e infraestructuras económicas y productivas y de relaciones entre las formas de vida rural y urbana, en el que se desarrolla la sociedad colombiana y hacia donde debe tender el modelo de Estado republicano unitario. 
En lo relacionado a las directrices constitucionales el proyecto en la identificación de los elementos conceptuales y metodológicos como lineamientos hacia la visión de la región se contempla las bases de la visión de desarrollo hacia la complementariedad, con el fin de fortalecer la unidad nacional en los siguientes aspectos: Sostenibilidad; Participación. Solidaridad y equidad territorial; Diversidad; Gradualidad y flexibilidad. Además para aumentar su capacidad planificadora, administrativa y de Gestión la ley se fundamenta en los siguientes principios: Prospectiva; Paz y convivencia; Asociatividad; Responsabilidad y transparencia; Equidad social y equilibrio territorial finalmente la Economía y buen gobierno.

Por último en lo relacionado a la participación de las distintas instancias institucionales en los contextos nacional, regional y municipal se reconocen los siguientes ejercicios de competencias entendibles por la facultad o poder jurídico que tienen la Nación, las entidades territoriales y las figuras de integración territorial para atender de manera general responsabilidades estatales y se rige con las siguientes: Coordinación; Concurrencia y la Subsidiariedad ${ }^{47}$.

\subsection{LA CONSTITUCIÓN DE LA REGIÓN ADMINISTRATIVA Y DE PLANEAMIENTO ESPECIAL (RAPE) ENTRE EL DISTRITO CAPITAL DE BOGOTÁ Y EL DEPARTAMENTO DE CUNDINAMARCA.}

A partir de la Constitución de 1991, y conforme a su artículo 325, el Distrito Capital podrá conformar una región con otras entidades territoriales de carácter departamental, con el fin de garantizar la ejecución de planes y programas de desarrollo integral como también la prestación oportuna de los servicios a su cargo. Posteriormente se vieron algunos actos administrativos como respaldo a la iniciativas como el Decreto ley 1421 de 1993, se dan iniciativas al Alcalde Mayor para presentar iniciativas de carácter asociativo, de conformidad con las normas; igualmente, el Plan de Desarrollo Económico, Social, Ambiental y de Obras públicas para Bogotá D.C., 2008 - 2012 "BOGOTÁ POSITIVA PARA VIVIR MEJOR" incluyó el objetivo estructurante Ciudad Global, como la meta para la creación de la Región Administrativa de Planeamiento Especial (RAPE).

Según la exposición de motivos del proyecto de acuerdo por la cual se autoriza la constitución de la región administrativa o de Planeación especial "esta perspectiva que asume el concepto de región como categoría de análisis, a más de consultar realidades que rebasan los límites político-administrativos, exime de recurrir a la descripción territorial como elemento definitorio de la RAPE. Así, la RAPE está llamada a ser una entidad abierta cuya configuración puede variar en tanto está determinada por la densidad de las relaciones resultantes de la interacción de los diversos factores. Su diseño, en consecuencia y consonancia con el concepto de región debería reconocer, potenciar y fortalecer esas relaciones entre los territorios".

\footnotetext{
${ }^{47}$ Coordinación. La Nación y las entidades territoriales deberán ejercer sus competencias de manera articulada, coherente y armónica. En desarrollo de este principio, las entidades territoriales se articularán con las autoridades nacionales y regionales, con el propósito especial de garantizar los derechos colectivos y del ambiente establecidos en la Constitución Política. Concurrencia. La Nación y las entidades territoriales desarrollarán oportunamente acciones conjuntas en busca de un objeto común, cuando así esté establecido, con respeto de su autonomía. Subsidiariedad. La Nación, las entidades territoriales y los esquemas de integración territorial apoyarán en forma transitoria y parcial, a las entidades de menor desarrollo económico y social en el ejercicio de sus competencias, cuando se demuestre su imposibilidad de ejercer debidamente determinadas competencias. El gobierno nacional desarrollará la materia.
} 
De acuerdo a lo anterior, la RAPE, buscará como estrategia territorial, unificar las tendencias de crecimiento y de desarrollo, asegurando con ello la expansión de las mejores oportunidades educativas, laborales y económicas de la Sabana hacia la periferia del departamento de Cundinamarca. A través de esta figura de armonización territorial se aprovecharán las ventajas de la proximidad y de cercanía de los factores productivos en el territorio, teniendo en cuenta las economías de escala y asegurando por supuesto las condiciones para garantizar mayor competitividad, mejores condiciones de calidad de vida a la ciudadanía, como enfrentar los retos determinados por la globalización.

Igualmente, la ciudad de Bogotá, como unidad administrativa y territorial ha sido excedida por complejas dinámicas que hacen necesario renunciar la noción de ciudad para abrir paso al concepto de región (trátese aquella de Región Metropolitana, Ciudad Región, Región Capital, entre otras); tal como lo plantea la Nueva Ley Orgánica de Ordenamiento Territorial (Ley 1454 de 2011), por tres razones:

a) El impacto que generan las decisiones de la ciudad en materia de planificación y de utilización de los recursos naturales que en parte se ubican dentro del área de la región.

b) La falta de control que tienen los habitantes de la región sobre organismos de gobierno y sus decisiones, lo que genera efectos adversos en el territorio y en los recursos regionales.

c) la posibilidad de generar economías de escala a nivel regional y una mejora en la prestación de los servicios públicos, lo que tendría consecuencias positivas sobre la calidad de vida de los habitantes de la región.

La conformación de la RAPE, permitirá que Bogotá y Cundinamarca, cuenten con una nueva institucionalidad que promueva la participación de los municipios para la formulación de políticas públicas, la ejecución de proyectos de interés regional y por supuesto la toma de decisiones en cuestiones y ámbitos de mutuo interés; la institucionalidad deberá entender como la redefinición de los mecanismos de relación entre las dos entidades, a través de la adopción de reglas de juego que permitan la viabilizarían de acciones conjuntas para la consecución del desarrollo.

Finalmente, se busca la armonización territorial cuyo objeto consiste en aunar esfuerzos para articular la inversión entre los entes territoriales, correspondientes a los planes de desarrollo de las entidades que conforma la RAPE, con el propósito de promover el desarrollo económico de sus territorios y el mejoramiento social de los habitantes de Bogotá y Cundinamarca.

Para tal fin, el área de cada una de las subcuencas del Río Bogotá conformada por los 38 municipios y la ciudad de Bogotá, establece como elemento estructurante el componente ambiental, a través de la cuenca hidrográfica y su armonización con la Estructura Ecológica Regional, donde se establecerán los conectores de gestión y de planificación territorial, que conlleven a los fortalecimientos de los procesos participativos de la ciudadanía, gremios y sectores protagonistas en el desarrollo territorial desde la visión regional. 


\subsection{LA NORMATIVIDAD QUE RIGE LA ACTIVIDAD MINERA Y LA ORDENACIÓN DEL TERRITORIO}

A continuación se presenta de manera general la regulación, la cual controla y planifica el sector minero. Para su mayor comprensión se especifican las relacionadas con la planificación territorial, ambiental. (Ley 1382 de 2010 que modifica la Ley 685 Código de Minas).

$>$ Fomentar la exploración técnica y la explotación de los recursos mineros estatales y privados.

$>$ Estimular las actividades de exploración y explotación minera, con el fin de satisfacer los requerimientos de la demanda interna y externa con los principios y normas de explotación de los recursos naturales no renovables.

$>$ Promover el aprovechamiento de los recursos mineros dentro del concepto integral de desarrollo sostenible y fortalecimiento económico y social del país.

En general, la normatividad establece el principio de sostenibilidad como "el deber de manejar adecuadamente los recursos naturales renovables y la integridad y disfrute del ambiente, lo cual es compatible y concurrente con la necesidad de fomentar el aprovechamiento racional de los recursos mineros como componentes básicos de la economía nacional y el bienestar social".

\subsection{AMENAZAS Y ATENCIÓN DE DESASTRES EN EL ORDENAMIENTO DEL TERRITORIO.}

El Ministerio de Ambiente, Vivienda y Desarrollo Territorial, en el marco de sus competencias y en especial con el fin de apuntar a los objetivos planteados en el Plan Nacional de Prevención y Atención de Desastres (Decreto 93 de 1998), ha venido desarrollando un programa orientado al manejo de los asentamientos humanos precarios y a la gestión del riesgo, cuyo fin es la incorporación del tema de riesgo en los procesos de planificación y de ordenamiento territorial. Este programa contempla la asistencia técnica a municipios, el desarrollo de políticas y herramientas metodológicas que permitan fortalecer y orientar la gestión en los entes territoriales del nivel regional y local.

\subsubsection{Obligaciones y funciones de los actores con relación a la gestión del riesgo.}

Según la normatividad vigente (Ley 9a/89, Ley 291 de 1996, Ley 152/94, Ley 388/97, Ley 902/04, Decreto 4002/04), son responsabilidades de los municipios, a través del alcalde:

$>$ Garantizar la protección del medio ambiente; la prevención de desastres y su incorporación en los procesos de planeación y ordenamiento territorial; mantener actualizada la información relacionada con población en condiciones de riesgo; garantizar la seguridad de los habitantes así como la integridad de los bienes.

$>$ Considerar las apropiaciones necesarias para efectos presupuestales; establecer mecanismos para promover el ordenamiento de su territorio y definir normas urbanísticas de conformidad con el POT.

Las Corporaciones Autónomas Regionales, asumen un papel de asesoría a las entidades 
territoriales para incorporar en sus planes de ordenamiento y planes de desarrollo el componente de prevención y reducción del riesgo, mediante la elaboración de inventarios y análisis de zonas de alto riesgo y el diseño de mecanismos de solución. Así mismo, reciben las áreas de riesgo liberadas por parte de los municipios para su manejo y control (Decreto 919/89, Ley 99/93, Ley 388/97), y realizan acciones coordinadas con las demás autoridades ambientales competentes en el tema del riesgo y prevención de desastres.

\subsection{EL CONTEXTO LOCAL}

\subsubsection{Aspectos normativos y legales: Planes de Desarrollo del Distrito Capital}

La interdependencia o vínculo existente entre Bogotá y los municipios de Cundinamarca cada día se hace más fuerte y se ha visto reflejada en el surgimiento de políticas y estrategias que permitan la integración interregional y desarrollar una región más competitiva. La Constitución de 1991, estableció en su artículo 325, "que el distrito podría conformar un área metropolitana con los municipios circunvecinos y una región con otras entidades territoriales de carácter departamental, estableciendo así posibles alianzas entre el distrito capital."

En ese sentido, las políticas públicas, que se han formulado en las dos últimas décadas han estado orientando a estos temas. De igual forma, es importante tener en cuenta que en el caso Colombiano, en el de Bogotá y Cundinamarca, en particular, la adopción de una política pública ambiental no ha sido un proceso fácil. La Ley 128 de 1994 o Ley Orgánica de las Áreas Metropolitanas, se ha quedado en el olvido.

En el tema de las políticas públicas, entendidas éstas como "actuaciones de los gobiernos y de otras agencias del Estado, cuando las competencias constitucionales así lo determinen, caracterizadas por que constituyen flujos de decisión orientadas a resolver un problema que se ha constituido como público, que moviliza recursos institucionales y ciudadanos bajo una forma de representación de la sociedad que potencia o delimita esta intervención"48, es necesario reconocer que los distintos alcaldes de Bogotá desde Jaime Castro, hasta Samuel Moreno, han impulsado en mayor o menor grado la consolidación de un escenario regional para Bogotá. A continuación se presenta una síntesis de la temática regional ambiental en los planes de desarrollo Distritales. (Véase tabla 3.4.)

Tabla 3. 4. Planes de Desarrollo Distritales

\begin{tabular}{|c|l|l|l|}
\hline \multicolumn{1}{|c|}{ AÑO } & \multicolumn{1}{|c|}{ ALCALDE } & \multicolumn{1}{c|}{$\begin{array}{c}\text { PLAN DE } \\
\text { DESARROLLO }\end{array}$} & $\begin{array}{l}\text { PRINCIPIOS DE POLÍTICA PÚBLICA } \\
\text { Y ACCIÓN }\end{array}$ \\
\hline $1992-1994$ & JAIME CASTRO & $\begin{array}{l}\text { "Estrategias para la } \\
\text { generación de empleo e } \\
\text { ingresos" }\end{array}$ & $\begin{array}{l}\text { Crear y organizar la Ciudad-Región y } \\
\text { al interior de aquella algunas } \\
\text { avanzadas formas de democracia local }\end{array}$ \\
\hline $1995-1998$ & ANTANAS & MOCKUS & $\begin{array}{l}\text { Mega proyectos que requieren } \\
\text { concertación con el nivel regional y } \\
\text { nacional. } \\
\text { Plan integrado de transporte. } \\
\text { Recuperación del Río Bogotá } \\
\text { Desarrollo del borde occidental de la } \\
\text { ciudad } \\
\text { Infraestructura Metropolitana Santafé }\end{array}$ \\
\hline
\end{tabular}

\footnotetext{
${ }^{48}$ Cuervo Jorge. Ensayos Sobre Políticas Públicas. Universidad Externado de Colombia (2007 Pag 86).
} 


\begin{tabular}{|c|c|c|c|}
\hline AÑo & ALCALDE & $\begin{array}{c}\text { PLAN DE } \\
\text { DESARROLLO }\end{array}$ & $\begin{array}{l}\text { PRINCIPIOS DE POLÍTICA PÚBLICA } \\
\text { Y ACCIÓN }\end{array}$ \\
\hline & & & $\begin{array}{l}\text { 1. 5. plan de acción social en salud, } \\
\text { educación y empleo. } \\
\text { Seguridad ciudadana. }\end{array}$ \\
\hline $1998-2000$ & $\begin{array}{l}\text { ENRIQUE } \\
\text { PEÑALOZA }\end{array}$ & $\begin{array}{l}\text { "Por la Bogotá que } \\
\text { queremos" }\end{array}$ & $\begin{array}{l}\text { El tema regional recibió poca atención. } \\
\text { Se privilegió el tema urbano ambiental } \\
\text { con un conjunto de acciones que } \\
\text { transformaron la ciudad al interior de } \\
\text { ella, más que en relación con la } \\
\text { región. }\end{array}$ \\
\hline 2001-2003 & $\begin{array}{l}\text { ANTANAS } \\
\text { MOCKUS }\end{array}$ & $\begin{array}{l}\text { "Bogotá para vivir todos } \\
\text { del mismo lado" }\end{array}$ & $\begin{array}{l}\text { Impulsa la creación de la Mesa de } \\
\text { Planificación y los estudios de } \\
\text { competividad regional, que aportaron } \\
\text { elementos para dinamizar e impulsar } \\
\text { el tema de la región vista como } \\
\text { instrumento de desarrollo. Lo } \\
\text { ambiental es muy precario en este } \\
\text { periodo. }\end{array}$ \\
\hline 2004-2008 & $\begin{array}{l}\text { LUIS EDUARDO } \\
\text { GARZON } \\
\text { LUIS EDUARDO } \\
\text { GARZON }\end{array}$ & $\begin{array}{l}\text { "Bogotá sin indiferencia" } \\
\text { "Bogotá sin indiferencia" }\end{array}$ & $\begin{array}{l}\text { INTEGRACION TERRITORIAL PARA } \\
\text { LA SOSTENIBILIDAD. Este programa } \\
\text { aborda la sostenibilidad urbana. } \\
\text { CIUDAD - REGION. Este programa } \\
\text { construye el concepto regional urbano } \\
\text { para Bogotá en el contexto de la } \\
\text { articulación regional. } \\
\text { SOSTENIBLIDAD AMBIENTAL. Se le } \\
\text { otorga un énfasis especial a la } \\
\text { Construcción colectiva del equilibrio } \\
\text { entre el sistema ambiental y los } \\
\text { procesos de uso y aprovechamiento } \\
\text { de los recursos. } \\
\text { Se formula la política Distrital de } \\
\text { Humedales }\end{array}$ \\
\hline 2009-2012 & $\begin{array}{l}\text { SAMUEL MORENO } \\
\text { ROJAS }\end{array}$ & "Bogotá Positiva" & $\begin{array}{l}\text { El tema regional adquiere un carácter } \\
\text { más institucional y permanente. Se } \\
\text { firma el acuerdo REGION CAPITAL en } \\
\text { febrero de } 2009 \text { entre la Gobernación } \\
\text { de Cundinamarca y la Alcaldía Mayor. } \\
\text { POBLACIÓN Y TERRITORIO: Este } \\
\text { programa enfoca su trabajo en el tema } \\
\text { de la ocupación del territorio y la } \\
\text { sociedad bajo una concepción que } \\
\text { integra lo urbano - rural y regional. } \\
\text { AMBIENTE Y TERRRITORIO. Se } \\
\text { percibe la continuidad del trabajo } \\
\text { ambiental Distrital, incorporando } \\
\text { acciones ambientales de la Región } \\
\text { Capital. } \\
\text { Se establece un enfoque para el } \\
\text { transporte a nivel regional, buscando } \\
\text { la conectividad de la región con la } \\
\text { ciudad. } \\
\text { Se mantiene la continuidad en el tema } \\
\text { de competitividad regional. }\end{array}$ \\
\hline
\end{tabular}

Fuente "Líneas Estratégicas Ambientales para la Región Capital" Contrato 1441 Interinstitucional Secretaria Distrital de Ambiente y la Universidad Santo Tomas 2010.

También es válido reconocer que en las dos últimas décadas las políticas públicas en relación a los temas de desarrollo regional y de medio ambiente han sido bastantes 
escasas. El instrumento que se ha encargado de manera directa e indirecta de dinamizar el tema ha sido el Plan de Ordenamiento Territorial de Bogotá, pero éste no es una política pública, pues esencialmente es un instrumento técnico para la planificación urbana. Adicionalmente es importante reconocer la formulación de los lineamientos de política ambiental para la región central con énfasis en la Estructura Ecológica Regional $(\mathrm{EER}){ }^{49}$

A pesar de estos esfuerzos, se hace verdaderamente necesaria y urgente la formulación de una política pública para la integración regional que incorpore la dimensión ambiental como elemento constitutivo y no marginal, como hasta ahora se sigue percibiendo el tema en distintas instancias públicas y privadas.

En este aparte se analizará la visión de algunas entidades que tienen injerencia directa con el tema del desarrollo regional para Bogotá. En ese sentido, vale la pena mencionar que la integración regional, el tema de Región Capital y la formulación de un escenario regional para Bogotá siguen en un evidente atraso. Lo anterior, a pesar que en la última década se han generado una serie de actividades, eventos, investigaciones, acuerdos y agendas comunes, que muestran el interés de los actores por construir las condiciones para que el desarrollo regional supere los límites clásicos de la planificación.

Vale la pena mencionar que recientemente se presentó el documento: "2019 Visión Colombia segundo centenario", que plantea: "un país de regiones prosperas, integradas, articuladas y competitivas a nivel nacional e internacional" y a la formación de un modelo de organización que estructure territorios con una calificada dotación de infraestructuras y equipamientos, con un sistema urbano - regional articulado en red". ${ }^{50}$ Esta propuesta evidencia la necesidad de retomar el tema regional y darle la importancia a la región como unidad esencial para un país diverso en lo social, físico, ambiental, económico y cultural.

\subsubsection{La Constitución Política Nacional de 1991, eje central del ordenamiento del territorio para la ordenación de la Cuenca del Río Bogotá.}

La Constitución política de Colombia se la llama "Constitución ecológica" ya que por lo menos ciento cuarenta y tres (143) de sus disposiciones, de manera directa o indirecta tocan el medio ambiente y otros aspectos que son significativos y que tienen que ver con protección, conservación, mitigación, prevención de los recursos naturales del país, haciendo énfasis en que la responsabilidad y la solución de los factores del deterioro ambiental no corresponden solamente al Estado ni a los particulares, independientemente cada uno, sino a los dos actores interrelacionados, planteando así un nuevo sistema de gestión, el cual se desarrolló en la Ley 99 de 1993.

Por lo tanto, el Plan de Ordenamiento y Manejo de la Cuenca hidrográfica del Río Bogotá (POMCA), tiene el reto de articular a las entidades municipales que comprenden su jurisdicción, ya sea desde la entidad ambiental CAR de Cundinamarca la cual coordine la ejecución de programas y proyectos para la descontaminación definitiva del Río Bogotá, para ello, se debe disponer de las mejores condiciones de participación del desarrollo territorial en temas de gestión y administración, jalonadas por la misma constitución.

\footnotetext{
${ }^{49}$ Instituto Alexander Von Humboldt. 2008.

${ }^{50}$ Departamento Nacional de Planeación. Bogotá. 2005. 2019 Visión Colombia segundo centenario.
} 


\subsubsection{Antecedentes políticos en la construcción del concepto regional en el área de la cuenca del Río Bogotá}

El desarrollo del concepto regional en Colombia, está fuertemente asociado al tema del desarrollo urbano. La construcción del territorio y de la región en el país tienen como epicentro las dinámicas económicas y sociales ligadas directamente a la movilidad. Los procesos de urbanización incrementados desde mediados del siglo XX, configuraron espacios y territorios heterogéneos y complejos. Sin embargo dichos espacios fueron marcadas por el crecimiento acelerado de la urbanización que en la década de los 50 , paralelamente al conflicto armado por la violencia bipartidista configurando escenarios cada vez más relevantes e importantes dentro del espacio territorial.

En 1973, el estudio denominado: "Ecología y expansión urbana" planteaba su preocupación por la expansión de la ciudad de Bogotá y su influencia con el área de su periferia. Algunos de los comentarios del autor mencionaban que "el departamento de planeación distrital, ha intentado definir un área de influencia inmediata de la ciudad, cuya extensión alcanza alrededor de 286.000 hectáreas y que comprende 17 municipios y gran parte del Distrito Especial de Bogotá ${ }^{51}$. Infortunadamente, la definición de los límites de esta área no ha sido constatada con ningún método científico para la determinación de la zona de influencia de la gran ciudad". ${ }^{5}$

Igualmente, este estudio indicaba que la región presentaba ya un fenómeno de degradación ambiental matizado especialmente por la erosión, que para la época se calculaba en $31 \%$ del territorio, del cual un $7 \%$ correspondía a erosión propiamente dicha y el restante $24 \%$ a bosques degradados ${ }^{53}$. De este estudio sus resultados cumplen 40 años, lo cual se debe disponer de acciones inmediatas para la intervención de dichas áreas, la aplicación de la base ambiental propuesta por el decreto 3600 de 1997, reconoce la Estructura Ecológica Principal como el eje rector para la conservación ambiental, protección ambiental y restauración ambiental de los ecosistemas que por motivos de intervención antrópica o degradación por eventos naturales necesita de una intervención inmediata.

"Haciendas de la Sabana" es otro texto importante para entender el proceso de formación del territorio en la región. Su autor planteaba hacia 1946 lo siguiente: "lo que sucede es que Bogotá y la Sabana son una cosa y el resto de Cundinamarca es otra, muy distinta. La Sabana pertenece espiritualmente a la ciudad, y las dos se compenetran absoluta y definitivamente. En la Sabana, cada uno de sus pueblecillos - Funza, Fontibón, Serrezuela, Chía, Usaquén, Engativá, Mosquera, Suba, Cajicá, Bosa, Bojacá, Soacha, Cota, Tenjo, Tabio, etc., tienen su personalidad, como la tiene Bogotá; pero todos están unidos por un alma común, por una especie de cordón umbilical del espíritu, que nada tiene que ver con la que anima el resto del desaparecido imperio Chibcha". ${ }^{54}$

Lo anterior indica claramente que el territorio de la Sabana de Bogotá y la ciudad de Bogotá tienen una relación histórica. Se hace evidente que los municipios que conforman

\footnotetext{
51 Denominación administrativa dada a la ciudad de Bogotá antes de la actual hoy se llama Distrito Capital desde la Constitución Nacional de 1991.

52 Universidad Nacional de Colombia. Facultad de Artes. Bogotá. 1973 pág. 79: Este documento hace relación directamente concepto de área metropolitana. Hoy en día este concepto esta dentro del instrumento de planificación de la Ley 128 de 1994

${ }^{53}$ Universidad Nacional de Colombia. Facultad de Artes. Bogotá. 1973 pág. 82

${ }^{54}$ Pardo, Camilo. Haciendas de la Sabana. 1946. Bogotá.
} 
el territorio tienen esa identidad necesaria para la conformación de un espacio regional donde no desaparezcan las diferencias de los entes territoriales.

De otro lado, es importante reconocer que las ciudades colombianas adquieren una fuerte importancia desde mediados del siglo pasado y especialmente las cuatro principales ciudades Bogotá, Medellín, Cali y Barranquilla. Esta prevalencia ha generado un modelo urbano concentrado en las dos últimas décadas del siglo pasado en el país, estimulado por complejos procesos de movilidad social, para los cuales según Orlando Fals Borda el conflicto armado ha sido uno de sus principales factores ${ }^{55}$, junto con los Planes de Desarrollo Nacionales, en los cuales eran las cuatro ciudades que se beneficiaban de las distintas inversiones públicas. La consolidación de la ciudad como centro de atracción reconfigura el territorio regional, entendiéndose aquel territorio que se encuentra en influencia directa con la ciudad, tal como lo afirma un documento de la Contraloría de Bogotá: "La propia expansión de la ciudad principal ha ocasionado la aparición de nuevas formas de asentamiento y ocupación del suelo. En los nuevos territorios urbanoregionales tiende a desaparecer el clásico y nítido ordenamiento jerárquico que va de ciudad mayor a ciudad intermedia, a centro menos, asentamiento rural e hinterland agrario." 56

La configuración de territorios urbano-regionales cobra más importancia en países latinoamericanos, como quiera que existen variables fuertemente asociadas a la construcción del territorio, como son la pobreza, la desigualdad, la ilegalidad en la construcción de vivienda, la ausencia de servicios públicos adecuados y en general una serie de elementos asociados a la calidad de vida urbana, que determinan fenómenos de ocupación ilegal del territorio y la desaparición de valiosos ecosistemas, tal como lo ha venido haciendo la ciudad de Bogotá desde la década de 1950, cuando inicia un proceso de relleno de humedales para dar paso a una urbanización acelerada directamente desde la vivienda; además de las intervenciones de los urbanizadores piratas o clandestinos.

Sin embargo, es importante reconocer el proceso de descentralización que se viene dando a lo largo de las últimas décadas desde la primera elección de alcaldes en 1988.

\subsubsection{Resolución No. 3194 del 23 de noviembre de 2006, por la cual se aprueba el Plan de Ordenación y Manejo de la Cuenca del Río Bogotá.}

De acuerdo al Decreto 1729 de 2002, establece los lineamientos y fases para la ordenación de cuencas hidrográficas, define el proceso de ordenación de una cuenca y tiene como objetivo el planeamiento del uso y manejo sostenible de sus recursos naturales renovables, de manera que se consiga establecer el equilibrio entre el aprovechamiento económico y la conservación de la estructura físico-biótica de la cuenca. Por lo tanto, la resolución No 3194 de 2006 mostró los resultados de diagnóstico, prospectiva y formulación de la cuenca hidrográfica del Río Bogotá desarrollando las fases de diagnóstico, prospectiva y formulación.

Sin embargo, dada la complejidad de la problemática, y las características de la cuenca del río, cuyo recorrido involucra la competencia de varios organismos de control, como de entes municipales (42 municipios), que desde sus cabeceras son responsables de la alta contaminación del río. EI POMCA establece un plan de acción para su descontaminación,

\footnotetext{
${ }^{55}$ Fals Borda Orlando. Región e historia: elementos sobre ordenamiento y equilibrio regional en Colombia. TM editores. Bogotá. 1996.

${ }^{56}$ De Bogotá a la Región. Contraloría de Bogotá. Bogotá. 2003. Pág. 88.
} 
donde se revisen los agentes contaminantes y su caracterización, la gestión institucional y su articulación, la eficiencia de los recursos invertidos, así como la participación de la ciudadanía en la formulación y ejecución de los proyectos encaminados a la descontaminación del río.

Finalmente, a través de las audiencia públicas promovidas por la Contraloría General de la Republica (CGR, 2007 - 2010), se busca que la democracia deliberativa contribuya a fortalecer la democracia participativa y, así, forjar una cultura ciudadana de interés por su descontaminación para los usos y servicios que debe prestar este recurso. Según la CGR espera que con el control social y la vigilancia de la gestión pública sea una realidad que aporte s la protección de los recursos públicos, la lucha contra la corrupción y el ejercicio mismo del control fiscal. (Julio Cesar Turbay Quintero ex contralor de la CGR, Estrategias para la armonización y seguimiento al programa de descontaminación del Río Bogotá Informe 2007 - 2010 Pág. 10).

\subsection{LOS PLANES DE ORDENAMIENTO TERRITORIAL EN LA REGIÓN BOGOTÁ CUNDINAMARCA.}

En el Diagnóstico de la Región Bogotá Cundinamarca del Departamento Nacional de Planeación (2003), se establece que la armonización del POT de Bogotá, en el contexto regional solo hizo referencia a la Sabana de Bogotá, y que su alcance fue limitado ni efectuó articulación entre regulación de los usos del suelo y dinámicas del desarrollo regional.

De acuerdo con la Secretaria de Planeación de Cundinamarca (2006), en los 116 municipios del Departamento se ha adoptado un Plan de Ordenamiento Territorial, el último de ellos en el municipio de Bituima en el mes de noviembre de 2005.

En el año 2004 se realizó una consultoría ${ }^{57}{ }^{58}$ para la Gobernación de Cundinamarca, cuyo objetivo fue la articulación de los planes de ordenamiento territorial de los municipios del departamento de Cundinamarca y el diseño e implementación del Sistema de Información Geográfica Regional, donde uno de los resultados fue la definición de once Subregiones de Planificación, en las cuales la estructura territorial de cada una de ellas contiene parcialmente ecosistemas constitutivos del territorio. Las subregiones de planificación definidas por el estudio corresponden a las indicadas en las tablas (Véase anexo 1), que responden a la articulación de los POT.

\subsection{LOS DOCUMENTOS CONPES ${ }^{59}$ (Promulgados en el área de estudio).}

La información compilada data del año 1989, desarrollándose diferentes documentos nacionales y regionales que encausan el accionar hacia un punto de integración regional e intervención para la descontaminación del Río Bogotá e como el Documento CONPES 3320 de 2004, Estrategias para el Manejo ambiental del río Bogotá).

\footnotetext{
57 GOBERNACION DE CUNDINAMARCA. (2004). Articulación de los POT de los municipios del Departamento de Cundinamarca. Tomo I

${ }^{58}$ GOBERNACION DE CUNDINAMARCA. (2004). Articulación de los POT de los municipios del Departamento de Cundinamarca. Tomo II.

${ }^{59}$ Los documentos CONPES (Comisión Nacional de Políticas Económicas y Sociales), son reuniones interministeriales que se reúnen con el fin de darle viabilidad a proyectos y programas de desarrollo que inciden directamente en el desarrollo social de las comunidades, de las regiones entre otras.
} 
En la tabla se enuncian los19 documentos del Consejo Nacional de Política Económica y Social (CONPES), (Véase Tabla 3.5.), alusivos a la temática ambiental, a los recursos naturales, a diferentes temáticas transversales y a la integración regional de Bogotá y de Cundinamarca.

\section{Tabla 3.5. ASPECTOS NORMATIVOS CONSEJO NACIONAL DE POLÍTICAS ECONÓMICA Y SOCIAL CONPES}

\begin{tabular}{|c|c|c|c|}
\hline $\begin{array}{l}\text { DOCUMENTO } \\
\text { CONPES }\end{array}$ & AÑOS & TEMA & ORDEN \\
\hline 2429 & 1989 & Plan de Acción Forestal para Colombia & Nacional \\
\hline 2544 & 1991 & Una Política Ambiental para Colombia & Nacional \\
\hline 2625 & 1993 & $\begin{array}{l}\text { Plan de Mejoramiento Integral de Ciudad Bolívar y Áreas } \\
\text { Subnormales del Sur y Alternativas para la localización de la } \\
\text { población pobre de Bogotá }\end{array}$ & Regional \\
\hline 2825 & 1995 & $\begin{array}{l}\text { Estrategia para el Desarrollo de un Puerto Carbonero Integrado en } \\
\text { la Costa Caribe para los Carbones del Cesar, Córdoba y el Interior } \\
\text { del País }\end{array}$ & Nacional \\
\hline 2834 & 1996 & Política de Bosques & Nacional \\
\hline 2910 & 1997 & $\begin{array}{l}\text { Evaluación de la Política Nacional Ambiental hacia un Desarrollo } \\
\text { Humano Sostenible }\end{array}$ & Nacional \\
\hline 3120 & 2001 & $\begin{array}{l}\text { Estrategia para el Mejoramiento de la Gestión Ambiental en el } \\
\text { Sector Energético. }\end{array}$ & Nacional \\
\hline 3177 & 2002 & $\begin{array}{l}\text { Acciones Prioritarias y Lineamientos para la Formulación del Plan de } \\
\text { Manejo de Aguas Residuales. }\end{array}$ & Nacional \\
\hline 3242 & 2002 & $\begin{array}{l}\text { Estrategia Institucional para la Venta de Servicios Ambientales de } \\
\text { Mitigación del Cambio Climático. }\end{array}$ & Nacional \\
\hline 3256 & 2003 & $\begin{array}{l}\text { Políticas y Estrategias para la Gestión Concertada del Desarrollo de } \\
\text { la Región Bogotá-Cundinamarca. }\end{array}$ & Regional \\
\hline 3305 & 2004 & Lineamiento para Optimizar la Política de Desarrollo Urbano. & Nacional \\
\hline 3320 & 2004 & Estrategia para el Mejoramiento Ambiental del Río Bogotá. & Regional \\
\hline 3343 & 2005 & $\begin{array}{l}\text { Lineamientos y Estrategias de Desarrollo Sostenible para los } \\
\text { Sectores de Agua, Ambiente y Desarrollo Territorial. }\end{array}$ & Nacional \\
\hline 3344 & 2005 & $\begin{array}{l}\text { Lineamientos para la Formulación de la Política de Prevención y } \\
\text { Control de la Contaminación del Aire. }\end{array}$ & Nacional \\
\hline $\begin{array}{l}3433 \\
3433\end{array}$ & $\begin{array}{l}2006 \\
2006\end{array}$ & $\begin{array}{l}\text { Construcción y Mantenimiento Avenida Longitudinal de Occidente- } \\
\text { ALO- Sector Río Bogotá-Chusacá. }\end{array}$ & $\begin{array}{l}\text { Regional } \\
\text { Regional }\end{array}$ \\
\hline 3451 & 2006 & Estrategia para el Manejo Ambiental de la Cuenca Ubaté-Sumapáz. & Regional \\
\hline 3463 & 2007 & $\begin{array}{l}\text { Planes Departamentales de Agua y Saneamiento para el Manejo } \\
\text { Empresarial de los Servicios de Acueducto, Alcantarillado y Aseo. }\end{array}$ & Nacional \\
\hline 3490 & 2007 & $\begin{array}{l}\text { Estrategia Institucional para el Desarrollo del Macroproyecto Urbano } \\
\text { - Regional del Aeropuerto el Dorado de Bogotá. }\end{array}$ & Regional \\
\hline 3550 & 2008 & $\begin{array}{l}\text { Lineamientos para la Formulación de la Política Integral de Salud } \\
\text { Ambiental con Énfasis en los Componentes de la Calidad del Aire, } \\
\text { Calidad del Agua y Seguridad Química. }\end{array}$ & Nacional \\
\hline
\end{tabular}
Fuente: Documentos CONPES vigentes

Finalmente, a lo largo del capítulo se reconocieron desde el marco normativo, los alcances de la política pública recurrente para la intervención específicamente en la cuenca del Río Bogotá, sus aspectos que relacionan el aporte conceptual en la determinación de acciones que se deben tomar en el caso de la determinante de ordenación regional teniendo su alcance en los lineamientos en la puesta de la cuenca hidrográfica, como instancia para gestionar planear y ordenar política y administrativamente el territorio. 


\section{CAPÍTULO}

DIAGNOSTICO Y CARACTERIZACIÓN 


\subsection{EI DIAGNÓSTICO}

El cuarto capítulo hace referencia al desarrollo del diagnóstico y caracterización del área establecida a partir de la cuenca alta y baja del Rio Bogotá desde su nacimiento en el páramo de Guacheneque, en el municipio de Villapinzón, y su articulación espacial con el territorio de la Ciudad de Bogotá Distrito Capital, como área estratégica teniendo en cuenta que la subcuenca del Río Negro, Carare, Gachetá, Batá y la subcuenca del Sumapáz, se suscriben al área como ecosistemas articulados a través de la Estructura Ecológica Regional ${ }^{61}$, como eje estructural del ordenamiento ambiental territorial identificada como subregiones en el departamento de Cundinamarca, además de contener un sistema espacial y funcional vital para el mantenimiento del equilibrio ecosistémico que garantiza el suministro de bienes ambientales para una alta población demandante en el presente, y con un futuro incierto si no se toman las acciones inmediatas que se han venido identificando en los capítulos anteriores. Por lo tanto, su caracterización deberá dar los insumos para planificar y gestionar desde las instituciones comprometidas que comparten el área como a los municipios que integran su jurisdicción, protegiendo el manejo del recurso hídrico respondiendo a la conservación, protección, preservación y recuperación de la biodiversidad y los servicios ecosistémicos.

Así, se recogerá la información de las características biofísicas del área que identificamos como de referencia que está determinada directamente a la Estructura Ecológica Regional, y por lo tanto, el área objetivo lo caracteriza la cuenca hidrográfica alta y media el río Bogotá; ${ }^{62}$ indagando en cada una de ellas tanto sus problemas y potencialidades para incorporarlas al marco de referencia para la gestión y administración territorial. Algunas características de requerimiento se pueden identificar de la siguiente forma: desde la dimensión ambiental (componente físico-biótico), dimensión social referente a la población (aspectos demográficos y asentamientos), económica, (lo relacionado a la producción en los sectores de la economía) lo político-administrativa entre otras, dependerá del marco legal y normativo con el cual se pueda implementar el concepto regional o a su vez demostrar la importancia de su implementación a partir de la puesta en marcha en armonización de los instrumentos de planificación como el Plan de Ordenamiento territorial municipal y su articulación a los Planes de Desarrollo.

Por tal razón, para el análisis del diagnóstico, e interpretación su énfasis estará enmarcado en la naturaleza actual de los conflictos de uso del suelo que viene sucediendo a lo largo del Río Bogotá, por su utilización y manejo y administración de los recursos disponibles en la Subcuenca alta y media, su alta dependencia con la ciudad de Bogotá Distrito, como mayor usuario de su explotación y contaminación del recurso hídrico del río Bogotá. Como también la composición de las distintas alternativas en la solución de lo anterior visto desde la integración municipal y regional. El enfoque se hace sobre conclusiones dominantes o sobre grupo o cosa, se conduce o funciona en el presente $^{63}$. Por lo tanto, el trabajo desde una investigación descriptiva sobre realidades de

\footnotetext{
${ }^{61}$ Estructura Ecológica Principal, según el artículo 1 - Capitulo 1 - Disposiciones generales - literal 1 del Decreto 3600 de 2007, adopta la siguiente definición, como el conjunto de elementos bióticos y abióticos que dan sustento a los procesos ecológicos esenciales del territorio, cuya finalidad principal es la preservación. Conservación, restauración, uso y manejo sostenible de los recursos naturales renovables, los cuales brindan la capacidad de soporte para el desarrollo socioeconómico de las poblaciones. Para ello, la Secretaría Distrital de Ambiente de la ciudad de Bogotá D.C., en compañía de la Corporación Autónoma Regional de Cundinamarca, determinaron el alcance de la Estructura Ecológica en términos de región, con el fin de articular a La ciudad de Bogotá D.C., con los municipios de primer orden de su periferia al departamento de Cundinamarca; es aquí donde aparece la figura de Estructura Ecológica regional.

${ }^{62}$ Región de referencia se entiende al territorio o áreas adyacentes que interactúan con el área de intervención directa llamada región o área objetivo.

${ }^{63}$ El proceso de la investigación científica. Mario Tamayo y Tamayo, pagina 54, Editorial Limusa 2000.
} 
hecho y su característica fundamentadas en presentarnos una interpretación correcta de las condiciones de desarrollo de dicho territorio. En este trabajo de tesis, se cuenta con un instrumento, de fácil manejo que permite estimar, y a la vez, representar de manera rápida, en una imagen espacial, el grado relativo de desarrollo territorial, como herramienta hacia el proceso regional de integración que se pretende establecer entre las instancias de la cuenca hidrográfica.

Por lo tanto, la cartografía de apoyo en la espacialización territorial suministrada por la Gobernación de Cundinamarca, Corporación Autónoma Regional de Cundinamarca (CAR), la cual, generan un gran mosaico donde se encuentran definidas la territorialidad y su división en Subcuencas en alta y media; permitiéndonos identificar las bases de la estructura político/administrativa de los municipios, el uso del suelo y la Estructura Ecológica que se establecerá como ámbito regional en fin, de implementar las herramientas de planificación y de Gestión Territorial, sus relaciones y desequilibrios en el territorio de la cuenca armonizando tanto la Subcuenca del Río Negro y la subcuenca del Sumapáz.

A lo largo del trabajo, se identificarán conceptos que serán utilizados como una guía de acompañamiento y apoyo en el proceso del mejoramiento metodológico en el fortalecimiento del recurso hídrico que se fundamenta en la política, los objetivos y las estrategias en términos del ordenamiento territorial para el fortalecimiento de la gestión y la planificación territorial. A partir del entendimiento de que el recurso hídrico se convierte en el enlace de armonización interinstitucional, que permite comunicar y reducir su impacto ambiental.

Finalmente, por esta razón se consolida el diagnóstico en una herramienta de gestión que debe ser caracterizada hacia el progreso continuo de los procesos y procedimientos ambientales, orientada hacia la satisfacción de las necesidades que en materia ambiental se requieran estableciéndose un orden de ejecución y cumplimiento coherente con la dinámicas de la Región que se pretende armonizar desde el concepto de cuenca hidrográfica.

\subsubsection{Los Antecedentes}

La planificación territorial se concibe aquí como la última parte del proceso en la caracterización del territorio, en donde se podrán identificar la aplicabilidad de los lineamientos conceptuales y metodológicos y de las bases teóricas y conceptuales descritas en el capítulo I, II y III. Consiste básicamente en diseñar, en función del diagnóstico elaborado, un modelo territorial o imagen objetivo a largo plazo y en definir las medidas necesarias para hacerlo realidad teniendo en cuenta la estructura de la cuenca hidrográfica en un planteamiento que será objeto del capítulo de formulación.

Metodológicamente, la identificación de los objetivos parte de la relación de problemas identificados en el diagnóstico. Todo problema debe quedar contemplado al menos en un objetivo y todo objetivo debe atender al menos a un problema, sin que la correspondencia sea biunívoca, sino tal que un mismo objetivo pueda orientarse hacia varios problemas y un solo problema estar contemplado en varios objetivos. 
La línea establecida para el proceso de consolidación de los marcos de referencia para los lineamientos y conceptos metodológicos están dados a partir de la cuenca alta y media del Río Bogotá y sus ecosistemas estratégicos que conforman una Estructura Ecológica Regional con las subcuencas del Río Negro, Carare, Gachetá, Batá y Sumapáz; que respalda el área para delinear los lineamientos conceptuales y metodológicos para la planificación y gestión sostenible del territorio, desde una perspectiva regional, objetivo central del trabajo de tesis. A su vez, la Planificación, la Gestión y el Ordenamiento Ambiental con la articulación de la Cuenca Hidrográfica, los conceptos de región desde la estructura ecológica, conocer y armonizar los resultados de otros instrumentos de planificación como los Planes de Desarrollo y de Ordenamiento Territorial municipal establecidos por la Ley 152/94 y 388/97 (POTS). Y estos a la vez armonizados con los Planes de Desarrollo Nacional, Departamental y municipal.

La interrelación de lo anterior, se complementa con el concepto de Estructura Ecológica definida en el decreto 3600 de 2007, como insumo ambiental al ordenamiento y planificación del territorio, con el fin de delinear el proceso de organización regional, ya que no existe hasta el momento la decisión política que integre las diferentes disposiciones normativas en materia de organización territorial ${ }^{64}$, a través de la cuenca hidrográfica.

Para el cumplimiento del objetivo general como de los específicos, se identifican las características territoriales que podemos denominar área de estudio. Hace referencia a la identificación de las Subcuenca Alta y Media del Río Bogotá, y, área que determina elementos ambientales y geomorfológicos de la Subcuenca del Río Negro Río Carare, Gachetá, Batá y la Subcuenca del Sumapáz (Véase Mapa 4.8.), siendo estas Subcuencas importantes para la consolidación ambiental de las subcuenca del Río Bogotá; conformada por 38 municipios y la ciudad de Bogotá D.C., desde la división de sus áreas político-administrativas,

Por lo tanto, los lineamientos conceptuales y metodológicos para la planificación y gestión sostenible, se orientan a la consolidación de un modelo de ocupación del territorio, que a través del ordenamiento territorial, certifique su sostenibilidad ambiental garantizando la prestación de los servicios ecosistémicos y ambientales indispensables para el desarrollo sostenible de la población asentada dentro y fuera del territorio. (Véase mapa 4.9.).

De esta forma surge la necesidad de llevar el concepto de la cuenca hidrográfica al ordenamiento y gestión del territorio teniendo un marco teórico y conceptual armónico y articulado hacia el concepto de región. Para ello, el ordenamiento territorial, definido de manera concertada con autoridades departamentales y locales y una participación activa de la sociedad civil a través de verdaderos espacios participativos dada la complejidad del problema en el área de estudio, se busca contribuir al fortalecimiento de la democracia participativa y, así, forjar una cultura ciudadana de interés por lo público, en este caso representado por la cuenca hidrográfica del Río Bogotá, su cuenca demanda urgente su descontaminación para los usos y servicios que debe prestar este recurso, el control

\footnotetext{
${ }^{64}$ La Universidad Distrital Francisco José de Caldas, elaboró la línea estratégica ambiental en la Armonización del Ordenamiento Territorial y la Estructura Ecológica Regional (EER), Identificando cinco líneas estratégicas ambientales para la Región Capital través de Contrato 1206-2009 entre la Secretaría Distrital de Ambiente y la Universidad.
} 
social en la vigilancia de la gestión pública sea una realidad que aporte a la protección de los recursos públicos teniendo en cuenta los principios constitucionales en la coordinación, concurrencia y subsidiaridad de la función administrativa, este es el sentido rector del trabajo de investigación.

Como parte de los documentos técnicos que hacen parte de esta investigación como información secundaría, se relaciona la documentación y literatura de base, entre ellos, la línea estratégica ambiental armonización del ordenamiento territorial y la estructura ecológica en la región capital propuesta por la Secretaría Distrital de Ambiente de la ciudad de Bogotá, los conceptos como el estado de conservación, protección y preservación del recurso hídrico a través de las distintas políticas públicas, los instrumentos de planeamiento para la armonización a largo plazo, la normatividad existente estudiadas en el capítulo anterior, la identificación de actores, sectores y gremios conducentes, al fortalecimiento y consolidación del proceso regional objeto de este capítulo entre otros.

\subsubsection{La localización del área de estudio}

Algunas de las características que se identificaron dentro del marco conceptual fue el del Convenio Interadministrativo, celebrado entre el Ciudad de Bogotá Distrito Capital y el Departamento de Cundinamarca en el 2008 que conforma el territorio de la Región Capital con los 116 municipios del departamento de Cundinamarca. Para efectos del análisis, se selecciona dentro de la Región Capital un área de estudio constituida por 38 municipios que hacen parte de la Cuenca del Río Bogotá (Cuenca alta, media) y (las Subcuencas del Río Negro, Carare, Gachetá, Batá la subcuenca del Sumapáz); lo cual fue establecido por la Secretaría Distrital de Medio Ambiente de la ciudad de Bogotá (2009), como parte del ejercicio interadministrativo para desarrollar las bases en la organización regional, a través del concepto de Estructura Ecológica Regional (EER).

Teniendo en cuenta el área establecida por la Secretaría Distrital de Ambiente en el 2009, se identificaron los municipios seleccionados y dado que los ecosistemas traspasan los límites político-administrativos, el área de estudio se delimitó desde una visión ecosistémica. Para esta visión, se tomaron en cuenta elementos de paisaje considerados indispensables para la conservación y preservación del sistema ambiental y los servicios ecosistémicos que presta la biodiversidad: coberturas presentes, áreas protegidas, paramos y corredores biológicos como sistema de conexión y reconocidos desde la Estructura Ecológica Regional. Los ecosistemas presentes en estos municipios se constituyen por supuesto como base para la formulación de los lineamientos y conceptos metodológicos para determinar los alcances del fortalecimiento, de una actitud lógica, al tener la cuenca hidrográfica como elemento determinante ambiental para el ordenamiento regional, en asocio con la EER, según lo establece el decreto 3600 de 2007.

A continuación se relaciona el área de estudio identificada y seleccionada teniendo como marco de referencia los criterios expuestos así como la distribución de los 39 municipios en ella. 
Mapa 4. 8. LOCALIZACIÓN GENERAL DEL ÁREA DEL ÁREA DE ESTUDIO

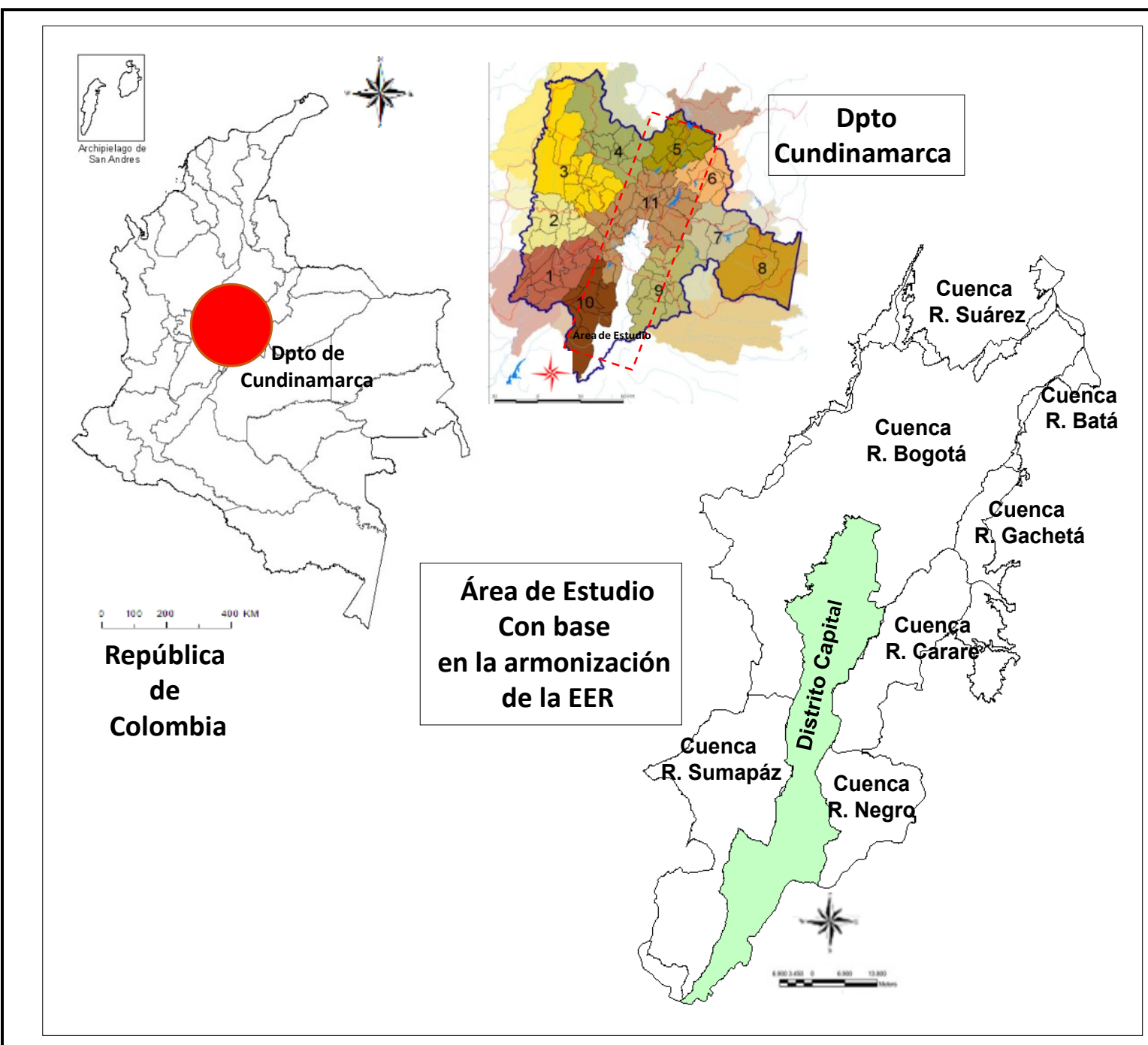

El mapa 4.8: muestra la localización del área de estudio que comprende la cuenca del Río Bogotá (Subcuenca Alta y Media), y las Subcuenca del Río Negro, Carare, Gacheta, Batá y la subcuenca del Rio Sumapáz las cuales caracterizadas conforman la Estructura Ecológica Regional lo cual nos permitirá desarrollar el respectivo trabajo.

Fuente: Elaboración a partir de información de la Secretaría Distrital de Ambiente contrato 1441 con la Universidad Santo Tomas Aquino sede ciudad de Bogotá D.C.

\subsubsection{Generalidades estructurales y descripción de la localización del área de estudio.}

Cundinamarca junto con las cuencas de los ríos Sumapáz, Magdalena, Negro, Minero, Suárez, Blanco, Gacheta y Machetá, conformando el grupo de corrientes de segundo orden del departamento. Tiene una superficie total de $\mathbf{8 2 9 . 4 3 3 , 4 7}$ hectáreas conformadas por 38 unidades administrativas municipales más la ciudad de Bogotá D.C. 
La Cuenca del Río Bogotá limita en su extremo Norte con el Departamento de Boyacá, en el extremo Sur con los municipios de Fusagasugá, Pasca, el área rural del Distrito Capital (Localidad de Sumapáz), Gutiérrez, Une y Chipaque; al occidente con los municipios de Bituima, Guayabal de Síquima, Albán, Sasaima, La Vega, San Francisco, Supatá y Pacho; al oriente, en el área incluida dentro del presente estudio es decir sin incluir la Subcuenca del río Tunjuelo, con los municipios de Nilo, Tibacuy, Silvana, Chipaque, Ubaque y Choachí65. Está ubicada en el centro del país y del departamento de Cundinamarca, sobre la cordillera Oriental. El Río Bogotá nace en la región nororiental de Cundinamarca, en el sitio conocido como el Páramo de Guacheneque, de la Laguna del Valle, en el Municipio de Villapinzón, de la cordillera Oriental a $3.300 \mathrm{msnm}$. Los municipios anteriormente nombrado se relacionan en la siguiente tabla (Véase Tabla 4.6.), incluyendo su área de influencia y su porcentaje en el área de estudio.

Tabla 4. 6. LOS MUNICIPIOS ÁREA DE ESTUDIO

\begin{tabular}{|c|c|c|c|c|c|c|c|}
\hline \multicolumn{8}{|c|}{ MUNICIPIOS QUE INTEGRAN EL ÁREA DE ESTUDIO } \\
\hline No & MUNICIPİO & ÁREA/HA & $\%$ & No & MUNICIPİO & ÁREA/HA & $\%$ \\
\hline 1 & GACHANCIPA & 4129,63 & 0,5 & 22 & SUESCA & 17444,88 & 2,1 \\
\hline 2 & CAJICA & 5167,68 & 0,6 & 23 & SOACHA & 18179,99 & 2,2 \\
\hline 3 & COTA & 5600,98 & 0,7 & 24 & TAUSA & 19208,87 & 2,3 \\
\hline 4 & FUNZA & 6923,90 & 0,8 & 25 & ZIPAQUIRA & 19491,72 & 2,4 \\
\hline 5 & TOCANCIPA & 7275,98 & 0,9 & 26 & SUBACHOQUE & 21017,13 & 2,5 \\
\hline 6 & TABIO & 7535,25 & 0,9 & 27 & CHOACHI & 21324,32 & 2,6 \\
\hline 7 & CHIA & 7977,85 & 1,0 & 28 & UNE & 21701,08 & 2,6 \\
\hline 8 & EL ROSAL & 8942,11 & 1,1 & 29 & FUSAGASUGA & 21738,27 & 2,6 \\
\hline 9 & NEMOCON & 9848,24 & 1,2 & 30 & VILLAPINZON & 22580,46 & 2,7 \\
\hline 10 & BOJACA & 10054,73 & 1,2 & 31 & SAN BERNARDO & 24285,01 & 2,9 \\
\hline 11 & MOSQUERA & 10652,31 & 1,3 & 32 & PASCA & 24550,17 & 3,0 \\
\hline 12 & UBAQUE & 10866,11 & 1,3 & 33 & GUATAVITA & 24704,22 & 3,0 \\
\hline 13 & SOPO & 11076,21 & 1,3 & 34 & CHOCONTA & 30105,31 & 3,6 \\
\hline 14 & TENJO & 11263,94 & 1,4 & 35 & LA CALERA & 33010,75 & 4,0 \\
\hline 15 & MADRID & 11845,59 & 1,4 & 36 & GUASCA & 36411,98 & 4,4 \\
\hline 16 & SIBATE & 12252,84 & 1,5 & 37 & CABRERA & 44394,34 & 5,4 \\
\hline 17 & COGUA & 13325,47 & 1,6 & 38 & GUTIERREZ & 45863,72 & 5,5 \\
\hline 18 & CHIPAQUE & 13680,75 & 1,6 & 39 & \multicolumn{2}{|l|}{ BOGOTA D.C. } & 20,6 \\
\hline 19 & SESQUILE & 14061,30 & 1,7 & & \multirow{3}{*}{ ÁREA TOTAL } & \multirow{3}{*}{\multicolumn{2}{|c|}{ 829.433.47 Ha }} \\
\hline 20 & ARBELAEZ & 14248,18 & 1,7 & & & & \\
\hline 21 & FACATATIVA & 15462,95 & 1,9 & & & & \\
\hline
\end{tabular}

En la Tabla 4.6., se presenta el área de estudio identificada y seleccionada teniendo como marco de referencia los 38 municipios y el Distrito Capital (Bogotá); su identificación está dada por características de su ocupación en el territorio. Siendo Bogotá el $20 \%$, seguido por Gutiérrez y Cabrera con un 5.5 \% sobre los demás. Para la espacialización se tomó cada uno de los archivos POT/EOT.

Los municipios de mayor extensión dentro del área sobresalen en un 24,9\%, localizados en el área; los municipios que ocupan el 20,2 \% entre ellos Nemocón, Sopo, Facatativá, Madrid, Mosquera, Tenjo entre otros, en ellos con predominio hacia la urbanización y la conurbación; seguido con los municipios de Gutiérrez y Cabrera localizados en al sur

${ }^{65}$ POMCA del Río Bogotá 2006 
oriente y occidente 10,9\%; continúan en jerarquía los municipios de Pasca, Guatavita y Chocontá cuya base en su desarrollo es el desarrollo rural (sector productivo) 9,6\%; solo dos municipios, Guasca y la Calera, ocupan el $8.4 \%$ del área; con un 5,4 \% municipios cuyas áreas son las más pequeñas en el área entre ellos: Funza, Chía, Tabio, Cajicá y Tocancipá con un predominio entre lo urbano por estar en las periferia de la gran ciudad (Bogotá) y otros de carácter agropecuario. (Véase Tabla 4.6. y mapa 4. 9.)

\section{Mapa 4. 9. CARACTERIZACIÓN DE LOS MUNICIPIOS DEL ÁREA DE ESTUDIO.}

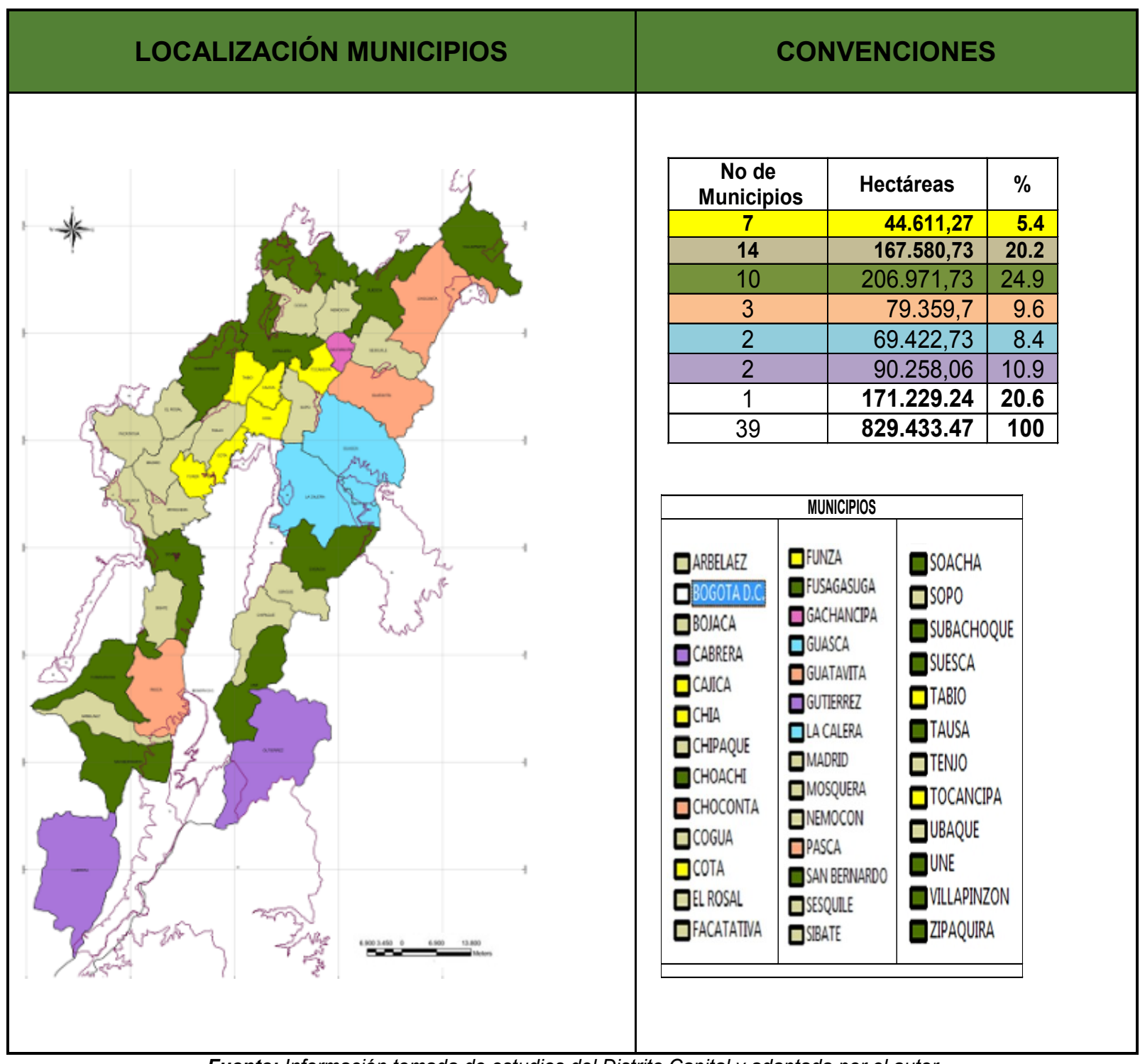

Fuente: Información tomada de estudios del Distrito Capital y adaptada por el autor 


\section{Mapa 4.10. ESPACIALIZACIÓN DEL ÁREA DE ESTUDIO}

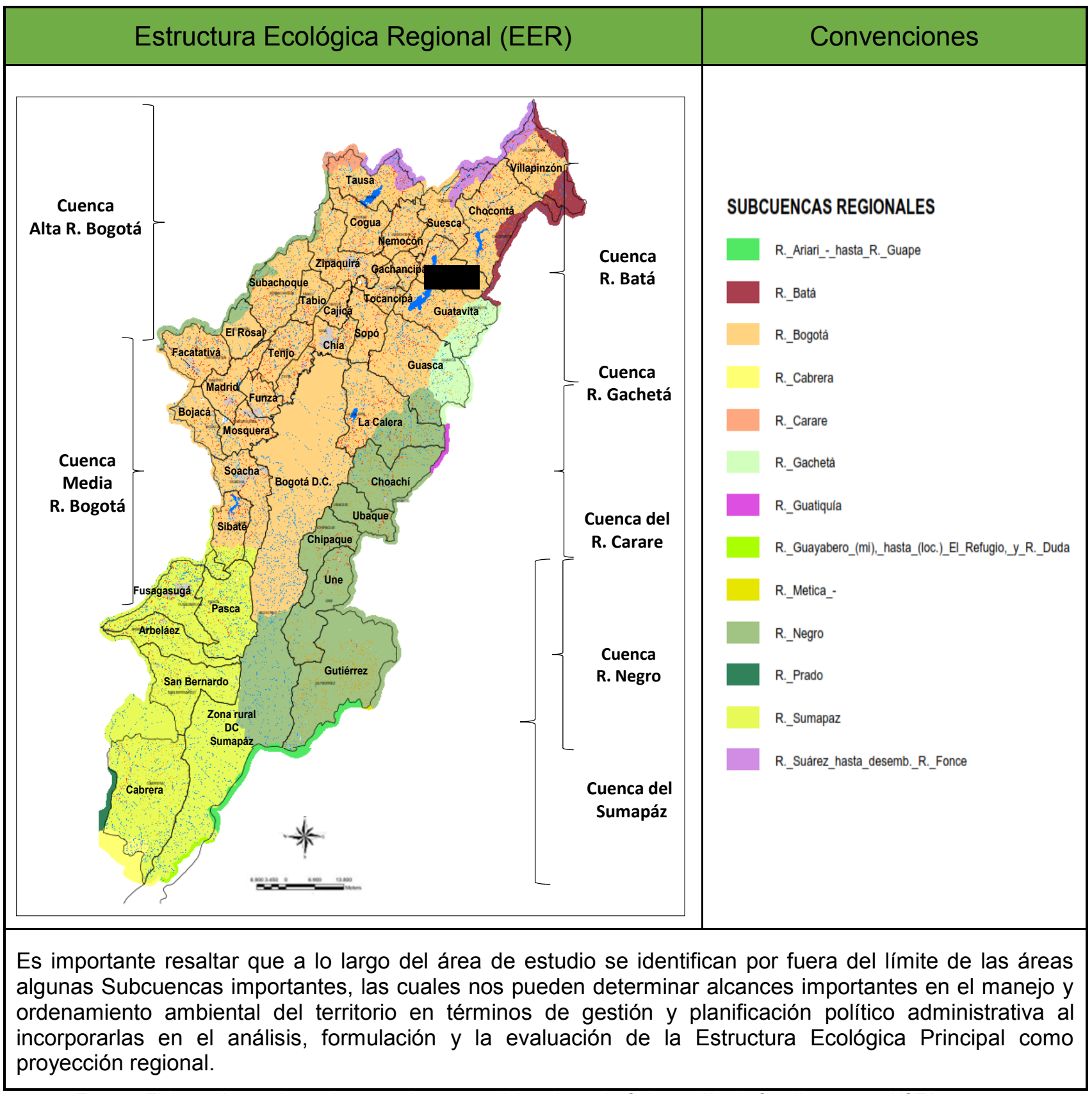

Fuente: Elaboración propia con base en el mapa suministrado por la Gobernación de Cundinamarca y USTA.

Para el análisis de algunas generalidades conocidas desde las teorías del desarrollo regional, se puede decir que el área presenta un modelo territorial desconcentrado. El cual, es el insumo como hoja de ruta para materializar la integración regional, planteando la concertación entre los municipios que conforman la región de la cuenca hidrográfica de las Subcuencas Alta y Media del Río Bogotá y las Subcuencas del Río Negro, Carare, Gachetá, Batá y la subcuenca del Sumapáz, discusiones que se han venido dando desde otros sectores en el caso del sector privado a través de la Mesa de Planificación Regional de Bogotá- Cundinamarca, liderado por la Cámara de Comercio de Bogotá y del Centro de las Naciones Unidas para el Desarrollo Regional (UNCRD). 
La intención del modelo territorial es revertir el proceso de concentración de la población en la ciudad de Bogotá, creando una red articulada de ciudades que se integren y funcionen como un solo sistema. Aunque el punto de partida del planteamiento es que la mayor concentración de población, infraestructura y servicios seguirá estando a corto y mediano plazo en Bogotá y la Sabana, con esta estrategia se espera consolidar el desarrollo de localizaciones alternas a partir de ciudades y sitios existentes con alto potencial para que se ubiquen actividades económicas, servicios y población, las cuales están también específicamente dentro del contexto físico de las subcuenca alta y media del Río Bogotá.

Además la presión del mercado inmobiliario por desarrollar el suelo de la Sabana hace que en las provincias de Sabana Centro y Sabana Occidente (Subcuenca Media) la tercera actividad económica más dinámica en términos de sociedades la constituya la actividad inmobiliaria. ${ }^{66}$ El mercado del suelo sin regulación se ha convertido en un proceso de especulación que ha provocado el aumento del precio del suelo. En lo corrido del presente siglo, las superficies suburbanas ocupadas con residencia se vienen expandiendo a una tasa promedio del $5,5 \%$ anual ${ }^{67}$, lo que implica que cerca de 200 hectáreas de uso agrícola se sustituyen anualmente por usos residenciales. Esto mientras en Bogotá, en el primer semestre de 2008, se licenciaban $1.852 .207 \mathrm{~m}^{2}$ para construcción de vivienda (185 ha) ${ }^{68}$.

Al lado de lo anterior, las políticas nacionales han abierto la puerta a los procesos de expansión y conurbación con Bogotá. Los macro proyectos en Mosquera y en Soacha pretenden desarrollar unas 60.000 viviendas, lo que implicaría alrededor de 200 mil personas. Por su parte, según Julio $\mathrm{Gómez}^{69}$, la vaga definición en regímenes de los usos del suelo ha permitido que en los Planes de Ordenamiento Territorial (POT), de los municipios vecinos se localicen grandes áreas para bodegas y usos industriales, lo que en un futuro acentuará la tendencia hacia la conurbación entre la ciudad de Bogotá y el área alta y media de la cuenca hidrográfica del río Bogotá.

Según J.C. Gómez ${ }^{70}$, la consolidación de los municipios de la Sabana está supeditada a la concertación y formulación de acciones concretas para dar cumplimiento a una promoción de una nueva ruralidad, equidad en las cargas y beneficios derivados del desarrollo territorial, gestión racional del suelo en perspectiva del modelo para la subregión y la consolidación de una estrategia para la administración compartida entre municipios, Departamento de Cundinamarca y la ciudad de Bogotá.

Para garantizar la sostenibilidad territorial del área, se debe lograr la conservación, restauración, preservación y aprovechamiento sostenible de los recursos naturales y el ambiente, mediante la ejecución de proyectos coordinados, concertados y cofinanciados que promuevan y garanticen la conservación, recuperación, restauración, uso y

\footnotetext{
${ }^{66}$ Según registros mercantiles de 2008 de la Cámara de Comercio Bogotá, en Chía el 22,1\% de las sociedades del municipio estaban dedicadas a actividades inmobiliarias, por encima de la actividad industrial $(9,4 \%$ de las sociedades $)$.

${ }^{67}$ Los municipios de Chía $(18,2 \%)$, Anapoima $(8,6 \%)$, La Calera $(8,4 \%)$, Fusagasugá $(7,2 \%)$ y Sopó $(5,9 \%)$ son dominantes en cuanto a las áreas rurales ocupadas con usos suburbanos residenciales en Cundinamarca (urbanizaciones tipo condominio).

${ }^{68} 262.608$ metros cuadrados para casas y $1.589 .599 \mathrm{~m}^{2}$ para apartamentos.

${ }^{69}$ GÓMEZ, J. Formulación de un modelo de ocupación territorial regional para los municipios de las provincias Sabana Centro, Sabana Occidente y Soacha, con su sistema de información geográfico y coadyuvar en su adopción. Gobernación a Cundinamarca. Contrato SUB-2355 entre el Progrmama de las Naciones Unidas para el Desarrollo y la Unión Temporal Julio Gómez - Grupo de Estudios Urbanos Ltda. 2008

${ }^{70}$ GÓMEZ SANDOVAL, J.C. Estudio "Diagnóstico y valoración de la estructura socioeconómica y espacial y desarrollar lineamientos de formulación en el proceso de revisión y ajustes del POT”. 2009.
} 
aprovechamiento sostenible de los bienes y servicios ambientales de la llamada Región Capital, la cual debe estar soportada en el bienestar social y desarrollo económico a través de la propuesta de la estructura que en los dos últimos años se ha venido promoviendo entre la ciudad de Bogotá y el departamento de Cundinamarca identificada como la Estructura Ecológica Regional (EER), haciéndose parte de una área de Cundinamarca. Además a lo largo de los años la Región Capital ha sido la principal proveedora de bienes y servicios de la ciudad de Bogotá D.C. en alimentos, transporte, turismo, vivienda, diversidad biológica y recurso hídrico.

\subsubsection{Identificación de los problemas asociados al diagnóstico de las Subcuencas alta y media del Río Bogotá.}

A continuación se hace una síntesis del diagnóstico de las Subcuenca Hidrográfica del Río Bogotá, que contribuyen el desarrollo de la propuesta de la estrategia de armonización del ordenamiento territorial y de la Estructura Ecológica en la Región Capital, a la planificación y la gestión territorial y la falta de visión y armonización regional de cada uno de los municipios que hacen parte integral del área de estudio; problemas identificados desde lo económico, social, cultural e institucional en la tomas de decisión, en temas relacionados con los recursos naturales compartidos. Los cuales deben ser mejorados desde una visión en los servicios ecosistémicos y ambientales que el área presta.

A continuación se presentan algunas de las problemáticas identificadas dentro del estudio del Diagnóstico de la Cuenca. (Resolución 3194 de ordenación de la Cuenca del Río Bogotá).

$>$ Deterioro de los elementos de importancia ambiental en el área municipal para evidenciar la necesidad de armonizar el ordenamiento territorial al desarrollo de las unidades de las cuencas hidrográficas hacia las revisiones y modificación futuras de los Planes de Ordenamiento Territorial (POT).

$>$ Se señala como los municipios ante los problemas ambientales evidenciados han tenido como respuesta una serie de iniciativas individuales las cuales no tienen ninguna articulación regional evidenciados conflictos de uso de suelo.

> Expansión urbana que pone en evidencia como las presiones económicas del mercado inmobiliario favorecen la expansión de áreas de uso residencial sustituyendo áreas anteriormente usadas para usos agrícolas en los municipios.

$>$ Las áreas protegidas del área de estudio con la categoría de cada una y su extensión se evidencia problemáticas asociadas a las áreas protegidas destacándose la presión antrópica en cada una de ellas así como la expansión de la frontera agrícola y la ocupación de territorios por otras actividades no compatibles con los usos del suelo.

- Las problemáticas planteadas para los páramos se destacan por la expansión de la frontera agrícola y fenómenos conexos como la perdida de cobertura vegetal, erosión, deforestación, contaminación de causes con material derivado de actividades agrarias, además del proceso relacionados con la minería. 
> Las problemáticas identificadas para algunos de los humedales del área de estudio son: Invasión del área para expansión agrícola o construcción, relleno de su área con desechos de construcción, vertimiento de aguas residuales, invasión de la ronda.

$>$ Pero en el caso especial del uso del suelo de protección el problema no es la diferencia de los determinantes ambientales de cada una de las Corporaciones Autónomas Regionales, sino de la falta de visión del concepto de región.

$>$ La falta de articulación de los municipios que componen el área de estudio, para trabajo integral para resolver problemas ambientales en común.

$>$ Falta de armonización en la aplicación de los determinantes ambientales por parte de los municipios, dificultando el proceso de consolidación de la Región.

$>$ Una de las problemáticas identificadas en el diagnóstico es el impacto regional de la actividad minera, en donde su espacialización muestra el avance de la actividad en los recursos naturales produciendo cambios importantes en el medio ambiente de la región.

> La cuantificación del territorio del departamento de Cundinamarca de 2`413.248 de $\mathrm{Ha}$, de las cuales $314.007 \mathrm{ha}$, son áreas protegidas se encuentran en vigencia 82 títulos mineros, que afectan alrededor de 16.209 ha, para un total de $11,51 \%$ del total de las áreas protegidas del departamento.

> Para la Sabana de Bogotá con 587.651 ha, donde el $24,9 \%$ es área protegida, para septiembre de 2011 se han solicitado 743 títulos donde la extensión de estos corresponde al $38 \%$ del área de reserva.

$>$ La disposición de residuos sólidos a nivel regional, se asocia al mejoramiento de la economía local y se ve reflejado en el aumento de la cantidad de residuos sólidos generados por los habitantes. Por esto, se plantea el crear rellenos sanitarios regionales.

$>$ Estudios realizados por el Instituto de Hidrología, Meteorología y Estudios Ambientales de Colombia. (IDEAM), estiman que el vertimiento de aguas residuales domesticas estimadas por el DBO solamente en Bogotá, llega a 1'244.520) toneladas de DBO/ año.

Por lo tanto, acciones a asociadas a la separación en fuente de los residuos así como el reciclaje y el compostaje disminuirían de manera importante el volumen de los residuos sólidos depositados en las Subcuenca del Rio Bogotá en la Subcuenca media. 


\subsubsection{El recurso hídrico como determinante del ordenamiento ambiental del territorio.}

El recurso hídrico como determinante del ordenamiento del territorio se considera como el eje integrador de la gestión del territorio cuyo objetivo general es promover el manejo y desarrollo coordinado de la planificación y uso del agua en interacción con los demás recursos naturales, maximizando el bienestar social y económico resultante, de manera equitativa, sin comprometer la sostenibilidad de los ecosistemas vitales. (Fuente Comité Asesor Técnico - Global Water Parnertship, Girh, Dinamarca 2000 - Política Nacional Recurso Hídrico de Colombia).

Por lo tanto, su interrelación con el marco normativo logra caracterizar un referente en materia de planeación. Siempre y cuando, en lo que tiene que ver con el recurso hídrico como determinante del ordenamiento del territorio, se identifica el Artículo $9^{\circ}$ de la Ley 1454 de 2011 (LOOT), señala que el gobierno nacional promoverá la asociación entre Corporaciones Autónomas Regionales (CAR) para diseñar y ejecutar programas de protección ambiental y, en especial, de cuidado de las zonas productoras de agua y abre la posibilidad que las (CAR) hagan inversiones por fuera de su jurisdicción con el fin de cumplir estos objetivos en cumplimiento de convenios adelantados entre las mismas. Ahora bien, el recurso hídrico como determinante del ordenamiento ambiental del territorio se convierte en el articulador institucional y el armonizador de proyectos y programas que se puedan ejecutar de forma coordinada y planificada entre las 39 entidades municipales, que comprende el área de estudio.

Por su parte, el artículo $10^{\circ}$ de la Ley 388 de 1997, considera como determinante del ordenamiento territorial "las normas y directrices para el manejo de las cuencas hidrográficas expedidas por la Corporación Autónoma Regional o la autoridad ambiental de la respectiva jurisdicción". De tal manera que las cuencas hidrográficas, desde esta perspectiva, se convierten en determinantes del ordenamiento.

Además por su parte, el artículo $4^{\circ}$ del Decreto 3600 de 2007, al reglamentar el artículo $10^{\circ}$ de la Ley 388 de 1997, define dentro de las áreas de protección ambiental a tener en cuenta en los planes de ordenamiento territorial "Las áreas de especial importancia ecosistémica, tales como páramos y subpáramos, nacimientos de agua, zonas de recarga de acuíferos, rondas hidráulicas de los cuerpos de agua, humedales, pantanos, lagos, lagunas, ciénagas, manglares y reservas de flora y fauna".

El enlace, que se busca con la apropiación normativa especialmente entre la ley 388 de 1997 y el decreto 1729 de 2002, es la conexión territorial para el diagnóstico de la región de la cuenca alta y media del Río Bogotá, por su interacción en el desarrollo y crecimiento en la proyección y localización de nuevas firmas como de actuaciones administrativas que inciden en el bienestar de los ecosistemas que hacen parte integral en el territorio. Por ello, se hace el reconocimiento de algunos instrumentos de planificación como la ley 388/97 y el Decreto 1729/02, como instancias en la planificación y gestión del territorio que después de más de 15 y 10 años de promulgadas siguen incidiendo directamente en la planificación y gestión territorial con sus herramientas que para el objetivo general del trabajo, como tesis para optar el título de magister en el manejo integral de cuencas hidrográficas desde la caracterización de un proyecto de caso se logren establecer las condiciones del fortalecimiento institucional y valorar y reconocer la importancia de la gestión pública en la ordenación y planificación territorial y administrativamente, desde la 
unidad de la cuenca hidrográfica y de la Estructura Ecológica Regional, para explorar los conceptos y lineamientos para la integración regional en el territorio.

El anterior numeral 1.4 del artículo $10^{\circ}$ de la Ley 388 de 1997 conduce necesariamente al Decreto 1729 de 2002 en lo relacionado con los Planes de Ordenación y Manejo de Cuencas Hidrográficas, como un factor determinante del ordenamiento del territorio dentro de los Planes de Ordenamiento Territorial POT, de tal manera, que estos se convierten en factor determinante del ordenamiento territorial. En ese sentido, el inciso $2^{\circ}$ del artículo 17 del Decreto 1729 de 2002 señala: "De acuerdo con lo previsto en el artículo 10 de la Ley 388 de 1997, el plan de ordenación y manejo de una cuenca hidrográfica constituye norma de superior jerarquía y determinante de los planes de ordenamiento territorial".

Siguiendo esta lógica jurídica, el Distrito Capital, en el artículo 105 del Decreto 190 de 2004, al adoptar la revisión del POT, de la ciudad, estableció que la integración del territorio distrital a la región se haría en el marco de la cuenca hidrográfica del Río Bogotá y del conjunto de ecosistemas estratégicos de la misma y que esta integración depende, principalmente, de la recuperación y conservación del río, sus afluentes y riberas. Este mismo artículo 105 del POT de Bogotá señala que el sistema hídrico y el orográfico se definen como los principales elementos de la Estructura Ecológica Regional y por esta razón deben conformarse como un elemento estructural a partir del cual se deben organizar los sistemas urbano y rural.

\subsection{LA CARACTERIZACIÓN AMBIENTAL}

Hoy en el territorio que comprende las Subcuenca Media del Rio Bogotá, viven más de nueve millones de personas, una población mayor que la de muchos países, el 80 por ciento en el Distrito Capital de Bogotá y el resto en la Sabana, en las montañas, mesas y valles y en los centros urbanos medianos y pequeños que constituyen el territorio del área de la Subcuenca alta. Las características biofísicas de este territorio, especialmente su relieve, la sal, el carbón y que constituyen parte de sus suelos, así como la diversidad de sus microclimas, han sido hasta ahora complemento suficiente para sostener a todos sus millones de habitantes, proporcionándoles energía, agua, alimentos y recreación en cantidades y calidades difíciles de igualar en otros territorios los cuales se identifican en las Subcuencas del Río Frio y Rio Negro. Todos estos procesos tienden a aumentar la concentración de conocimiento, recreación, poder y riqueza en la concepción y fortalecimiento de la región.

El estudio del Plan de Ordenamiento y Manejo de Cuenca Hidrográfica (POMCA) del Río Bogotá desarrollado en el año 2006 aprobada con la resolución No 3194, identificó dentro de la cuenca del Río Bogotá, especialmente en alta y Media, tres tipos de áreas estratégicas por las características de sus ecosistemas, dichas áreas se pueden establecer de la siguiente manera. ${ }^{71}$

\footnotetext{
${ }^{71}$ Ecosistemas declarados: Son aquellos que se encuentran en una de las categorías del sistema de áreas protegidas.

Ecosistemas a declarar: Aquellos que por sus condiciones estructurales y su oferta de bienes y servicios ambientales deben pasar a la categoría de declarados.

Ecosistemas a proteger: como aquellos ecosistemas que requieren de un manejo especial al momento de darle uso, conservando siempre las características ecosistémicas, con el fin de preservar y proteger especies de Fauna y Flora en vía de extinción de áreas de páramo y bosque alto andino y de proporcionar oportunidades para la investigación, educación y recreación compatibles con la preservación de los recursos y sin causar deterioro y de proteger el complejo hídrico de cuencas superiores de los ríos de importancia especial para la región.
} 


\subsubsection{Los Corredores Biológicos.}

El concepto de corredor biológico o ecológico implica una conectividad entre zonas protegidas y áreas con una biodiversidad importante, con el fin de contrarrestar la fragmentación de los hábitats, (Evaluación de los Ecosistemas del Milenio, noviembre 2005). En la actualidad son propuestos como una herramienta novedosa para promover la conservación de la naturaleza. A continuación se presentan los ecosistemas estratégicos más relevantes identificados en cada subcuenca.

\subsection{LA SITUACIÓN AMBIENTAL DE LA CUENCA}

La experiencia ha demostrado la importancia de una herramienta operativa para reducir la incertidumbre, la frecuencia de las fallas imprevistas en la infraestructura y administración de Cuencas, que son causa de emergencias que pueden ser muy graves, puede ser disminuida en forma importante asegurando niveles adecuados del gasto en operación y mantenimiento. Varios factores han determinado que esos niveles sean marcadamente insuficientes en la mayoría de las jurisdicciones de las Corporaciones Autónomas Regionales llamadas (CAR), relacionados tanto con reformas en la organización del sector que fueron inadecuadas o mal implementadas, como con actitudes y expectativas que prevalecen y que es posible y necesario modificar. Cuando el gasto en mantenimiento es insuficiente, su aumento es una acción de prevención de altísima prioridad.

La cuenca como instrumento de planificación y de gestión territorial, se fundamenta en los desafíos de asegurar el agua para la producción de alimentos que no afecte la calidad y la cantidad del agua y protegiendo los ecosistemas vitales incluidos dentro de la región, forjando la voluntad política del desarrollo de acciones incluidas en los Planes de Ordenamiento y Manejo de Cuencas (POMCAS) y garantizando la colaboración de sectores gremiales, privados o públicos, que estimulen la conservación, la protección y la mitigación del recurso, teniendo en cuenta las actividades humanas porque la cantidad y la calidad del agua disponible son generalmente lo que limita la posibilidad del desarrollo futuro y condiciona la sustentabilidad del desarrollo actual.

A partir de los resultados obtenidos en la revisión, análisis e información secundaria relacionada con la Conservación, protección y preservación del recurso hídrico de la cuenca Alta Media del Río Bogotá y las Subcuencas del Río Frio y Río Negro. Se adquirieron las siguientes problemáticas generales que son condiciones importantes para tener en cuenta para la conceptualización en la formulación de los instrumentos de planeación y de gestión para el fortalecimiento del desarrollo y futura consolidación de lo regional a partir del análisis del recurso hídrico (La calidad del agua del río Bogotá (Fuente Memorias II foro del Agua III navegación por el Río Bogotá, septiembre 2001).

> Vertimiento de aguas residuales domesticas e industriales en los municipios área de estudio, en especial por la ciudad de Bogotá.

$>$ Descargas residuales de los habitantes que se encuentran en asentamientos cercanos en las zonas de ronda de los municipios área de estudio.

$>$ Uso de agua contaminada para riego en los municipios área de estudio, las cuales puede generar enfermedades al ser consumidas. 
> Manejo de la agricultura intensiva con prácticas inadecuadas, como aplicación de agroquímicos, alta densidad de siembra, riego inadecuado. En zonas destinadas por los municipios para el desarrollo ambiental.

> Falta de educación y cultura para el uso eficiente del agua, su conservación y preservación en la ciudad de Bogotá D.C. y los municipios de estudio.

$>$ Falta de control, protección y monitoreo de los cuerpos de agua tanto urbanos como rurales en la ciudad de Bogotá y los municipios pertenecientes al área de estudio.

$>$ Desinformación y la no aceptación de las problemáticas en factores de riesgo ambiental, que han traído consecuencias para la calidad de vida de la población área de estudio por parte de las entidades de control y administrativas de la Región.

Estas problemáticas generales han sido observadas por las diferentes entidades y organismos de control de los municipios del área de estudio. Algunas acciones han sido formuladas y ubicadas dentro del POMCA del rio Bogotá y en un programa estratégico de Conservación y Protección de Cuerpos de Agua: Estas acciones son:

> Planes de regulación de corrientes.

$>$ Dragado y limpieza de cauces.

$>$ Plan de manejo de aguas subterráneas.

$>$ Reglamentación de cuencas.

$>$ Protección con rondas en la red primaria y proyectos legales de reversión a la propiedad pública.

$>$ Estudio de niveles de inundación para diferentes periodos de retorno en los cauces principales.

$>$ Programa de uso eficiente del agua.

$>$ Control permanente de la demanda hídrica.

$>$ Saneamiento Ambiental y manejo hídrico de humedales.

$>$ Ampliación de la red hidrometereológica y de control ambiental.

$>$ Monitoreo del recurso hídrico.

\subsection{LAS CUENCAS HIDROGRÁFICAS}

A continuación se presenta una descripción de las cuencas presentes en el área de estudio conforme a la Guía técnico científica para la ordenación y manejo del cuencas hidrográficas en Colombia (IDEAM, 2004) en la cual se identifican las zonas hidrográficas, cuencas y Subcuencas. La identificación de las cuencas hidrográficas facilita la comprensión del recurso hídrico en el área de estudio ya que la cuenca constituye un "área física productora de agua o área de aguas superficiales y subterráneas que vierten a una red hidrográfica natural" (IDEAM, 2004). Además, las cuencas hidrográficas son espacios geográficos homogéneos donde se reconoce una interrelación de aspectos físicos, bióticos, socioeconómicos y culturales. ${ }^{72}$

\footnotetext{
${ }^{72}$ Las cuencas constituyen un área donde inter-dependen e interactúan, en un proceso permanente y dinámico, el agua con los sistemas físico (recursos naturales) y bióticos (flora y fauna). - Una característica fundamental de las cuencas, es que en sus territorios se produce la interrelación e interdependencia entre los sistemas físicos y bióticos, y el sistema socio económico, formado por los usuarios de las cuencas, sean habitantes o interventores de la misma. La dependencia de un
} 


\subsubsection{La cuenca del Río Bogotá.}

La cuenca del Río Bogotá está localizada en el Departamento de Cundinamarca; constituye en una corriente de segundo orden del Departamento. ${ }^{73}$. Dentro del área de estudio tiene la mayor extensión con $586.781,51$ ha, que representan el $48,9 \%$. Con el Acuerdo 58 de 1987, la CAR, ha distinguido tres zonas que generan tres cuencas a lo largo de la trayectoria del Río Bogotá: Cuenca Alta, Cuenca Madia, y Cuenca Baja. Como se muestran a continuación (Véase Figuras 4.10, 4.11, 4.12 y 4.13).

Figura 4. 10. LA CUENCA DEL RÍO BOGOTÁ

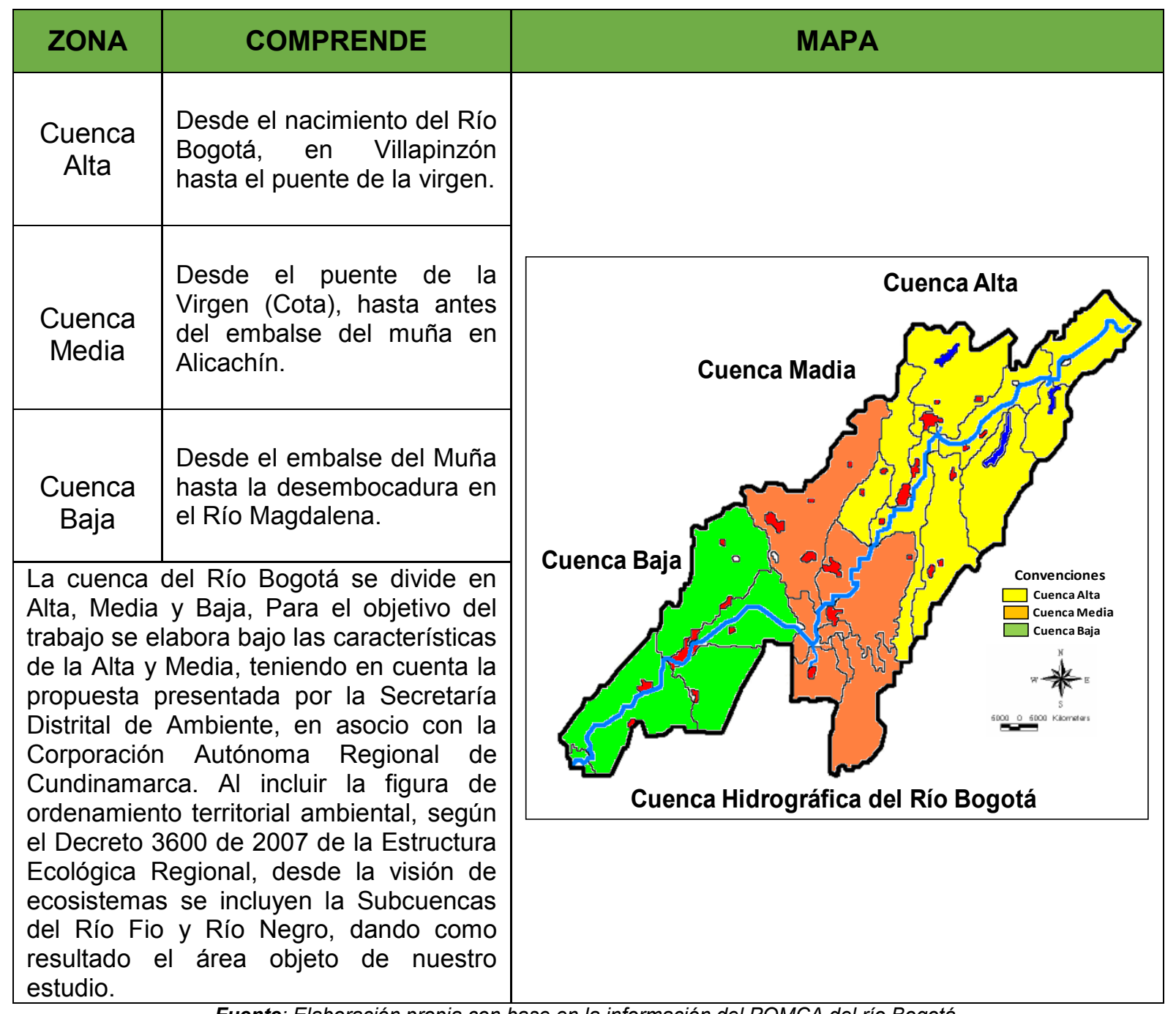

Fuente: Elaboración propia con base en la información del POMCA del río Bogotá.

sistema hídrico compartido y de los caminos y vías de acceso, y el hecho de que deban enfrentar riesgos similares, confieren a los habitantes de una cuenca características socioeconómicas y culturales comunes. Crisis de gobernabilidad en la gestión del agua .Dourejeanni CEPAL. 2001.

${ }^{73}$ La cuenca del rio Bogotá tiene una superficie total de 428.278,9 hectáreas que corresponden a cerca del $32 \%$ del total de la superficie de Cundinamarca, en donde se enmarca y se extiende la Sabana de Bogotá.(CAR, 2006). 
En esta cuenca habita el $20 \%$ de la población del país, incluyendo el Distrito Capital, y genera el $28 \%$ de la actividad económica nacional, está conformada por 45 municipios y el Distrito Capital. (CAR, 2010). Para esta cuenca se han identificado tres sectores mediante Acuerdo $\mathrm{N}^{\circ} 43$ de la Corporación Autónoma Regional de Cundinamarca (CAR) (CAR, 2010) a saber:

> Subcuenca Alta, con una longitud de $145 \mathrm{~km}$, desde su nacimiento en Villapinzón hasta el lugar conocido como Puente La Virgen.

$>$ Subcuenca Media, con una longitud de $68 \mathrm{~km}$, se prolonga desde el sitio Puente La Virgen, en cota hasta antes del embalse del Muña en Alicachín, en el extremo sur de la Sabana de Bogotá.

$>$ Subcuenca Baja, con una longitud de $133 \mathrm{~km}$, desde el embalse del Muña hasta la desembocadura en el Río Magdalena en el municipio de Girardot.

En al área de la cuenca del Río Bogotá, la mayor extensión la tiene la Subcuenca media siendo el $37 \%$ del total, la cuenca alta el $34 \%$ y la Subcuenca baja constituye el sector con menor extensión siendo el 29\%.El sistema hídrico de la cuenca del Rio Bogotá, está compuesto por elementos naturales asociado a los cauces naturales del rio, sus afluentes, lagunas y humedales. También se encuentran elementos artificiales conformados por nueve embalses, el distrito de riego de la Ramada y las formaciones de acuíferos que contienen las aguas subterráneas.

\subsubsection{La subcuenca alta del Rio Bogotá.}

La Subcuenca Alta comprende 15 municipios: Cajicá, Chía, Chocontá, Cogua, Gachancipá, Guatavita, La Calera, Nemocón, Sesquilé, Sopo, Suesca, Tabio, Tocancipá, Villapinzón, Zipaquirá.

En la Subcuenca alta se encuentra el área de nacimiento del Río Bogotá, la cual fue declarada como reserva forestal protectora mediante el Acuerdo 010 de 1982. El área total de la reserva forestal protectora tiene una extensión de 1.128 ha.

Es una zona de importancia para el manejo hídrico regional ya que La Cuchilla del Choque constituye una estrella fluvial donde nacen diez corrientes de agua, de la cuales cuatro conforman la cuenca del Río Bogotá.

En el período húmedo (meses de abril a junio y octubre a diciembre), se presenta una adecuada disponibilidad del recurso por la demanda de usos agropecuarios, industriales, doméstico y de caudal ecológico. La demanda es de $1,74 \mathrm{~m} 3 / \mathrm{s}$, siendo la oferta de 3,74 $\mathrm{m} 3 / \mathrm{s}$ en el período húmedo. Sin embargo, en el período seco (enero a marzo y julio a septiembre) se presenta un déficit ya que la oferta es de $0,94 \mathrm{~m} 3 / \mathrm{s}$, con un saldo negativo de $0,8 \mathrm{m3} / \mathrm{s}$ (fuente Planeación Ecológica Ltda. Ecoflores 2006).

En esta Subcuenca la cobertura natural ha sido transformada constituyendo el $42 \%$ y la cobertura antrópica el $58 \%$. Dentro de la cobertura natural la mayor participación la tiene la vegetación especial de zonas secas de xerofitas y subxerófitas (6.3\%), la vegetación boscosa $(6 \%)$ y la vegetación de páramo constituye el $3.2 \%$. De lo anterior se puede identificar que la vegetación natural presenta una fuerte presión por la actividad antrópica asociada al establecimiento de coberturas de uso agropecuario (Consultoría USTA 2011). 
Conforme al análisis multitemporal del cambio de la cobertura realizado para el POMCA, del río Bogotá en 2006, esta subcuenca ha perdido para un período de 18 años (1985 a 2003), más de 3.000 hectáreas de páramo, vegetación que se ha quemado y tumbado para el establecimiento de cultivos y pastos para ganadería (Planeación Ecológica Ltda. Ecoforest Ltda. 2006).

Figura 4. 11. CUENCA DEL RÍO BOGOTÁ ALTA

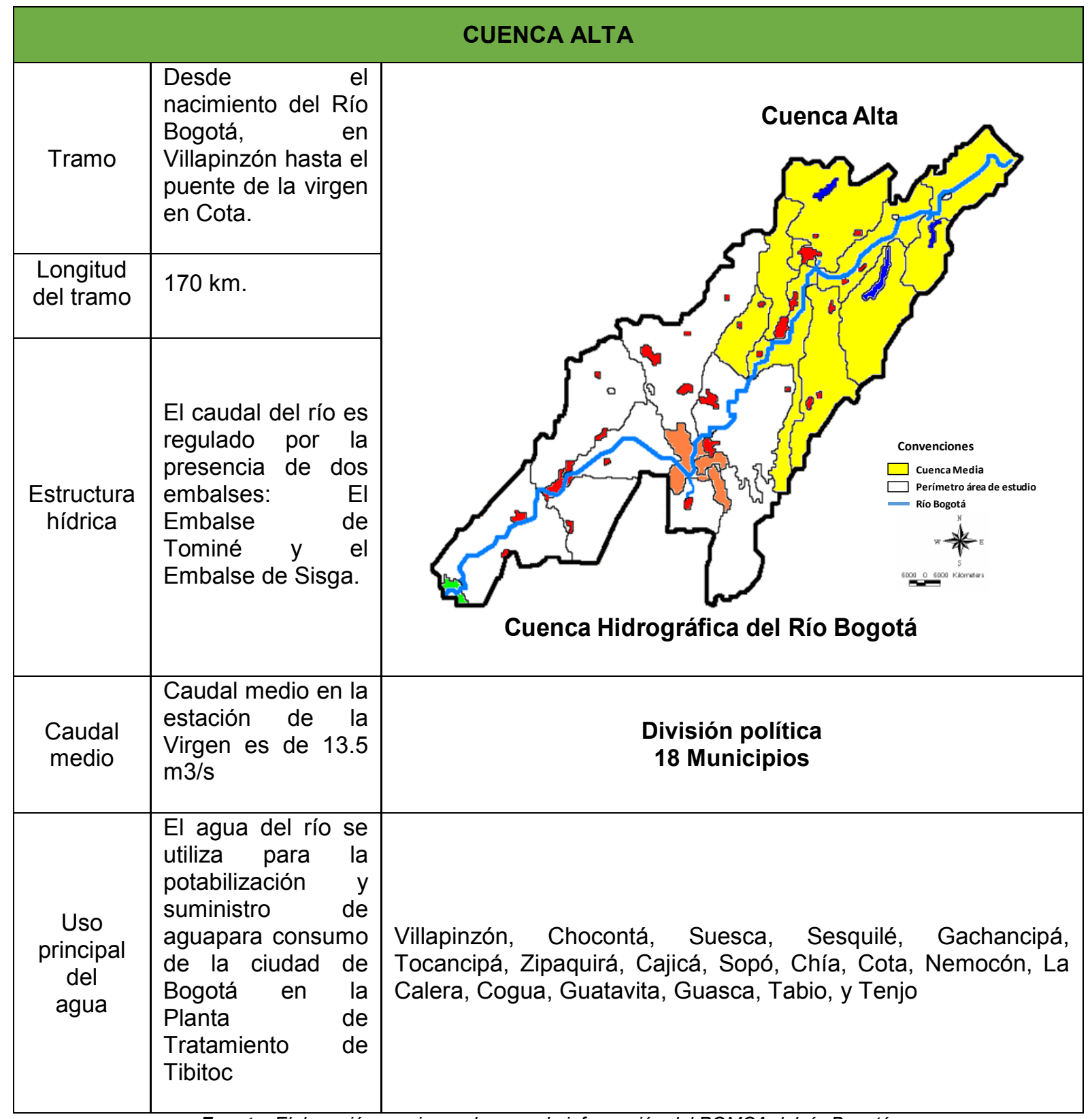

Fuente: Elaboración propia con base en la información del POMCA del río Bogotá. 


\subsubsection{La Subcuenca Media del Rio Bogotá}

La subcuenca Media comprende 12 municipios Bojacá, Cota, El Rosal, Faca, Funza, Mosquera, La Calera, Sibaté, Soacha, Subachoque, Tenjo y la ciudad de Bogotá Distrito Capital con sus zonas urbanas. El cauce principal del Río Bogotá, en esta subcuenca tiene una longitud de $113 \mathrm{Km}$ (CAR, 2006). En este sector, el Río Bogotá recibe el aporte de numerosas corrientes y canales que tienen relación directa con los humedales del Distrito Capital tales como el Canal Torca, la Quebrada La Salitrosa, Río Juan Amarillo, Río Fucha, Río Tunjuelo, Teusacá, así como las aguas drenadas de los Cerros Orientales. $^{74}$

En esta cuenca la cobertura natural ha sido transformada constituyendo el $45 \%$ y la cobertura antrópica el $55 \%$. Dentro de la cobertura natural la mayor participación la tiene la vegetación de páramo $(3,9 \%)$, y la vegetación especial de zonas secas de xerofitas y subxerófitas $(2,9 \%)$, la vegetación boscosa $(4,6 \%)$.De lo anterior se puede identificar que la vegetación natural presenta una fuerte presión por la actividad antrópica asociada al establecimiento de coberturas de uso agropecuario, tal como sucede en la Subcuenca alta. (Consultoría USTA 2011).

Conforme al análisis multitemporal del cambio de las cobertura realizados para el POMCA del Río Bogotá, esta subcuenca ha perdido, para un período de 18 años (1985 a 2003), un total de $17 \%$ de áreas de páramo, las cuales han sido destinadas a actividades agropecuarias, acciones que van en detrimento de la calidad y cantidad de agua aprovechable para la cuenca y su población.

En términos generales la problemática de las Subcuenca del Rio Bogotá señalada en el POMCA realizado en 2006, y la Auditoria especial a la gestión sobre el Río Bogotá realizada por la Contraloría General de la Republica y la Contraloría Distrital de Bogotá en 2009, está asociada a:

Vertimientos de aguas domesticas e industriales sin tratar.

$>$ Descargas de los habitantes de asentamientos en zonas de ronda.

$>$ Prácticas inadecuadas de agricultura (riego con aguas contaminadas), que evidencian una agricultura agresiva contra el medio ambiente.

$>$ Deforestación de nacederos y márgenes hídricas.

$>$ Falta de educación y cultura para el uso eficiente del agua.

$>$ Deficiente gestión de las autoridades ambientales a cargo del manejo de la cuenca.

El POMCA del Río Bogotá (Resolución No 3194 de 23 de noviembre de 2006), identifica y describe la problemática ambiental de la cuenca (Véase tabla 4.7.), así mismo, el POMCA del río Bogotá, realizó un ejercicio de prospectiva a través de talleres de participación comunitaria con una visión de futuro a 13 años (2019), el cual refleja el deterioro ambiental al que está sometida la cuenca ${ }^{75}$

\footnotetext{
${ }^{74} \mathrm{EI}$ Distrito Capital hace parte de la cuenca media del rio Bogotá, donde el sistema hídrico es considerado como el conjunto de cuerpos de agua natural y/o artificial superficial y subterráneo, además los cuerpos de agua superficial cuentan con zona de ronda hidráulica y la Zona de Manejo y Preservación Ambiental (ZMPA).SDA, 2008

${ }^{75} \mathrm{El}$ diagnóstico muestra un paulatino deterioro ambiental debido a la presión sobre las zonas que aún conservan su vegetación natural, en especial bosques montanos altos y páramos por expansión de la frontera agrícola; lo cual se
} 
Figura 4. 12. SUBCUENCA MEDIA DEL RÍO BOGOTÁ

\begin{tabular}{|c|c|c|}
\hline \multicolumn{3}{|c|}{ CUENCA MEDIA } \\
\hline Tramo & $\begin{array}{l}\text { Desde el puente de la Virgen } \\
\text { (Cota), hasta antes } \\
\text { embalse del } \\
\text { Alicachín }\end{array}$ & \\
\hline $\begin{array}{l}\text { Longitud } \\
\text { del tramo }\end{array}$ & $90 \mathrm{~km}$. & S \\
\hline $\begin{array}{l}\text { Estructura } \\
\text { hídrica }\end{array}$ & $\begin{array}{l}\text { Recibe las aguas residuales } \\
\text { del sistema de drenaje urbano } \\
\text { de Bogotá y sus áreas } \\
\text { periféricas. Las aguas de } \\
\text { drenaje urbano de Bogotá } \\
\text { reciben el nombre de las } \\
\text { principales corrientes naturales } \\
\text { que cruzan la ciudad: río Juan } \\
\text { amarillo o Salitre, río Fucha, y } \\
\text { río Tunjuelo. }\end{array}$ & Cuenca Hidrográfica del Río Bogotá \\
\hline $\begin{array}{l}\text { Caudal } \\
\text { medio }\end{array}$ & $\begin{array}{l}\text { El aporte medio de aguas, } \\
\text { principalmente de aguas } \\
\text { residuales domésticas, en esta } \\
\text { cuenca es el más importante } \\
\text { con caudales medios de } 37 \\
\mathrm{~m} 3 / \mathrm{s}\end{array}$ & $\begin{array}{l}\text { División Político } \\
\text { Bogotá y } 8 \text { Municipios }\end{array}$ \\
\hline $\begin{array}{l}\text { Uso } \\
\text { principal } \\
\text { del } \\
\text { Agua }\end{array}$ & $\begin{array}{l}\text { Existe una demanda } \\
\text { significativa de agua para riego } \\
\text { a través del Distrito de Riego } \\
\text { de la Ramada. }\end{array}$ & $\begin{array}{l}\text { Bogotá, Funza, Mosquera, Soacha, Sibaté, } \\
\text { Subachoque, El Rosal, Madrid, Bojacá, y } \\
\text { Facatativá. }\end{array}$ \\
\hline
\end{tabular}

Fuente: Elaboración propia con base en la información del POMCA del río Bogotá.

manifiesta, en un incremento de las amenazas, contaminación, incendios y pérdida de biodiversidad manifiesto principalmente en la disminución de la oferta hídrica.

El deterioro ambiental, la carencia de organización social, la falta de sistemas productivos eficientes, llevarán a una disminución en la productividad agropecuaria y mayor dependencia de mercados externos, presión sobre las áreas no intervenidas actualmente y demanda sobre las Instituciones para la generación de alternativas y fuentes de empleo.

Las instituciones tendrán una baja ejecución de los planes y proyectos y, por tanto, la credibilidad y confianza de la comunidad en sus representantes será baja. 


\section{Tabla 4.7. SÍNTESIS DE LAS PRINCIPALES PROBLEMÁTICAS IDENTIFICADAS EN EL DIAGNÓSTICO POMCA DEL RÍO BOGOTÁ}

\begin{tabular}{|c|c|}
\hline Elemento & Problemática \\
\hline \multirow[b]{2}{*}{ Páramos } & Incremento frontera agropecuaria en detrimento de área de páramos \\
\hline & $\begin{array}{l}\text { Perdida de área de páramos calculada en } 9.000 \text { ha para el período } 1993-2005 \text {. Es } \\
\text { decir una tasa anual de } 500 \text { ha. }\end{array}$ \\
\hline \multirow{5}{*}{ Humedales } & $\begin{array}{l}\text { Sedimentación y relleno de humedales del altiplano, generando riesgo de } \\
\text { inundación por desborde y encharcamiento. }\end{array}$ \\
\hline & $\begin{array}{l}\text { Falta de manejo ambiental de curtiembres, con vertimientos tóxicos que afectan la } \\
\text { calidad del agua con altos contenidos de sulfuro de sodio y de cromo. }\end{array}$ \\
\hline & $\begin{array}{l}\text { Deterioro de la Laguna de la Herrera, por incremento de macrófitas en un } 95 \% \text {, } \\
\text { incremento del aporte de sedimentos por presencia de canteras, potrerización para } \\
\text { construcción y cultivo. }\end{array}$ \\
\hline & $\begin{array}{l}\text { Deterioro de la Laguna el Juncal por vertimiento de aguas negras provenientes de } \\
\text { la planta de tratamiento de Madrid y perdida del cuerpo de agua por expansión de } \\
\text { predios en la ronda. }\end{array}$ \\
\hline & $\begin{array}{l}\text { Deterioro de la Laguna el Salitre por monocultivo de papa y presencia de bosques } \\
\text { de Eucalipto en la ronda. }\end{array}$ \\
\hline \multirow{5}{*}{$\begin{array}{l}\text { Cuerpos de } \\
\text { Agua }\end{array}$} & Agotamiento de fuentes hídricas por uso agropecuario. \\
\hline & $\begin{array}{l}\text { Concentración de sedimentos, productos químicos, materia orgánica y malos } \\
\text { olores en el cauca del Río Bogotá por actividades agropecuarias e industriales. }\end{array}$ \\
\hline & $\begin{array}{l}\text { Afectación distrito de riego La Ramada por perdida del espejo de agua con el } \\
\text { incremento de macrófitas, contaminación por basuras y aguas residuales del río } \\
\text { Bogotá, relleno del humedal con escombros y expansión urbana. }\end{array}$ \\
\hline & $\begin{array}{l}\text { Sector Tibitoc.-Soacha como la zona de mayor impacto por vertimiento de sólidos, } \\
\text { líquidos y gaseosos. Cauce principal altamente contaminado. }\end{array}$ \\
\hline & $\begin{array}{l}\text { Deterioro del Embalse del Muña por vertimiento de aguas del río Bogotá, } \\
\text { proliferación de zancudos y jején, infecciones y malos olores. }\end{array}$ \\
\hline
\end{tabular}

Fuente: POMCA del Río Bogotá.2006.

\subsubsection{La Subcuenca Rio Sumapáz}

La subcuenca cuenta con una extensión de 173.556 ha que representan el $19,8 \%$ del área de estudio. Comprende los municipios de Arbeláez, Cabrera, Fusagasugá, Pasca, San Bernardo y Bogotá D.C.

El Rio Sumapáz, nace en el páramo del mismo nombre, a tres mil ochocientos treinta metros de altura, en el Alto de las Cazuelas a $3.830 \mathrm{msnm}$ y sus aguas fluyen al occidente para desembocar en el río Magdalena, en Girardot, a $280 \mathrm{mts}$, sobre el nivel del mar después de un recorrido de 57 kilómetros, formando límite entre los departamentos del Tolima y Cundinamarca. 
La cobertura natural ha sido transformada y en la actualidad la cobertura antrópica tiene una participación del $43 \%$. Las coberturas naturales constituyen el mayor porcentaje siendo el $57 \%$. De las coberturas naturales los páramos tienen la mayor representación (la tercera parte) y la vegetación boscosa el 18,9\%. (Consultoría USTA 2011).

Al occidente de la Subcuenca del Río Sumapáz, se encuentra el Parque Nacional Natural Sumapáz, administrado por la Unidad de Parques del Ministerio del Medio Ambiente. La Corporación Autónoma Regional de Cundinamarca (CAR), tiene proyectado la delimitación y declaratoria del Distrito de Manejo Integrado de la Región del Sumapáz, como complemento a la protección del Parque Nacional y aquellas áreas de interés estratégico para los municipios de la cuenca.

\subsubsection{La Subcuenca Rio Negro}

En el área de estudio, la Subcuenca del Rio Negro, tiene una extensión de 74.967 ha, y hace parte de los municipios de Choachí, Chipaque, La Calera, Une y Ubaque. Constituye el $8,6 \%$ del área de estudio. Es una cuenca muy intervenida donde el $69 \%$ de la cobertura está constituida por elementos antrópica y solo el $31 \%$ corresponde a coberturas naturales. La cobertura de páramo corresponde al $19,93 \%$ y la vegetación boscosa corresponde al $13,94 \%$.

Un pequeño sector de la parte norte de la cuenca hace parte del Parque Nacional Natural Chingaza. La mayor parte presenta una cobertura de Páramo el cual desempeña un importante papel en la producción y regulación del recurso hídrico. El Parque fue creado en el año 1977, con el propósito de conservar las áreas de páramo, selva húmeda andina y subandina en estado natural principalmente (UAESPNN, 2008).

La cercanía del Parque Nacional a la ciudad de Bogotá y su importancia para el recurso hídrico ha permitido que la población se beneficie del agua potable proveniente del Parque y en la actualidad hace parte del sistema de abastecimiento de la ciudad ${ }^{76}$.

En el Parque se encuentran numerosas turberas y lagunas cuyo origen glaciar las ubica dentro de los límites de mayor altitud del Parque, arriba de los $3.250 \mathrm{msnm}$ y la mayoría están ubicadas por encima de los $3.500 \mathrm{msnm}$. El tamaño de las lagunas es pequeño comparado con las de otras áreas similares, pues de los 66 cuerpos de agua identificados dentro del Parque, únicamente 26 sobrepasan una hectárea de superficie (UAESPNN, 2008).

En términos generales existe un incremento en la demanda de agua en las principales cuencas de la región de jurisdicción de la CAR, siendo las de mayor incremento proyectado para el año 2.020 Sumapáz, Río Suarez, Ubaté y Río Bogotá.

\footnotetext{
${ }^{76}$ A partir de la Ley 99 de 1993, se estableció una Tasa por Uso de Agua que deben pagar los usuarios a la autoridad ambiental competente por concepto del uso de agua, para la conservación y manejo de la cuenca respectiva. A través de las normas reglamentarias del artículo que establece las Tasas por Uso de Agua, se estableció una tarifa mínima y la fórmula para calcular su valor. Desde ese entonces la Unidad de Parques Nacionales de Colombia ha venido cobrando las Tasas a la Empresa de Acueducto por concepto del uso del agua en Chingaza
} 
La demanda estimada por la CAR en el año 2020 para el área jurisdiccional, se calculó con base al consumo destinado al abastecimiento humano, agropecuario y actividades industriales, entre las cuales se incluye la generación hidroeléctrica. (Véase Tabla No 4.8.)

Tabla 4. 8. OFERTA Y DEMANDA DE AGUAS SUPERFICIALES EN LAS
SUBCUENCAS ALTA Y MEDIA DEL RÍO BOGOTÁ

\begin{tabular}{|c|c|c|c|c|c|c|c|c|}
\hline \multirow[b]{2}{*}{ SUBCUENCA } & \multicolumn{2}{|c|}{ OFERTA (M3/S) } & \multicolumn{4}{|c|}{ DEMANDA (M3/S) } & \multicolumn{2}{|c|}{ ÍNDICE DE ESCASEZ } \\
\hline & 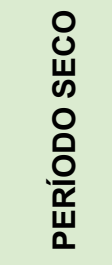 & 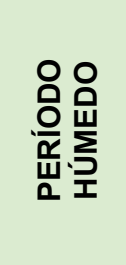 & 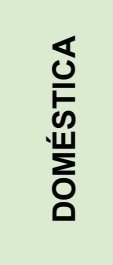 & 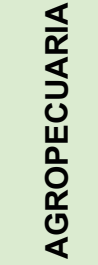 & 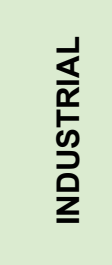 & 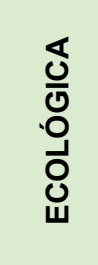 & 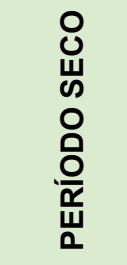 & 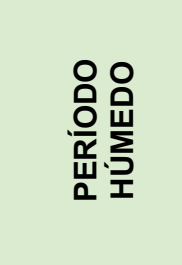 \\
\hline Río Alto Bogotá & 0,94 & 3,74 & 0,034 & 1,66 & 0,002 & 0,04 & Alto & Medio Alto \\
\hline Embalse Sisga & 1,06 & 4,6 & 0,006 & 0,77 & & 0,03 & Alto & Medio \\
\hline Embalse Tominé & 3,51 & 10,05 & 0,021 & 1,76 & & 0,04 & Alto & Medio \\
\hline $\begin{array}{c}\text { Sector Sisga- } \\
\text { Tibitoc }\end{array}$ & 7,73 & 10,29 & 0,035 & 1,81 & 0,015 & 0,11 & Medio & Alto Medio \\
\hline Río Neusa & 3,02 & 4,86 & 0,161 & 2,33 & 0,2 & 0,31 & Alto & Alto \\
\hline Río Negro & 0,25 & 0,47 & 0,003 & 0,12 & 0,1 & Alto & Medio & Alto \\
\hline Río Teusacá & 2,73 & 5,38 & 0,05 & 1,95 & 0,002 & 0,15 & Alto & Medio Alto \\
\hline Río Frío & 1,47 & 2,82 & 0,049 & 8,93 & 0,007 & 0,17 & Alto & Medio Alto \\
\hline Río Chicú & 0,61 & 1,12 & 0,006 & 0,9 & 0,001 & 0,04 & Alto & Alto \\
\hline $\begin{array}{l}\text { Sector Tibitoc - } \\
\text { Soacha }\end{array}$ & 15,21 & 20,67 & 5,244 & 2,26 & 0,006 & 2,27 & Alto & Medio Alto \\
\hline Río Balsillas & 3,34 & 7,14 & 0,062 & 3,3 & 0,024 & 0,15 & Alto & Medio Alto \\
\hline Río Soacha & 0,18 & 0,32 & 0,007 & 0,07 & 0,01 & Alto & Medio & Alto \\
\hline Embalse Muña & 0,58 & 1,06 & 0,044 & 0,63 & 0,002 & 0,04 & Alto & Alto \\
\hline
\end{tabular}

\subsection{EL TRANSVASE DE CUENCAS}

En temas de transvase de cuencas se encuentran condiciones importantes como el aumento de población en los municipios periférico a la ciudad de Bogotá, denominada la Sabana de Bogotá, ha generado un crecimiento en la demanda del recurso hídrico; para satisfacerla se construyeron sistemas de regulación de caudales y trasvase de agua de la Cuenca del Río Guatiquia, hoya hidrográfica del Río Orinoco, mediante el proyecto Chingaza. (Fuente: Estudio desarrollado por la Universidad Santo Tomas (USTA) para la Secretaria Distrital de Ambiente (SDA) contrato 1441 de 2010).

El sistema de abastecimiento de agua potable de Bogotá, deriva aguas de las cuencas del Guatiquia y Río Blanco, ambas de la vertiente del Orinoco. El sistema que se conoce como Chuza toma aportes de los ríos La Playa y Frío, de la Quebrada Leticia y del río Chuza. Mientras que el sistema Río Blanco lo constituyen las captaciones de las quebradas Cortadera, Palacios, Piedras Gordas y Horqueta, Peñas Blancas, Chocolatal, 
Carrascales, Calostros, Mangón, Blancas, Siberia, Colorada y otras 12 quebradas menores (SDA,2008).

El sistema de captación está conformado por la desviación del río Guatiquia al embalse de Chuza, mediante un túnel de $3,2 \mathrm{~km}$, y de la quebrada Leticia, mediante un túnel de 0,3 km; así como del sistema de captaciones de Río Blanco constituido por cuatro pozos que llevan el agua a la conducción Palacio-Río Blanco. La Empresa de Acueducto y Alcantarillado de Bogotá (EAAB), tenía previstos o bien el Proyecto Sumapáz para la provisión de agua con la desviación de algunas corrientes del Río Blanco a la cuenca del río Tunjuelo y la construcción del embalse Chisacá II, o la desviación de los caudales de los Ríos Blanco y Ariari a la cuenca del Muña y la construcción del Embalse Alto Muña.

A la fecha no se tienen en claro las repercusiones o impactos ambientales generado por el proceso de captación de aguas de otras cuencas, particularmente a las que hacen parte de la Zona Hidrográfica del Orinoco. ${ }^{77}$

\subsection{EL NIVEL DE VULNERABILIDAD Y DE AMENAZA DEL RECURSO HÍDRICO; CON BASE EN EL REFERENTE DE LA OLA INVERNAL.}

El referente de la ola invernal trajo consigo la identificación de las condiciones de vulnerabilidad para los habitantes que se encuentran en cercanía del Río Bogotá por los factores de inundación, como también a sectores localizados en periferias con mitigaciones con obras de infraestructura como jarillones que no han podido proteger sus propias inversiones. Para ello, los distintos gobiernos han invertido grandes recursos adoptados desde los planes de desarrollo municipales, cuyos recursos deben ser focalizados para la mitigación del riesgo.

Es recurrente que grandes inversiones para la mitigación, prevención y gestión del riesgo serán invertidos periódicamente a través de planes de desarrollo, teniendo en cuenta el concepto del colombiano representante de la Organización Meteorológica Mundial Oscar, cuando dice: la atmósfera del planeta es una sola y la energía debe distribuirse en el espacio. "Cuando hay un exceso en un lugar - hay un déficit en otro lado". La dificultad es que este patrón climático se está transformando por cuenta del cambio climático. Según Oscar Arango, poco a poco se ampliaran los límites climáticos que experimentamos Entonces las lluvias serán cada vez más fuertes y las sequias cada vez más drásticas.

Lo cual se pudo comprobar en el periodo 2010-2011, por la ola invernal causada por el fenómeno natural de la NIÑA, lo cual pone en evidencia la puesta en marcha de acciones y estrategias a través de acciones directas del Estado, ya que en ellas se reúnen cuatro grandes desafíos: el de la naturaleza, que pese a los avances de la ciencia, nunca permite predecir a plenitud las dimensiones de las lluvias; el de la falta de estrategias de adaptación y mitigación del cambio climático, el de la pobreza y la consecuente urbanización desordenada e improvisada, y el acostumbrado de edificar en zonas destruidas por inundaciones anteriores.

\footnotetext{
${ }^{77}$ Por las implicaciones que tiene para la ciudad en lo ambiental, lo económico y en lo social ese crecimiento de la población "El Plan Maestro de Acueducto y Alcantarillado de Bogotá, estima que en el 2020 Bogotá tendrá una población de 9.643.798" y la captación de aguas de sitios cada vez más lejanos en el marco de una política de expansión de la EAAB; captaciones que además no obedecen claramente a una demanda real del Distrito, sino a proyectos económicos de venta del suministro de agua a otras poblaciones.SDA,2008.
} 
Algunos conceptos importantes que se tienen en cuenta en el manejo de los problemas de inundaciones como de avalanchas, causa en el manejo de suelos se relacionan a continuación:

> INUNDACIÓN: en planicie, de mucho menor impacto como evento aislado pero de especial importancia debido a su recurrencia y a sus efectos acumulados en períodos de semanas o meses, tal como se describió en la sección relacionada con desastres menores y recurrentes.

AVALANCHAS Y FLUJOS, generados por la acción volcánica o fenómenos hidrometeorológicos extremos. Su afectación puede llegar a ser mucho más puntual que los anteriores, pero en algunos casos pueden llegar a ser devastadores, como el flujo de escombros generado por la erupción volcánica del Nevado del Ruiz en 1985.

Las lluvias en municipios de la Sabana de Bogotá y en algunas otras zonas de la región, o en el área de estudio, demuestran que las obras que debieron hacerse desde un horizonte colectivo, nunca se realizaron, sino en intervenciones individuales alterando las dinámicas hidráulicas en este caso específico del río (Río Bogotá), y por lo tanto, ocasionando las inundaciones producidas por las obras las cuales su visión era el de solucionar el problema individual.

Algunos de los problemas más representativos en la infraestructura vial en el departamento, son en laderas, consideradas como las zonas críticas, al menos en cinco tramos de Cundinamarca, por eventos de remoción en masa, causados por las intensas precipitaciones, las vías La vega - Villeta, Boquerón - Pandi y Pacho - la Palma, fueron obstruidas por derrumbes de las laderas a orillas de la infraestructura vial.

Las obras de mitigación del riesgo, que se pueden realizar en las vías son necesarias. Sin embargo, un asunto de fondo es, aún más importante: el uso del suelo que se está dando a este tipo de laderas en las que se debería promover la revegetación, (Véase Figura 4.13), cuyas características para su manejo se muestran algunos de los daños, generados por causa de los deslizamientos incidentes por la saturación de agua en el suelo.

Figura 4. 13. DESLIZAMIENTOS Y DAÑOS EN LA INFRAESTRUCTURA.

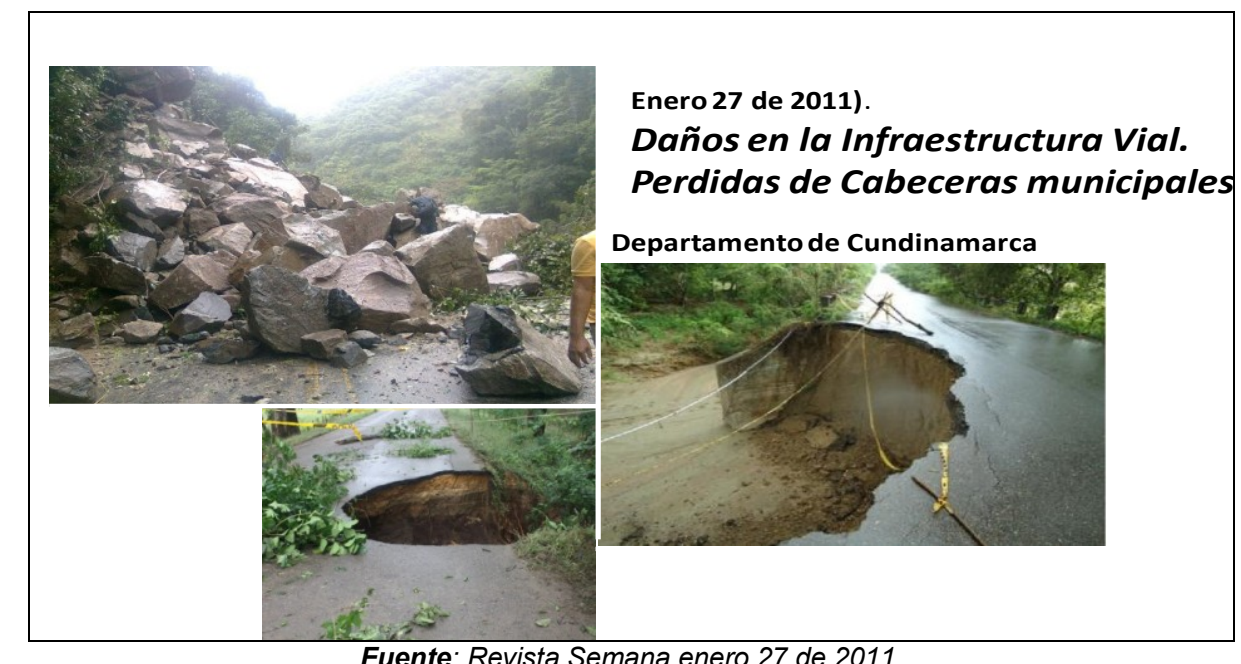


Más de 1500 hectáreas se han inundado en las provincia de Ubaté, según información de la gobernación de Cundinamarca, las inundaciones han producido, pese a la gran inversión por más de 1500 millones en labores de mitigación (2011, noviembre 22), luego de que la pasada ola invernal afectara más de 1900 hectáreas (2010). La preocupación en muchos de los municipios que han sufrido extensas inundaciones, por el retroceso en la recuperación de los suelos; esto sumado al perdida en viviendas, sino que además el trabajo o mano de obra disminuyen cada vez más.

Son muchas las opiniones que alrededor del problema de las inundaciones y la pérdida de miles de hectáreas para la agricultura como para la ganadería; que se dan por urbanistas y directores de departamentos especializados, como por ejemplo del Instituto de Estudios urbanos de la UNAL; aseguran la falta de una política integral del agua, debe incluir la localización de las poblaciones y las actividades humanas que se desarrollan en las antiguas áreas de inundación de los ríos.

Para evitar los estragos a largo plazo de los inviernos hay que desalojar las zonas que serán inundadas tarde o temprano como lo asegura la experta en medio ambiente la doctora Margarita Pacheco. Los Alcaldes deberán tener en cuenta los temas relacionados con la gestión del riesgo en los planes de Ordenamiento Territorial. Además, que el gobierno nacional, de la mano de las autoridades ambientales, despliegue una labor de capacitación a los funcionarios en planificación ambiental del territorio. Actualmente, el Gobierno diseña un Plan Nacional de Adaptación y la CAR de Cundinamarca resalta que en el marco del megaproyecto de recuperación del Río Bogotá se tiene prevista la compra de terrenos que servirá como espacio de inundación.

Para el análisis en la caracterización ambiental es relevante para la conceptualización la cobertura y usos del suelo que se han venido dando, teniendo en cuenta los estados de desarrollo y crecimiento en temas de inversión industrial, el crecimiento de la población en la ciudad de Bogotá, que demanda de sus municipios de periferia cualquier tipo de servicios referente al mantenimiento de las condiciones de vida.

A lo largo de la cuenca se observan un gran número de ecosistemas que han sido intervenidos por la gran demanda de ellos. Como se observó en el análisis del Biograma, treinta y seis municipios (36), prestan un nivel crítico en temas, relacionados a la conservación, protección y restauración de los valores ambientales ecosistémicos, en donde el Municipio de Chía con el de Soacha, por las altas tendencias a la urbanización y suburbanización están en condiciones de inestabilidad ambiental.

Las variables de las unidades de análisis en las que se genera mayor nivel de inestabilidad ambiental están directamente relacionada con: las zonas de conservación de bosques naturales, las zonas de recuperación ambiental, las zonas de desarrollo forestal, las zonas de desarrollo agropecuario con y sin restricciones, las amenazas naturales, las zonas de conservación de suelo y de restauración ecológica y, por supuesto, las áreas destinadas al crecimiento y al desarrollo urbano. Lo cual, se establecieron con la metodología del Biograma el análisis para identificar los desequilibrios territoriales. (Véase mapa 4.11 y Tabla 4.9.). 


\section{Mapa 4.11. LA LOCALIZACIÓN DE ECOSISTEMAS EN LA CUENCA HIDROGRÁFICA DE RÍO BOGOTÁ}

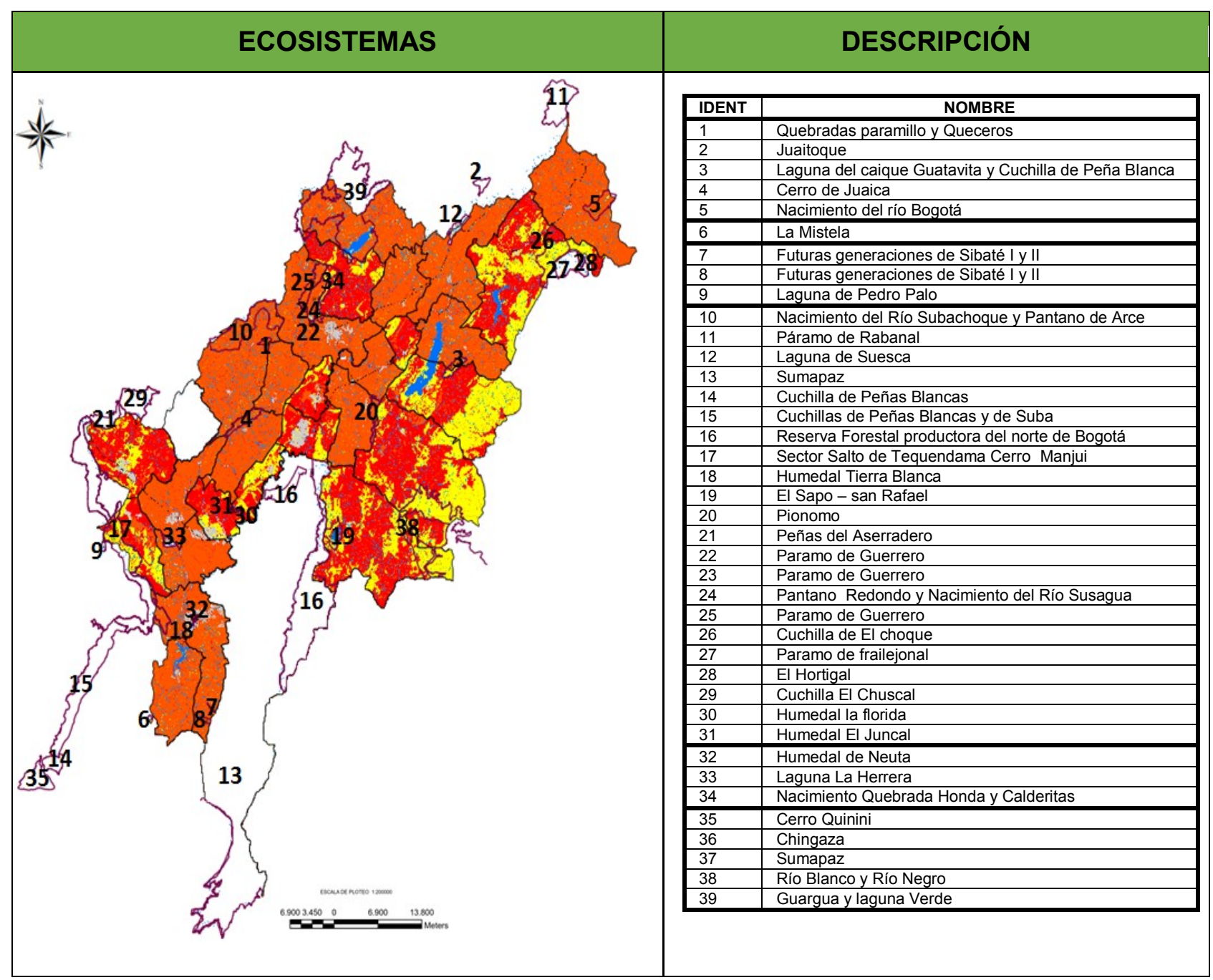

Fuente: Elaboración propia con base en la información POTS y Universidad Santo Tomas sede Bogotá. (USTA). 
Tabla 4. 9. COBERTURA Y USOS DEL SUELO

\begin{tabular}{|c|c|c|c|c|c|c|c|c|c|c|c|c|}
\hline 3 & Cabrera & 12425,08 & 1878,53 & & & & 23110,99 & & 5576,08 & & 157,48 & 11,17 \\
\hline 4 & Cajicá & & 345,23 & 828,77 & 116,30 & & 422,63 & 54,19 & 3206,16 & & & 260,73 \\
\hline 5 & Chipaque & & 288,86 & 83,58 & 3780,37 & & 1223,23 & 1748,66 & 4208,57 & & 54,61 & 24,05 \\
\hline 6 & Choachí & & 115,93 & 7207,99 & 21,11 & & & 11392,20 & 103,31 & & 1430,62 & 108,88 \\
\hline 7 & Chocontá & & 70,73 & 9588,33 & 204,67 & 5033,45 & & 5817,00 & 2020,92 & & 7010,20 & 145,69 \\
\hline 12 & Facatativá & 35,13 & 711,82 & & 2452,97 & & & 1961,45 & 7755,23 & & 357,13 & 639,33 \\
\hline 13 & Funza & & 1233,51 & & 176,48 & 8,30 & & 555,26 & 3503,84 & & & 872,13 \\
\hline 14 & Fusagasugá & & 584,10 & 3963,42 & 123,32 & & 2259,36 & 653,68 & 7326,95 & & & 1367,97 \\
\hline 15 & Gachancipá & & 670,30 & 11,40 & 1045,20 & & & 505,13 & 2314,25 & 6,88 & & 56,17 \\
\hline 16 & Guasca & 3104,69 & 1846,70 & 7211,90 & 97,82 & 319,67 & 3336,35 & 15894,45 & 98,80 & & 66,84 & 88,28 \\
\hline 17 & Guatavita & 252,96 & 4557,69 & 777,97 & 8957,20 & 24,82 & 102,76 & 3716,19 & 3874,46 & & 931,06 & 73,62 \\
\hline 18 & Gutiérrez & & 401,14 & 17417,60 & 105,56 & 6552,23 & & 2990,40 & 8624,54 & & 8037,21 & 16,39 \\
\hline 19 & La Calera & 312,66 & 1771,06 & 6757,75 & & & 1,64 & 5868,70 & 12711,70 & 113,39 & 4284,30 & 242,46 \\
\hline 20 & Madrid & & 583,34 & 446,62 & 843,19 & 30,68 & & 854,34 & 6304,87 & 6,91 & 12,94 & 542,60 \\
\hline 21 & Mosquera & & 390,70 & 4114,79 & 28,63 & 1937,48 & & 646,54 & 442,29 & & & 753,39 \\
\hline 22 & Nemocón & & 185,77 & 381,96 & 69,55 & 8,53 & 652,07 & 2067,79 & 5851,79 & & 213,06 & 391,78 \\
\hline
\end{tabular}




\begin{tabular}{|c|c|c|c|c|c|c|c|c|c|c|c|c|}
\hline í & 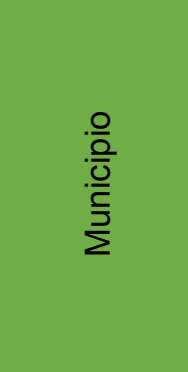 & 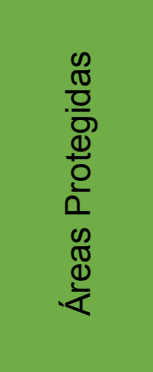 & 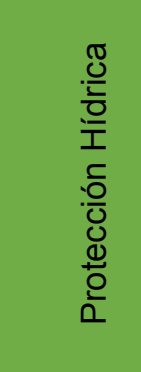 & 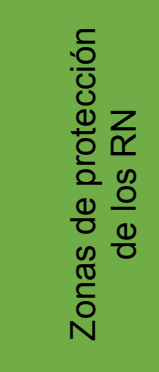 & 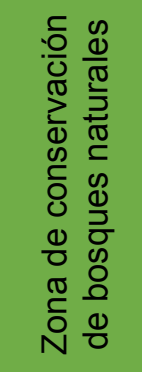 & 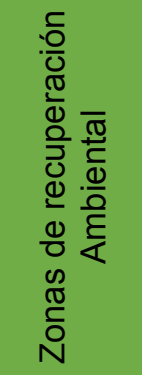 & 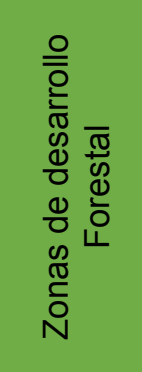 & 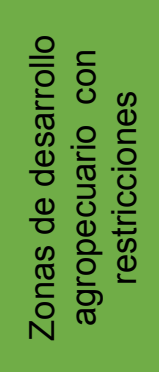 & 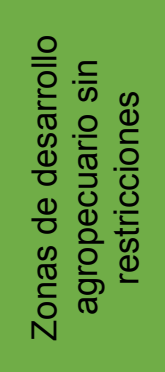 & 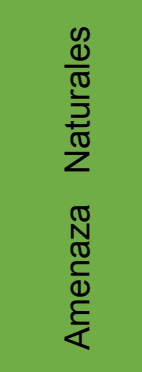 & 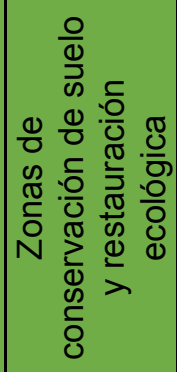 & 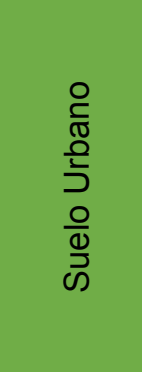 \\
\hline 23 & Pasca & 1419,24 & 1354,35 & 12889,36 & 0,06 & & 2079,87 & 2987,94 & 4497,83 & & & 44,71 \\
\hline 24 & $\begin{array}{c}\text { San } \\
\text { Bernardo }\end{array}$ & & 1777,11 & 8260,91 & 3244,28 & & 880,77 & 1608,80 & 6786,66 & & & 69,91 \\
\hline 25 & Sesquilé & & 3009,94 & 3066,05 & 48,80 & 22,25 & 0,002 & 5633,51 & 1385,76 & & 21,97 & 29,97 \\
\hline 26 & Sibaté & & 349,74 & 1386,01 & 2537,52 & & 453,58 & 1891,73 & 2125,02 & & 689,87 & 172,62 \\
\hline 27 & Soacha & & 23,14 & 8720,74 & 20,92 & & 29,14 & 2432,76 & 18,47 & & & 2258,56 \\
\hline 28 & Sopó & 596,67 & 775,08 & 1363,28 & 34,43 & & 13,84 & 4763,60 & 353,52 & 75,33 & 100,31 & 125,75 \\
\hline 29 & Subachoque & & 37,53 & 2184,38 & 1696,65 & & 47,20 & 12995,31 & 3000,06 & 15,81 & 64,13 & 338,65 \\
\hline 30 & Suesca & & 1024,98 & 2994,14 & 405,45 & 773,27 & 630,43 & 5767,97 & 5674,31 & & 196,55 & 225,02 \\
\hline 31 & Tabio & & 924,34 & 1251,02 & 90,48 & & & 2781,65 & 1958,32 & & & 68,27 \\
\hline 32 & Tausa & & 802,20 & 5785,87 & & & 190,55 & 5949,38 & 3177,48 & & 8,74 & 88,82 \\
\hline 33 & Tenjo & 0,07 & 761,00 & 882,39 & 186,21 & & & 8061,89 & 65,22 & 331,58 & & 119,04 \\
\hline 34 & Tocancipá & 9,75 & 70,26 & 270,14 & 37,71 & & & 2229,35 & 1980,05 & 117,00 & 179,95 & 56,32 \\
\hline 35 & Ubaque & & 1422,56 & 1337,63 & 2526,51 & & 47,09 & 247,11 & 6124,52 & & 16,01 & 20,86 \\
\hline 36 & Une & & 160,49 & 13141,94 & 3543,44 & 302,47 & 1,90 & 3940,03 & 1159,83 & & 37,77 & 41,60 \\
\hline 37 & Villapinzón & & 1922,97 & 565,16 & 6921,30 & & & 8840,65 & 1518,40 & & & 96,74 \\
\hline 38 & Zipaquirá & & 5,84 & 1524,19 & 6045,39 & & 86,73 & 2321,48 & 6465,74 & & & 481,93 \\
\hline 39 & Bogotá D.C. & 363,92 & 101,37 & 584,66 & 312,63 & 524,54 & 31,31 & 77,97 & 307,71 & & 835,57 & 693,93 \\
\hline & TOTAL & $19.720,26$ & $32.971,46$ & $130.072,60$ & $51.427,59$ & $15.672,60$ & $43.764,91$ & $133.605,22$ & $136.560,16$ & $12.261,23$ & $25.533,36$ & $11.653,91$ \\
\hline
\end{tabular}

Fuente: Elaboración propia con base en la información de los POT municipales, suministrados por la gobernación del Departamento Cundinamarca. ${ }^{8}$

\footnotetext{
${ }^{78}$ La información de cobertura y usos del suelo constituyen el valor agregado de la información. Ya que desde los planes de ordenamiento territorial se pudo averiguar la información referente a las coberturas por municipios. $Y$ valorar por supuesto el tema de la variable ambiental con exactitud.
} 


\subsection{LA CARACTERIZACIÓN DE LAS DIMENSIONES DEL DESARROLLO.}

Con base en el cuadro anterior (Cobertura y Usos del Suelo), cada eje del Biograma representa un indicador que varía entre 0 y 1 , siendo 0 el nivel mínimo de desempeño y 1 siendo el máximo, permitiendo visualizar las variables que desequilibran el sistema, y por ende la utilización de cinco colores que permiten identificar el estado en el cual se encuentra cada municipio; (Véase anexos 5, 6 y 7). La fuente en la elaboración propia se tomó como referencia de base en la metodología de desequilibrios territoriales de Sergio Sepúlveda 2008. De igual forma se debe tener en cuenta la clasificación de los indicadores ambientales, sociales y económicos (Véase Tablas 4.10, 4.11 y 4,12).

Tabla 4. 10. CLASIFICACIÓN DE INDICADORES AMBIENTAL

\begin{tabular}{|l|l|l|}
\hline ABREVIATURA & \multicolumn{1}{|c|}{ VARIABLE } & RELACIÓN \\
\hline \multicolumn{1}{|c|}{ DIMENSIÓN AMBIENTAL } \\
\hline A1 & Áreas Protegidas. & Positivo (1) \\
\hline A2 & Protección Hídrica. & Positivo (1) \\
\hline A3 & Zonas de protección de los RN. & Positivo (1) \\
\hline A4 & Zona de conservación de bosques naturales. & Positivo (1) \\
\hline A5 & Zonas de recuperación Ambiental. & Positivo (1) \\
\hline A6 & Zonas de desarrollo Forestal. & Positivo (1) \\
\hline A7 & Zonas de desarrollo agropecuario con restricciones. & Positivo (1) \\
\hline A8 & Zonas de desarrollo agropecuarios in restricciones. & Negativo (0) \\
\hline A9 & Amenaza naturales. & Negativo (0) \\
\hline A10 & Zonas de conservación de suelo y restauración ecológica. & Positivo (1) \\
\hline A11 & Suelo Urbano. & Positivo (1) \\
\hline
\end{tabular}

Fuente: Elaboración Propia.

Tabla 4. 11. CLASIFICACIÓN DE INDICADORES SOCIAL

\begin{tabular}{|c|c|c|}
\hline ABREVIATURA & VARIABLE & RELACIÓN \\
\hline \multicolumn{3}{|c|}{ DIMENSIÓN SOCIAL } \\
\hline S1 & Necesidades de vivienda Zona Urbana. & Negativo (0) \\
\hline S2 & Necesidades de vivienda Zona Rural. & Negativo (0) \\
\hline S3 & Tasa Bruta de Analfabetismo Zona Urbana. & Negativo (0) \\
\hline S4 & Tasa Bruta de Analfabetismo Zona Rural. & Negativo (0) \\
\hline S5 & NBI Zona Urbana. & Negativo (0) \\
\hline S6 & NBI Zona Rural & Negativo (0) \\
\hline S7 & Miseria Zona Urbana. & Negativo (0) \\
\hline S8 & Miseria Zona Rural. & Negativo (0) \\
\hline S9 & Población Urbana Cuenca Hidrográfica del Río Bogotá. & Negativo (0) \\
\hline $\mathbf{S 1 0}$ & Extensión Municipio Cuenca Hidrográfica del Río Bogotá. & Negativo (0) \\
\hline S11 & $\begin{array}{l}\text { Densidad poblacional Territorial Cuenca Hidrográfica del } \\
\text { Río Bogotá. }\end{array}$ & Negativo (0) \\
\hline \multicolumn{3}{|c|}{$\begin{array}{l}\text { La clasificación de los indicadores, se basa directamente de las tablas anteriores, en donde para cada eje } \\
\text { del Biograma representa un indicador que varía entre } 0 \text { y } 1 \text {, siendo } 0 \text { el nivel mínimo de desempeño y } 1 \text { e } \\
\text { máximo, permitiendo visualizar las variables que desequilibran el sistema, y por ende la utilización de cinco } \\
\text { colores que permiten identificar el estado en el cual se encuentra cada municipio como se puede analiza } \\
\text { en los resultados del ejercicio de los desequilibrios territoriales a través de la graficación del Biograma. }\end{array}$} \\
\hline
\end{tabular}

Fuente: Elaboración Propia. 
Tabla 4. 12. CLASIFICACIÓN DE INDICADORES ECONÓMICO

\begin{tabular}{|c|c|c|}
\hline ABREVIATURA & VARIABLE & RELACIÓN \\
\hline \multicolumn{3}{|c|}{ DIMENSION ECONÓMICA } \\
\hline E1 & \begin{tabular}{|l} 
Ingreso tributario 2007. \\
\end{tabular} & Positivo (1) \\
\hline E2 & Ingreso no tributario 2007. & Positivo (1) \\
\hline E3 & Ingreso tributario 2008. & Positivo (1) \\
\hline E4 & Ingreso no tributario 2008. & Positivo (1) \\
\hline E5 & Ingreso tributario 2009. & Positivo (1) \\
\hline E6 & Ingreso no tributario 2009. & Positivo (1) \\
\hline
\end{tabular}

Fuente: Elaboración Propia.

\subsection{LA CARACTERIZACIÓN Y LA VALORACIÓN DE LA DIMENSIÓN AMBIENTAL (BIOGRAMA.)}

La dimensión ambiental se determina como la base estructural para la conceptualización metodológica para fortalecer la conformación de la región. Desde el conocimiento de los elementos que hacen parte para ello, desde la Estructura Ecológica Regional.

Sergio Sepúlveda (2008), al reconocer la dimensión ambiental como base de la vida y como fundamento del desarrollo, también reconoce al ser humano como parte integral del ambiente y valora, con especial atención, los efectos negativos y positivos, de su accionar en la naturaleza, pero también, la forma en que la naturaleza afecta a los seres humanos.

Al valorar la dimensión ambiental e incorporarla al concepto de desarrollo, surge la necesidad, de proteger los recursos naturales y recuperar aquellos que han sido degradados por el ser humano. Agua, suelo, bosques, biodiversidad y poblaciones humanas constituyen un solo sistema y son interdependientes y un solo cambio en uno de ellos genera un cambio en los otros. Por tal razón, se identifica en los sistemas ambientales la cuenca hidrográfica por el manejo de los recursos naturales al exigirse una mirada comprensiva y participativa, al incluir estratégicamente a los actores locales, gremios sectores públicos y privados e internacionales entre otros.

En efecto la participación ciudadana resulta fundamental, para generar un cambio e impulsar patrones de uso que aseguren un equilibrio entre la producción y la conservación ambiental, la identificación y el análisis de cuáles los actores sociales son los más susceptibles de convertirse en agentes multiplicadores de cambio, para integrar los recursos naturales al mejoramiento de las condiciones sociales de la población.

La dimensión ambiental, por lo tanto, debe destacar el papel de los sectores público y privado, sus mecanismos de interacción y los dispositivos legales que puedan hacer viable el uso racional de los recursos naturales y del ambiente. Para ello (Véase Tabla 4.10.), en la cual se muestran las variables con las cuales se valoró la incidencia del medio ambiente en el territorio, por lo tanto, esta visualización representa de manera 
comprensible e instantánea, el estado de desarrollo general de la unidad o variable de análisis en un momento determinado. También nos permite analizar varias unidades de análisis (UA) $)^{19}$, en el mismo momento.

En las gráficas siguientes se detalla la incidencia de los desequilibrios de cada una de las variables, en cada uno de los municipios, identificando la incidencia de cada factor en el territorio, lo cual, nos ayudará a proponer las acciones de caso o el tipo de lineamiento que se requiere aplicar, inversiones u otros instrumentos específicos, para corregir dicha situación. Con el fin de adaptar los indicadores a una escala común, se utiliza una función de relativización, basada en la metodología planteada por el PNUD para calcular el Índice de Desarrollo Humano. Para el caso en que los indicadores presentan una relación positiva se adoptó la siguiente fórmula:

$$
f(x)=\frac{\mathrm{x}-\mathrm{m}}{\mathrm{M}-\mathrm{m} a}(1)
$$

Para el caso en que los indicadores presentan una relación inversa, se modificó la fórmula anterior con el fin de mantener sus propiedades:

$$
f(x)=\frac{\mathrm{x}-\mathrm{M}}{\mathrm{m}-\mathrm{M}}(2)
$$

Sergio Sepúlveda (2008), en tales fórmulas: $(\boldsymbol{x})$, es el valor correspondiente de la variable o indicador para una unidad de análisis determinada en un período determinado; $(\boldsymbol{m})$, es el valor mínimo de la variable en un período determinado; $(\boldsymbol{M})$, es el nivel máximo en un período determinado.

Como se observa en las fórmulas (1) y (2), con el fin de hacer comparables los indicadores, es necesario establecer un valor máximo y un valor mínimo para cada categoría de los datos que se analizan. (Véase anexo 5), en el cual se presenta lo anteriormente descrito para el área de estudio desde la dimensión ambiental.

Aleatoriamente se identificaron tres entidades municipales como abstracción al a la problemática del análisis del resultado del biograma, el municipio de Tenjo, Soacha y chía. El primero Tenjo, entidad municipal con características netamente rurales con grandes tensiones sociales económicas y por lo tanto con gran presión sobre sus recursos naturales, los cuales están dado a la presión de desarrollo urbanísticos; segundo Soacha entidad municipal con características de concentración poblacional altísima conurbado con la ciudad de Bogotá D.C. Lo cual, para las tres entidades municipales su gran incidencia territorial en términos ambientales, es el gran impacto en la intervención administrativa en lo relacionado a las temáticas ambientales e incluirlas en los procesos de ordenación ambiental, como tal en los Planes de Desarrollo como en los mismos Planes de Manejo de Cuencas Hidrográficas. POMCA

\footnotetext{
${ }^{19}$ La Unidad de Análisis (UA), es un territorio en el cual se realiza el análisis y evaluación del nivel de desarrollo sostenible. En este caso la Unidad de Análisis es la cuenca hidrográfica.
} 
Figura 4.14. SÍNTESIS Y CARACTERIZACIÓN DE LA ESPACIALIZACIÓN DEL BIOGRAMA EN LA DIMENSIÓN AMBIENTAL

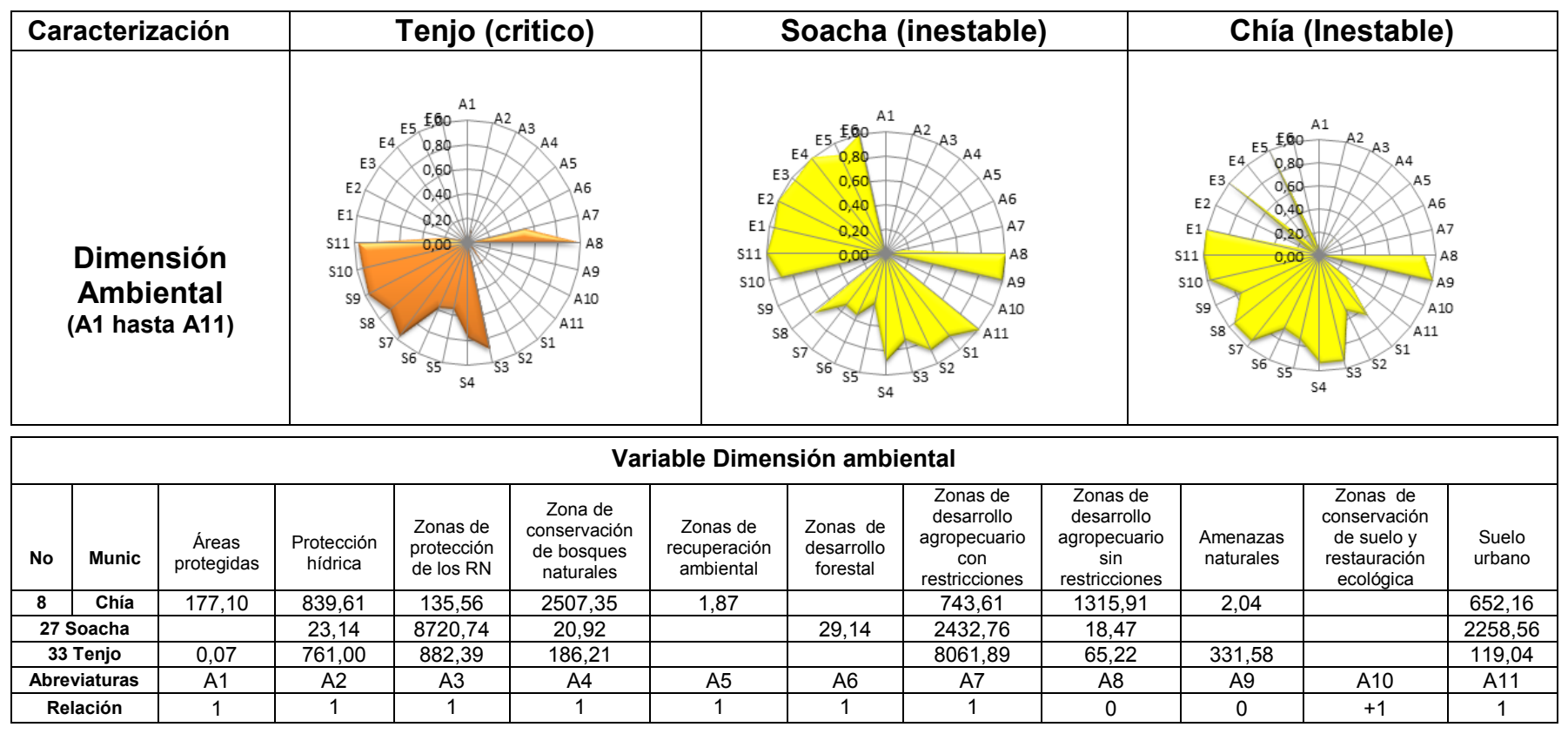

Fuente. Elaboración Propia

Algunos porcentajes representativos se pueden establecer en los siguientes datos con respecto a los niveles de desequilibrio territorial, teniendo en cuenta el análisis de la dimensión ambiental. Los cuales se pueden observar con mayor detalle (Véase anexo 8 $y$ 11). Al final de este capítulo, se pueden ver los análisis teniendo en cuenta las respectivas dimensiones del desarrollo.

\subsection{CARACTERIZACIÓN DE LA DIMENSIÓN SOCIAL}

\subsubsection{La situación social de la cuenca y su área de referencia con la estructura ecológica regional.}

Las diez y seis Subcuencas en las cuales está dividido el territorio de la Subcuenca alta y media del Río Bogotá, guarda proporciones porcentuales de alguna manera con cierto equilibrio territorial, posibilitando a futuro un mejor sistema de gestión en lo relacionado con la planificación territorial; siempre y cuando se logre relacionar los distintos actores y sectores participativos en el desarrollo, en coordinación con los del esquema de gestión conjunta en asocio con los Comités de Cuencas y Consejos por ejemplo; como será objeto en la estrategia para la concreción de los lineamientos conceptuales y metodológicos para el desarrollo regional teniendo en cuenta la unidad territorial de la cuenca hidrográfica.

La cuenca del Río Bogotá cuenta con una población total de 1032819 habitantes, de los cuales el $75 \%$ corresponde a población urbana y el $25 \%$ restante a población rural. Las Subcuencas, Río Medio Bogotá sector Salto Tequendama Río Teusacá, Río Neusa, Río Bogotá sector Sísga - Tibitoc, Embalse Tominé y embalse Sísga, se caracterizan por su predominio de población rural respecto a la urbana. Por otra parte las Subcuencas Río 
Balsillas, Río Bogotá sector Tibitoc - Soacha, son las que mayor número de habitantes aportan al total de población de la cuenca. En la tabla anterior se presenta la población total, urbana y rural para las subcuenca Río Bogotá y las Subcuencas que la conforman.

Con relación a la densidad poblacional las Subcuencas del, Río Negro y del Río Soacha, que a su vez son las de menor tamaño, presentan el mayor número de habitantes por unidad de superficie, con 2305 y 2500, habitantes por kilómetro cuadrado, respectivamente. En contraste las Subcuencas Embalse Sísga y Embalse Tominé presentan las menores densidades poblacionales con 36 y 44 habitantes por kilómetro cuadrado. (Véase Tabla 4.13.)

La primacía de la población urbana en Bogotá es indiscutible, con más de 6,5 millones de habitantes, aporta el $92 \%$ del total de la población con una tasa de crecimiento demográfico cercana al $2,7 \%$ anual. En términos de volumen poblacional, pueden distinguirse 8 grandes grupos de municipios.

Si se consideran los 28 municipios (Cuenca Alta del Río Bogotá entre Villapinzón y Sibaté), ellos representan el $48 \%$ total del departamento y el $64 \%$ de la población urbana, pero apenas el $24 \%$ de la población rural. Considerada en conjunto la población de Bogotá y de los municipios sabaneros representa el $87 \%$ de la población total de la región, el $94 \%$ de la población urbana y el $26 \%$ de la rural. Lo anterior se debe a que en la cuenca del Río Bogotá, se encuentran cinco de las cinco ciudades más pobladas de Cundinamarca: Soacha, Facatativá, Zipaquirá, Chía y la ciudad de Fusagasugá. (Véase Tabla 4.14.).

\subsubsection{La Población Rural}

En el área específica de la cuenca del Río Bogotá, se encuentran tres de los dos municipios mayor densidad de población rural, estos son: Cajicá, y Cota, en el todos con más de 150 habitantes/km2. De los 28 municipios que conforman la cuenca, 11 tienen una densidad superior al promedio regional (40 habitantes/ $/ \mathrm{km} 2$ ) y de ellos, 4 superan los 100 habitantes/km2. El municipio de Cajicá presenta la mayor densidad de población rural en la cuenca con más de 200 hab/km2. (Véase Tabla 4.15).

Tabla 4.13. DENSIDAD DE LA POBLACIÓN

\begin{tabular}{|c|l|}
\hline \multicolumn{2}{|c|}{ DENSIDAD DE POBLACIÓN RURAL EN LA CUENCA DEL RÍO BOGOTÁ } \\
\hline DENSIDAD & \multicolumn{1}{|c|}{ MUNICIPIOS } \\
\hline < de $\mathbf{1 5}$ hab / km2 & Bogotá D.C. \\
\hline $\mathbf{1 5 - 5 0 ~ h a b ~ / ~ k m 2 ~}$ & Villapinzón, Chocontá, Sesquilé, Guatavita, Guasca, La Calera, EI \\
(16 municipios) & Rosal, Bojacá, Mosquera, Soacha. \\
\hline $\mathbf{5 0 - 1 0 0 ~ h a b ~ / ~ k m 2 ~}$ & Suesca, Nemocón, Gachancipá, Cogua, Zipaquirá, Sopó, Chía, \\
(15 municipios) & Subachoque, Funza, Madrid, y Sibaté. \\
\hline $\begin{array}{c}100-\mathbf{2 0 0} \text { hab / km2 } \\
\text { (8 municipios) }\end{array}$ & Tocancipá, Tabio, Tenjo y Cota. \\
\hline >200 hab / km2 & Cajicá. \\
(2 municipios) & \\
\hline
\end{tabular}


El $42 \%$ de los municipios que conforman la cuenca crecieron a tasas entre el 2 -3 \%, margen en el que se sitúa Bogotá con una tasa de 2,7\% anual. Una proporción similar del $40 \%$ creció a tasas entre el 3 y el $4 \%$, mientras que cinco municipios equivalentes al $12 \%$ del total de la cuenca lo hicieron a una tasa entre el 4 y el $6 \%$ anual. (Véase Tabla 4.14.).

\section{Tabla 4. 14. TASA ANUAL DE CRECIMIENTO DEL TOTAL DE LA POBLACIÓN.}

\begin{tabular}{|c|l|}
\hline \multicolumn{3}{|c|}{$\begin{array}{c}\text { TASA ANUAL DE CRECIMIENTOS DEL TOTAL } \\
\text { DE LA POBLACIÓN DE LA CUENCA (1993-2002). }\end{array}$} \\
\hline $\begin{array}{c}\text { TASA DE } \\
\text { CRECIMIENTO }\end{array}$ & \multicolumn{1}{|c|}{ MUNICIPIOS } \\
\hline $\mathbf{0 - 2} \%$ & Sesquilé. \\
\hline $\begin{array}{c}\mathbf{2}-\mathbf{3} \% \\
\text { (Bogotá y } 17 \\
\text { Municipios) }\end{array}$ & $\begin{array}{l}\text { Bogotá, Villapinzón, Chocontá, Guatavita, Gachancipa, Cogua, Guasca, } \\
\text { Tabio, EI Rosal y Bojacá. }\end{array}$ \\
\hline $\begin{array}{c}3-4 \% \\
(16 \text { municipios) }\end{array}$ & $\begin{array}{l}\text { Suesca, Nemocón, Zipaquirá, Tocancipá, Sopó, Cajicá, Chía, } \\
\text { Subachoque, Tenjo, Cota, Las Calera, Madrid y Mosquera. }\end{array}$ \\
\hline $\begin{array}{c}\mathbf{4 - 6} \% \\
\text { (5 municipios) }\end{array}$ & Funza. \\
\hline
\end{tabular}

Fuente: Adaptación del autor con base en el Anuario estadístico de Cundinamarca.

\subsubsection{La Información Económica y Social del área de estudio}

En términos generales, los municipios de las zonas Sabana Centro, Soacha y Sabana Occidente, son los más poblados del Departamento (Tabla 4. 2) y tienen una importante participación en la economía departamental, pues aportan el 23,4; 17,1 y 15,3\% del PIB departamental respectivamente, jalonando la economía de Cundinamarca con actividades principalmente agropecuarias e industriales (ACR 2008), siendo unos de los mayores aportantes al PIB departamental. El 99\% de estas empresas se encuentran en municipios cercanos a Bogotá D.C (Cota, Facatativá, Funza, Mosquera, Sibaté, Soacha, Sopo, Subachoque, Tenjo, Tocancipá, Zipaquirá). En 2007, los municipios con mayor concentración de empresas eran también de estas zonas: Soacha (66), Mosquera (34), Funza (29) y Cajicá (24). (Véase Tabla 4.15).

Tabla. 4.15. COBERTURA RELICTUAL DE ECOSISTEMAS Y VALORES MEDIOS DE LA TASA DE CRECIMIENTO POBLACIONAL (\%) EN LAS PROVINCIAS DE CUNDINAMARCA DEFINIDAS EN EL POMCA.

\begin{tabular}{|l|r|r|c|c|}
\hline $\begin{array}{c}\text { COBERTURA DE } \\
\text { ECOSISTEMAS }\end{array}$ & \multicolumn{1}{|c|}{$\mathrm{Km}^{2}$} & \multicolumn{1}{c|}{$\%$} & $\begin{array}{c}\text { ÁREA DEL } \\
\text { TOTAL }\end{array}$ & $\begin{array}{c}\text { TASA DE CRECIMIENTO } \\
\text { POBLACIÓN (\%) }\end{array}$ \\
\hline Bogotá D.C & 888,21 & 50,91 & 3,67 & 2,7 \\
\hline Almeidas & 295,29 & 23,25 & 1,22 & 0,44 \\
\hline Guavio & 1065,24 & 40,65 & 4,41 & $-1,56$ \\
\hline Sabana Centro & 172,99 & 20,39 & 0,72 & 7,32 \\
\hline Sabana Occidente & 205,68 & 19,08 & 0,85 & 1,8 \\
\hline Soacha & 66,84 & 21,31 & 0,28 & 5,04 \\
\hline
\end{tabular}




\begin{tabular}{|l|c|c|c|c|}
\hline $\begin{array}{c}\text { COBERTURA DE } \\
\text { ECOSISTEMAS }\end{array}$ & $\mathrm{Km}^{2}$ & $\%$ & $\begin{array}{c}\text { ÁREA DEL } \\
\text { TOTAL }\end{array}$ & $\begin{array}{c}\text { TASA DE CRECIMIENTO } \\
\text { POBLACIÓN (\%) }\end{array}$ \\
\hline Ubaté & 208,17 & 14,56 & 0,86 & 1,96 \\
\hline Sumapáz & 589,62 & 33,45 & 0,44 & 1,51 \\
\hline
\end{tabular}

Fuente: IDEA, 2002.

No obstante, las zonas de Sabana Occidente y Soacha presentan los valores de pobreza más altos (10,8 y 14,1\% respectivamente). Soacha por ejemplo, tiene un índice de necesidades básicas insatisfechas (NBI) superior al 50\% (ACR 2008), lo anterior incide directamente en el uso que se le da al río Bogotá durante su recorrido, siendo Soacha el segundo centro poblado que mayor contaminantes le arroja a las corrientes del río Bogotá.

\subsubsection{La caracterización social del área de la cuenca hidrográfica del Rio Bogotá, y su entorno con la Estructura Ecológica Regional por municipio.}

El componente o dimensión del desarrollo socioeconómico determina los alcances con los cuales la población dependiendo de sus necesidades físicas en el territorio, actúan individualmente o colectivamente en el mejoramiento de sus necesidades básicas. Por lo tanto, las necesidades de vivienda, su ocupación por hogares, su nivel de analfabetismo y su calidad en lo relacionado a los servicios básicos como el alcantarillado determina los equilibrios o desequilibrios territoriales en el área, condiciones que para el objetivo de la investigación es básica, teniendo en cuenta que el Estado es el primer proveedor de estas necesidades. (Véase Tabla 4.16.).

Tabla 4.16. POBLACIÓN DE LA CUENCA HIDROGRÁFICA DEL RÍO BOGOTÁ Y DEL ÁREA DE REFERENCIA - 2011.

\begin{tabular}{|l|l|r|r|c|}
\hline No & MUNICIPIO & $\begin{array}{c}\text { POBLACIÓN } \\
\text { URBANA }\end{array}$ & EXTENSIÓN MUNICIPIO & $\begin{array}{c}\text { DENSIDAD } \\
\text { POBLACIONAL } \\
\text { TERRITORIAL }\end{array}$ \\
\hline 1 & Arbeláez & 12.107 & 15.200 & 1,25 \\
\hline 2 & Bojacá & 10.433 & $10.054,73$ & 0,96 \\
\hline 3 & Cabrera & 4.580 & 44.900 & 9,80 \\
\hline 4 & Cajicá & 52.244 & $5.167,68$ & 0,09 \\
\hline 5 & Chía & 114.881 & $7.977,85$ & 0,06 \\
\hline 6 & Chipaque & 8.421 & 139.450 & 16,55 \\
\hline 7 & Choachí & 10.923 & 22.300 & 2,04 \\
\hline 8 & Chocontá & 22.804 & $30.105,31$ & 1,32 \\
\hline 9 & Cogua & 20.682 & $13.325,47$ & 0,65 \\
\hline 10 & Cota & 22.879 & $5.600,98$ & 0,24 \\
\hline 11 & El Rosal & 15.731 & $8.942,11$ & 0,56 \\
\hline 12 & Facatativá & 122.320 & $15.462,95$ & 0,12 \\
\hline 13 & Funza & 69.783 & $6.923,90$ & 0,09 \\
\hline 14 & Fusagasugá & 124.110 & 23.900 & 0,19 \\
\hline 15 & Gachancipá & 12.944 & $4.129,63$ & 0,31 \\
\hline 16 & Guasca & 13.810 & $36.411,98$ & 0,24 \\
\hline 17 & Guatavita & 6.819 & $24.704,22$ & 3,62 \\
\hline
\end{tabular}




\begin{tabular}{|l|l|r|r|c|}
\hline No & MUNICIPIO & $\begin{array}{c}\text { POBLACIÓN } \\
\text { URBANA }\end{array}$ & EXTENSIÓN MUNICIPIO & $\begin{array}{c}\text { DENSIDAD } \\
\text { POBLACIONAL } \\
\text { TERRITORIAL }\end{array}$ \\
\hline 18 & Gutiérrez & 3.836 & 52.700 & 13,73 \\
\hline 19 & La Calera & 26.077 & $33.010,75$ & 1,26 \\
\hline 20 & Madrid & 71.564 & $11.845,59$ & 0,16 \\
\hline 21 & Mosquera & 74.654 & $10.652,31$ & 0,14 \\
\hline 22 & Nemocón & 12.613 & $9.848,24$ & 0,78 \\
\hline 23 & Pasca & 11.760 & 26.424 & 2,24 \\
\hline 24 & San Bernardo & 10.518 & 24.898 & 2,36 \\
\hline 25 & Sesquilé & 12.152 & $14.061,30$ & 1,15 \\
\hline 26 & Sibaté & 35.681 & $12.252,84$ & 0,34 \\
\hline 27 & Soacha & 466.216 & $18.179,99$ & 0,03 \\
\hline 28 & Sopó & 24.489 & $11.076,21$ & 0,45 \\
\hline 29 & Subachoque & 14.864 & $21.017,13$ & 1,41 \\
\hline 30 & Suesca & 16.024 & $17.444,88$ & 1,08 \\
\hline 31 & Tabio & 24.487 & $7.535,25$ & 0,30 \\
\hline 32 & Tausa & 8.364 & $19.208,87$ & 2,29 \\
\hline 33 & Tenjo & 19.366 & $11.263,94$ & 0,58 \\
\hline 34 & Tocancipá & 28.732 & $7.275,98$ & 0,25 \\
\hline 35 & Ubaque & 6.445 & 10.500 & 1,62 \\
\hline 36 & Une & 8.717 & 21.100 & 2,42 \\
\hline 37 & Villapinzón & 18.429 & $22.580,46$ & 1,22 \\
\hline 38 & Zipaquirá & 114.161 & $19.491,72$ & 0,17 \\
\hline & & & & \\
\hline
\end{tabular}

En lo referente a la territorialización de dichas necesidades, se determinan cuáles son los municipios jalonadores del desarrollo y, en ello, el mejor en lo relacionado al liderazgo, lo cual nos da la posibilidad de identificar la posible coordinación como veedores en el mejoramiento de la infraestructura básica; (Véase Mapas 4.12., 4.13., 4.14. y Tablas 4.17., 4.18., 4.19.), se muestran tanto en lo urbano como en lo rural las incidencias de los servicios mencionados anteriormente. 


\section{Mapa 4. 12. NECESIDADES DE LA VIVIENDA URBANA Y DE LA VIVIENDA RURAL EN LOS CONTEXTOS DE LA CUENCA Y DE LA ESTRUCTURA ECOLÓGICA REGIONAL.}

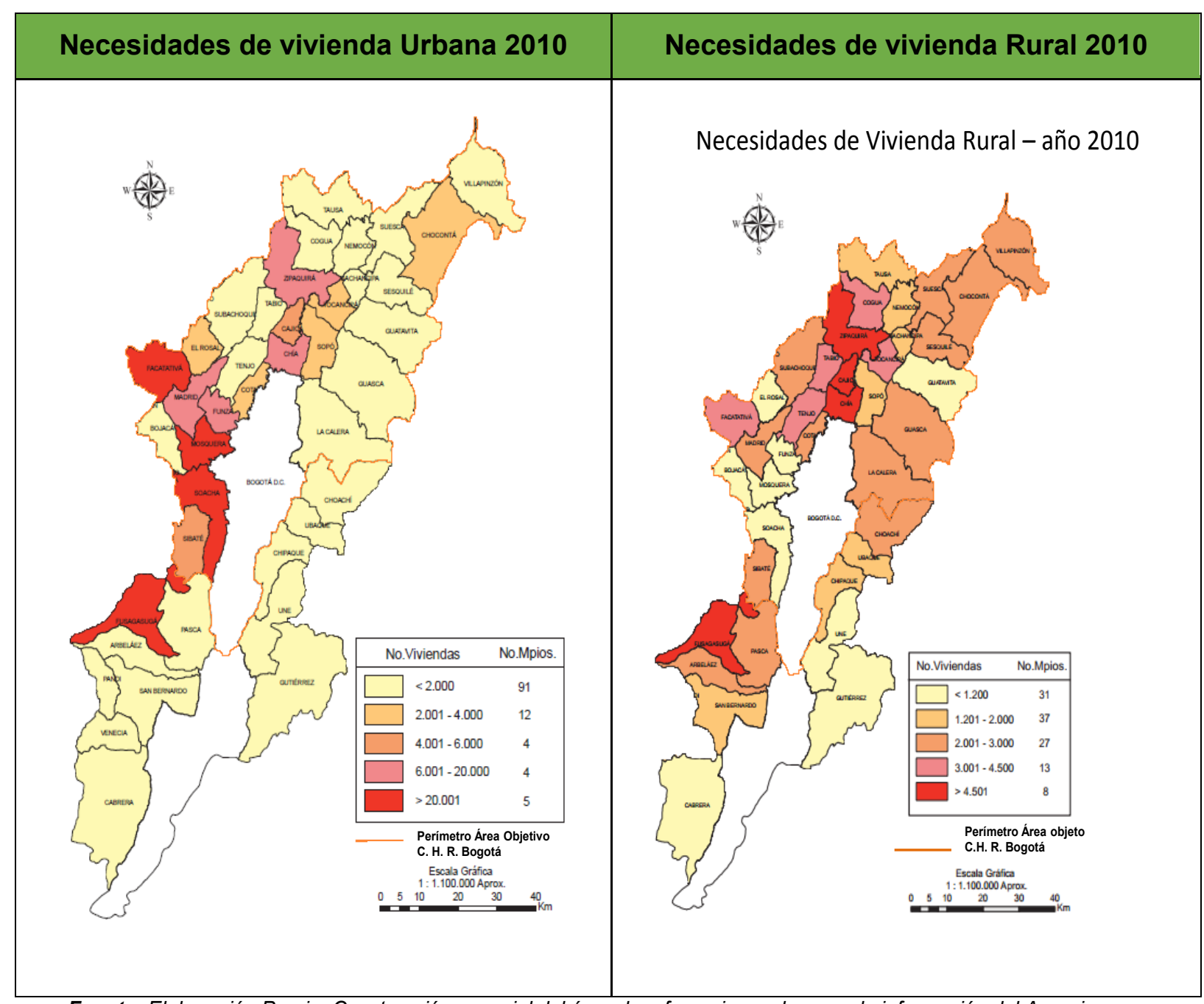

Fuente: Elaboración Propia. Construcción espacial del área de referencia con base en la información del Anuario estadístico de Cundinamarca 2010 (datos de SISBEN).

Teniendo en cuenta la información de base del departamento de Cundinamarca se encuentra un déficit aproximado de 618783 viviendas, de las de las cuales el 60,9 \%corresponden al área urbana. Los municipios con mayores necesidades de soluciones de vivienda son Soacha (94800), Facatativá (32960), Fusagasugá (32185). Conforme a las cifras del SISBEN, ${ }^{20}$ sigue siendo el municipio de Soacha, el mayor, 3387 de hogares que cocinan con leña, carbón mineral y Kerosene.

\footnotetext{
${ }^{20}$ Sistema de Identificación de Potenciales Beneficiarios de Programas Sociales
} 


\section{Mapa 4.13. NECESIDADES DE VIVIENDA POR HOGARES}

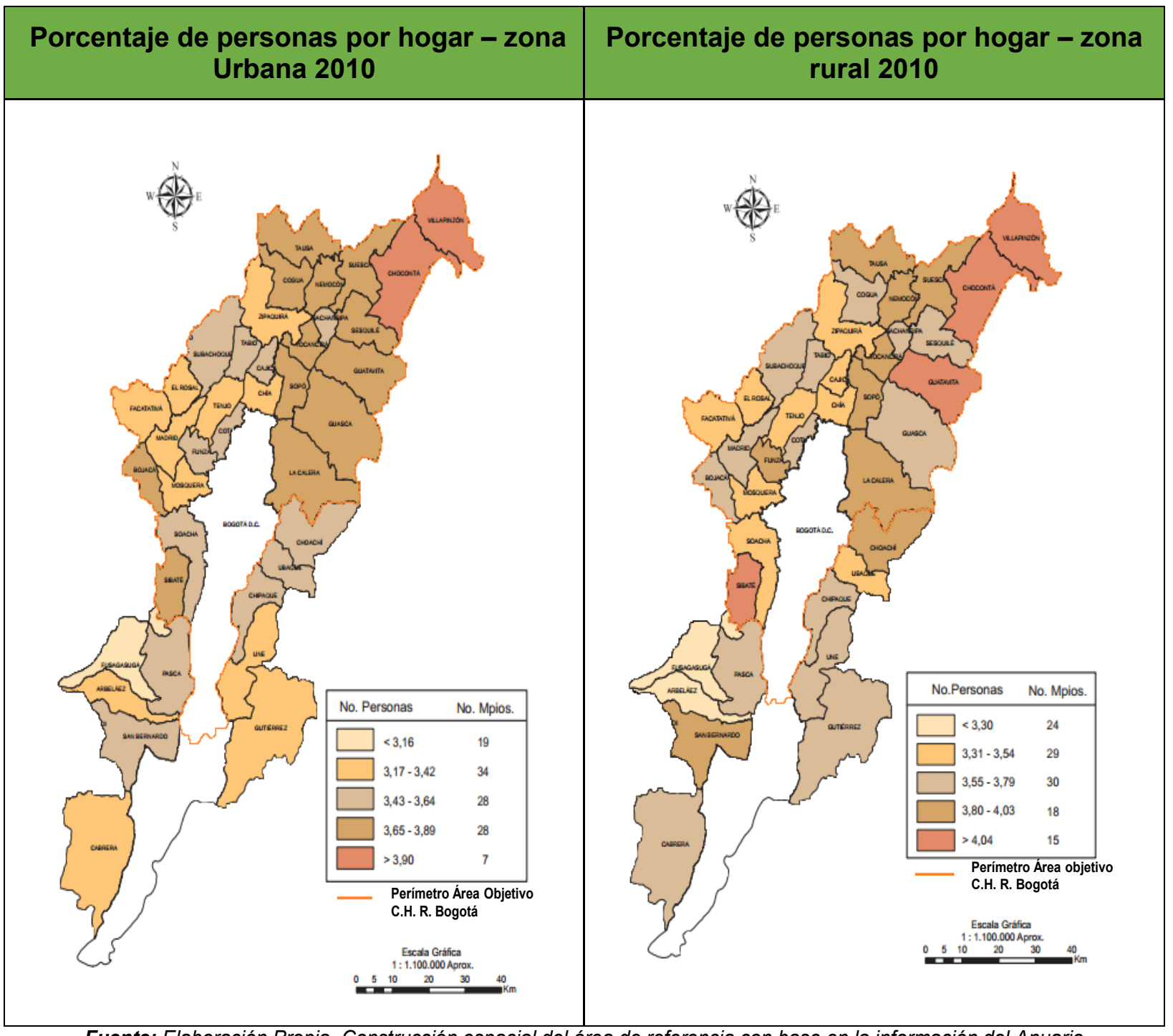

Fuente: Elaboración Propia. Construcción espacial del área de referencia con base en la información del Anuario estadístico de Cundinamarca 2010 (datos del SISBEN).

Tabla 4. 17. NECESIDADES DE VIVIENDA POR MUNICIPIO (ZONA RURAL Y ZONA URBANA).

\begin{tabular}{|l|l|r|r|r|r|r|c|}
\hline \multirow{2}{*}{ No } & \multirow{2}{*}{ Municipios } & \multicolumn{2}{|c|}{ Zona Urbana } & \multicolumn{2}{c|}{ Zona Rural } & \multicolumn{2}{c|}{ Total } \\
\cline { 3 - 8 } & & Hogar & \multicolumn{1}{c}{$\%$} & Hogar & $\%$ & Hogar & $\%$ \\
\hline $\mathbf{1}$ & Arbeláez & 1.040 & 32,60 & 2.360 & 18,43 & 3.400 & 22,76 \\
\hline $\mathbf{2}$ & Bojacá & 1.356 & 66,15 & 505 & 21,39 & 1.861 & 54,00 \\
\hline $\mathbf{3}$ & Cabrera & 353 & 39,94 & 1.157 & 20,22 & 1.510 & 24,83 \\
\hline $\mathbf{4}$ & Cajicá & 5.972 & 26,24 & 6.014 & 29,45 & 11.986 & 27,85 \\
\hline $\mathbf{5}$ & Chía & 15.970 & 32,19 & 8.833 & 30,16 & 24.803 & 31,46 \\
\hline $\mathbf{6}$ & Chipaque & 705 & 17,45 & 1.899 & 13,06 & 2.604 & 14,25 \\
\hline $\mathbf{7}$ & Choachí & 1.011 & 26,71 & 2.209 & 11,14 & 3.220 & 16,02 \\
\hline
\end{tabular}




\begin{tabular}{|c|c|c|c|c|c|c|c|}
\hline \multirow{2}{*}{ No } & \multirow{2}{*}{ Municipios } & \multicolumn{2}{|c|}{ Zona Urbana } & \multicolumn{2}{|c|}{ Zona Rural } & \multicolumn{2}{|c|}{ Total } \\
\hline & & Hogar & $\%$ & Hogar & $\%$ & Hogar & $\%$ \\
\hline 8 & Chocontá & 2.058 & 19,53 & 2.527 & 2,97 & 4.585 & 10,40 \\
\hline 9 & Cogua & 1.407 & 30,42 & 3.355 & 24,83 & 4.762 & 26,48 \\
\hline 10 & Cota & 2.248 & 37,50 & 2.809 & 27,20 & 5.057 & 31,78 \\
\hline 11 & El Rosal & 3.859 & 44,96 & 1.058 & 28,17 & 4.917 & 41,35 \\
\hline 12 & Facatat & 29.470 & 31,55 & 3.490 & 29,68 & 32.960 & 31,35 \\
\hline 13 & Funza & 14.983 & 45,74 & 470 & 34,04 & 15.453 & 45,39 \\
\hline 14 & Fusagasugá & 25.298 & 32,84 & 6.887 & 28,59 & 32.185 & 31,93 \\
\hline 15 & Gachanci & 1.309 & 22,92 & 1.543 & 19,18 & 2.852 & 20,90 \\
\hline 16 & Guasca & 1.151 & 30,41 & 2.189 & 18,78 & 3.340 & 22,78 \\
\hline 17 & Guatavita & 393 & 5,34 & 1.117 & 6,18 & 1.510 & 5,96 \\
\hline 18 & Gutiérrez & 234 & 36,32 & 749 & 19,23 & 963 & 23,30 \\
\hline 19 & La Calera & 1.505 & 19,07 & 2.739 & 12,05 & 4.244 & 14,54 \\
\hline 20 & Madrid & 15.660 & 48,73 & 2.051 & 25,50 & 17.711 & 46,04 \\
\hline 21 & Mosquera & 20.228 & 27,78 & 352 & 44,60 & 20.580 & 28,07 \\
\hline 22 & . & 31 & 2 & 3 & 3 & 3.104 & 21,91 \\
\hline 23 & Pasca & 726 & 84,30 & 2.147 & 20,54 & 2.873 & 36,65 \\
\hline 24 & Sall & 960 & 31,04 & 1.720 & 10,76 & 2.680 & 18,02 \\
\hline 25 & Sesquilé & 556 & 29,32 & 2.068 & 27,61 & 2.624 & 27,97 \\
\hline 26 & ihtó & 57 & 7 & 36 & 23,64 & 7.693 & 34,13 \\
\hline 27 & Soacha & 93.820 & 16,07 & 980 & 10,41 & 94.800 & 16,01 \\
\hline 28 & Sopó & 2.736 & 20,80 & 1.942 & 23,17 & 4.678 & 21,78 \\
\hline 29 & Subacho & 1.441 & 22,76 & 2.200 & 12,36 & 3.641 & 16,48 \\
\hline 30 & Suesca & 1.441 & 79,74 & 2.243 & 22,83 & 3.684 & 45,09 \\
\hline 31 & Tabio & 1.031 & 18,04 & 3.480 & 14,97 & 4.511 & 15,67 \\
\hline 31 & Tausa & 263 & 23,19 & 1.701 & 10,93 & 1.964 & 12,58 \\
\hline 33 & Tenjo & 932 & 64,16 & 3.785 & 61,14 & 4.717 & 61,73 \\
\hline 34 & Tocancipá & 2.908 & 25,31 & 4.164 & 19,86 & 7.072 & 22,10 \\
\hline 35 & Ubaque & 268 & 45,15 & 1.864 & 21,30 & 2.132 & 24,30 \\
\hline 36 & Une & 975 & 70,26 & 1.110 & 33,51 & 2.085 & 50,70 \\
\hline 37 & Villapinzón & 1.258 & 22,10 & 2.660 & 5.86 & 3.918 & 11,08 \\
\hline 38 & Zipaquirá & .804 & 56,79 & 6.028 & 50,85 & 4.832 & 55,35 \\
\hline
\end{tabular}

Fuente: Construcción espacial del área de referencia con base en la información del Anuario estadístico de Cundinamarca 2010 (datos del SISBEN). 


\section{Mapa 4.14. TASA DE ANALFABETISMO URBANO Y RURAL.}

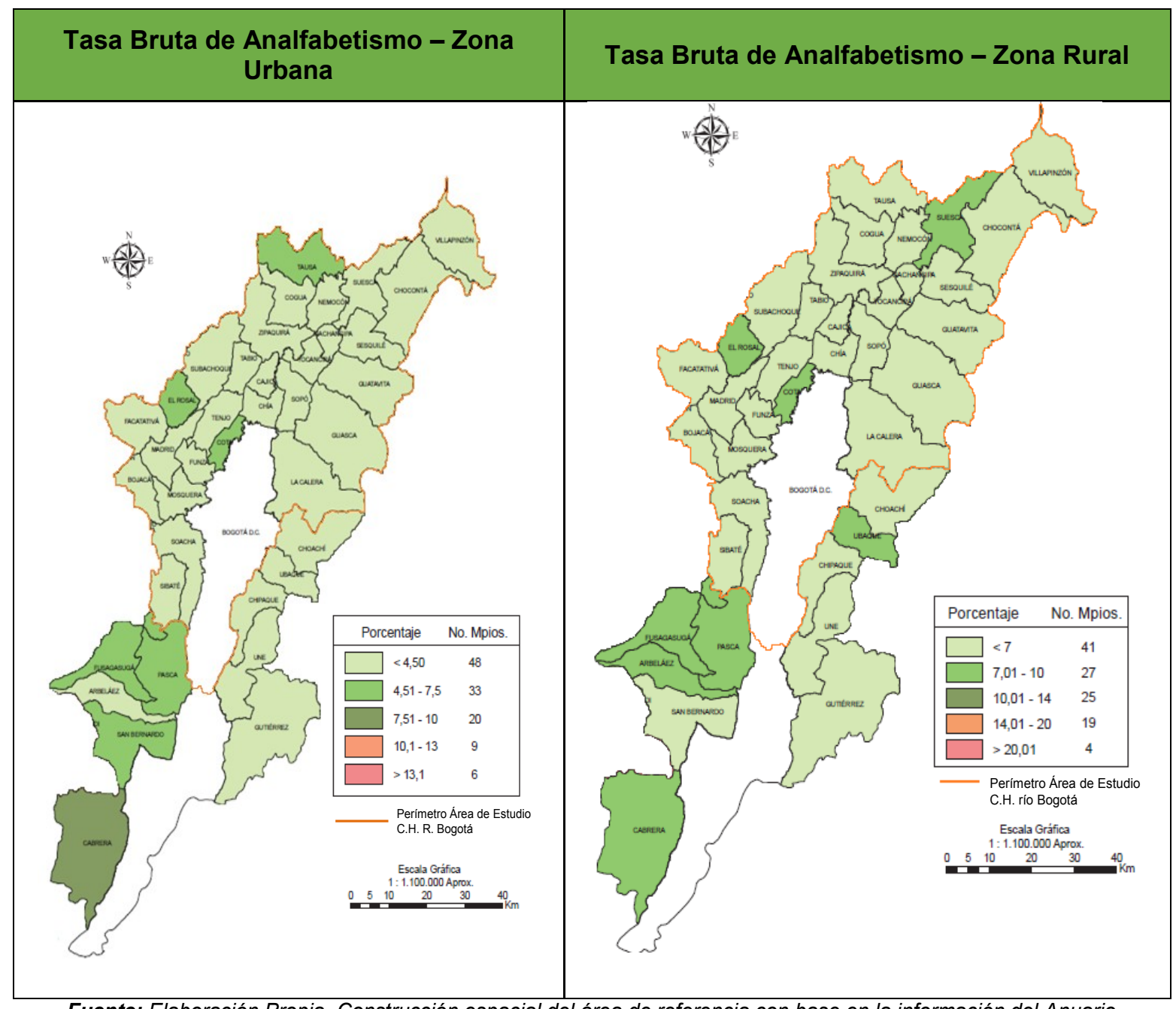

Fuente: Elaboración Propia. Construcción espacial del área de referencia con base en la información del Anuario estadístico de Cundinamarca 2010 (datos del SISBEN).

Tabla 4.18. TASA BRUTA DE ANALFABETISMO POR MUNICIPIO (ZONA URBANA Y ZONA RURAL) PARA LA POBLACIÓN MAYOR DE 15 AÑOS.

\begin{tabular}{|c|c|c|c|c|c|c|c|c|c|c|}
\hline \multirow[b]{2}{*}{ No } & \multirow[b]{2}{*}{ Municipio } & \multicolumn{3}{|c|}{ Zona Urbana } & \multicolumn{3}{|c|}{ Zona Rural } & \multicolumn{3}{|c|}{ Total Municipio } \\
\hline & & 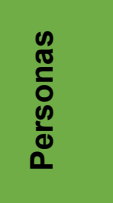 & ○ & 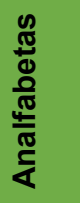 & 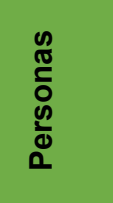 & ๙ீ & 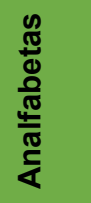 & 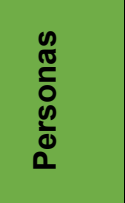 & ๙ீ & 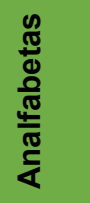 \\
\hline 1 & Arbeláez & 2.385 & 4,4 & 104 & 5.234 & 7,3 & 381 & 7.619 & 6,4 & 485 \\
\hline 2 & Bojacá & 3.281 & 4,1 & 135 & 1.185 & 5,7 & 67 & 4.466 & 4,5 & 202 \\
\hline 3 & Cabrera & 755 & 8,5 & 64 & 2.583 & 9,7 & 251 & 3.338 & 9,4 & 315 \\
\hline 4 & Cajicá & 14.073 & 2,4 & 335 & 14.018 & 3,2 & 453 & 28.091 & 2,8 & 788 \\
\hline 5 & Chía & 37.111 & 2,0 & 741 & 19.406 & 3,4 & 651 & 56.517 & 2,5 & 1.392 \\
\hline 6 & Chipaque & 1.660 & 2,6 & 43 & 4.652 & 5,4 & 251 & 6.312 & 4,7 & 294 \\
\hline
\end{tabular}




\begin{tabular}{|c|c|c|c|c|c|c|c|c|c|c|}
\hline \multirow[b]{2}{*}{ No } & \multirow[b]{2}{*}{ Municipio } & \multicolumn{3}{|c|}{ Zona Urbana } & \multicolumn{3}{|c|}{ Zona Rural } & \multicolumn{3}{|c|}{ Total Municipio } \\
\hline & & 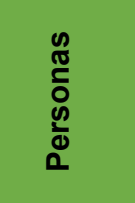 & ¿0 & 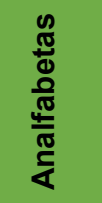 & 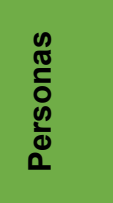 & ๙0 & 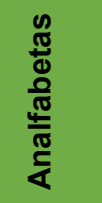 & 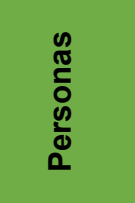 & d0 & 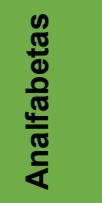 \\
\hline 7 & Choachí & 2.377 & 2,7 & 64 & 5.761 & 3,9 & 222 & 8.138 & 3,5 & 286 \\
\hline 8 & Chocontá & 5.354 & 3,1 & 168 & 7.173 & 6,6 & 471 & 12.527 & 5,1 & 639 \\
\hline 9 & Cogua & 3.419 & 3,4 & 116 & 7.726 & 5,7 & 440 & 11.145 & 5,0 & 556 \\
\hline 10 & Cota & 5.324 & 5,1 & 274 & 6.577 & 7,4 & 488 & 11.901 & 6,4 & 762 \\
\hline 11 & El Rosal & 7.711 & 6,0 & 466 & 2.309 & 9,8 & 226 & 10.020 & 6,9 & 692 \\
\hline 12 & Facatativá & 59.893 & 3,1 & 1.852 & 7.223 & 5,1 & 365 & 67.116 & 3,3 & 2.217 \\
\hline 13 & Funza & 35.114 & 3,4 & 1.190 & 1.131 & 5,2 & 59 & 32.245 & 3,4 & 1.249 \\
\hline 14 & Fusagasugá & 51.665 & 5,6 & 2.917 & 14.653 & 8,7 & 1.272 & 66.318 & 6,3 & 4.189 \\
\hline 15 & Gachancipá & 2.906 & 2,4 & 71 & 3.463 & 4,0 & 140 & 6.369 & 3,3 & 211 \\
\hline 16 & Guasca & 2.720 & 3,1 & 84 & 5.272 & 5,0 & 261 & 7.992 & 4,3 & 345 \\
\hline 17 & Guatavita & 954 & 1,7 & 16 & 2.922 & 5,2 & 152 & 3.876 & 4,3 & 168 \\
\hline 18 & Gutiérrez & 503 & 2,6 & 13 & 1.685 & 3,1 & 52 & 2.188 & 3,0 & 65 \\
\hline 19 & La Calera & 3.932 & 2,2 & 86 & 7.218 & 4,0 & 290 & 11.150 & 3,4 & 376 \\
\hline 20 & Madrid & 32.518 & 3,6 & 1.168 & 4.419 & 5,8 & 258 & 36.937 & 3.9 & 1.426 \\
\hline 21 & Mosquera & 40.461 & 2,9 & 1.164 & 784 & 6,9 & 54 & 41.245 & 3,0 & 1.218 \\
\hline 22 & Nemocón & 3.453 & 3,4 & 117 & 3.895 & 6.2 & 243 & 7.348 & 4,9 & 360 \\
\hline 23 & Pasca & 1.688 & 6,6 & 111 & 5.135 & 7,2 & 370 & 6.823 & 7,0 & 481 \\
\hline 24 & San Bernardo & 2.261 & 5.3 & 120 & 4.349 & 6,8 & 295 & 6.610 & 6,3 & 415 \\
\hline 25 & Sesquilé & 1.350 & 2,1 & 29 & 4.865 & 4,4 & 213 & 6.215 & 3,9 & 242 \\
\hline 26 & Sibaté & 13.486 & 3,6 & 484 & 5.407 & 6,0 & 322 & 18.893 & 4,3 & 806 \\
\hline 27 & Soacha & 212.970 & 3,4 & 7.204 & 2.077 & 3,7 & 76 & 215.047 & 3,4 & 7.280 \\
\hline 28 & Sopó & 6.898 & 1,5 & 106 & 4.868 & 2,9 & 140 & 11.766 & 2,1 & 246 \\
\hline 29 & Subachoque & 3.341 & 3,2 & 108 & 5.126 & 4,3 & 221 & 8.467 & 3,9 & 329 \\
\hline 30 & Suesca & 3.313 & 4,3 & 143 & 5.436 & 7,1 & 388 & 8.749 & 6,1 & 531 \\
\hline 31 & Tabio & 2.502 & 1,9 & 47 & 8.331 & 3,1 & 262 & 10.833 & 2,9 & 309 \\
\hline 32 & Tausa & 614 & 4,6 & 28 & 4.285 & 6,4 & 275 & 4.899 & 6,2 & 303 \\
\hline 33 & Tenjo & 2.097 & 2,3 & 48 & 8.007 & 4,5 & 357 & 10.104 & 4,0 & 405 \\
\hline 34 & Tocancipá & 6.768 & 2,2 & 152 & 10.023 & 4,2 & 419 & 16.791 & 3,4 & 571 \\
\hline 35 & Ubaque & 631 & 4,0 & 25 & 4.427 & 8,5 & 377 & 5.058 & 7,9 & 402 \\
\hline 36 & Une & 2.250 & 4,2 & 94 & 2.632 & 6,0 & 158 & 4.882 & 5,2 & 252 \\
\hline 37 & Villapinzón & 3.246 & 2,1 & 69 & 7.114 & 5,0 & 358 & 10.360 & 4,1 & 427 \\
\hline 38 & Zipaquirá & 40.070 & 3,0 & 1.217 & 13.340 & 4,1 & 546 & 53.410 & 3,3 & 1.763 \\
\hline
\end{tabular}

Fuente: Anuario Estadístico de Cundinamarca2010. 


\section{Mapa 4.15. VIVIENDAS Y SANEAMIENTO.}

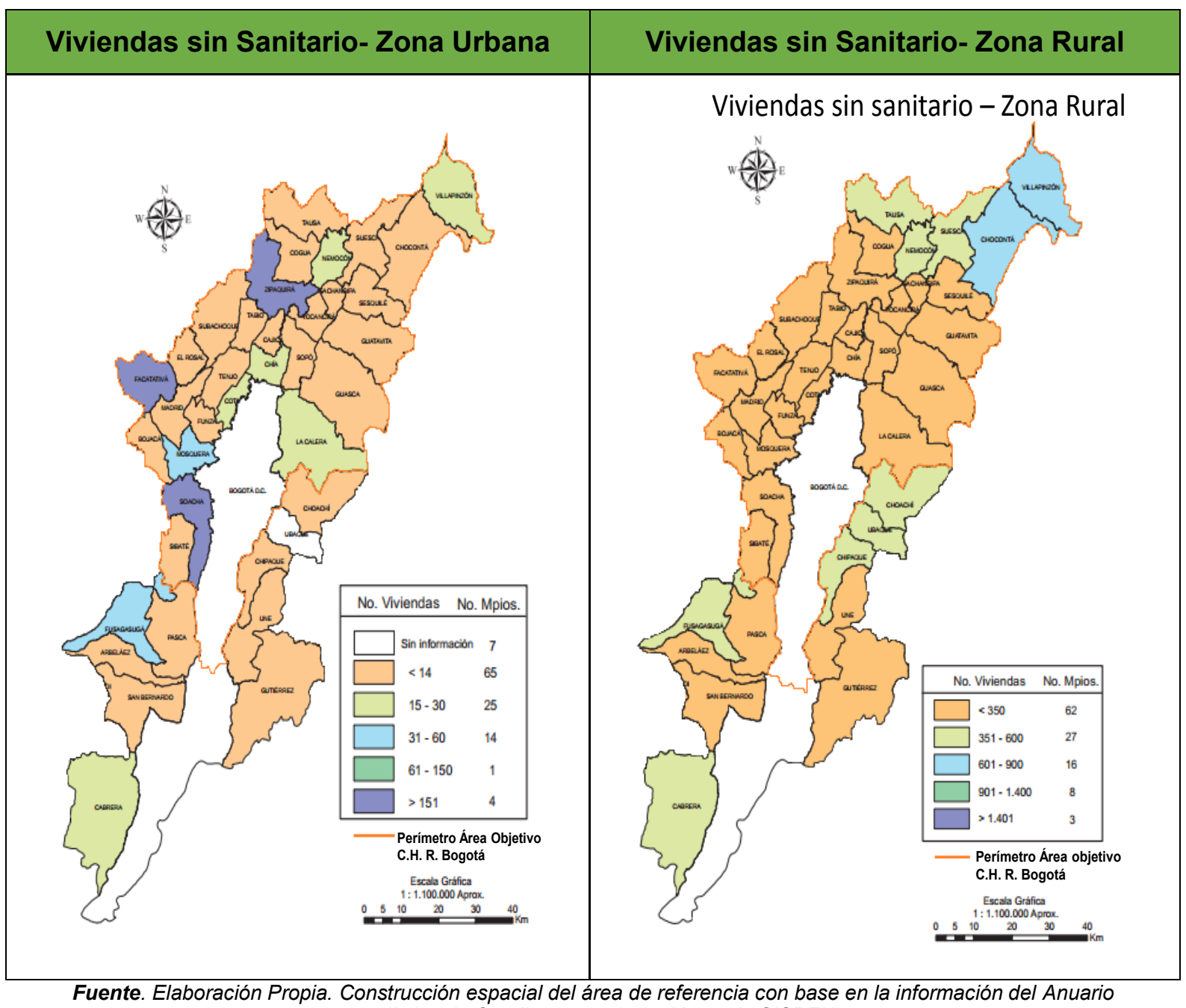
estadístico de Cundinamarca 2010 (datos de SISBEN).

\section{Tabla 4.19. POBLACIÓN POBRE SEGÚN NBI Y MISERIA POR MUNICIPIO (ZONA URBANA Y ZONA RURAL).}

\begin{tabular}{|l|l|r|r|r|r|r|r|r|r|}
\hline \multirow{2}{*}{ No } & \multirow{3}{*}{ Municipio } & \multicolumn{4}{|c|}{ NBI } & \multicolumn{4}{c|}{ Miseria } \\
\cline { 3 - 10 } & & \multicolumn{2}{|c|}{ Zona Urbana } & \multicolumn{2}{c|}{ Zona Rural } & \multicolumn{2}{c|}{ Zona Urbana } & \multicolumn{2}{c|}{ Zona Rural } \\
\cline { 3 - 10 } & & Personal & \% & Personal & \% & Personal & $\%$ & Personal & $\%$ \\
\hline $\mathbf{1}$ & Arbeláez & 3.466 & 25,6 & 7.756 & 39,4 & 3.466 & 5,0 & 7.756 & 9,0 \\
\hline $\mathbf{2}$ & Bojacá & 5.108 & 24,6 & 1.859 & 35,0 & 5.108 & 3,6 & 1.859 & 8,1 \\
\hline $\mathbf{3}$ & Cabrera & 1.159 & 50,1 & 4.218 & 80,9 & 1.159 & 18,0 & 4.218 & 33,0 \\
\hline $\mathbf{4}$ & Cajicá & 21.386 & 21,8 & 21.284 & 23,5 & 21.386 & 2,3 & 21.284 & 2,1 \\
\hline $\mathbf{5}$ & Chía & 53.953 & 14,3 & 30.886 & 23,6 & 53.953 & 1,3 & 30.886 & 2,0 \\
\hline $\mathbf{6}$ & Chipaque & 2.495 & 25,2 & 6.853 & 48,7 & 2.495 & 4,2 & 6.853 & 16,4 \\
\hline $\mathbf{7}$ & Choachín & 3.585 & 20,0 & 8.711 & 46,0 & 3.585 & 2,6 & 8.711 & 14,1 \\
\hline $\mathbf{8}$ & Chocontán & 8.455 & 36,4 & 11.397 & 55,5 & 8.455 & 10,4 & 11.397 & 21,0 \\
\hline $\mathbf{9}$ & Cogua & 5.234 & 19,2 & 12.121 & 23,6 & 5.234 & 1,7 & 12.121 & 2,1 \\
\hline
\end{tabular}




\begin{tabular}{|c|c|c|c|c|c|c|c|c|c|}
\hline \multirow{3}{*}{ No } & \multirow{3}{*}{ Municipio } & \multicolumn{4}{|c|}{ NBI } & \multicolumn{4}{|c|}{ Miseria } \\
\hline & & \multicolumn{2}{|c|}{ Zona Urbana } & \multicolumn{2}{|c|}{ Zona Rural } & \multicolumn{2}{|c|}{ Zona Urbana } & \multicolumn{2}{|c|}{ Zona Rural } \\
\hline & & Personal & $\%$ & Personal & $\%$ & Personal & $\%$ & Personal & $\%$ \\
\hline 10 & Cota & 8.150 & 32,4 & 10.311 & 32,0 & 8.150 & 7,4 & 10.311 & 7,0 \\
\hline 11 & El Rosal & 13.067 & 56,8 & 3.737 & 29,3 & 13.067 & 23,0 & 3.737 & 3,9 \\
\hline 12 & Facatativá & 93.731 & 50.9 & 11.709 & 42,9 & 93.731 & 19,6 & 11.709 & 12,7 \\
\hline 13 & Funza & 54.374 & 27,3 & 1.808 & 38,7 & 54.374 & 6,0 & 1.808 & 9,6 \\
\hline 14 & Fusagasugá & 77.999 & 25,3 & 22.466 & 58,4 & 77.999 & 3,8 & 22.466 & 18,9 \\
\hline 15 & Gachancipá & 4.754 & 29,9 & 5.750 & 23,3 & 4.754 & 11,8 & 5.750 & 2,0 \\
\hline 16 & Guasca & 4.222 & 23,6 & 8.113 & 26,8 & 4.222 & 3,1 & 8.113 & 4,3 \\
\hline 17 & Guatavita & 1.459 & 24,7 & 4.598 & 47,9 & 1,459 & 2,1 & 4.598 & 16,0 \\
\hline 18 & Gutiérrez & 775 & 38,5 & 2.787 & 63,7 & 775 & 3,1 & 2.787 & 23,4 \\
\hline 19 & La Calera & 5.801 & 16,6 & 10.777 & 31,5 & 5.801 & 2,8 & 10.777 & 5,4 \\
\hline 20 & Madrid & 53.141 & 32,1 & 7.521 & 41,4 & 53.141 & 5,5 & 7.521 & 10,2 \\
\hline 21 & Mosquera & $\begin{array}{l}\text { Sin } \\
\text { información }\end{array}$ & & & & & & & \\
\hline 22 & Nemocón & 5.305 & 23,0 & 6.554 & 40,4 & 5.305 & 4,9 & 6.554 & 10,6 \\
\hline 23 & Pasca & 2.596 & 41,6 & 8.066 & 41,1 & 2.596 & 11,7 & 8.066 & 11,6 \\
\hline 24 & $\begin{array}{l}\text { San } \\
\text { Bernardo }\end{array}$ & 3.345 & 36,4 & 6.564 & 69,6 & 3.345 & 10,8 & 6.564 & 26,6 \\
\hline 25 & Sesquilé & 2.053 & 16,9 & 7.790 & 28,2 & 2.053 & 3,0 & 7.790 & 5,4 \\
\hline 26 & Sibaté & 21.010 & 25,9 & 8.799 & 39,7 & 21.010 & 3,6 & 8.799 & 6,9 \\
\hline 27 & Soacha & 336.767 & 32,5 & 3.259 & 35,4 & 336,767 & 10,6 & 3.259 & 7,5 \\
\hline 28 & Sopó & 10.437 & 14,9 & 7.835 & 23,5 & 10.437 & 1,7 & 7.835 & 3,1 \\
\hline 29 & Subachoque & 4.979 & 21,7 & 7.929 & 26,2 & 4.979 & 3,1 & 7.929 & 4,1 \\
\hline 30 & Suesca & 5.537 & 31,8 & 8.589 & 38,6 & 5.537 & 6,3 & 8.589 & 10,2 \\
\hline 31 & Tabio & 3.585 & 11,7 & 13.109 & 19,2 & 3.585 & 2,1 & 13.109 & 2,5 \\
\hline 32 & Tausa & 997 & 37,5 & 6.802 & 40,8 & 997 & 7,5 & 6.802 & 10,0 \\
\hline 33 & Tenjo & 3.127 & 25,5 & 12.914 & 33,7 & 3.127 & 0,9 & 12.914 & 4,0 \\
\hline 34 & Tocancipá & 10.949 & 19,6 & 16.743 & 25,1 & 10.949 & 2,5 & 16.743 & 3,0 \\
\hline 35 & Ubaque & 926 & 32,5 & 6.456 & 40,6 & 926 & 4,9 & 6.456 & 11,8 \\
\hline 36 & Une & 3.280 & 32,1 & 4.016 & 53,0 & 3.280 & 6,6 & 4.016 & 19,0 \\
\hline 37 & Villapinzón & 5.052 & 27,1 & 11.785 & 44,3 & 5.052 & 4,9 & 11.785 & 10,9 \\
\hline 38 & Zipaquirá & 61.227 & 20,2 & 20.681 & 21,1 & 61.277 & 3,5 & 20.681 & 2,1 \\
\hline
\end{tabular}

\subsection{LA CARACTERIZACIÓN Y LA VALORACIÓN DE LA DIMENSIÓN SOCIAL.}

En el centro de la discusión se encuentra el ser humano, su organización social y cultural, modos de producción y patrones de consumo. Se trata, entre otros, de un proceso de fortalecimiento de sujetos, grupos y organizaciones para que puedan constituirse en actores sociales y consolidarse como tales. De ahí que la equidad se destaque como unos de los objetivos primordiales del desarrollo.

Así mismo, en esta dimensión se reconoce el desarrollo social su posición dentro del contexto del territorio, con elementos distintivos de la ruralidad del departamento de Cundinamarca como de la ciudad de Bogotá y su influencia entre ambas territorialidades. Estos aspectos entrelazan el conjunto de relaciones sociales y económicas que establecen y determinan, en buena medida, el grado de acceso a las diversas formas del poder político regional y local. Para tal efecto, (Véase Tabla 4.11.), donde se identifican las variables establecidas desde la dimensión social para su análisis y clasificación de indicadores. 
En el análisis del Biograma en lo social, sobresale el color azul, en donde se identifica que el sistema está estable para un total de veintidós municipios (22), en donde la inversión a cubierto las necesidades referentes a la miseria en la zona urbana y rural; le sigue, nueve municipios (9), con un desarrollo óptimo; seis municipios (6) inestables y un municipio en desarrollo social crítico. (Véase anexo 6, 8 y 9).

\section{Figura 4.15. SÍNTESIS Y CARACTERIZACIÓN DE LA ESPACIALIZACIÓN DEL BIOGRAMA EN LA DIMENSIÓN SOCIAL}

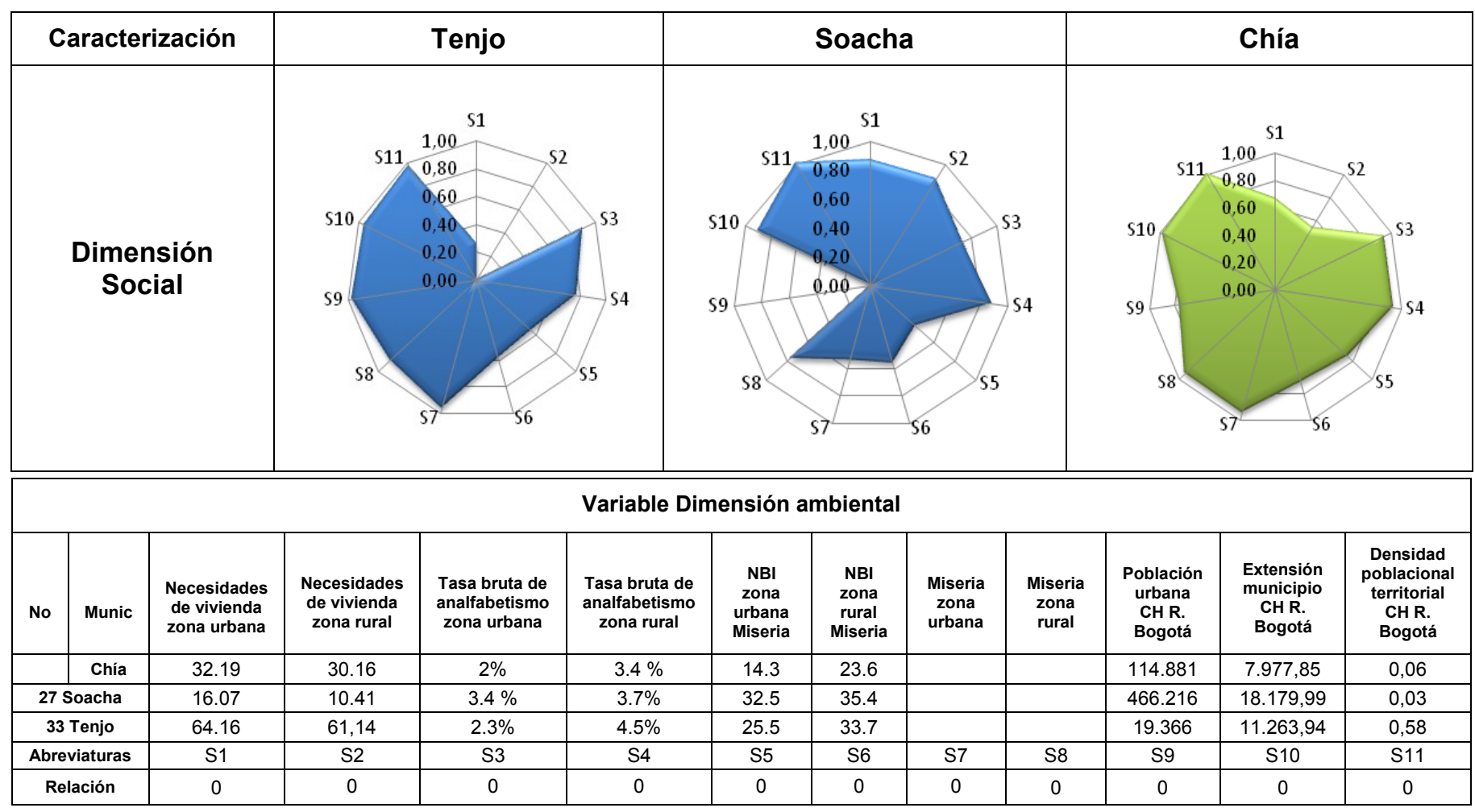

Fuente. Elaboración Propia.

\subsection{LA JERARQUIA URBANA, LA ESPACIALIZACIÓN TERRITORIAL DEL ÁREA DE LA CUENCA HIDROGRÁFICA DEL RIO BOGOTÁ Y SU ENTORNO CON LA ESTRUCTURA ECOLÓGICA REGIONAL.}

Las ciudades constituyen un sistema en el cual la red urbana cumple un destacado papel. El tamaño demográfico de las ciudades es una de las bases de la jerarquía urbana y su posicionamiento en el territorio, en el área de la cuenca hidrográfica del Río Bogotá, se viene observando un crecimiento acelerado de las cabeceras municipales perimetrales a la ciudad de Bogotá, con cerca de ocho millones de habitantes, donde muchas de las cabeceras se han transformado en ciudades o centros dormitorios, puesto que sus residentes se desplazan a diario, bien sea para trabajar en la industria, el comercio o en los servicios.

Paralelamente al mejoramiento de la infraestructura de movilidad; es el caso suroccidente que colinda con el municipio de Soacha, además del Noroccidente 
(avenida ochenta o llamada Autopista Medellín), que conecta a los municipios sabaneros con características rurales, que han venido siendo presionados en su crecimiento urbano, en condominios campestres y localización de grandes centros de bodegaje denominados zonas francas en sus áreas suburbanas.

\section{$>$ Polo Principal}

Dentro del área de estudio sobresale la ciudad de Bogotá como el polo principal. Por lo tanto, nos referimos a la concentración poblacional en un casco urbano principal con sus áreas de expansión, que puedan en sí mismas convertirse en un centro funcional que provea servicios a los municipios que se encuentran dentro de la subregión. Los polos y sub-polos concentrarán mayor población y tendrán funciones de mayor jerarquía funcional y de mayor cubrimiento poblacional que las demás cabeceras urbanas; dentro del área encontramos a la ciudad de Bogotá como jalonadora en la región.

Estos polos están fortalecidos de manera que: (a) puedan albergar una mayor cantidad de población (b) puedan reemplazar a aquellos municipios que hoy están ejerciendo esa función o (c) sigan ejerciendo la función de a tractores en su subregión y funcionalmente dependan cada día menos de la ciudad de Bogotá. Estos polos pueden también localizarse fuera de los límites departamentales; entre ellos podemos identificar a: Soacha y Facatativá. (Véase Mapa 4.16.). 


\section{Mapa 4.16. LA JERARQUÍA URBANA DE LA CUENCA DEL RÍO BOGOTÁ Y SU RELACIÓN DENTRO DE LA ESTRUCTURA ECOLÓGICA REGIONAL.}

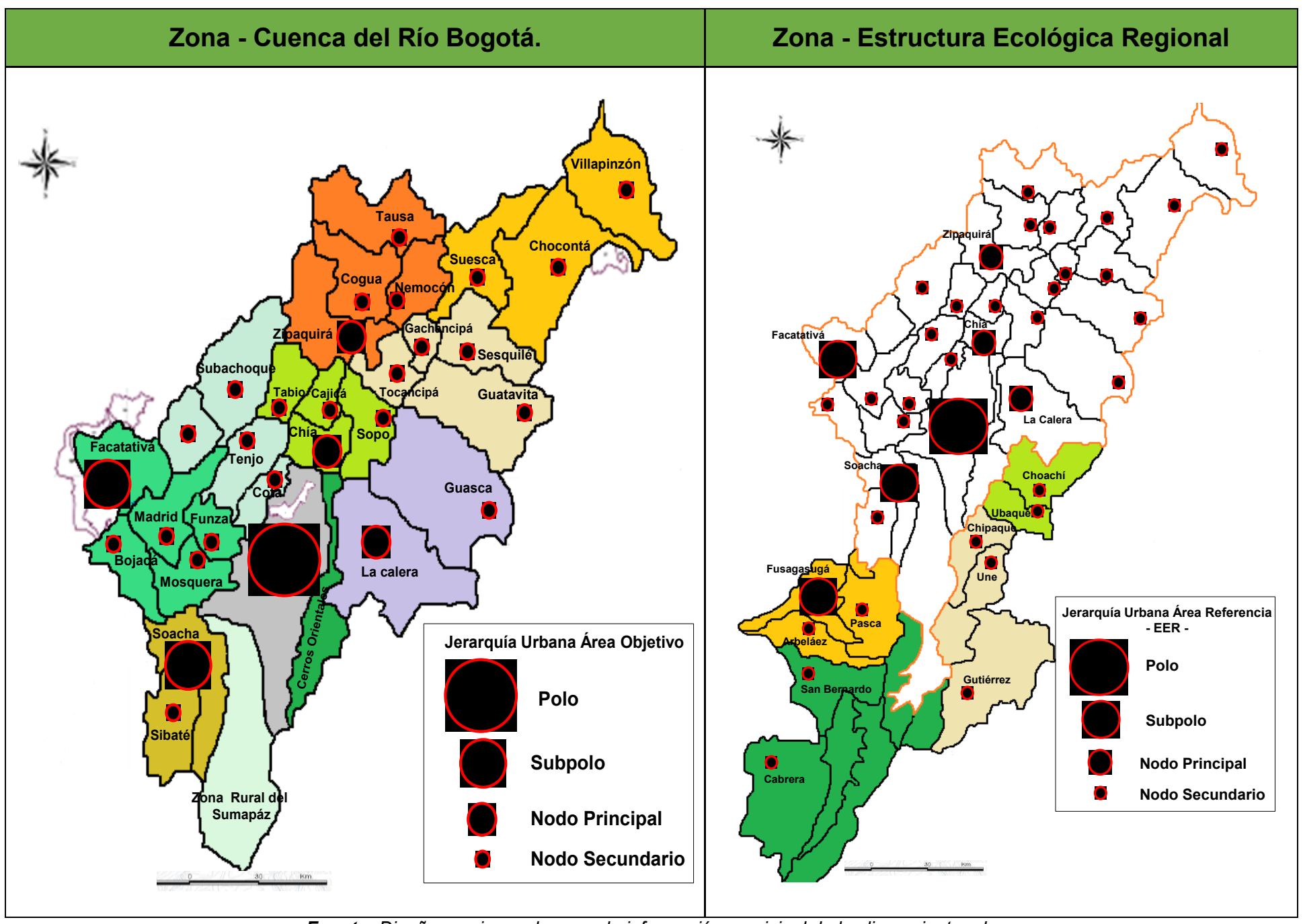

Fuente: Diseño propio con base en la información municipal de los lineamientos de Armonización de los POT de los municipios de Cundinamarca.

\section{$>$ Subpolos}

Se refieren a la población o casco urbano y sus áreas de expansión que puedan en sí mismas convertirse en un centro funcional que atraiga a las poblaciones de los municipios que se encuentran dentro de la región pero que cuente con un menor número de funciones y de menor jerarquía que el polo regional; entre ellos se pueden encontrar: Facatativá, Soacha y con tendencias por su desarrollo y crecimiento urbano las cabeceras de los municipios de, Zipaquirá, Chía y la Calera.

\section{$>$ Área De Influencia}

Se refiere al área de sostenibilidad geoambiental que rodea el polo o subpolo de la subregión. Esta área comprende las áreas rurales y poblados donde se producen tanto los alimentos (hortalizas, frutas, ganadería), para la subregión o para suplir a 
otras subregiones. Asimismo, estas zonas pueden contener las áreas de productividad agroindustrial, industrial o minera de la subregión. Los municipios pertenecientes al área de influencia subregional dependen funcionalmente del polo a tractor en cuanto a servicios y comercio. Por otra parte se deberán planificar para que puedan expandirse y albergar una mayor población. Estos Subpolos, pueden también localizarse fuera de los límites departamentales. Es de anotar que la subregión central denominada Sabana de Bogotá cuenta con un área de influencia muy grande cuya tendencia es a extenderse si no se actúa para promover la desconcentración.

\section{Nodos}

Alrededor de los ejes hay poblaciones que por diferentes características se desarrollan más que otras, bien sea porque allí se concentran mayores servicios, comercios o negocios. Estas poblaciones dependen del funcionamiento del eje y por lo tanto configuran una red a lo largo del mismo. Si el eje decae en importancia estas disminuyen su crecimiento; y si por el contrario se crea un nuevo eje o hay incremento en el flujo vehicular del mismo, sus nodos prosperan. (Fuente: De las Ciudades a las Regiones Desarrollo regional integrado en Bogotá - Cundinamarca).

\subsubsection{El Análisis Espacial (Centros Poblados)}

Se identifica en la estructura regional de la cuenca del Río Bogotá y su área de referencia la cuenca del Río Negro y la cuenca del Sumapáz; en ella se observan la composición de polo central identificado como la ciudad de Bogotá que contiene una parte importante de la población y que puede caracterizarse como una subregión central por sus características sociales, económicas y culturales. Los principales Subpolos de desarrollo se identifican como: Zipaquirá, Facatativá, Soacha y Chía; sobresaliendo en el área Chía y La Calera; todas estas cabeceras municipales tienen un grado relativamente alto de sostenibilidad por razones ecológicas, sociales, económicas y políticas; Donde el municipio de Facatativá (122.320 habitantes), el municipio de Soacha (466.216 habitantes), se identifican como Subpolos denominados centros menores de actividad variada, pero predominante con un número poblacional representativa, con la cual, guarda una relación con el gran polo de desarrollo como lo es la ciudad de Bogotá D.C.

En su orden aparecen los centros denominados nodos principales, que forma parte de un sistema urbano provincial y que cumplen un rol significativo en la producción de bienes y servicios en el contexto de la economía provincial; como es el caso, del centro poblado de la cabecera del municipio de Chía con una población de 114.881habitantes, seguido por el municipio de Zipaquirá 114.161 habitantes, y el municipio de La Calera (26.077habitantes). Veintitrés municipios son los nodos secundarios que por su tamaño poblacional y su vocación económica son dedicados a los servicios agrícolas.

Por lo tanto, la Estructura Ecológica Regional está integrada por treinta y ocho municipios y la ciudad de Bogotá, siendo el municipio de Fusagasugá el jalonador de la subcuenca del Sumapáz, siendo los municipios de Cabrera, San Bernardo con Gutiérrez, los de mayor extensión Territorial y menos ocupación población; lo complementan como nodos secundarios los municipios de Une; Chipaque, Ubaque y Choachí. Predominando su composición ambiental, con grandes valores escénicos 
ecológicos importantes en el suministro de servicios ambientales para la gran ciudad de Bogotá D.C.

\subsubsection{La Situación político administrativa de la cuenca del Rio Bogotá y su área de la Estructura Ecológica Regional.}

Sin pretender hacer un examen exhaustivo de los componentes, objetivos e implicaciones de cada una de las formas actuales de la división política y administrativa tanto del área de estudio como de referencia, se pueden observar tres instancias de orden administrativas que inciden de alguna manera en el fortalecimiento de la institucionalidad en el área de estudio, entre ellas la Provincia, la división de las Corporaciones Autónomas Regionales (CAR) y para el desarrollo de proyectos que se ha venido dando la Asociación Municipal (Véase Mapa 4.17); se identificaron y delimitaron cartográficamente en forma general en relación con el modelo y su construcción efectiva de la división departamental y abstraída al área de estudio y de referencia.

Este ejercicio determinó la base para ver los diferentes tipos de regionalización del territorio y si había algún patrón de coincidencia entre ellos. El ejercicio de superposiciones de estos mapas entre sí y con los mapas correspondientes a la zonificación natural del territorio, permitió establecer las relaciones de prevalencia, coincidencia o discrepancia entre unos y otros. 
Mapa. 4. 17. LA INTEGRACIÓN ESPACIAL.

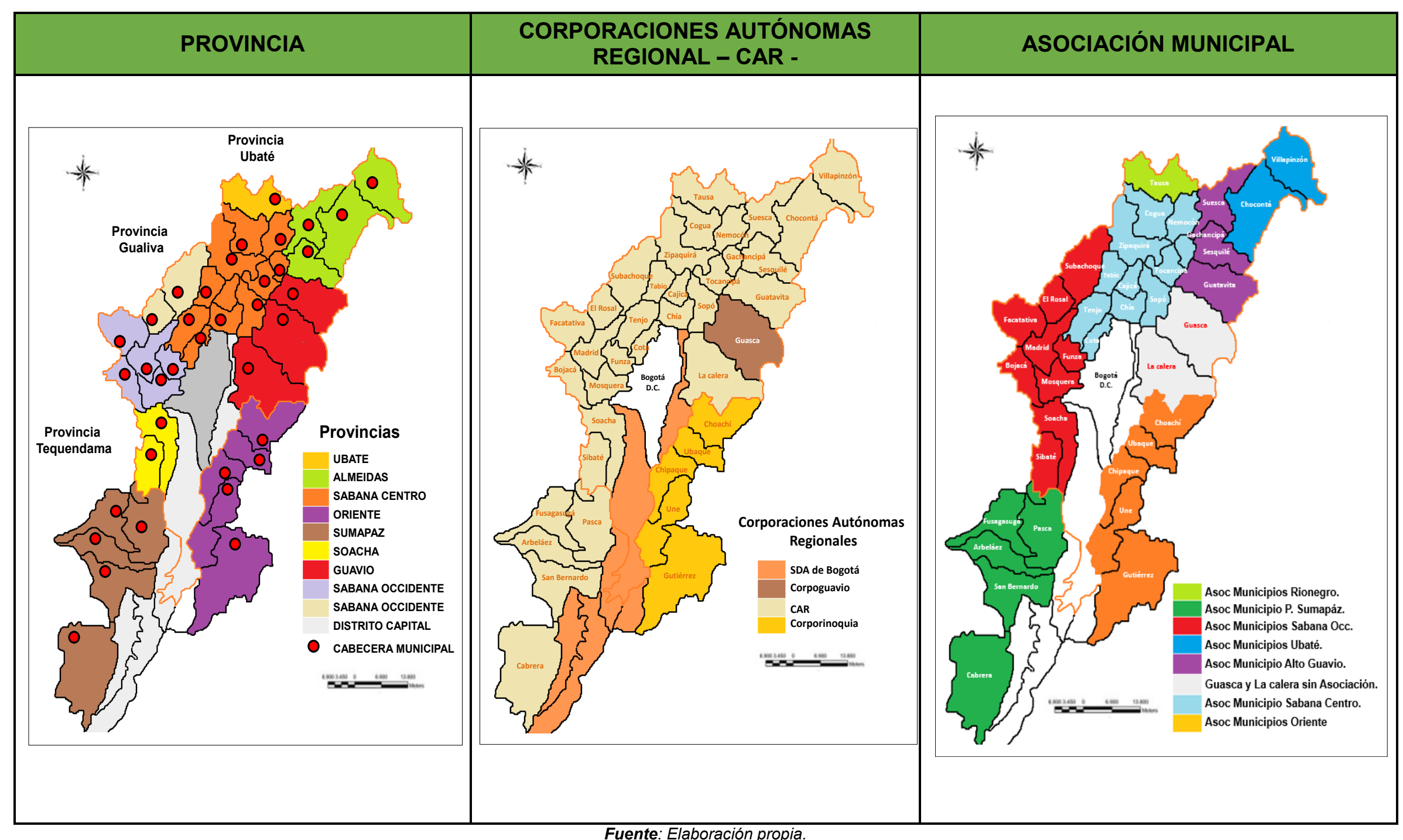

Fuente: Elaboración propia. 


\subsubsection{Los Actores en La Participación y en la Gestión del Territorio.}

La participación activa de la comunidad en el ordenamiento territorial en la valoración de sus problemas y sus soluciones a la medida que se desarrollaban las distintas fases de la planificación territorial cobró vigencia a partir de la promulgación de la Ley 388 de 1997. Hoy en día, la participación se ha constituido en una de las herramientas básicas para legitimarlas inversiones públicas, expuestas en un plan de desarrollo y articuladas a las directrices de la ocupación territorial desde los planes de ordenamiento. Es común encontrar mayor participación de la ciudadanía en la construcción de un plan en un municipio pequeño, llevadas con mayor credibilidad hacia las instancias públicas por su identificación con la administración de turno, son niveles de identidad ciudadana de los residentes con sus problemas, y estos con los cuales lo depositan en las administraciones para sus soluciones.

Cada uno de los actores identifica su responsabilidad social en el territorio a medida que las administraciones han venido interviniendo en obras de infraestructura, las cuales cubren de alguna manera sus necesidades básicas.

Por lo tanto, para los actores institucionales que se identifican dentro del área de la cuenca, son de carácter decisorio las Autoridades Ambientales que tienen su jurisdicción en el área urbana; dependiendo del tamaño del municipio y de su nivel de fortalezas técnicas, se verá más representativo dentro de las decisiones en el territorio.

La jurisdicción de las CAR, están demarcadas por divisiones administrativas, específicamente hacia áreas rurales, por su tamaño y desarrollo son las que determinan el cumplimiento de la política con mayor fuerza, donde actores heterogéneos involucrados en las relaciones de las decisiones en el manejo y distribución de la riqueza, generan relaciones sociales con las cuales actores públicos deberán concertar los escenarios futuros deseables hacia el mejoramiento ambiental del territorio y de la comunidad en general.

En la ciudad de Bogotá se cuenta con la Secretaría Distrital de Ambiente (SDA), cuya jurisdicción se limita al área urbana de la ciudad. La mayoría de los municipios tanto de la cuenca hidrográfica como del área que se ha determinado en la Estructura Ecológica Regional están bajo la jurisdicción de la Corporación Autónoma Regional de Cundinamarca (CAR) que comparte la administración de los recursos naturales con CORPOGUAVIO y CORPORINOQUIA.

Estas instituciones dadas sus competencias son las encargadas de definir los determinantes ambientales, que serán adoptados por los municipios del área, incorporándolos como directrices de manejo a los planes de desarrollo y por supuesto a los planes de ordenamiento territorial municipal. Así mismo, estas autoridades ambientales, trabajando de manera conjunta, pueden armonizar características más homogéneas a las bases de la percepción de lo regional. 


\subsubsection{Las Instancias de Participación de los Actores}

A continuación se presenta el listado de los actores entre ellos: el internacional, nacional, regional, departamental y local; además las entidades descentralizadas que por sus actividades administrativas aportan las bases científicas para el desarrollo la planificación y la gestión territorial.

\subsubsection{Actores Internacionales}

$>$ ICA Instituto Interamericano de Cooperación para la Agricultura.

$>$ Centro de las Naciones Unidas para el Desarrollo Regional.

$>$ FAO Organización de las Naciones Unidas para la agricultura y la alimentación.

$>$ PNUMA. Programa de las Naciones Unidas para el Medio Ambiente.

$>$ PNUD Colombia Programa de las Naciones Unidas para el Desarrollo en Colombia.

$>$ GTZ - Oficina de Cooperación Colombo Alemana.

$>$ JICA Agencia Internacional de Cooperación del Japón.

$>$ USAID Agencia de Estados Unidos para el Desarrollo Internacional.

$>$ CEPAL Comisión Económica para América Latina y el Caribe.

\subsubsection{Actores Nacionales}

$>$ Ministerio de Ambiente, Vivienda y Desarrollo Territorial.

$>$ Consejo Empresarial Colombiano para el Desarrollo Sostenible - CECODES.

$>$ Corporación Autónoma Regional de Cundinamarca - CAR.

$>$ Corporación Autónoma Regional de la Orinoquia - CORPORINOQUIA.

$>$ Corporación Autónoma Regional del Guavio - CORPOGUAVIO.

$>$ Unidad Administrativa Especial del Sistema de Parques Naturales Nacionales UAESPNN.

$>$ Instituto de Hidrología, Meteorología y Estudios Ambientales de Colombia IDEAM.

$>$ Instituto ALEXANDER VON HUMBOLDT.

$>$ Ministerio de Comercio, Industria y Turismo.

$>$ Departamento Nacional de Planeación - DNP.

$>$ Superintendencia de Servicios Públicos.

$>$ Comisión de Regulación de Agua Potable y Saneamiento Básico.

$>$ Instituto Geográfico Agustín Codazzi - IGAC.

$>$ Sistema Nacional de Gestión del Riesgo.

$>$ Instituto Nacional de Vias - INVIAS.

$>$ Instituto Colombiano para el Desarrollo Rural - INCODER.

$>$ Asociación Nacional de Empresarios de Colombia - ANDI- Cámaras sectoriales Responsabilidad Integral.

$>$ Asociación Colombiana de las Micro, Pequeñas y Medianas Empresas - ACOPI.

$>$ Asociación Colombiana de Exportadores de Flores - ASOCOLFLORES.

$>$ Asociación Colombiana de Industriales del Calzado, el Cuero y sus Manufacturas - ACICAM.

$>$ Federación Nacional de Comerciantes - FENALCO.

$>$ Federación Nacional de Lonjas de Propiedad Raíz - FEDELONJAS.

$>$ Cámara Colombiana de la Construcción - CAMACOL.

> Federación Nacional de Ganaderos de Colombia -FEDEGAN. 
> Sociedad de Agricultores de Colombia - SAC.

$>$ Federación Nacional de productores de papa - FEDEPAPA.

> Asociación Colombiana de Agencias de Viajes y Turismo (ANATO).

$>$ Asociación Colombiana De Ingeniería Sanitaria Y Ambiental - ACODAL.

$>$ Federación Colombiana de Municipios.

$>$ Instituto de Estudios Urbanos IDEA e instituto de estudios urbanos.

$>$ Asociación colombiana de investigadores urbana regional - ACIUR. Pontificia Universidad Javeriana.

$>$ Centro de Estudios en Política y Legislación Ambiental de Colombia - CEPLAC.

$>$ ECOFONDO.

$>$ Fundación Natura Colombia.

$>$ Caja de Herramientas - Red Colombiana De Productores Comunitarios Ambientalmente Amigables.

\subsubsection{Actores Regionales}

$>$ Consejo Regional de Competitividad Bogotá y Cundinamarca.

$>$ Asociación de Corporaciones Autónomas Regionales y de Desarrollo SostenibleASOCARS.

$>$ Corporación Ambiental Empresarial - CAEM.

$>$ Cámara de Comercio de Bogotá - Megaproyecto agroindustrial BogotáCundinamarca.

$>$ Universidad de la Sabana.

$>$ Universidad Nacional de Colombia.

$>$ Universidad de Cundinamarca.

$>$ Servicio Nacional de aprendizaje - SENA - Regional Cundinamarca.

$>$ Universidad Piloto de Colombia.

> Universidad Minuto de Dios UNIMINUTO.

$>$ Asociación de Municipios Oriente - Asoriente Chipaque, Une, Cáqueza, Choachí, Fómeque, Fosca, Quetame, Gutiérrez, Guayabetal, Y Ubaque.

> Asociación de Municipios Sabana Centro - Asocentro, Cajicá, Cota, Chía, Cajicá, Gachancipá, Nemocón, Sopo, Tabio, Tenjo, Tocancipá, Zipaquirá.

$>$ Asociación de Municipios Sabana Norte-Chocontá, Y Villapinzón.

$>$ Asociación de Municipios Sabana Occidente - Amsoc, Funza, Madrid, Mosquera, Bojacá, Facatativá, Subachoque, Soacha, Sibaté y El Rosal.

$>$ Asociación de Municipios Provincia De Sumapáz - Asosumapáz, Fusagasugá, Arbeláez, Pasca, San Bernardo, y Cabrera.

\subsubsection{Actores Departamentales}

> Gobernación del Departamento de Cundinamarca, Secretaria de Ambiente Departamental.

$>$ Empresas Públicas de Cundinamarca S.A.

$>$ CREPAD: Consejo Regional de Prevención y Atención de Desastres.

\subsubsection{Actores Distritales}

$>$ Secretaria Distrital de Ambiente - SDA.

> Alcaldía Mayor de Bogotá (Sus Secretarias: Hábitat, Ambiente, Planeación).

$>$ Instituto Distrital de Recreación y Deporte (IDRD). 
Universidades - Centro de Investigaciones.

\subsubsection{Actores Municipales}

Alcaldes Municipales.

$>$ Secretarios de Despacho.

\subsubsection{Otros Actores}

$>$ Fundación Humedales.

$>$ Fundación Al Verde Vivo.

$>$ Fundación Cerros Orientales.

$>$ Mesa Ambiental de los Cerros Orientales.

$>$ Mesa de Planificación Regional.

La identificación y participación de actores para el fortalecimiento en la toma de decisiones en cada una de los NOAT que se establezcan en la fase de formulación, serán de suma importancia teniendo en cuenta que son las bases para la planificación y ordenamiento del territorio, además para la proyección regional.

\subsection{CARACTERIZACIÓN DE LA DIMENSIÓN ECONÓMICA Y SU ÁREA DE REFERENCIA ${ }^{83}$}

La ley 617 de 2000, modificó la categorización en el país, tanto para los departamentos, como para los municipios. En el artículo sexto, dicha ley clasifica los distritos y los municipios de acuerdo con su población y sus ingresos corrientes de libre destinación.

Los ingresos percibidos por los municipios se dividen en ingresos corrientes e ingresos de capital. Dentro de los ingresos corrientes se encuentran los ingresos tributarios y los no tributarios. Los tributarios son creados por el ente territorial y son el resultado de la gestión fiscal municipal; dentro de los no tributarios, el mayor rubro corresponde a las transferencias del Sistema General de Participación (que está compuesto por las transferencias de libre destinación y las transferencias para inversión). Estos ingresos están formados principalmente por los recursos de cofinanciación, los recursos de crédito (banca comercial pública y banca comercial privada) y los recursos de balance ${ }^{84}$.

La capacidad de endeudamiento (o de pago) de los municipios está dada por el cálculo de los intereses de la deuda, el ahorro operacional, el saldo de la deuda y los ingresos corrientes. Esta capacidad de pago se basa en tres niveles de endeudamiento, los cuales se relacionan a continuación:

$>$ El endeudamiento autónomo: se presenta cuando el cociente entre los intereses de la deuda y el ahorro operacional es menor o igual al $40 \%$ y el cociente del saldo de la deuda y los ingresos corrientes es menor o igual al $80 \%$.

\footnotetext{
83 A continuación se presenta soportes con base en la Información del Anuario estadístico del Departamento de Cundinamarca 2010 (datos de SISBEN).

${ }^{84}$ Ingresos municipales Anuario estadístico de Cundinamarca 2011
} 
$>$ Endeudamiento intermedio: se presenta cuando el cociente entre los intereses de la deuda y el ahorro operacional es mayor al $40 \%$ y menor al $60 \%$, y el cociente entre el saldo de la deuda y los ingresos corrientes son menores al $80 \%$.

$>$ Endeudamiento crítico: se ocasiona cuando el cociente entre los intereses de la deuda y el ahorro operacional es mayor al $60 \%$ y el cociente del saldo de la deuda y los ingresos corrientes son mayores al $80 \%$.

De acuerdo con el informe de la Dirección de Finanzas Públicas de la Secretaría de Planeación de la Gobernación de Cundinamarca, en el 63,4\% de los municipios la capacidad de pago se encuentra en "endeudamiento autónomo", es decir, no requieren autorización del Ministerio de Hacienda para adquirir empréstitos con la banca privada o pública y el $36,6 \%$ de los municipios no poseen deudas con entidades del sector financiero.

Con relación a la sostenibilidad de los municipios (saldo deuda/ingresos corrientes $=<$ $80 \%)$, los que presentan mayores porcentajes son: Cajicá $(49,5 \%)$, Mosquera $(33,8 \%)$, Facatativá $(34,9 \%),(32,9 \%)$ y Chía $(29,6 \%)$, dentro del área de referencia que comprende la Estructura Ecológica Regional, como se evidencia en los resultados de dimensión económica - índice de desarrollo sostenible (Véase anexo 8 y 10).

Según lo anterior los municipios en el área se clasifican de la siguiente manera:

> Categoría Especial: Comprende los municipios con población mayor a 500.001 habitantes e ingresos corrientes superiores a 400.00 salarios mínimos légales mensuales vigentes (SMLM).

> Categoría Primera: Son los municipios que poseen una población entre 100.001 y 500.00 habitantes e ingresos corrientes entre 100.00 y 400.000 SMLMV.

> Categoría Segunda: Municipios que poseen una población entre 50.001 y 100.00 habitantes e ingresos corrientes entre 50.00 y 100.000 SMLMV.

$>$ Categoría Tercera: Son los municipios que poseen una población entre 30.001 y 50.00 habitantes e ingresos corrientes entre 30.000 y 50.000 SMLMV.

> Categoría Cuarta: Son los municipios que poseen una población entre 20.001 y 30.000 habitantes e ingresos corrientes entre 25.000 y 30.000 SMLMV.

> Categoría Quinta: Son los municipios que poseen una población entre 10.001 y 20.000 habitantes e ingresos corrientes entre 15.000 y 25.000 SMLMV.

$>$ Categoría Sexta: En esta categoría se encuentran los municipios que poseen una población igualo menor a 10.000 habitantes e ingresos corrientes menores e igual a 15.000 SMLMV. (Véase Tabla 4.20 y Mapa 4.18).

Según información del anuario estadístico del Departamento de Cundinamarca, en el 2008 los municipios de Chía, Mosquera y Soacha se encontraban en la segunda categoría, Cajicá, Cota, Facatativá, Funza, Fusagasugá, Tocancipá y Zipaquirá se 
ubicaron en la categoría Tercera. La situación durante 2010 no varió para estos municipios.

\section{Figura 4.16. SÍNTESIS Y CARACTERIZACIÓN DE LA ESPACIALIZACIÓN DEL BIOGRAMA EN LA DIMENSIÓN ECONOMICA.}

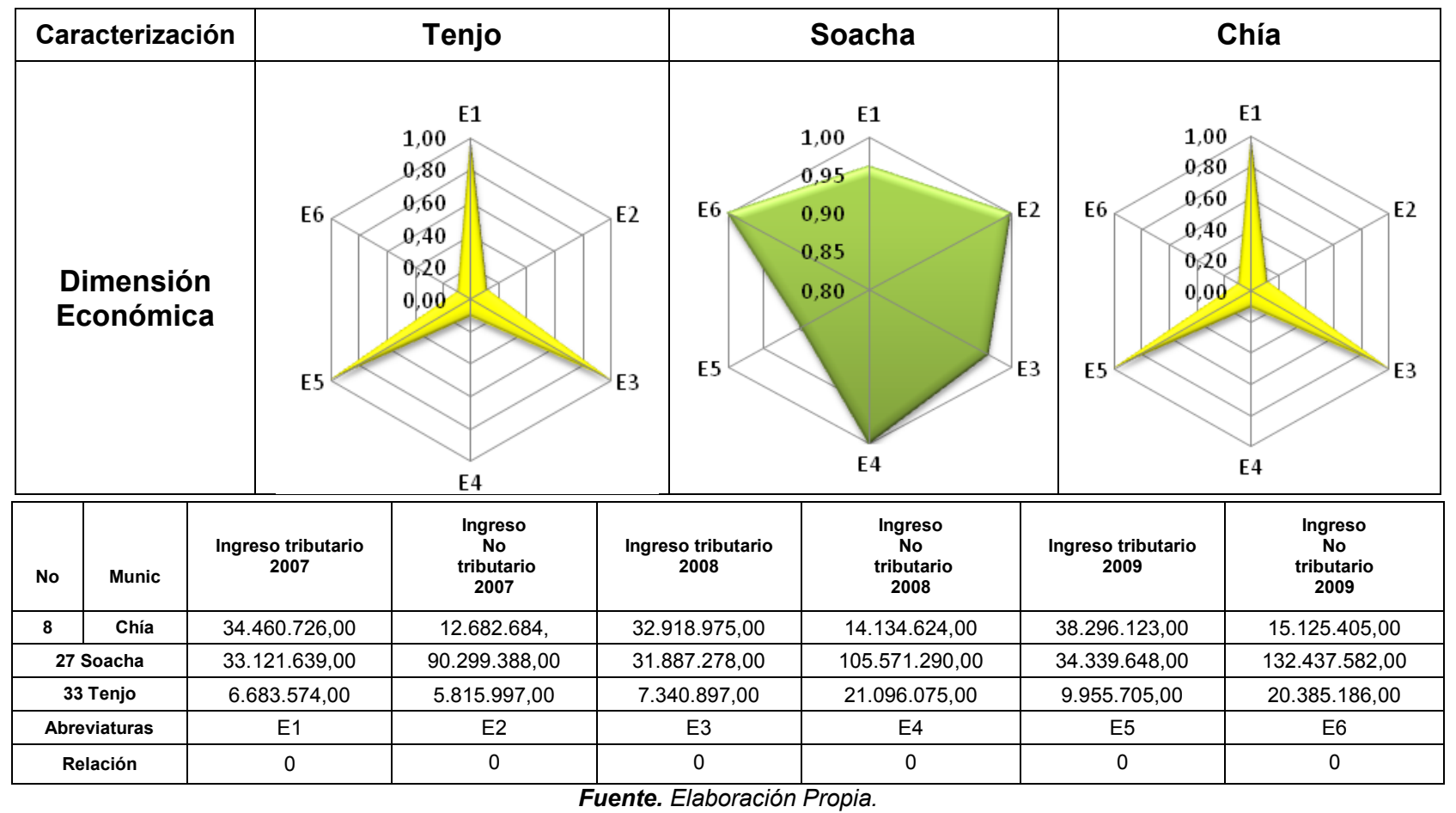

Tabla 4. 20. CATEGORIZACIÓN DE LOS MUNICIPIOS EN 2010.

\begin{tabular}{|l|l|c|l|}
\hline No & \multicolumn{1}{|c|}{ MUNICIPIO } & $\begin{array}{c}\text { CATEGORÍA } \\
2010\end{array}$ & \multicolumn{1}{|c|}{ DECRETO } \\
\hline 1 & Arbeláez & $6 a$ & $\begin{array}{l}\text { Decreto } \text { No 27/10/1009 } \\
\text { aclaratorioD13322/10/2008 de }\end{array}$ \\
\hline 2 & Bojacá & $6 a$ & Decreto No 130DE23/10/2009 \\
\hline 3 & Cabrera & $6 a$ & Decreto No 63 de 28/10/2009 \\
\hline 4 & Cajicá & $3 a$ & Decreto No 076 Sep./22/de 2009 \\
\hline 5 & Chía & $2 a$ & Decreto No 074 Agosto/ de 2009 \\
\hline 6 & Chipaque & $6 a$ & Decreto No 058 de 07 de octubre/2009 \\
\hline 7 & Choachí & $6 a$ & Decreto No 100.09-074 de 02 de 0ctubre/2009 \\
\hline 8 & Chocontá & $6 a$ & Decreto No 114 de 01/10/2009 \\
\hline 9 & Cogua & $5 a$ & Decreto No 074 Sep./1 de 2009 \\
\hline 10 & Cota & $3 a$ & Decreto No2060 octubre 18/2009 \\
\hline
\end{tabular}




\begin{tabular}{|c|c|c|c|}
\hline No & MUNICIPIO & $\begin{array}{c}\text { CATEGORÍA } \\
2010\end{array}$ & DECRETO \\
\hline 11 & El Rosal & $6 a$ & Decreto No 098 de 07/10/2009 \\
\hline 12 & Facatativá & $3 a$ & Decreto No 251 de 02/10/2009 \\
\hline 13 & Funza & $4 a$ & Decreto No 0009 de 19/10/2009 \\
\hline 14 & Fusagasugá & $3 a$ & Decreto No 459 de 9/10/2008 \\
\hline 15 & Gachancipá & $6 a$ & Decreto No 073 Sep./22/2009 \\
\hline 16 & Guasca & $6 a$ & Decreto No 055 de 26 de octubre/2009 \\
\hline 17 & Guatavita & $6 a$ & Decreto No 075 de 07 de octubre/2009 \\
\hline 18 & Gutiérrez & $6 a$ & Decreto No 060 de 03 de agosto /2009 \\
\hline 19 & La Calera & $6 a$ & Decreto No 111 de octubre /2009 \\
\hline 20 & Madrid & $4 a$ & Decreto No 142 de 19/10/2009 \\
\hline 21 & Mosquera & $2 a$ & Decreto No 150 de 26/10/2009 \\
\hline 22 & Nemocón & $6 a$ & Decreto No 56 Sep./22/2009 \\
\hline 23 & Pasca & $6 a$ & Decreto No 041 de 25/10/2008 \\
\hline 24 & San Bernardo & $6 a$ & Decreto No 050 de 31/10/2008 \\
\hline 25 & Sesquilé & $6 a$ & Decreto No 075 de 25/08/2009 \\
\hline 26 & Sibaté & $5 a$ & Decreto No 060 de 03 agosto/2009 \\
\hline 27 & Soacha & $2 a$ & Decreto No 381 de 29 de octubre/2009 \\
\hline 28 & Sopó & $4 a$ & Decreto No 091 Octubre 14/2009 \\
\hline 29 & Subachoque & $6 a$ & Resolución No 553 de 27/10/1009 Contraloría G.N \\
\hline 30 & Suesca & $6 a$ & Decreto No 056 de 30/09/2009 \\
\hline 31 & Tabio & $6 a$ & Decreto No 067 octubre 19 de 2009 \\
\hline 32 & Tausa & $6 a$ & Decreto No 035 sep7/2009 \\
\hline 33 & Tenjo & $5 a$ & Decreto No 065 Agosto 03/2009 \\
\hline 34 & Tocancipá & $5 a$ & Decreto No 067 Octubre/2009 \\
\hline 35 & Ubaque & $6 a$ & Decreto No 037 de octubre/2009 \\
\hline 36 & Une & $6 a$ & Decreto No 049 de 01 de octubre/2009 \\
\hline 37 & Villapinzón & $6 a$ & Decreto No 169 de 24/08/2009 \\
\hline 38 & Zipaquirá & $3 a$ & Decreto No 150 sep. de 2009 \\
\hline
\end{tabular}

Fuente: Elaboración propia desde la información del Anuario Estadístico de Cundinamarca. 
Mapa 4.18. LA ESPACIALIZACIÓN Y LA CATEGORIZACIÓN MUNICIPAL

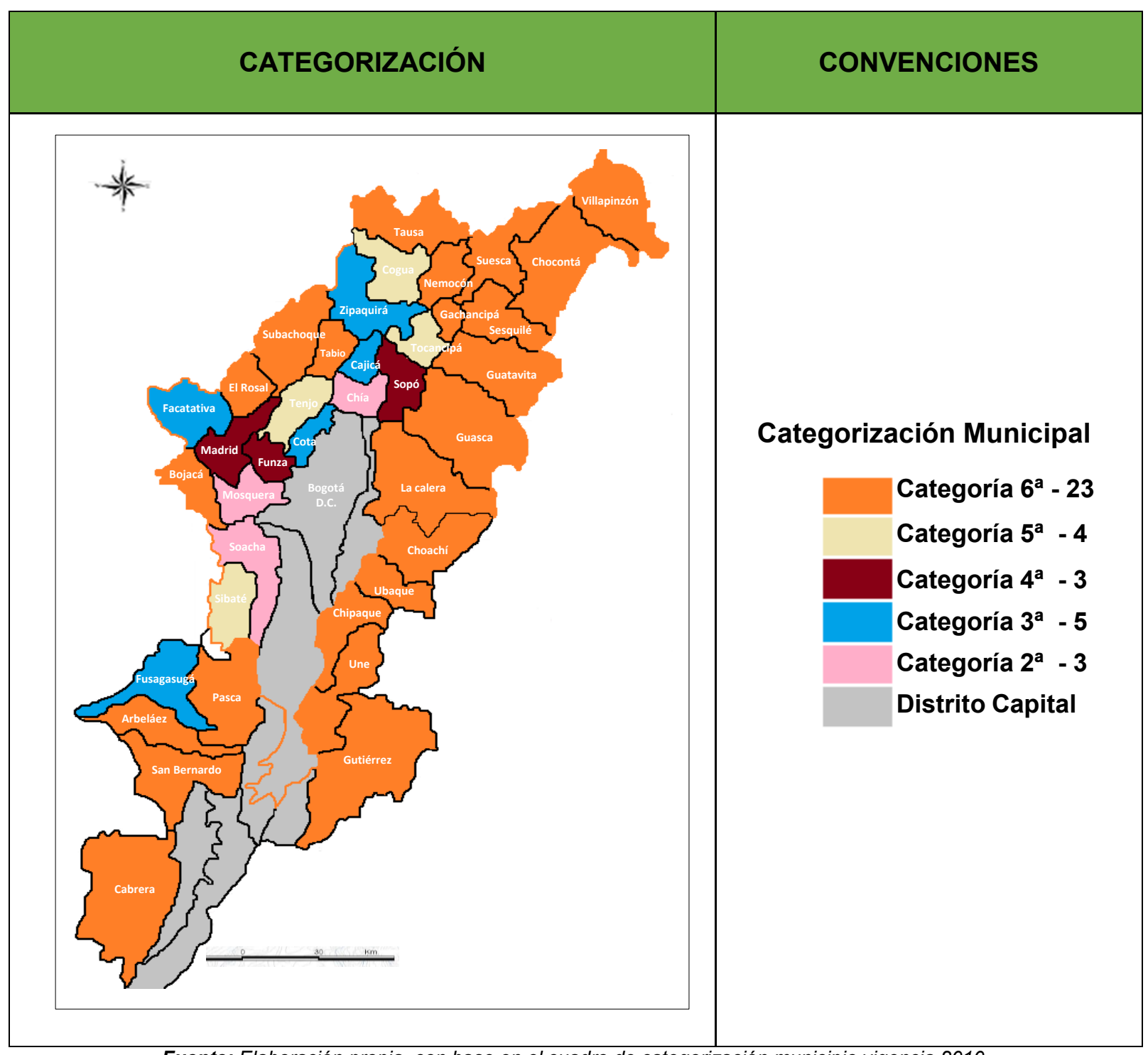

Fuente: Elaboración propia, con base en el cuadro de categorización municipio vigencia 2010.

Tabla 4.21. INGRESOS POR MUNICIPIO AÑOS 2007 - 2008 - 2009.

\begin{tabular}{|l|l|l|r|r|r|}
\hline \multirow{2}{*}{ No } & \multirow{2}{*}{ MUNICIPIO } & DETALLE & \multicolumn{1}{|c|}{2007} & \multicolumn{1}{c|}{2008} & \multicolumn{1}{c|}{2009} \\
\hline \multirow{2}{*}{1} & \multirow{2}{*}{ Arbeláez } & Tributario & $816.142,00$ & $895.876,00$ & $872.372,00$ \\
\cline { 3 - 6 } & & No Tributario & $4.186 .563,00$ & $4.361 .124,00$ & $4.837 .962,00$ \\
\hline \multirow{2}{*}{2} & \multirow{2}{*}{ Bojacá } & Tributario & $1.576 .569,00$ & $1.703 .714,00$ & $1.799 .896,00$ \\
\cline { 3 - 6 } & & No Tributario & $2.714 .310,00$ & $3.565 .487,00$ & $4.169 .256,00$ \\
\hline \multirow{2}{*}{3} & \multirow{2}{*}{ Cabrera } & Tributario & $172.200,00$ & $245.221,00$ & $245.148,00$ \\
\cline { 3 - 6 } & No Tributario & $2.847 .342,00$ & $2.633 .854,00$ & $3.419 .786,00$ \\
\hline \multirow{2}{*}{4} & \multirow{2}{*}{ Cajicá } & Tributario & $15.377 .110,00$ & $16.878 .838,00$ & $19.199 .160,00$ \\
\cline { 3 - 6 } & No Tributario & $6.458 .532,00$ & $7.891 .198,00$ & $9.280 .165,00$ \\
\hline 5 & Chía & Tributario & $34.460 .726,00$ & $32.918 .975,00$ & $38.296 .123,00$ \\
\hline
\end{tabular}




\begin{tabular}{|c|c|c|c|c|c|}
\hline No & MUNICIPIO & DETALLE & 2007 & 2008 & 2009 \\
\hline & & No Tributario & $12.682 .684,00$ & $14.134 .624,00$ & $15.125 .405,00$ \\
\hline \multirow{2}{*}{6} & \multirow{2}{*}{ Chipaque } & Tributario & $901.862,00$ & $1.065 .352,00$ & $1.232 .521,00$ \\
\hline & & No Tributario & $3.537 .513,00$ & $3.423 .228,00$ & $4.231 .215,00$ \\
\hline \multirow{2}{*}{7} & \multirow{2}{*}{ Choachí } & Tributario & $1.019 .018,00$ & $1.019 .917,00$ & $1.178 .676,00$ \\
\hline & & No Tributario & $3.648 .390,00$ & $3.691 .587,00$ & $4.964 .765,00$ \\
\hline \multirow{2}{*}{8} & \multirow{2}{*}{ Chocontá } & Tributario & $1.980 .520,00$ & $1.999 .005,00$ & $2.376 .406,00$ \\
\hline & & No Tributario & $8.162 .343,00$ & $9.171 .633,00$ & $8.381 .924,00$ \\
\hline \multirow{2}{*}{9} & \multirow{2}{*}{ Cogua } & Tributario & $6.010 .983,00$ & $7.098 .619,00$ & $6.808 .503,00$ \\
\hline & & No Tributario & $4.172 .732,00$ & $4.433 .035,00$ & $5.121 .430,00$ \\
\hline \multirow{2}{*}{10} & \multirow{2}{*}{ Cota } & Tributario & $17.673 .320,00$ & $19.586 .438,00$ & $23.758 .651,00$ \\
\hline & & No Tributario & $5.164 .586,00$ & $6252.446,00$ & $4.959 .563,00$ \\
\hline \multirow[b]{2}{*}{11} & \multirow{2}{*}{ El rosal } & Tributario & $1.566 .014,00$ & $1.726 .671,00$ & $2.943 .535,00$ \\
\hline & & No Tributario & $4.018 .230,00$ & $5.144 .496,00$ & $5.375 .826,00$ \\
\hline \multirow{2}{*}{12} & \multirow{2}{*}{ Facatativá } & Tributario & $13.724 .000,00$ & $17.127 .000,00$ & $21.990 .290,00$ \\
\hline & & No Tributario & $14.644 .025,00$ & $19.669 .314,00$ & $20.552 .096,00$ \\
\hline \multirow{2}{*}{13} & \multirow{2}{*}{ Funza } & Tributario & $12.052 .333,00$ & $11.956 .044,00$ & $19.329 .378,00$ \\
\hline & & No Tributario & $9.213 .315,00$ & $12.684 .895,00$ & $9.631 .178,00$ \\
\hline \multirow{2}{*}{14} & \multirow{2}{*}{ Fusagasugá } & Tributario & $11.501 .533,00$ & $12.287 .792,00$ & $15.310 .720,00$ \\
\hline & & No Tributario & $38.012 .261,00$ & $42.007 .734,00$ & $51.436 .052,00$ \\
\hline \multirow{2}{*}{15} & & Tributario & $1.514 .056,00$ & $1.604 .853,00$ & $4.719 .519,00$ \\
\hline & Gachancıpa & No Tributario & $2.251 .793,00$ & $3.570 .566,00$ & $6.050 .969,00$ \\
\hline & & Tributario & $2.506 .312,00$ & $2.238 .558,00$ & $2.671 .092,00$ \\
\hline 16 & Guasca & No Tributario & $3.543 .132,00$ & $3.837 .719,00$ & $4.336 .278,00$ \\
\hline & & Tributario & $870.489,00$ & $798.843,00$ & $954.915,00$ \\
\hline 18 & Guatavita & No Tributario & $4.735 .119,00$ & $4.209 .725,00$ & $4.236 .075,00$ \\
\hline & & Tributario & $333.114,00$ & $189.513,00$ & $160.344,00$ \\
\hline 10 & Gutientez & No Tributario & $3.655 .954,00$ & $2.826 .877,00$ & $3.208 .794,00$ \\
\hline & & Tributario & $5.467 .062,00$ & $5.679 .949,00$ & $5.816 .041,00$ \\
\hline 19 & La calera & No Tributario & $4.261 .821,00$ & $47.528 .570,00$ & $4.924 .033,00$ \\
\hline & & Tributario & $10.915 .799,00$ & $11.684 .460,00$ & $16.732 .634,00$ \\
\hline 20 & Madrıd & No Tributario & $16.095 .911,00$ & $11.844 .752,00$ & $10.703 .928,00$ \\
\hline & & Tributario & $19.248 .813,00$ & $20.649 .626,00$ & $30.930 .569,00$ \\
\hline 21 & Mosquera & No Tributario & $8.673 .153,00$ & $12.021 .037,00$ & $11.934 .160,00$ \\
\hline & & Tributario & $3.372 .935,00$ & $1.382 .239,00$ & $1.422 .133,00$ \\
\hline 22 & Nemocon & No Tributario & $3.406 .297,00$ & $3.823 .669,00$ & $7.649 .606,00$ \\
\hline & Pasca & Tributario & $739.883,00$ & $667.926,00$ & $693.575,00$ \\
\hline 23 & & No Tributario & $3.907 .501,00$ & $3.432 .216,00$ & $3.665 .005,00$ \\
\hline & & Tributario & $506.246,00$ & $416.134,00$ & $482.028,00$ \\
\hline 24 & San Bernardo & No Tributario & $5.153 .417,00$ & $4.457 .808,00$ & $4.909 .743,00$ \\
\hline & & Tributario & $1.384 .539,00$ & $1.391 .152,00$ & $1.942 .550,00$ \\
\hline 25 & Sesquile & No Tributario & $2.951 .655,00$ & $3.854 .294,00$ & $4.060 .818,00$ \\
\hline & & Tributario & $10.036 .449,00$ & $10.757 .596,00$ & $11.073 .632,00$ \\
\hline 26 & Sibate & No Tributario & $6.081 .815,00$ & $6.298 .822,00$ & $7.672 .559,00$ \\
\hline 27 & & Tributario & $33.121 .639,00$ & $31.887 .278,00$ & $34.339 .648,00$ \\
\hline 21 & soacha & No Tributario & $90.299 .388,00$ & $107.571 .290,00$ & $132.437 .582,00$ \\
\hline 28 & Sono & Tributario & $9.560 .808,00$ & $10.616 .868,00$ & $12.073 .472,00$ \\
\hline 20 & sopo & No Tributario & $4.019 .962,00$ & $4.091 .103,00$ & $4.787 .663,00$ \\
\hline & & Tributario & $2.688 .616,00$ & $3.792 .200,00$ & $3.333 .763,00$ \\
\hline 29 & Subach & No Tributario & $4.101 .423,00$ & $4.237 .737,00$ & $4.731 .068,00$ \\
\hline & & Tributario & $969.623,00$ & $1.287 .671,00$ & $1.204 .254,00$ \\
\hline 30 & & No Tributario & $2.945 .886,00$ & $5.338 .824,00$ & $5.581 .562,00$ \\
\hline & & Tributario & $2.881 .494,00$ & $2.575 .088,00$ & $2.894 .707,00$ \\
\hline 31 & Iablo & No Tributario & $4.011 .125,00$ & $5.062 .905,00$ & $5.173 .003,00$ \\
\hline 32 & Tausa & Tributario & $598.346,00$ & $590.287,00$ & $800.825,00$ \\
\hline
\end{tabular}




\begin{tabular}{|c|c|c|c|c|c|}
\hline No & MUNICIPIO & DETALLE & 2007 & 2008 & 2009 \\
\hline & & No Tributario & $3.370 .076,00$ & $3.287 .815,00$ & $4.092 .007,00$ \\
\hline \multirow{2}{*}{33} & \multirow{2}{*}{ Tenjo } & Tributario & $6.683 .574,00$ & $7.340 .897,00$ & $9.955 .705,00$ \\
\hline & & No Tributario & $5.815 .997,00$ & $4.068 .816,00$ & $5.230 .580,00$ \\
\hline \multirow[b]{2}{*}{34} & \multirow{2}{*}{ Tocancipá } & Tributario & $19.496 .755,00$ & $21.096 .075,00$ & $20.385 .186,00$ \\
\hline & & No Tributario & $7.209 .114,00$ & $6.632 .242,00$ & $7.019 .925,00$ \\
\hline \multirow{2}{*}{35} & \multirow{2}{*}{ Ubaque } & Tributario & $328.796,00$ & $380.472,00$ & $418.544,00$ \\
\hline & & No Tributario & $2.630 .733,00$ & $3.112 .758,00$ & $3.531 .733,00$ \\
\hline \multirow{2}{*}{36} & \multirow{2}{*}{ Une } & Tributario & $748.227,00$ & $505.124,00$ & $554.970,00$ \\
\hline & & No Tributario & $7.427 .310,00$ & $3.849 .845,00$ & $4.127 .974,00$ \\
\hline \multirow{2}{*}{37} & \multirow{2}{*}{ Villapinzón } & Tributario & $1.444 .052,00$ & $1.633 .952,00$ & $1.800 .624,00$ \\
\hline & & No Tributario & $8.470 .557,00$ & $7.141 .657,00$ & $7.131 .203,00$ \\
\hline \multirow{2}{*}{38} & \multirow{2}{*}{ Zipaquirá } & Tributario & $10.973 .827,00$ & $13.325 .427,00$ & $16.916 .027,00$ \\
\hline & & No Tributario & $23.242 .186,00$ & $22.027 .295,00$ & $32.371 .791,00$ \\
\hline
\end{tabular}

Fuente: Anuario Estadístico del Departamento de Cundinamarca 2011.

\subsubsection{El Ingreso Municipal como parte del Desarrollo Territorial}

Para los fines del ordenamiento gestión y administración territorial, son definitivos los ingresos, ya que estos determinan las posibilidades de endeudamiento. Están divididos los ingresos percibidos por los municipios en ingresos corrientes e ingresos de capital.

Dentro de los ingresos corrientes se encuentran los ingresos tributarios y los no tributarios. Los tributarios son creados por el ente territorial y son el resultado de la gestión fiscal municipal; dentro de los no tributarios el mayor rubro corresponde a las transferencias del Sistema General de Participación (que está compuesto por las transferencias de libre destinación y las transferencias para inversión). Los ingresos de capital están formados principalmente por los recursos de cofinanciación, los recursos de crédito (banca comercial pública y banca comercial privada) y los recursos de balance. (Véase Tabla 4.21.).

\subsubsection{Las Capacidades de Endeudamiento}

La capacidad de endeudamiento (o de pago) de los municipios está dada por el cálculo de los intereses de la deuda, el ahorro operacional, el saldo de la deuda y los ingresos corrientes.

Esta capacidad de pago se basa en tres niveles de endeudamiento:

$>$ El endeudamiento autónomo se presenta cuando el cociente entre los intereses de la deuda y el ahorro operacional es menor o igual al $40 \%$ y el cociente del saldo de la deuda y los ingresos corrientes es menor o igual al $80 \%$.

$>$ El endeudamiento intermedio se presenta cuando el cociente entre los intereses de la deuda y el ahorro operacional es mayor al $40 \%$ y menor al $60 \%$, y el cociente entre el saldo de la deuda y los ingresos corrientes son menores al $80 \%$.

$>$ El endeudamiento crítico se ocasiona cuando el cociente entre los intereses de la deuda y el ahorro operacional es mayor al $60 \%$ y el cociente del saldo de la deuda y los ingresos corrientes son mayores al $80 \%$. 
De acuerdo con el informe de la Dirección de Finanzas Públicas de la Secretaría de Planeación de la Gobernación de Cundinamarca, en el 63,4\% de los municipios la capacidad de pago se encuentra en "endeudamiento autónomo", es decir, no requieren autorización del Ministerio de Hacienda para adquirir empréstitos con la banca privada o pública y el $36,6 \%$ de los municipios no poseen deudas con entidades del sector financiero.

Con relación a la sostenibilidad de los municipios (saldo deuda/ingresos corrientes $=<$ $80 \%)$, los que presentan mayores porcentajes son: Cajicá $(49,5 \%)$, Mosquera $(33,8 \%)$, Facatativá $(34,9 \%),(32,9 \%)$ y Chía $(29,6 \%)$, dentro del área de referencia que comprende la Estructura Ecológica Regional.

\subsection{LA CARACTERIZACIÓN Y LA VALORACIÓN DE LA DIMENSIÓN ECONÓMICA.}

En esta dimensión se relaciona la capacidad presupuestal de cada uno de los municipios, para generar los bienes y riquezas necesarias para el presente y el futuro de sus habitantes, Se reconoce la importancia de la categorización municipal en lo referente a la construcción del plan de desarrollo, determinando en el manejo de sus ingresos en la promoción de mercados e industrias locales, y la valoración de los recursos naturales en los ámbitos regionales y local. (Véase Tabla 4.22.).

La capacidad de gestión de los municipios es otro componente fundamental, pues de ello depende que se logre avanzar para un nuevo modelo de organizacional administrativa con fines en la distribución de proyectos colectivos. La capacidad de manejar de formas eficiente y competitiva los ingresos, en un contexto de cambios drásticos, es sin duda, un factor decisivo para garantizar el éxito de la transformación institucional desde lo económico en lo concerniente a su inserción potencial en la visión de la región, más si el nivel de contextualización es la cuenca hidrográfica.

Las relaciones económicas y productivas son tan importantes como las que se generan en los mercados globales, pues ambos afectan y modifican las tendencias productivas tradicionales. Para ello, se tomaron los ingresos de los últimos años 2007, 2008 y 2009 , para determinar el nivel de endeudamiento municipal, dependiendo de su propia categoría municipal, como parte del posicionamiento en el territorio. (Véase Tabla 4.22).

Lo cual posibilita entender el nivel de fortalecimiento institucional, su relación con otros contextos como el departamental o en el mismo sentido en el nacional, ello, enmarca a los municipios o entidades territoriales en el manejo de programas y proyectos teniendo en cuenta las características analizadas desde la dimensión ambiental y social. En la espacialización del Biograma el colapso económico en el mismo manejo de sus propios ingresos, demuestra el colapso de las finanzas públicas en el caso de intervenir mejoras en algunas políticas públicas, como por ejemplo las relacionadas con proyectos de ejecución identificados desde sus propios Planes de Ordenamiento Territorial (POT).

Por lo tanto, el interés de visualizar a través de la metodología del Biograma, son las tendencias de los ingresos de cada uno de los municipales que integran el área de estudio. Las particularidades de los compromisos que cada uno de ellos, han venido estableciendo en el mejoramiento de la calidad de vida de sus pobladores como de la intervención en el territorio en términos de infraestructura básica. 
En la gráfica síntesis del Biograma - Desequilibrio territorial en lo Ambiental, Social y Económico el resultado del Biograma encontró para los 38 municipios en lo: Ambiental 5,26\% Inestables; el 94,74\% Crítico; en lo Social el 23,68\% Optimo, el 57,89\% Estable, el 15,78\% Inestable, el 2,63 Crítico; en lo Económico el 2,63\% Optimo el 2,63\% Inestable, el $23,68 \%$ Crítico y el $71,05 \%$ en Colapso. Ver grafica al final.

En este contexto, el grado de desarrollo sostenible en relación a la competitividad económica, la equidad social y a la sustentabilidad medio ambiental conforma un proceso cuyas tendencias precisan al planteamiento de políticas públicas más acordes al desarrollo financiero y lo económico referentes al fortalecimiento de los procesos de descentralización. (Véase Anexo 7).

\subsection{GESTIÓN FISCAL DE LAS ENTIDADES TERRITORIALES}

Al presentar el desempeño fiscal en los años 2009/10/11, caso por caso en los 38 municipios, a partir de la medición de seis indicadores, los resultados indican que las entidades territoriales más consolidadas mantienen buenos desempeños financieros y tradicionalmente han venido ocupando los mejores lugares en la medición, mientras que el resto de entidades territoriales con algunas excepciones, evidencian bajos desempeños fiscales y persiste el rezago que las acompaña hace varios años ${ }^{85}$.

Cuyo propósito es fortalecer institucionalmente la territorialidad sobre el manejo fiscal que los alcaldes están dando a las finanzas públicas, caso indagado en la dimensión económica por medio del Biograma demostrándose el nivel de colapso en la puesta en marcha de los planes de desarrollo y la inversión pública en sectores sociales y de infraestructura en el comportamiento de los recursos directos e indirectos del plan. Por lo tanto, para mejorar los resultados focalizar sus acciones preventivas y de acompañamiento para la presentación de propuestas que contribuyan a mejorar la descentralización fiscal del área territorialmente demarcada por la Estructura Ecológica Regional.

La fuente de información se realizó con base en la siguiente información suministrada por el Departamento de Planeación Nacional (DNP) a través de: la ejecución presupuestales reportadas al Ministerio de Hacienda y Crédito Público - Min Hacienda a través del análisis municipal efectuado con la información reportada por las entidades territoriales por medio del Formulario Único Territorial (FUT). Cuyos objetivos es el de analizar las entidades territoriales de mejores desempeños fiscales; determinar las entidades territoriales con mayores recursos fiscales; la capacidad de las entidades territoriales para autofinanciar su funcionamiento; el grado de transferencia de los recursos fiscales; la capacidad de ahorro; el peso relativo de la inversión en el gasto; la capacidad de respaldo del servicio de la deuda y los cambios en resultados fiscales frente a los resultados fiscales frente a los alcanzados en la vigencia anterior.

Una vez identificados los municipios del área, se realiza el cálculo de seis indicadores de gestión financiera $(2009$ - 2010 - 2011), su agregación es un indicador simplificado mediante la técnica de componentes principales y el establecimiento de un escalafón (Ranking), de desempeño a partir de este índice agregado. (Véase Anexos 2,3 y 4). El

\footnotetext{
${ }^{85}$ Desempeño fiscal de los departamentos y municipios (informe del Departamento Nacional de Planeación, 2011 Artículo 79 Ley 617 de 2000
} 
indicador mide globalmente el resultado fiscal de gestión alcanzado en cada año y se encuentra en una escala de 0 a 100, donde valores cercanos a 0 reflejan bajo desempeño fiscal y valores cercanos a 100 significa que la entidad territorial municipal logró en conjunto los siguientes resultados:

Buen balance en su desempeño fiscal.

> Suficientes recursos para sostener su funcionamiento.

$>$ Cumplimiento a los límites de gastos de funcionamiento según la Ley 617/00.

$>$ Importante nivel de recursos propios (solvencia tributaria).

$>$ Altos niveles de inversión.

$>$ Adecuada capacidad de respaldo del servicio de su deuda

$>$ Generación de ahorro corriente, necesario para garantizar su solvencia financiera.

Tabla 4.22. Resumen de esfuerzo Fiscal 2009 - 2010 - 2011.

\begin{tabular}{|c|c|c|c|c|}
\hline No & Municipio & $\begin{array}{c}\text { Indicador de } \\
\text { Desempeño fiscal } \\
2009\end{array}$ & $\begin{array}{c}\text { Indicador de } \\
\text { Desempeño fiscal } \\
2010\end{array}$ & $\begin{array}{c}\text { Indicador de } \\
\text { Desempeño fiscal } \\
2011\end{array}$ \\
\hline 1 & Arbeláez & 59,32 & 70,89 & 67,43 \\
\hline 2 & Bojacá & 67,09 & 75,68 & 74,46 \\
\hline 3 & Cabrera & 57,00 & 64,54 & 67,38 \\
\hline 4 & Cajicá & 77,58 & 84,13 & 90,00 \\
\hline 5 & Chía & 77,53 & 86,56 & 81,87 \\
\hline 6 & Chipaque & 69,70 & 79,00 & 72,61 \\
\hline 7 & Choachí & 65,00 & 71,64 & 71,97 \\
\hline 8 & Chocontá & 67,92 & 70,97 & 72,26 \\
\hline 9 & Cogua & 75,27 & 73,86 & 83,12 \\
\hline 10 & Cota & 84,17 & 90,40 & 91,90 \\
\hline 11 & El Rosal & 72,10 & 80,01 & 80,12 \\
\hline 12 & Facatativá & 70,94 & 83,44 & 78,25 \\
\hline 13 & Funza & 73,23 & 81,74 & 85,65 \\
\hline 14 & Fusagasugá & 65,13 & 82,95 & 74,02 \\
\hline 15 & Gachancipá & 81,14 & 88,00 & 82,34 \\
\hline 16 & Guasca & 70,54 & 80,66 & 78,51 \\
\hline 17 & Guatavita & 67,75 & 75,44 & 76,87 \\
\hline 18 & Gutiérrez & 58,24 & 61,57 & 61,79 \\
\hline 19 & La Calera & 68,92 & 82,83 & 78,23 \\
\hline 20 & Madrid & 72,96 & 83,54 & 83,05 \\
\hline 21 & Mosquera & 75,65 & 87,20 & 85,53 \\
\hline 22 & Nemocón & 57,23 & 71,92 & 68,92 \\
\hline 23 & Pasca & 60,33 & 69,57 & 69,27 \\
\hline 24 & San Bernardo & 61,45 & 74,37 & 71,55 \\
\hline 25 & Sesquilé & 72,15 & 79,24 & 77,57 \\
\hline 26 & Sibaté & 76,59 & 83,90 & 83,40 \\
\hline 27 & Soacha & 63,28 & 80,47 & 76,47 \\
\hline 28 & Sopó & 76,31 & 86,59 & 86,58 \\
\hline 29 & Subachoque & 69,24 & 82,29 & 77,58 \\
\hline 30 & Suesca & 63,40 & 75,56 & 75,42 \\
\hline 31 & Tabio & 63,49 & 73,11 & 71,42 \\
\hline
\end{tabular}




\begin{tabular}{|c|c|c|c|c|}
\hline No & Municipio & $\begin{array}{c}\text { Indicador de } \\
\text { Desempeño fiscal } \\
2009\end{array}$ & $\begin{array}{c}\text { Indicador de } \\
\text { Desempeño fiscal } \\
2010\end{array}$ & $\begin{array}{c}\text { Indicador de } \\
\text { Desempeño fiscal } \\
2011\end{array}$ \\
\hline 32 & Tausa & 58,41 & 68,16 & 68,20 \\
\hline 33 & Tenjo & 80,93 & 89,81 & 88,71 \\
\hline 34 & Tocancipá & 82,67 & 92,10 & 86,16 \\
\hline 35 & Ubaque & 63,09 & 67,94 & 61,57 \\
\hline 36 & Une & 63,64 & 71,39 & 67,78 \\
\hline 37 & Villapinzón & 64,60 & 73,87 & 72,87 \\
\hline 38 & Zipaquirá & 66,65 & 83,42 & 77,64 \\
\hline
\end{tabular}

Los seis indicadores financieros definidos para la evaluación del desempeño fiscal, (Departamento de Planeación Nacional DNP). Teniendo en cuenta que se han utilizado, en los elaborados en años anteriores. Los cuales se relacionan a continuación:

1. La autofinanciación de los gastos de funcionamiento.

2. El respaldo del servicio a la deuda.

3. Dependencia de las transferencias de la nación y las regalías.

4. Generación de los recursos propios.

5. Magnitud de la inversión.

6. Capacidad de ahorro.

La tendencia general de la evaluación del desempeño fiscal señala a algunas entidades territoriales como las más fortalecidas financieramente, el área reconoce a los municipios de Cota, Cajicá, Tocancipá y Tenjo, ubicados en los mejores lugares en la tabla del ranking fiscal. Tal es el caso de la ciudad de Bogotá, que pasó del puesto 76 ocupado el año anterior al puesto 19 en esta evaluación; en términos del indicador pasó de 80.98 puntos en 2010 a 83.70 puntos en 2011. Esto quiere decir que Bogotá se ubica en el máximo rango de la evaluación que clasifica como solventes a los municipios que obtienen calificaciones superiores a los 80 puntos.

En segundo lugar, Sopó, Mosquera y Chía que sin ser municipios de gran desarrollo económico tienen condiciones económicas que sustentan un importante nivel de ingresos y que tienen una estructura financiera sólida y que se han venido consolidando a través de los años. Se destaca el municipio de Cogua el cual estaba en el 2010 en la posición 229 al 23.

Los rangos clasifican a las entidades de acuerdo con los resultados ubicándolos entre los más débiles o los más avanzados de acuerdo con el lugar que ocupen en la evaluación fiscal, esos rangos se clasifican en:

Entidades en deterioro, cuyos resultados muestran a las entidades territoriales que están rezagadas en su desempeño y que obtienen menos de cuarenta (40) puntos en su evaluación. 
> En riesgo, clasifica las entidades cuyo resultado es mayor a cuarenta (40) puntos y menor de sesenta (60) puntos significa que sus resultados fiscales son débiles y las tienen cerca a la inviabilidad.

$>$ Vulnerable, clasifica a las entidades que por sus resultados en el desempeño fiscal obtienen un puntaje mayor de sesenta (60) puntos y menor de setenta (70) puntos y que dadas sus características mantienen una solvencia financiera básica.

$>$ Sostenible, clasifica a las a las entidades que tienen mejor desempeño fiscal, que pueden cubrir sus compromisos y generar recursos que garantizan la ejecución de acciones de desarrollo, sus resultados se ubican entre un rango superior a setenta (70) puntos y hasta ochenta (80) puntos.

$>$ Solvente, es el mayor de los rangos, en este se ubican las entidades territoriales que obtuvieron más de 80 puntos y que realizan el mejor uso de los recursos financieros en torno al desarrollo territorial.

Esto quiere decir, que las entidades territoriales anteriormente reconocidas son aquellas que han aplicado medidas de buenas prácticas fiscales y que ahora son llamadas a hacer buen uso de los nuevos y frescos recursos para los municipios con la reciente reforma constitucional al régimen de regalías (acto Legislativo 05 de 2011). En síntesis esta lectura facilita entender como existen entidades territoriales que efectuaron importantes acciones de gestión fiscal (por ejemplo, desarrollaron programas de saneamiento fiscal o apropiaron los recursos para el pago de las pensiones o incrementaron las rentas propias, etc.) que las condujeron a mejorar su calificación agregada, pero que el resultado final, si bien están mejor que antes de los ajustes, no las ubica en las primeras posiciones del ranking en 2011.

Por esta razón, un aumento de la calificación significa que la entidad territorial mejoró su gestión fiscal, particularmente este cambio en el indicador entre los años 2009 - 2010 y 2011 da cuenta de cómo están manejando sus finanzas los mandatarios municipales y sus equipos de gobierno luego de su cuarto año al frente de sus respectivas entidades. La evaluación del último año es muy importante porque da cuenta de una gestión al $100 \%$ de los mandatarios locales, es decir que estos resultados de los tres años sean la radiografía de su gestión financiera; fortaleciendo el resultado anterior del Biograma, en lo referente a la aplicabilidad de los recursos según la Ley 152 de 1994.

Lo anterior, fortalece para las decisiones territoriales, teniendo en cuenta los avances administrativos en la gestión y planificación de la inversión territorial de los últimos años, lo cual, debe garantizar la inversión de recursos municipales tanto en la conservación, protección, preservación y restauración ambiental en los recursos que deben proteger la sostenibilidad territorial, como también la inversión social en el mejoramiento de la calidad de vida del total de la población. Para ello, la contribución de los Planes de Desarrollo y su armonización con los proyectos de los Planes de Ordenamiento Territorial como de manejo integral de cuencas hidrográficas, teniendo en cuenta que este instrumento es de mayor jerarquía que los POTs municipales.

Finalmente, como contribución al conflicto nacional colombiano, el trabajo de tesis desde el diagnóstico, sitúa las bases, con el fin de determinar los lineamientos conceptuales y metodológicos para la planificación y la gestión sostenible del territorio; teniendo en 
cuenta para ello, la articulación con la Estructura Ecológica Regional (EER), planteando el Modelo de Desarrollo Regional, teniendo en cuenta las Unidades de Planificación y de Gestión Territorial, que en la fase de formulación se identifican con el nombre de NOAT (Núcleos de Ordenamiento Ambiental Territorial), además comprometidos por las últimas leyes como son:

Ley 614 del 18 de septiembre de 2000, por medio del cual se adiciona a la Ley 388 de 1997 y se crean los comités de Integración territorial para la adopción de los planes de ordenamiento territorial. Cuyo El objetivo el de establecer mecanismos de integración, coordinación y armonización de las diferentes entidades competentes en materia de ordenamiento del territorio, para la implementación de los planes de ordenamiento territorial. Los Comités de Integración Territorial recopilarán la información que sea necesaria para el desarrollo de su objeto, proveniente de cualquier institución pública o privada y en particular de aquellas en él representadas; también promoverán la creación de un sistema de información geográfico integrado para el área de influencia. Así mismo, los comités expedirán el reglamento necesario para sus deliberaciones y funcionamiento.

El Decreto 4161 de 2011, que complementa lo anterior, en la creación de la Unidad Administrativa Especial para la Consolidación Territorial (PNCRT), el cual establece los acuerdos interinstitucionales sobre el concepto, la identificación y solución de las principales debilidades estructurales del proceso del conflicto interno colombiano, así como su incorporación en los temas prioritarios de la agenda Gubernamental, y se definen estrategias y planes de acción sectorial para la creación de la Política Nacional de Consolidación y Reconstrucción Territorial-PNCRT. 
Figura 4.17. SÍNTESIS DEL BIOGRAMA - DESEQUILIBRIO TERRITORIAL EN LO AMBIENTAL, SOCIAL Y ECONÓMICO

\begin{tabular}{|c|c|c|c|c|c|c|c|c|c|c|}
\hline \multicolumn{4}{|c|}{ Caracterización Municipios - se toma tres como ejemplo en la gráfica de síntesis } & \multicolumn{7}{|c|}{ Caracterización Biograma Total Municipios } \\
\hline Dimensión & Tenjo & Soacha & Chía & $\begin{array}{c}\text { Total } \\
\text { de Minicipios }\end{array}$ & $\begin{array}{l}\text { Criticidad } \\
\text { IIDS }\end{array}$ & $\begin{array}{l}\% \\
\text { Optimo }\end{array}$ & $\begin{array}{c}\% \\
\text { Estable }\end{array}$ & $\begin{array}{c}\% \\
\text { Inestable }\end{array}$ & $\begin{array}{l}\% \\
\text { Critico }\end{array}$ & $\begin{array}{c}\% \\
\text { Colapso }\end{array}$ \\
\hline $\begin{array}{l}\text { Dimensión } \\
\text { Ambiental }\end{array}$ & & & & 38 & Municipios & 0 & 0 & $\begin{array}{c}2 \\
5,26 \%\end{array}$ & $\begin{array}{c}36 \\
94,74 \%\end{array}$ & 0 \\
\hline Caracterización & Tenjo & Soacha & Chía & $\begin{array}{c}\text { Total } \\
\text { de Minicipios }\end{array}$ & Criticidad & $\begin{array}{l}\% \\
\text { Optimo }\end{array}$ & $\begin{array}{c}\% \\
\text { Estable }\end{array}$ & $\begin{array}{c}\% \\
\text { Inestable }\end{array}$ & $\begin{array}{l}\% \\
\text { Critico }\end{array}$ & $\begin{array}{c}\% \\
\text { Colapso }\end{array}$ \\
\hline $\begin{array}{c}\text { Dimensión } \\
\text { Social }\end{array}$ & & & $\begin{array}{l}0,60 \\
0,40 \\
0,20 \\
0,00\end{array}$ & 38 & Municipios & $\begin{array}{c}9 \\
23.68 \%\end{array}$ & $\begin{array}{c}22 \\
57,89 \%\end{array}$ & $\begin{array}{c}6 \\
15,78 \%\end{array}$ & $\begin{array}{c}1 \\
2,63 \%\end{array}$ & 0 \\
\hline Caracterización & Tenjo & Soacha & Chía & $\begin{array}{c}\text { Total } \\
\text { de Minicipios }\end{array}$ & Criticidad & $\begin{array}{l}\% \\
\text { Optimo }\end{array}$ & $\begin{array}{c}\% \\
\text { Estable }\end{array}$ & $\begin{array}{c}\% \\
\text { Inestable }\end{array}$ & $\begin{array}{l}\% \\
\text { Critico }\end{array}$ & $\begin{array}{c}\% \\
\text { Colapso }\end{array}$ \\
\hline $\begin{array}{l}\text { Dimensión } \\
\text { Económica }\end{array}$ & & & $\begin{array}{l}1,00 \\
01 \\
0,80 \\
0,60 \\
0.40 \\
0,20 \\
0,00\end{array}$ & 38 & Municipios & $\begin{array}{c}1 \\
2,63 \%\end{array}$ & $\begin{array}{l}0 \\
\%\end{array}$ & $\begin{array}{c}1 \\
2,63 \%\end{array}$ & $\begin{array}{c}9 \\
23,68 \%\end{array}$ & $\begin{array}{c}27 \\
71,05 \%\end{array}$ \\
\hline \multicolumn{4}{|c|}{ TOTAL } & \multicolumn{7}{|c|}{38 Municipios } \\
\hline
\end{tabular}

Fuente: Elaboración propia a través de la información de las Dimensiones del Desarrollo. 


\section{CAPÍTULO}

FORMULACIÓN DE LOS LINEAMIENTOS CONCEPTUALES Y METODOLOGICOS PARA LA PLANIFICACIÓN Y LA GESTIÓN SOSTENIBLE DE LAS SUBCUENCA DEL RÍO BOGOTA Y SU ÁREA DE INFLUENCIA DESDE UNA PERSPECTIVA REGIONAL 
De aquí en adelante, se establecerán los lineamientos conceptuales y metodológicos con los cuales se pretende constituir las características básicas, desde la unidad física de la cuenca hidrográfica determinada en el área del Río Bogotá y su área de influencia, que a lo largo de su recorrido armoniza un gran número de municipios que corresponden al departamento de Cundinamarca.

Dicha formulación, conducirá al establecimiento de la metodología de análisis donde su indagación en los aspectos ambientales, sociales, económicos y administrativos establecerá los equilibrios como desequilibrios territoriales a través del análisis del Biograma. Dichos resultados llevaran a la determinación espacial, fortalezas que serán asumidas ante los compromisos políticos y administrativos en la consolidación de instituciones territoriales que tomarán las decisiones en la inversión pública como privada a través de las denominadas unidades territoriales de planificación.

Afianzamientos que determinarán los instrumentos jurídicos en la mejor estrategia administrativa desde la cuenca hidrográfica, como enlace en la postulación hacia una perspectiva regional. Para ello, se espera desde esta aproximación conceptual establecer las bases de un concepto regional más determinante en la toma de decisiones políticas, en el marco jurídico disponible hasta la fecha que debe ser objeto de análisis a través de la base de la cuenca hidrográfica como tal, como se mostrará a continuación en el siguiente abordaje.

\subsection{DIRECTRICES Y ESTRUCTURA PARA LA ARMONIZACIÓN DE LOS LINEAMIENTOS}

Con base en lo anterior, para llegar al Modelo de Desarrollo Regional (MDR) como eje central de la propuesta desde la cuenca hidrográfica $(\mathrm{CH})$, y su articulación con los parámetros establecidos desde la Estructura Ecológica Regional (EER), con el fin de determinar los lineamientos conceptuales y metodológicos para la planificación y gestión sostenible del territorio. Para ello, se establecieron tres objetivos específicos los cuales deben:

a) Analizar los elementos conceptuales del desarrollo territorial con el fin de identificar los factores que inciden en la interpretación del concepto de región en el área de influencia de las subcuenca del Río Bogotá (Río Negro, Río Carare, Gachetá, Batá y Sumapáz).

b) Determinar los elementos de articulación de las Subcuenca del Río Bogotá con el fin de considerar el nivel de desarrollo sostenible a partir del ordenamiento territorial y la gestión del recurso hídrico.

c) Aplicar el concepto de Unidades de Planificación y de Gestión a fin de identificar, en términos de los desequilibrios territoriales, los lineamientos conceptuales y metodológicos para la planificación y la gestión sostenible desde la visión de la cuenca hidrográfica del Río Bogotá y su articulación a la EER. Por lo tanto, en la armonización del ordenamiento territorial con la cuenca hidrográfica, la identificación de lineamientos para la zonificación del territorio y armonización con los instrumentos de planificación territorial son los criterios en el cumplimiento de 
los objetivos anteriormente identificados y su abordaje se caracterizan seguidamente.

\subsubsection{Armonización del ordenamiento territorial y las subcuencas hidrográficas del Río Bogotá.}

Algunos parámetros que se deben llevar a cabo en la identificación de los distintos escenarios de gestión territorial para la adopción de la Cuenca Hidrográfica como instancia regional, entre los municipios, la gobernación de Cundinamarca y las diferentes autoridades ambientales existentes dentro del área, como la misma identificación de actores públicos y privados a través de la sociedad civil, para instaurar los lineamientos conceptuales y metodológicos para la planificación y la gestión sostenible desde una perspectiva regional, valorado metodológicamente desde el Biograma.

El alcance es llegar a la sostenibilidad del territorio para el área de estudio, teniendo en cuenta la base de "cuenca hidrográfica", en el Modelo de Desarrollo Regional (MDR), en primera instancia, corresponde a la identificación de las zonas del territorio en las áreas de actividad sociales y económicas dadas en la conservación, protección, preservación, (Véase Mapa 5.19. La armonización espacial de los instrumentos de planificación NOAT), cuyos límites son los consignados en el mapa de cobertura y usos del suelo y constituye la base para el manejo de la base natural del territorio.

\subsection{LINEAMIENTOS PARA LA ZONIFICACIÓN DEL TERRITORIO Y LA ARMONIZACIÓN CON LOS INSTRUMENTOS DE PLANIFICACIÓN DEL TERRITORIO}

A continuación se presentan las fases utilizadas para la armonización del ordenamiento territorial y la cuenca hidrográfica con los instrumentos de planificación del territorio. Este enfoque se diseña para ayudar a analizar el territorio con la Estructura Ecológica Regional y manejar variables de tipo espacial; parte de considerar que el territorio y su ocupación se puede concebir como una superposición de sistemas especializados en los cuales las formas del territorio se interrelacionan entre la: división político-administrativa; la Estructura Ecológica Principal; La Estructura Ambiental Complementaria; Ecosistemas estratégicos; Conflictos entre los POTS y la cobertura y usos del suelo y la organización establecida bajo la figura de subcuencas hidrográficas, dentro del área de estudio.

Definido lo anterior, la fase de Formulación, de acuerdo con el objetivo general como los específicos planteado en el capítulo uno (Aspectos metodológicos) e identificados al inicio de este capítulo. Se identifica el escenario de gestión territorial probable de acuerdo a la adopción de la Estructura Ecológica Regional entre los Municipios, e instituciones como la gobernación de Cundinamarca y Autoridades Ambientales en la determinación de los alcances territoriales. Para el desarrollo de la propuesta de la estrategia de armonización, se determinaron el desarrollo de tres momentos que garantizan fortalezas en la formulación en la línea base y en la participación y gestión de la ciudadanía a través de los actores identificados:

1. El Primer Momento: denominado Aproximación a los instrumentos de planeamiento para la formulación de la estrategia de armonización y desarrollo de las Subcuenca Hidrográfica. 
2. El Segundo Momento denominado Aproximación de la línea base para la estrategia de armonización.

3. El Tercer Momento denominado Aproximación a las determinantes de Gestión y de participación ciudadana. "Hacia el desarrollo regional". Las cuales se determinarán bajo el análisis e implementación de los Comités de Cuencas y Consejos; el fortalecimiento en la participación de los sectores en las decisiones en las distintas Unidades de Planificación se denominarán en el estudio como NOAT.

\subsubsection{Momento uno: Aproximación a los Instrumentos de Planeamiento para la Formulación de la Estrategia de Armonización y Desarrollo de las Subcuencas Hidrográficas.}

Lo que se busca a partir de este momento, es la identificación de concepto de instrumentos de planeamiento para la formulación de la estrategia de armonización y desarrollo de la cuenca hidrográfica. Se identifican entre ellos, a la Estructura Ecológica Regional, la variabilidad de los distintos Planes de Desarrollo, Planes de Ordenamiento Territorial, la identificación de los distintos servicios ambientales que inciden en el desarrollo del territorio y las distintas posibilidades de armonización territorial a través de distintos convenios que se identifican desde el mismo marco jurídico actual.

Como se ha venido señalando en el capítulo 4, es importante tanto tener claridad sobre los servicios ambientales que se ofrecerán dentro del área de la cuenca hidrográfica del Río Bogotá, conocer los beneficios directos e indirectos de dichos servicios, y establecer el valor a proveer a la sociedad, como contar con los elementos técnicos requeridos para montar un instrumento de gestión para la planificación del territorio acorde.

Sin embargo, para el fortalecimiento de los instrumentos de planificación se reconoce la importancia de instituir un sistema de monitoreo y de seguimiento a los servicios ambientales, el vincular mecanismos de gestión ya existentes, lo que hace parte de los principios rectores establecidos en la ley Orgánica de Ordenamiento Territorial (LOOT); como es la coordinación, la complementariedad y la subsidiaridad, iniciativas que se deberán implementar a lo largo de la cuenca hidrográfica que a la vez se conviertan en mecanismos para la coordinación de los recursos, y dar coherencia a las inversiones identificadas en los distintos instrumentos de planeamiento, tanto en el contexto del Distrito Capital de Bogotá, como en el Departamento de Cundinamarca y la Nación.

Por lo tanto, la identificación de iniciativas para el apalancamiento de recursos de inversión, para desarrollar en conjunto programas y proyectos que serán identificados en los Planes de Desarrollo, municipales, departamental y de algunos planes de Acción de Entidades ambientales; como también en algunas entidades de iniciativas privadas.

Algunas estrategias de armonización territorial y desarrollo en el manejo y ordenamiento de cuenca, se pueden fortalecer a través de la figura con personas jurídicas, particularmente mediante la celebración de convenios de asociación, o la creación e personas jurídicas para el desarrollo, conjunto de actividades en relación con los cometidos y funciones asignadas por la Ley 489 de 1998, sobre la organización y 
funcionamiento de las entidades del orden nacional como por ejemplo, La Unidad de Parques Nacionales Naturales con la Empresa de Acueducto y Alcantarillado de la ciudad de Bogotá D.C., con el motivo de proteger el recurso hídrico, (Véase Figura 5.14), en la cual, se muestra la relación entre los distintos instrumentos y de las entidades territoriales.

\subsubsection{El Acercamiento de las Regiones Administrativas y de Planificación (RAP), Hacia el Desarrollo Regional.}

La Cuenca hidrográfica y la Estructura Ecológica Regional son el punto de partida para el planteamiento y consolidación del concepto regional en Colombia y para el caso en particular en nuestra propuesta. Por lo tanto, en el área de estudio se ha venido proponiendo algunas figuras como la Región Capital (RC) constituyéndose en la instancia territorial como Subregión en el área de la (RC), con fines de ordenación, establecida por 28 municipios y la ciudad de Bogotá D.C., la aproximación en el debate institucional, académico y por supuesto legal, es caracterizado con base en los instrumentos de gestión y de planificación, como subregión viable y coherente dentro de la posición de los lineamientos rectores de la Ley Orgánica de Ordenamiento Territorial LOOT.

Convenios Interadministrativos firmados en la administración "BOGOTÁ POSITIVA: PARA VIVIR MEJOR" 2008 - 2012, se estableció la constitución de la figura de Regiones Administrativas y de Planificación (RAP), permitiéndose la puesta en funcionamiento entre las entidades municipales y departamentales; consolidándose la primera región en este tipo de organización administrativa, que tendrán impactos en lo referente a las acciones Distritales Departamentales y municipales referente a la participación de cada uno de los entes territoriales y administrativos (RAPE) ${ }^{86}$. Lo anterior busca garantizar la reducción de los desequilibrios y las divergencias en el desarrollo, por una integración económica por ejemplo.

Lo cual, podría complementarse a partir de reconocer la cuenca hidrográfica como la unidad física y desde lo administrativo planteamientos de armonización, desde el reconocimiento de un nuevo marco institucional para la dotación de infraestructura, la focalización a través de intervenciones concretas en programas y proyectos nacionales departamentales y municipales, vistos desde los planes de desarrollo y planes de ordenamiento territorial.

Por supuesto, en el Capítulo II de la LOOT, se identifican los siguientes esquemas de asociatividad territorial que complementan la posición administrativa anteriormente planteada y reconocida desde la cuenca hidrográfica como unidad de armonización teniendo como unidades de gestión el planteamiento de los NOAT, como soporte administrativo y técnico en lo territorial para la conformación y fortalecimiento entre la RAP y los NOAT $^{87}$.

Esquemas asociativos territoriales.

$>$ Conformación de asociaciones de entidades territoriales.

\footnotetext{
${ }^{86}$ La RAPE permite a los entes territoriales conservar su identidad política y territorial, pero les da la oportunidad de abordar de manera coherente y articulada los grandes retos regionales y los asuntos que hoy exceden la capacidad individual de las dos entidades territoriales en materia de la planeación y el ordenamiento territorial, la sostenibilidad ambiental, la gestión y prevención de riesgos y desastres, el desarrollo económico y la movilidad entre otras.

${ }_{87}$ Dichas unidades NOAT, se pueden respaldar jurídicamente a través de la figura del instrumento de planificación del Decreto 3600 de 2007.
} 


\begin{tabular}{l}
\hline \hline Asociaciones de departamentos. \\
$>$ Asociaciones de distritos especiales. \\
$>$ Asociaciones de municipios. \\
$>$ Asociaciones de las Áreas Metropolitanas. \\
$>$ Provincias administrativas y de planificación. \\
$>$ Regiones de planeación y de gestión. \\
$>$ Unidad Mínima de Actuación. \\
$>$ Unidad de Planificación Rural. \\
$>$ Planeamiento intermedio del suelo rural.
\end{tabular}

Con base en lo anterior, se complementaría desde las propuestas institucionales que se vienen realizando pero que se debe buscar el eje conector con el cual se posibilite la realización ajustes institucionales y pertinentes para que en el ejercicio de una nueva figura espacial en lo político y administrativo. Esquema que integra una nueva estructura administrativa, funciones y jurisdicciones, que asegure el cumplimiento de los principios de carácter unitario de la estructura estatal nacional identificada en la Constitución Nacional Colombiana. Sin embargo, el reacondicionamiento de la composición técnica de los órganos de decisión de las distintas entidades que comprenden el área, resultaría imprescindible un adecuado soporte técnico científico para el manejo coordinado a nivel de cuencas hidrográficas referente a la planificación y gestión territorial.

Como se ha venido diciendo, estos ajustes permitirán al mismo tiempo la estrecha articulación entre el Gobierno nacional y los entes territoriales locales (municipios), a través de la gestión de las instancias regionales planteadas como RAP y gestionadas y ordenadas a través de la figura de los NOAT, que se detallan más adelante, para incorporar en ellas, los requisitos jurídicos sobre la atención de riesgo ambiental, vulnerabilidad climática y salvaguarda de la Estructura Ecológica Principal y/o Regional, en la respectiva toma de decisiones hacia las generaciones futuras y por supuesto, en las inversiones de reconstrucción y rehabilitación de infraestructura, condiciones socio económicas del territorio, en las áreas que puedan ser afectadas por eventos naturales como por ejemplo la caída de grandes precipitaciones que ocasionaron inundaciones en un gran porcentaje del territorio nacional, denominada con el nombre de ola invernal (2010-2011).

\subsubsection{La Constitución de los Núcleos de Ordenamiento Ambiental Territorial (NOAT), como Unidades de Gestión.}

El concepto de Núcleos de Ordenamiento Ambiental Territorial (NOAT) deriva del principio del concepto de tierras, descrito por la FAO en el año 1976, engloba con atención a la vegetación, el suelo y las formas de relieve, además los aportes del profesor Roberto Sánchez (2009), utiliza dicho concepto para el ordenamiento territorial como estrategia en la unidad ecológica permitiendo abordajes sistémicos de la ecología del territorio ${ }^{88}$. Para el caso colombiano existe la aproximación de Unidades de Planificación Rurales definidas como el instrumento de planificación de escala intermedia que desarrolla y complementa el plan de ordenamiento territorial para el suelo rural, dicha unidad se determina en el Decreto 3600 de 2007 en el artículo 1 numeral 5.

\footnotetext{
${ }^{88}$ Verse el libro de Roberto Sánchez I "Bases y estrategias metodológicas para el ordenamiento ecológico y ambiental de tierras, 2009.
} 
Para el caso del trabajo de grado, identificamos dicha unidad, pero le damos la connotación al relacionar la gestión territorial y administrativa al formularse y agruparse con las instancias municipales en términos de los principios ambientales, sociales y administrativos analizados metodológicamente en los resultados del esquema del Biograma (desequilibrios territoriales en el capítulo de Diagnostico), en ellas, como unidad de gestión podrá incluir los distintos tratamientos o potencialidades de utilización del suelo y las normas urbanísticas específicas sobre uso y aprovechamiento del suelo que para el desarrollo de las actuaciones que se definirán de forma coordinada entre cada unidad a través del Plan de Ordenamiento Territorial.

Por lo tanto, se formula la Unidad de Planificación con el nombre de Núcleo de Ordenamiento Ambiental Territorial (NOAT), acogiéndose a los principios normativos, y aplicado como instrumento para el desarrollo territorial, donde se establecen articulaciones administrativas y territoriales con el fin de fortalecer los procesos de descentralización y fortalecimiento regional, se determina su agrupación por unificación de entidades municipales. La constitución de dichos núcleos de ordenamiento territorial están caracterizados desde la visión del decreto 3600 de 2007, utilizada como instrumento valioso para el fin de la gestión territorial objetivo del trabajo propositivo como unidad de gestión regional.

Los NOAT como Unidades de Planificación Territorial (UPT) y de gestión regional se generan como propuesta, se determinan de acuerdo con los elementos estructurantes de los resultados del diagnóstico, que dan paso al momento tres, en donde se establecen las bases para la formulación de la armonización de los instrumentos de planificación y de gestión regional con la estructura de las subcuenca hidrográfica del Río Bogotá.

Para diseñar implementar, desarrollar y precisar las condiciones para el ordenamiento de cada uno de los NOAT, se determinan teniendo en cuenta el criterio de los niveles de prevalencia del decreto 3600/07 Articulo 6, teniendo en cuenta los siguientes aspectos.
$>$ La división municipal y/o vereda ${ }^{89}$.
$>$ La red vial y de asentamientos existentes y futura.
$>$ La estructura ecológica regional - principal y complementaria.
$>$ La disposición de las actividades productivas.
$>$ Las divisiones de sub-cuencas hidrográficas, cerros y planicies u otros elementos
$>$ Geográficos.

Finalmente, los NOAT, como apoyo al desarrollo y al crecimiento de los territorios facilitan la orientación de la localización y de la gestión de infraestructura vial para la prestación de servicios (escuelas, centros de salud, etc.).

\footnotetext{
${ }^{89}$ La vereda se constituye en Colombia la división municipal, donde el poblador rural se identifica con su cultura y desarrollo productivo, es la identificación del municipio hacia el interior de sus comunidades. En el caso del ordenamiento territorial es una unidad territorial donde la participación de la comunidad toma importancia en la legitimidad de programas y proyectos en la gestión de un plan.
} 


\subsubsection{La Armonización De Los Instrumentos de Gestión Regional NOAT.}

En la Figura 5.18., se identifican los contextos administrativos con algunos instrumentos, con los cuales se debe armonizar el territorio. Los NOAT, como instrumentos de gestión son ruciales para la toma de decisiones al articular los Planes de desarrollo y Planes de Ordenamiento territorial entre otros. Es de vital importancia el conocimiento y la valoración cualitativa y cuantitativa del territorio; se debe orientar a futuro y resaltar las limitaciones, establecer la capacidad de uso, la localización y detección de los bienes y servicios de que dispone o proporciona el territorio. Igualmente se debe incidir la dimensión social, ambiental, económica y administrativa, pues se considera que estas dimensiones éste influyen de manera importante para la toma de decisiones para la armonización de los distintos instrumentos de gestión.

\section{Figura 5. 18. LA ARMONIZACIÓN DE LOS INSTRUMENTOS DE PLANEACIÓN Y DE GESTIÓN TERRITORIAL}

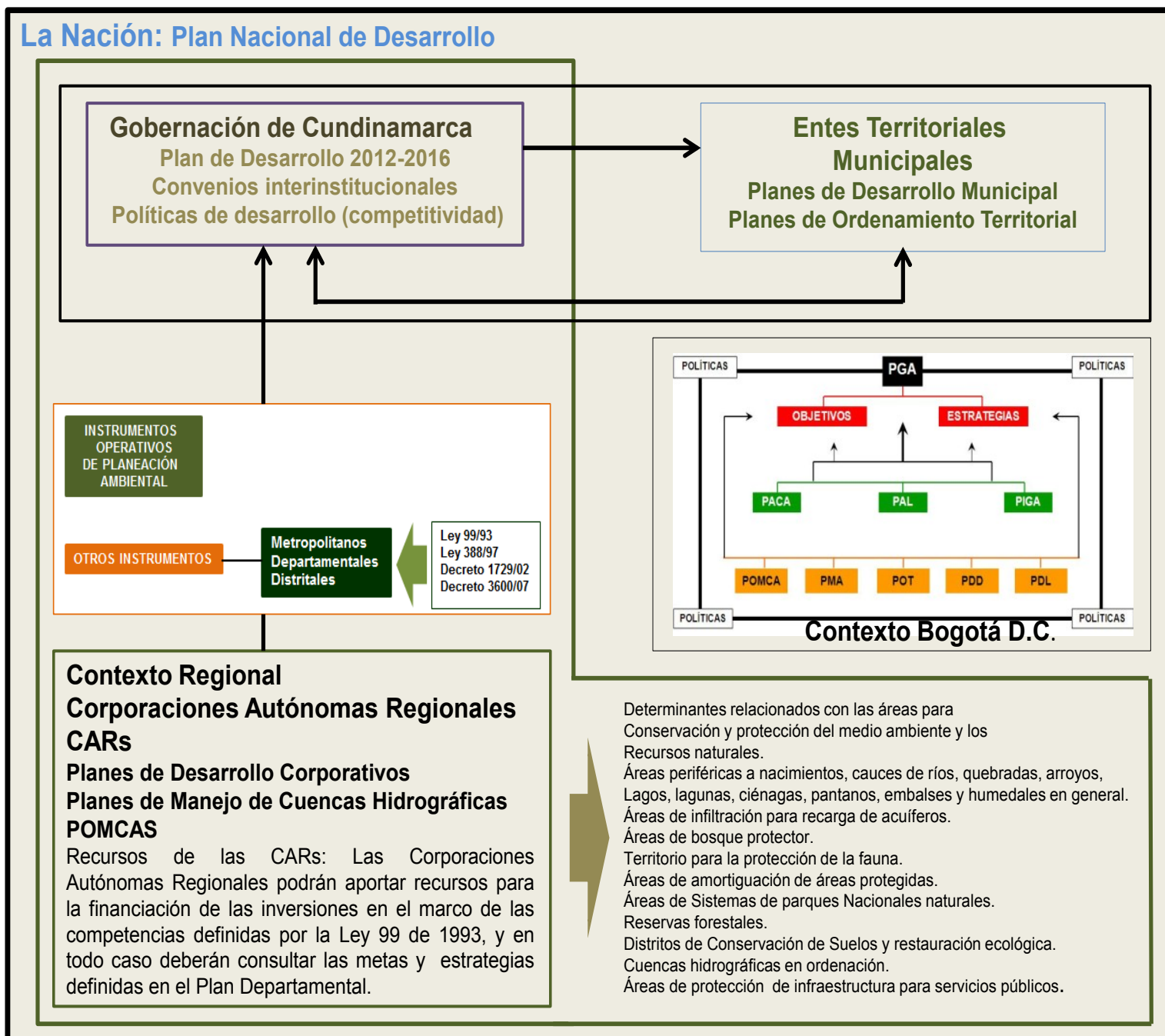

Fuente elaboración propia. 
Los NOAT, serán la síntesis para la planificación regional teniendo en cuenta las instancias administrativas municipales y la unidad física de la cuenca hidrográfica, la información primaria territorial en lo relacionado a la diversidad biológica, ocupación del suelo, edafología, gestión del riesgo entre otros etc.) y la secundaria derivada de la estructura del paisaje, capacidad de uso, calidad del paisaje, serán sistematizados con ayuda de los Sistemas de Información Geográfica (SIG), La modelación espacial en el entorno de los SIG facilita la consideración simultánea de múltiples variables sociales, económicas y ambientales), que se estudiaron en el diagnóstico con el nombre Dimensiones del Desarrollo (DD) y sus interacciones de cara a comprender el funcionamiento integral del territorio especialmente, a la evaluación técnica aportada en el capítulo dos de este trabajo con el nombre de "La incidencia de cada una de las dimensiones del desarrollo en el concepto de región".

En este momento de la armonización de los instrumentos de planificación del territorio, es fundamental el papel de las nuevas tecnologías (SIG, Sensores Remotos, Biograma etc.) y técnicas de evaluación multicriterio, modelos de distribución espacial, estadística espacial, etc.). Para modelar la realidad, hay que establecer unidades territoriales homogéneas y facilitándose la toma de decisiones y la participación de los distintos actores tanto públicos como privados.

Con los NOAT, cartografiadas y/o espacializados, será posible analizar las relaciones horizontales entre las unidades funcionales definidas y plantear criterios para estudiar y gestionar el medio natural y sus recursos como una unidad integrada. Cada NOAT, poseerá una organización y un dinamismo particular que se debe mantener para determinar su propia identidad funcional, y desde el punto de vista de la gestión y de la conservación, tiene una integridad ecológica característica. En la figura 5.18, se establecen los distintos contextos que deben estar armonizados los instrumentos de planeación y de gestión territorial.

Estos instrumentos permiten dentro de cada uno de los contextos territoriales lo siguiente:

1. Realizar un eficiente ejercicio de competencias y funciones ambientales entre entes territoriales.

2. Establecer procedimientos administrativos adecuados para la Gestión Ambiental Municipal.

3. Implementar las instancias y dependencias más idóneas en los municipios.

4. Optimizar recursos financieros para el desarrollo territorial.

5. Fortalecer la participación de la sociedad civil.

6. Fortalecer los instrumentos de gestión entre el departamento y los municipios.

7. Fortalecer los procesos de participación entre sociedad civil y sector público como privado a través de los comités de cuencas y consejos de cuenca.

8. Implementar coherentemente un plan general con visión regional.

Al interior de cada uno de los NOAT, se pueden fraccionar en sub núcleos, quedando simultáneamente disminuidas sus áreas de intervención identificando de manera cualitativa y cuantitativa las características físico-bióticas, como zonas para ecosistemas, parques, zonas verdes, uso y cobertura del suelo, de tipo vial, de equipamientos, entre otras; para el desarrollo de políticas, que permitan la consolidación de los indicadores de crecimiento rural y/o urbano y, que cada división por sub núcleos permitirá tener un mayor 
detalle de la capacidad de carga rural y urbana en los suelos destinados para conservación ambiental, protección, preservación, producción y desarrollo urbanístico.

Para ello, es importante establecer la jerarquía de cada uno de los centros urbanos que hacen parte de cada uno de los NOAT (Mapa No 5.20), con el fin de plantear en ellos las relaciones espaciales urbanas regionales. Además permiten la consolidación de los distintos desarrollos urbanísticos teniendo en cuenta sus dinámicas en la densificación, construcción y ocupación, de nuevas construcciones por la aplicación de la misma normatividad vigente, y por supuesto las tendencias de crecimiento de la ciudad de Bogotá D.C. Por lo tanto, cada uno de los NOAT, se soportan desde lo teórico en la profundización de los análisis y resultados en los distintos capítulos que componen el presente trabajo de propuesta del modelo de desarrollo regional, con el fin de determinar los lineamientos conceptuales y metodológicos para la planificación y gestión sostenible del territorio. (Véase Mapa 5.19.).

\section{Mapa 5.19. LA ARMONIZACIÓN ESPACIAL DE LOS INSTRUMENTOS DE PLANIFICACIÓN NOAT}

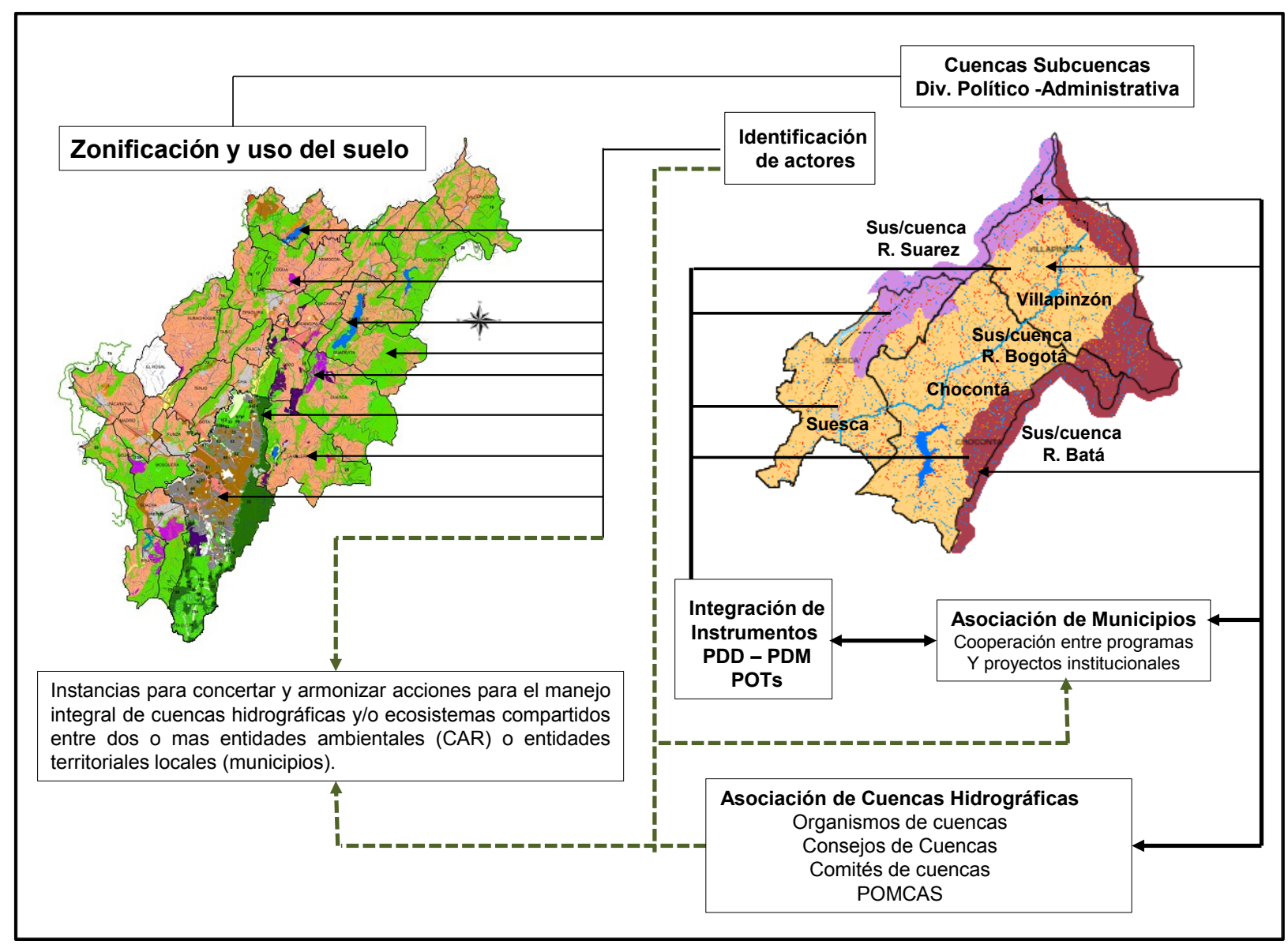

Fuente: Elaboración propia. 
Finalmente se divide el territorio en cinco unidades de integración territorial respetándose la división político - administrativa y estableciéndose su jerarquía urbana como núcleos de gestión territorial. Lo cual es soportado en el marco jurídico de la Ley 614 de 2000, por medio de la cual se adiciona la Ley 388/97, y se crea la integración territorial, con el fin de establecer mecanismos de integración coordinación y armonización para la implementación de los instrumentos de planificación. Posteriormente se dividen 14 NOAT, los cuales estarán reunidos por las autoridades competentes a través de los Consejos de Cuencas, que serán armonizados a través de los elementos de la Estructura Ecológica Regional (Véase Mapa 5.20.).

\section{Mapa 5. 20. LA ESPACIALIZACIÓN DE LAS UNIDADES DE PLANIFICACIÓN NOAT.}

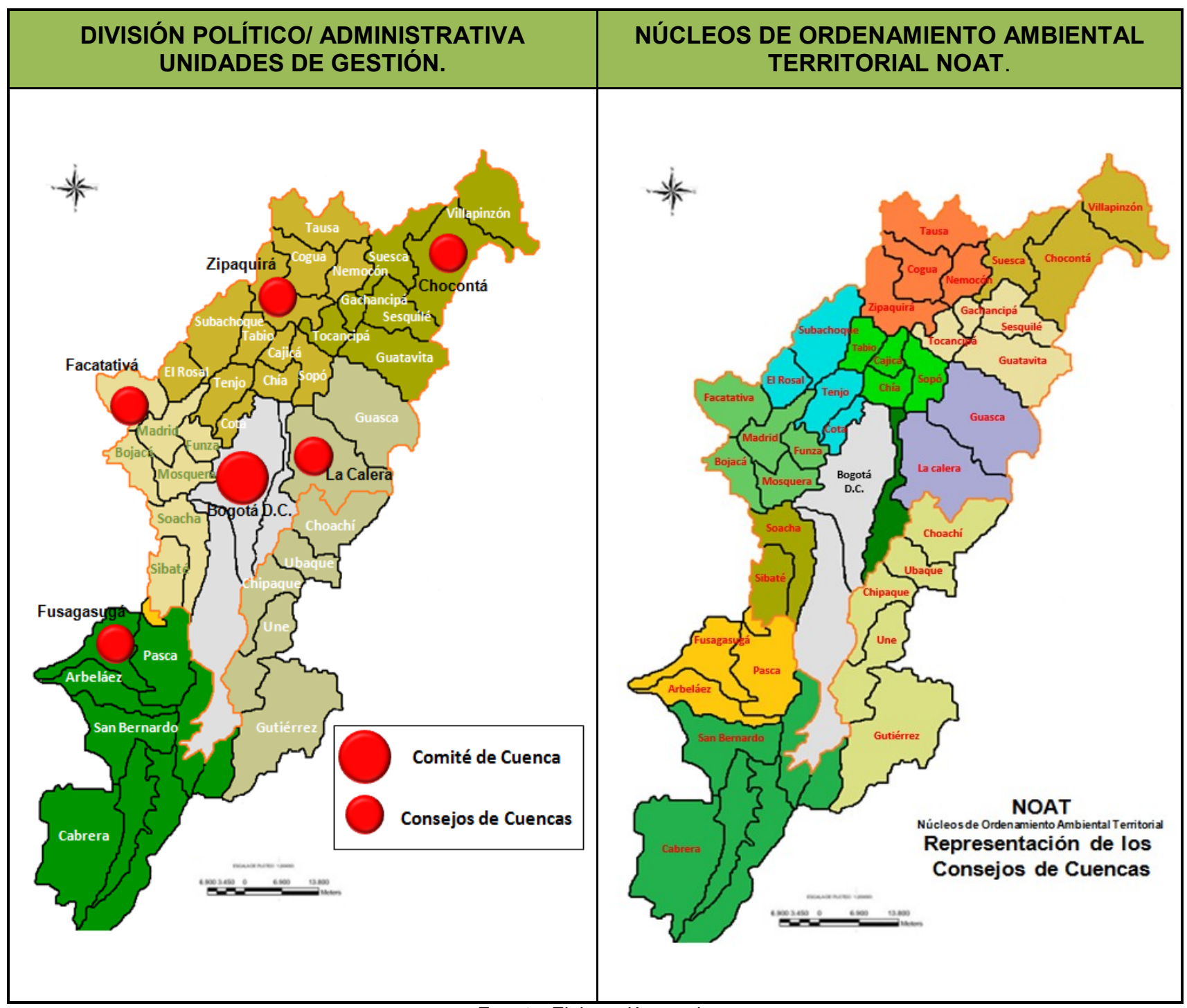

Fuente: Elaboración propia. 
Mapa 5. 21. LA ESPECIALIZACIÓN DE LOS IMPACTOS AMBIENTALES SOCIALES Y ECONÓMICOS EN EL TERRITORIO A PARTIR DEL BIOGRAMA.

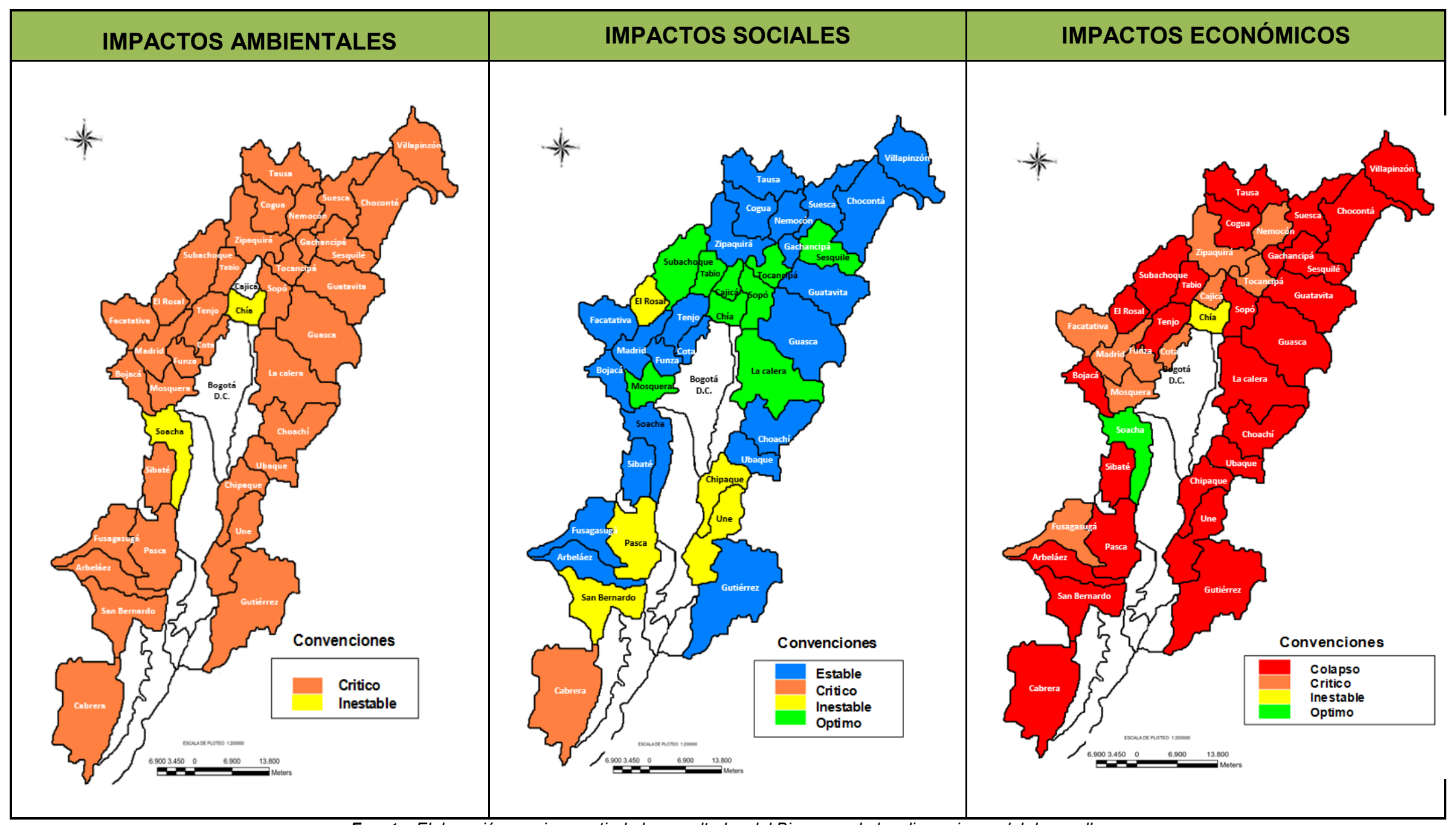

Fuente: Elaboración propia a partir de los resultados del Biograma de las dimensiones del desarrollo. 
La espacialización de los Impactos ambientales sociales y economicos (Véase Mapa 5.21.), se logró a traves de los resultados del Biograma en el capitulo del Diagnóstico, a traves de las variables ambientales, sociales y economicas, se resalta en la dimensión economica, la incertidumbre en la mayorias de los municipios en manejo de los recursos de inversión en el Plan de Desarrollo Territorial, espacializado con el colores los cuales se denominan en terminos de colapso y criticos.

Los ambientales por supuesto son identificados criticos por la alta intervención antropica en los ecosistemas de las cuenca. Este resultado garantiza la puesta en marcha de instrumentos que faciliten la recuperación economica y ambiental en el area a traves de la propuesta de los mecanismos de integración NOAT.

\subsubsection{Momento Dos: Aproximación de la Estrategia para la Armonización.}

Con la ayuda de la cartografía y las bases geográficas donde unas o más variables espaciales adquieren especificidad interna, a referencias y cualidades ambientales. Sin embargo, el proceso de zonificación exigirá analizar y comprender su variabilidad espacial, interpretando cambios en la información visual relativa a la relación al interrelacionar las variables de las dimensiones sociales, económica y ambiental. (Véase Mapas 5.22 y 5.23), se establecen los elementos cartográficos con los cuales se llevó a cabo el análisis para la propuesta de la armonización territorial con los instrumentos de planificación y gestión del territorio.

La aplicación de los resultados del diagnostico, la revisión y análisis de la información secundaria determinaron aquellos alcances para el seguimiento y evaluación de los programas y proyectos futuros que se puedan implementar teniendo en cuenta la dimensión ambiental Social y económica, al considerarse como críticas y en colapso en el territorio por la misma intervención de recursos institucionales como la misma degradación ambiental por el crecimiento y demanda de los servicio ambientales por los desarrollo urbanísticos de los núcleos poblacionales existentes en el área.

Los resultados de inventario del diagnóstico a partir del análisis de la cartografía y entendiendo como se ha venido construyendo el territorio, determinados por la mirada local por entidades acostumbradas a trabajar de manera aislada e independiente, utilizando programas y proyectos a través de los planes de desarrollo Territorial con inversiones comunes, Por lo tanto, la formulación de programas y proyectos a través de los Planes de Desarrollo Territorial y Planes de Ordenamiento Territorial, proporcionan ingresos que deben ser invertidos de forma conjunta a través de los NOAT, como instrumento que deberá ser aplicado coordinadamente por las administraciones municipales que los conforman, facilitando los escenarios de participación comunitaria en términos previstos en el artículo $4^{\circ}$ de la Ley 388 de 1997. 


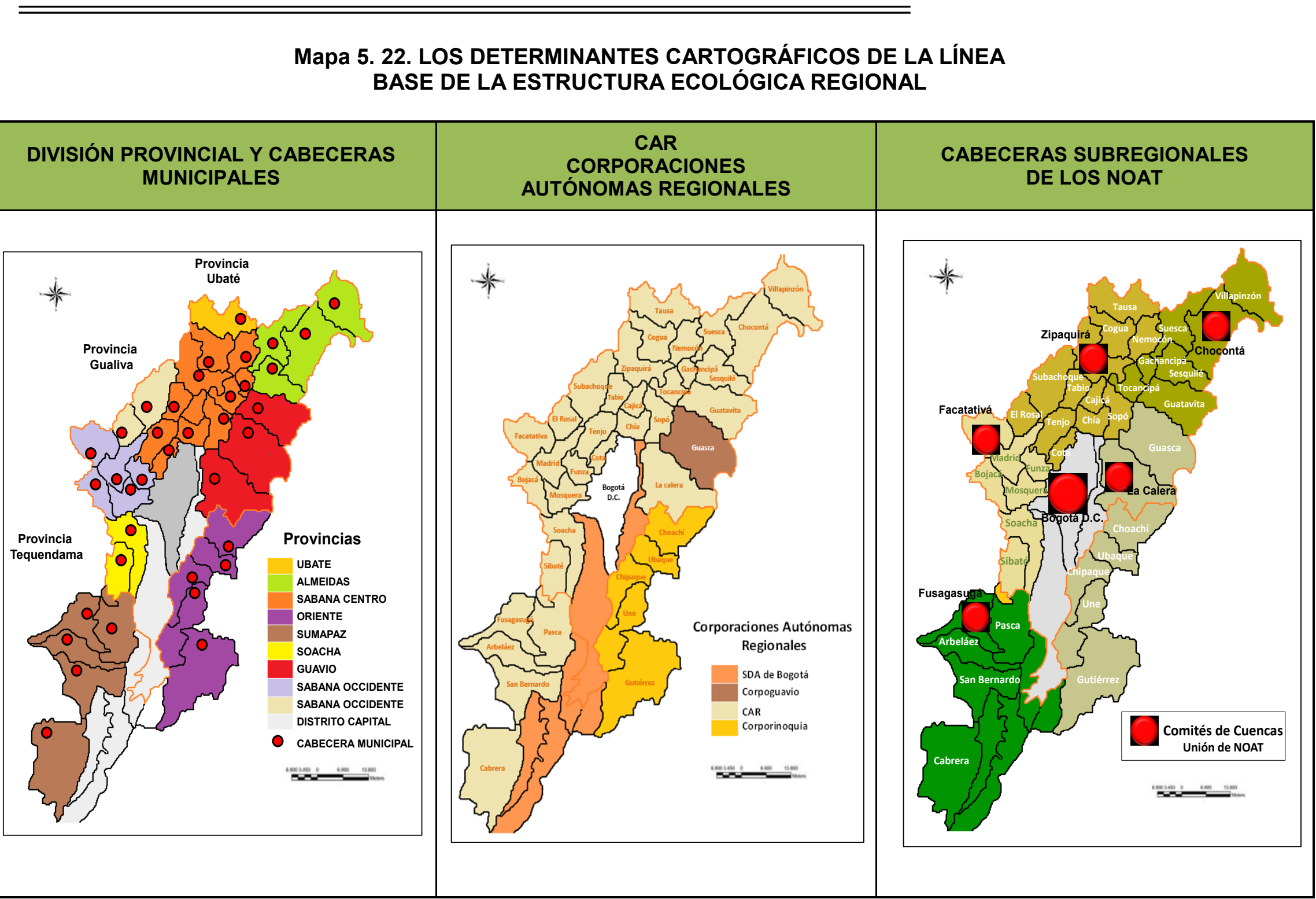

Fuente Elaboración propia. 
CAPITULO 5 - FORMULACIÓN DE LOS LINEAMIENTOS CONCEPTUALES Y METODOLOGICOS PARA LA PLANIFICACIÓN Y LA GESTIÓN SOSTENIBLE DE LAS SUBCUENCA DEL RÍO BOGOTA Y SU ÁREA DE INFLUENCIA DESDE UNA PERSPECTIVA REGIONAL.

\section{Mapa 5. 23. LA ARMONIZACIÓN INTEGRACIÓN Y GESTIÓN TERRITORIAL ARMONIZACIÓN.}

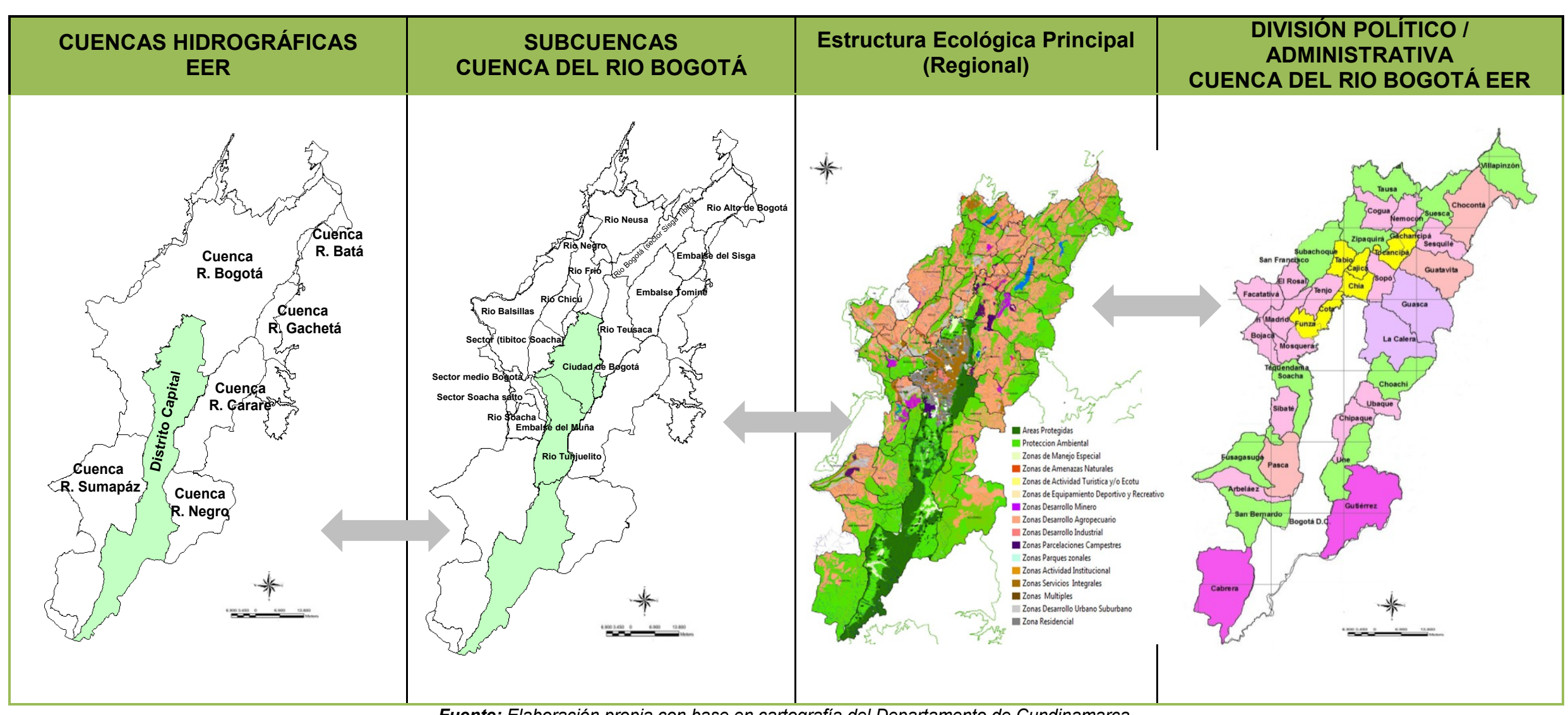

Fuente: Elaboración propia con base en cartografía del Departamento de Cundinamarca. 


\subsubsection{Momento tres: La Aproximación a las determinantes de Gestión de la Participación Comunitaria.}

En este momento, se identifican dos elementos importantes. El primero, está relacionado con las determinantes de gestión para la participación ciudadana, cuyas características están enmarcadas en el territorio a través de una lectura espacial de los usos y coberturas del suelo, correspondiente a la presencia de sectores de la producción, como de los sectores públicos enmarcados en la administración territorial (Alcaldías - Gobernación), Segundo, la gestión del recurso hídrico, a través de la puesta en marcha de los Consejos y Comité de Cuenca, funciones complementarias y articuladas a las Unidades de Planificación denominadas NOAT.

Por lo tanto, este momento lo caracterizamos con fin de formular la instancia de gestión territorial teniendo en cuenta lo establecido en el diagnostico en lo referente a la identificación de actores.

\subsubsection{Identificación y clasificación de los actores para el fortalecimiento de las unidades de planificación y de gestión NOAT.}

A continuación se presenta el análisis y la participación de los actores, los cuales estarán determinados desde sus competencias en cinco grupos a saber hacia el fortalecimiento del Comité y Consejo de Cuenca para la participación y concertación en las decisiones desde el sector público (Político), y la sociedad civil (Privado).

\section{$>$ Consejo de Cuenca Su Creación.}

La creación del Consejo de Cuenca se hará dentro de las competencias y responsabilidades establecidas en el manual de la gestión integral del recurso hídrico, además lo dispuesto en la resolución 0509 de mayo de 2013, como instancia decisoria para la conformación de los Consejos de Cuenca en acciones orientadas al ordenamiento y administración del territorio por medio del reconocimiento de cada una de las Unidades de Planificación en la que se ha zonificado el territorio. Los lineamientos estarán dados hacia el manejo y la conservación de los recursos naturales allí presentes; a esta instancia se le denominará "Consejos de Cuenca", la jurisdicción del consejo es netamente

participativo hacia el sector privado y sociedad civil en general, con jurisdicción local, el esquema de participación y articulación de los actores sociales propuesto para los Consejos de Cuenca estarán determinados dentro de la jurisdicción de cada uno de los NOAT y se identifican por los siguientes grupos.

\section{$>$ Del Grupo De Expertos.}

Las instancias creadas para el fortalecimiento de la Estructura Ecológica Regional, podrán contar con la asesoría y apoyo especializado, adoptando los principios de coordinación, subsidiaridad y concurrencia establecidos en el instrumento de planificación Ley 152 de 1994, como también de la Ley 1454 de 2011, en aquellos casos donde la asesoría especializada genere erogaciones, sus costos deberán sufragarse con cargo a los programas y proyectos formulados de la línea estratégica ambiental "armonización del ordenamiento territorial y la estructura 
ecológica en la Región Capital como en los Lineamientos para la Formulación de Estrategia Financiera y Económica; una vez este se encuentre debidamente adoptado".

\section{$>$ Del grupo gestor.}

Constituir el grupo gestor como instancia líder y jalonadora; los aportes estarán directamente relacionados al incluir los esclarecimientos importantes para la aplicación de la norma. Por lo tanto, el grupo gestor será considerado el enlace con los grupos que hacen parte integral del consejo consultivo o Consejo de cuenca al interior del área de la Estructura Ecológica Regional. En ello, pueden determinarse la colaboración de las instancias superiores en el Estado, asociaciones, federaciones entre otros, como se puede ver a continuación.

\section{$>$ Del Grupo Consultivo.}

Crear el Grupo Consultivo como la instancia asesora, propositiva y de discusión técnica para el ordenamiento y manejo de cada una de las unidades de gestión propuestas, este espacio será abierto y deliberatorio, al cual podrán asistir en calidad de invitados personas naturales o jurídicas.

\section{$>$ Del equipo técnico de apoyo a la ejecución.}

El equipo técnico ejecutor será integrado por los servidores públicos de la Corporación Autónoma Regional de Cundinamarca (CAR), de la Corporación Autónoma de la Orinoquia - Corporinoquia, de Corpoguavio y de la Alcaldía Mayor de Bogotá, además representantes de los Municipios en quienes recaerá la responsabilidad de brindar el apoyo técnico al desarrollo del proceso de consolidación en la ordenación y la gestión territorial de cada una de las unidades propuestas, con el fin de fortalecer los procesos de consolidación de la región. (Véase Figura 5.15).

\section{$>$ Mesas de concertación.}

Se promoverá el establecimiento de mesas de concertación con los distintos actores de las subcuenca del área. Dichas mesas estarán constituidas por los actores que representan los grupos de municipios en las que se ha subdividido el territorio y (NOAT), lo cual se constituirán en el punto de partida para la planificación y la gestión del territorio. Los temas a tratar y los actores que serán convocados a las mesas de estas unidades de planificación serán elegidos por concertación dentro de cada una de ellas y estarán convocados a través de la figura del Consejos de Cuenca. 


\subsection{LA CONFORMACIÓN DE LOS MIEMBROS DEL CONSEJO DE CUENCA.}

Teniendo en cuenta la identificación de los grupos anteriores:

$>$ Comunidades indígenas tradicionalmente asentadas en el área.

$>$ Comunidades negras asentadas en el área que hayan venido ocupando tierras en zonas rurales y hayan conformado su consejo comunitario de conformidad con lo dispuesto en la Ley 70 de 1993.

$>$ Organizaciones que asocien o agremien campesinos.

> Organizaciones que asocien o agremien sectores productivos.

> Personas prestadoras de servicios de acueducto y alcantarillado.

> Organizaciones no gubernamentales cuyo objeto exclusivo sea la protección del medio ambiente y los recursos naturales renovables.

$>$ Las juntas de Acción Comunal.

$>$ Instituciones de educación superior.

$>$ Los demás que resulten del análisis de los actores.

Por cada uno de los actores anteriormente listados se podrá elegir un máximo una (1) representante al respectivo Consejo de Cuenca, teniendo en cuenta los grupos identificados con anterioridad. Salvo las comunidades étnicas, los demás actores deberán desarrollar actividades en la respectiva Unidad o NOAT.

\subsubsection{Comité de Cuenca y Consejos de Cuenca.}

Para los organismos de cuencas es la relación compartida entre las partes interesadas gobiernos y territorio, se pueden poner prácticas de inmediato la elaboración conjunta de presupuestos, además de decidir conjuntamente las actuaciones sobre ecosistemas compartidos, como la revisión en conjunto de planes y programas como de informes de impacto ambiental. En fin, el organismos de cuenca es la herramienta viable para el fortalecimiento en conjunto de la gestión administrativa en el territorio, teniendo colectivamente el manejo de las políticas públicas, como es el caso del planteamiento y desarrollo del recurso hídrico, en coordinación con el Plan Nacional de Desarrollo y el Plan departamental hacia las entidades territoriales representadas por los NOAT.

Seguidamente, la localización del Comité de Cuenca (CC), estará en la ciudad de Bogotá, los Consejos de Cuencas (COC), teniendo en cuenta las Unidades de Planificación que hemos denominado NOAT., se asociará por medio de la Ley 614 de 2000, en su artículo $5^{\circ}$, lo cual, nos permite crear los comités de integración territorial que facilitará la localización de cada uno de los Consejo de Cuenca que expedirán el reglamento necesario para sus deliberaciones y funcionamiento.

Para el análisis de las características territoriales se presentan (Véase mapas 5.24., 5.25. y 5.26.), los Núcleos de Ordenamiento Ambiental Territorial (NOAT), localizados en las Subcuencas alta y media del Río Bogotá, subcuenca del Río Negro, Río Carare, Río Gachetá Río Bata y Subcuenca del Sumapáz armonizados por la Estructura Ecológica Regional. En cada uno de los NOAT, se puede determinar el uso del suelo y la participación de cada de uno de los actores a través de su naturaleza jurídica según las actividades que desarrollan, según su jerarquía administrativa y legal según sus 
competencias. En grupo de expertos, grupo gestor, grupo consultivo, equipo técnico de apoyo a la ejecución y mesas de concertación.

Por lo tanto, la zonificación y análisis de los catorce (14) NOAT, tendrán un valor estratégico dentro de las cinco (5) áreas de integración territorial, siempre y cuando, la construcción de los espacios políticos para la coordinación y armonización de las diferentes entidades competentes para la implementación de los Planes de Ordenamiento Territorial como de los Planes de Desarrollo en programas y proyectos colectivos en una decisión integral de la inversión pública y de participación de los mismos actores.

Por lo tanto, la propuesta para la armonización, se propone la consolidación de dos (2), instancias las cuales la primera, a través del Comité de Cuenca se legitima las decisiones políticas desde los actores representantes de instancias territoriales (Alcaldes y Concejos Municipales, Gobernador y Asambleas, representantes de las entidades descentralizadas). Segundo los Consejos de Cuencas desde la participación del sector privado gremios, universidades y la sociedad civil representantes de las juntas locales

De alguna manera, se busca fortalecer la gestión territorial desde organismos espacialmente integrados en el territorio con visión regional, constituyéndose como el instrumento de gestión territorial, el Comité y los Consejos para la implementación de los distintos instrumentos vigentes como los Planes de Ordenamiento y Manejo de Cuencas Hidrográficas (POMCA), los Planes de Ordenamiento Territorial Municipal (POTS), Planes de Desarrollo Territorial; los cuales generan recursos de inversión en ingresos provenientes de la nación y del departamento.

En este sentido, se pueden plantear cuatro herramientas fundamentales que se deben tener en cuenta para dicha implementación:

a) La parte normativa. Se entiende como la serie de instrumentos a los que debe ajustarse y someterse las actuaciones previstas en los POMCA y en los POT y PD. Algunas de estas normas pueden ser de aplicación directamente a nivel nacional, mientras otras operan mediante planeamiento territorial mediante la gestión de otras instituciones a través de planes de acción.

b) Los programas y proyectos. Contribuyen a implementar las estrategias del POMCA y de los POT a partir de la identificación de los problemas que se presentaron en la cuenca y formulados como proyectos o programas a ser desarrollados o ejecutados.

c) Los espacios de gestión y de planificación. (Comité de Cuenca y los espacios participativos de los Consejos de Cuencas).

d) Las instancias participativas de los NOAT. Tienen el objetivo práctico y real de aplicar los resultados que arrojan los análisis de la información que serán objeto de revisión y de actualización de forma integral por sus asociados para los procesos de constitución de información para el desarrollo de temas específicos de inversión social y de infraestructura, en conocimiento y desarrollo del marco normativo como de los programas y proyectos. (Véase Mapa 5.24). 


\section{Mapa 5.24. ZONIFICACIÓN ESPACIAL DEL COMITÉ DE CUENCA Y DE LOS CONSEJOS DE CUENCAS A TRAVÉS DE LA INTEGRACIÓN TERRITORIAL DE LOS NOAT.}

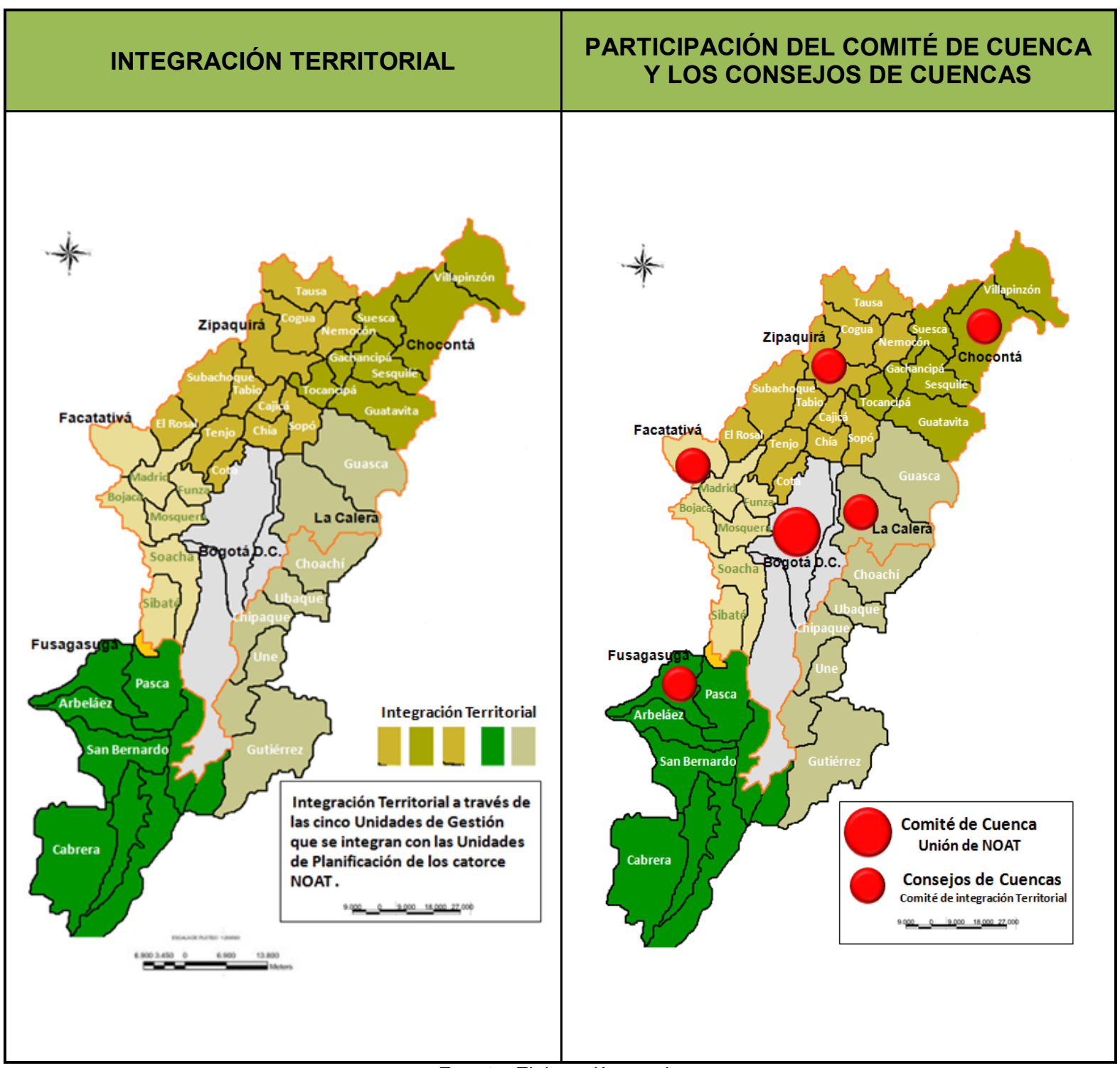

Fuente: Elaboración propia.

Por lo tanto, los Consejos de Cuencas se constituyen como la base de la planificación y de la gestión del territorio, desde la participación comunitaria, con el objeto de fortalecer los mecanismos de participación de los NOAT, como unidades de planificación territorial. Los Consejos de Cuencas, se reconocerán como la instancia participativa en la deliberación de proyectos planteados a través de los POMCA y de los POT - Municipales, como de proyectos gestionados, y su localización estará desde las dinámicas reconocidas en los resultados de la Dimensión del Desarrollo, económica, la cual, basados en la Ley 617 de 2000, se determina la nueva recategorización de las entidades territoriales que logren su mejor desempeño y gestión fiscal a través de su capacidad de gestión administrativa y fiscal y de acuerdo a su población e ingresos corrientes de libre 
CAPITULO 5 - FORMULACIÓN DE LOS LINEAMIENTOS CONCEPTUALES Y METODOLOGICOS PARA LA PLANIFICACIÓN Y LA GESTIÓN SOSTENIBLE DE LAS SUBCUENCA DEL RÍO BOGOTA Y SU ÁREA DE

INFLUENCIA DESDE UNA PERSPECTIVA REGIONAL.

destinación. Lo cual, donde de forma integral se muestra el proceso de armonización de las entidades territoriales para el ordenamiento territorial en los NOAT como unidades de planificación (Véase Figura 5.19.).

\section{Figura 5. 19. ESQUEMA ORGANIZACIONAL PARA LA PLANIFICACIÓN REGIONAL DESDE EL TERRITORIO DE LAS SUBCUENCA HIDROGRÁFICA}

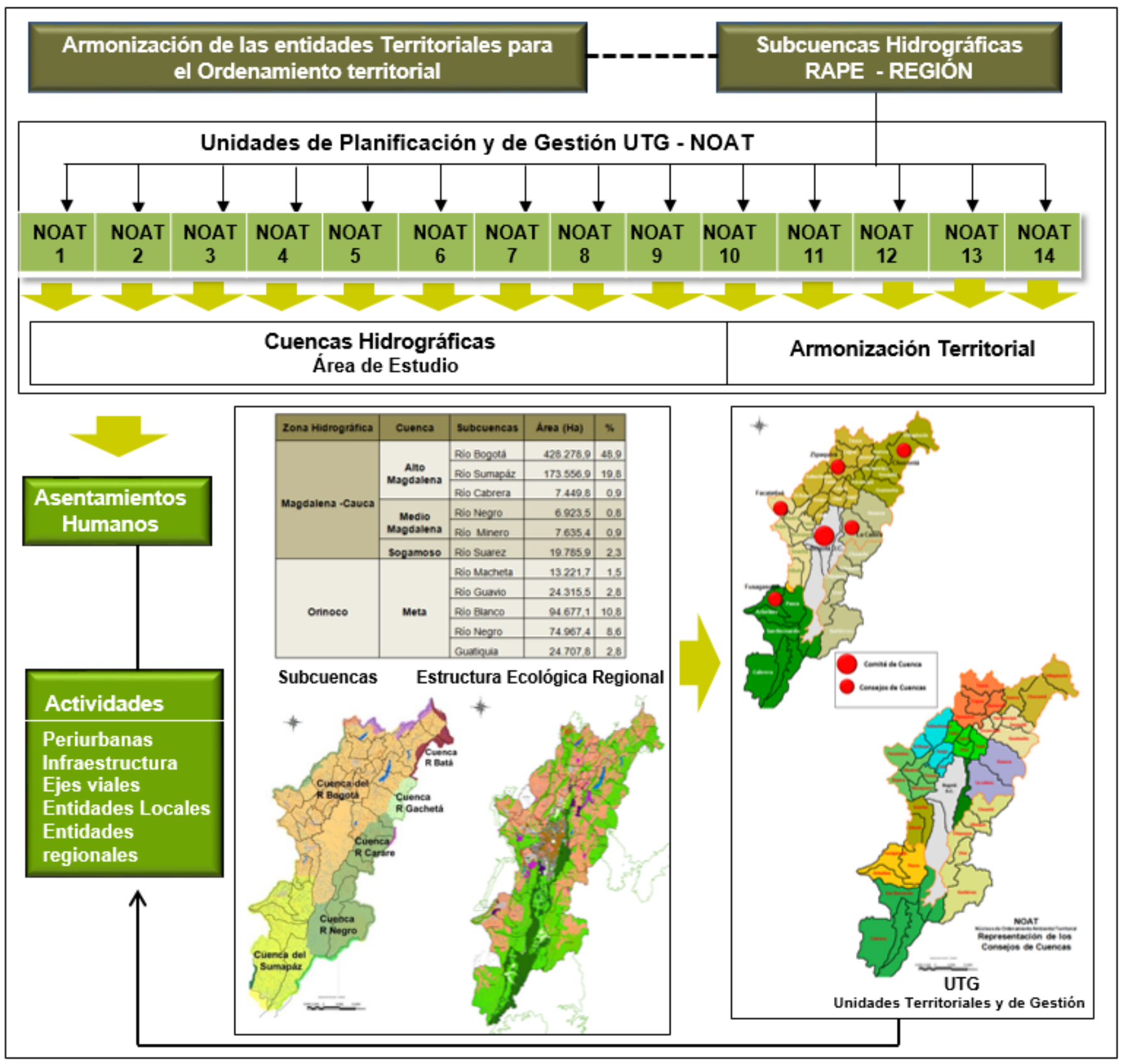

Fuente: Elaboración propia. 
Figura 5.20. ESQUEMA ORGANIZACIONAL DEL COMITÉ DE CUENCA

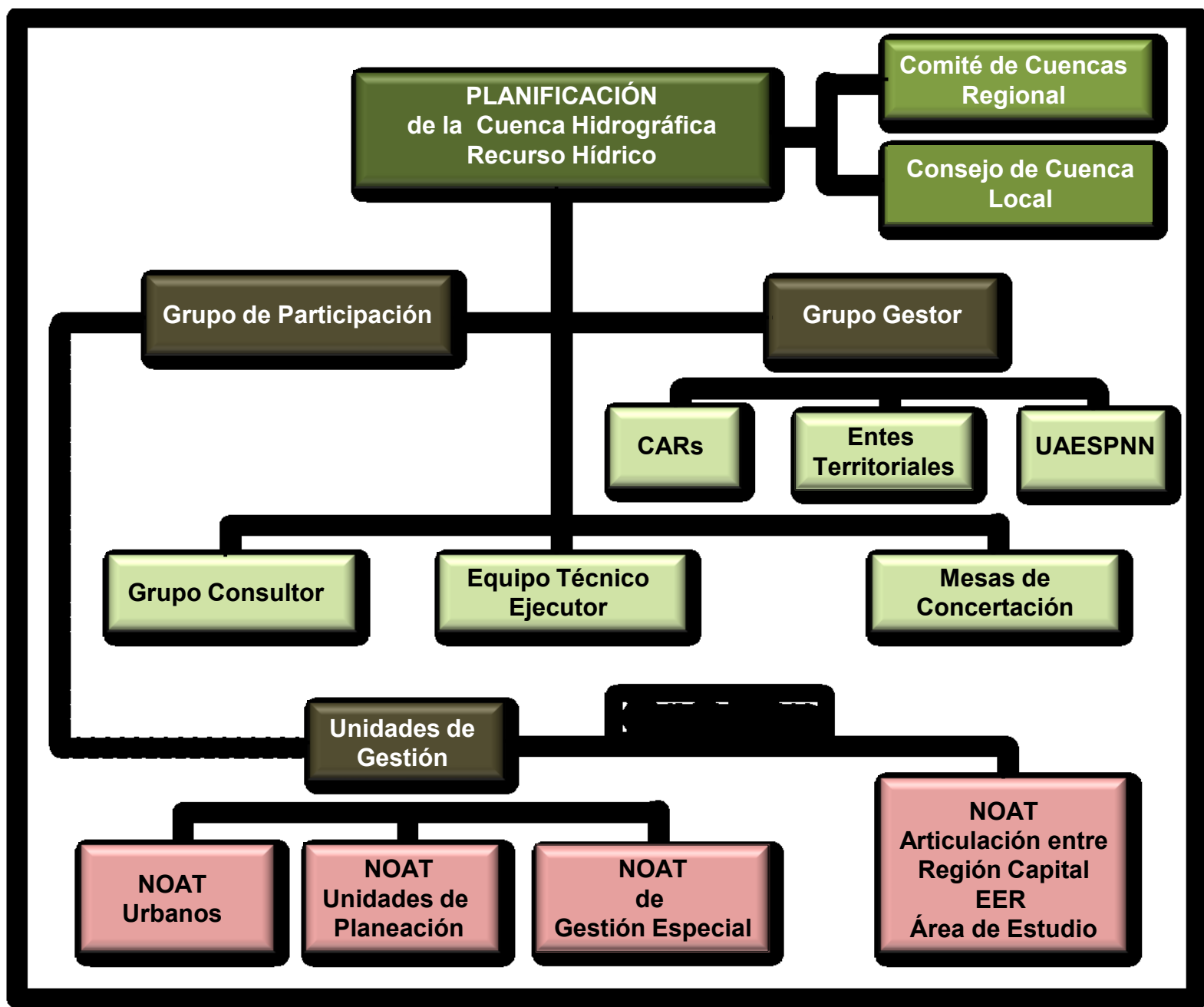

Fuente: Elaboración propia.

En el Comité de Cuenca para la gestión del ordenamiento y el manejo ambiental del área debe estar involucrada de forma indispensable toda la población, es decir, que no se debe dejar a un lado a nadie que quiera o pueda participar. El Comité de Cuenca, se rige bajo los parámetros siguientes de la Asociación Mundial para el Agua (GWP): la planificación, la organización, la toma de decisiones, la coordinación, el control y el mejoramiento de la eficiencia en los resultados de la administración y en uso del suelo y la distribución de responsabilidades (Véase Figura 5.20., 5.21. y 5.22.) 


\section{Figura 5.21. DIRECTRICES PARA EL FUNCIONAMIENTO Y LA COORDINACIÓN PARA LA GESTIÓN DEL PLAN DE ORDENACIÓN Y MANEJO DE LA CUENCA DEL RÍO BOGOTÁ.}

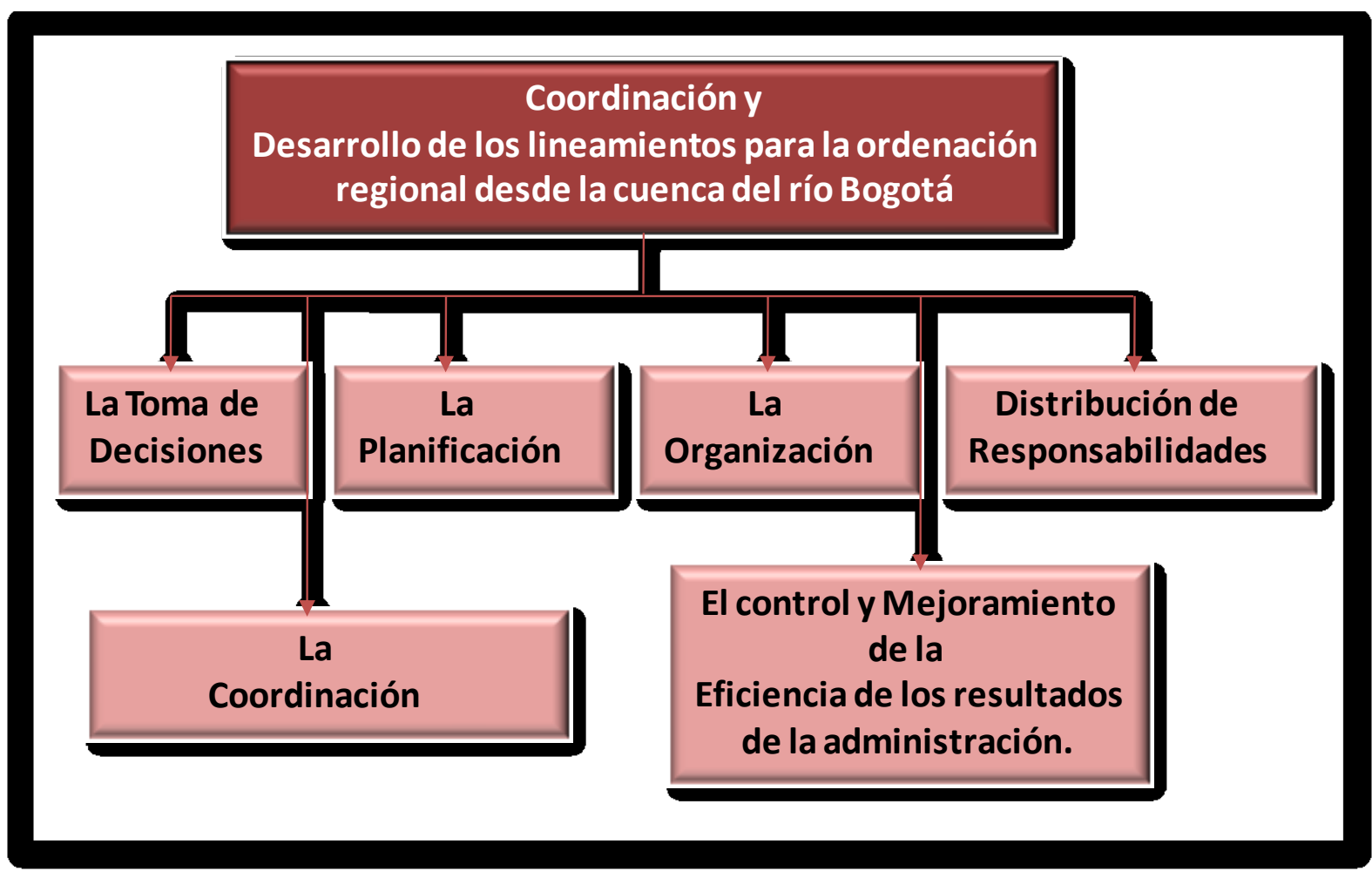

Fuente: Elaboración propia.

Lo anterior se hace con base en los planteamiento de los lineamientos presentados para las determinantes del Comité de Cuenca, elaboradas por el arquitecto Ernesto Villegas Rodríguez, a los Planes de Manejo y Ordenamiento y Manejo de Cuencas Hidrográficas del Río Guarapas en el departamento del Huila entre los municipios de Pitalito y Palestina, igualmente en aspectos propositivos en los municipios de Piedras Blancas (Cuenca del Río Copacabana) y en el municipio Caldas (cuenca del Río La Valeria) del Valle de Aburra en Medellín Antioquia Colombia.

\subsubsection{Las competencias del Comité de Cuenca}

Tienen la visión para garantizar la seguridad hídrica, teniendo en cuenta los parámetros que se identifican en el manual para la gestión integrada de recursos hídricos en cuencas, donde GWP apoya el desarrollo y gestión sostenible de los recursos hídricos en todos los niveles. Ya que lo temas relacionados con el agua afectan a todos los segmentos de la sociedad y a todos los sectores económicos.

$>$ La aplicación de los instrumentos de planificación. Para la armonización de los ordenamientos y manejos hidrológicos de las subcuencas que se hayan ordenado, así como de las otras subcuencas que se encuentran en proceso de ordenación, será directamente establecido desde los criterios de planificación del Decreto 1729 del 06 agosto de 2.002; el Decreto 1640 del 02 de agosto de 
2012 y las resoluciones 1907 del 27 de diciembre de 2013, por el cual se expide la Guía Técnica para la Formulación de los Planes de Ordenamiento y Manejo de Cuencas Hidrográficas y la resolución 0509 de los lineamientos para el desarrollo de los consejos de cuencas; además el Decreto 3600 del 20 de septiembre de 2007, cuyas determinantes influirán directamente en la planificación del territorio en temas de armonización y ordenamiento Territorial, en cumplimiento de las propuestas contenidas en los instrumentos de planificación de los planes de desarrollo y planes de ordenamiento territorial.

- La definición de las estrategias, programas y proyectos. Que se deban adoptar para el desarrollo de la conservación del área rural, como el control al desarrollo urbano dentro de la jurisdicción de las subcuenca del Río Negro, Río Carare; Río Gachetá; Río Bata y Sumapáz, en consonancia con los objetivos de los Planes de Ordenamiento Territorial, POTS, de los municipios que hacen parte integral del territorio. La Estructura Ecológica Regional, definirá las áreas de conservación, protección, preservación ambiental, de producción y de áreas dedicadas al desarrollo urbano y su crecimiento, como insumo para los Planes de Desarrollo Departamental y Municipales, planes de acción de las Corporación Autónoma Regional de Cundinamarca de la Orinoquia (Corporinoquia y de Corpoguavio), con las cuales se comparten jurisdicciones en el territorio.

$>$ Desde la dimensión institucional. Se buscará el abordaje directo para el fortalecimiento de convenios, mecanismos de cooperación con instituciones educativas no formales, del nivel superior, presentes en el área de estudio que le brinden asesoría a la sociedad civil en la aplicación de los instrumentos de planificación.

- El control de la presión sobre los territorios urbanos construidos. Por medio de la aplicación tanto de los usos, índices de ocupación, construcción y edificación definidos en los POT, como de los usos del suelo corroborados por la ordenación de las subcuenca y la Estructura Ecológica Regional.

- La sociedad contemplará su participación en todo el proceso metodológico. Además de visualizar la atención a la población residente, por medio de asesorías técnicas y legales para futuros proyectos inmobiliaria de la ciudad para el mejoramiento de la construcción y mejoramiento de las viviendas siempre y cuando no estén en áreas en condiciones de ilegalidad o de riesgo siendo así se deberá promulgar por su reubicación.

La armonía entre Planes de Desarrollo y Planes de Ordenamiento Territorial. En la definición de los proyectos futuros de infraestructuras y dotacionales, en coordinación con las Unidades de Planificación y de Gestión en asocio con los municipios que integran cada uno de los NOAT.

La aplicación de Unidades de Planificación articuladas con los mecanismos de comunicación y coordinación para los Núcleos de Ordenamiento Ambiental Territorial (NOAT), identificados en el área de ordenación, de manera que se planteen acciones conjuntas que se dirijan a la formulación de programas y 
proyectos donde se articulen con el área rural como su consolidación de las áreas urbanas, en defensa del patrimonio ecológico, paisajístico para el área de las sub cuencas, a través de la Estructura Ecológica Regional.

La continuidad institucional desde las administraciones de turno, para la definición de estrategias, programas y proyectos que faciliten el control conjunto de la presión de proyectos en el desarrollo urbano y del desarrollo rural, generado por el crecimiento poblacional y la demanda de servicios de infraestructura tanto en el sector productivo como de servicios.

> Las bases de los objetivos del Milenio promulgados en la Asamblea general de las Naciones Unidas del año 2000, de los cuales uno de ellos se encamina a garantizar la seguridad alimentaria de la población, en este caso en el área que se establece como Estructura Ecológica Regional, en la cual, se suscribe territorialmente las subcuenca, de acuerdo con los lineamientos de los Planes de Desarrollo, Nacional, Departamental por medio del apoyo y fortalecimiento a las instancias municipales.

\subsubsection{Las responsabilidades del Comité de Cuenca}

$>$ La toma de decisiones. La sociedad civil y el sector público implican una correlación continua teniendo en cuenta que el proceso de ordenamiento es un proceso que involucra la definición previa de criterios como base en la selección de las actuaciones, de forma tal, que siempre se puedan justificar las decisiones respecto a la población local, en referentes establecidos en la concertación de los instrumentos de planificación desarrollados con anterioridad para su continuidad en programas y proyectos.

$>$ La planificación. Como parte del proceso de planificación supone la identificación y formulación del conjunto de prioridades, estrategias y objetivos específicos.

> La organización. Los NOAT, identificados en la cuenca suponen la distribución de los papeles que cada persona, grupo y academia, acordarán las tareas y recursos necesarios para la puesta en marcha de las estrategias que se hayan definido a lo largo de la estructura metodológica en el abordaje de las fases de la Armonización de los instrumentos de planificación, buscando una óptima participación y adecuada distribución de recursos, tanto logísticos como de los recursos de inversión.

La distribución de responsabilidades. La puesta en marcha de acciones que conlleven al éxito es necesario en todo el proceso, así como la coordinación de las responsabilidades en la planificación y ejecución de programas y proyectos para un funcionamiento eficaz de la entidad gestora.

La coordinación. La coordinación supone la determinación de las diferentes disciplinas y modalidades para volver a situar cada actividad en un contexto más global, referentes que serán la base de la gestión que cada vez toma más importancia en garantizar los aspectos sociales, económicos y ambientales en 
la coordinación para la armonización de los instrumentos de planeación, en torno a los diferentes ejes de los programa y proyectos que se establezcan a lo largo del Plan gestor en el desarrollo regional.

El control y la mejora de la eficiencia de los resultados. Los indicadores territoriales y urbanos identificados como estrategia para el desarrollo del sistema de seguimiento y evaluación, tienen como propósito verificar que los proyectos se desarrollen según lo previsto, que se alcanzan los objetivos y los procedimientos de seguimiento, permitiendo la modificación del rumbo en la armonización de los instrumentos de planeación entre las dos instanciaos territoriales; la de la Cuenca y la Estructura Ecológica Regional.

Figura 5.22. COMITÉ DE CUENCA

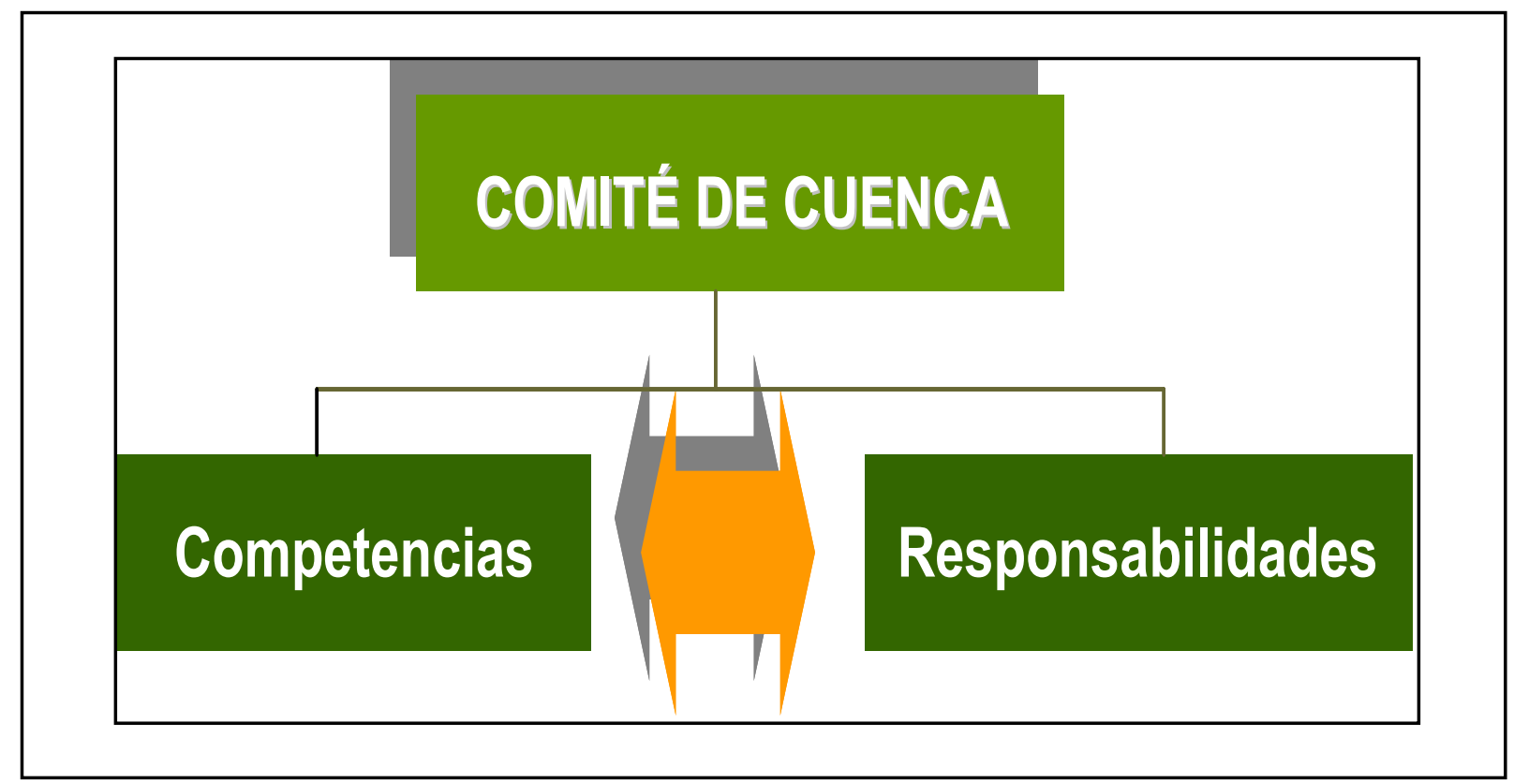

Fuente: Elaboración propia teniendo en cuenta lineamientos para el ordenamiento y manejo de cuencas del Rio Guarapas en el Huila entre los municipios de Pitalito y Palestina, igualmente en Cuencas localizadas en el Valle de Aburra Medellín departamento de Antioquia. 


\section{Mapa 5.25. INSTANCIAS TERRITORIALES DE GESTIÓN Y DE PLANIFICACIÓN TERRITORIAL.}

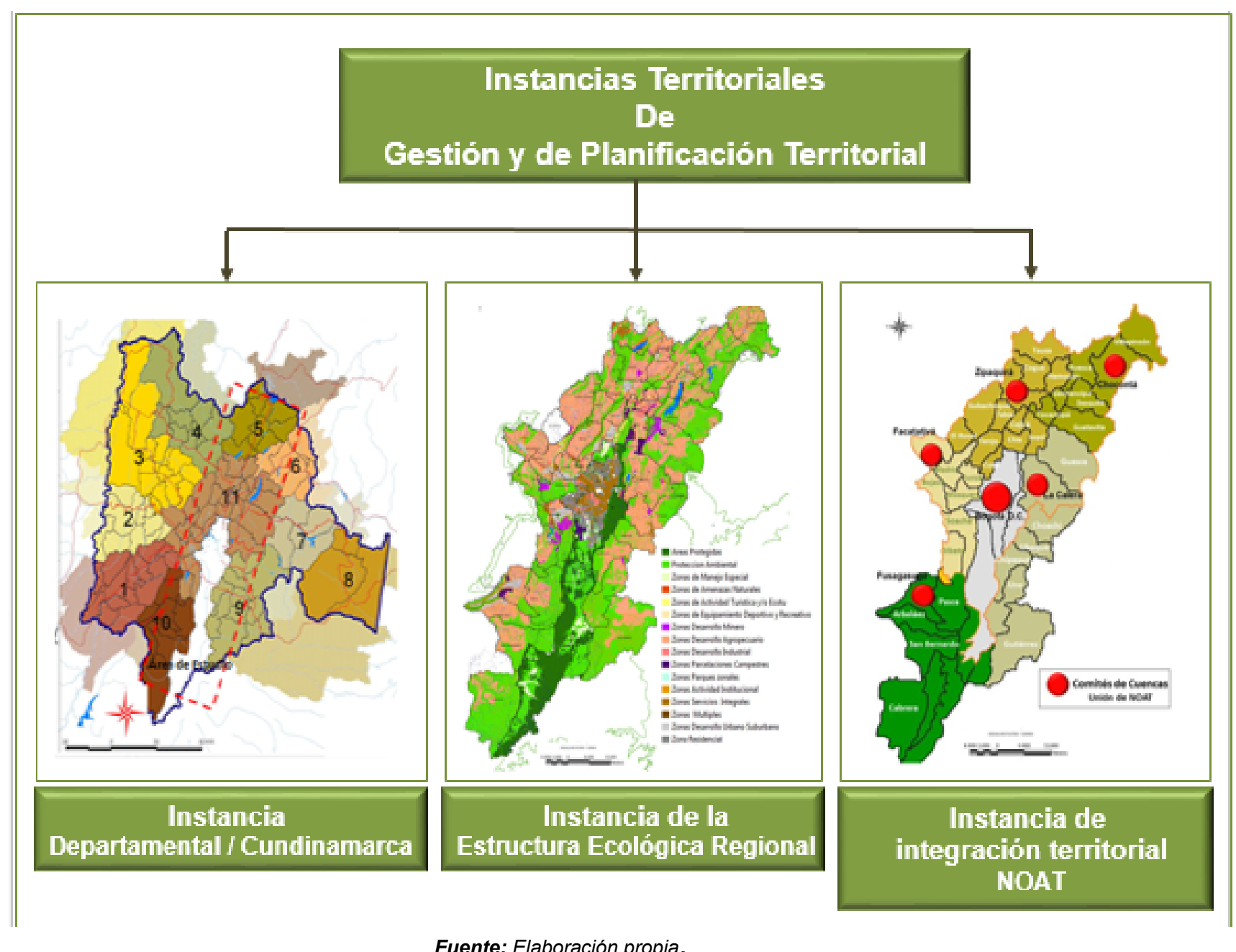

\subsubsection{La conformación de los miembros del Comité de Cuenca.}

El Comité de Cuenca, inicialmente debe estar conformado por instancias gubernamentales, por las entidades ambientales con las cuales se comparte jurisdicción (Corporación Autónoma Regional de Cundinamarca "CAR", Corporinoquia y Corpoguavio), del mismo modo debe contar con activos de la sociedad civil. El Comité estará conformado teniendo en cuenta el artículo $5^{\circ}$ de la ley 614 de 2000, por:

$>$ El Alcalde del municipio principal (ciudad de Bogotá D.C.).

$>$ Los alcaldes de los municipios circunvecinos que parte del área.

$>$ El gobernador al cual pertenecen los municipios que hacen parte del área o sus delegados.

> El director o directores de la Corporación Autónoma Regional que tengan jurisdicción en el área. 
$>$ Un delegado del Ministerio de ambiente y Desarrollo Sostenible, con voz y sin voto.

$>$ Un delegado del Ministerio del Interior, con voz y sin voto.

$>$ Dos (2) representantes de los gremios productivos y/o económicos de la región.

$>$ Un (1) representante de las organizaciones no gubernamentales de las entidades asociadas.

Para efectos en caso de conflictos para integrar un municipio en el caso de los NOAT, se entenderá por área de Influencia el territorio conformado por dos o más municipios, en los cuales se presenten hechos que hagan indispensable la implementación conjunta de los planes de ordenamiento territorial y los planes de desarrollo municipal, tales como fenómenos de oferta y demanda de agua, conurbación y su disposición final de aguas residuales, entre otros como se verá a continuación:

$>$ El equilibrio entre oferta y demanda de agua. En la cuenca para sus diversos usos deberá tener en cuenta la relación entre sector productivo y extractivo de la economía regional o territorial de la cuenca.

$>$ La intervención del subsistema antrópico deberá. Responder directamente a las dimensiones del desarrollo y a los procesos de apropiación de espacios donde el saneamiento de la subcuenca, y cuerpos receptores de agua, son los afectados por la disposición final de aguas residuales, así como de la disposición de basuras producto de consolidaciones urbanas, por lo tanto, se debe prevenir, detener y corregir su contaminación.

$>$ La conservación, preservación y mejoramiento. De los ecosistemas de la cuenca con los que el agua forma sistemas naturales indivisibles.

$>$ Se debe buscar el uso eficiente y sostenible del agua. En todas las fases del ciclo hidrológico.

\subsection{DIVISIÓN TERRITORIAL Y REGIONALIZACIÓN EN EL ÁREA}

El objetivo era delimitar y caracterizar el concepto de Región a través de la propuesta de armonizar las subcuencas del Río Negro, Carare, Gachetá, Batá y subcuenca del Sumapáz, que contribuyen efectivamente a la consolidación de la armonización de las entidades territoriales desde su división política-administrativamente articulados bajo la figura de la Estructura Ecológica Regional "donde el conjunto de elementos bióticos y abióticos los cuales le dan sustento a los procesos ecológicos del territorio, cuya finalidad es la preservación, conservación y restauración, uso y manejo sostenible de los recursos naturales renovables, los cuales le brindan la capacidad de soporte para el desarrollo social y económico de las poblaciones". Ayudan a la conformación en integración de los Núcleos de Ordenamiento Ambiental Territorial para llegar al fortalecimiento del Comité y de los Consejos de cuenca, en la gráfica siguiente se puede observar los anterior.

\subsubsection{La articulación institucional}

La articulación institucional sin embargo como base para la que deberá implementarse al momento de adoptar y poner en marcha el modelo, donde se analiza la relación entre la 
propuesta de regionalización funcional y las divisiones territoriales vigentes expuestas en los contenidos del capítulo 2 y 3.

Las relaciones con las provincias. Seis (6) de las subregiones propuestas coinciden con las respectivas provincias, en cuatro casos, incluyendo la región central, se integran provincias. En dos casos se dividen provincias actuales, uno de ellos correspondiente a los municipios de La Calera, Guasca y Guatavita, que están actualmente solicitando su incorporación a la provincia de Sabana Norte.

$>$ Las relaciones con las Corporaciones Autónomas Regionales. A excepción de los municipios que pertenecen al ámbito de jurisdicción de Corpoguavio y Corporinoquia, los límites de las subregiones coinciden con los límites jurisdiccionales de las tres Corporaciones.

$>$ Las relaciones con las asociaciones de municipios. En Cundinamarca funcionan diez (10) Asociaciones de Municipios que no cobijan la totalidad de los mismos porque los municipios de las subregiones de Guavio la de Piedemonte y Llanos no cuentan con asociaciones de municipios. Si recordamos su definición la asociación entre municipios son entidades administrativas de derecho público, con personería jurídica y patrimonio propio e independiente de los entes que la conforman. Se asocian para la ejecución de obras o el cumplimiento de funciones administrativas, procurando eficiencia en los mismos, así como el desarrollo integral de sus territorios y colaborar mutuamente en la ejecución de obras públicas. (Art. 148 y 149, Ley 136 de 1994); Art 14 de la Ley 1454/11.

Por lo tanto, las variables para la regionalización funcional como factor territorial en la gestión y la planificación, nos lleva a la caracterización de las determinantes de las subcuencas; asociación de municipios; Asociación de Provincias; y con estas entidades territoriales armonizamos a través de las cinco unidades de gestión que se integran con las Unidades de Planificación y de Gestión denominados NOAT. A partir de este momento se identifica la Estructura Ecológica Regional, donde cada uno de los NOAT identifica los actores, usos del suelo en este caso desde lo ambiental (conservación - protección preservación - restauración ambiental - producción y desarrollo urbanístico identificando los centros poblados jalonadores de las Unidades de Gestión conformados por los NOAT; donde Zipaquirá - Chocontá - La Calera - Facatativá - Fusagasugá y la ciudad de Bogotá D.C. como centro jalonador principal de la región. (Mapa 5.26. En los siguientes mapas a partir de la trayectoria en el proceso de ordenación y planificación administrativa se concreta la Propuesta de los Lineamientos Conceptuales y Metodológicos para la Planificación de la Gestión Sostenible de la Cuenca Hidrográfica del Río Bogotá, desde una perspectiva regional. 


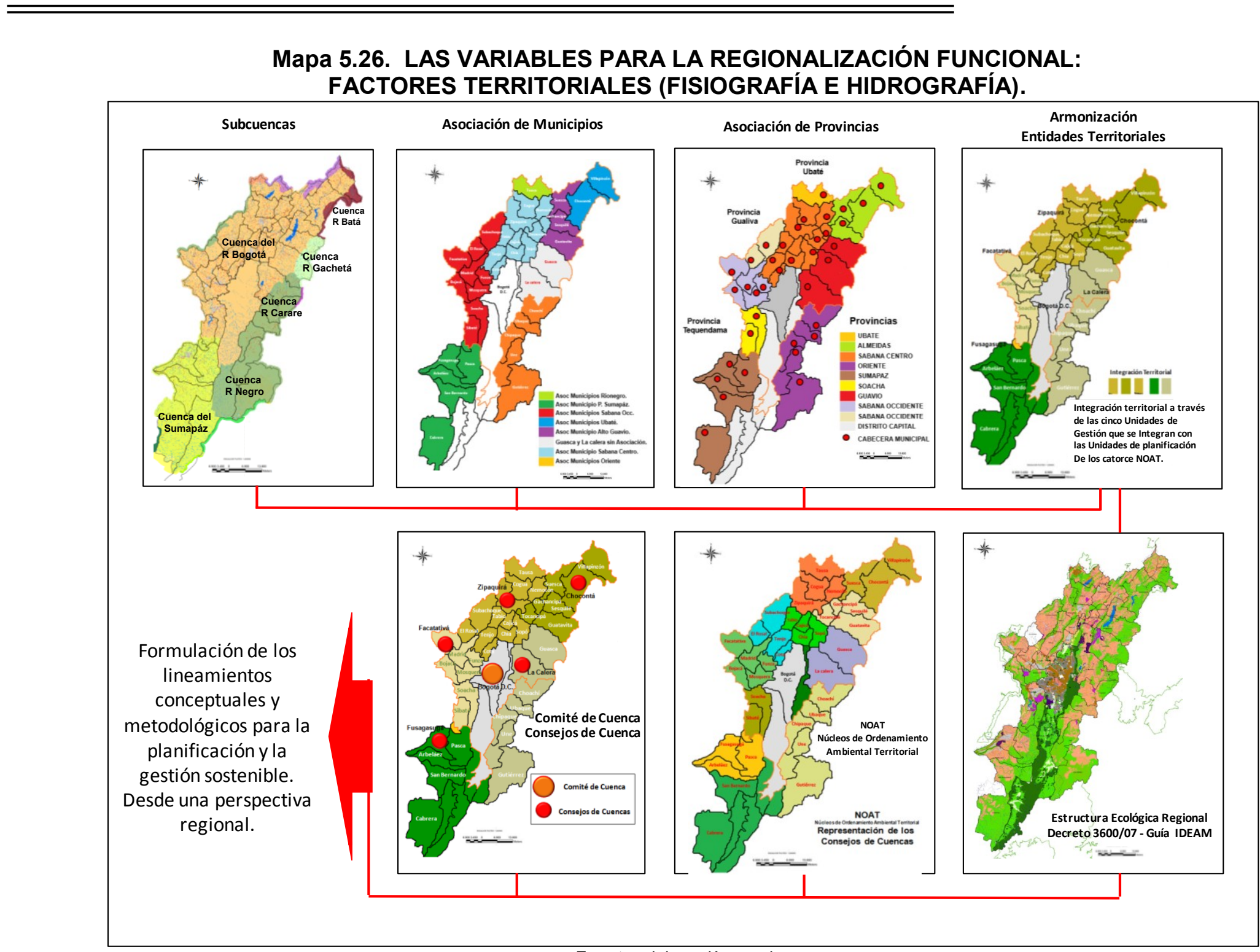

Fuente: elaboración propia 
6 CONCLUSIONES 


\subsection{CONCLUSIONES}

En cuanto al Diagnostico, el conocimiento del Marco Conceptual y Teórico en su distinta contextualización y el Marco Político Legal y Normativo, constituyeron las bases para la caracterización análisis y argumentación de la información. La cual, el departamento de Cundinamarca proporcionó la suficiente información proveniente de la cartografía de los POTS, municipales, como también los estudios proveniente de la Corporación Autónoma Regional CAR y oficinas de Planeación Municipales. En términos generales llevó al desarrollo del análisis territorial para la propuesta de la Formulación de los Lineamientos conceptuales y metodológicos para la planificación y la Gestión Sostenible del área de estudio integrada por la subcuenca alta y media del Río Bogotá y su área de influencia constituida por las Subcuencas de los Ríos Negro, Carare, Gachetá, Batá y la del Sumapáz.

Por lo tanto, se logró establecer el conocimiento necesario del territorio a través del de los distintos Planes de Desarrollo su alcance como política en el municipio, y los Planes de Ordenamiento territorial elaborados por la promulgación de la Ley 388 de 1997. Dichos planes se denominaron instrumentos de planificación y de gestión. Los datos que se compararon para el análisis del territorio, por medio de las cinco Dimensiones del Desarrollo como: La ambiental, social, económica. administrativa y territorial.

> La dimensión ambiental se elaboraron once (11) elementos que dieron la lectura de cómo se encontraba el estado de los recursos naturales, proporcionando el nivel crítico en un porcentaje muy alto por la incidencia antrópica por proyectos agropecuarios, la conservación de los bosques, lo cual determina hacia las administraciones municipales un mejor uso de la política ambiental.

La dimensión social, mostró el avance de la inversión pública en elevar las necesidades básicas insatisfechas (NBI), dando una visualización en el color azul en un gran porcentaje en el territorio en lo urbano y rural, en lo referente a la dimensión económica se analizaron tres periodos específicos 2007, 2008 y 2009, donde se obtuvieron resultados de los ingresos tributarios provenientes de las Regalías por explotación de recursos naturales, IVA, impuesto a las ventas, los ingresos corporativos, ingresos individuales, impuesto a alcohol, tabaco, etc.; otro de los análisis fueron los resultados de los recursos obtenidos por la prestación de servicios en el desarrollo de contratos, tasas, multas, contribuciones y participaciones, entre otros; mostrando un estado en colapso donde se muestra el uso que se ha venido dando a los ingresos presupuestales a través de los planes de desarrollo, lo cual, dio como resultado la promulgación por parte del Estado de la Ley 617 de 2000, de ajuste fiscal y racionalización del gasto.

El análisis de las variables con las cuales se determinaron los niveles de criticidad, inestabilidad, estabilidad, optimo y de colapso para cada una de las Dimensiones de Desarrollo, referente al manejo del territorio, son variables que incidieron directamente en la conservación de los recursos naturales; en áreas protegidas, protección del recurso hídrica, protección de los recursos naturales, conservación de bosques naturales, además de incluir los impactos de las zonas de desarrollo agropecuario con y $\sin$ 
restricciones de desarrollo, las amenazas naturales se concluyeron importantes resultados en los cuales las decisiones a futuro por medio de los Planes de Desarrollo Planes de Ordenamiento Territorial, en términos de inversión y de ejecución de recursos, como la identificación de nuevos proyectos de ejecución a través de la revisión o desarrollo de nuevos Planes de Ordenamiento Territorial, generaran un nuevo enfoque si se entiende que en el año 2007 y 2012, se han venido introduciendo los Planes de Manejo Integral de Cuencas Hidrográficas conocidos como los POMCAS, los cuales tienen y tendrán gran influencia en la construcción del territorio.

Dichos resultados, evidencian importantes efectos en los cuales la variable ambiental es la más comprometida en términos de desarrollo, teniendo en cuenta la interposición social y económica las cuales comprometen las relaciones humanas e inversiones públicas invertidas a través de los distintos instrumentos de planificación. En los tres mapas siguientes se muestra espacialmente el resultado obtenido a través del Biograma nivel de estimación del Índice Integrado de Desarrollo Sostenible (IIDS - S ${ }^{3}$ ). (Véase Mapa 6.27.)

Las inversiones presupuestales realizadas al sector de la educación en lo referente a la tasa de analfabetismo, necesidades de vivienda tanto en urbano como rurales, saneamiento básico, población pobre según NBI y miseria; evaluación que dio como resultado para los treinta y ocho municipios del área de estudio, es la que territorialmente se encuentra en un estado óptimo y estable, esto quiere decir, que las inversiones realizadas en los últimos planes de desarrollo han dado resultado al menos en el mejoramiento de la calidad de vida de sus pobladores.

En lo referente, al tema económico en primer lugar vale la pena resaltar el nivel municipal dependiente de su población como del presupuesto de inversión, encontrándose la clasificación de 23 municipios en categoría sexta; $(61 \%)$, en categoría tercera 5 municipios (14\%), en categoría cuarta $3(7,9 \%)$ y, segunda $3(7,9 \%)^{90}$. Esto refleja un alto grado de las entidades territoriales municipales en términos del desarrollo rural, dependientes directamente de las políticas públicas gubernamentales en desarrollo económico entre ellas las del sector primario de la economía (agricultura) cómo dependientes también de autorizaciones del Ministerio de Hacienda para adquirir endeudamientos para su inversión futura. De alguna manera, en el área de estudio esta categorización se refleja especialmente para el sistema de análisis "el estado de colapso" y en "nivel crítico" del manejo de la economía; proceso que deben ser subsanados desde visiones conjuntas entre entidades municipales las cuales son las identificables a través del estudio presentado.

Con fines de reconocer la importancia de la Ley 617/00, de ajuste fiscal, la evolución del desempeño fiscal tomando los periodos de los años 2009, 2010 y 2011, partiendo del último análisis del año 2009, lo cual, nos permitió reconocer las condiciones que estaban los municipios dentro del área en términos en el manejo de sus inversiones territoriales, lo cual se puede observar en los mapas de espacialización de los impacto de cada una de las dimensiones en el territorio. (Véase Mapa 6.27.)

90 Clasificación establecida desde la Ley 617/00, denominada de ajuste fiscal, tendiente a modernizar la organización y el funcionamiento y recategorización de los municipios. 
La tendencia general de la evaluación del desempeño fiscal en los 38 municipios evaluados, señala algunas entidades territoriales como las más fortalecidas financieramente, reconoce a los municipios de Cota, Cajicá, Tocancipá y Tenjo, ubicados en los mejores lugares en la tabla del ranking fiscal. Tal es el caso de la ciudad de Bogotá, ocupado el puesto 19 en esta evaluación; en términos del indicador pasó de 80.98 puntos en 2010 a 83.70 puntos en 2011. Esto quiere decir que Bogotá D.C., se ubica en el máximo rango de la evaluación que clasifica como solventes a los municipios que obtienen calificaciones superiores a los 80 puntos; lo cual, nos permite establecer la localización del Comité de Cuenca y preferiblemente en las instalaciones de la Secretaría de Medio Ambiente del Distrito Capital; para los Consejos de Cuenca, se reconocen a los municipios que se han venido fortaleciendo financieramente.

En segundo lugar, Sopó, Mosquera y Chía, que sin ser municipios de gran desarrollo económico tienen condiciones económicas que sustentan un importante nivel de ingresos y que tienen una estructura financiera sólida y que se han venido consolidando a través de los años. Se destaca el municipio de Cogua el cual estaba en el 2010, en la posición 229 y pasó al puesto 23. Esto, quiere decir, que las entidades territoriales anteriormente reconocidas son aquellas que han aplicado medidas de buenas prácticas fiscales y que ahora son llamadas a hacer buen uso de los nuevos y frescos recursos para los municipios con la reciente reforma constitucional al régimen de regalías (acto Legislativo 05 de 2011).

\section{Mapa 6.27. ESPACIALIZACIÓN DE LOS IMPACTO DE CADA UNA DE LAS DIMENSIONES EN EL TERRITORIO.}

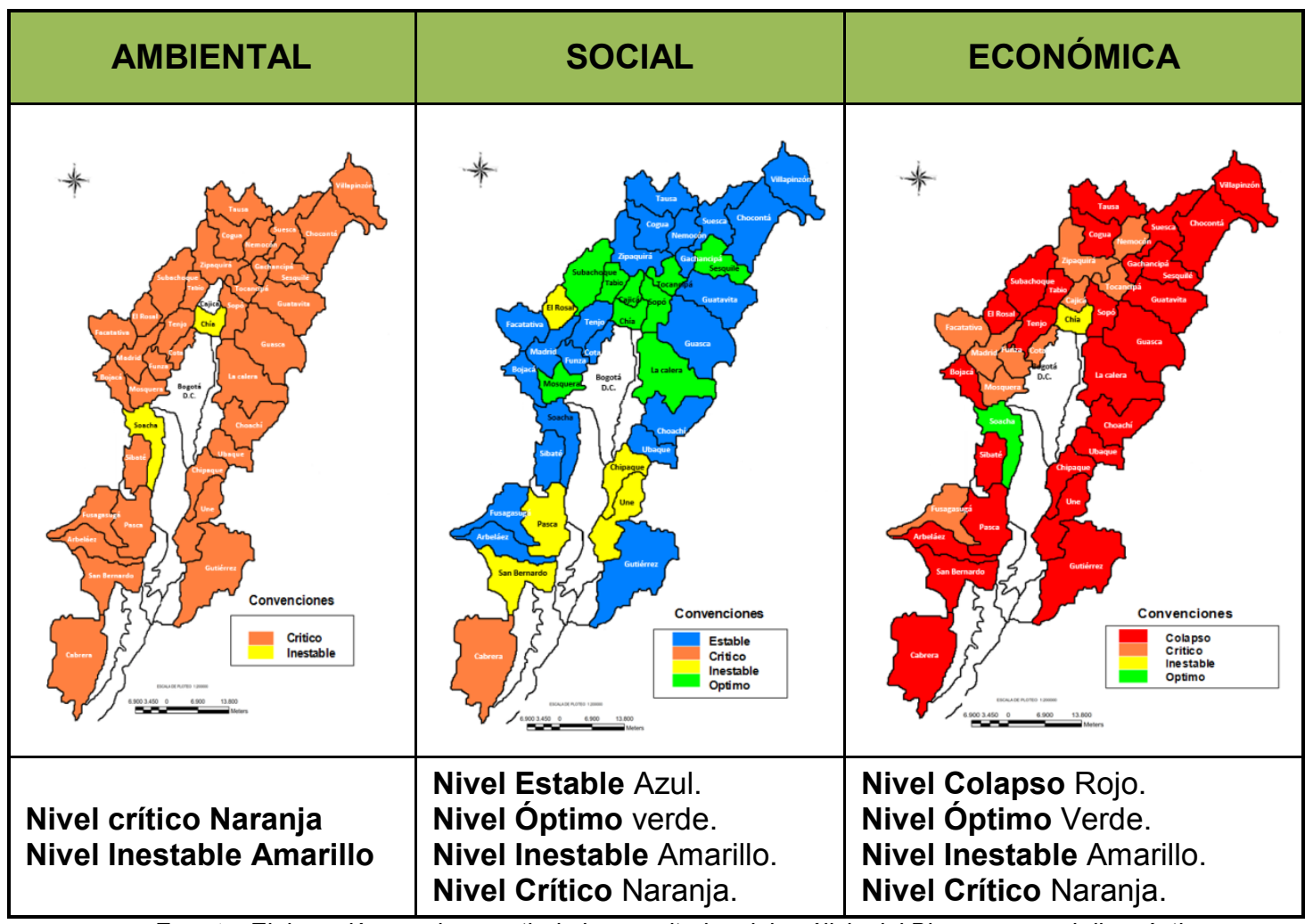

Fuente: Elaboración propia a partir de los resultados del análisis del Biograma en el diagnóstico. 
> Por esta razón, un aumento de la calificación significa que la entidad territorial mejoró su gestión fiscal, particularmente entre los años 2009 2010 y 2011, da cuenta de cómo están manejando sus finanzas los mandatarios municipales y sus equipos de gobierno luego de su cuarto año al frente de sus respectivas entidades. La evaluación del último año es muy importante porque da cuenta de una gestión al $100 \%$ de los mandatarios locales, es decir, que estos resultados de los tres años sean la radiografía de su gestión financiera; fortaleciendo el resultado anterior del Biograma, en lo referente a la aplicabilidad de los recursos según la Ley 152 de 1994. Lo cual, nos permitió mantener los criterios que se establecieron tanto en lo conceptual y metodológico en la armonización territorial.

$>$ Otro factor de análisis fue el marco normativo se cotejó las normas jurídicas desde contextos territoriales diferentes y con visiones encontradas entre distintos gobiernos o administraciones, lo que permitió verificar la compleja relación entre cada una de ellas hacia un marco integral de desarrollo institucional, posiblemente con la contraposición en recursos de inversión que quedan en manos de los distintos Planes de Desarrollo, para su inversión. Así mismo, dicho resultado ha impedido posiblemente el ir avanzando en la regionalización territorial, teniendo en cuenta aspectos sociales, económicos, y administrativos.

En el marco de la Constitución de 1991, la Ley Orgánica de Ordenamiento Territorial LOOT (1454 de 2011), sin dejar de lado el marco legal y normativo que sustenta el ordenamiento territorial, en el Manejo Integral de Cuencas Hidrográficas, propósito del Modelo de Desarrollo Regional (MDR), que se propone, en armonía con los catorce (14), NOAT y las cinco (5) Unidades de Planificación que constituyen el lineamiento en la armonización territorial para impulsar y promover la participación de los actores, en asocio entre gobernantes y gobernados en temas de gestión conocida como la cogestión administrativa hacia una gobernanza territorial.

$>$ En cuanto, a la formulación de la propuesta de lineamientos conceptuales y metodológicos para la planificación de la gestión sostenible de la cuenca hidrográfica del río Bogotá, desde una perspectiva regional, la cual, está desarrollada en el capítulo 5 , lo que se buscó fue una respuesta propositiva teniendo en cuenta la organización del territorio a partir de la "cuenca hidrográfica" respaldada en el marco legal del decreto 1729/02, 1640/12 y la resolución 0509 de 2013, marco legal que nos posibilita la aplicación de instrumentos de planificación y de gestión territorial desde la visión en la ordenación de cuencas hidrográficas, desde una perspectiva regional y que permitan alcanzar el desarrollo económico, social, administrativo y el mejoramiento de la dimensión ambiental en el manejo de los recursos naturales en todo el área de estudio y que se pueda replicar en otros espacios territoriales. Ahora bien, en la etapa de organización territorial que se inicia en lo denominado el Postconflicto, donde dos normas importantes como la ley 614 del 2000 por la cual se orienta para las entidades territoriales la creación de los Comités de Integración territorial (CIT), el Decreto 4161 de 2011, la creación de la Unidad Administrativa Especial para la Consolidación Territorial (UAECT)

Por lo tanto, los resultados de armonización de los instrumentos de planificación, conllevaron a la zonificación, contribuyendo a garantizar la ejecución de los Lineamientos Conceptuales y Metodológicos para la 
planificación y la gestión sostenible del territorio, desde una perspectiva regional, a partir de las subcuencas alta y media del Río Bogotá y su influencia directa con las subcuencas del Río Negro, Carare, Gacheta, Batá, y Sumapáz.

La formulación vista en el capítulo 5 implica un nuevo enfoque en la concepción de la planificación del desarrollo hacia lo regional, introduciendo la dimensión ambiental en la interpretación de las políticas públicas, mediante el desarrollo económico y social que debe ser compatible con la preservación, la protección y la recuperación ambiental de los recursos naturales, que requieren las próximas generaciones para su desarrollo; lo cual constituye el marco general de orientación en los conceptos y lineamentos metodológicos para el nuevo Modelo de Desarrollo Regional desde una dimensión administrativa fortalecida para armonizar sus programas y proyectos de forma colectiva e integrarse territorialmente teniendo como construcción de territorio la Cuenca Hidrográfica.

En general, la propuesta de formulación para la planificación y la gestión sostenible desde una perspectiva regional desde un sentido prospectivo, se basó en criterios institucionales (división Municipal), y geográficos (EER y Subcuencas), donde una o más variables espaciales adquieren cierta especificidad e importancia en el momento de tomar decisiones a través del análisis ambiental del territorio donde obligatoriamente los conceptos de desarrollo y crecimiento social y económico se respalda desde la conservación, preservación y restauración ambiental del territorio, de la consolidación de un sector rural producción y la consolidación del desarrollos urbanísticos en los distintos centros poblados existentes en cada una de las cinco (5) zonas y los 14 NOAT establecidos para el desarrollo y fortalecimiento de los lineamientos para la planificación y la gestión sostenible de las subcuencas, donde la dimensión administrativa es la galante para garantizar la participación de los distintos actores (públicos, privados y sociedad en general) a través del fortalecimiento del Comité de Cuenca y de los Consejos de Cuenca respectivos dentro del área constituida desde una perspectiva regional.

Los catorce (14), NOAT y las cinco (5) unidades, con las cuales se integraron las entidades territoriales, son los criterios y la expectativa de aplicar la estructura de la base administrativa para la región. Conllevando a la localización del Comité de Cuenca en la ciudad de Bogotá D.C., preferiblemente en las instancias de la alcaldía (Secretaría de Medio Ambiente), con la instancia administrativa de toda el área de estudio y su coordinación con el nivel nacional, esta instancia está armonizada con los Consejos de Cuenca, cuyo escenario es la concertación con los actores que pertenecen al área y específicamente a cada uno de los NOAT.

Con base en lo anterior, las Unidades de Planificación NOAT, teniendo en cuenta las fortalezas identificadas en lo social, por las inversiones públicas que han dado como resultado el mejoramiento de la calidad y por ende en la posibilidad de participar activamente en programas y proyectos territoriales desde cada uno de los municipios que integral el territorio y estos de forma más integral a través de los NOAT, que posibilitan tener el desarrollo y crecimiento territorial de forma más integral. 
En cuanto al fortalecimiento institucional en el territorio a través de la dimensión administrativa, se plantea la puesta en marcha de las Unidades de Planificación y de Gestión, correspondiente a las unidades que conforman el desarrollo de los NOAT, teniendo en cuenta, la participación de los distintos sectores tanto en lo públicos como en lo privado y sociedad civil generando alianza estratégica en la asociación público privado que se vean reflejadas en la competitividad social y económica e institucionalmente más viables a nivel de la armonización e integración territorial.

En cuanto al Manejo Integral de Cuencas Hidrográficas, la Planificación y la Gestión Territorial se recupera gran importancia en el contexto político, al entenderse que los recursos naturales entre ellos el suelo y el agua es el sustento del desarrollo y crecimiento del sector rural y de la consolidación de centros urbanos más sostenibles y por supuesto, el mejoramiento de la calidad de la población en general. En el curso de esta búsqueda, la Maestría en Manejo y Gestión de Cuencas Hidrográficas se constituye en el baluarte del desarrollo y crecimiento territorial, fortaleciendo el conocimiento territorial desde una visión concreta en la armonización e integración de territorios con propósitos colectivos de desarrollo y crecimiento ambiental social y económicos además de fortalecer a las administraciones públicas para las futuras tomas de decisiones a través de gerentes y personal idóneo.

Por lo tanto, el conocimiento de incorporar la participación activa de la comunidad y sociedad civil en general, donde los ciudadanos tendrán iniciativas para presentar proyectos de acuerdo ante el Comité de Cuenca, a través de los Consejos de Cuencas. En cuanto a sus funciones y competencias, su creación se hará dentro de las responsabilidades establecidas como se indicó en el (Capitulo 5), como instancia decisoria para la ejecución de acciones orientadas al ordenamiento de la administración pública, uso y aprovechamiento del recurso hídrico de cada una de las unidades en la que se ha zonificado el territorio. En tanto, a las subcuencas de los Ríos Negro, Carare, Gacheta, Batá y Sumapáz componen el ordenamiento ambiental del área de estudio a través de la armonización de la Estructura Ecológica Regional (EER), cuya base se constituye en el elemento o componente para el ordenamiento y manejo de Cuencas Hidrográficas.

Los lineamientos y conceptos metodológicos estarán dados hacia el manejo de la conservación y la protección ambiental de los recursos naturales presentes en el área; a esta instancia se determina el alcance de la creación del Comité de Cuenca el cual valorará las decisiones en conjunto con las distintas instituciones en la conveniencia de desarrollar o disposición de los recursos naturales de forma integral entre sus asociados (municipios). Para la valoración de la participación de sectores privados y sociedad civil, en general se constituirán los Consejos de Cuencas, con jurisdicción local, este esquema de participación y articulación de los actores sociales propuesto para el Consejo de Cuenca, estarán determinados en la jurisdicción en la conformación de las Unidades Territoriales y de Gestión NOAT, y sus funciones estarán enmarcadas dentro de las competencias y responsabilidades identificadas en el capítulo 5. 
Finalmente, se reconocen algunos instrumentos para la regionalización, teniendo en cuenta la división político/administrativa y la integralidad de la zonificación ecológica, con el fin de impedir que la región propuesta, no constituya un nuevo fraccionamiento de territorio sino, por el contrario contribuya efectivamente a la integración, a la articulación administrativa y a la recomposición del sistemas y redes sociales, económicas, administrativas y ambientales, el trabajo de investigación a lo largo de los capítulo dos y tres se fortalecen las directrices para los lineamientos conceptual metodológicos para determinar los alcances del desarrollo regional y su fortalecimiento desde lo administrativo, articuladas al desarrollo sostenible del territorio. 
7 RECOMENDACIONES 


\subsection{RECOMENDACIONES}

Las recomendaciones están dirigidas a proporcionar sugerencias en tanto al ordenamiento territorial y la importancia de planteamientos regionales, teniendo en cuenta a la luz los resultados de la investigación, la conveniencia de identificar la cuenca hidrográfica como el escenario propicio en las tomas de decisiones para planificadores y gestores económicos que incidan en el manejo de posturas integrales en la inversión pública y privada en la explotación de recursos ambientales y su utilización como tal. Por lo tanto, las recomendaciones, pueden clasificarse en tres posturas analíticas: una postura académica, una postura hacia las instituciones y una postura en cuanto a la incidencia de la participación ciudadana, del sector privado en las decisiones en los procesos de participación en la aplicabilidad de los instrumentos de planificación y de gestión definidos.

\subsection{UNA POSTURA ACADÉMICA.}

La academia, a través de los estudios de posgrado fortalece la capacidad técnica de profesionales de diversas disciplinas, en la planeación en la gestión del desarrollo territorial, en el caso Colombiano, profesionales como docentes tendrán la visión integral en las tomas de decisiones en el complejo arte de ordenar y planificar el territorio desde una lectura en armonía con el contexto y articulación entre los planes de desarrollo y planes de ordenamiento territorial y, su visión al complementarlas con la unidad física en el manejo integral del territorio como es la cuenca hidrográfica y Estructura Ecológica Regional, donde confluyen las variables de las Dimensiones del Desarrollo (DD), identificas como la social, económico, ambiental, administrativo y territorial, a través de las cuales se debe trascender los limites político-administrativos de los municipios y departamentos, fortaleciendo en las decisiones del planteamiento de los concepto regionales ${ }^{91}$.

Por lo tanto, esta investigación, puede ser un instructivo para Capacitar a funcionarios públicos, profesionales de diversas áreas del conocimiento, en los fundamentos y principios de la gestión pública; en bases legales y normatividad; metodologías y procedimientos para la actuación en los nuevos escenarios de la planeación y de la gestión territorial, que enmarcan y caracterizan los ejercicios de armonización de los instrumentos de planificación y de gestión tanto en Planes de Ordenamiento Territorial municipal y Planes de Manejo Integral de Cuencas Hidrográficas, como instrumentos de planificación y desarrollo del territorio desde una visión regional.

\subsection{UNA POSTURA HACIA LAS INSTITUCIONES.}

Para funcionarios públicos y asesores de Estado, que involucren el concepto regional en el ordenamiento territorial para la formulación y la implementación de políticas públicas relacionadas con la armonización el ordenamiento territorial y el desarrollo regional. Como se llevó a cabo a lo largo de los cinco capítulos, la atención metodológica en el desarrollo de la investigación refleja la continuidad de cada uno de los capítulos que proporcionan el conocimiento como es el caso del marco legal,

\footnotetext{
${ }^{91}$ A manera de instructivo, la investigación desarrollada, plantea respectivos niveles de socialización en los escenarios apropiados como: universidades, seminarios, congresos o coloquios, donde se muestren los resultados en la aproximación a un debate hacia lo político, en la conveniencia de plantear un nuevo orden en la discusión de lo político y administrativo en términos de ordenamiento territorial y de gestión en la planificación, que obedezca a planteamientos directos en el conocimiento de nuestra geográfica en lo social, económico y ambiental. Es así que la cuenca hidrográfica debe recobrar su espacio en el ordenamiento territorial tanto en lo físico, como en lo decisorio en las nuevas políticas públicas desde una visión regional, teniendo como escenario la academia y sus distintos escenarios de discusión.
} 
conceptual y teórico como aporte a la nueva postura hacia las instituciones de cambio de pensamiento de un sector público que decide, un sector privado que compromete recursos y una sociedad civil que legitima y participa con los dos anteriores.

Sin embargo, la organización territorial por departamentos, conlleva a inexactitudes en la aplicación de los mecanismos de articulación regional en la toma de decisiones por parte de algunas instituciones que dificultan la interrelación con los diferentes niveles de organización territorial y de planeación como se ha venido observando a través de los últimos eventos naturales sucedidos específicamente en el área de estudio, donde compromisos presupuestales a la hora de invertir, no se tenía claramente quien y como se debía utilizar el recurso. Por el contrario, la organización del territorio a partir de figuras como los Núcleos de Ordenamiento Ambiental Territorial (NOAT) posibilitara la aplicación de instrumentos de planificación y gestión territorial, que sea sostenibles en el tiempo desde una perspectiva regional, de modo que se pueda alcanzar el desarrollo económico, social en todo el país y ambientalmente más equitativo en términos de su uso y disponibilidad de los recursos naturales.

La definición de cuencas hidrográficas en la cual, se considera la realidad políticoadministrativa, con una visión ambiental, social y económica, posibilita reordenar al país con un criterio científico y conducente a establecer las políticas de desarrollo requeridas a través de las distintas instituciones territoriales pertenecientes en el área de estudio, como su relación de referencia con la periferia en las decisiones en su conjunto.

No obstante existen instrumentos jurídicos, algunos de ellos planteados para la articulación regional ${ }^{92}$, la Cuenca Hidrográfica debe ser el eje estructural para el ordenamiento del territorial y la toma de decisiones desde una perspectiva regional, el armonizar y articular las instancias político-administrativas existentes, y estas a las dimensiones del desarrollo en términos de equilibrio entre oferta y demanda en lo ambiental (coberturas y recurso hídrico), y en lo social, económico, administrativa y territorial, cuyo fin, es llegar a los lineamientos del desarrollo regional equitativo igualitario y competitivo en los contextos departamental y municipal. Al permitir su articulación con la acción local y aprovechando las ventajas competitivas de cada uno de los municipios, lo regional, se fundamenta teniendo instituciones fuertes capaces de diseñar y construir espacios donde la inversión social con mayor cohesión e igualdad económica y geográfica en los territorios del área de la cuenca alta y media del Río Bogotá y su área de influencia comprendida y articulada con las subcuencas del Río negro, Carare, Gachetá, Batá y Sumapáz y hacer de ellas las bases para el desarrollo de la región ejemplo en la armonización de territorios en la construcción de país con énfasis en los preceptos de región.

Finalmente, las instituciones públicas posibilitan las bases de armonización de asociación territorial en lo político-administrativas, flexibles y dinámicas entre las entidades territoriales municipales. Para el caso del área de estudio, la estructura Ecológica Regional aporta la relación, armonización e integración de las distintas entidades territoriales en el sentido de integrar los NOAT como instancias de gestión para que los Consejos de Cuenca, consoliden las dinámicas de participación territorial hacia el fortalecimiento del concepto de región.

Lo que nos lleva a decir que la organización territorial por departamentos en Colombia, ha llevado a la centralización en las decisiones de las políticas públicas en la aplicación de los mecanismos e instrumentos territoriales de articulación regional

92 Constitución 91, Ley 99, Ley 388, Decreto 3600, Decreto 1729 de 2002, ley 1454 de 2011 Proyecto de Ley Orgánica de Ordenamiento Territorial. 
que han dificultado la interrelación con los diferentes niveles de organización territorial y de planeación. Por lo tanto, la organización del territorio a partir de la cuenca hidrográfica posibilita la aplicación de herramientas de planificación y de gestión territorial, promoviendo el uso sostenible desde la perspectiva regional contribuyendo al desarrollo económico, social y administrativo.

De todo ello, la definición de cuencas hidrográficas $(\mathrm{CH})$ que consideren la realidad político-administrativa y tengan una visión ambiental, social y económica, posibilita reordenar al país con un criterio científico y conducente a establecer las políticas de desarrollo requeridas. Este criterio de organización y armonización entre la $\mathrm{CH}$ y EEP hacia lo regional, donde se considera la diversidad de paisajes, posibilita que se establezcan las bases que demuestren la necesidad de definir formas de asociación político-administrativas flexibles y dinámicas entre entidades territoriales de diferente orden desde lo municipal y departamental, cumpliendo así claramente con la posición de la hipótesis.

\subsection{UNA POSTURA EN CUANTO A LA INCIDENCIA DE LA PARTICIPACIÓN CIUDADANA Y DEL SECTOR PRIVADO EN LAS DECISIONES EN LOS PROCESOS DE PARTICIPACIÓN EN LA APLICABILIDAD DE LOS INSTRUMENTOS DE PLANIFICACIÓN Y DE GESTIÓN DEFINIDOS.}

El capítulo quinto hace referencia a la participación y conformación de los actores, tanto para el Comité de Cuenca como para los Concejos de Cuenca donde espacialmente se caracteriza la interrelación y aplicabilidad tanto del sector público y privado y sociedad civil para el fortalecimiento del desarrollo regional a través de la conformación de las Unidades Planificación y de Gestión, por parte de la conformación y armonización de las entidades territoriales.

Por lo tanto, la armonización territorial garantiza la implementación de los lineamientos conceptuales y metodológicos para la planificación y la gestión sostenible del territorio, desde una perspectiva regional, fortaleciendo la participación de la ciudadanía y de actores que han venido teniendo importante presencia en el área y en especial atención en cada una de las unidades de los municipios. Los NOAT buscan fomentar la participación social en interrelación con organismos locales, autonómicos, y estatales. Estos serían los encargados de fomentar y facilitar diferentes mecanismos para que la población tenga acceso a las decisiones del gobierno, de manera independiente, sin formar parte de éste o de algún partido político.

En síntesis, se trata de integrar a la población en general en los procesos de toma de decisiones, que fomentan la participación colectiva o individual en el desarrollo de las política públicas, entendida esta como algo de lo que todos formamos parte; la participación ciudadana impulsará la democracia real, y no debe ser privilegio de unos pocos, es un derecho y un deber de todos los ciudadanos. La creación de las Unidades de Planificación y de Gestión (NOAT), que son los canales de participación ciudadana, debe ser impulsada y generada por los propios ciudadanos, quienes se organizan, para el seguimiento, la evaluación de programas y proyectos, e inciden directamente en el Comité de Cuenca e integralmente a través de los Comités y Consejos de Cuenca. 


\section{REFERENCIAS BIBLIOGRAFICAS}




\subsection{MARCO REFERENCIAL}

ALCALDÍA MAYOR DE BOGOTÁ, SECRETARÍA DISTRITAL DE PLANEACIÓN. WIESNER, D. 2006. Formulación del plan zonal de ordenamiento y gestión del territorio para la franja de adecuación o transición entre la ciudad y los cerros orientales.

AGUIRRE NÚÑEZ Mario - TORRES Humberto - RUIZ Rosa, Manual de procedimientos para la delimitación y codificación de cuencas hidrográficas del Perú $\mathrm{P}$ 11, Edición 2003.

AGS LTDA, Lineamientos para el ordenamiento y Manejo de las cuencas hidrográficas del río Guarapas en el departamento del Huila entre los Municipios de Pitalito y Palestina; Cuencas de las quebradas La Quintana localizada en la ciudad de Medellín departamento de Antioquia y Piedras Blancas y La Valeria en el Valle del Aburra Área Metropolitana de Medellín Antioquia, 2006-2009.

AVH, INSTITUTO DE INVESTIGACIÓN DE RECURSOS BIOLÓGICOS ALEXANDER VON HUMBOLDT. Estimación de un conjunto de indicadores que aporten a un programa de monitoreo de la biodiversidad, a nivel de ecosistemas, en la jurisdicción de la CAR. Convenio 07-548 Instituto de Investigación de Recursos Biológicos Alexander von Humboldt IAvH - CAR, Corporación Autónoma Regional de Cundinamarca. Informe final de Resultados. 2009. Bogotá.

BERNEX Nicole y OBLITAS Lidia, Cuenca del Zaña "Programas para la construcción de bases institucionales y operativas para la gestión integrad de la cuenca", (cuenca del río Jaquetepeque Lima Perú), Pontificia Universidad Católica del Perú, Centro de estudios sociales solidaridad, Global Wáter Partnerschip South América, Foroi peruano para el agua, P 120 Lima 2008.

CASTRO Jaime, La Cuestión Territorial, año 2003, Edición 2da Oveja Negra, P 245 - 81 - 122 publicado en Bogotá Colombia.

CASTELLS, Manuel. (2.000) Globalización, Sociedad y Política en la era de la Información. EN Revista Bitácora Urbano Territorial No 4. P 42-53. Bogotá. Universidad Nacional de Colombia.

CARRIZOSA UMAÑA julio, Desequilibrios Territoriales y Sostenibilidad Local, "Conceptos, metodologías y realidades" Universidad Nacional de Colombia Instituto der Estudios Ambientales IDEA primera edición enero 2006, P 174 Bogotá D.C. Colombia.

CEPAL MONTES LIRA Pedro Felipe, Serie medio ambiente y desarrollo, "El ordenamiento territorial como opción de políticas urbanas y regionales en América Latina y el Caribe, P 64 Santiago de Chile, diciembre de 2001.

CONGRESO DE LA REPÚBLICA DE COLOMBIA, Los Caminos del Ordenamiento Territorial, "memorias de los Foros Regionales", Comisión de Ordenamiento Territorial, Año 2001, P 190, edición Senado de la República de Colombia, publicado Bogotá D.C. Colombia.

CORPOCALDAS - CARDER - PARQUES NACIONALES NATURALES, Cuenca del Río Campoalegre, P 166 Agosto de 2009. 
CORPORACIÓN AUTÓNOMA REGIONAL DE CUNDINAMARCAL, Plan de Ordenación y Manejo de la Cuenca Hidrográfica del Río Bogotá, P 104 Resumen ejecutivo 2006, publicado CAR, Bogotá Colombia.

CORPORACIÓN AUTÓNOMA REGIONAL DE CUNDINAMARCAL Plan Ambiental de la Cuenca Alta del Río Bogotá "Análisis y orientaciones para el ordenamiento territorial (Tomas Van Der Hammen) P 138 edición Bogotá D.C. 1998.

CONSEJO REGIONAL DE COMPETITIVIDAD, Bogotá - Cundinamarca hacia una región competitiva, Bases plan regional de competitividad 2004 2014; P 80 Bogotá diciembre de 2003.

CONTRALORÍA GENERAL DE LA REPÚBLICA, Estrategias para la armonización y Seguimiento al programa de descontaminación del Río Bogotá, Audiencias públicas y Mesa interinstitucional (2007 - 2010), P 132, Bogotá D.C. Colombia.

CARRILLO-RIVERA, J.J. 2000.Application of the groundwater - balance equation to indicateinterbasin and vertical flow in two semi-arid drainage basins. Hydrogeology Journal, V8 (5): P 503-520.

DEPARTAMENTO NACIONAL DE PLANEACIÓN, Resultados del desempeño fiscal de los departamentos y municipios de la vigencia 2009, de conformidad con lo establecido en la Ley 617 de 2000.

DEPARTAMENTO NACIONAL DE PLANEACIÓN, Resultados del desempeño fiscal de los departamentos y municipios de la vigencia 2010, de conformidad con lo establecido en la Ley 617 de 2000.

DEPARTAMENTO NACIONAL DE PLANEACIÓN, Resultados del desempeño fiscal de los departamentos y municipios de la vigencia 2011, de conformidad con lo establecido en la Ley 617 de 2000.

ESTUDIO FAO MONTES 150; Libro de consulta para profesionales y autoridades locales, basado en los resultados y las recomendaciones de una sistematización de la FAO; La nueva generación de programas y proyectos de gestión de cuencas hidrográficas; Organización de las Naciones Unidas para la Agricultura y la Alimentación; P 154, Roma, 2007.

FARINÓS Joaquín, Romero Joan (eds.), Territorialidad y Buen Gobierno para el Desarrollo Sostenible, "Nuevos principios y nuevas políticas en el espacio europeo" Año 2007 P 258, Universidad de Valencia, Edición Publidisa, Unión Europea.

GASPARI Fernanda J., Gabriela E. Senisterra, María Isabel Delgado, Alfonso M. Rodríguez V, Sebastián I. Besteir, año 2009, P 321 1-65 Bases, Manual de manejo integral de cuencas hidrográficas, publicado en la ciudad de Buenos Aires Argentina.

GUHL Nannetti Ernesto, WILLS HERRERA Eduardo, MACÍAS Luis FernandoAlejandro, BOADA ORTIZ Claudia, edición 1998, Guía para la Gestión Ambiental Regional y Local, P 287 publicado FONADE Colombia.

IDEAM, Guía Técnico Científica para la Elaboración y Manejo de Cuencas Hidrográficas en Colombia, P 65 Financiado por la Embajada de los Países Bajos y gtz, Julio 2006. 
INSTITUTO GEOGRÁFICO AGUSTÍN CODAZZI (IGAC), año 1996. Aplicación metodológica al Ordenamiento Territorial Ibagué, P 279 publicado en la ciudad Bogotá Colombia.

INSTITUTO GEOGRÁFICO AGUSTÍN CODAZZI (IGAC), año 1997. Guía metodológica para la formulación del Plan de Ordenamiento Territorial Municipal $P$ 185, publicado en la ciudad Bogotá Colombia.

INSTITUTO GEOGRÁFICO AGUSTÍN CODAZZI (IGAC), año 1997. Bases conceptuales y guía metodológica para la formulación del Plan de Ordenamiento Territorial departamental. P 350 publicado en la ciudad Bogotá Colombia.

INSTITUTO GEOGRÁFICO AGUSTÍN CODAZZI (IGAC), Gestión del suelo urbano "En el marco de Ordenamiento Territorial", año 2007. P 91 publicado en la ciudad Bogotá Colombia.

GLOBAL WATER PARTNERSHIP, Manual para la Gestión Integrada de recursos Hídricos en Cuencas, P 111, Republica de Francia.

KONRAD-ADENAUER - Stiftung, integración Regional "Una condición para la paz y el desarrollo, año 2001, P 247, Bogotá D.C. Colombia.

KONRAD-ADENAUER - Stiftung, Ciudad - Región Integración y Desarrollo, Memorias del seminario en Ibagué Colombia P 77, Bogotá D.C. Colombia.

MENDOZA MORALES Alberto, Colombia Estado Región "Ordenamiento Territorial", Metodología, año 2000, Editora Guadalupe Ltda, P 185 publicado en la ciudad de Bogotá Colombia.

MENDOZA MORALES, Alberto (1989). Evolución histórica de las divisiones político administrativa de Colombia desde 1509 Hasta hoy. Boletín de la Sociedad Geográfica de Colombia 122-123. Recuperado el 12 de Noviembre de 2012 de http://www.sogeoco.edu.co/documentos/evol_fron.pdf.

MINISTERIO DEL EXTERIOR - MINISTERIO DE HACIENDA Y CRÉDITO PÚBLICO - DEPARTAMENTO NACIONAL DE PLANEACIÓN - PROGRAMA MEJOR GESTIÓN DE LOS DEPARTAMENTOS, PMGD La Encrucijada de la Figura Departamental en Colombia, "Un diagnóstico preliminar de la situación del departamento en Colombia y algunos alcances para su análisis y ajuste", año 2001, P 87, edición Unión Grafica, Bogotá Colombia.

MINISTERIO DE AMBIENTE Y DESARROLLO SOSTENIBLE, Dirección General ambiental Sectorial, Grupo de Gestión Urbana y Salud, Lineamientos Ambientales para la Gestión Urbano Regional en Colombia, P 45 Bogotá 2003.

MINISTERIO DE AMBIENTE Y DESARROLLO SOSTENIBLE Planificación y Manejo Ambiental de Cuencas Hidrográficas, , ICFES, Año 1997, Universidad del Tolima, P 131 publicado Ibagué Colombia.

PERSPECTIVAS TERRITORIAL DE LA OCDE, Organización para la Cooperación y el Desarrollo Económicos, Edición 2001. Recuperado junio 12 de 2014. http://browse.oecdbookshop.org/oecd/pdfs/free/9789264189911-sum-es.pdf 
PNUMA; "Planificación para el cambio"; Guías para programas nacionales sobre consumo y producción sustentable; 2008. P $10514-30$.

PLAN ESTRATEGICO DE LA MACROCUENCA CON LA PARTICIPACIÓN DE LA UPRA, Unidad de Planificación Rural Agropecuaria 2010.

RANGELSUAREZ Alfredo, El Desarrollo Regional, Escuela Superior de Administración Pública, Año 1993, Edición ESAP, P 193, publicado en la ciudad de Bogotá Colombia.

REMOLINA ANGARITA, Fernando. Propuesta de Estructura Ecológica Regional para la región capital y guía técnica para su declaración y consolidación. Informe final. Orden de prestación de servicios No. 014 -UEFMA-2010 perteneciente al contrato interadministrativo de ciencia y tecnología No. 1392 de 2009 entre la Universidad Distrital Francisco José de Caldas y la Secretaría Distrital de Ambiente. 2010.

SÁNCHEZ Roberto O., año 2009. Ordenamiento Territorial Bases y Estrategias metodológicas para la ordenación ecológica y ambiental de tierras, P 260 publicado en la ciudad de Buenos Aires Argentina.

SEPÚLVEDA Sergio Metodología para Estimar el Nivel de Desarrollo Sostenible de Territorios, Biograma 2008. P 133 San José, Costa Rica Marzo, 2008.

SECRETARIA DE PLANEACIÓN DE CUNDINAMARCA. SERVICIOS MAPAS. Provinciales de Cundinamarca. Recuperado el 19 de Julio de 2012 de http://www.planeación.cundinamarca.gov.co/BancoConocimiento/Mmapas_provinciale s/mapas_provinciales.asp.

TÓTH, J. 2000. Las aguas subterráneas como agente geológico: causas procesos y manifestaciones. Boletín Geológico y Minero, Instituto Tecnológico GeoMinero de España, V111:49-26.

VITAE CIVILIS, Instituto para Desenvolvimiento, Meio Ambiente e Paz; "Gobernanza AMBIENTAL INTERNACIONAL; Perspectivas, Cenários e Recomendacoes; P 47 BrasiliaSao Paulo Setembro de 2007.

VAN DER HAMMEN, T., 1998, Plan ambiental de la Cuenca Alta del río Bogotá (Análisis y Orientaciones para el Ordenamiento Territorial), Corporación Autónoma Regional de Cundinamarca, CAR, Bogotá, 142 pp.

UNCRD - Y EL Departamento de Asuntos Económicos y Sociales de la Secretaria de las Naciones Unidas UNDESA, Agosto de 2005, De las Ciudades a las Regiones, Desarrollo Regional Integrado en Bogotá - Cundinamarca, Mesa de Planificación Regional Bogotá - Cundinamarca, Centro de las Naciones Unidas para el Desarrollo Regional.

UNIVERSIDAD DISTRITAL “FRANCISCO JOSÉ DE CALDAS”. Identificación de cinco líneas estratégicas ambientales para la Región Capital. Contrato 1206-2009 entre la Secretaría Distrital de Ambiente y la Universidad Distrital "Francisco José de Caldas. Bogotá. 2011.

URUBE OCHOA, Johnny Alexander. La provincia en el modelo territorial colombiano. Estado del arte. Recuperado el 21 de julio de 2012 de htt://doctrina.vlex.com.co/vid/provincia-modelo-territorial-colombiano-arte-59710574 


\subsection{NORMAS Y ACUERDOS}

Convenio Interadministrativo entre el Distrito Capital de Bogotá y el departamento de Cundinamarca para la Conformación de la Región Capital. Agenda Común 14 de Noviembre de 2007, Bogotá D.C. - Cundinamarca, Colombia.

Ley 617 de 2000, por la cual se reforma parcialmente la Ley 136 de 1994, el Decreto extraordinario 1222 de 1986, se adiciona la Ley Orgánica de Presupuesto, el Decreto 1421 de 1993, se dictan otras normas tendientes a fortalecer la descentralización y se dictan normas para la racionalización del gasto público nacional. Ministerio de Hacienda y crédito Público República de Colombia.

Ley 614 de 2000, (septiembre 18), Por medio de la cual se adiciona la Ley 388 de 1997 y se crean los comités de integración territorial para la adopción de los planes de ordenamiento territorial.

Decreto No 1729 de 2002, del 6 de agosto, "Cuencas Hidrográficas. Por el cual se reglamenta la parte XIII, Titulo 2, Capitulo III del Decreto ley 2811 de 1974 sobre cuencas hidrográficas.

Decreto 3600 de 2007, Septiembre 20, Por el cual se reglamentan las disposiciones de las Leyes 99 de 1993 y 388 de 1997 relativas a las determinantes de ordenamiento del suelo rural y al desarrollo de actuaciones urbanísticas de parcelación y edificación en este tipo de suelo y se adoptan otras disposiciones. Congreso de la República de Colombia.

Decreto 1640 de 2012, agosto 02, por medio del cual se reglamentan los instrumentos para la planificación, ordenamiento y manejo de las cuencas hidrográficas.

Documento CONPES No 3320, Estrategias para el Manejo Ambiental del Río Bogotá, Versión aprobada, Diciembre 6 de 2004 Consejo Nacional de Política Económica y Social República de Colombia, Departamento de Planeación Nacional.

Ley 152 de 1994, Por la cual se establece la Ley Orgánica de los Planes de Desarrollo, Diario oficial año CXXX. N. 41450. 19 de Julio. 1994, Congreso de la República de Colombia.

Ley 388 de 1997, (Julio 18), Por la cual se modifica la ley $9^{a}$ de 1989 y la ley $3^{a}$ de 1991, es la ley llamada de los POTS Municipales, Congreso de la República de Colombia.

Ley Orgánica de Ordenamiento Territorial, Ley 1454 de 2011, Por la cual se dictan normas Orgánicas sobre Ordenamiento Territorial y se modifican otras disposiciones.

PROYECTO DE ACUERDO, Exposición de motivos, por el cual se autoriza la constitución de la Región Administrativa y de Planeación Especial (RAPE) entre el Distrito Capital de Bogotá y el Departamento de Cundinamarca y se dictan otras disposiciones, Alcaldía Mayor de Bogotá, 2011.

Proyecto de Ley No 024 Cámara/2007, Por el cual, se expiden normas orgánicas en materia de ordenamiento territorial. Congreso de la República - Cámara de Representantes. 
Resolución No 3194 del 23 de Noviembre de 2006, Por la cual se aprueba el Plan de Ordenación y Manejo de la Cuenca Hidrográfica del río Bogotá y se toman otras disposiciones, Corporación Autónoma Regional de Cundinamarca.

Resolución 0509 de 2013 del 21 de mayo, por la cual se definen los lineamientos para la conformación de los Consejos de Cuenca y su participación en las fases del Plan de Ordenación de la Cuenca.

\subsection{NORMAS Y ACUERDOS INTERNACIONALES}

Ley de Planificación Nacional de la República de Costa Rica, No 5525

\subsection{FUENTES DE INTERNET}

COHESIÓN SOCIAL TERRITORIAL Y DE LOS GOBIERNOS LOCALES, Recuperado junio 12 de 2014, http://www.urbal3.eu/uploads/descargas/CS1 tema1.pdf, Unidad Temática 1 La nueva agenda de la Cohesión Social

DELIMITACIÓN DE MLAS UNIDADES AMBIENTALES HOMOGENEAS, Recuperado 12 DE JUNIO DE 2014 , http://www.tenerife.es/planes/PTEOSistemaViarioAMetro/adjuntos/II0205f.pdf

DIRECTRICES VOLUNTARIAS SOBRE LA GOBERNANZA RESPONSABLE DE LA TENENCIA DE LA TIERRA, LA PESCA Y LOS BOSQUES EN EL CONTEXTO DE LA SEGURIDAD ALIMENTARIA NACIONAL 2011. Recuperado Junio 12 de 2014, http://www.csm4cfs.org/files/Pagine/6/first draft of the vgs (with proposed changes fro $\underline{m}$ july and october negotiations) march 2012 es.pdf

FUNCIÓN ADMINISTRATIVA Y UNIDADES TERRITORIALES, recuperado junio 12 de 2014, http://publicacions.iec.cat/repository/pdf/00000077/00000010.pdf

GALEANO, Eumelia. Diseño de proyectos en la investigación cualitativa, Fondo Editorial Universidad Eafit, Medellín, 2004, 82 p.

JULIÁN ALBERTO RENGIFO RENGIFO, Docente T.C. Universidad de Nariño (Pasto - Colombia). Candidato a Doctor en Geografía, Planificación Territorial y Gestión Ambiental Universidad de Barcelona (España), irengifomaster@yahoo.es, Evolución de la planificación en Colombia "Tendencias y Perspectivas del Desarrollo" Recuperado junio 12 de 2014, http://www.ub.edu/geocrit/coloquio2012/actas/04-JRengifo.pdf

LAURA ALFARO MAYKALL, Ministra de Planificación Nacional y Política Económica en Costa Rica, Recuperado junio 12 de 1014, https://www.google.com.co/?gfe $r d=c r \& e i=F J a p U 53 z O s b y g A S A y 4 C 4 B Q \& g w s \quad r d=s s l \# q=L A U R$ A+ALFARO+MAYKALL\%2C+Ministra+de+Planificaci\%C3\%B3n+Nacional+y+Pol\%C3\%ADtica+Eco n\%C3\%B3mica+en+Costa+Rica

PRINCIPIOS DE LA ORDENACIÓN DEL TERRITORIO Recuperado 12 de junio de 2014 http://www.geogra.uah.es/enrique/pdf/TEMA 7 ALUMNOS.pdf 
VIDAL PERDOMO, Jaime (2001). La Región en la Organización Territorial del Estado. Centro Editorial Universidad del Rosario 2001. Recuperado el 20 de Noviembre de 2012

http://books.google.com.co/books?hl=es\&lr=\&id=XMy3glie4Y3wC\&oi=fnd\&pg=PA4\&dp =organizacion+territorial+entidades++administrativas+colombia\&ots=LRja2tWUTM\&sig =Srw17ef3N9 yORo6BQAKA7rTf-

$\mathrm{w} \# \mathrm{v}=$ onepage \&q=organizacion $\% 20$ territorial\%20entidades $\% 20 \%$ administrativas $\% 20 \mathrm{co}$ $\underline{\text { lombia\&f}=\text { false }}$ 
9 LISTADO DE SIGLAS
Y GLOSARIO 


\subsection{LISTADO DE SIGLAS}

ACIUR. La Asociación Colombiana de Investigadores Urbano Regionales.

ACICAM. Asociación Colombiana de Industriales del Calzado, el Cuero y sus Manufacturas.

ACODAL. Ingeniería Sanitaria Y Ambiental.

ANATO. Asociación Colombiana de Agencias de Viajes y Turismo Asociación Colombiana.

ASOCARS. Asociación de Corporaciones Autónomas Regionales y de Desarrollo Sostenible.

ASOCOLFLORES. Asociación Colombiana de Exportadores de Flores.

APPs. Asociación Publico Privadas.

ADAM. Áreas de Desarrollo Alternativo Municipal

CCs. Comités de Cuenca.

CAEM. Corporación Ambiental Empresarial.

CAMACOL. Cámara Colombiana de la Construcción.

CAR. Corporaciones Autónomas Regionales.

CECODES. Consejo Empresarial Colombiano para el Desarrollo Sostenible Centro de las Naciones Unidas para el Desarrollo Regional.

CEPAL. Comisión Económica para América Latina y el Caribe.

CEPLAC. Centro de Estudios en Política y Legislación Ambiental de Colombia.

CGR. Contraloría General de la Republica.

CIT. Comité de Integración Territorial.

CH. Cuenca Hidrográfica.

CIDER. Centro Interdisciplinario de Estudios Regionales.

CONPES. Consejo Nacional de Políticas Económicas y Sociales.

CC. Consejos de Cuencas.

CORPES. Corporación Regional de Planificación Económica y Social.

CORPOGUAVIO. Corporación Autónoma Regional del Guavio.

CORPORINOQUIA. Corporación Autónoma Regional de la Orinoquia.

CREPAD. Consejo Regional de Prevención y Atención de Desastres.

CVC. Corporación Autónoma Regional del Valle del Cauca.

EAAB. Empresa de Acueducto y Alcantarillado de Bogotá.

\section{ECOFONDO.}

EE. Estructura Ecológica.

EED. Estructura Ecológica Distrital.

EEP. Estructura Ecológica Principal.

EER. Estructura Ecológica Regional.

EOT. Esquema de Ordenamiento Territorial.

FAO. Organización de las Naciones Unidas para la agricultura y la alimentación.

FEDEGAN. Federación Nacional de Ganaderos de Colombia.

FEDELONJAS. Federación Nacional de Lonjas de Propiedad Raíz.

FEDEPAPA. Federación Nacional de productores de papa.

FENALCO. Federación Nacional de Comerciantes.

FOREC. Programa de Reconstrucción del Eje Cafetero.

FUT. Formulario Único Territorial.

GTZ. Oficina de Cooperación Colombo Alemana.

GWP. Asociación Mundial para el Agua.

IAVH. Instituto de Investigación de Recursos Biológicos Alexander Von Humboldt.

ICA. Instituto Interamericano de Cooperación para la Agricultura.

IDEA. Instituto de Estudios Ambientales. 
IDEA. Instituto de Estudios Urbanos e instituto de estudios urbanos.

IDEAM. (Instituto de Hidrología, Meteorología y Estudios Ambientales.

IDRD. Instituto Distrital de Recreación y Deporte.

IEPRI. Instituto de Estudios Políticos.

IICA. Instituto Interamericano de Cooperación para la Agricultura.

IIDS. Índice Integrado de Desarrollo Sostenible

INCODER. Instituto Colombiano para el Desarrollo Rural.

INVIAS. Instituto Nacional de Vias.

JICA. Agencia Internacional de Cooperación del Japón.

LOOT. Ley Orgánica de Ordenamiento Territorial.

OCAD. Órganos Colegiados de Administración y Decisión

NOAT. Núcleos de Ordenamiento Ambiental Territorial.

ONG. Organizaciones No Gubernamentales.

PGA. Plan de Gestión Ambiental.

PGAR. Plan de Gestión Ambiental Regional.

PGIRS. Planes de Gestión Integral de Residuos Sólidos.

PND. Plan Nacional de Desarrollo 2010 - 2014.

PNUD Colombia Programa de las Naciones Unidas para el Desarrollo en Colombia.

PNUMA. Programa de las Naciones Unidas para el Medio Ambiente.

PNGIBSE. Política Nacional de Gestión Integral para la Conservación de la Biodiversidad

POMCA. Ordenamiento y Manejo Integral de Cuencas Hidrográficas.

POT. Planes de Ordenamiento Territorial.

PNCRT. Política Nacional de Consolidación y Reconstrucción Territorial.

POTM. Planes de Ordenamiento territorial Municipal.

PSMV. Plan de Saneamiento y Manejo de Vertimientos.

UPRA, Unidad de Planificación Rural Agropecuaria.

RAP. Regiones Administrativas y de Planificación

RAPE. Región Administrativa y de Planeamiento Especial.

RET. Red de Espacio y Territorio.

RC. Región Capital

SAC. Sociedad de Agricultores de Colombia.

SDA. Secretaria Distrital de Ambiente.

SIG. Sistemas de Información Geográfica

SENA. Servicio Nacional de aprendizaje.

SINA. Sistema Nacional Ambiental.

SIRAP. Sistema Regional de Áreas Protegidas.

SISBEN. Sistema de Identificación de Potenciales Beneficiarios de Programas Sociales.

SMLM. Salarios Mínimos Légales Mensuales Vigentes.

UA. Unidades de Análisis.

UAECT. Unidad Administrativa Especial para la Consolidación Territorial.

UAESPNN. Unidad Administrativa Especial del Sistema de Parques Naturales Nacionales

UNCRD. Centro de las Naciones Unidas para el Desarrollo Regional.

USAID Agencia de Estados Unidos para el Desarrollo Internacional.

USTA. Universidad Santo Tomas de Aquino.

UTG. Las Unidades Territoriales Y De Gestión.

UPT. Unidades de Planificación Territorial

UPGT. Unidad de Planificación y de Gestión Territorial.

UPR. Unidades de Planeamiento Intermedio del suelo rural. 


\subsection{GLOSARIO}

Área protegida: Área definida geográficamente que haya sido designada, regulada y administrada a fin de alcanzar objetivos específicos de conservación.

Biograma: Es un indicador multidimensional de representación gráfica del "estado de un sistema". Dicha imagen representa el grado de desarrollo sostenible de la unidad de análisis en cuestión, el desequilibrio que puede haber entre las diferentes dimensiones y por ende, los posibles conflictos existentes. Existe tanto un Biograma global, que reúne las diferentes dimensiones de análisis que se desean incluir, como Biogramas específicos de cada una de ellas. Cada eje de análisis que representa un indicador, ajustado de tal forma que cuanto más amplia sea el área sombreada, mejor es la situación del sistema.

Conocimiento: Son los saberes, innovaciones y prácticas científicas, técnicas, tradicionales o cualquier otra de sus formas, relacionados con la conservación de la biodiversidad.

Composición: Atributo de la biodiversidad que hace referencia a los componentes físicos y bióticos de los sistemas biológicos en sus distintos niveles de organización.

Conservación: Es la conservación in situ de los ecosistemas y los hábitats naturales y el mantenimiento y recuperación de poblaciones viables de especies en su entorno natural y, en el caso de las especies domesticadas y cultivadas, en los entornos en que hayan desarrollado sus propiedades específicas. La conservación in situ hace referencia a la preservación, restauración, uso sostenible y conocimiento de la biodiversidad.

Comunidad: Nivel de la biodiversidad que hace referencia a un conjunto de diversas especies que habitan en una localidad particular, incluyendo sus complejas interacciones bióticas.

Ecosistema: Nivel de la biodiversidad que hace referencia a un complejo dinámico de comunidades vegetales, animales y de microorganismos y su medio no viviente que interactúan como una unidad funcional.

Especie: Nivel de la biodiversidad que hace referencia al conjunto de poblaciones cuyos individuos se entrecruzan actual o potencialmente dando origen a descendencia fértil y que están reproductivamente aislados de otros grupos.

Estructura: Atributo de la biodiversidad que hace referencia a la disposición u ordenamiento físico de los componentes de cada nivel de organización.

Diversidad biológica: Es la variabilidad de organismos vivos de cualquier fuente, incluidos, entre otras cosas, los ecosistemas terrestres y marinos y otros ecosistemas acuáticos y los complejos ecológicos de los que forman parte; comprende la diversidad dentro de cada especie, entre las especies y de los ecosistemas.

Función: Atributo de la biodiversidad que hace referencia a la variedad de procesos e interacciones que ocurren entre sus componentes biológicos. 
Índice de Desarrollo Sostenible $\left(\mathbf{S}^{3}\right)$ : Es un valor de desempeño del desarrollo sostenible, con el cual se puede comparar la evolución de una unidad de análisis, ya sea en el tiempo o bien con otras unidades de desempeño de cada una de éstas.

Paisaje: Nivel de la biodiversidad que expresa la interacción de los factores formadores (biofísicos y antropogénicos) de un territorio.

Población: Nivel de la biodiversidad que hace referencia a un grupo de individuos de una especie que se entrecruzan y producen población fértil.

Preservación: Mantener la composición, estructura y función de la biodiversidad, conforme su dinámica natural y evitando al máximo la intervención humana y sus efectos.

Restauración: Restablecer parcial o totalmente la composición, estructura y función de la biodiversidad, que hayan sido alterados o degradados.

Uso sostenible: Utilizar los componentes de la biodiversidad de un modo y a un ritmo que no ocasione su disminución o degradación a largo plazo alterando los atributos básicos de composición, estructura y función, con lo cual se mantienen las posibilidades de ésta de satisfacer las necesidades y las aspiraciones de las generaciones actuales y futuras.

\subsubsection{Definiciones Según El Decreto 3600 De 2007}

Estructura Ecológica Principal (Regional). Conjunto de elementos bióticos y abióticos que dan sustento a los procesos ecológicos esenciales del territorio, cuya finalidad principal es la preservación, conservación, restauración, uso y manejo sostenible de los recursos naturales renovables, los cuales brindan la capacidad de soporte para el desarrollo socioeconómico de las poblaciones.

Unidad Mínima de Actuación. Superficie mínima de terreno definida en el componente rural del plan de ordenamiento territorial que puede incluir una 0 varias unidades prediales para la ejecución de actuaciones urbanísticas de parcelación y edificación de inmuebles, de conformidad con los usos permitidos en el suelo rural suburbano.

Unidad de Planificación Rural. Instrumento de planificación de escala intermedia que desarrolla y complementa el plan de ordenamiento territorial para el suelo rural.

Zonas de amortiguación de áreas protegidas. Son aquellas reas delimitadas con la finalidad de prevenir perturbaciones causadas por actividades humanas en zonas aledañas a un área protegida. 
ANEXOS 


\section{Anexo 1. TABLA DE SUBREGIONES DE PLANIFICACIÓN SEGÚN LA GOBERNACIÓN DE CUNDINAMARCA}

\begin{tabular}{|c|c|c|c|}
\hline SUBREGION & \multicolumn{2}{|c|}{ MUNICIPIOS } & CARACTERÍSTICAS PRINCIPALES \\
\hline $\begin{array}{c}\text { Alto Magdalena - } \\
\text { Tolima }\end{array}$ & $\begin{array}{l}\text { Agua de Dios } \\
\text { Anapoima } \\
\text { Apulo } \\
\text { El Colegio } \\
\text { Girardot } \\
\text { Guataquí } \\
\text { Jerusalén } \\
\text { La Mesa } \\
\text { Nariño }\end{array}$ & $\begin{array}{l}\text { Nilo } \\
\text { Ricaurte } \\
\text { San Antonio de } \\
\text { Tequendama } \\
\text { Tena } \\
\text { Viota } \\
\text { Tocaima }\end{array}$ & $\begin{array}{l}\text { Crear circuito de municipios turísticos } \\
\text { complementados con artesanías e } \\
\text { industria liviana. } \\
\text { Impulsar la vocación agrícola intensiva } \\
\text { a Guataquí, Nariño y Jerusalén. } \\
\text { Dotar de infraestructura a Jerusalén } \\
\text { para que se convierta en centro } \\
\text { articulador urbano rural para la agrored } \\
\text { y para prestación de servicios en la } \\
\text { zona. }\end{array}$ \\
\hline $\begin{array}{c}\text { Magdalena Centro - } \\
\text { Tolima }\end{array}$ & $\begin{array}{l}\text { Anolaima } \\
\text { Beltrán } \\
\text { Bituima } \\
\text { Cachipay } \\
\text { Chaguaní } \\
\text { Guayabal de } \\
\text { Siquima }\end{array}$ & $\begin{array}{l}\text { Pulí } \\
\text { Quipile } \\
\text { San Juan } \\
\text { Rioseco } \\
\text { Viani } \\
\text { Zipacon }\end{array}$ & $\begin{array}{l}\text { Mejoramiento de la infraestructura vial } \\
\text { secundaria y local. } \\
\text { Fortalecer red de comercialización } \\
\text { urbana rural en Puli y Quipile. } \\
\text { Establecer a Anolaima como un centro } \\
\text { de comercialización y transformación } \\
\text { frutícola y centro de habitación. } \\
\text { Cachipay y Anolaima dentro del } \\
\text { circuito de municipios turísticos en el } \\
\text { eje ferroviario Girardot Facatativá. } \\
\text { Cambao será un nodo secundario para } \\
\text { la comercialización de productos }\end{array}$ \\
\hline $\begin{array}{c}\text { Bajo Magdalena y } \\
\text { Caldas }\end{array}$ & $\begin{array}{l}\text { Albán } \\
\text { Caparrapí } \\
\text { Guaduas } \\
\text { La Peña } \\
\text { La Vega } \\
\text { Nimaima } \\
\text { Nocaima }\end{array}$ & $\begin{array}{l}\text { Puerto Salgar } \\
\text { Quebradanegra } \\
\text { San Francisco } \\
\text { Sasaima } \\
\text { Supatá } \\
\text { Utica } \\
\text { Vergara } \\
\text { Villeta }\end{array}$ & $\begin{array}{l}\text { Puerto Salgar - La Dorada será un } \\
\text { puerto multimodal como centro de } \\
\text { transformación, bodegaje e } \\
\text { intercambio de productos para } \\
\text { consumo nacional y exportación } \\
\text { Mejorar la infraestructura vial de } \\
\text { Caparrapí para procesamiento y } \\
\text { comercialización de productos } \\
\text { agrícolas. } \\
\text { Creación de red de ciudades turísticas } \\
\text { y de comercio incluyendo Guaduas, } \\
\text { Villeta, Yacopí y Caparrapí, La Palma. }\end{array}$ \\
\hline Rionegro y Boyacá & $\begin{array}{l}\text { El Peñón } \\
\text { La Palma } \\
\text { Pacho } \\
\text { Paime }\end{array}$ & $\begin{array}{l}\text { San Cayetano } \\
\text { Topaipí } \\
\text { Villagómez } \\
\text { Yacopí }\end{array}$ & $\begin{array}{l}\text { Potencial esmeraldífero en Paime y } \\
\text { Yacopí complementario } \\
\text { Impulsar vocación frutícola y } \\
\text { maderable en El Peñón, Paime, } \\
\text { Topaipí, La Palma y Yacopí. } \\
\text { Mejorar infraestructura vial de Yacopí - } \\
\text { la Palma. } \\
\text { Incentivar siembra comercial de } \\
\text { maderables en San Cayetano, Pacho, } \\
\text { Villagómez. } \\
\text { Mejorar conexión vial Pacho - Puerto } \\
\text { Salgar }\end{array}$ \\
\hline $\begin{array}{l}\text { Valle de Ubaté } \\
\text { Fúquene y Boyacá }\end{array}$ & $\begin{array}{l}\text { Carmen de } \\
\text { Carupa } \\
\text { Cucunubá } \\
\text { Fúquene } \\
\text { Guachetá } \\
\text { Lenguazaque }\end{array}$ & $\begin{array}{l}\text { Simijaca } \\
\text { Susa } \\
\text { Sutatausa } \\
\text { Tausa } \\
\text { Ubate }\end{array}$ & $\begin{array}{l}\text { Conformar conjuntamente con Boyacá } \\
\text { una red de municipios agroturísticos } \\
\text { implementando la denominación de } \\
\text { origen. } \\
\text { Dotar a Guachetá y Carmen de Carupa } \\
\text { de infraestructura para que sean }\end{array}$ \\
\hline
\end{tabular}




\begin{tabular}{|c|c|c|c|}
\hline SUBREGION & \multicolumn{2}{|c|}{ MUNICIPIOS } & CARACTERÍSTICAS PRINCIPALES \\
\hline $\begin{array}{l}\text { Valle de Ubaté } \\
\text { Fúquene y Boyacá }\end{array}$ & $\begin{array}{l}\text { Carmen de } \\
\text { Carupa } \\
\text { Cucunubá } \\
\text { Fúquene } \\
\text { Guachetá } \\
\text { Lenguazaque }\end{array}$ & $\begin{array}{l}\text { Simijaca } \\
\text { Susa } \\
\text { Sutatausa } \\
\text { Tausa } \\
\text { Ubate }\end{array}$ & $\begin{array}{l}\text { centros industriales } \\
\text { comercialización (agroredes) y } \\
\text { transformación de la papa, otros } \\
\text { productos agrícolas y artesanías } \\
\text { Racionalizar en establos la industria } \\
\text { lechera e incentivar pequeñas } \\
\text { agroindustrias de transformación de } \\
\text { leche. } \\
\text { Condicionar la explotación de carbón, } \\
\text { carbón de coque que incentiva } \\
\text { ladrilleras y artesanías en arcilla. }\end{array}$ \\
\hline $\begin{array}{l}\text { Cuenca alta del río } \\
\text { Bogotá y Boyaca }\end{array}$ & $\begin{array}{l}\text { Chocontá } \\
\text { Machetá } \\
\text { Manta }\end{array}$ & $\begin{array}{l}\text { Suesca } \\
\text { Tiribita } \\
\text { Villapinzón }\end{array}$ & $\begin{array}{l}\text { Conformar conjuntamente con Boyacá } \\
\text { una red de municipios agroturísticos } \\
\text { implementando la denominación de } \\
\text { origen. } \\
\text { Controlar el área cultivada con papa y } \\
\text { otros productos e incentivar siembra } \\
\text { de cultivos maderables para } \\
\text { exportación. } \\
\text { Convertir a Villapinzon, Macheta y } \\
\text { Suesca en agroredes y centros de } \\
\text { servicios para la zona }\end{array}$ \\
\hline Guavio y Boyacá & $\begin{array}{l}\text { Gachalá } \\
\text { Gachetá } \\
\text { Gama }\end{array}$ & $\begin{array}{l}\text { Junín } \\
\text { Ubalá }\end{array}$ & $\begin{array}{l}\text { Generación de agua para el } \\
\text { departamento y Boyacá } \\
\text { Generación de energía. } \\
\text { Incentivar la industria de maderables } \\
\text { (roble, cedro, nogal). } \\
\text { Elevar a Gachetá y a Ubalá en centros } \\
\text { de industrias livianas para } \\
\text { comercialización de muebles, } \\
\text { procesamiento de madera } \\
\text { incrementando la conectividad vial } \\
\text { para ello. }\end{array}$ \\
\hline $\begin{array}{c}\text { Piedemonte de los } \\
\text { Ilanos Orientales y del } \\
\text { Meta }\end{array}$ & $\begin{array}{l}\text { Medina } \\
\text { Paratebueno }\end{array}$ & & $\begin{array}{l}\text { Promover la producción intensiva de } \\
\text { cereales, maderables, ganadería de } \\
\text { carne y leche, piscicultura, porcicultura } \\
\text { Mejorar accesibilidad vial y dotar de } \\
\text { infraestructura a Medina y } \\
\text { Paratebueno para consolidarlos como } \\
\text { agroredes. }\end{array}$ \\
\hline $\begin{array}{c}\text { Cuenca del Río Negro } \\
\text { y Guayuriba }\end{array}$ & $\begin{array}{l}\text { Cáqueza } \\
\text { Chipaque } \\
\text { Choachí } \\
\text { Fómeque } \\
\text { Fosca }\end{array}$ & $\begin{array}{l}\text { Guayabetal } \\
\text { Gutiérrez } \\
\text { Quetame } \\
\text { Ubaque } \\
\text { Une }\end{array}$ & $\begin{array}{l}\text { No incentivar el crecimiento de } \\
\text { Caquezá por su inestabilidad geológica } \\
\text { Organizar el comercio asociado a la } \\
\text { comercialización de carne del llano } \\
\text { Incrementar cultivos maderables del } \\
\text { bosque nativo en zonas altas y en } \\
\text { zonas bajas frutales y legumbres } \\
\text { Mejorar conectividad de la región, } \\
\text { consolidar a Gutiérrez y Choachí como } \\
\text { agroredes. industrias } \\
\text { Conformación de illavicencio } \\
\text { transformadoras en Villa }\end{array}$ \\
\hline Sumapaz y Tolima & $\begin{array}{l}\text { Arbeláez } \\
\text { Cabrera } \\
\text { Fusagasuga } \\
\text { Granada } \\
\text { Pandi }\end{array}$ & $\begin{array}{l}\text { Pasca } \\
\text { San Bernardo } \\
\text { Silvania } \\
\text { Tibacuy } \\
\text { Venecia }\end{array}$ & $\begin{array}{l}\text { Sembrar una alta porción de } \\
\text { maderables nativos para garantizar la } \\
\text { producción de agua como fuente del } \\
\text { Sumapaz. } \\
\text { Incentivar la producción de árboles } \\
\text { frutales y legumbres. }\end{array}$ \\
\hline
\end{tabular}




\begin{tabular}{|c|c|c|c|}
\hline SUBREGION & \multicolumn{2}{|c|}{ MUNICIPIOS } & CARACTERÍSTICAS PRINCIPALES \\
\hline Sumapaz y Tolima & $\begin{array}{l}\text { Arbeláez } \\
\text { Cabrera } \\
\text { Fusagasuga } \\
\text { Granada } \\
\text { Pandi }\end{array}$ & $\begin{array}{l}\text { Pasca } \\
\text { San Bernardo } \\
\text { Silvania } \\
\text { Tibacuy } \\
\text { Venecia }\end{array}$ & $\begin{array}{l}\text { Mejorar infraestructura vial secundaria } \\
\text { de Cabrera, San Bernardo, Venecia y } \\
\text { Pasca. } \\
\text { Convertir a San Bernardo, Venecia y } \\
\text { Arbeláez en agroredes. } \\
\text { Incentivar industrias de transformación } \\
\text { de loa productos derivados de la } \\
\text { actividad avícola, fruticol y piscícola en } \\
\text { Fusagasuga. }\end{array}$ \\
\hline Sabana de Bogotá & $\begin{array}{l}\text { Bojacá } \\
\text { Cajicá } \\
\text { Chía } \\
\text { Cogua } \\
\text { Cota } \\
\text { El Rosal } \\
\text { Facatativá } \\
\text { Funza } \\
\text { Gachancipá } \\
\text { Guasca } \\
\text { Guatavita } \\
\text { La calera }\end{array}$ & $\begin{array}{l}\text { Madrid } \\
\text { Mosquera } \\
\text { Nemocón } \\
\text { Sesquilé } \\
\text { Sibaté } \\
\text { Soacha } \\
\text { Sopó } \\
\text { Subachoque } \\
\text { Tabio } \\
\text { Tenjo } \\
\text { Tocancipa } \\
\text { Zipaquirá }\end{array}$ & $\begin{array}{l}\text { Consolidar a la Sabana como centro } \\
\text { nacional y departamental } \\
\text { Ordenar el crecimiento poblacional y } \\
\text { socioeconómico de la Sabana } \\
\text { Impulsar a Facatativa como polo y } \\
\text { capital de Cundinamarca, incentivando } \\
\text { la industria de transformación y } \\
\text { comercialización agrícola del } \\
\text { Departamento. } \\
\text { En la parte central crear en } 10.000 \text { ha } \\
\text { una zona de baja densidad para } \\
\text { parques, universidades, y centros de } \\
\text { capacitación, controlando } \\
\text { crecimiento de Funza, Madrid y } \\
\text { Mosquera. } \\
\text { Planificar y controlar el crecimiento de } \\
\text { Soacha como polo industrial y de } \\
\text { vivienda. } \\
\text { Promover el cultivo de flores y } \\
\text { agroindustrias tecnificadas } \\
\text { Sembrar para su aprovechamiento, } \\
\text { maderables nativos en el } 70 \% \text { del } \\
\text { territorio de actividad forestal de La } \\
\text { Calera, Guasca, Guatavita, Sesquilé, } \\
\text { Cogua, Zipaquirá, Tabio, Subachoque } \\
\text { y Sibaté Sembrar legumbres y papa } \\
\text { como estrategia de seguridad } \\
\text { alimentaria. } \\
\text { Al norte de la Sabana promover } \\
\text { circuitos agroturísticos promoviendo la } \\
\text { denominación de origen }\end{array}$ \\
\hline
\end{tabular}




\section{Anexo 2. TABLA RANKING DE DESEMPEÑO FISCAL MUNICIPAL 2009.}

\begin{tabular}{|c|c|c|c|c|c|c|c|c|c|c|}
\hline 울 & $\frac{. \frac{0}{\frac{0}{3}}}{\frac{0}{\frac{1}{5}}}$ & 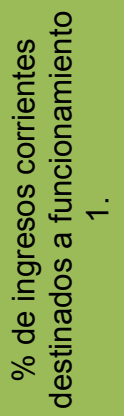 & $\begin{array}{l}\dot{0} \\
0 \\
0 \\
\frac{0}{0} \\
0 \\
0 \\
\frac{0}{0} \\
0 \\
0 \\
0 \\
\frac{0}{3} \\
\frac{1}{0} \\
\frac{\pi}{2}\end{array}$ & 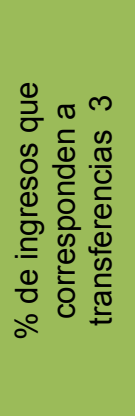 & 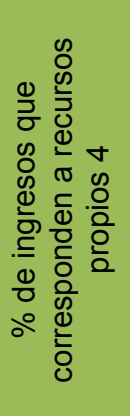 & 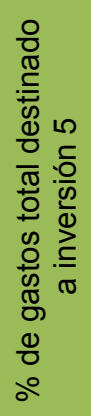 & $\begin{array}{l}0 \\
0 \\
\frac{0}{0} \\
0 \\
\frac{1}{4} \\
0 \\
0 \\
0 \\
\frac{0}{0} \\
\frac{0}{0} \\
\frac{0}{0} \\
\frac{0}{\pi} \\
0\end{array}$ & 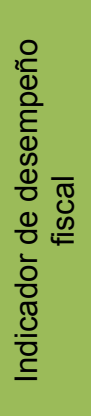 & 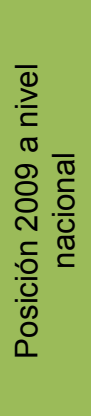 & 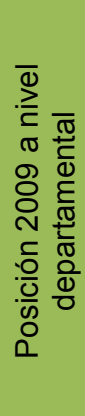 \\
\hline 1 & Arbeláez & 77,18 & 2,08 & 69,87 & 16,65 & 80,04 & 21,43 & 59,32 & 542 & 93 \\
\hline 2 & Bojacá & 71,86 & 5,96 & 49,20 & 31,84 & 80,67 & 38,20 & 67,09 & 117 & 34 \\
\hline 3 & Cabrera & 65,71 & 0,48 & 75,53 & 6,90 & 81,57 & 19,04 & 57,00 & 767 & 104 \\
\hline 4 & Cajicá & 21,29 & 34,78 & 24,39 & 63,26 & 87,99 & 73,18 & 77,58 & 10 & 5 \\
\hline 5 & Chía & 27,14 & 23,96 & 20,23 & 69,98 & 72,59 & 65,51 & 77,53 & 11 & 6 \\
\hline 6 & Chipaque & 34,41 & - & 54,57 & 19,03 & 86,75 & 60,32 & 69,70 & 67 & 21 \\
\hline 7 & Choachí & 44,63 & 4,85 & 67,39 & 20,11 & 86,40 & 48,08 & 65,00 & 189 & 43 \\
\hline 8 & Chocontá & 58,42 & 3,83 & 54,23 & 21,95 & 84,42 & 52,50 & 67,92 & 94 & 28 \\
\hline 9 & Cogua & 37,02 & 10,94 & 33,22 & 57,15 & 74,55 & 60,32 & 75,27 & 21 & 10 \\
\hline 10 & Cota & 26,07 & 9,27 & 14,79 & 79,31 & 76,09 & 71,77 & 84,17 & 3 & 1 \\
\hline 11 & El Rosal & 43,73 & - & 46,90 & 36,04 & 76,11 & 61,52 & 72,10 & 35 & 15 \\
\hline 12 & Facatativá & 49,78 & 17,24 & 36,81 & 44,52 & 79,07 & 51,93 & 70,94 & 49 & 16 \\
\hline 13 & Funza & 38,35 & 38,60 & 25,68 & 61,06 & 81,74 & 60,09 & 73,23 & 28 & 11 \\
\hline 14 & Fusagasugá & 57,44 & 5,25 & 68,73 & 23,16 & 87,25 & 46,62 & 65,13 & 183 & 42 \\
\hline 15 & Gachancipá & 13,64 & 3,48 & 20,16 & 37,73 & 87,11 & 82,83 & 81,14 & 5 & 3 \\
\hline 16 & Guasca & 52,99 & 4,75 & 42,11 & 36,68 & 79,98 & 47,38 & 70,54 & 52 & 17 \\
\hline 17 & Guatavita & 50,36 & - & 38,95 & 18,19 & 80,64 & 39,43 & 67,75 & 99 & 29 \\
\hline 18 & Gutiérrez & 57,54 & 0,10 & 76,81 & 4,34 & 80,44 & 31,69 & 58,24 & 646 & 99 \\
\hline 19 & La Calera & 49,21 & 12,37 & 25,16 & 39,07 & 66,49 & 40,72 & 68,92 & 77 & 24 \\
\hline 20 & Madrid & 34,21 & 26,27 & 31,47 & 58,30 & 77,61 & 57,13 & 72,96 & 29 & 12 \\
\hline 21 & Mosquera & 23,97 & 27,85 & 22,33 & 62,42 & 72,91 & 67,70 & 75,65 & 17 & 9 \\
\hline 22 & Nemocón & 66,61 & 2,58 & 71,19 & 14,33 & 73,09 & 19,84 & 57,23 & 744 & 66,61 \\
\hline 23 & Pasca & 71,32 & - & 68,28 & 13,68 & 82,68 & 24,11 & 60,33 & 471 & 84 \\
\hline 24 & San Bernardo & 57,12 & - & 73,85 & 9,58 & 86,85 & 36,74 & 61,45 & 380 & 75 \\
\hline 25 & Sesquilé & 52,60 & 2,00 & 37,95 & 25,05 & 82,88 & 59,36 & 72,15 & 34 & 14 \\
\hline 26 & Sibaté & 35,01 & 3,15 & 19,44 & 36,36 & 82,25 & 59,22 & 76,59 & 13 & 7 \\
\hline 27 & Soacha & 58,49 & 4,43 & 74,02 & 20,28 & 90,05 & 39,16 & 63,28 & 264 & 58 \\
\hline 28 & Sopó & 30,79 & 9,80 & 34,53 & 47,91 & 83,66 & 66,84 & 76,31 & 15 & 8 \\
\hline 29 & Subachoque & 47,51 & 9,13 & 40,99 & 35,73 & 73,79 & 50,70 & 69,24 & 72 & 23 \\
\hline 30 & Suesca & 39,02 & 3,53 & 58,29 & 18,02 & 78,14 & 38,18 & 63,40 & 260 & 57 \\
\hline 31 & Tabio & 57,14 & 27,27 & 46,38 & 37,00 & 72,47 & 40,62 & 63,49 & 257 & 56 \\
\hline 32 & Tausa & 74,47 & 9,77 & 73,63 & 16,68 & 80,60 & 27,79 & 58,41 & 630 & 98 \\
\hline
\end{tabular}




\begin{tabular}{|c|c|c|c|c|c|c|c|c|c|c|}
\hline 운 & $\frac{\frac{0}{0}}{\frac{0}{0}}$ & 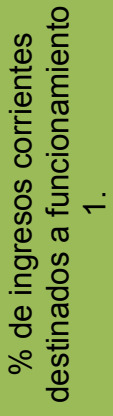 & $\begin{array}{l}\text { N } \\
\frac{0}{0} \\
0 \\
0 \\
0 \\
0 \\
\frac{0}{0} \\
\frac{0}{0} \\
0 \\
\frac{0}{2} \\
\frac{0}{0} \\
\frac{\pi}{2}\end{array}$ & 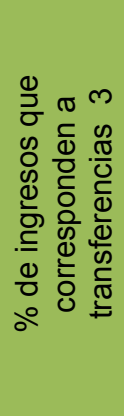 & 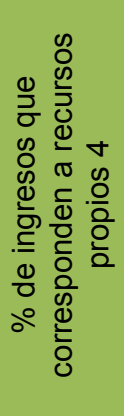 & 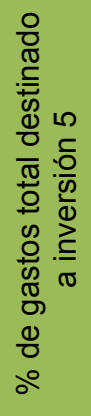 & $\begin{array}{l}0 \\
0 \\
0 \\
0 \\
\frac{1}{4} \\
\frac{1}{0} \\
0 \\
0 \\
0 \\
\frac{\pi}{0} \\
\frac{0}{0} \\
\frac{\pi}{0} \\
\frac{0}{\pi} \\
0\end{array}$ & 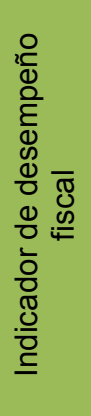 & 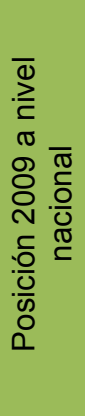 & 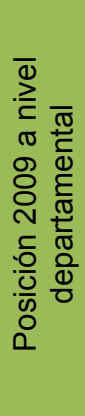 \\
\hline 33 & Tenjo & 25,69 & 3,07 & 17,96 & 49,99 & 80,79 & 72,72 & 80,93 & 6 & 4 \\
\hline 34 & Tocancipá & 32,24 & 14,70 & 16,98 & 72,34 & 84,32 & 69,24 & 82,67 & 4 & 2 \\
\hline 35 & Ubaque & 57,18 & - & 59,10 & 8,16 & 89,23 & 31,27 & 63,09 & 280 & 62 \\
\hline 36 & Une & 63,00 & 2,51 & 65,73 & 12,17 & 87,63 & 41,97 & 63,64 & 249 & 53 \\
\hline 37 & Villapinzón & 55,22 & 2,21 & 63,37 & 21,05 & 79,93 & 44,34 & 64,60 & 205 & 46 \\
\hline 38 & Zipaquirá & 38,56 & 31,64 & 47,93 & 35,01 & 81,91 & 59,49 & 66,65 & 134 & 38,56 \\
\hline
\end{tabular}

Fuente: Departamento de Planeación Nacional de Colombia (Desempeño Fiscal Desarrollo Territorial). 
Anexo 3. TABLA RANKING DE DESEMPEÑO FISCAL MUNICIPAL 2010.

\begin{tabular}{|c|c|c|c|c|c|c|c|c|c|c|}
\hline 을 & $\frac{\frac{0}{\frac{0}{2}}}{\frac{0}{\frac{1}{2}}}$ & 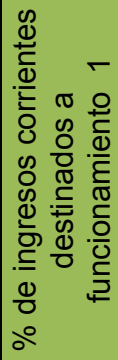 & 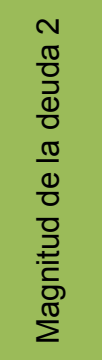 & 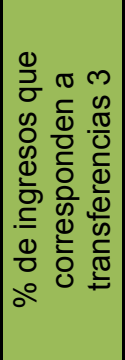 & 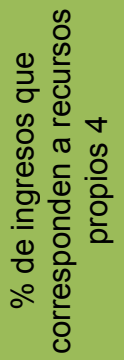 & 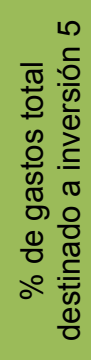 & $\begin{array}{l}0 \\
0 \\
\frac{0}{2} \\
0 \\
\frac{1}{4} \\
0 \\
\frac{0}{0} \\
\frac{\pi}{0} \\
\frac{0}{U} \\
\frac{0}{\pi} \\
\frac{0}{\pi} \\
0\end{array}$ & 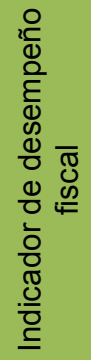 & 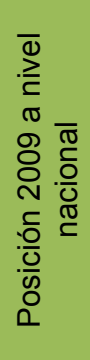 & 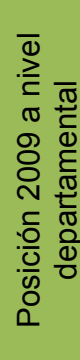 \\
\hline 1 & Arbeláez & 60,28 & - & 66,98 & 75,93 & 78,11 & 30,10 & 70,89 & 334 & 60 \\
\hline 2 & Bojacá & 63,57 & 7,84 & 45,39 & 85,08 & 77,38 & 39,25 & 75,68 & 169 & 32 \\
\hline 3 & Cabrera & 63,55 & 1,20 & 68,65 & 39,91 & 83,59 & 24,40 & 64,54 & 639 & 94 \\
\hline 4 & Cajicá & 21,31 & 33,88 & 17,44 & 100,00 & 82,29 & 74,66 & 84,13 & 33 & 8 \\
\hline 5 & Chía & 28,52 & 10,78 & 18,50 & 98,94 & 81,39 & 66,38 & 86,56 & 18 & 7 \\
\hline 6 & Chipaque & 38,80 & 11,11 & 51,31 & 76,50 & 86,45 & 57,90 & 79,00 & 102 & 25 \\
\hline 7 & Choachí & 51,17 & 1,65 & 56,92 & 69,47 & 83,06 & 39,83 & 71,64 & 305 & 55 \\
\hline 8 & Chocontá & 65,65 & 5,56 & 55,04 & 76,65 & 75,25 & 27,32 & 70,97 & 330 & 58 \\
\hline 9 & Cogua & 41,30 & 26,21 & 39,31 & 90,23 & 67,37 & 48,27 & 73,86 & 229 & 43 \\
\hline 10 & Cota & 20,79 & 4,46 & 11,27 & 99,74 & 83,24 & 73,40 & 90,40 & 4 & 2 \\
\hline 11 & El Rosal & 40,35 & - & 51,99 & 84,22 & 81,40 & 61,11 & 80,01 & 87 & 23 \\
\hline 12 & Facatativá & 45,14 & 7,08 & 27,40 & 96,38 & 83,74 & 51,18 & 83,44 & 45 & 12 \\
\hline 13 & Funza & 38,31 & 10,51 & 27,57 & 93,87 & 75,94 & 55,54 & 81,74 & 67 & 38,31 \\
\hline 14 & Fusagasugá & 59,98 & 5,21 & 37,07 & 99,44 & 86,69 & 49,31 & 82,95 & 53 & 59,98 \\
\hline 15 & Gachancipá & 18,39 & 3,79 & 29,11 & 90,56 & 86,71 & 81,24 & 88,00 & 10 & 4 \\
\hline 16 & Guasca & 34,16 & 3,54 & 41,53 & 85,44 & 77,35 & 61,91 & 80,66 & 79 & 21 \\
\hline 17 & Guatavita & 62,26 & -4 & 45,08 & 66,37 & 81,48 & 43,50 & 75,44 & 177 & 34 \\
\hline 18 & Gutiérrez & 72,01 & 1,46 & 67,34 & 32,08 & 78,75 & 17,74 & 61,57 & 803 & 103 \\
\hline 19 & La Calera & 33,55 & 7,84 & 23,70 & 95,98 & 71,79 & 57,67 & 82,83 & 55 & 16 \\
\hline 20 & Madrid & 38,41 & 11,22 & 24,55 & 95,80 & 80,91 & 57,43 & 83,54 & 43 & \\
\hline 21 & Mosquera & 20,00 & 11,25 & 24,26 & 99,98 & 85,75 & 71,07 & 87,20 & 13 & 5 \\
\hline 22 & Nemocón & 49,24 & 6,75 & 59,63 & 78,81 & 79,82 & 32,31 & 71,92 & 291 & 53 \\
\hline 23 & Pasca & 57,78 & - & 67,21 & 65,60 & 82,90 & 27,55 & 69,57 & 387 & 65 \\
\hline 24 & San Bernardo & 60,37 & - & 49,07 & 55,91 & 87,37 & 45,33 & 74,37 & 212 & 40 \\
\hline 25 & Sesquilé & 62,51 & 1,19 & 44,61 & 84,65 & 79,54 & 51,62 & 79,24 & 99 & 24 \\
\hline 26 & Sibaté & 36,24 & 2,20 & 32,32 & 94,87 & 78,77 & 60,37 & 83,90 & 36 & 10 \\
\hline 27 & Soacha & 54,07 & 6,74 & 43,05 & 99,66 & 88,65 & 38,92 & 80,47 & 81 & 22 \\
\hline 28 & Sopó & 25,06 & 3,56 & 20,40 & 95,70 & 75,72 & 69,52 & 86,59 & 17 & 6 \\
\hline 29 & Subachoque & 35,69 & 6,79 & 35,13 & 88,75 & 85,62 & 57,29 & 82,29 & 60 & 17 \\
\hline 30 & Suesca & 36,48 & 2,51 & 56,52 & 76,68 & 77,20 & 52,56 & 75,56 & 173 & 33 \\
\hline 31 & Tabio & 53,90 & 11,81 & 43,27 & 84,45 & 63,98 & 40,34 & 73,11 & 255 & 49 \\
\hline 32 & Tausa & 60,09 & 8,86 & 70,76 & 68,86 & 78,05 & 34,29 & 68,16 & 433 & 70 \\
\hline 33 & Tenjo & 17,71 & 4,51 & 17,44 & 95,57 & 85,67 & 77,68 & 89,81 & 6 & 3 \\
\hline 34 & Tocancipá & 28,45 & 3,69 & 11,47 & 99,86 & 87,20 & 79,21 & 92,10 & 3 & 1 \\
\hline 35 & Ubaque & 63,82 & - & 72,57 & 58,40 & 79,35 & 33,88 & 67,94 & 442 & 71 \\
\hline 36 & Une & 51,82 & 1,79 & 70,41 & 66,94 & 85,88 & 39,93 & 71,39 & 317 & 56 \\
\hline 37 & Villapinzón & 55,48 & 5,02 & 60,47 & 76,54 & 81,46 & 44,20 & 73,87 & 227 & 42 \\
\hline 38 & Zipaquirá & 39,16 & 24,79 & 25,71 & 98,58 & 86,90 & 64,34 & 83,42 & 46 & 13 \\
\hline
\end{tabular}

Fuente: Departamento de Planeación Nacional de Colombia (Desempeño Fiscal Desarrollo Territorial. 
Anexo 4. TABLA RANKING DE DESEMPEÑO FISCAL MUNICIPAL 2011.

\begin{tabular}{|c|c|c|c|c|c|c|c|c|c|c|}
\hline 은 & $\frac{\frac{0}{0}}{\frac{0}{\frac{0}{5}}}$ & 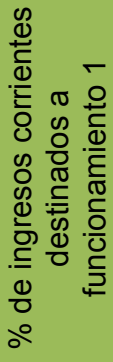 & $\begin{array}{l}N \\
\frac{\pi}{0} \\
\frac{0}{2} \\
0 \\
0 \\
\frac{\pi}{0} \\
0 \\
0 \\
0 \\
\frac{0}{2} \\
\frac{.}{0} \\
0 \\
\frac{\pi}{2}\end{array}$ & 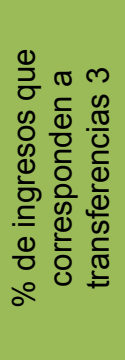 & 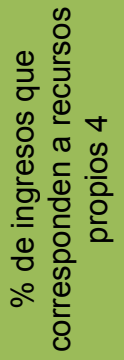 & 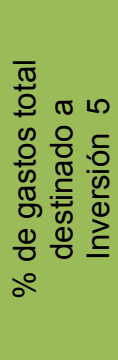 & $\begin{array}{l}0 \\
0 \\
\frac{2}{0} \\
0 \\
\frac{C}{4} \\
\frac{0}{0} \\
\frac{0}{0} \\
\frac{\pi}{0} \\
\frac{0}{0} \\
\frac{\pi}{0} \\
\frac{0}{0}\end{array}$ & 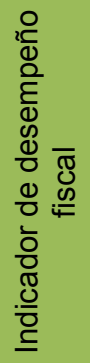 & 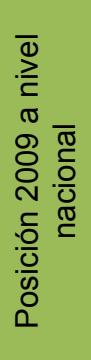 & 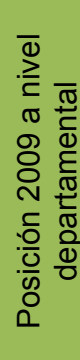 \\
\hline 1 & Arbeláez & 67,66 & 0,29 & 57,88 & 51,40 & 78,31 & 24,55 & 67,43 & 487 & 67,66 \\
\hline 2 & Bojacá & 48,79 & 1,93 & 50,74 & 53,88 & 87,19 & 52,11 & 74,46 & 192 & 38 \\
\hline 3 & Cabrera & 55,14 & 0,00 & 59,70 & 34,34 & 83,51 & 38,05 & 67,38 & 489 & 55,14 \\
\hline 4 & Cajicá & 20,94 & 0,00 & 13,60 & 85,33 & 84,15 & 82,11 & 90,00 & 3 & 20,94 \\
\hline 5 & Chía & 35,44 & 5,47 & 32,12 & 79,35 & 81,50 & 64,34 & 81,87 & 33 & 13 \\
\hline 6 & Chipaque & 36,93 & 9,46 & 56,88 & 58,35 & 85,25 & 52,69 & 72,61 & 240 & 41 \\
\hline 7 & Choachí & 45,30 & 8,13 & 58,35 & 60,87 & 83,55 & 47,74 & 71,97 & 259 & 45,30 \\
\hline 8 & Chocontá & 53,94 & 2,29 & 46,29 & 52,76 & 78,33 & 44,67 & 72,26 & 249 & 53,94 \\
\hline 9 & Cogua & 31,61 & 8,26 & 26,75 & 81,52 & 83,19 & 66,09 & 83,12 & 23 & 10 \\
\hline 10 & Cota & 17,22 & 3,47 & 5,53 & 96,54 & 82,91 & 79,77 & 91,90 & 1 & 1 \\
\hline 11 & El Rosal & 35,93 & 0,87 & 27,43 & 49,10 & 87,44 & 68,30 & 80,12 & 54 & 14 \\
\hline 12 & Facatativá & 55,75 & 2,92 & 51,98 & 81,24 & 81,94 & 55,80 & 78,25 & 82 & 20 \\
\hline 13 & Funza & 30,82 & 7,83 & 12,27 & 82,26 & 78,19 & 71,67 & 85,65 & 9 & 30,82 \\
\hline 14 & Fusagasugá & 57,25 & 5,46 & 67,94 & 80,64 & 83,76 & 46,49 & 74,02 & 205 & 39 \\
\hline 15 & Gachancipá & 26,32 & 0,00 & 28,02 & 55,96 & 86,84 & 75,55 & 82,34 & 27 & 26,32 \\
\hline 16 & Guasca & 42,59 & 3,53 & 42,14 & 72,90 & 78,79 & 60,35 & 78,51 & 76 & 42,59 \\
\hline 17 & Guatavita & 47,30 & 0,00 & 32,87 & 54,28 & 88,49 & 45,45 & 76,87 & 115 & \\
\hline 18 & Gutiérrez & 69,25 & 1,80 & 62,00 & 23,15 & 78,38 & 23,90 & 61,79 & 826 & 105 \\
\hline 19 & La Calera & 43,48 & 7,91 & 22,14 & 84,34 & 69,70 & 41,17 & 78,23 & 83 & 43,48 \\
\hline 20 & Madrid & 37,39 & 9,96 & 21,55 & 92,37 & 77,55 & 56,99 & 83,05 & 24 & 37,39 \\
\hline 21 & Mosquera & 17,93 & 5,82 & 34,61 & 86,87 & 87,85 & 75,97 & 85,53 & 10 & 17,93 \\
\hline 22 & Nemocón & 78,67 & 0,00 & 44,30 & 59,31 & 73,20 & 17,26 & 68,92 & 414 & 78,67 \\
\hline 23 & Pasca & 64,03 & 0,00 & 46,47 & 37,94 & 85,75 & 30,61 & 69,27 & 398 & 64 \\
\hline 24 & San Bernardo & 52,70 & 3,79 & 57,69 & 50,23 & 89,99 & 43,52 & 71,55 & 279 & 47 \\
\hline 25 & Sesquilé & 46,95 & 0,00 & 42,73 & 53,17 & 83,28 & 66,65 & 77,57 & 98 & 46,95 \\
\hline 26 & Sibaté & 37,00 & 5,23 & 25,93 & 92,63 & 76,44 & 59,10 & 83,40 & 20 & \\
\hline 27 & Soacha & 36,59 & 7,94 & 72,28 & 98,87 & 86,24 & 47,68 & 76,47 & 130 & 27 \\
\hline 28 & Sopó & 25,27 & 5,41 & 17,01 & 90,98 & 76,74 & 72,06 & 86,58 & 6 & 4 \\
\hline 29 & Subachoque & 45,81 & 6,89 & 41,13 & 80,65 & 74,72 & 53,54 & 77,58 & 97 & 45,81 \\
\hline 30 & Suesca & 41,64 & 1,48 & 48,27 & 63,74 & 80,44 & 52,16 & 75,42 & 161 & 41,64 \\
\hline 31 & Tabio & 54,22 & 8,53 & 39,58 & 59,85 & 68,53 & 42,89 & 71,42 & 54,22 & 8,53 \\
\hline 32 & Tausa & 54,69 & 6,83 & 64,96 & 54,06 & 77,96 & 41,88 & 68,20 & 448 & 71 \\
\hline 33 & Tenjo & 13,58 & 1,89 & 10,28 & 70,41 & 87,45 & 84,79 & 88,71 & 5 & 3 \\
\hline 34 & Tocancipá & 21,40 & 3,33 & 6,56 & 45,82 & 90,35 & 89,09 & 86,16 & 8 & 21,40 \\
\hline
\end{tabular}




\begin{tabular}{|c|c|c|c|c|c|c|c|c|c|c|}
\hline 운 & $\begin{array}{l}\frac{0}{\frac{2}{2}} \\
\frac{\mathrm{O}}{\frac{1}{2}} \\
\frac{2}{2}\end{array}$ & 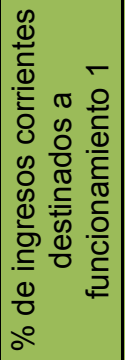 & $\begin{array}{l}N \\
\frac{0}{0} \\
\frac{0}{0} \\
0 \\
0 \\
\frac{0}{0} \\
0 \\
0 \\
0 \\
\frac{0}{2} \\
\frac{D}{0} \\
\frac{\pi}{2}\end{array}$ & 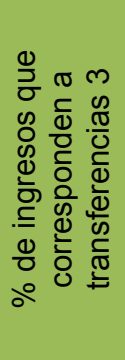 & 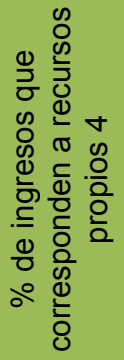 & 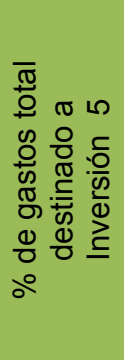 & $\begin{array}{l}6 \\
0 \\
0 \\
0 \\
\frac{2}{4} \\
\frac{1}{0} \\
\frac{0}{0} \\
\frac{\pi}{0} \\
\frac{0}{0} \\
\mathbb{0} \\
\frac{0}{\pi} \\
0\end{array}$ & 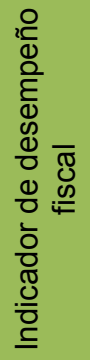 & 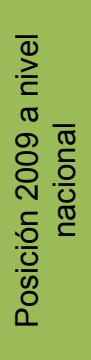 & 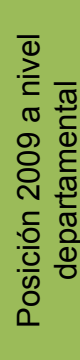 \\
\hline 35 & Ubaque & 71,66 & 0,00 & 75,97 & 33,69 & 78,64 & 23,24 & 61,57 & 832 & 71,66 \\
\hline 36 & Une & 77,00 & 3,64 & 57,45 & 45,51 & 86,37 & 27,84 & 67,78 & 470 & 73 \\
\hline 37 & Villapinzón & 57,31 & 2,81 & 50,43 & 52,03 & 85,49 & 46,41 & 72,87 & 234 & 40 \\
\hline 38 & Zipaquirá & 29,00 & 13,99 & 45,38 & 68,63 & 86,98 & 65,97 & 77,64 & 94 & 29,00 \\
\hline
\end{tabular}

Fuente: Departamento de Planeación Nacional de Colombia (Desempeño Fiscal Desarrollo Territorial. 
Anexo 5. DIMENSIÓN AMBIENTAL RESULTADO DEL BIOGRAMA TENIENDO EN CUENTA

CADA UNA DE LAS VARIABLES POR MUNICIPIO DENTRO DEL ÁREA DE ESTUDIO.

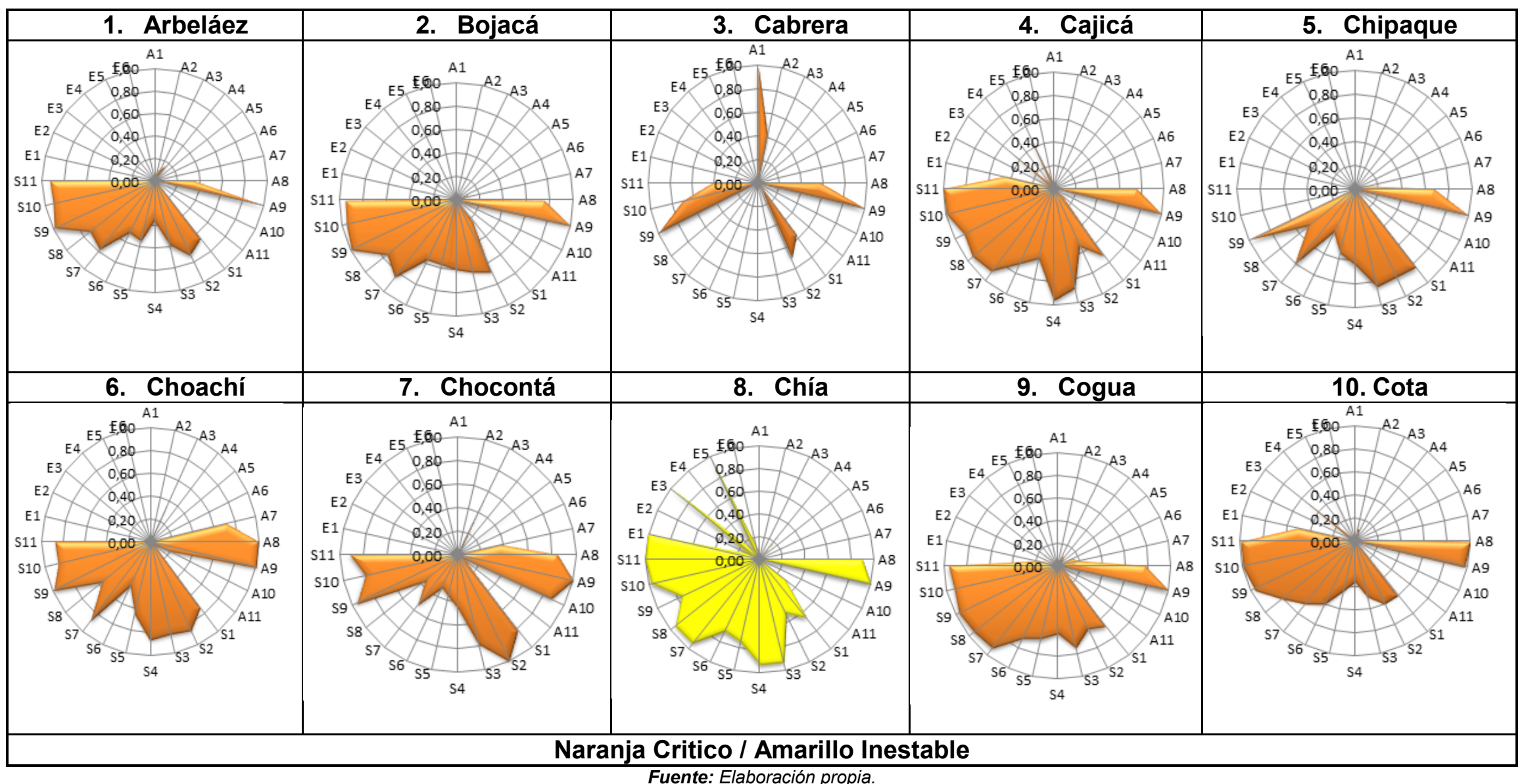

Fuente: Elaboración propia. 


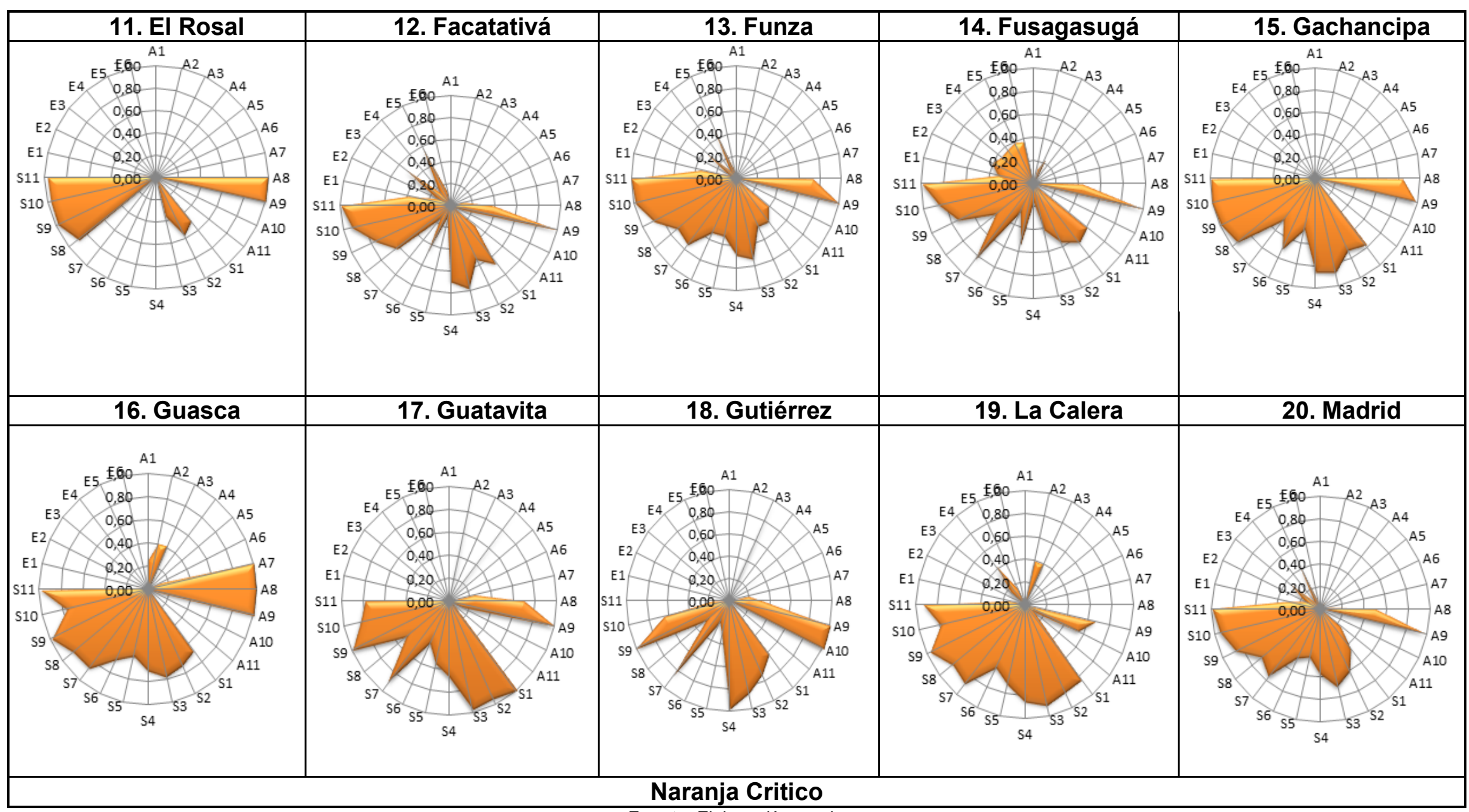

Fuente: Elaboración propia. 


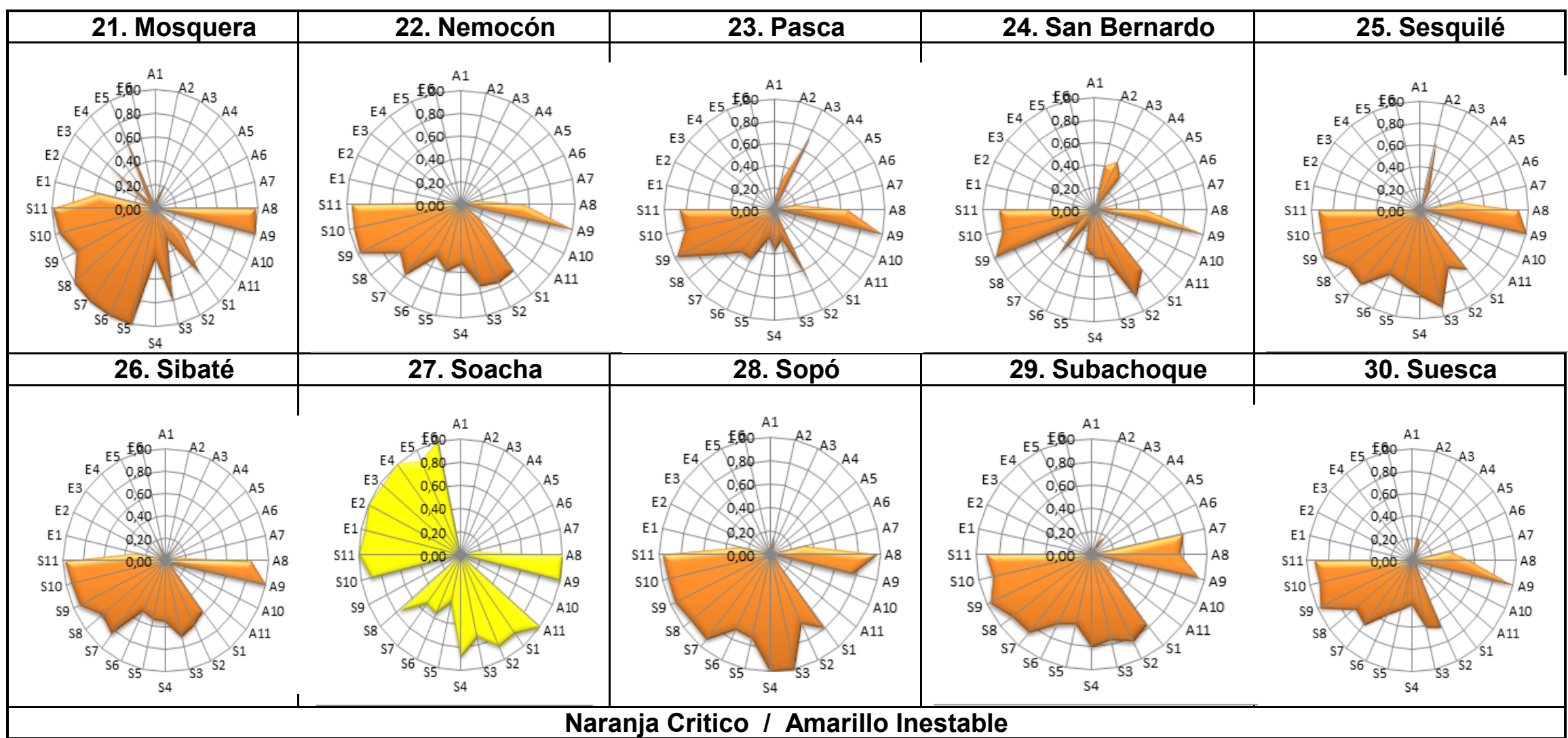

Fuente: Elaboración propia. 


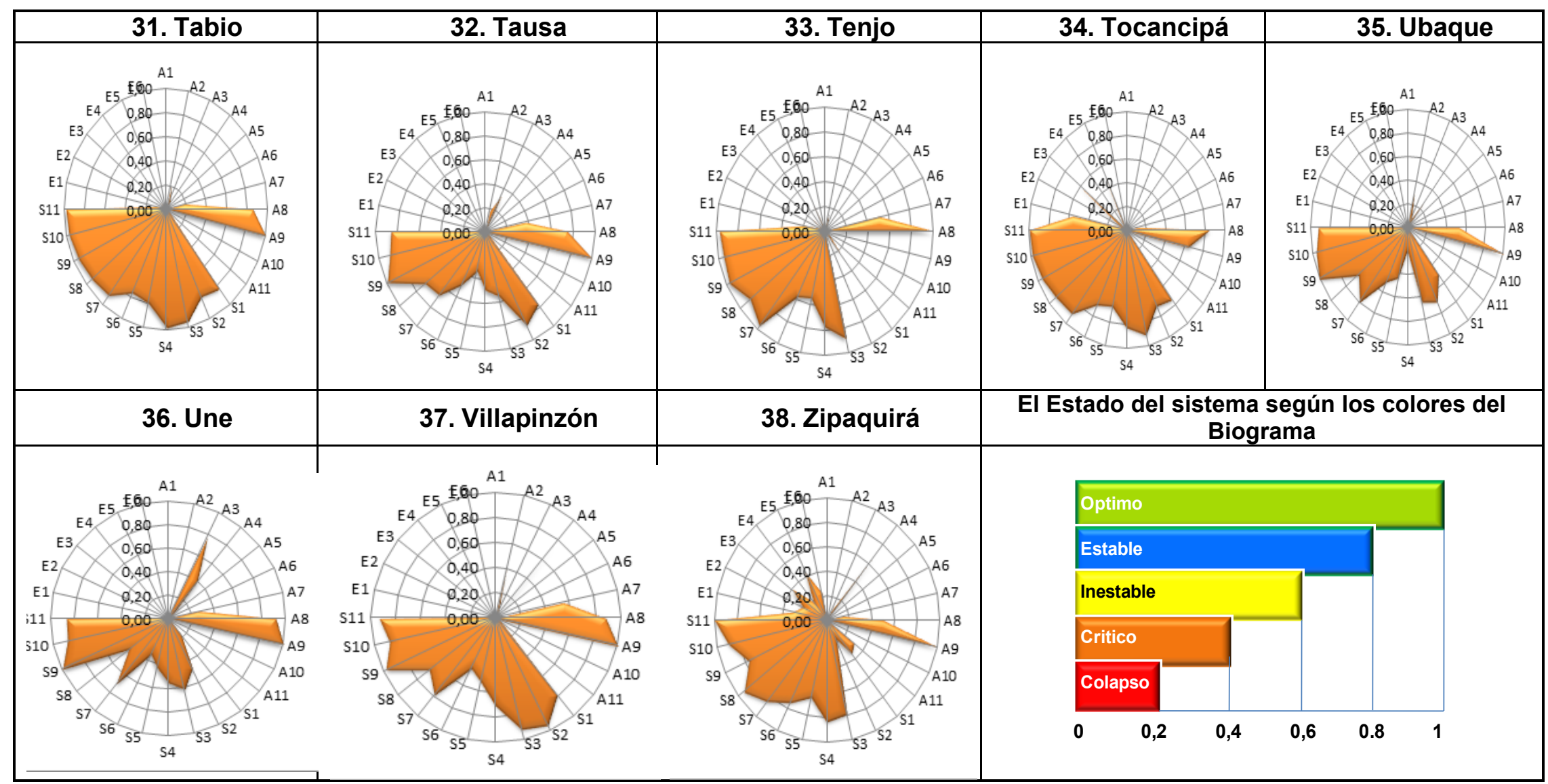

Fuente: Elaboración propia. 
Anexo 6. DIMENSIÓN SOCIAL. RESULTADO DEL BIOGRAMA TENIENDO EN CUENTA

CADA UNA DE LAS VARIABLES POR MUNICIPIO DENTRO DEL ÁREA DE ESTUDIO.

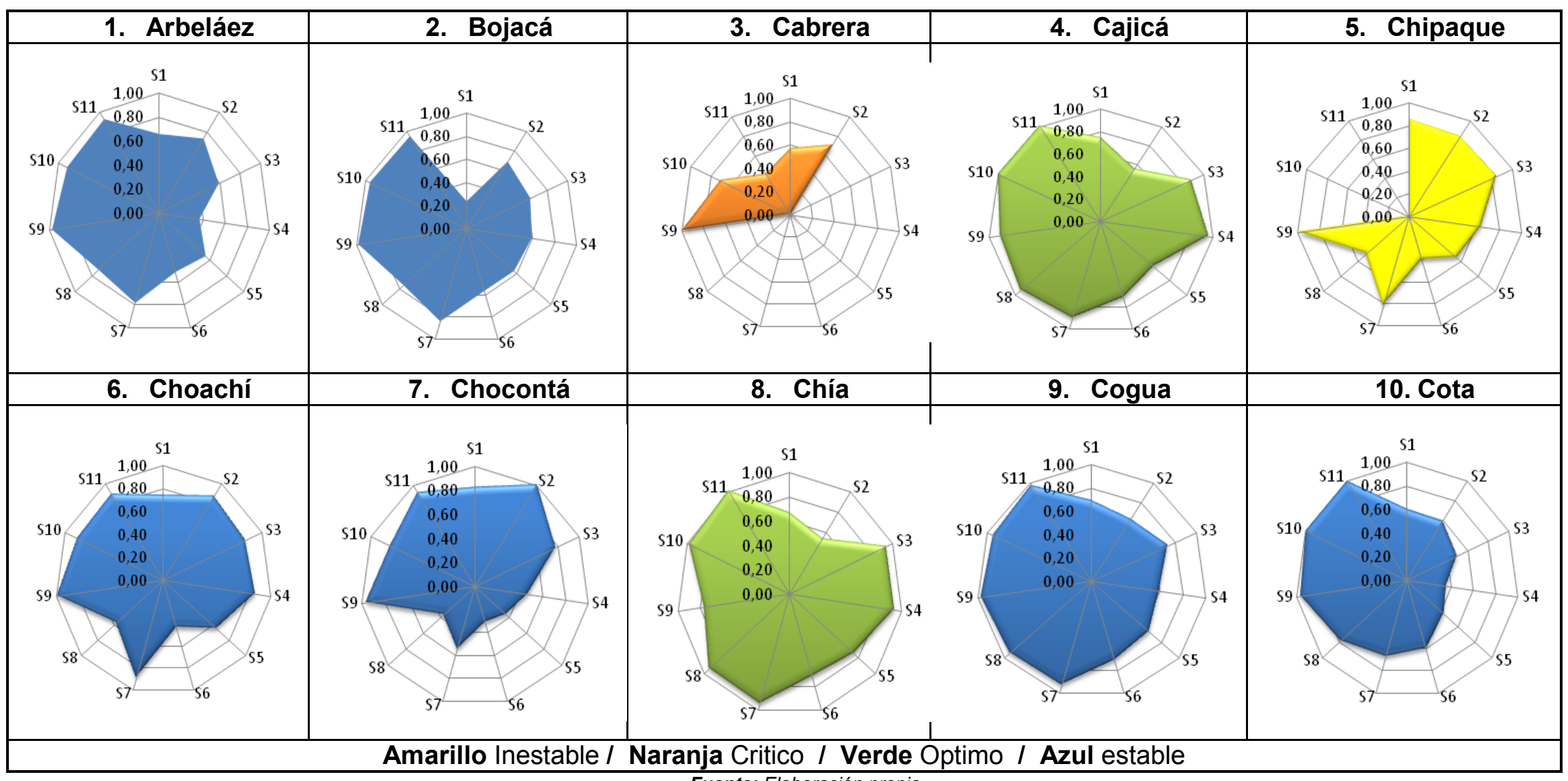




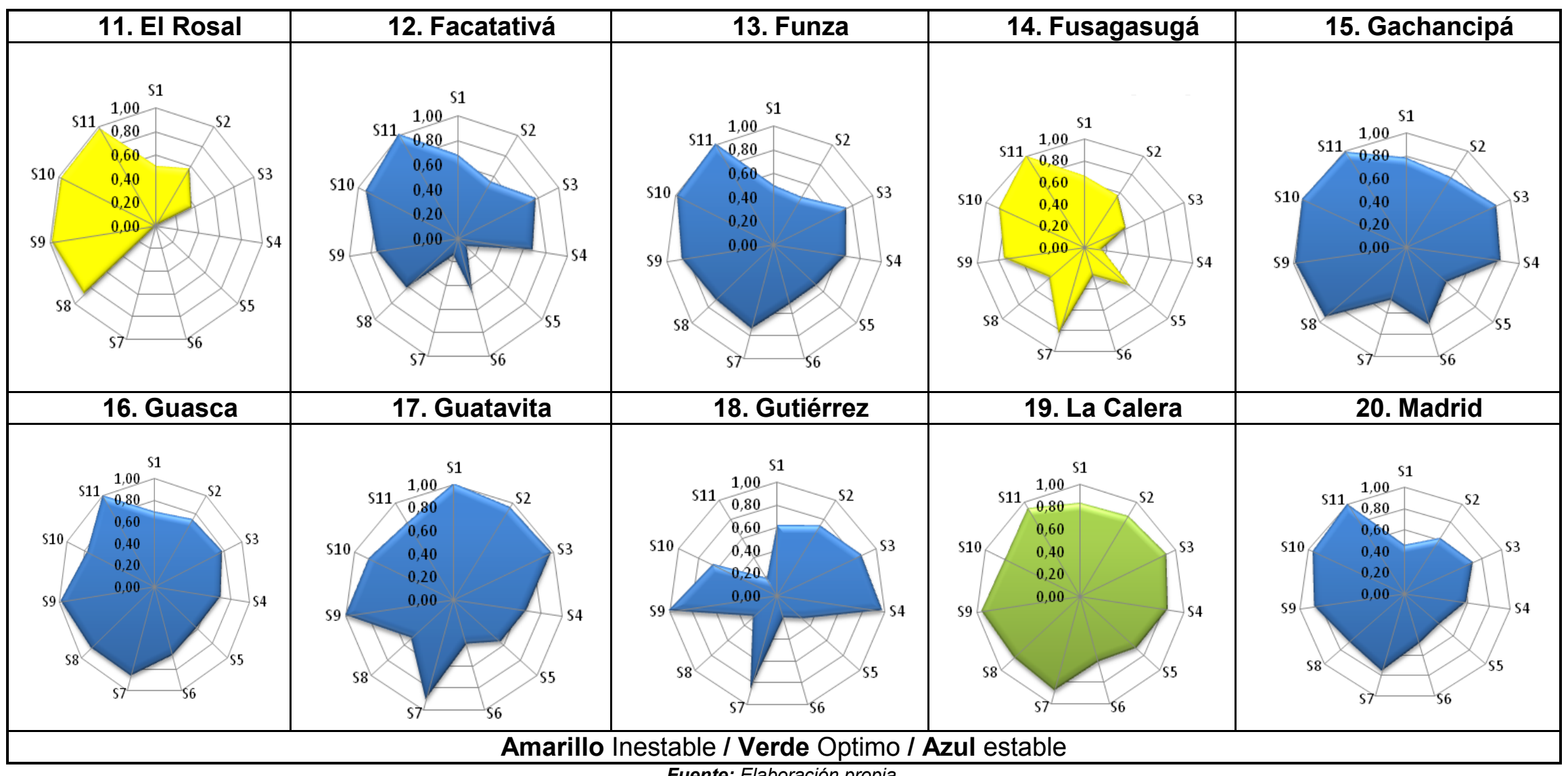

Fuente: Elaboración propia. 


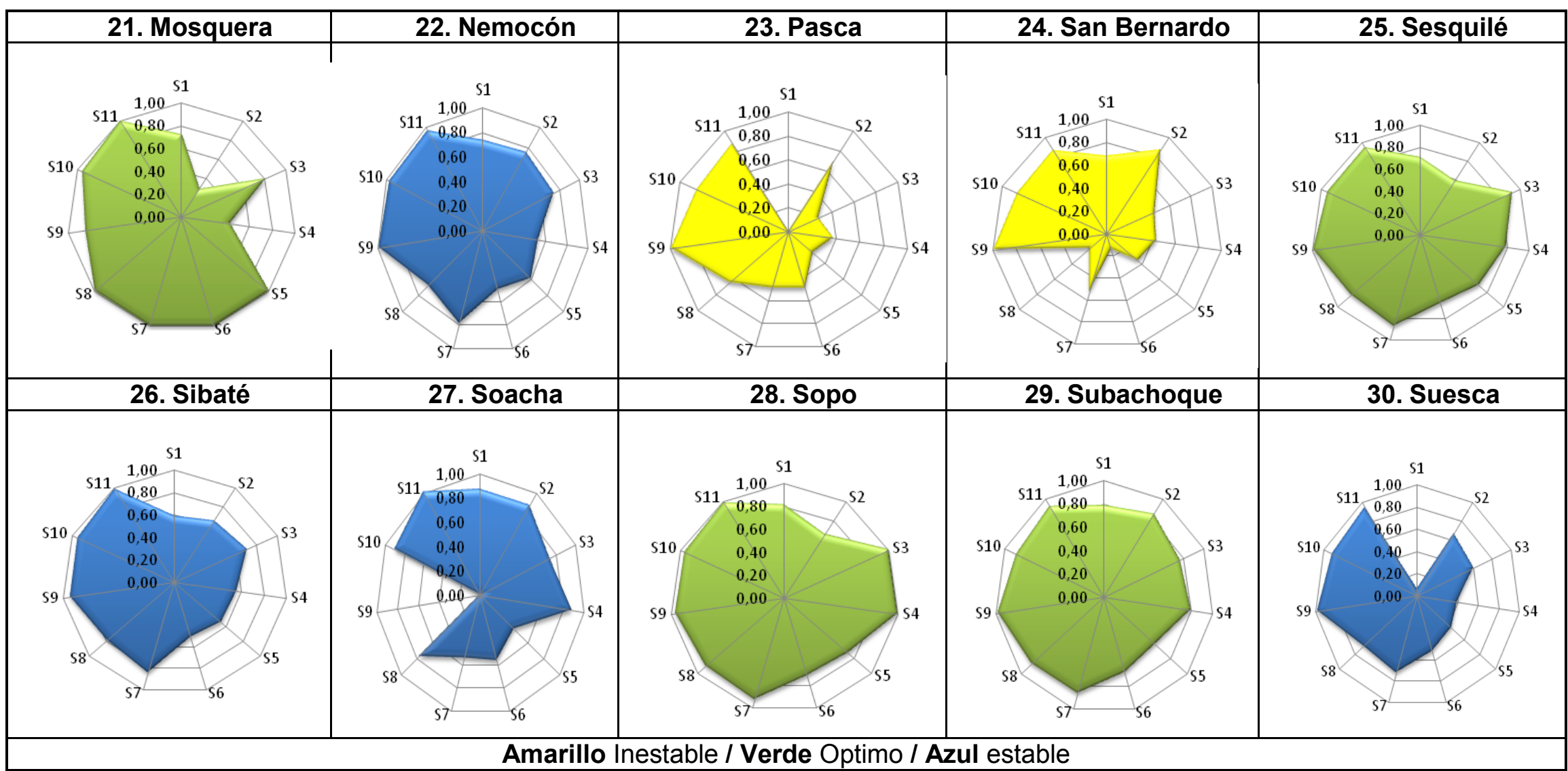

Fuente: Elaboración propia. 


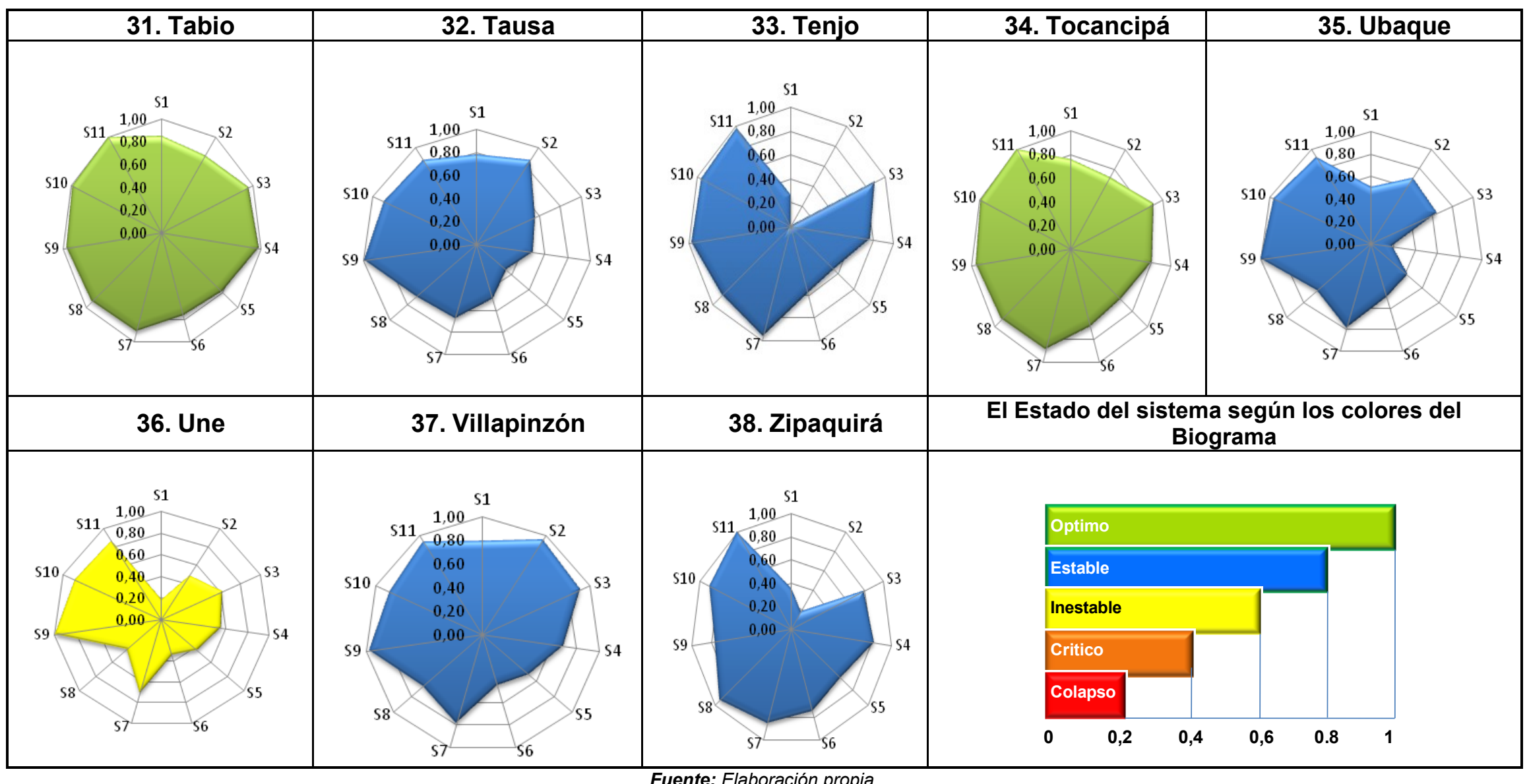


Anexo 7. DIMENSIÓN ECONÓMICA. RESULTADO DEL BIOGRAMA TENIENDO EN CUENTA CADA UNA DE LAS VARIABLES ECONÓMICA POR MUNICIPIO DENTRO DEL ÁREA DE ESTUDIO.

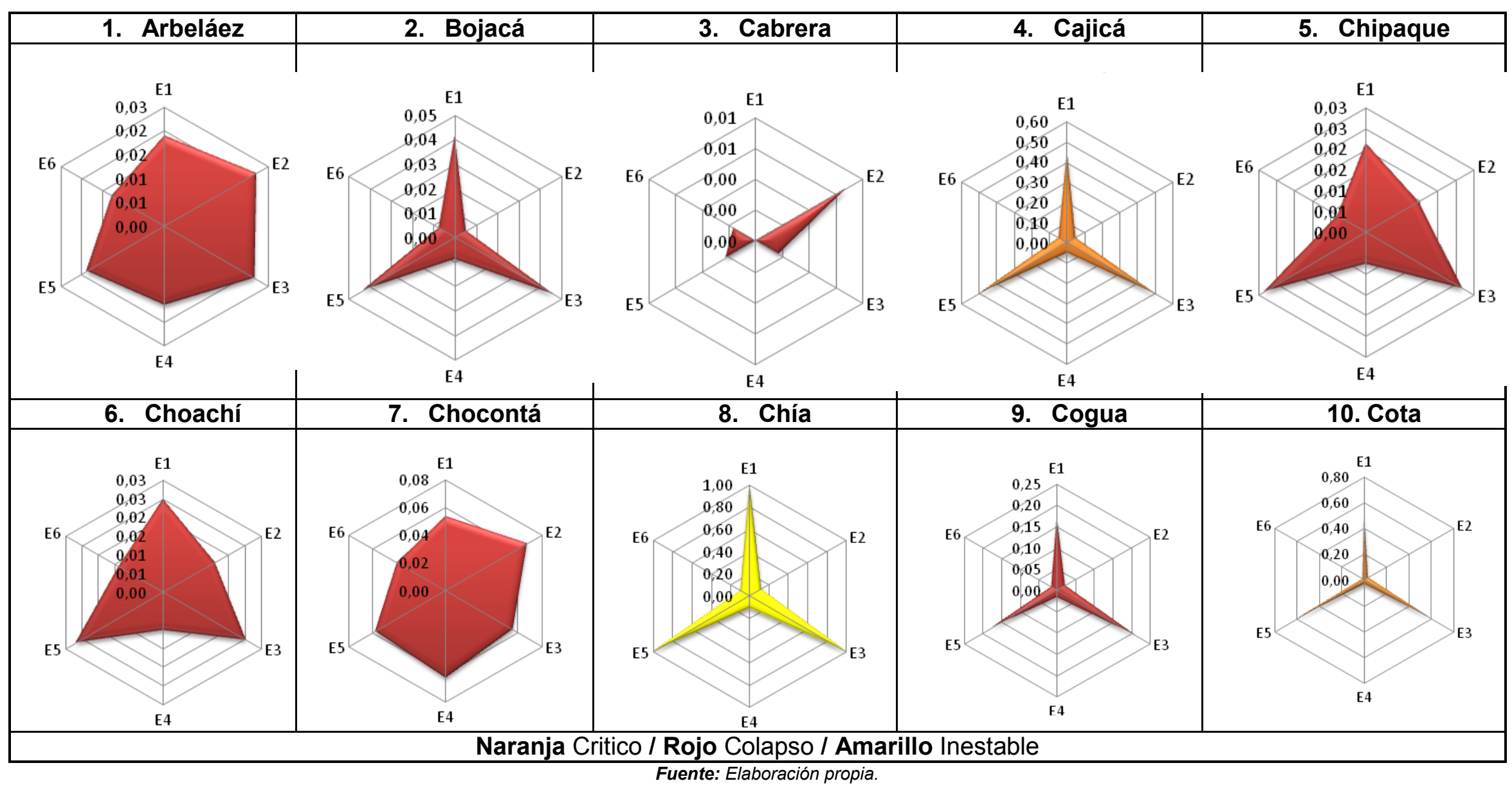




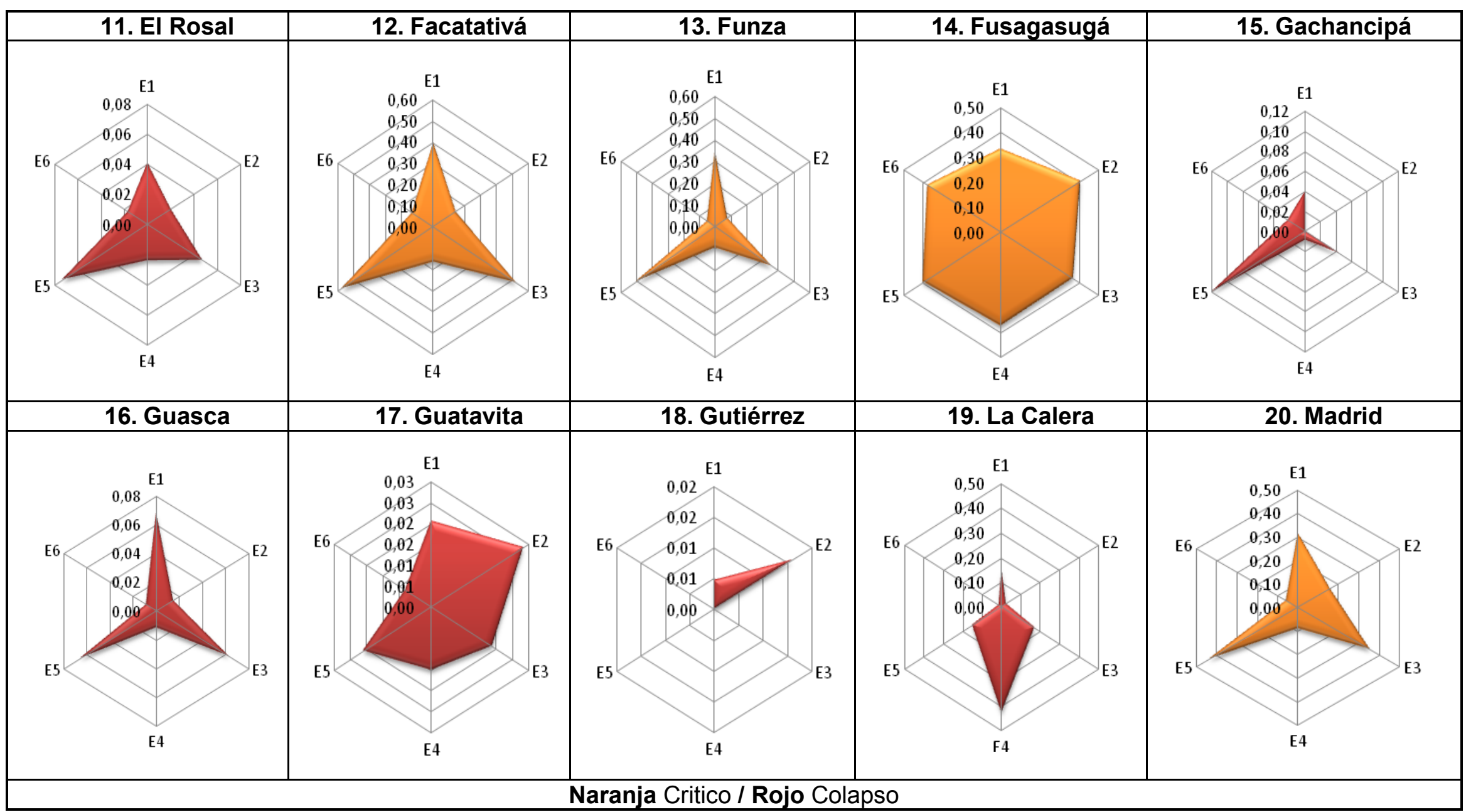

Fuente: Elaboración propia. 


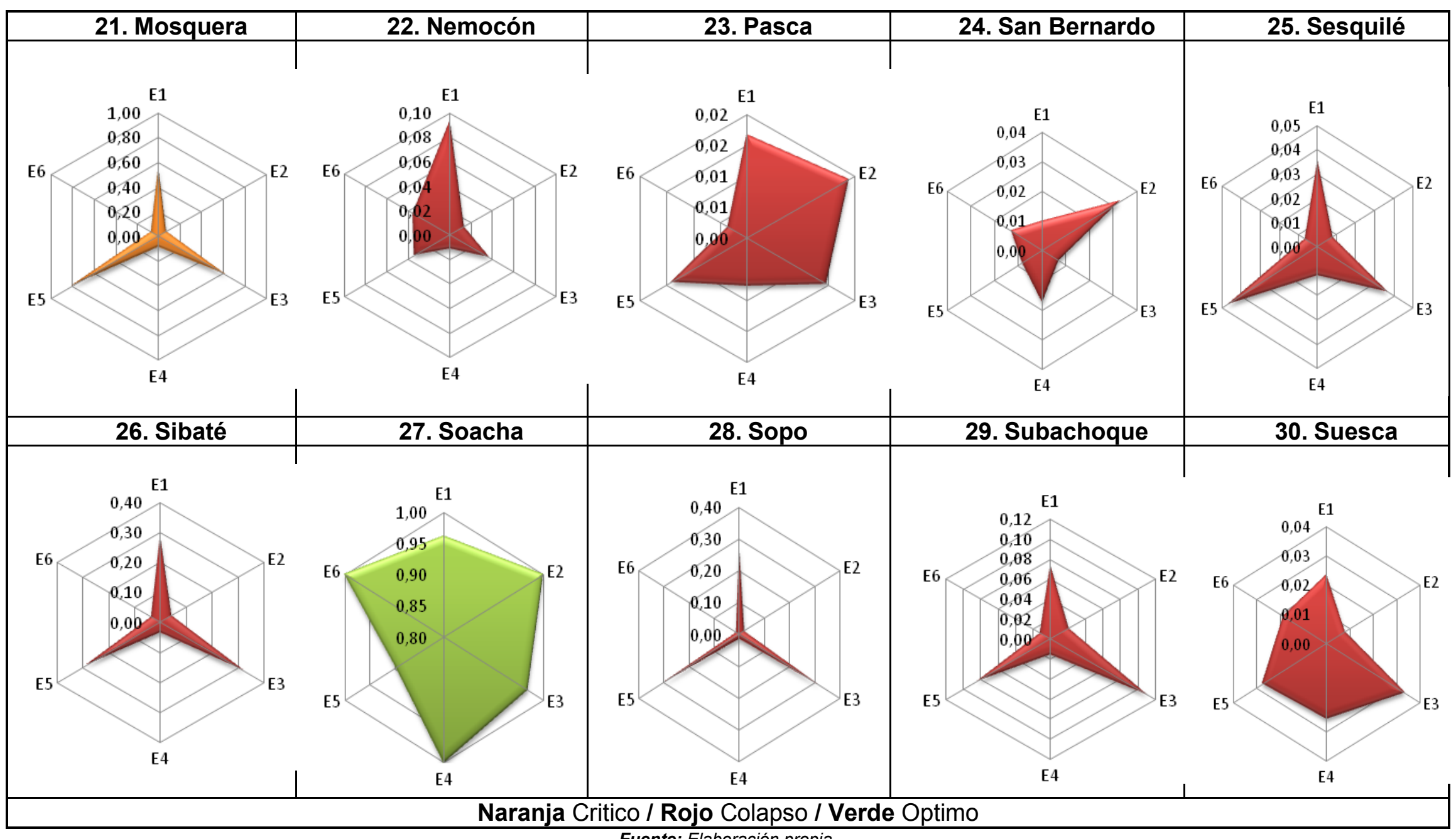

Fuente: Elaboración propia. 


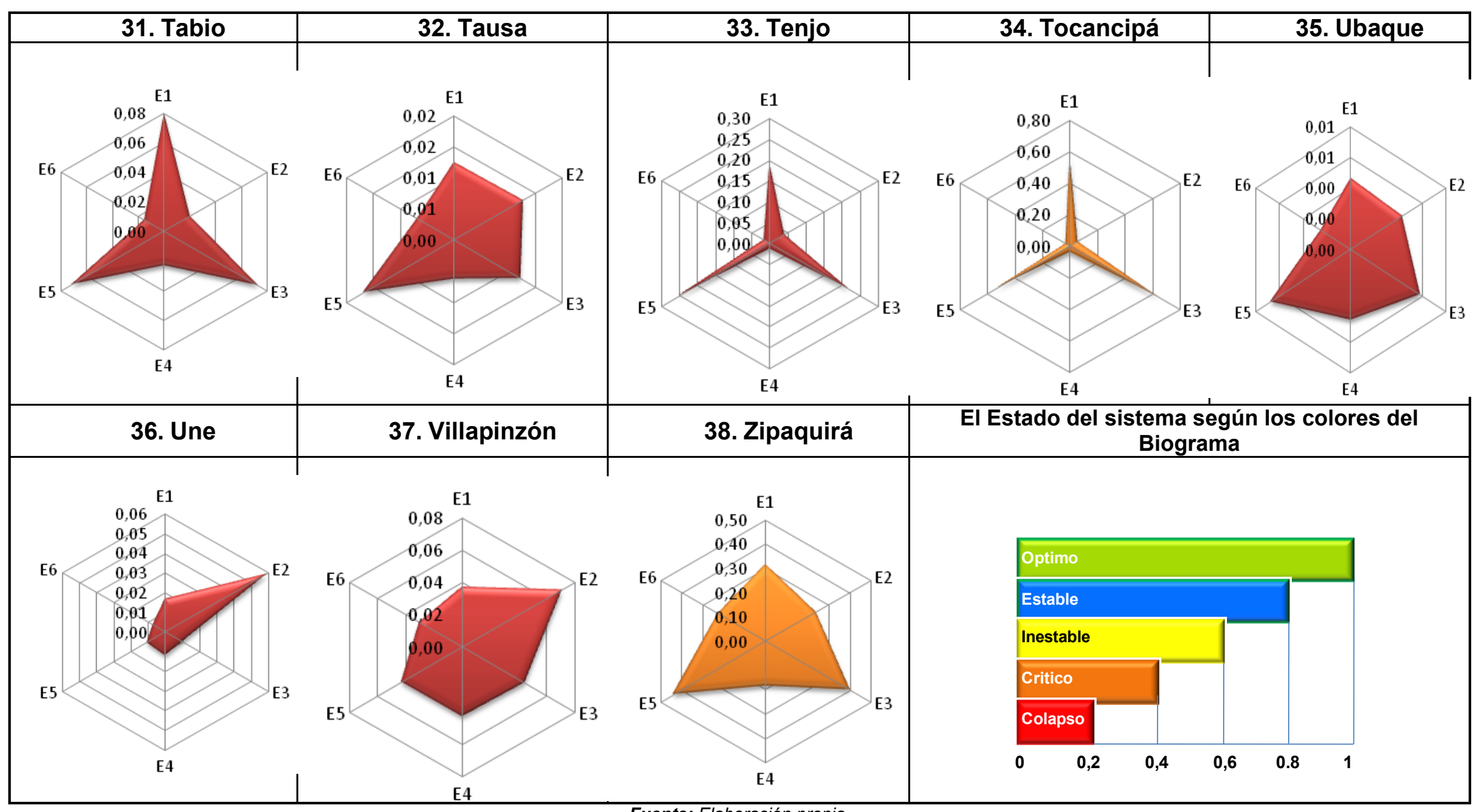

Fuente: Elaboración propia. 
Anexo 8. RESULTADOS GENERALES DEL DIAGNÓSTICO PARA EL ANALISIS DEL INDICE DE DESARROLLO SOSTENIBLE

\begin{tabular}{|c|c|c|c|c|c|c|c|c|c|c|c|c|c|c|c|c|c|c|c|c|c|c|c|c|c|c|c|c|c|c|c|c|c|c|}
\hline \multirow{3}{*}{ MUHICIPIO } & \multicolumn{11}{|c|}{ SMLESEG } & \multicolumn{11}{|c|}{ SWENGGY } & \multicolumn{11}{|c|}{ IMENESG } & \multirow[b]{2}{*}{ imoor } \\
\hline & A1 & $A 2$ & $A_{3}$ & A1 & ${ }_{A 5}$ & As & $A 7$ & At & As & A10 & A11 & A1 & $A_{2}$ & A3 & A4 & A5 & At & $A 7$ & At & A9 & A11 & A11 & A1 & \begin{tabular}{|l|} 
A2 \\
\end{tabular} & A3 & \begin{tabular}{|l|} 
A4 \\
\end{tabular} & \begin{tabular}{|l|} 
A5 \\
\end{tabular} & \begin{tabular}{|l|}
$A 6$ \\
\end{tabular} & \begin{tabular}{ll|} 
A? \\
\end{tabular} & At & As & A10 & A11 & \\
\hline & 1 & 1 & & - & & 1 & 1 & 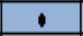 & - & & 1 & 1 & & 1 & 1 & 1 & & & 1 & . & 1 & 1 & t & 4 & t & & (4) & 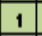 & 1 &. & 1 & 1 & 1 & \\
\hline Artolasez & 48096 & 284,606964 & 47736 & 1583,2552 & & 1518,42394 & $224,25840 \mid$ & \begin{tabular}{|l|l|}
$834,1,50445$ \\
\end{tabular} & 0,000000 & 800000 & $89,394,8,8$ & 1020,48 & 288,61 & \begin{tabular}{|l|l|}
176,49 \\
\end{tabular} & 1558,26 & 0,00 & \begin{tabular}{|l|l|}
151,92 \\
\end{tabular} & 224,26 & $.8341,50$ & 0,00 & 0,00 & 89,39 & 0,08 & 0,06 & 0,10 & 0,1 & $0,0,0$ & 0,07 & 0,01 & 0,34 & 1,00 & 0,00 & 0,04 & 0,17 \\
\hline & 0000 & 86732 & 2561 & 1060,63504 & 2379 & 3399,107800 & 19513 & 3226,78978 & 0,000000 & 53,10471 & 47,86139 & 0,00 & \begin{tabular}{|l|l|}
766,87 \\
\end{tabular} & 27,23 & 1060,64 & \begin{tabular}{|l|l|}
117,02 \\
\end{tabular} & 3319,11 & \begin{tabular}{|l|l|}
653,20 \\
\end{tabular} & \begin{tabular}{|c|}
326,79 \\
\end{tabular} & \begin{tabular}{|l|l|}
0,00 \\
\end{tabular} & 533,10 & 47,86 & 0,00 & 0,17 & 0,00 & 0,12 & 0,02 & 0,14 & 0,04 & 0,74 & 1,00 & \begin{tabular}{ll|}
0,07 \\
\end{tabular} & \begin{tabular}{|l|}
0,02 \\
\end{tabular} & 0,21 \\
\hline & 008802 & 1977,52364 & 0000 & 0,000000 & 800000 & 23110,94180 & 800000 & 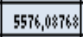 & 0,000000 & 157,48887 & 11,17612 & 12825,094 & \begin{tabular}{|l|l|}
1978,593 \\
\end{tabular} & 00 & 0,00 & 0,00 & 23110,94 & 0,00 & $.5577,09$ & 0 & 157,49 & $11,1,13$ & 1,00 & 0,41 & 0,00 & $0,0,00$ & 0,00 & 1,00 & 0,00 & 0,56 & 1,00 & 0,02 & 0,000 & 0,36 \\
\hline isa & 00000 & 45,236866 & $m 7 m 82$ & 111,306060 & (100000 & 422,63232 & 54,19458 & \begin{tabular}{|l|l|}
3206,177840 \\
\end{tabular} & 0,0000000 & 0,000000 & 266,73827 & 0,00 & \begin{tabular}{|l|l|}
345,24 \\
\end{tabular} & 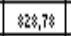 & 116,31 & 0,00 & 422,63 & 54,19 & $-32366,17$ & \begin{tabular}{|l|l|}
0,00 \\
\end{tabular} & 0,00 & 266,74 & 0,000 & , 0,08 & 0,05 & 0,0 & 0,00 & $0,0,02$ & 0,00 & 0,75 & 1,00 & 0,00 & $0,0,12$ & $0,1 \pm$ \\
\hline Baque & 0000 & $28,8,86380$ & 53,599900 & 3780,37244 & 00000 & 1223,23866 & 18,69916 & 4202,57269 & 0,000000 & $54,6(1640)$ & 24,05332 & 0,00 & 238,86 & 599 & 3780,37 & 0,000 & \begin{tabular}{|l|l|}
1223,23 \\
\end{tabular} & \begin{tabular}{|l|}
1748,67 \\
\end{tabular} & $-420,59$ & 0,00 & 54,62 & 24,05 & 0,00 & 0,06 & 0,00 & 0,4 & 0,00 & $0,0,05$ & 0,11 & 0,69 & 1,00 & 0,01 & 0,01 & 0,21 \\
\hline Chossti & & 43532 & 7,99119 & $2,1,|1| 3 \mid$ & 0,00000 & 00000 & 11394,201919 & 103,31989, & 0,000000 & 1930,62290 & $10,8,8325$ & 0,000 & 115,94 & 7207,94 & 21,11 & 0,00 & 0,00 & $92,2,21$ & $-103,32$ & 0,00 & 1938,62 & 10,88 & 0,00 & $0,0,03$ & 0,41 & 0,000 & 0,00 & $0,0,04$ & 0,72 & 0,999 & 1,00 & 0,018 & $0,0,05$ & 31 \\
\hline-1 & & 70,73949 & 133866 & 200,677802 & 5033,45259 & 0000 & $5 \$ 17,00019$ & 2020,92766 & 0,00000 & 70101,20746 & 145,69005 & 0,000 & 70,74 & 45588,34 & 204,68 & 5033,45 & 0,00 & 5817,00 & 2020,93 & $0,0,00$ & 0,21 & 145,69 & 0,00 & 0,02 & 0,55 & 0,02 & 0,77 & 0,00 & 0,37 & 0,84 & 1,00 & 0,87 & 0,06 & \\
\hline is & 09661 & 839,61597 & 56230 & 2507,35278 & 1,87449 & 0,00000 & 3,64427 & 1315,91479 & 2,04303 & 0,000000 & 652,16436 & 177,11 & 4,62 & 5,56 & 2500,35 & 1,87 & II0 & 743,61 & -1315,91 & $\cdot 2,04$ & 00 & 655,16 & 0,0 & 0,18 & 0,01 & 0. & 0,00 & 0,00 & 0,05 & 4 & 0,99 & 0,00 & 0,29 & .25 \\
\hline aqua & tonot & 663,34137 & , 25176 & 647,20485 & 00000 & 3356,76676 & 5,97121 & 2488,67075 & 0,000000 & 293,93447 & 200,67068 & 0,00 & 3,39 & 1700,25 & 647,21 & 0,00 & 3356,77 & 3015,97 & 2998,67 & $\begin{array}{ll}0,00 \\
\end{array}$ & 293,93 & 200,67 & 0,00 & 0,06 & 0,10 & $0,0,07$ & 0,00 & $0,0,15$ & 0.14 & $0, n$ & 1,00 & 0,04 & 0,099 & 22 \\
\hline Cots & 222 & 8,705004 & 0,15521 & 0,01380 & 2004 & 0,000000 & 2,194484 & 22,27586 & 493838 & 0,000000 & 137,203897 & 2,62 & 8,71 & \begin{tabular}{|l|}
1940,16 \\
\end{tabular} & 4 & 16,22 & 0,00 & 1452,61 & $22,2,28$ & \begin{tabular}{|l|}
$9,2,29$ \\
\end{tabular} & .60 & 137,20 & 0,000 & 0,14 & $0,0,08$ & 0,000 & 0,000 & 0,000 & 0,09 & 1,00 & 0,97 & 0,00 & $0,0,06$ & 21 \\
\hline ElRaral & (000) & $0,0,09922$ & 10000 & 1),00000 & 0,000000 & 00000 & 258,49795 & 92,37792 & 0,00000 & 0,000000 & 0,000000 & 0,00 & 0,01 & 0,00 & 0,00 & 0,00 & 0,00 & $25 \%, 50$ & $-94,38$ & 0,00 & oin & 0,00 & 0,00 & 0,00 & 0,00 & 0,00 & 0,00 & 0,00 & 0,02 & 0,99 & 1,00 & 0,00 & 0,00 & 17 \\
\hline 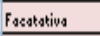 & 3320 & 711,82068 & 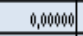 & 2455,99833 & 00000 & 00000 & 1,45328 & \begin{tabular}{|l|l|}
7755,235384 \\
\end{tabular} & 0,000000 & 357,13396 & 639,3395 & 35,13 & $711,1,2$ & nit & $2455,98 \%$ & (i) & 0,00 & 61,45 & -77755,24] & 0,00 & 7,13 & 639,33 & 0,00 & 0,16 & 0,00 & 0,027 & 0,000 & 0,00 & 0,12 & 0,394 & 1,00 & 0,04 & 0,28 & 21 \\
\hline & (2000 & 1233,51064 & $0,0,00000$ & 176,48876 & 4550 & 0,000000 & 5,626941 & \begin{tabular}{|l|}
3503,844503 \\
\end{tabular} & $0,0,00000$ & $0,0,00000$ & 133669 & 0,00 & 3,51 & 0,00 & 176,49 & 8,30 & 0,00 & 5,27 & 003,85 & \begin{tabular}{|l|l|}
0,00 \\
\end{tabular} & 0,00 & 2,13 & 0,00 & 0,27 & 0,00 & & $0,0,00$ & 0,00 & t & 0,73 & 1,00 & 0,00 & 0,39 & 22 \\
\hline 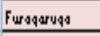 & & 584,10502 & 463,42877 & $\begin{array}{ll}212,323033 \\
\end{array}$ & 1000 & 2259,36132 & 68021 & \begin{tabular}{|l|l|}
7326,45012 \\
\end{tabular} & tonot & 50000 & 1366,97352 & 0,000 & 4,11 & \begin{tabular}{|l|}
3963,43 \\
\end{tabular} & 123,32 & 0,00 & 2259,36 & 3,68 & 26,95 & \begin{tabular}{|l|l|}
0,00 \\
\end{tabular} & (i0 & 1367,97 & 0,00 & 0,13 & 0,23 & in & 0,00 & 0,10 & 0,04 & 0,42 & 1,00 & 0,00 & \begin{tabular}{|l|}
0,61 \\
\end{tabular} & 23 \\
\hline Gachanciti & (000) & 670,30538 & 11,401515 & \begin{tabular}{|l|l|}
5 & 1045,206394 \\
\end{tabular} & 000000 & 0,000000 & 505,13529 & \begin{tabular}{|l|}
2314,25192, \\
\end{tabular} & 6,88721 & 0,000000 & $\quad 56,17545$ & 0,00 & 0,31 & 11,40 & 1045, 21 & 0,00 & 0,00 & 505,14 & 2314,25 & \begin{tabular}{|l|l|}
6,89 \\
\end{tabular} & 0,000 & $56,1 \frac{18}{8}$ & 0,00 & 0,15 & 0,00 & 0,12 & 0,00 & 0,00 & 0,03 & 0,82 & 0,98 & 0,00 & \begin{tabular}{|l|}
0,02 \\
\end{tabular} & 19 \\
\hline Guars & 99493 & 1846,70455 & 1,90032 & 97,82775 & 391,67075 & 8,35664 & 15599,45219 & 98,84043 & $0,0,00000$ & if 66,84428 & 83,23226 & 3104,70 & 1846,71 & 7211,90 & \begin{tabular}{|l|}
9,38 \\
\end{tabular} & 39,67 & 3336,36 & 45894,45 & $.48,80$ & ,ii - & 66,84 & sis & 0,25 & 0,41 & 0,41 & 0,01 & $0,0,5$ & 0,19 & 1,00 & 0,94 & 1,00 & 0,01 & 0,04 & 39 \\
\hline Guskstiva & 6720 & 4557,691968 & $m 77,999 \%$ & 8497,203599 & 24,42558 & 102,76558 & 376,19273 & \begin{tabular}{|l|}
3874,462534 \\
\end{tabular} & 0,000000 & 931,06739 & 62571 & $252,9 ?$ & \begin{tabular}{|l|}
4557,69 \\
\end{tabular} & \begin{tabular}{|l|}
$m, 98$ \\
\end{tabular} & 4945,20 & 24,83 & 102,77 & 376,19 & $-3879,46$ & 0,00 & . & 63 & 0,02 & 1,00 & 0,04 & 1,000 & 0,000 & 0,00 & 0,33 & 0,70 & 1,00 & 0,12 & 0,08 & . \\
\hline & nato & 401,148020 & 17847,6079 & $9 \quad 105,56603$ & 6552,23404 & No00 & 2990,040301 & 1,54017? & 0,000000 & 8037,21342 & 39327 & 0,00 & ,1,5 & 178417,61 & 105,57 & 65552,23 & 0,00 & 90,40 & $\$ \$ 624,54$ & \begin{tabular}{|l|l|}
0,00 \\
\end{tabular} & 7,21 & 39 & 0,000 & 0,094 & 1,00 & 0,01 & 1,00 & 0,00 & 0,19 & 0,32 & 1,00 & 1,00 & 0,010 & - \\
\hline & & 0.65546 & 3993: & & & 397. & $5 \% 8 \%, 70095$ & 12711,704800 & 113,398799 & 4828,30127 & 282,46710 & 32,67 & \begin{tabular}{|l|}
1777,07 \\
\end{tabular} & 6795,75 & 0,60 & 0,00 & 5 & 68,70 & $-12711,70$ & \begin{tabular}{|c|}
$-113,40$ \\
\end{tabular} & 4284,30 & 248,47 & 0,0 & 0,39 & 0,39 & 0,00 & 0,00 & 0,00 & 0,37 & 0,00 & 0,66 & \begin{tabular}{l|l|}
0,53 \\
\end{tabular} & 0,11 & 22 \\
\hline Madri & (600) & $583,3,3776$ & 62529 & 4843,19400 & 685868 & 0000 & 1,304049 & \begin{tabular}{|l|l|}
6304,876066 \\
\end{tabular} & 6,99196 & $12,901+18$ & 542,69944 & 0,00 & \begin{tabular}{|l|}
583,35 \\
\end{tabular} & 6,63 & $\$ 43,19$ & 30,69 & 00 & 854,34 & 63014,85 & 6,92 & 94 & 548,61 & 0,00 & 0,13 & 0,03 & $0,0,09$ & 0,00 & 0,00 & 0,05 & 0,50 & \begin{tabular}{ll|}
0,988 \\
\end{tabular} & 0,00 & 0,24 & , 17 \\
\hline Marsyuor & (100) & 0,70283 & 799002 & $2 \quad 23,63187$ & 1937,48790 & 00000 & 5,54988 & 2,29928 & 0,000000 & 0,000000 & 759,39528 & 0,0 & 390,71 & 4,80 & 28,63 & \begin{tabular}{|l|}
1937,49 \\
\end{tabular} & 0,00 & 6,55 & $-442,30$ & 0,00 & 0,06 & 753,40 & 0,00 & 0,099 & 0,24 & 0,000 & 0,30 & 0,00 & 0,04 & $0,97]$ & 1,00 & 0,00 & 0,33 & 27 \\
\hline Nomesesen & (1000) & 185,727240 & 331,94418 & $\begin{array}{ll}69,558828 \\
\end{array}$ & $\$, 53687$ & .074848 & 7,99663 & \begin{tabular}{|l|l|}
5851,792999 \\
\end{tabular} & 0,000000 & 213,06962 & 391,728285 & 0,00 & 195,77 & 331,46 & 69,56 & 8,54 & 2,07 & 2066,79 & \begin{tabular}{|l|l|}
5851,79 \\
\end{tabular} & 0 & 3,07 & 39,78 & 0,00 & 0,04 & 0,02 & 0,01 & 0,00 & $0,0,03$ & 0,13 & 0,54 & 1,00 & 0,03 & 0,17 & 17 \\
\hline & & 135 & $123 \% 9,396464$ & & & 87301 & 9,4289 & 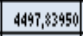 & 0,000000 & 50000 & , 1791812 & \begin{tabular}{|l|l|}
1449,25 \\
\end{tabular} & 1354,36 & 12889,37 & 0,66 & 0,00 & 79,97 & , 94 & \begin{tabular}{|l|l|l|} 
\\
\end{tabular} & $0,0,00$ & 4 & .12 & 0,11 & 0,30 & 0,74 & 0,000 & 0,00 & $0,0,09$ & 0,19 & 0,65 & , 1,00 & 0,00 & $\begin{array}{l}0,02 \\
\end{array}$ & 28 \\
\hline & & $17 m 7,1258$ & 919180 & 3244,23151 & af & $\$ 80,77209$ & 1608,80497 & \begin{tabular}{|l|l|}
6736,66279 \\
\end{tabular} & 0,000000 & 00000 & ,919355 & 0,00 & 7,11 & $\$ 260,92$ & 3244,28 & 0,60 & \begin{tabular}{|l|} 
\\
\end{tabular} & 1600,80 & $-6786,66$ & \begin{tabular}{|l|l|}
0,00 \\
\end{tabular} & 6in & 191 & 0,00 & 0,39 & 0,47 & 0,36 & 0,00 & 0,04 & 0,10 & 0,47 & 1,00 & 0,00 & \begin{tabular}{|l|l|}
0,03 \\
\end{tabular} & 26 \\
\hline Sagvile & aid & 3009,4528 & 8,05685 & \begin{tabular}{ll|l}
5 & 48,00543 \\
\end{tabular} & 22,25829 & 30266 & 3,51034 & \begin{tabular}{|l|l|}
1335,766790 \\
\end{tabular} & 0,000000 & 1,97623 & 97078 & 0,0 & 3009,95 & 3066,06 & $4 \leqslant, 41$ & 22,26 & 0,00 & 5633,51 & $-1335,76$ & 0,00 & 9.98 & 29,97 & 0,00 & 0,66 & 0,18 & 0,01 & 0,000 & 0,00 & 0,35 & 0,89 & 1,00 & 0,00 & 0,01 & 28 \\
\hline Silisto & ato & 349,74529 & 1336,01394 & 2537,52442 & 0,000000 & 年, & 1,73573 & 2125,022204 & 0,0000000 & 689,877614 & 172,62172 & 0,00 & 34,75 & 6,01 & 2593,52 & 0,00 & 3,59 & 1,79 & 22125,02 & 0,00 & 699,89 & 172,62 & 0,00 & $0,0,08$ & 0,08 & 0,28 & 0,000 & 0,02 & 0,12 & 0,83 & 1,00 & 0,09 & $0,0,08$ & 23 \\
\hline Soset & & 23,14499 & 8720,74658 & 92719 & 10000 & 45686 & 2432,764894 & 47741 & touol & 00000 & 2258,56861 & (ivi) & , 14 & $\$ 720,75$ & 20,93 & 0,00 & 29,15 & 2,76 & 47 & $0,0,00$ & in & 2258,57 & 0,00 & 0,01 & 0,50 & 0,00 & 0,00 & 0,00 & 0,15 & 0 & 1,00 & 0,00 & 1,00 & 33 \\
\hline Sopi. & 7968 & 775,088890 & $28 \times 411$ & $\begin{array}{l}1 \quad 34,43231 \\
\end{array}$ & & 4048 & 4783,69110 & \begin{tabular}{|l|l|}
353,529282 \\
\end{tabular} & 75,37351 & 100,31287 & $\quad 125,75366$ & \begin{tabular}{|l|l|}
599,67 \\
\end{tabular} & 775,09 & \begin{tabular}{|l|l|}
$136,2,28$ \\
\end{tabular} & 34,43 & 0,00 & 84 & 4763,60 & $\cdot 353,53$ & \begin{tabular}{|l|l|}
$-75,344$ \\
\end{tabular} & \begin{tabular}{|l|l|} 
& 100,31 \\
\end{tabular} & 5,75 & 0,05 & 0,17 & 0,08 & 0,00 & 0,00 & 0,00 & 0,30 & $0,97]$ & 0,77 & 0,01 & $0,0,66$ & 22 \\
\hline & & 37,53998 & 4,380404 & 16996,65394 & m & 05594 & 12995,31730 & 3000,06282, & 15,81126 & $\begin{array}{ll}64,13975 \\
\end{array}$ & 5338,65568 & 0,000 & 1,53 & 2018,438 & 1696,65 & 0,00 & 47,21 & 124995,32 & 30000,06 & \begin{tabular}{|l|}
$-15,81$ \\
\end{tabular} & 19 & 338,66 & 0,00 & 0,01 & 0,13 & 0,19 & 0,00 & 0,00 & 0,82 & $0,7 n$ & $\begin{array}{ll}0,95 \\
\end{array}$ & 0,01 & 0,15 & 27 \\
\hline Emare & (0000) & $1024,98880 \mid$ & 9,188001 & $1405,4548,3$, & 773,27673 & 433663 & $576,978 \% 99$ & \begin{tabular}{|l|l|}
5674,391919 \\
\end{tabular} & 0,000000 & 196,5578 & $\begin{array}{r}225,02590 \\
\end{array}$ & 0,0 & 4,99 & \begin{tabular}{|l|}
2999,15 \\
\end{tabular} & 405,45 & 773,28 & \begin{tabular}{|l|l|}
630,43 \\
\end{tabular} & \begin{tabular}{|l|}
5767,98 \\
\end{tabular} & 5679,32 & \begin{tabular}{|l|l|}
0,00 \\
\end{tabular} & 196,56 & ,03. & 0,00 & 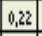 & 0,17 & $0,0,05$ & 0,12 & $\begin{array}{ll}0,03 \\
\end{array}$ & 0,36 & 0.55 & 1,00 & $\begin{array}{ll}0,02 \\
\end{array}$ & 0,10 & 24 \\
\hline Taki & (000) & $92,0,34503$ & 4,028455 & \begin{tabular}{ll|}
5 & 90,48602 \\
\end{tabular} & 100000 & 00000 & $27 \%, 6513$ & \begin{tabular}{|l|l|}
1958,325554 \\
\end{tabular} & 0,000000 & 0,000000 & \begin{tabular}{|l|l|} 
& 68,27450 \\
\end{tabular} & $0,0,00$ & 4,35 & \begin{tabular}{|l|l|}
1251,03 \\
\end{tabular} & 90,49 & 0,00 & 0,00 & 2781,65 & \begin{tabular}{|l|l|}
$-195 \%, 33$ \\
\end{tabular} & \begin{tabular}{|l|l|}
0,00 \\
\end{tabular} & 00 & 68,27 & & 0,20 & 0,07 & 0,01 & 0,00 & 0,00 & 0,18 & 0,55 & 1,00 & 0,00 & \begin{tabular}{|l|}
0,03 \\
\end{tabular} & 21 \\
\hline Taw & (20) & $\{02,206997$ & $5,2,79190$ & 0,000000 & 0 & 199,55576 & 5949,3885010 & 3177,48428 & 0,000000 & 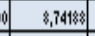 & 88,82452 & 0,00 & 2,21 & \begin{tabular}{|l|}
$575,5,97$ \\
\end{tabular} &, 000 & 1006 & 190,56 & 5949,39 & -3177, 48 & $0,0,00$ & 74. & 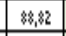 & & $0,0,18$ & 0,33 & 0,00 & 0,00 & 0,01 & 0,37 & 0,75 & 1, 1,00 & 0,00 & 0,04 & 24 \\
\hline fonit & & $76,0,0046$ & 34239 & $4 \quad 186,214660$ & & & $8061, \$ 9498$ & 5,225004 & 331,59447 & 0,000000 & 119,04099 & 0,08 & 761,00 & 39 & \begin{tabular}{|l|l|} 
\\
68,21
\end{tabular} & 0,00 & 0,00 & 1,90 & $\mid 65,23$ & $|-331,194|$ & 0,000 & .04 & 0,00 & 0,17 & 0,05 & 0,02 & 0,00 & 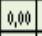 & 0,51 & iv & , i. & 0,00 & 0,05 & 16 \\
\hline & & & & & & & 2229,35495 & \begin{tabular}{|l|l|}
1987,058384 \\
\end{tabular} & $117,0,0074$ & 495838 & 87045 & 9,75 & & 19 &, 72 & 0,00 & & 9,36 & \begin{tabular}{|l|l|}
$-1980,06$ \\
\end{tabular} & \begin{tabular}{|l|l|}
$-117,00$ \\
\end{tabular} & 179,96 & 32 & 0,00 & 0,026 & 0,02 & & 0,00 & I & 0,14 & & 65 & 0,02 & 02 & 14 \\
\hline Ubag & & 1922,56110 & $6331+1$ & 12526,57744 & 2000 & 48483 & 117786 & 6124,52240 & 0,000000 & 16,01668 & 62325 & 0,00 & 2,56 & 1337,63 & 2566,52 & 0,00 & 47,04 & 12 & $4,5.5$ & $0,0,00$ & 4 & 66 & 0,00 & 0,31 & 0,08 & 0 & 0,00 & 0,000 & 0,02 & 0,52 & if & 0,00 & 0,01 & 20 \\
\hline Une & noou & 160,49876 & 1314,94988 & $3543,4457 \%$ & 302,47941 & 10131 & 3940,03525 & \begin{tabular}{|l|}
1159,339195 \\
\end{tabular} & 0,000000 & (1) 37,77046 & ,60950 & 0,000 & 160,50 & 13141,95 & 354,45 & 302,47 & 1,90 & 940,09 & \begin{tabular}{|c|}
1159,483 \\
\end{tabular} & \begin{tabular}{|l|l|}
0,00 \\
\end{tabular} & $n$ & 41,61 & 0,000 & 0,04 & 0,75 & 0,40 & $0,0,05$ & 0,00 & 0,25 & 0,41 & $\begin{array}{ll}, 00 \\
\end{array}$ & 0,00 & $\begin{array}{l}0,02 \\
\end{array}$ & 31 \\
\hline Villapi & (000) & \begin{tabular}{|l|}
1922,976655 \\
\end{tabular} & 16620 & 6921,39935 & $0,0,000$ & 300000 & $\$ \$ 840,65446$ & \begin{tabular}{|l|l|}
1518,40038 \\
\end{tabular} & 0,000000 & 0,000000 & 96,74246 & 0,00 & \begin{tabular}{|l|l|}
1922,98 \\
\end{tabular} & 565,17 & 6981,31 & 0,00 & $0,0,00$ & $\$ \$ 80,65$ & $\mid 151,80$ & 0,00 & 0,00 & 96,74 & 0,000 & 0,42 & 0,03 & 7 & 0,00 & 0,00 & 0,56 & 8 & 1,00 & 0,00 & 0,04 & 34 \\
\hline & & 5,8 & 1,98908 & 6045,59334 & 0,000 & 33071 & 2321,48770 & \begin{tabular}{|l|l|l|} 
& $645,7,7283$ \\
\end{tabular} & 0,000000 & & 693,23945 & L & 5,85 & 4,20 & 6045,39 & $\perp$ & $\$ 6,73$ & 2321,48 & ;.74 & L & iin- & 24 & & & & & & on & & II & & 0,00 & 0,31 & 25 \\
\hline & & & & & 137364 & & & 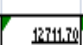 & & & $2438.5]$ & 184642 & 4552,64 & 174126 & 4 & 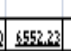 & 3.310 .99 & 17894.45 & & & 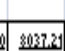 & 3258.57 & & & & & & & & & & & & \\
\hline & & & 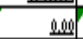 & & 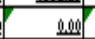 & inan & 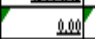 & 这部 & ind & ind & ind & Inam & . & ing & and & . & 0 & 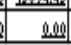 & 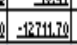 & \begin{tabular}{|r|}
.31 .59 \\
\end{tabular} & 20.00 & 20.00 & & & & & & & & & & & & \\
\hline
\end{tabular}


Anexo 9. RESULTADOS DIMENSIÓN SOCIAL - INDICE DE DESARROLLO SOSTENIBLE.

\begin{tabular}{|c|c|c|c|c|c|c|c|c|c|c|c|c|c|c|c|c|c|c|c|c|c|c|c|c|c|c|c|c|c|c|c|c|c|c|}
\hline \multirow{3}{*}{ MUNICIPIO } & \multicolumn{11}{|c|}{ IWWENGWW SOCONL } & \multicolumn{11}{|c|}{ CWNENWW } & \multicolumn{11}{|c|}{ CWWENACW SCOCWL } & \multirow[b]{2}{*}{ ZNOWCE } \\
\hline & $\$ 1$ & $\overline{\mathrm{S2}}$ & \begin{tabular}{|l|} 
S3 \\
\end{tabular} & 54 & S5 & 56 & 57 & \begin{tabular}{|l|}
58 \\
\end{tabular} & S9 & 10 & & $\mathrm{~A} 1$ & A2 & 3 & $\mathbf{A}$ & $\mathrm{A5}$ & A6 & A7 & A8 & A9 & A10 & A11 & S1 & S2 & \begin{tabular}{|l|} 
S3 \\
\end{tabular} & \begin{tabular}{|l|l} 
S4 \\
\end{tabular} & \begin{tabular}{|l|l}
55 & 5 \\
\end{tabular} & \begin{tabular}{|l|l}
56 & 5 \\
\end{tabular} & \begin{tabular}{l|l}
57 & 5 \\
\end{tabular} & \begin{tabular}{l|l}
58 & 5 \\
\end{tabular} & \begin{tabular}{l|l} 
S9 & \\
\end{tabular} & \begin{tabular}{|l|l} 
S10 \\
\end{tabular} & S11 & \\
\hline & v & 0 & 0 & 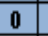 & & 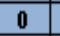 & & & & 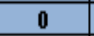 & & & & & - & & & & & & & & 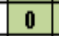 & & & 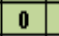 & 0 & 0 & & & & & & \\
\hline & 32,60 & 18,43 & \begin{tabular}{|l|l}
4,40 \\
\end{tabular} & 7,30 & & 9,40 & & & $70 \mathrm{P}$ & 0,0 & & 32,60 & 43 & 40 & $.7,30$ & 5,60 & 9,40 & 00 & 00 & & & 25 & 0,65 & 0,73 & 0,59 & 0,360 & \begin{tabular}{|l|l}
0,55 & 0 \\
\end{tabular} & \begin{tabular}{|l|l}
0,51 & 0
\end{tabular} & \begin{tabular}{|l|l}
0,78 & 0,
\end{tabular} & \begin{tabular}{l|l}
0,73 & 0,
\end{tabular} & 0,98 & \begin{tabular}{|l|}
0,92 \\
\end{tabular} & 0,93 & .70 \\
\hline jat & & 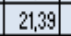 & \begin{tabular}{|l|l|l}
4,10 \\
\end{tabular} & 5,70 & 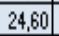 & & 360 & 8,10 & & & & $.66,15$ & 39 & 10 & \begin{tabular}{|l|l|}
$.5,70$ \\
\end{tabular} & & & , & & & & 96 & 0,23 & 0,68 & 0,63 & & \begin{tabular}{|l|l}
0,57 & 0 \\
\end{tabular} & \begin{tabular}{|l|l}
0,57 & 0 \\
\end{tabular} & 0, & \begin{tabular}{l|l}
0,75 & 0,
\end{tabular} & 0,99 & 0,96 & 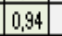 & 70 \\
\hline 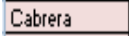 & 94 & 20,22 & 8,50 & 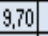 & 50,10 & 80,90 & 18,00 & 33,00 & 80,00 & 00,00 & 9,800 & $-39,94$ & $.20,22$ & \begin{tabular}{|r|}
8,50 \\
\end{tabular} & \begin{tabular}{|r|}
$-9,70$ \\
\end{tabular} & \begin{tabular}{|l|l|}
$\cdot 50,10$ \\
\end{tabular} & \begin{tabular}{|r|}
80,90 \\
\end{tabular} & $.18,00$ & \begin{tabular}{|r|}
33,00 \\
\end{tabular} & 580,00 & & 80 & 0,56 & 0,70 & 0,00 & 0,01 & \begin{tabular}{|l|l}
0,12 & 0 \\
\end{tabular} & \begin{tabular}{l|l}
0,00 & 0
\end{tabular} & \begin{tabular}{l|l}
0,22 & 0. \\
\end{tabular} & \begin{tabular}{l|l}
0,00 & 1,1 \\
\end{tabular} & 1,00 & 0,70 & 0,41 & 34 \\
\hline & 24 & 29,45 & 2,403 & & 21,80 & & & 2,10 & 44,0 & & 09 & $2.26,24$ & $.29,45$ & 10 & & & & & 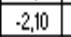 & & & 99 & $\mid 0,74$ & 0,54 & \begin{tabular}{|l|}
0,87 \\
\end{tabular} & 0,960 & & 0,710 & & \begin{tabular}{l|l}
0,94 & 0, \\
\end{tabular} & 0,90 & 0,99 & 1,00 & 3 \\
\hline & & 13,06 & 2,60 & f & & & 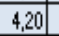 & 1640 & & & & $-17,45$ & t & & & & 70 & 80 & & & & & 0,85 & 0,83 & 0,84 & \begin{tabular}{|l|l|l|l|l|}
0,64 \\
\end{tabular} & & 0,400 & & \begin{tabular}{l|l}
0,50 & 0,
\end{tabular} & 0,99 & 0,00 & 0,00 & \\
\hline ha & & 11,14 & 2,70 & & & & 60 & \begin{tabular}{|l|l|}
14,10 \\
\end{tabular} & & & 04 & $.26,71$ & 14 & 0 & \begin{tabular}{|l|l|}
$-3,90$ \\
\end{tabular} & & 00 & 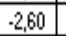 & 10 & & & 4 & 0,73 & 0,86 & 0,83 & 0,860 & & & $\begin{array}{lll}0,89 & 0,5\end{array}$ & \begin{tabular}{l|l}
0,57 & 0, \\
\end{tabular} & 021 & \begin{tabular}{|l|l|}
0,87 \\
\end{tabular} & & 78 \\
\hline & & 2,97 & 3,10 & & 36,40 & & 10,40 & 21,00 & & & 1,32 & \begin{tabular}{|l|l|}
$-19,53$ \\
\end{tabular} & 97 & 10 & \begin{tabular}{|l|l|}
6,600 \\
\end{tabular} & \begin{tabular}{|l|l|}
$-36,40$ \\
\end{tabular} & \begin{tabular}{|l}
55,50 \\
\end{tabular} & 4 & .00 & & & 22 & 0,82 & 1,00 & & & & 0,310 & 0 & 0,36 & 千 & & & 67 \\
\hline & & 30,16 & 2,00 & & 14,30 & & & 2,00 & & & 06 & $.32,19$ & & at & & & $.23,60$ & & & & & 96 & 0,66 & 0,53 & 0,93 & 0,030 & & & \begin{tabular}{|l|l|l}
0.94 & 0.8 \\
\end{tabular} & \begin{tabular}{l|l}
0,94 & 0,
\end{tabular} & 0,16 & $\begin{array}{lll}97 & 0\end{array}$ & & \\
\hline & & 24,83 & \begin{tabular}{|l|l|l}
3,405 \\
\end{tabular} & & 19,4 & & & 2,10 & & & & \begin{tabular}{|l|l} 
\\
\end{tabular} & & & \begin{tabular}{|l|l|}
$.5,70$ \\
\end{tabular} & & 23,60 & & $-\angle, 1$ & & & & 0,68 & 0,62 & 0,73 & \begin{tabular}{l|l}
0,59 & 0 \\
\end{tabular} & & & 0,8 & $0,94[0$, & 0,960 & 0,93 & & \\
\hline & & 27,20 & 5,10 & & 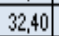 & & 7,40 & 7,00 & & & & $-37,50$ & & & & & $.32,00$ & & & & & & 0,59 & 0,58 & 0,49 & & & & & 0 & & & & \\
\hline & & 28,17 & 6,000 & & 56,8 & & 23,0 & 3,90 & & $=111$ & 56 & \begin{tabular}{|l|l}
$.44,96$ \\
\end{tabular} & & $-6,00$ & \begin{tabular}{|l|}
$-9,80$ \\
\end{tabular} & & 29,30 & & & & & & \begin{tabular}{|l|}
0,50 \\
\end{tabular} & & & \begin{tabular}{ll|l}
0,00 & 0 \\
\end{tabular} & & & \begin{tabular}{l|l}
0,00 \\
\end{tabular} & 0.8 & & & & \\
\hline & & 29,68 & \begin{tabular}{|l|l|}
3,10 \\
\end{tabular} & & 50,9 & & 19,6 & 70 & & 295 & 0,12 & 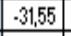 & & $-3,10$ & \begin{tabular}{|c|}
$-5,10$ \\
\end{tabular} & \begin{tabular}{|l|l|}
$.50,90$ \\
\end{tabular} & \begin{tabular}{|r|}
$-42,90$ \\
\end{tabular} & & & & & & \begin{tabular}{|l|}
0,67 \\
\end{tabular} & 0,54 & & \begin{tabular}{|l|l}
0,68 & 0 \\
\end{tabular} & & & $0,150,6$ & 0,6 & & & & \\
\hline & & 34,04 & 3,40 & & 27,3 & & 10 & 9,60 & & & 09 & \begin{tabular}{|l|}
45,74 \\
\end{tabular} & & 10 & \begin{tabular}{|l|l|}
$.5,20$ \\
\end{tabular} & & $.38,70$ & & $-s_{1}$ & & & & 0,49 & 0,47 & 0,73 & \begin{tabular}{|l|l|}
0,67 & 0 \\
\end{tabular} & & \begin{tabular}{l|l}
0,52 & 0, \\
\end{tabular} & \begin{tabular}{|l|l}
0,74 & 0, \\
\end{tabular} & \begin{tabular}{ll|l}
0,71 & 0, \\
\end{tabular} & 0,8610 & 0,98 & & \\
\hline & & 28,59 & 560 & & 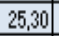 & & & 18,90 & & & & \begin{tabular}{|l|l|} 
\\
\end{tabular} & $\Rightarrow$ & & & & \begin{tabular}{|l|}
$.58,40$ \\
\end{tabular} & & & & & & 0,65 & 0,56 & 0,41 & \begin{tabular}{|l|l}
0,16 & 0 \\
\end{tabular} & & & \begin{tabular}{l|l}
0,83 & 0,4
\end{tabular} & 0,4 & $0,7 4 \longdiv { 0 }$ & & & \\
\hline & & 19,18 & 2,406 & & 29,9 & 23 & 11,8 & 2,00 & & & & \begin{tabular}{|l|l|}
22,92 \\
\end{tabular} & & 40 & & & & & & & & & \begin{tabular}{|l|}
0,78 \\
\end{tabular} & 0,72 & & & & {$[0,4$} & \begin{tabular}{l|l}
0,49 & 0,8
\end{tabular} & 0. & 8 & 1 & & 30 \\
\hline 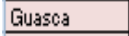 & \begin{tabular}{|l|l|}
30,41 \\
\end{tabular} & \begin{tabular}{l|l|l|l|}
18,78 \\
\end{tabular} & \begin{tabular}{|l|l|l|}
3,105 \\
\end{tabular} & & 23,60 & & 310 & 4,30 & 001 & & 24 & \begin{tabular}{|l|}
$-30,41$ \\
\end{tabular} & \begin{tabular}{|c|}
18,78 \\
\end{tabular} & $\begin{array}{r}-3,10 \\
\end{array}$ & \begin{tabular}{|r|}
5,00 \\
\end{tabular} & 60 & $-26,80$ & & & & & 24 & 0,68 & 0,73 & & & & & $\begin{array}{l}0,87 \\
0,8\end{array}$ & 0.8 & 0,980 & & & \\
\hline & 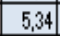 & 6,18 & \begin{tabular}{|l|l|}
1,70 \\
\end{tabular} & & 24,70 & & 2,10 & 00 & & & & \begin{tabular}{|l|l|}
$\cdot 5,34$ \\
\end{tabular} & & it & \begin{tabular}{|l|l|}
$.5,20$ \\
\end{tabular} & & $.47,90$ & & & & & & 1,00 & \begin{tabular}{|l|}
0,94 \\
\end{tabular} & \begin{tabular}{|l|}
0,97 \\
\end{tabular} & & & \begin{tabular}{l|l}
0,41 & 0,
\end{tabular} & \begin{tabular}{l|l}
0,91 & 0,5
\end{tabular} & \begin{tabular}{l|l}
0,52 & 0, \\
\end{tabular} & 0,990 & & & \\
\hline & & 19,23 & 2,60 & & 38,50 & & $\begin{array}{l}3,10 \\
\end{array}$ & 23,40 & & & 3 & 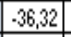 & .1923 & if & \begin{tabular}{|l|}
$-3,10$ \\
\end{tabular} & 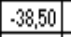 & \begin{tabular}{|l|l|}
63,70 \\
\end{tabular} & & 23,40 & & & 3 & 0,61 & 0,72 & 0,840 & \begin{tabular}{|l|l}
0,97 & 0 \\
\end{tabular} & & \begin{tabular}{l|l}
, 21 & 0, \\
\end{tabular} & \begin{tabular}{l|l}
0,87 & 0,2 \\
\end{tabular} & \begin{tabular}{l|l}
0,29 & 1,1 \\
\end{tabular} & 1,000 & to & & \\
\hline & & 2,05 & 2,20 & & 16,60 & 3 & 2,80 & 5,40 & & & & \begin{tabular}{|l|l|}
19,07 \\
\end{tabular} & & & .4 & & \begin{tabular}{|l|l|}
$-31,50$ \\
\end{tabular} & & & & & & 0,83 & 0,84 & 0,900 & \begin{tabular}{|l|l}
0,84 & 0 \\
\end{tabular} & \begin{tabular}{l|l}
0,71 & 0
\end{tabular} & \begin{tabular}{l|l|l}
0,61 & 0.8
\end{tabular} & 0,8 & 0,8 & 0,9560 & & & \\
\hline $9 \mathrm{dt}$ & & 25,50 & 3,60 & 证 & 32,10 & 41,40 & $\begin{array}{r}5,50 \\
\end{array}$ & 10,20 & 84,00 & & 16 & \begin{tabular}{|l|l} 
\\
\end{tabular} & 8,50 & $-3,60$ & $-5,80$ & 32,10 & 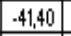 & & 20 & & & 16 & 0,45 & 0,61 & 0,700 & \begin{tabular}{|l|l|l|}
0,58 & 0 \\
\end{tabular} & \begin{tabular}{|l|l}
, 43 & 0, \\
\end{tabular} & \begin{tabular}{l|l}
0,49 & 0, \\
\end{tabular} & $\begin{array}{lll}0,76 & 0,6 \\
\end{array}$ & 0,69 & {$[0$} & & & \\
\hline & & 44,60 & 2,90 & & & & & & & & & $.27,78$ & $.44,60$ & & \begin{tabular}{|r|}
$-6,90$ \\
\end{tabular} & & \begin{tabular}{|l|l|}
0,00 \\
\end{tabular} & & & & & & 0,72 & 0,28 & 0,800 & \begin{tabular}{|l|l}
0,42 & 1 \\
\end{tabular} & & & \begin{tabular}{l|l}
1,00 & 1,0
\end{tabular} & 1,0 & $5] 0$ & & & \\
\hline & & 17,63 & 3,40 & & & & & & & & & 26,90 & .176 & & $-6,20$ & 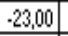 & \begin{tabular}{|r|}
$-40,40$ \\
\end{tabular} & & & & & & 0,73 & 0,75 & 0,730 & \begin{tabular}{|l|l}
0,52 & 0 \\
\end{tabular} & & \begin{tabular}{c|c}
0,50 \\
0
\end{tabular} & \begin{tabular}{l|l|l}
0,79 & 0,6 \\
\end{tabular} & \begin{tabular}{l|l}
0,68 & 0, \\
\end{tabular} & 0,980 & & & \\
\hline & & 20,54 & & & 41,6 & & & 11,6 & & & & $.84,30$ & - & & 7 & & & & & & & & 0,00 & 0 & 0,270 & \begin{tabular}{|l|l}
0,38 & 0 \\
\end{tabular} & & & \begin{tabular}{l|l}
0,49 & 0,6
\end{tabular} & \begin{tabular}{l|l}
0,65 & 0,
\end{tabular} & 0 & & & \\
\hline in Bernane & & 10,76 & 5,30 & & 36,40 & 69,60 & 10,80 & 26,60 & 8,00 & 988,00 & 2,36 & \begin{tabular}{|l|}
31,04 \\
\end{tabular} & \begin{tabular}{|c|}
$-10,76$ \\
\end{tabular} & \begin{tabular}{|l|l|}
5,30 \\
\end{tabular} & $-6,80$ & $-36,40$ & $-69,60$ & 10 & 8,60 & 0 & & 6 & \begin{tabular}{|c|}
0,67 \\
\end{tabular} & \begin{tabular}{|l|}
0,87 \\
\end{tabular} & $0,0,460$ & \begin{tabular}{|l|l}
0,43 & 0 \\
\end{tabular} & & \begin{tabular}{l|l}
0,14 & 0. \\
\end{tabular} & \begin{tabular}{l|l}
0,53 & 0,1 \\
\end{tabular} & \begin{tabular}{l|l}
0,19 & 0, \\
\end{tabular} & 0,996 & & & \\
\hline squile & & 27,61 & 2,10 & & 16,90 & 28,20 & 3,00 & 5,40 & & & 1,15 & \begin{tabular}{|l|l|}
29,32 \\
\end{tabular} & $.27,61$ & $.2,10$ & $\begin{array}{l}-4,40 \\
\end{array}$ & & $.28,20$ & & & & & & 0,70 & 0,58 & 0,910 & \begin{tabular}{l|l|l}
0,78 & 0 \\
\end{tabular} & & \begin{tabular}{c|c}
0,65 & 0,8
\end{tabular} & \begin{tabular}{l|l}
0,87 & 0,8 \\
\end{tabular} & \begin{tabular}{l|l}
0,84 & 0, \\
\end{tabular} & $0,98 \mid 0$ & & & \\
\hline & & 23,64 & 3,600 & & $2 v_{1}$ & & 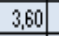 & 0,4 & & & 34 & -38,17 & $.23,6$ & & -6 & & & & & & & & 0,58 & & 0,700 & \begin{tabular}{l|l|}
0,55 & 0 \\
\end{tabular} & & & 0,7 & 0,7 & 0,93 & & & \\
\hline & & 1041 & 3,403 & & 20 & 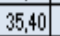 & 10,60 & 7,50 & & & & \begin{tabular}{|l|l|}
16,07 \\
\end{tabular} & 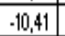 & & -3 & & $.35,40$ & & .7 & & & & 0,86 & 0,87 & 0,730 & \begin{tabular}{|l|l|}
0,88 & 0 \\
\end{tabular} & & & \begin{tabular}{l|l}
0,54 & 0,7
\end{tabular} & \begin{tabular}{l|l}
0,77 & 0, \\
\end{tabular} & & & & \\
\hline & & 23,17 & $1,50 \mid$ & & 14,90 & 23 & 47 & 3,10 & - & & 45 & \begin{tabular}{|l|l|}
20,80 \\
\end{tabular} & & & $-2,90$ & & \begin{tabular}{|l|}
$.23,50$ \\
\end{tabular} & & .3 & & & & 0,80 & 0,65 & \begin{tabular}{l|l|}
1,00 & 1 \\
\end{tabular} & 1,000 & & & \begin{tabular}{l|l}
0,93 & 0.9 \\
\end{tabular} & \begin{tabular}{l|l}
0,91 & 0, \\
\end{tabular} & \begin{tabular}{l|l}
0,96 & 0 \\
\end{tabular} & I & & 87 \\
\hline bac & \begin{tabular}{|l|}
22,76 \\
\end{tabular} & 12,36 & 3,204 & 4,30 & 21,70 & 26,20 & 3,10 & 4,10 & 14864,00 & 7,13 & 1,41 & \begin{tabular}{|l|}
$-22,76$ \\
\end{tabular} & $-12,36$ & \begin{tabular}{|l|}
$-3,20$ \\
\end{tabular} & $-4,30$ & 21,70 & \begin{tabular}{|r|}
26,20 \\
\end{tabular} & .3 & -4, & & & 41 & 0,78 & 0,84 & 0,760 & \begin{tabular}{|l|l}
0,80 & 0 \\
\end{tabular} & \begin{tabular}{l|l}
0,62 & 0,8 \\
\end{tabular} & $\begin{array}{l}0,68 \\
0,8\end{array}$ & $\begin{array}{l}0,87 \\
0,8,8\end{array}$ & \begin{tabular}{l|l}
0,88 & 0,
\end{tabular} & $\begin{array}{l}0,98 \\
\end{array}$ & 80 & 0 & 82 \\
\hline & \begin{tabular}{|l|l|}
79,74 \\
\end{tabular} & 22,83 & 4,30 & 7,10 & 31,80 & 38,60 & 6,30 & 10,20 & & & 1,08 & \begin{tabular}{|l|}
$.79,74$ \\
\end{tabular} & $.22,83$ & & \begin{tabular}{ll|}
$.7,10$ \\
\end{tabular} & 31,80 & \begin{tabular}{|l|l|}
$.38,600$ \\
\end{tabular} & $-6_{1}$ & $\cdot-10,20$ & & & 8 & 0,06 & 0,66 & 0,600 & \begin{tabular}{l|l|l}
0,39 & 0 \\
\end{tabular} & \begin{tabular}{l|l}
0,44 & 0, \\
\end{tabular} & \begin{tabular}{l|l}
0,52 & 0,7 \\
\end{tabular} & $0,730,6$ & \begin{tabular}{l|l}
0,69 & 0, \\
\end{tabular} & 0,970 & & & \\
\hline & & 14,97 & 1,90 & 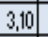 & t & & & 250 & & & & \begin{tabular}{|l|}
$-18,04$ \\
\end{tabular} & & & 310 & & & & & & & & 0,84 & & & & & & & $\overline{0.8}$ & & & & \\
\hline & & 10,93 & 4,600 & & $3 i$ & & f & & & & & & & & $.6,40$ & & & & & & & & 0,77 & & & & & & \begin{tabular}{l|l}
0,67 & 0,7 \\
\end{tabular} & \begin{tabular}{l|l}
0,70 & 0,
\end{tabular} & & & & \\
\hline & & 61,14 & 2,304 & 4,50 & 25,50 & 33,70 & 0,90 & 4,00 & 000 & & 58 & \begin{tabular}{|l|}
64,16 \\
\end{tabular} & -61,14 & $-2,30$ & $-4,50$ & $.25,50$ & \begin{tabular}{|r|}
33,70 \\
\end{tabular} & 0 & 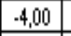 & & & 8 & 0,26 & 0,00 & 0,890 & \begin{tabular}{|l|l}
0,77 & 0 \\
\end{tabular} & \begin{tabular}{l|l}
0,55 & 0,5 \\
\end{tabular} & $\begin{array}{l}0,58 \\
0,9\end{array}$ & $0,96 \quad 0,8$ & \begin{tabular}{l|l}
0,88 & 0,
\end{tabular} & $\begin{array}{l}0,97 \\
\end{array}$ & 50 & 0,97 & 71 \\
\hline & \begin{tabular}{|l|}
25,31 \\
\end{tabular} & 19,86 & 2,20 & 4 & 19,60 & 25,10 & 2,50 & 3,00 & 28732,00 & & 25 & \begin{tabular}{|l|l|}
$.25,31$ \\
\end{tabular} & $\begin{array}{l}19,86 \\
\end{array}$ & 20 & $\begin{array}{ll}-4,20 \\
\end{array}$ & 50 & \begin{tabular}{|l|}
$.25,10$ \\
\end{tabular} & -2.5 & $-3,00$ & & & 25 & 0,75 & 0,71 & 0,900 & 0,810 & \begin{tabular}{c|c}
0,65 & 0, \\
\end{tabular} & $\begin{array}{l}0,69 \\
0,8\end{array}$ & $0,890,0$ & \begin{tabular}{l|l}
0,91 & 0, \\
\end{tabular} & \begin{tabular}{l|l}
0,95 & 0 \\
\end{tabular} & 80 & 0 & 34 \\
\hline & & 21,30 & 4,00 & 8.5 & 32,5 & & $, 1,00$ & 11,80 & & & & 45,15 & 20,0 & & 8,50 & i0 & 8 & & - $-11,8 \mathrm{U}$ & & & & 0,50 & 0,68 & 0,640 & \begin{tabular}{|l|l}
0,19 & 0 \\
\end{tabular} & \begin{tabular}{l|l}
0,43 & 0,5 \\
\end{tabular} & $\begin{array}{lll}0,50 & 0,7 \\
\end{array}$ & 0,6 & \begin{tabular}{l|l}
0,64 & 0, \\
\end{tabular} & $\begin{array}{l}0,99 \\
\end{array}$ & & & 66 \\
\hline & & 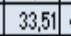 & 4,20 & & 30 t & & + & & & & & \begin{tabular}{|c|}
$.70,26$ \\
\end{tabular} & - & & & + & & & & & & & 0,18 & \begin{tabular}{|l|l|}
0,47 \\
\end{tabular} & 0,610 & & & & & 0, & & & & \\
\hline & 22,10 & 5,86 & 2,105 & 5,00 & 27,10 & 44, & 4,90 & 10,90 & & 150 & 1,22 & \begin{tabular}{|l|l|}
22,10 \\
\end{tabular} & $-0_{1}$ & 10 & $.5,00$ & 271 & \begin{tabular}{|l|l|}
44,30 \\
\end{tabular} & -4 & -10 & & & 2 & 0,79 & 0,95 & 0,910 & \begin{tabular}{|l|l|}
0,70 & 0 \\
\end{tabular} & \begin{tabular}{l|l}
0,52 & 0,4 \\
\end{tabular} & \begin{tabular}{l|l}
0,45 & 0,7 \\
\end{tabular} & 0,6 & \begin{tabular}{l|l|l}
0,67 & 0, \\
\end{tabular} & $\begin{array}{l}0.97 \\
0.9\end{array}$ & & 0,8 & 78 \\
\hline paquira & 06,13 & 50,85 & 3,00 & 4,10 & 20,20 & 21,10 & 3,50 & 2,10 & 114161,00 & 19491,72 & $\begin{array}{l}0,17 \\
\end{array}$ & \begin{tabular}{|l|l|}
$.56,79$ \\
\end{tabular} & $.50,85$ & $.3,00$ & $-4,10$ - & $.20,20$ & \begin{tabular}{|l|l|}
$\cdot 21,10$ \\
\end{tabular} & $\cdot 3,50$ & $\cdot 2,10$ & $.114161,00$ & $.19491,72$ & $\begin{array}{l}.0,17 \\
\end{array}$ & 0,35 & 0,18 & 0,790 & \begin{tabular}{l|l}
0,83 & 0 \\
\end{tabular} & \begin{tabular}{l|l}
0,64 & 0,7 \\
\end{tabular} & \begin{tabular}{l|l|l}
0,74 & 0,8
\end{tabular} & $0,850,9$ & & & 0,890 & 0,99 & 0,72 \\
\hline
\end{tabular}

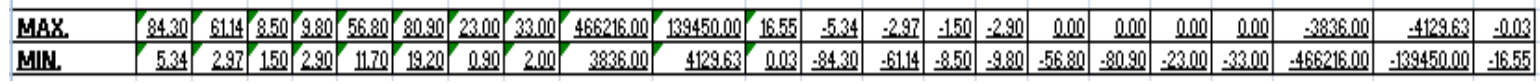

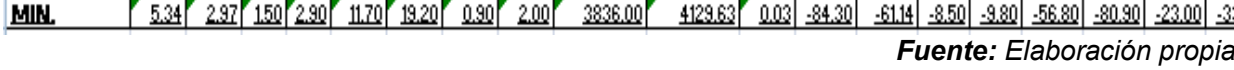


Anexo 10. RESULTADOS DIMENSIÓN ECONÓMICA - INDICE DE DESARROLLO SOSTENIBLE.

\begin{tabular}{|c|c|c|c|c|c|c|c|c|c|c|c|c|c|c|c|c|c|c|c|}
\hline \multirow{3}{*}{ MUNICIPIO } & \multicolumn{6}{|c|}{ 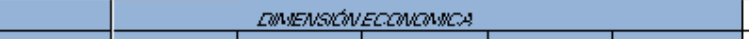 } & \multicolumn{6}{|c|}{ CMNENACCW } & \multicolumn{6}{|c|}{ CONENACONECONOWNC, } & \multirow[b]{2}{*}{ ZNOACE } \\
\hline & E1 & E2 & E3 & E4 & E5 & E6 & A1 & A2 & A3 & A4 & A5 & A6 & E1 & E2 & E3 & E4 & E5 & E6 & \\
\hline & 1 & 1 & 1 & 1 & 1 & 1 & 1 & 1 & 1 & 1 & 1 & 1 & & & & & & & \\
\hline belaez & 816142,00 & 4186563,00 & 895876,00 & 4361124,00 & 872372,00 & 4837962,00 & 816142,00 & 4186563,00 & 895876,00 & 4361124,00 & 872372,00 & 4837962,00 & 0,02 & 0,02 & 0,02 & 0,02 & \begin{tabular}{|l|}
0,02 \\
\end{tabular} & 0,01 & 0.02 \\
\hline Bojaca & 1576569,00 & 2714310,00 & 1703714,00 & 3565487,00 & 1799896,00 & 4169256,00 & 1576569,00 & 2714310,00 & 1703714,00 & \begin{tabular}{|l|}
3565487,00 \\
\end{tabular} & 1799896,00 & 4169256,00 & 0,04 & 0,01 & 0,05 & 0,01 & 0,04 & 0,01 & 0.03 \\
\hline Cabrera & 172200,00 & 2847342,00 & 245221,00 & 2633854,00 & 245148,00 & 3419786,00 & 172200,00 & 2847342,00 & 245221,00 & 2633854,00 & 245148,00 & 3419786,00 & 0,00 & 0.01 & 0,00 & 0,00 & 0,00 & 0,00 & $\mathbf{0 . 0 0}$ \\
\hline Cajica & 15377110,00 & 6458532,00 & 16878838,00 & 7891198,00 & 19199160,00 & 9280165,00 & 15377110,00 & 6458532,00 & 16878838,00 & 7891198,00 & 19199160,00 & 9280165,00 & 0,44 & 0,05 & 0.51 & 0,05 & 0,50 & 0,05 & 0.27 \\
\hline Chipaque & 901862,00 & 3537513,00 & 1065352,00 & 3423228,00 & 1232521,00 & 4231215,00 & 901862,00 & 3537513,00 & 1065352,00 & 3423228,00 & 1232521,00 & 4231215,00 & 0,02 & 0,01 & 0,03 & 0,01 & 0,03 & 0,01 & 0.02 \\
\hline Choachi & 1019018,00 & 3648390,00 & 1019917,00 & 3691587,00 & 1178676,00 & 4964765,00 & 1019018,00 & 3648390,00 & 1019917,00 & 3691587,00 & 1178676,00 & 4964765,00 & 0,02 & 0,02 & 0,03 & 0,01 & 0,03 & 0,01 & 0.02 \\
\hline Choconta & 1980520,00 & 8162343,00 & 1999005,00 & 9171633,00 & 2376406,00 & 8381924,00 & 1980520,00 & 8162343,00 & 1999005,00 & 9171633,00 & 2376406,00 & 8381924,00 & 0,05 & 0,07 & 0.06 & 0,06 & 0,06 & 0,04 & 0.06 \\
\hline Chia & 34460726,00 & 12682684,00 & 32918975,00 & 14134624,00 & 38296123,00 & 15125405,00 & 34460726,00 & 12682684,00 & 32918975,00 & 14134624,00 & 38296123,00 & 15125405,00 & 1,00 & 0,12 & 1.00 & 0,11 & 1,00 & 0,09 & 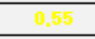 \\
\hline Cogua & 6010983,00 & 4172732,00 & 7098619,00 & 4433035,00 & 6808503,00 & 5121430,00 & 6010983,00 & 4172732,00 & 7098619,00 & 4433035,00 & 6808503,00 & 5121430,00 & 0,17 & 0,02 & 0.21 & 0,02 & \begin{tabular}{|l|}
0.17 \\
\end{tabular} & 0,01 & 0.10 \\
\hline Cota & 17673320,00 & 5164586,00 & 19586438,00 & 6252446,00 & 23758651,00 & 4959563,00 & 17673320,00 & 5164586,00 & 19586438,00 & 6252446,00 & 23758651,00 & 4959563,00 & 0.51 & 0,03 & 0.59 & 0,03 & \begin{tabular}{|l|}
0.62 \\
\end{tabular} & 0,01 & 0,30 \\
\hline El Rosal & 1566014,00 & 4018230,00 & 1726671,00 & 5144496,00 & 2943535,00 & 5375826,00 & 1566014,00 & 4018230,00 & 1726671,00 & 5144496,00 & 2943535,00 & 5375826,00 & 0,04 & 0,02 & 0.05 & 0,02 & \begin{tabular}{|l|}
0,07 \\
\end{tabular} & 0,02 & 0.04 \\
\hline Facatativa & 13724000,00 & 14644025,00 & 17127000,00 & 19669314,00 & 21990290,00 & 20552096,00 & 13724000,00 & 14644025,00 & 17127000,00 & 19669314,00 & 21990290,00 & 20552096,00 & 0,40 & 0.14 & 0.52 & 0.16 & 0.57 & 0,13 & 0,32 \\
\hline Enza & 52333,00 & 9213315,00 & 11956044,00 & 12684895,00 & 19329378,00 & 9631178,00 & 12052333,00 & 9213315,00 & 11956044,00 & 12684895,00 & 19329378,00 & 9631178,00 & 0,35 & 0,08 & 0,36 & 0,10 & \begin{tabular}{|l|}
0.50 \\
\end{tabular} & 0.05 & 0,24 \\
\hline Fusagasuga & 11501533,00 & 38012261,00 & 12287792,00 & 42007734,00 & 15310720,00 & 51436052,00 & 11501533,00 & 38012261,00 & 12287792,00 & 42007734,00 & 15310720,00 & 51436052,00 & 0,33 & 0,41 & 0,37 & 0,38 & 0,40 & 0,37 & 0.38 \\
\hline Gachancipa & 1514056,00 & 2251793,00 & 1604853,00 & $\begin{array}{r}3570566,00 \\
\end{array}$ & 4719519,00 & 6050969,00 & 1514056,00 & 2251793,00 & 1604853,00 & 3570566,00 & 4719519,00 & 6050969,00 & 0,04 & 0,00 & 0,04 & 0.01 & \begin{tabular}{|l|}
0,12 \\
\end{tabular} & 0,02 & 0.04 \\
\hline Guasca & 2506312,00 & 3543132,00 & 2238558,00 & 3837719,00 & 2671092,00 & 4336278,00 & 2506312,00 & 3543132,00 & 2238558,00 & 3837719,00 & 2671092,00 & 4336278,00 & 0,07 & 0,01 & 0,06 & 0,01 & \begin{tabular}{|l|} 
\\
\end{tabular} & 0,01 & 0.04 \\
\hline Guatatativa & 870489,00 & 4735119,00 & 798843,00 & 4209725,00 & 954915,00 & 4236075,00 & 870489,00 & 4735119,00 & 798843,00 & 4209725,00 & 954915,00 & 4236075,00 & 0,02 & 0,03 & 0,02 & 0,02 & \begin{tabular}{|l|}
0,02 \\
\end{tabular} & 0,01 & 0.02 \\
\hline Gutierrez & 333114,00 & 3655954,00 & 99513,00 & 2826877,00 & 160344,00 & 3208794,00 & 333114,00 & 3655954,00 & 189513,00 & \begin{tabular}{|l|}
2826877,00 \\
\end{tabular} & 160344,00 & 3208794,00 & 0,00 & 0,02 & 0,00 & 0,000 & 0,00 & 0,00 & 0.00 \\
\hline Calera & 5467062,00 & 4261821,00 & 5679949,00 & 47528570,00 & 5816041,00 & 4924033,00 & 5467062,00 & 4261821,00 & $\begin{array}{l}5679949,00 \\
\end{array}$ & 47528570,00 & 5816041,00 & 4924033,00 & 0.15 & 0,02 & 0,17 & 0,43 & 0.15 & 0,01 & 0.16 \\
\hline Madrid & 15799,00 & 16095911,00 & 11684460,00 & 11844752,00 & 16732634,00 & 10703928,00 & 10915799,00 & 16095911,00 & 11684460,00 & 11844752,00 & 16732634,00 & 10703928,00 & 0.31 & 0,16 & 0,35 & 0,09 & 0,43 & 0,06 & 0,23 \\
\hline Mosquera & 19248813,00 & 8673153,00 & 20649626,00 & 12021037,00 & 30930569,00 & 11934160,00 & 19248813,00 & 8673153,00 & 20649626,00 & 12021037,00 & 30930569,00 & 1934160,00 & 0.56 & 0.07 & 0,63 & 0.09 & 0,81 & 0.07 & 0,37 \\
\hline Nemocon & 3372935,00 & 3406297,00 & 1382239,00 & 3823669,00 & 1422133,00 & 7649606,00 & 3372935,00 & 3406297,00 & 1382239,00 & 3823669,00 & 1422133,00 & 7649606,00 & 0,09 & 0.01 & 0,04 & 0,01 & 0,03 & 0,03 & 0.04 \\
\hline Pasca & 739883,00 & 3907501,00 & 667926,00 & 3432216,00 & 693575,00 & 3665005,00 & 739883,00 & 3907501,00 & 667926,00 & 3432216,00 & 693575,00 & 3665005,00 & 0,02 & 0,02 & 0,01 & 0,01 & 0,01 & 0,00 & 0.01 \\
\hline San Bernar & 246,00 & 5153417,00 & 416134,00 & 4457808,00 & 482028,00 & 4909743,00 & 506246,00 & 5153417,00 & 416134,00 & 4457808,00 & 482028,00 & 4909743,00 & 0,01 & \begin{tabular}{|l|}
0,03 \\
\end{tabular} & 0,01 & 0,02 & 0,01 & 0,01 & 0.01 \\
\hline Sesquile & 1384539,00 & 2951655,00 & 1391152,00 & 3854294,00 & 1942550,00 & 4060818,00 & 1384539,00 & 2951655,00 & 1391152,00 & 3854294,00 & 1942550,00 & 4060818,00 & 0,04 & 0.01 & 0,04 & 0,01 & \begin{tabular}{|l|}
0,05 \\
\end{tabular} & 0,01 & 0.02 \\
\hline Sibate & 10036449,00 & 6081815,00 & 10757596,00 & 6298822,00 & 11073632,00 & 7672559,00 & 10036449,00 & 6081815,00 & 10757596,00 & 6298822,00 & 11073632,00 & 7672559,00 & 0,29 & 0,04 & 0,32 & $0,0.03$ & 0,29 & 0,03 & 0.17 \\
\hline , & 33121639,00 & 90299388,00 & 31887278,00 & 107571290,00 & 34339648,00 & 132437582,00 & 33121639,00 & 90299388,00 & 31887278,00 & $\begin{array}{l}107571290,00 \\
\end{array}$ & 34339648,00 & 132437582,00 & 0,96 & 1,00 & 0,97 & 1,00 & 0,90 & 1,00 & 0.97 \\
\hline Sopo & 9560808,00 & 4019962,00 & 10616868,00 & 4091103,00 & 12073472,00 & 4787663,00 & 9560808,00 & 4019962,00 & 10616868,00 & 4091103,00 & 12073472,00 & $\begin{array}{r}4787663,00 \\
\end{array}$ & 0,27 & 0,02 & 0,32 & 0.01 & 0,31 & 0,01 & 0.16 \\
\hline Subachoque & 2688616,00 & 4101423,00 & 3792200,00 & 4237737,00 & 3333763,00 & 4731068,00 & 2688616,00 & 4101423,00 & 3792200,00 & 4237737,00 & 3333763,00 & 4731068,00 & 0,07 & 0,02 & 0,11 & 0.02 & 0,08 & 0,01 & 0.05 \\
\hline Suesca & 969623,00 & 2945886,00 & 1287671,00 & 5338824,00 & 1204254,00 & 5581562,00 & 969623,00 & 2945886,00 & 1287671,00 & 5338824,00 & 1204254,00 & 5581562,00 & 0,02 & 0,01 & 0,03 & \begin{tabular}{|l|}
0.03 \\
\end{tabular} & \begin{tabular}{|l|}
0.03 \\
\end{tabular} & 0,02 & 0.02 \\
\hline Tabio & 2881494,00 & 4011125,00 & 2575088,00 & 5062905,00 & 2894707,00 & 5173003,00 & 2881494,00 & 4011125,00 & 2575088,00 & 5062905,00 & 2894707,00 & 5173003,00 & 0,08 & 0,02 & 0,07 & 0,02 & 0.07 & tom & 0.05 \\
\hline Tausa & 598346,00 & 3370076,00 & 590287,00 & 3287815,00 & 800825,00 & 4092007,00 & 598346,00 & 3370076,00 & 590287,00 & 3287815,00 & 800825,00 & 4092007,00 & 0,01 & 0,01 & 0,01 & 0,01 & \begin{tabular}{|l|}
0.02 \\
\end{tabular} & 0,01 & 0.01 \\
\hline Tenio & 6683574,00 & 5815997,00 & 7340897,00 & 4068816,00 & 9955705,00 & 5230580,00 & 6683574,00 & 5815997,00 & 7340897,00 & 4068816,00 & 9955705,00 & 5230580,00 & 0,19 & 0,04 & 0,22 & 0,01 & \begin{tabular}{|l|l|}
0.26 \\
\end{tabular} & 0,02 & 0.12 \\
\hline Tocancip & 19496755,00 & 7209114,00 & 21096075,00 & 6632242,00 & 20385186,00 & 7019925,00 & 19496755,00 & 7209114,00 & 21096075,00 & 6632242,00 & 20385186,00 & 7019925,00 & 0.56 & 0,06 & 0,64 & 0.04 & 0,53 & 0,03 & 0.31 \\
\hline Ubaque & 328796,00 & 2630733,00 & 380472,00 & 3112758,00 & 418544,00 & 3531733,00 & 328796,00 & 2630733,00 & 380472,00 & 3112758,00 & 418544,00 & 3531733,00 & 0,00 & 0,00 & 0,01 & 0,00 & 0,01 & tat & 0.00 \\
\hline Une & 748227,00 & 7427310,00 & 505124,00 & 3849845,00 & 554970,00 & 4127974,00 & 748227,00 & 7427310,00 & 505124,00 & 3849845,00 & 554970,00 & 4127974,00 & 0,02 & 0,06 & 0,01 & 0,01 & 0,01 & 0,01 & 0.02 \\
\hline Yillapinzon & 1444052,00 & 8470557,00 & 1633952,00 & 7141657,00 & 1800624,00 & 7131203,00 & 1444052,00 & 8470557,00 & 1633952,00 & 7141657,00 & 1800624,00 & 7131203,00 & 0,04 & 0.07 & 0,04 & 0,04 & 0,04 & 0,03 & 0.04 \\
\hline Zipaquira & 773827.00 & 23242186,00 & 13325427,00 & 2027295,00 & 8916027,00 & 2371791,00 & 0973827,00 & 23242186,00 & 13325427,00 & 22027295,00 & 916027,00 & 2371791,00 & 0,32 & 0,24 & 0,40 & 0,18 & \begin{tabular}{|l|}
0.44 \\
\end{tabular} & 0.23 & 0.30 \\
\hline & & & & & & 2010II & 34460726,00 & 90299388.00 & 3291897500 & 290000 & 300 & 13243758200 & & & & & & & \\
\hline & & & & & & & & & 等 & & & & & & & & & & \\
\hline
\end{tabular}

Fuente: Elaboración propia 


\section{Anexo 11. RESULTADOS DIMENSIÓN AMBIENTAL - INDICE DE DESARROLLO SOSTENIBLE.}

\begin{tabular}{|c|c|c|c|c|c|c|c|c|c|c|c|c|c|c|c|c|c|c|c|c|c|c|c|c|c|c|c|c|c|c|c|c|c|c|c|}
\hline \multirow{3}{*}{ MUNICIPIO } & \multicolumn{11}{|c|}{ DIMENSIOH AMBIENT AL } & \multicolumn{11}{|c|}{ DIMEMSION AMBIERT AL } & \multicolumn{6}{|c|}{ DIMENSIÓN } & \multirow{3}{*}{ ÍHDICE } & \multirow{3}{*}{ B1 } & \multirow{3}{*}{ ÍNDICE } & \multirow{3}{*}{ B2 } & \multirow{3}{*}{ ÍHDICE } & \multirow{3}{*}{ B3 } & \multirow{3}{*}{$\begin{array}{c}\text { ÍMDICE } \\
\text { DESARROLL } \\
\text { SOSTEMIBLE }\end{array}$} \\
\hline & A1 & $A 2$ & A3 & A4 & As & A6 & Ar & $A 8$ & A9 & A10 & A11 & s1 & s2 & \begin{tabular}{|l|}
53 \\
\end{tabular} & s4 & s5 & \begin{tabular}{|l|}
56 \\
\end{tabular} & \begin{tabular}{|l|} 
s7 \\
\end{tabular} & \begin{tabular}{|l|} 
s8 \\
\end{tabular} & \begin{tabular}{|l|} 
ss \\
\end{tabular} & \begin{tabular}{|l|} 
s10 \\
\end{tabular} & s11 & E1 & E2 & E3 & E4 & \begin{tabular}{|l|l} 
ES & 1 \\
\end{tabular} & E6 i & & & & & & & \\
\hline & 1 & 1 & 1 & 1 & 1 & 1 & 1 & 0 & 0 & 1 & 1 & 0 & 0 & $\mathbf{0}$ & 0 & 0 & $\mathbf{0}$ & o & 0 & 0 & - & - & 1 & 1 & - & 1 & 1 & 1 & & & & & & & \\
\hline eloes & 0,08 & 0,06 & 0,10 & 0,17 & 0,00 & 0,07 & 0.01 & 0,34 & 1,00 & 0,00 & 0,04 & 0,65 & 0,73 & 0,59 & 0,36 & 0,55 & 0,51 & 0,78 & 0,73 & \begin{tabular}{|l|}
0.98 \\
\end{tabular} & 0,92 & 0,93 & 0,02 & 0,02 & 0,02 & 0,020 & \begin{tabular}{l|l}
0,02 & 0 \\
\end{tabular} & 0,01 & 0,17 & $0,60 \mid$ & 0,70 & 0,20 & 0,02 & 0,20 & 0.25 \\
\hline jijcs & 0,00 & 0,17 & 0,00 & 0,12 & 0,02 & 0,14 & 0,04 & 0,74 & 1,00 & 0,07 & 0,02 & 0,23 & 0,68 & 0.63 & 0,59 & \begin{tabular}{|c|}
0,57 \\
\end{tabular} & 0,57 & 0,84 & 0,75 & 0,99 & 0.96 & 0,94 & 0,04 & 0,01 & 0,05 & 0,010 & 0.040 & 0,01 & 0,21 & 0,60 & 0,70 & 0,20 & 0,03 & 0,20 & 0.27 \\
\hline cobrers & 1,00 & 0.41 & 0,00 & 0,00 & 0,00 & 1,00 & 0,00 & 0.56 & 1,00 & 0,02 & 0,00 & 0,56 & 0,70 & 0,000 & 0,01 & \begin{tabular}{|l|l|}
0,12 \\
\end{tabular} & 0,000 & \begin{tabular}{|l|}
0,22 \\
\end{tabular} & 0,00 & 1,00 & \begin{tabular}{|l|l|}
0,70 \\
\end{tabular} & \begin{tabular}{|l|}
0,41 \\
\end{tabular} & 0,00 & 0,01 & 0,00 & 0,000 & 0,000 & 0,00 & 0,36 & \begin{tabular}{|l|}
0,60 \\
\end{tabular} & 0,34 & \begin{tabular}{|l|l|}
0,20 \\
\end{tabular} & 0,00 & \begin{tabular}{|l|l|}
0,20 \\
\end{tabular} & 0.29 \\
\hline Cojico & 0,00 & 0,08 & 0,05 & 0,01 & 0,00 & 0,02 & 0,00 & $\begin{array}{l}0,75 \\
\end{array}$ & 1,00 & 0,00 & \begin{tabular}{|l|l|}
0,12 \\
\end{tabular} & \begin{tabular}{|l|}
0.74 \\
\end{tabular} & \begin{tabular}{|l|}
0,54 \\
\end{tabular} & \begin{tabular}{|l|}
0.87 \\
\end{tabular} & 0,96 & 0,62 & 0,71 & 0,90 & 0.94 & 0,90 & \begin{tabular}{|l|l|}
0,99 \\
\end{tabular} & \begin{tabular}{|l|l|} 
\\
\end{tabular} & \begin{tabular}{|l|}
0,44 \\
\end{tabular} & 0,05 & \begin{tabular}{|l|l|}
0,51 \\
\end{tabular} & \begin{tabular}{|l|l}
0.05 \\
\end{tabular} & \begin{tabular}{|l|l|l|l|l}
0,50 & \\
\end{tabular} & 0,05 & 0.18 & \begin{tabular}{|l|}
0,60 \\
\end{tabular} & 0,83 & \begin{tabular}{|l|}
0,20 \\
\end{tabular} & 0.27 & 0,20 & 0.33 \\
\hline Ehipaque & 0,00 & 0,06 & 0,00 & 0.42 & 0,00 & 0,05 & \begin{tabular}{|l|} 
\\
\end{tabular} & $\begin{array}{l}0.67 \\
\end{array}$ & 1,00 & 0,01 & 0,01 & 0,85 & 0.83 & \begin{tabular}{|l|l|} 
\\
\end{tabular} & 0,04 & 0,56 & 0,40 & \begin{tabular}{|l|}
0.82 \\
\end{tabular} & 0,50 & \begin{tabular}{|l|l|}
0.99 \\
\end{tabular} & 0,00 & 0,000 & 0,02 & 0,01 & 0,03 & 0.010 & \begin{tabular}{|l|l|l}
0.03 & \\
\end{tabular} & 0,01 & 0.21 & \begin{tabular}{|l|} 
\\
\end{tabular} & 0,58 & \begin{tabular}{|l|}
0,20 \\
\end{tabular} & 0.02 & $0,0,20$ & 0.25 \\
\hline chooschi & 00 & 0.03 & 0.41 & 0.00 & 0.00 & 0,00 & 0.72 & 0,99 & 1,00 & $\begin{array}{l}0,18 \\
\end{array}$ & \begin{tabular}{|l|}
0,05 \\
\end{tabular} & 0,73 & 0.86 & 0,83 & 0,86 & 0,65 & 0,43 & 0,89 & 0,57 & \begin{tabular}{|l|}
0,98 \\
\end{tabular} & \begin{tabular}{|l|l|}
0,87 \\
\end{tabular} & 0,88 & 0,02 & 0,02 & 0,03 & 0,010 & \begin{tabular}{|l|l}
0,03 & 0 \\
\end{tabular} & 0,01 & 0,31 & $0,0,60$ & 0.78 & \begin{tabular}{|l|}
0,20 \\
\end{tabular} & 0.02 & 0,20 & 0.34 \\
\hline oces & 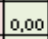 & 12 & 0.55 & & 0,77 & & & & 1,00 & 0,87 & 0,06 & \begin{tabular}{|l|}
0.82 \\
\end{tabular} & 1,00 & \begin{tabular}{|l|l|}
0,77 \\
\end{tabular} & \begin{tabular}{|l|l|} 
\\
\end{tabular} & 0,36 & 0,31 & 0,55 & 0,36 & 0,96 & \begin{tabular}{|l|l|}
0,81 \\
\end{tabular} & \begin{tabular}{|l|}
0,92 \\
\end{tabular} & 0,05 & 0,07 & 0,06 & \begin{tabular}{|l|l}
0,06 & 0
\end{tabular} & \begin{tabular}{|l|l}
0,06 & 0 \\
\end{tabular} & 0,04 & 0,41 & \begin{tabular}{|l|} 
\\
\end{tabular} & 0,67 & 0,20 & 0,06 & \begin{tabular}{|l|l|}
0,20 \\
\end{tabular} & 0.39 \\
\hline & 0,01 & 0,18 & $0,01 \mid$ & & 0,00 & 0,00 & 0,05 & & 0,99 & 0,00 & 0,29 & $0,66 \mid$ & 0,53 & $0,93 \mid$ & 0,93 & 0,75 & $0,71 \mid$ & $|0,94|$ & $0,94 \mid$ & 0,76 & \begin{tabular}{|l|l|} 
\\
\end{tabular} & \begin{tabular}{|l|l} 
\\
\end{tabular} & 1,00 & 0,12 & \begin{tabular}{|l|l|} 
\\
\end{tabular} & \begin{tabular}{|l|l}
0,11 & 1 \\
\end{tabular} & \begin{tabular}{|l|l}
1,00 & 0 \\
\end{tabular} & 0,09 & 0,25 & $|0,60|$ & 0,83 & 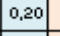 & 0.55 & 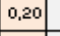 & 0.48 \\
\hline gus & 0,00 & 0,06 & 0,10 & 0,07 & 0,00 & 0,15 & 0,19 & 0.77 & 1,00 & 0,04 & 0,09 & 0,68 & \begin{tabular}{|l|}
0,62 \\
\end{tabular} & 0,73 & 0,59 & \begin{tabular}{|l|}
0,66 \\
\end{tabular} & 0.71 & $0,93 \mid$ & 0,34 & 0.96 & \begin{tabular}{|l|l|} 
\\
\end{tabular} & 0.96 & $0,17 \mid$ & 0,02 & 0,210 & \begin{tabular}{|l|l}
0,02 \\
\end{tabular} & \begin{tabular}{|l|l}
0,17 & 0 \\
\end{tabular} & 0,01 & 0,22 & $0,60 \mid$ & 0.79 & \begin{tabular}{|l|l|} 
\\
\end{tabular} & 0.10 & $0,20 \mid$ & 0.31 \\
\hline Cots & 0,00 & 0,14 & 0,08 & 0,00 & 0,00 & 0,00 & 0,09 & 1,00 & 0,97 & 0,00 & 0,06 & 0,59 & 0,58 & $0.49 \mid$ & 0,35 & $|0.43|$ & 0,60 & 0,68 & 0,79 & 0,96 & \begin{tabular}{|l|l|} 
\\
\end{tabular} & 0,99 & 0,51 & 0,03 & 0,59 & \begin{tabular}{|c|c|c|} 
\\
\end{tabular} & \begin{tabular}{ll|l}
0,62 & 0 \\
\end{tabular} & 0,01 & 0,21 & 0,60 & 0,68 & \begin{tabular}{|l|l|} 
\\
\end{tabular} & 0,30 & $0,20 \mid$ & 0,32 \\
\hline Rosal & 0,00 & 0,00 & 0.00 & 0,00 & 0,00 & 0,00 & 0.02 & 0,99 & 1,00 & 0,00 & 0,00 & \begin{tabular}{|l|}
0,50 \\
\end{tabular} & \begin{tabular}{|l|}
0,57 \\
\end{tabular} & $0,0,36$ & 0,00 & 0,00 & 0,64 & 0,00 & 0,86 & 0,97 & \begin{tabular}{|l|}
0.96 \\
\end{tabular} & \begin{tabular}{|l|}
0.97 \\
\end{tabular} & 0,04 & 0,02 & 0,05 & \begin{tabular}{|l|}
0,02 \\
\end{tabular} & \begin{tabular}{|l|l|l}
0,07 & \\
\end{tabular} & 0,02 & 0,18 & $0,0,60$ & 0,53 & 0,20 & .04 & 0,20 & 0,22 \\
\hline cotestiv & 0,00 & 0.16 & 0,00 & 0.27 & 0,00 & 0,00 & 0.12 & 0,39 & 1,00 & 0,04 & 0.28 & \begin{tabular}{|l|l|} 
\\
\end{tabular} & 0,54 & \begin{tabular}{|l|l|}
0,77 \\
\end{tabular} & \begin{tabular}{|l|}
0,68 \\
\end{tabular} & 0,10 & 0,47 & 0,15 & 0,62 & 0,74 & \begin{tabular}{|l|l|}
0,92 \\
\end{tabular} & \begin{tabular}{|l|l|}
0,99 \\
\end{tabular} & 0,40 & 0,14 & \begin{tabular}{|l|l|}
0,52 \\
\end{tabular} & \begin{tabular}{|l|l}
0.16 \\
\end{tabular} & $\begin{array}{l}0,57 \\
\end{array}$ & 0,13 & 0,21 & 0,60 & 0,60 & \begin{tabular}{|l|}
0,20 \\
\end{tabular} & 0,32 & 0,20 & 0.31 \\
\hline unzos & 0,00 & 0.27 & 0,00 & 0,02 & 0,00 & 0,000 & \begin{tabular}{|l|} 
\\
\end{tabular} & \begin{tabular}{|l|l|} 
\\
\end{tabular} & 1,00 & 0,00 & \begin{tabular}{|l|l|}
0,39 \\
\end{tabular} & \begin{tabular}{|l|l|} 
\\
\end{tabular} & \begin{tabular}{|l|}
0.47 \\
\end{tabular} & $0,0,73$ & \begin{tabular}{|l|}
0,67 \\
\end{tabular} & 0,52 & \begin{tabular}{|l|}
0,52 \\
\end{tabular} & \begin{tabular}{|l|l|}
0,74 \\
\end{tabular} & \begin{tabular}{|l|l|}
0,71 \\
\end{tabular} & 0,86 & \begin{tabular}{|l|l|}
0,98 \\
\end{tabular} & \begin{tabular}{|l|}
1,00 \\
\end{tabular} & 0,35 & 0,08 & 0,36 & \begin{tabular}{|l|l}
0,10 \\
\end{tabular} & \begin{tabular}{|l|l|l|l|l|l|l} 
& \\
\end{tabular} & 0,05 & 0,22 & \begin{tabular}{|c|}
0,60 \\
\end{tabular} & 0,70 & \begin{tabular}{|l|l|}
0,20 \\
\end{tabular} & 0,24 & 0,20 & 0,32 \\
\hline usagasugo & 0,00 & \begin{tabular}{|l|} 
\\
\end{tabular} & \begin{tabular}{|l|}
0,23 \\
\end{tabular} & \begin{tabular}{|l|}
0,01 \\
\end{tabular} & 0,00 & 0,10 & 0.04 & 42 & 1,00 & 0,000 & \begin{tabular}{|l|}
0,61 \\
\end{tabular} & \begin{tabular}{|l|}
0.65 \\
\end{tabular} & \begin{tabular}{|l|}
0,56 \\
\end{tabular} & \begin{tabular}{|l|}
0.41 \\
\end{tabular} & \begin{tabular}{|l|}
0.16 \\
\end{tabular} & \begin{tabular}{|l|}
0.55 \\
\end{tabular} & \begin{tabular}{|l|}
0,28 \\
\end{tabular} & 0,83 & 0.43 & 0,74 & \begin{tabular}{|l|l|}
0,85 \\
\end{tabular} & 0,99 & 0,33 & 0,41 & 0,37 & 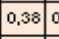 & \begin{tabular}{|l|l|l|l|l|l|l|l} 
\\
\end{tabular} & 0,37 & 0,23 & 0,60 & 0,59 & 0,020 & 0.38 & 0,20 & 0.33 \\
\hline achancipa & 0,00 & \begin{tabular}{|l|} 
\\
\end{tabular} & 0,00 & \begin{tabular}{|l|}
0,12 \\
\end{tabular} & 0,00 & 0,00 & 0.03 & 32 & 0,98 & 0,00 & 0,02 & 0.78 & 0,72 & 0,87 & 0,84 & 0,47 & 0,71 & 0,49 & 0.94 & 0,98 & 1,00 & 0,98 & 0,04 & 0,00 & 0,04 & 0,01 & \begin{tabular}{|l|l|l|l|} 
\\
\end{tabular} & 0,02 & 0,19 & 0,600 & 0,80 & \begin{tabular}{|l|l|}
0,20 \\
\end{tabular} & 0.04 & 0,20 & 0.28 \\
\hline 10560 & 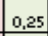 & \begin{tabular}{|l|l|} 
\\
\end{tabular} & 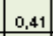 & 0,01 & 0,05 & 0,14 & \begin{tabular}{|l|l|l|} 
\\
\end{tabular} & 0,99 & \begin{tabular}{|l|l|l|} 
\\
\end{tabular} & 0,01 & \begin{tabular}{|l|}
0,04 \\
\end{tabular} & \begin{tabular}{|c|}
0.68 \\
\end{tabular} & 0.73 & \begin{tabular}{|l|l|} 
& 0.77 \\
\end{tabular} & \begin{tabular}{|l|}
0,70 \\
\end{tabular} & \begin{tabular}{|l|l|} 
\\
\end{tabular} & \begin{tabular}{|l|l|}
0,67 \\
\end{tabular} & \begin{tabular}{|l|l|} 
& 0.87 \\
\end{tabular} & \begin{tabular}{|l|l|}
0.87 \\
\end{tabular} & \begin{tabular}{|l|}
0.98 \\
\end{tabular} & \begin{tabular}{|l|}
0.76 \\
\end{tabular} & 0.99 & 0,07 & 0,01 & 0,06 & 0,01 & \begin{tabular}{|lll}
0,07 & 0 \\
\end{tabular} & 0,01 & 0,39 & \begin{tabular}{|l|}
0,60 \\
\end{tabular} & 0.78 & \begin{tabular}{|l|l|}
0,20 \\
\end{tabular} & 0.04 & 0,20 & 0,40 \\
\hline yotostive & 0,02 & 1,00 & 0,04 & 1,00 & 0,00 & $\begin{array}{l}0,000 \\
\end{array}$ & $\mid 0,23$ & 0.70 & 1,00 & \begin{tabular}{|l|l|} 
\\
\end{tabular} & 0,03 & 1,00 & \begin{tabular}{|l|} 
\\
\end{tabular} & 0.97 & $0,67 \mid$ & \begin{tabular}{|l|l|} 
\\
\end{tabular} & 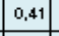 & $0,91 \mid$ & \begin{tabular}{|l|}
0,52 \\
\end{tabular} & $0,99 \mid$ & \begin{tabular}{|l|l|} 
\\
\end{tabular} & \begin{tabular}{|l|l|} 
\\
\end{tabular} & 0,02 & 0,03 & 0,02 & \begin{tabular}{|l|l|l}
0,02 & 0 \\
\end{tabular} & \begin{tabular}{l|l|l}
0,02 & 0 \\
\end{tabular} & 0,01 & 0,38 & \begin{tabular}{|l|}
0,60 \\
\end{tabular} & 0.78 & \begin{tabular}{|l|}
0,20 \\
\end{tabular} & 0,02 & 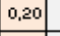 & 0.39 \\
\hline ierres & 0,00 & $\mid 0,09$ & 1,00 & 0,01 & 1,00 & 0,00 & \begin{tabular}{|l|l|l|} 
\\
\end{tabular} & $\mid 0,32$ & 1,00 & $\begin{array}{l}1,00 \\
\end{array}$ & 0,01 & $0,61 \mid$ & \begin{tabular}{|l|l|} 
\\
\end{tabular} & \begin{tabular}{|l|} 
\\
\end{tabular} & 0,97 & \begin{tabular}{|l|}
0,32 \\
\end{tabular} & 0,21 & \begin{tabular}{|l|l|} 
\\
\end{tabular} & $|0,29|$ & $\begin{array}{l}1,00 \\
\end{array}$ & \begin{tabular}{|l|l|} 
\\
\end{tabular} & \begin{tabular}{|l|l|} 
\\
\end{tabular} & 0,00 & 0,02 & 0,00 & 0,000 & \begin{tabular}{ll|l}
0,00 & 0 \\
\end{tabular} & 0,00 & 0,42 & $0,60 \mid$ & 0,60 & \begin{tabular}{|l|l|} 
\\
\end{tabular} & 0,00 & $|0,20|$ & 0.37 \\
\hline Collero & 0,03 & $\begin{array}{l}0,39 \\
0\end{array}$ & 0,39 & 0,00 & 0,00 & 0,00 & 0.37 & 0,00 & 0,66 & 0,53 & 0,11 & 0,83 & \begin{tabular}{|l|}
0,84 \\
\end{tabular} & 0,90 & \begin{tabular}{|l|}
0,84 \\
\end{tabular} & 0,71 & \begin{tabular}{|l|}
0,61 \\
\end{tabular} & 0,88 & 0,84 & 0,95 & \begin{tabular}{|l|l|} 
\\
\end{tabular} & 0,93 & $0,15 \mid$ & 0,02 & \begin{tabular}{|c|c}
0,17 \\
\end{tabular} & \begin{tabular}{|l|l}
0,43 \\
\end{tabular} & \begin{tabular}{|l|l}
0,15 & 0 \\
\end{tabular} & 0,01 & 0,22 & $|0,60|$ & .83 & $|0,20|$ & 16 & $0,20 \mid$ & 0.33 \\
\hline Modrid & 0,00 & 0,13 & 0,03 & 0,09 & 0,00 & 0,00 & 0,05 & 0,50 & 0,98 & 0,00 & \begin{tabular}{|l|}
0,24 \\
\end{tabular} & \begin{tabular}{|l|}
0.45 \\
\end{tabular} & \begin{tabular}{|l|}
0,61 \\
\end{tabular} & \begin{tabular}{|l|}
0.70 \\
\end{tabular} & \begin{tabular}{|l|}
0,58 \\
\end{tabular} & \begin{tabular}{|l|l|}
0.43 \\
\end{tabular} & \begin{tabular}{|l|l|}
0.49 \\
\end{tabular} & \begin{tabular}{|l|}
0.76 \\
\end{tabular} & 0.69 & \begin{tabular}{|l|}
0.85 \\
\end{tabular} & \begin{tabular}{|l|}
0.94 \\
\end{tabular} & \begin{tabular}{|l|}
0,99 \\
\end{tabular} & 0,31 & \begin{tabular}{|l|}
0.16 \\
\end{tabular} & \begin{tabular}{|l|l|}
0,35 \\
\end{tabular} & 0,090 & \begin{tabular}{|l|l}
0,43 & 0 \\
\end{tabular} & 0,06 & 0,18 & 0,60 & 0,68 & 0,20 & 0,23 & 0,20 & 0.29 \\
\hline equers & 0,00 & 0,09 & 0,24 & 0,00 & 0,30 & 0,00 & 0,04 & 0,97 & 1,00 & 0,00 & 0,33 & 0,72 & 0,28 & \begin{tabular}{|l|}
0,80 \\
\end{tabular} & \begin{tabular}{|l|}
0.42 \\
\end{tabular} & 1,00 & \begin{tabular}{|l|}
1,00 \\
\end{tabular} & \begin{tabular}{|l|}
1,00 \\
\end{tabular} & 1,00 & 0,85 & \begin{tabular}{|l|}
0,95 \\
\end{tabular} & 0,99 & 0,56 & 0,07 & 0,63 & \begin{tabular}{|l|l|l|l}
0,09 \\
\end{tabular} & \begin{tabular}{|l|l|l}
0.810 \\
\end{tabular} & 0,07 & 0,27 & 0,60 & 0.82 & \begin{tabular}{|l|l|}
0,20 \\
\end{tabular} & 0,37 & 0,20 & 0.40 \\
\hline Nemocon & 0,00 & 0,04 & 0.02 & $\begin{array}{l}0,01 \\
\end{array}$ & 0.00 & 0.03 & $\begin{array}{l}0,13 \\
\end{array}$ & \begin{tabular}{|l|} 
\\
\end{tabular} & 1,00 & 0,03 & \begin{tabular}{|l|}
0,17 \\
\end{tabular} & 0,73 & 0,75 & 0,73 & 0,52 & 0,60 & 0,50 & 0,79 & 0,68 & 0,98 & \begin{tabular}{|l|l|}
0,96 \\
\end{tabular} & 0,95 & 0,09 & 0,01 & \begin{tabular}{|l|}
0,04 \\
\end{tabular} & 0,010 & \begin{tabular}{|l|l|l}
0,03 & 0 \\
\end{tabular} & 0,03 & 0,18 & 0,60 & 0,74 & \begin{tabular}{|l|l|}
0,20 \\
\end{tabular} & 0,04 & 0,20 & 0.26 \\
\hline$P_{30<53}$ & 0,11 & 0,30 & 0.74 & 0,00 & 0,00 & 4 & 0,19 & 0.65 & 1,00 & 0,00 & 0,02 & 0,00 & \begin{tabular}{|l|}
0,70 \\
\end{tabular} & \begin{tabular}{|l|}
0,27 \\
\end{tabular} & 0,38 & \begin{tabular}{|l|}
0,27 \\
\end{tabular} & \begin{tabular}{|l|}
0.49 \\
\end{tabular} & \begin{tabular}{|l|}
0.49 \\
\end{tabular} & 0,65 & 0,98 & \begin{tabular}{|l|l|}
0,84 \\
\end{tabular} & \begin{tabular}{|l|}
0,87 \\
\end{tabular} & 0,02 & 0,02 & 0,01 & 0,01 & \begin{tabular}{|l|l|l}
0,01 & 0 \\
\end{tabular} & 0,00 & 0,28 & $0,0,60$ & 0,54 & 0,020 & 0,01 & \begin{tabular}{|l|l|l|l}
0,20 \\
\end{tabular} & 0.28 \\
\hline Esrnando & 0,00 & 0,39 & 0,41 & 0,36 & 0,00 & 4) & \begin{tabular}{|l|l|} 
\\
\end{tabular} & \begin{tabular}{|l|l|} 
\\
\end{tabular}, 47 & 1,00 & 0,00 & 0,03 & \begin{tabular}{|l|l|}
0,67 \\
\end{tabular} & 0,87 & 0.46 & 0,43 & 0,36 & 0,14 & 0,53 & 0,19 & 0,99 & \begin{tabular}{|l|l|}
0,85 \\
\end{tabular} & 0,86 & 0,01 & 0,03 & 0,01 & \begin{tabular}{|l|l|}
0,02 \\
\end{tabular} & \begin{tabular}{|l|l|l|l|l|}
0,01 & \\
\end{tabular} & 0,01 & 0,26 & 0,60 & 0,58 & \begin{tabular}{|l|l|}
0,20 \\
\end{tabular} & 0,01 & \begin{tabular}{|l|l|}
0,20 \\
\end{tabular} & 0.27 \\
\hline quile & 0,00 & 0,66 & \begin{tabular}{|l|l|} 
& 0,18 \\
\end{tabular} & \begin{tabular}{|l|}
0,01 \\
\end{tabular} & 0,00 & & 35 & 4 & 1,00 & 0,00 & 0,01 & $0,0.70$ & \begin{tabular}{|l|}
0,58 \\
\end{tabular} & \begin{tabular}{|l|}
0,31 \\
\end{tabular} & \begin{tabular}{|l|}
0.78 \\
\end{tabular} & \begin{tabular}{|l|}
0.70 \\
\end{tabular} & 0,65 & \begin{tabular}{|l|}
0.87 \\
\end{tabular} & 0,84 & 0.98 & \begin{tabular}{|l|l|}
0,93 \\
\end{tabular} & \begin{tabular}{|l|l|}
0.93 \\
\end{tabular} & 0,04 & 0,01 & 0,04 & 0,01 & 0,050 & 0,01 & 0,28 & 0,60 & 0,81 & 0,20 & 0,02 & 0,20 & 0.34 \\
\hline 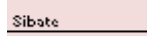 & 10 & 0,08 & & & & & 0,12 & 3 & 1,00 & $t$ & 0,08 & 0.58 & 0.64 & 0.70 & \begin{tabular}{|c|} 
\\
\end{tabular} & \begin{tabular}{|l|l|} 
\\
\end{tabular} & 0,51 & \begin{tabular}{|l|}
0.84 \\
\end{tabular} & 0.79 & 0.93 & \begin{tabular}{|l|l|} 
\\
\end{tabular} & 0.98 & 0,29 & 0,04 & 0,32 & \begin{tabular}{|l|l|l}
0,03 & 0 \\
\end{tabular} & \begin{tabular}{|l|l}
0,29 & 0 \\
\end{tabular} & 0,03 & 0,23 & $0,60 \mid$ & 0.73 & \begin{tabular}{|l|}
0,20 \\
\end{tabular} & 0.17 & 0,20 & 0.32 \\
\hline schis & 0,00 & 0,01 & 0,50 & 0,00 & 0,00 & 0,00 & 0,15 & 1,00 & 1,00 & 0,00 & 1,00 & 0,86 & 0,87 & 0.73 & $|0,88|$ & 0.43 & 0,56 & \begin{tabular}{|l|l|} 
\\
\end{tabular} & 0,77 & $0,00 \mid$ & \begin{tabular}{|l|l|} 
\\
\end{tabular} & $\begin{array}{l}1,00 \\
\end{array}$ & 0,96 & 1,00 & 0,97 & \begin{tabular}{|l|l}
1,00 & 0 \\
\end{tabular} & \begin{tabular}{|l|l}
, 990 & 1. \\
\end{tabular} & 1,00 & 33 & $|0,60|$ & 89 & \begin{tabular}{|l|l|} 
\\
\end{tabular} & 97 & $0,20 \mid$ & 0,53 \\
\hline Sopo & 0,05 & 0.17 & 0,08 & 0,00 & 0,00 & 0,00 & 0,30 & 0,97 & 0.77 & 0,01 & 0,06 & $0,80 \mid$ & \begin{tabular}{|l|}
0,65 \\
\end{tabular} & \begin{tabular}{|l|}
1,00 \\
\end{tabular} & 1,00 & 0,74 & \begin{tabular}{|l|}
0,71 \\
\end{tabular} & 0,93 & 0,31 & 0,96 & 0,95 & \begin{tabular}{|l|l|} 
\\
\end{tabular} & $|0,27|$ & 0,02 & \begin{tabular}{|l|l|}
0,32 \\
\end{tabular} & 0,010 & \begin{tabular}{|lll}
0,31 & 0 \\
\end{tabular} & 0,01 & 22 & 0,60 & 0,87 & \begin{tabular}{|l|l|} 
\\
\end{tabular} & 16 & $0,20 \mid$ & .34 \\
\hline Subschoog & 0,00 & 0.01 & \begin{tabular}{|l|}
0.13 \\
\end{tabular} & 0,19 & 0,00 & 0,00 & 0,82 & 0.77 & 0,95 & 0,01 & 0,15 & 0,78 & \begin{tabular}{|l|}
0,84 \\
\end{tabular} & \begin{tabular}{|l|}
0,76 \\
\end{tabular} & $0,80 \mid$ & 0,62 & 0,68 & 0,87 & $|0,88|$ & 0,98 & \begin{tabular}{|l|l|}
0,88 \\
\end{tabular} & 0,92 & $|0,07|$ & 0,02 & | 0,11 & \begin{tabular}{|l|l|l|}
0,02 & 0 \\
\end{tabular} & $\begin{array}{lll}0,08 & 0 \\
\end{array}$ & 0,01 & 0,27 & 0,60 & 0,82 & \begin{tabular}{|l|l|} 
\\
\end{tabular} & 0,05 & $0,20 \mid$ & 0,34 \\
\hline Suecess & 0,00 & 0,22 & 0,17 & 0,05 & 0,12 & \begin{tabular}{|l|} 
\\
\end{tabular} & 0,36 & 0,55 & 1,00 & 0,02 & \begin{tabular}{|l|}
0,10 \\
\end{tabular} & \begin{tabular}{|l|}
0.06 \\
\end{tabular} & \begin{tabular}{|l|}
0,66 \\
\end{tabular} & \begin{tabular}{|l|}
0,60 \\
\end{tabular} & 0,39 & \begin{tabular}{|l|}
0.44 \\
\end{tabular} & $\begin{array}{ll}0.52 \\
\end{array}$ & 0,73 & 0.69 & \begin{tabular}{|l|}
0,97 \\
\end{tabular} & \begin{tabular}{|l|l|}
0.90 \\
\end{tabular} & \begin{tabular}{|l|l|}
0.94 \\
\end{tabular} & 0,02 & 0,01 & 0,03 & 0,030 & \begin{tabular}{|l|l}
0,03 & 0 \\
\end{tabular} & 0,02 & 0.24 & \begin{tabular}{|l|}
0,60 \\
\end{tabular} & 63 & \begin{tabular}{|l|}
0,20 \\
\end{tabular} & .02 & 0,20 & 0.27 \\
\hline stio & 0,00 & 0,20 & 0,07 & 0,01 & 0,00 & 0,00 & 0,18 & 0,85 & 1,00 & 0,00 & 0,03 & \begin{tabular}{|l|l|}
0.84 \\
\end{tabular} & 0,79 & 0,94 & 0.97 & 0,79 & 0.76 & 0,91 & 0.92 & 0.96 & \begin{tabular}{|l|l|} 
\\
\end{tabular} & 0.98 & 0,08 & 0,02 & 0,07 & \begin{tabular}{|l|l}
0,02 & \\
\end{tabular} & \begin{tabular}{|l|l|l|l|l}
0,07 & \\
\end{tabular} & 0,02 & 0,21 & 0,60 & .90 & 0,20 & 0.05 & \begin{tabular}{|l|l|}
0,20 \\
\end{tabular} & 0.32 \\
\hline Taves & 0,00 & 0,18 & 0,33 & 0,00 & 0,00 & 0,01 & 0,37 & 0,75 & $\begin{array}{l}, 00 \\
\end{array}$ & 0,00 & \begin{tabular}{|l|}
0,04 \\
\end{tabular} & \begin{tabular}{|l|}
0.77 \\
\end{tabular} & \begin{tabular}{|l|}
0.86 \\
\end{tabular} & \begin{tabular}{|l|}
0,56 \\
\end{tabular} & \begin{tabular}{|l|}
0.49 \\
\end{tabular} & 0,34 & 0,50 & \begin{tabular}{|l|}
0.67 \\
\end{tabular} & 0,70 & 0,99 & \begin{tabular}{|l|l|}
0,89 \\
\end{tabular} & 0,86 & 0,01 & \begin{tabular}{|l|}
0,01 \\
\end{tabular} & \begin{tabular}{|l|}
0,01 \\
\end{tabular} & 0,010 & \begin{tabular}{|l|l}
0,02 & 0 \\
\end{tabular} & 0,01 & 0,24 & $0,0.60$ & 0.69 & \begin{tabular}{|l|l|}
0,20 \\
\end{tabular} & 0.01 & \begin{tabular}{|l|l|} 
\\
\end{tabular} & 29 \\
\hline Tenjo & 0,00 & 0,17 & 0.05 & 0,02 & 0,00 & 0,00 & 0,51 & 1,00 & 100 & 0,0 & \begin{tabular}{|l|}
0,05 \\
\end{tabular} & 0,26 & 0,00 & 0,89 & \begin{tabular}{|l|l|} 
\\
\end{tabular}, 77 & \begin{tabular}{|l|l|}
0,55 \\
\end{tabular} & 0,58 & 0,96 & 0,88 & 0,97 & \begin{tabular}{|l|}
0,95 \\
\end{tabular} & 0,97 & 0,19 & 0,04 & 0,22 & 0,010 & \begin{tabular}{|l|l}
0,26 & 0 \\
\end{tabular} & 0,02 & 0,16 & 0,60 & 0,71 & 0,20 & 0,12 & \begin{tabular}{|l|l|}
0,20 \\
\end{tabular} & 0.26 \\
\hline Toconcip & 0 & 0 & 0 & 0,00 & c & 0,00 & \begin{tabular}{|l}
0,14 \\
\end{tabular} & 0,85 & \begin{tabular}{|l|} 
\\
\end{tabular} & 0,02 & \begin{tabular}{|l|}
0,02 \\
\end{tabular} & \begin{tabular}{|l|}
0,75 \\
\end{tabular} & \begin{tabular}{|l|}
0,71 \\
\end{tabular} & \begin{tabular}{|l|}
0,90 \\
\end{tabular} & \begin{tabular}{|l|}
0,81 \\
\end{tabular} & \begin{tabular}{|l|}
0,65 \\
\end{tabular} & \begin{tabular}{|l|}
0,69 \\
\end{tabular} & \begin{tabular}{|l|}
0.89 \\
\end{tabular} & 0,91 & \begin{tabular}{|l|l|} 
\\
\end{tabular} & \begin{tabular}{|l|l|}
0,98 \\
\end{tabular} & \begin{tabular}{|l|l|}
0,99 \\
\end{tabular} & 0,56 & 0,06 & \begin{tabular}{|l|}
0,64 \\
\end{tabular} & \begin{tabular}{|l|l|} 
\\
\end{tabular} & \begin{tabular}{|l|l}
0,53 & 0 \\
\end{tabular} & 0,03 & 0.16 & 0,600 & 0.84 & \begin{tabular}{|l|}
0,20 \\
\end{tabular} & 0,31 & \begin{tabular}{|l|l|}
0,20 \\
\end{tabular} & 0,32 \\
\hline 0639 & 0. & 0 & & & & & & 0,52 & 1,00 & 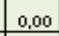 & 0,01 & 0,50 & 0,68 & 0,64 & 0,19 & 0,43 & 0,50 & 0,79 & 0,64 & 0,99 & 0,95 & 0,90 & 0,00 & 0,00 & 0,01 & 0,000 & 0,010 & 0,00 & 0,20 & 0,60 & 0.66 & \begin{tabular}{|l|l|}
0,20 \\
\end{tabular} & 0.00 & \begin{tabular}{|l|l|}
0,20 \\
\end{tabular} & 0.25 \\
\hline & 0. & & & 0,40 & & & & & \begin{tabular}{|l|l|l|} 
\\
\end{tabular} & 10 & 0,02 & 0,18 & 0,47 & $0,61 \mid$ & 0,55 & 0,43 & 0,34 & 0,71 & $0,42 \mid$ & 0,99 & \begin{tabular}{|l|l|} 
\\
\end{tabular} & 0,86 & 0,02 & 0,06 & 0,01 & 0,010 & $\begin{array}{lll}0,01 & 0 \\
\end{array}$ & 0,01 & 0,31 & $0,60 \mid$ & 0,59 & \begin{tabular}{|l|}
0,20 \\
\end{tabular} & 0.02 & \begin{tabular}{|l|}
0,20 \\
\end{tabular} & 0.31 \\
\hline inzon & 0,00 & & & & & & 0,56 & & 1,00 & 0,00 & 0,04 & 0,79 & 0,95 & 0,91 & 0,70 & 0,52 & 0.45 & 0,79 & 0,67 & 0.97 & \begin{tabular}{|l|l|} 
\\
\end{tabular} & 0.93 & 0,04 & 0,07 & 0,04 & 0,040 & $0,04 \mid 0$ & 0,03 & 0,34 & $0,60 \mid$ & 0.78 & \begin{tabular}{|l|}
0,20 \\
\end{tabular} & 0,04 & 0,20 & 0.37 \\
\hline quirs & 0,00 & 0,00 & 0,09 & 0,67 & 0,00 & 0,00 & 0,15 & & 1,00 & 0,00 & 0,31 & $|0,35|$ & \begin{tabular}{|l|l|} 
& 0.18 \\
\end{tabular} & \begin{tabular}{|l|}
0,79 \\
\end{tabular} & \begin{tabular}{|l|}
0,83 \\
\end{tabular} & \begin{tabular}{|l|}
0,64 \\
\end{tabular} & \begin{tabular}{|l|} 
\\
\end{tabular} & \begin{tabular}{|l|}
0,85 \\
\end{tabular} & $\mid 0.94$ & 0,76 & \begin{tabular}{|l|l|}
0,89 \\
\end{tabular} & 0,99 & 0,32 & 0,24 & 0,40 & \begin{tabular}{|l|l}
0.18 & 0 \\
\end{tabular} & \begin{tabular}{|l|l|l}
0,44 \\
\end{tabular} & 0,23 & 0,25 & $0,60 \mid$ & 0,72 & \begin{tabular}{|l|}
0,20 \\
\end{tabular} & 0,30 & 0,20 & 0.35 \\
\hline
\end{tabular}

Fuente: Elaboración propia. 